Pacific Northwest National Laboratory

Operated by Battelle for the

U.S. Department of Energy

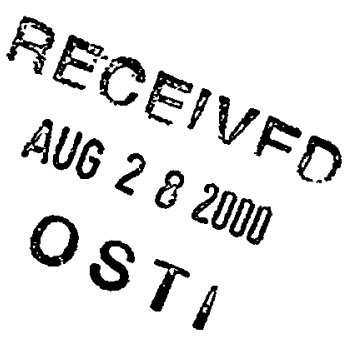

\title{
Characterization, Washing, Leaching, and Filtration of AZ-102 Sludge
}

\author{
K. P. Brooks \\ P. R. Bredt \\ S. K. Cooley \\ G. R. Golcar \\ L. K. Jagoda \\ K. G. Rappe \\ M. W. Urie
}

August 2000

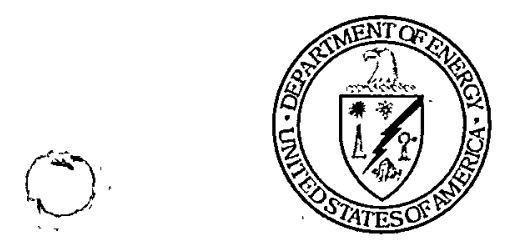

Prepared for BNFL, Inc.

under Contract W375-LC-98-4168 


\section{LEGAL NOTICE}

This report was prepared by Battelle Memorial Institute (Battelle) as an account of sponsored research activities. Neither Client nor Battelle nor any person acting on behalf of either:

MAKES ANY WARRANTY OR REPRESENTATION, EXPRESS OR IMPLIED, with respect to the accuracy, completeness, or usefulness of the information contained in this report, or that the use of any information, apparatus, process, or composition disclosed in this report may not infringe privately owned rights; or

Assumes any liabilities with respect to the use of, or for damages resulting from the use of, any information, apparatus, process, or composition disclosed in this report.

References herein to any specific commercial product, process, or service by trade name, trademark, manufacturer, or otherwise, does not necessarily constitute or imply its endorsement, recommendation, or favoring by Battelle. The views and opinions of authors expressed herein do not necessarily state or reflect those of Battelle. 


\section{DISCLAIMER}

This report was prepared as an account of work sponsored by an agency of the United States Government. Neither the United States Government nor any agency thereof, nor any of their employees, make any warranty, express or implied, or assumes any legal liability or responsibility for the accuracy, completeness, or usefuiness of any information, apparatus, product, or process disclosed, or represents that its use would not infringe privately owned rights. Reference herein to any specific commercial product, process, or service by trade name, trademark, manufacturer, or otherwise does not necessarily constitute or imply its endorsement, recommendation, or favoring by the United States Government or any agency thereof. The views and opinions of authors expressed herein do not necessarily state or reflect those of the United States Government or any agency thereof. 


\section{DISCLAIMER}

Portions of this document may be illegible in electronic image products. Images are produced from the best available original document. 


\title{
Characterization, Washing, Leaching, and Filtration of AZ-102 Sludge
}

\author{
K. P. Brooks \\ P. R. Bredt \\ S. K. Cooley \\ G. R. Golcar \\ L. K. Jagoda \\ K. G. Rappe \\ M. W. Urie
}

August 2000

Prepared for

BNFL, Inc.

under Contract W375-LC-98-4168

Battelle, Richland, Washington 99352 


\section{Summary}

BNFL, Inc. developed flowsheets for the River Protection Project Waste Treatment Plant that use caustic leaching and/or water washing to pretreat Envelope $D$ Hanford sludge before vitrifying the high-level waste (HLW). The pretreatment steps would remove a number of components to reduce the quantity of $\mathrm{HLW}$ generated. The flowsheets also use crossflow filtration to separate the leach and wash solutions from the solids between each step. The work reported here tested crossflow filtration and evaluated the washing and leaching characteristics of sludge from Tank AZ-102.

Battelle staff evaluated approximately $400 \mathrm{~g}$ of wet Hanford Tank AZ-102 Sludge by the pretreatment processes of ultrafiltration, dilute caustic washing, and elevated-temperature caustic leaching. The filterability of diluted AZ-102 sludge was measured with a 0.1- $\mu \mathrm{m}$ sintered metal Mott filter using a 24-in.-long, single-element, crossflow filtration system (cells unit filter [CUF]). Before washing and leaching, a 5.1-wt\% solids ${ }^{(a)}$ slurry was filtered using a matrix of six 1-h conditions of varying transmembrane pressure ( 30 to $70 \mathrm{psid}$ ) and axial velocity ( 7 to $13 \mathrm{ft} / \mathrm{s}$ ), with the filtrate being recirculated. The filtrate flux and backpulse efficiency were determined for each condition. The slurry was then concentrated to $13.7-\mathrm{wt} \%$ solids, a second matrix of six 1-h conditions performed at axial - velocities ranging from 6 to $11.5 \mathrm{ft} / \mathrm{s}$, and data analogous to that recorded in the first matrix obtained.

The low-solids-concentration matrix produced filtrate flux rates that ranged from 0.046 to $0.126 \mathrm{gpm} / \mathrm{ft}^{2}$. The high-solids-concentration matrix produced filtrate flux rates that ranged from 0.020 to $0.051 \mathrm{gpm} / \mathrm{ft}^{2}$. In the low solids matrix, the highest filtrate flux was at the first condition ( $50 \mathrm{psid}$, $9.5 \mathrm{ft} / \mathrm{s}$ ). The initial filtrate flux declined significantly over the next four conditions, indicating filter fouling or more likely, particle deagglomeration. In the subsequent conditions, the initial filtrate flux remained steadier, and the highest filtrate flux was measured at the highest axial velocity. In the high solids matrix, the optimum condition was clearer and was found at the highest axial velocity.

For each matrix, the last test condition was a repeat of the first test condition. In both matrices, there was a significant decrease in filtrate flux between these two tests. This indicates some filter fouling occurred during each test matrix that could not be removed by backpulsing alone, although the backpulse number and duration were not optimized. The nitric acid cleaning performed at the end of the testing could partially recover the initial fluxes caused by this filter fouling.

Following testing of these two matrices, the material was washed in the CUF by continuously adding approximately $2.7 \mathrm{~L}$ of $0.01 \mathrm{M} \mathrm{NaOH}$ and then removing it as permeate by filtration. The purpose of these washing steps with $0.01 \mathrm{M} \mathrm{NaOH}$ was to remove water-soluble components. After washing the sludge with dilute caustic, it was combined with a concentrated caustic solution to produce a slurry containing $\sim 3 \mathrm{M} \mathrm{NaOH}$, which was then leached in a stirred, stainless steel vessel at $85^{\circ} \mathrm{C}$ for $8 \mathrm{~h}$. This leaching was followed by two $0.01 \mathrm{M}$ caustic washes, each conducted in a stainless steel vessel to dilute remaining soluble analytes from the interstitial liquids. Each rinse was performed at $85^{\circ} \mathrm{C}$ for $8 \mathrm{~h}$. Permeate from each of these process steps was removed using the crossflow filter system. Samples of the permeate from each slurry-washing activity and all intermediate process steps were taken and analyzed

(a) Solids concentrations are generally reported on an insoluble solids basis. This is done by mathematically subtracting out the dissolved solids from the total solids. 
for chemical and radiochemical constituents. The fraction of each component removed at each step was calculated. Key results are presented in Table S.1.

The primary components in the initial tank sludge were aluminum, iron, and sodium in roughly equal proportions. Following washing and caustic leaching, these three components remained the highest concentrations, but iron became the primary constituent, more than twice the concentration of sodium and aluminum. Based on the aluminum + iron + zirconium concentration limits in the HLW glass, the potential glass volume was reduced by $\sim 23-30 \%$ as a result of washing and caustic leaching.

The rheological properties of the AZ-102 slurries were determined with a Haake viscometer. All three samples analyzed exhibited yield pseudoplastic and thixotropic behavior. This rheological behavior was expected, as the slurry initially added to the CUF was difficult to begin pumping, yet improved over time. The initial 5.1-wt\% material had a viscosity between 4 and $16 \mathrm{cP}$. The concentrated slurry used in the second matrix had a measured solids concentration of $13.7 \mathrm{wt} \%$ and a viscosity between 82 and $100 \mathrm{cP}\left(@ 33 \mathrm{~s}^{-1}\right.$ ) during the initial increase in shear ${ }^{\mathrm{a}}$. The viscosity steadily declined for both the decreasing shear curves and with subsequent runs. During the decreasing shear curve, the $13.7 \mathrm{wt} \%$ slurry had a measured viscosity at $33 \mathrm{~s}^{-1}$ of between 25 and $47 \mathrm{cP}$. The final slurry samples with solids concentration of 9.2-wt \% solids had viscosities at $33 \mathrm{~s}^{-1}$, ranging from 167 to $209 \mathrm{cP}$. Foaming was observed in the final pretreated slurry sample ( $9.2 \mathrm{wt} \%$ solids), which may have contributed to the higher observed viscosities for this sludge.

Table S.1. Solubility of AZ-102 Sludge Key Components in 0.01 M NaOH and.3 M NaOH

\begin{tabular}{|c|c|c|c|}
\hline Component & $\begin{array}{c}\text { Fraction Removed in } \\
\text { Water Washes (\%) }\end{array}$ & $\begin{array}{c}\text { Fraction Removed in } \\
\text { Caustic Leaches (\%) }\end{array}$ & $\begin{array}{c}\text { Fraction in Solids } \\
\text { Residue (\%) }\end{array}$ \\
\hline $\mathrm{Al}$ & 2.5 & 61.2 & 36.3 \\
\hline $\mathrm{Cr}$ & 44.1 & 14.2 & 41.7 \\
\hline $\mathrm{Fe}$ & 0.006 & 0.02 & 99.97 \\
\hline $\mathrm{Na}$ & 80.2 & - nd- & 11.2 \\
\hline $\mathrm{P}$ & 6.7 & 45.6 & 47.7 \\
\hline${ }^{90} \mathrm{Sr}$ & 0.003 & 0.007 & 99.99 \\
\hline${ }^{137} \mathrm{Cs}$ & 61.2 & 32.7 & 6.1 \\
\hline
\end{tabular}

-nd- : Not determined due to difficulty in distinguishing leached sodium from added sodium. The fraction $\mathrm{Na}$ in the solids residue may be that added during the caustic leaching rather than that initially present in the sludge.

Particle-size distribution was measured on the initial, as-received sludge, on the $13.7 \mathrm{wt} \%$ concentrated slurry, and on the final caustic leached slurry. The initial sludge had a significantly larger particle-size distribution than subsequent material. Approximately $50 \%$ of the particles (on a volume weighted distribution) had a peak mode of $24 \mu \mathrm{m}$ as compared to subsequent steps having $>60 \%$ of the particles with a peak mode of approximately $1 \mu \mathrm{m}$. Sonication had a larger effect on the particles of the final caustic leached slurry when compared to the earlier steps. The significant reduction in particle size due to sonication may indicate that the washing and leaching steps weakened the agglomerate strength.

(a) BNFL selected $33 \mathrm{~s}^{-1}$ as the reference point to compare all viscosity measurements. 


\section{Terms and Abbreviations}

$\begin{array}{ll}\text { AEA } & \text { alpha energy analysis } \\ \text { BNFL } & \text { BNFL, Inc; subsidiary of British Nuclear Fuels, Ltd. } \\ \text { CUF } & \text { cells unit filter } \\ \text { DF } & \text { decontamination factor } \\ \text { DI } & \text { deionized water } \\ \text { DOE-RL } & \text { U.S. Department of Energy-Richland Operations } \\ \text { GEA } & \text { gamma energy analysis } \\ \text { HLRF } & \text { High Level Radiochemistry Facility } \\ \text { HLW } & \text { high-level waste } \\ \text { IC } & \text { ion chromatography } \\ \text { ICP-AES } & \text { inductively coupled plasma-atomic emission spectroscopy } \\ \text { ICP-MS } & \text { inductively coupled plasma-mass spectrometry } \\ \text { LRB } & \text { laboratory record book } \\ \text { MSE } & \text { mean squared error } \\ \text { NIST } & \text { National Institute of Standards and Technology } \\ \text { PID } & \text { proportional-integral-derivative controller } \\ \text { PMG } & \text { precious metals group } \\ \text { PSD } & \text { particle size distribution } \\ \text { RPL } & \text { Radiochemical Processing Laboratory } \\ \text { RPP-WTP } & \text { River Protection Project Waste Treatment Plant } \\ \text { TMP } & \text { transmembrane pressure } \\ \text { TIC } & \text { total inorganic carbon } \\ \text { TOC } & \text { total organic carbon } \\ \text { TRU } & \text { transuranic } \\ \text { UPA } & \text { Ultrafine Particle Analyzer (Microtac) } \\ & \end{array}$




\section{Units}

$\begin{aligned}{ }^{\circ} \mathrm{C} & \text { degrees Celsius } \\ \mathrm{g} & \text { gram } \\ \mathrm{g} / \mathrm{mL} & \text { gram per milliliter } \\ \mu \mathrm{g} / \mathrm{g}-\mu \mathrm{g} / \mathrm{mL} & \text { microgram per gram/microgram per milliliter } \\ \mu \mathrm{Ci} / \mathrm{g}-\mu \mathrm{Ci} / \mathrm{mL} & \text { microcurie per gram/microcurie per milliliter } \\ \mathrm{mL} & \text { milliliter } \\ \mathrm{nCi} / \mathrm{g} & \text { nanocurie per gram } \\ \mathrm{pCi} / \mathrm{g} & \text { picocurie per gram } \\ \mathrm{Vol} \% & \text { volume percent } \\ \mathrm{Wt} \% & \text { weight percent } \\ \mathrm{M} & \text { molarity }\end{aligned}$




\section{Contents}

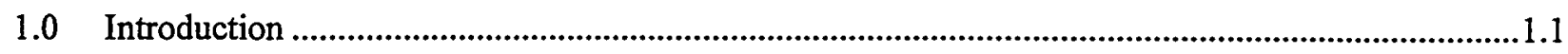

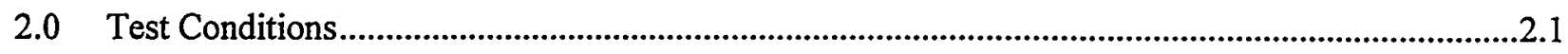

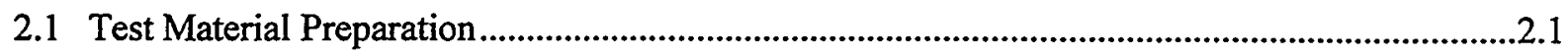

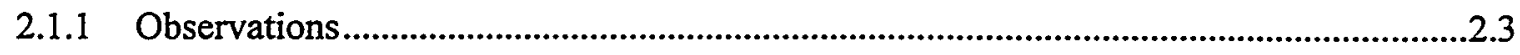

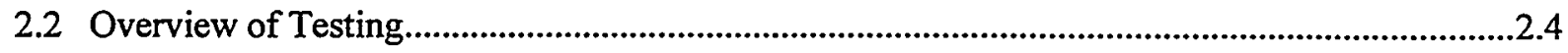

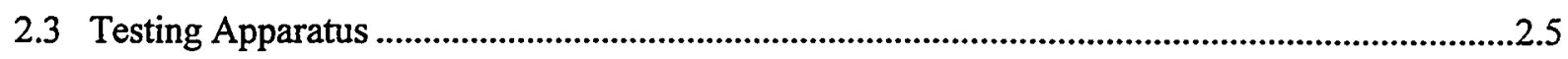

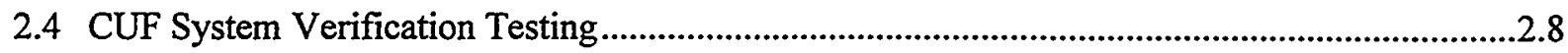

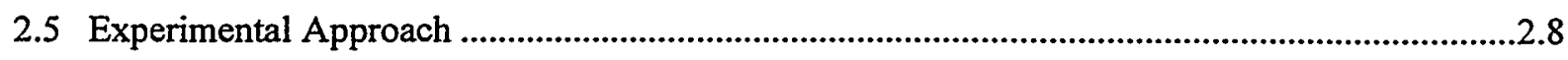

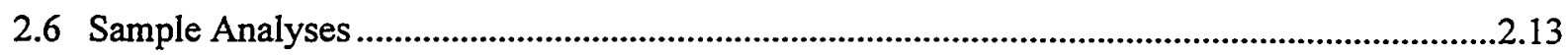

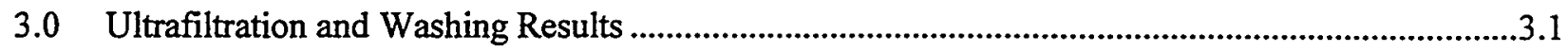

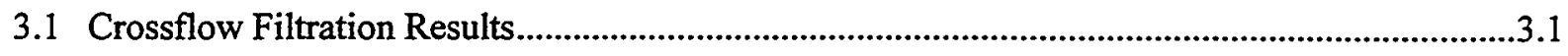

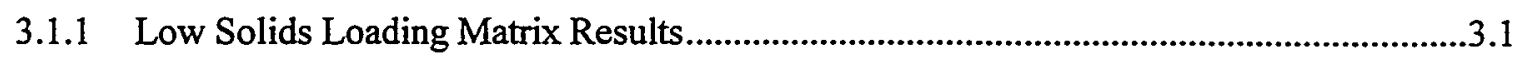

3.1.2 De-Watering from Low to High Solids Loading ............................................................3.3

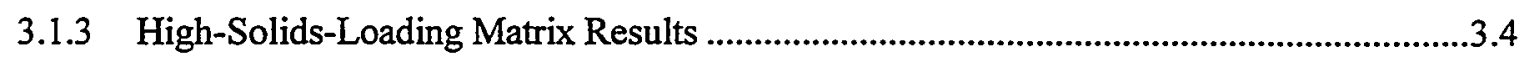

3.1.4 Filtration Results During the Washing and Caustic Leaching Steps................................

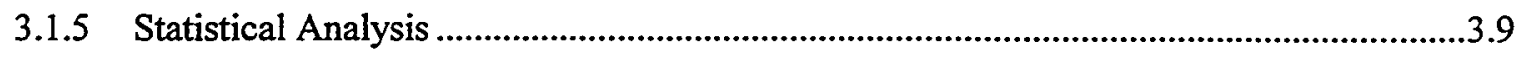

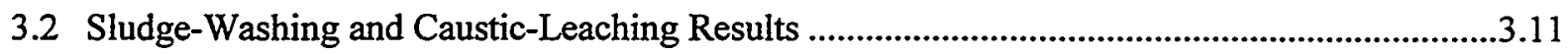

4.0 Physical-Properties and Rheological-Properties Testing.............................................................

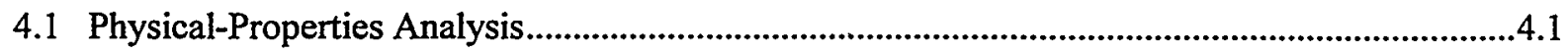

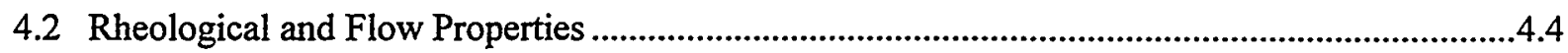

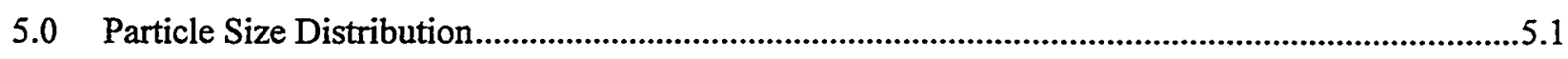

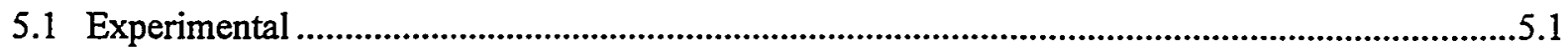

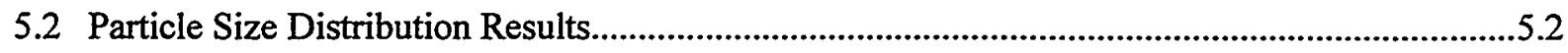

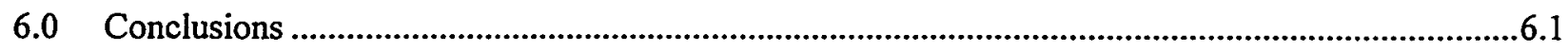

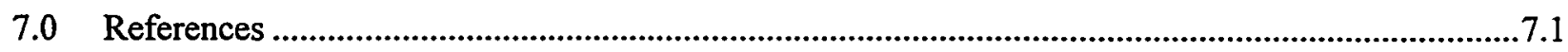

Appendix A: CUF Filtration, Washing and Leaching Test Instructions and Laboratory Record Book....A.1

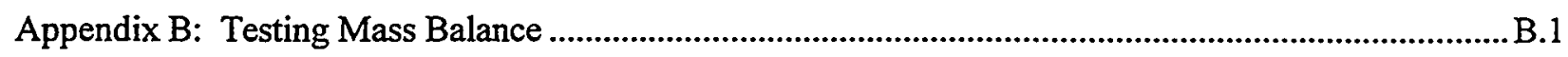

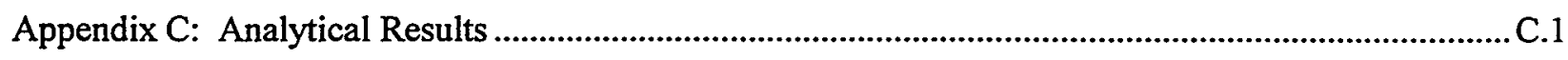

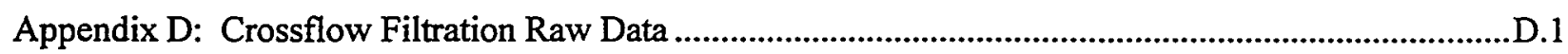

Appendix E: Physical Properties Test Instruction ............................................................................. E.

Appendix F: Rheograms for AZ-102 and Standards .......................................................................

Appendix G: Key Personnel Affiliated with AZ-102 Testing..........................................................1

Appendix H: Particle Size Distribution Simulant Recipes and Experimental Raw Data .........................H.1 


\section{Figures}

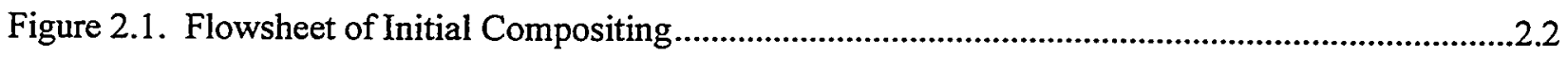

Figure 2.2. Crossflow Filtration Process Flow Diagram .........................................................................

Figure 2.3. AZ-102 Crossflow Filtration Test Experimental Steps........................................................2.9

Figure 3.1. Filtrate Flux as a Function of Time for the Low Solids Matrix ............................................3.2

Figure 3.2. Initial, Average, and Final Filtrate Flux for Each Condition in the Low Solids Matrix ..........3.3

Figure 3.3. Filtrate Flux as a Function of Time for the High Solids Matrix .............................................3.5

Figure 3.4. Filtrate Flux as a Function of Axial Velocity for the High Solids Matrix at $\sim 30$ psid TMP ..3.6

Figure 3.5. Initial, Average, and Final Filtrate Flux for Each Condition in the High-Solids Matrix .........3.7

Figure 3.6. Filtrate Flux Comparison between High and Low Solids Loading Matrices..........................3.8

Figure 5.1. Cumulative Under-Size Percentage Distribution for AZ-102 Slurries Using the

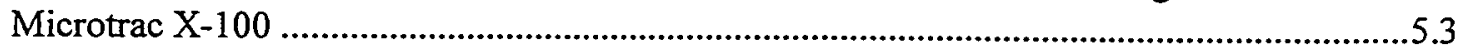

Figure 5.2. Volume-Weighted Distribution for AZ-102 Slurries Using the Microtrac X-100..................5.4

Figure 5.3. Cumulative Under-Size Percentage Distribution for AZ-102 Slurries Using the Microtrac UPA

Figure 5.4. Histogram of the Volume- Weighted AZ-102 Slurries Using the Microtrac X-100 at 40 and $60 \mathrm{~mL} / \mathrm{s}$ Circulation Flow Rate.

Figure 5.5. Histogram of the Number-Weighted AZ-102 Slurries Using the Microtrac X-100 at 40 and $60 \mathrm{~mL} / \mathrm{s}$ Circulation Flow Rate

Figure 5.6. Histogram of the Volume Weighted AZ-102 Slurries before and after Sonication Using the Microtrac X-100

Figure 5.7. Histogram of the Number Weighted AZ-102 Slurries before and after Sonication Using the Microtrac X-100. 


\section{Tables}

Table 2.1. AZ-102 Composite Initial Physical Properties Data ..............................................................2.1

Table 2.2. Test Conditions for Low-Solids-Loading Matrix ${ }^{(a)}$.........................................................2.10

Table 2.3. Test Conditions for High-Solids-Loading Matrix ${ }^{(a)}$...............................................................2.11

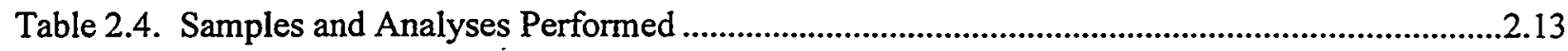

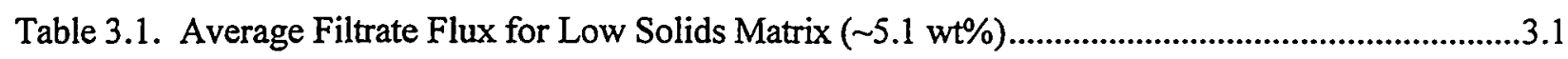

Table 3.2. Average Filtrate Flux for High-Solids Matrix $(-13.7$ wt\%) ....................................................

Table 3.3. Average Filtrate Flux for Dewatering During Washing and Caustic Leach ............................3.9

Table 3.4. Non-Radioactive Component Concentrations ......................................................................3.12

Table 3.5. Radioactive Component Concentrations ..........................................................................15

Table 3.6. Distribution of Non-Radioactive Analytes in the Wash Steps ..............................................17

Table 3.7. Distribution of Radioactive Analytes in the Wash Steps .....................................................19

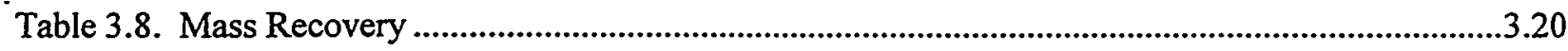

Table 4.1. Density Measurements for Samples of AZ-102 .......................................................................2

Table 4.2. $\mathrm{Wt} \%$ and Vol\% Solids Measurements for Samples of $\mathrm{AZ}-102$........................................4.2

Table 4.3. Results of $\mathrm{Wt} \%$ Residual Solids and Undissolved Solids Calculation Following Drying at

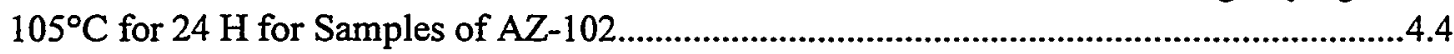

Table 4.4. Results for Yield Stress and Viscosity at $33 \mathrm{sec}^{-1}$ for Samples of AZ-102 Slurry Along with Observed Onset of Taylor Vortices ............................................................................................

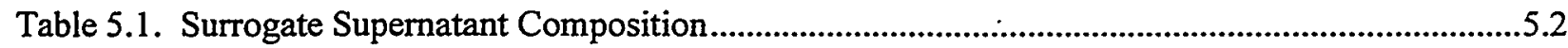

Table 5.2. Peak Mode Location for Volume-Weighted Particle Distribution of AZ-102 Samples...........5.5

Table 5.3. Peak Mode Location for Number-Weighted Particle Distribution of AZ-102 Samples ..........5.7 


\subsection{Introduction}

British Nuclear Fuels Limited (BNFL) Inc. developed the River Protection Project Waste Treatment Plant (RPP-WTP) flowsheets, which plan to use caustic leaching and/or water washing to pretreat the Envelope $D^{(a)}$ Hanford sludge before high-level waste (HLW) vitrification (DOE-RL 1996). These pretreatment steps reduce the quantity of $\mathrm{HLW}$ generated by removing components such as $\mathrm{Al}, \mathrm{Cr}, \mathrm{Na}$, and $\mathrm{P}$ that are soluble either in water or high-temperature caustic and often limit the waste loading in the glass.

The RPP-WTP flowsheets also use crossflow filtration to separate the leach and wash solutions from the solids between each step. Unlike traditional dead-end filtration, which has a declining filtration rate caused by the growth of a filter cake on the surface of the filter medium, in crossflow filtration, the majority of the filter cake is swept away by the fluid flowing across it. This filtration method is especially beneficial when there are very fine particles and when system simplicity is required.

The first objective of this work was to test crossflow filtration using actual Envelope D Hanford tank waste (AZ-102) in a modified cells unit filter (CUF) filtration rig fabricated at Battelle. Similar to the - studies done with AW-101, AN-107, and C-104, the permeability of the diluted AZ-102 sludge was evaluated for both high and low solids concentrations as a function of transmembrane pressure (TMP), axial velocity, and time through a single-element 0.1- $\mu \mathrm{m}$ Mott filter (Brooks et al. 1999; Hallen et al. 2000; Brooks et al. 2000). The radioactive tests with the single-element CUF unit will provide information for equipment-performance evaluation and a design basis for scaling up of the process.

The second objective of this work was to evaluate washing and leaching characteristics of the AZ-102 sludge. The slurried feed was de-watered and then washed multiple times with $0.01 \mathrm{M} \mathrm{NaOH}$ to determine the concentration of water-soluble components. It was subsequently leached with $3 \mathrm{M} \mathrm{NaOH}$ at elevated temperatures to determine the concentration of caustic-soluble components. The chemical and radiochemical composition of the filtrate and the final leached solids were measured to determine the efficiency of the filtration, leaching, and washing processes.

This report describes the test apparatus, the experimental approach, the results of the tests, and the chemical and radiochemical analysis of the sludge from Tank AZ-102 and filtrates generated during the washing and caustic-leaching steps. ${ }^{(b)}$ This report also provides a means of transmitting to BNFL the completed test instruction and raw filtration and analytical data.

(a) Envelope issues are explained in Specification 7 of Contract No. DE-RP06-96RL13308.

(b) The results presented in this report are based on work conducted under Test Plans TP-29953-069 and TP-29953075, test instruction TP-29953-076, and Procedure TP-29953-020, Rev 1. Some data are recorded in Laboratory Record Book (LRB) \#13745. Conditions for conducting these tests were given in the "AZ-102 Dewatering and Caustic Leach Test Specification," TSP-W375-99-014, Rev 0. 


\subsection{Test Conditions}

Small-scale radioactive crossflow filtration, water-washing, and caustic-leaching tests using slurry samples from Tank AZ-102 were conducted from 1/10/2000 through 1/14/2000. The work was performed in the High Level Radiochemistry Facility (HLRF) hot cells located in the Radiochemical Processing Laboratory (RPL) facilities. Before testing, the material was homogenized and sub samples were pulled for analytical work with the as-received sample. A description of the material preparation and testing are described in the following sections.

\subsection{Test Material Preparation}

Battelle received samples from Tank AZ-102 from Hanford's 222-S laboratory on September 13, 1999. This material was received in four $\sim 125$-mL glass jars. Figure 2.1 lists the sample numbers along with the mass of material recovered from each jar. A total of $538.9 \mathrm{~g}$ of material in the jars was transferred to a 1-L glass bottle. This bottle was placed on a standard laboratory rolling mill, and mixed for $29 \mathrm{~h}$ and $25 \mathrm{~min}$. The normal temperature in the hot-cell where the mixing process occurred is $\sim 30$ $35^{\circ} \mathrm{C}$.

Following mixing, the material was allowed to settle for slightly less than 4 days. After settling, the total amount of material was $\sim 350-\mathrm{mL}$, consisting of $300 \mathrm{~mL}$ of settled solids and $50 \mathrm{~mL}$ of supernate. Approximately $58.32 \mathrm{~g}$ of supernate was decanted from the top of the slurry to a container labeled AZ-102 SUP. Three density measurements were made of the supernate and the average density was determined to be $1.14 \mathrm{~g} / \mathrm{mL}$. Other properties measured during this phase of testing and their values are shown in Table 2.1 .

Table 2.1. AZ-102 Composite Initial Physical Properties Data

\begin{tabular}{|l|c|}
\hline \multicolumn{1}{|c|}{ Property } & \multicolumn{2}{|c|}{ Value } \\
\hline Settled Solids & \multicolumn{2}{|c|}{$85.7 \quad$ vol\% } \\
\hline Centrifuged Solids & Avg $75.5 \quad$ vol\% \\
\hline Supernate Dissolved Solids & \multicolumn{2}{|c|}{$28 \quad$ wt\% } \\
\hline Supernate Density & Avg $1.14 \quad$ g/mL \\
\hline Approximate Undissolved Solids wt\% & $25 \quad$ wt\% \\
\hline Approximate Composite wt\% Solids & $46 \quad$ wt\% \\
\hline
\end{tabular}




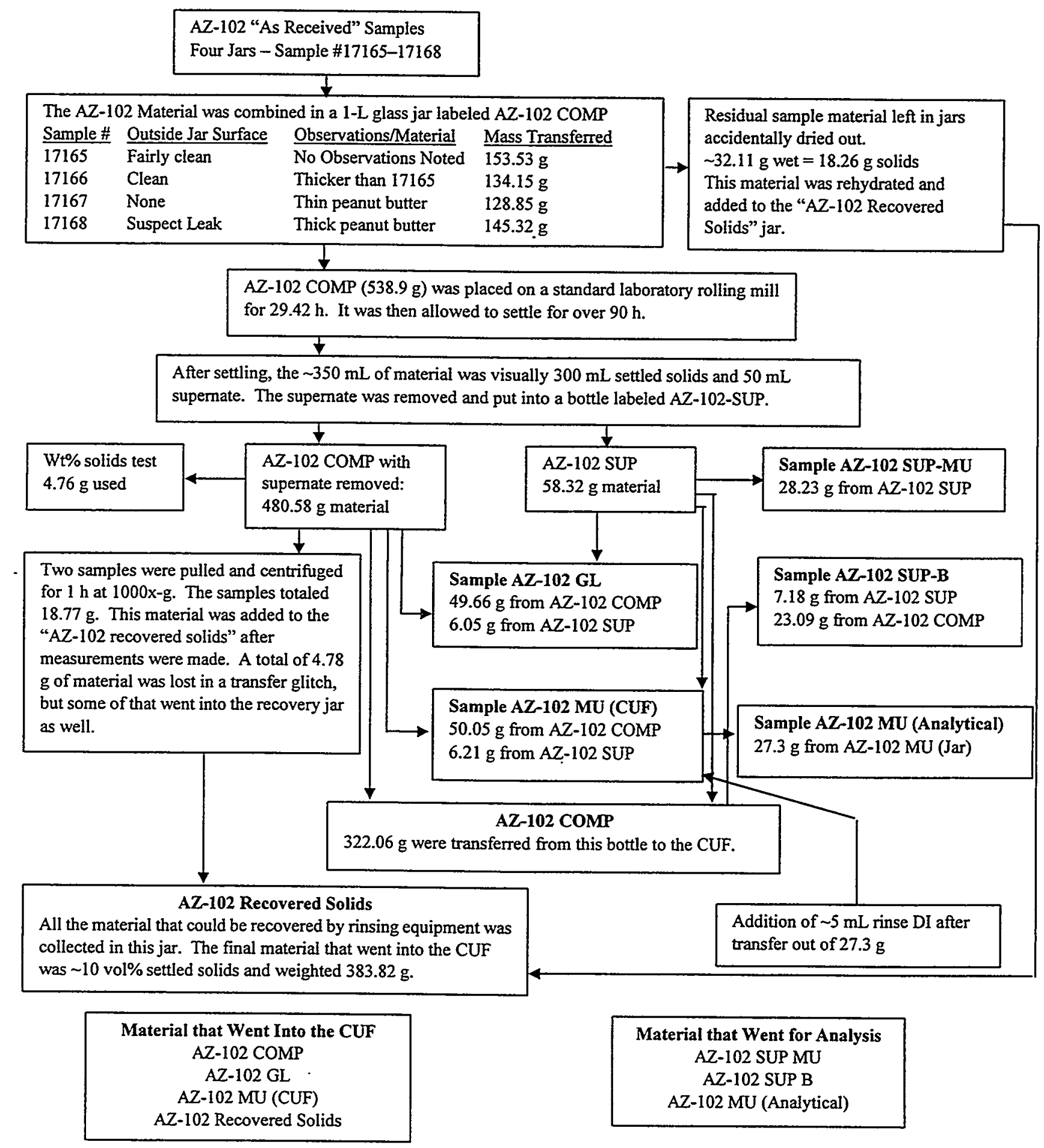

Figure 2.1. Flowsheet of Initial Compositing 
The slurry remaining in AZ-102 COMP was stirred, and two $\sim 8 \mathrm{~mL}$ samples were pulled with a widemouth pipet to verify physical homogeneity by comparing solid/liquid ratios. The two samples were put directly into centrifuge tubes and centrifuged for an hour at $1000 \mathrm{X}-\mathrm{G}$. The two subsamples were found to be 76.5 and 74.6 vol\% centrifuged solids. Given that these results varied by less than 2 vol\%, the sampling technique was determined to provide representative subsamples. The solids from the centrifuge tubes were recovered into a jar labeled AZ-102 Recovered Solids.

In the original test plan, two composite subsamples were needed for other tasks. The procedure for making composite subsamples involves transferring a target amount of solids material into sample jars and then adding a proportional amount of supernate back in based on the ratio of settled solids to supernatant in the original container. This procedure has been determined through previous testing to be the most consistent way to acquire repeatable representative slurry samples. The two composite subsamples were named AZ-102 MU and AZ-102 GL. Each had a target wt. of $50.0 \mathrm{~g}$ settled solids. The final compositions were $50.05 \mathrm{~g}$ of solids and $6.21 \mathrm{~g}$ supernate in AZ-102 MU and $49.66 \mathrm{~g}$ of solids and $6.05 \mathrm{~g}$ of supernate in AZ-102 GL. Additionally, $28.23 \mathrm{~g}$ of supernate was transferred from AZ-102 SUP to a bottle labeled AZ-102 SUP MU for supernatant analysis. After the supernate sample and two composites were prepared, the remaining supernate was added back to AZ-102 COMP, which was slated for CUF testing.

It was later determined that there were not enough solids to make the required amount of glass following CUF testing. Therefore, part of the solids from the composite subsamples would have to be used as CUF testing material. The work for which AZ-102 GL had been prepared was canceled and this material was used for CUF testing. AZ-102 MU was the sample intended for analytical testing. It was determined that the analytical work could be completed with less than $50.0 \mathrm{~g}$ of solids if extra supernate was provided. So a new bottle was labeled AZ-102 SUP-B, and $23.09 \mathrm{~g}$ of supernate from AZ-102 COMP and $7.18 \mathrm{~g}$ of supernate from AZ-102 SUP were transferred into it. Then AZ-102 MU was mixed with a steel scoop, and $27.3 \mathrm{~g}$ was transferred into a centrifuge tube labeled AZ-102 MU. From this point on in the report, these will be referred to as AZ-102 MU (CUF) and AZ-102 MU (analytical), respectively. AZ-102 MU (analytical) was analyzed to determine the starting composition. AZ-102 MU (CUF) was added to the CUF.

The original bottles and all tools were rinsed with $0.01 \mathrm{M} \mathrm{NaOH}$ into a bottle labeled AZ-102 Recovered Solids. AZ-102 Recovered Solids was added to the CUF during testing before the second testing matrix.

\subsubsection{Observations}

The AZ-102 material that was used for these tests is very cohesive/adhesive in nature. It was hard to transfer it into separate containers because the material would form a thick clinging layer on all the tools and sides of the vessels.

The material also forms strong agglomerations when it is allowed to sit for a few days. The first part of the composite work was finished toward the end of 1 week, and it was decided to pull some samples at the beginning of the next week. After the weekend when the material was being re-mixed, a couple of large lumps were observed. They broke apart without too much effort, and it was assumed that somehow they had been missed in the original mixing, even though the initial mixing had appeared quite thorough. 
However, when AZ-102 MU was split after having sat for a couple of weeks, it was filled with hard grainy agglomerates that had not been present when the sample was pulled. These agglomerates varied in size, some as large as $\sim 1 \mathrm{~mm}$ in diameter. These agglomerates were concentrated primarily in the bottom of the container. Attempts were made to break them apart during the re-mixing of the material, including vigorous stirring and compressing them between the jar wall and the steel scoop, with only moderate success.

\subsection{Overview of Testing}

For the AZ-102 crossflow filtration experiments, measurements of filtrate flux as a function of TMP and crossflow velocity were recorded for both a dilute and a concentrated slurry. The dilute feed was 5.1 $\mathrm{wt} \%$ solids, and the concentrated feed was $13.7 \mathrm{wt} \%$ solids ${ }^{\mathrm{a}}$. Due to minimum volume constraints in the CUF and the small quantity of AZ-102 sludge available, the high solids concentration target of $20 \mathrm{wt} \%$ solids could not be achieved. The filtrate was recycled back into the feed tank to maintain the steadystate solids concentration for testing. Each condition was run for $60 \mathrm{~min}$ with data taken at 10 -minute intervals. The system was back-pulsed at least twice between each condition, and not backpulsed at any time during the condition. The slurry temperature was maintained at $25 \pm 5^{\circ} \mathrm{C}$ for all filtrate testing.

The filtration test target conditions presented later in Tables 2.2 and 2.3 were based on an empirically derived matrix to determine the optimum de-watering conditions for the feed slurry. A 5-point matrix around the center-point at $50 \mathrm{psid}$ and $12.2 \mathrm{ft} / \mathrm{s}$ tested the conditions of TMP ( $30 \mathrm{psid}, 50 \mathrm{psid}, 70 \mathrm{psid}$ ) and axial velocity $(9.1 \mathrm{ft} / \mathrm{s}, 12.2 \mathrm{ft} / \mathrm{s}, 15.2 \mathrm{ft} / \mathrm{s})$. However, the air pressure available and pump capability, even with the air booster, was insufficient to achieve the target velocities and pressures with the AZ-102 material. Therefore, some of the matrix points are at lower velocities.

It was hypothesized that the subsurface filter fouling (that cannot be removed by simple backpulsing) may have influenced the selection of optimum de-watering conditions as each test was conducted. To incorporate error introduced by the subsurface filter fouling, and to account for such errors in selecting an optimum de-watering condition, the center-point was used for the initial testing conditions and repeated for the final testing conditions.

The initial AZ-102 material exhibited some unexpected physical properties that affected the testing at several stages. The AZ-102 sludge composite was very cohesive and tended to form agglomerates when it settled. This may have caused problems with material transfer and with plugging and flow fluctuations in the CUF. It also could have affected the rheology measurements. After all CUF processing was complete, it was noted that the material entrained air in quantities large enough to increase its volume by almost a third. This entrained air may have been the result of pumping in the CUF. It is possible that part of the reason the target flowrates could not be reached during testing was due to these two unexpected physical properties, although entrained air was only observed at the conclusion of testing.

Following the filtration tests, the slurry was washed with $0.01 \mathrm{M} \mathrm{NaOH}$ at $25^{\circ} \mathrm{C}$ in the CUF system. This was accomplished though consecutive additions of the washing solution to the CUF slurry feed tank,

(a) Solids concentrations presented in this report are reported on an insoluble solids basis unless specifically delineated. Insoluble solids concentration is calculated by subtracting out the dissolved solids from the total solids. 
followed by the removal of an equal amount of liquid as permeate using the crossflow filter. The filtrate from these washes was collected in three separate containers, and each was sampled for analysis.

The slurry was then put though a caustic leaching process. The slurry was transferred from the CUF to a separate leaching container, combined with $\mathrm{NaOH}$ to produce a slurry consisting of $\sim 3 \mathrm{M} \mathrm{OH}$, heated to $85^{\circ} \mathrm{C}$, and held with steady mixing for $8 \mathrm{~h}$. The leached slurry was then transferred back into the CUF, and de-watered. Following leaching, two 8-h, $0.01 \mathrm{M} \mathrm{NaOH}$ rinse cycles were performed at $85^{\circ} \mathrm{C}$ to reduce the dissolved solids contained in the interstitial liquid.

The available solids and the minimum operating volume of the CUF ( 800 to $900 \mathrm{~mL}$ ) limited the maximum solids concentration that could be attained in the CUF for the second matrix and the final slurry.

All wash solutions and slurry samples from selected process points were analyzed for chemical and radiochemical constituents. Additional samples were obtained to determine rheological properties and to verify the approximate solids loading at specified points. These samples were added back to the system after completion of the procedure when possible.

The final washed sludge was transferred into a storage container for melter feed rheological studies and $H L W$ vitrification tests.

\subsection{Testing Apparatus}

Crossflow filtration testing of the feed was conducted on a Battelle-constructed CUF, with the following specifications:

- single tube filter module, 24 -in. tube; $3 / 8$-in. ID

- 0.1- $\mu \mathrm{m}$ Mott liquid-service stainless steel filter

- re-circulation flow such that $5 \mathrm{~m} / \mathrm{s}(15 \mathrm{ft} / \mathrm{s})$ maximum linear crossflow velocity could be achieved with water; however, with the AZ-102 slurry, the target velocities $(9.1-15.2 \mathrm{ft} / \mathrm{s})$ could not be achieved.

- maximum TMP 80 psid with water.

A process flow diagram of the CUF is shown in Figure 2.2. The slurry feed is introduced into the CUF through the slurry reservoir. An Oberdorfer progressive cavity pump (powered by an air motor) pumped the slurry from the slurry reservoir through the magnetic flow meter and the filter element. Three baffles were installed in the slurry reservoir to prevent vortex formations. The axial velocity and TMP were controlled by the pump speed (which was controlled by the pressure of the air supplied to the air motor) and the throttle valve position. An air booster was added outside of the hot cell to increase the building pressure to the air motor. This was done in an attempt to achieve higher axial velocities during actual slurry testing. During operation, the air booster created a pulsation at an approximate rate of 1 per second and a TMP of 5-10 psig. These pressure fluctuations may have impacted the filtration characteristics, although a test performed during the $\mathrm{C}-104$ filtration compared this effect and indicated that it did not (Brooks et al. 2000). 
Deionized (DI) water and dilute caustic $(0.01 \mathrm{M} \mathrm{NaOH})$ additions into the CUF were made by adding pre-weighed volumes in through a chemical addition tank located outside the hot cell. The chemical addition tank was hard piped into the cell where a long piece of flexible tubing was attached that could be gravity drained into the slurry reservoir. Concentrated caustic or acid solutions were added to the CUF using pre-filled polyethylene bottles transferred manually into the cell.

Filtrate that passes through the filter can be either sent to the back-pulse chamber, reconstituted with the slurry in the slurry reservoir, or removed. The filtrate flow rate is measured by means of a graduated glass-flow monitor that is fill-and-drain operated. Higher filtrate flow rates can be monitored with an inline rotometer. Filtrate samples are taken at the three-way valve upstream from the slurry reservoir. This is also the point at which filtrate is removed for the de-watering step. Filter back-pulsing was conducted by partially filling the back-pulse chamber with filtrate, pressurizing the back-pulse chamber with air, and forcing the filtrate in the back-pulse chamber back through the filter.

During the majority of the testing with the CUF, the slurry temperature was maintained at $25 \pm 5^{\circ} \mathrm{C}$ by flowing cooling water in jackets around the slurry reservoir and through a jacket surrounding the tube between the magnetic flow meter and the filter. The slurry temperature was measured by a thermocouple installed in the slurry reservoir and controlled by a 1000-watt chiller. When filtering wash solutions at elevated temperatures $\left(85^{\circ} \mathrm{C}\right)$, the chiller was turned off and heat tape surrounding the slurry reservoir and pump inlet tubing heated. The temperature was then maintained using a proportional-integral-derivative controller (PID) temperature controller.

The elevated-temperature caustic leaches/washes were performed in a large 2-L stainless steel beaker. The slurry in the stainless steel container was heated on a hotplate while being continuously stirred with a mixing blade. A thermocouple, immersed in the slurry, measured temperature and fed the data into the temperature controller. This allowed for automatic temperature control for the 8-h wash cycles. To minimize evaporation loss, a stainless steel lid with a small hole for the mixer shaft was used. 


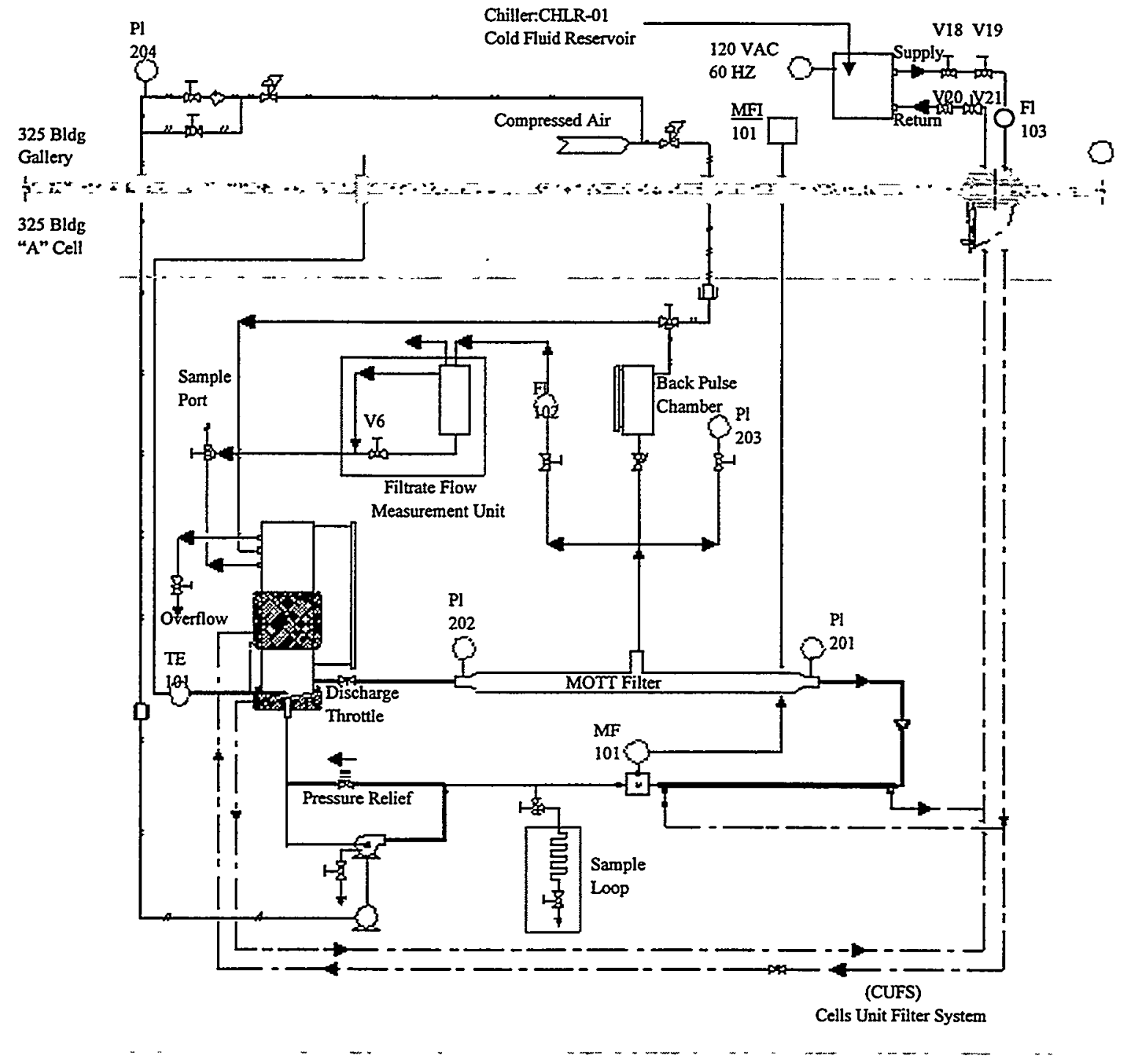

Figure 2.2. Crossflow Filtration Process Flow Diagram

The critical test measuring equipment included

- a magnetic flow meter to measure slurry re-circulation rate

- two flow meters to measure the filtrate flow rate at high and low levels

- three pressure gauges to measure the filter module inlet, filter module outlet, and filtrate pressures

- two thermocouples to measure the slurry temperature in the CUF and in the leaching beaker.

All measuring equipment was calibrated, and the calibration information was recorded in the testinstruction document. 


\subsection{CUF System Verification Testing}

Testing to establish a baseline filtrate flux was conducted with de-mineralized filtered water in the CUF at 20,10 , and 30 psid. The filtrate fluxes for these tests averaged $1.25,0.55$, and $1.54 \mathrm{gpm} / \mathrm{ft}^{2}$, respectively. These fluxes were lower than the fluxes obtained with water before the start of previous testing with a C-104 sample, which averaged $1.59,0.95$, and $2.38 \mathrm{gpm} / \mathrm{ft}^{2}$, respectively. This may indicate that a certain amount of irreversible fouling was occurring in the filter. The water testing showed very little filtrate flux reduction over the 60 -min test time for the 20 -psid test and 30 -min test time for the 10 -psid test. However, over the 30 -min test at 30 psid, the flux dropped from 1.70 to 1.34 . The majority of this drop was seen over the last 10-minute increment. It was decided that the CUF was sufficiently clean to begin testing with the $\mathrm{AZ}-102$ sample since attempting to achieve better fluxes would be costly in both time and budget, and the water fluxes were above the required start values.

\subsection{Experimental Approach}

A flow sheet of the testing is shown in Figure 2.3. The test instruction for this work is found in Appendix A, and a mass-balance spreadsheet is provided in Appendix B.

The homogenized AZ-102 samples were added to the CUF along with $0.01 \mathrm{M} \mathrm{NaOH}$ to create a slurry at $5.1-w t \%$ insoluble solids concentration.

The AZ-102 material plugged the CUF for the first 20 minutes of operation and could not be pumped smoothly. For several hours after the start of testing, the system continued to show large variations in flow and pressure, indicating continued plugging. These problems could be either due to agglomerates in the slurry or just its high solids loading and cohesive nature. Once the flow and pressure readings had stabilized, it was noted that the target flowrate of $12.2 \mathrm{ft} / \mathrm{s}$ at $50 \mathrm{psid}$ for the first condition could not be reached even with the help of an air booster. After several attempts to increase the flowrate, testing of the first matrix began with the highest flowrate achievable. During the first three hours of testing, occasional plugging of the CUF throttle valve occurred, resulting in pressure spikes. After that time, steady-state pressures and velocities were more easily achievable.

The first testing matrix to determine the optimum de-watering conditions for dilute slurry conditions was run at five combinations of TMP and crossflow velocity with two conditions being repeated to assess the effect of filter fouling over the course of testing (see Table 2.2). The system was back-pulsed two to four times between each condition. It was not backpulsed during the 1-hour test condition itself. The cognizant engineer determined the required amount of back-pulses required based on the drop in flux during the previous condition and on the amount of recovery achieved with the first two back-pulses. The filtrate flux results are found in Section 3.1. 


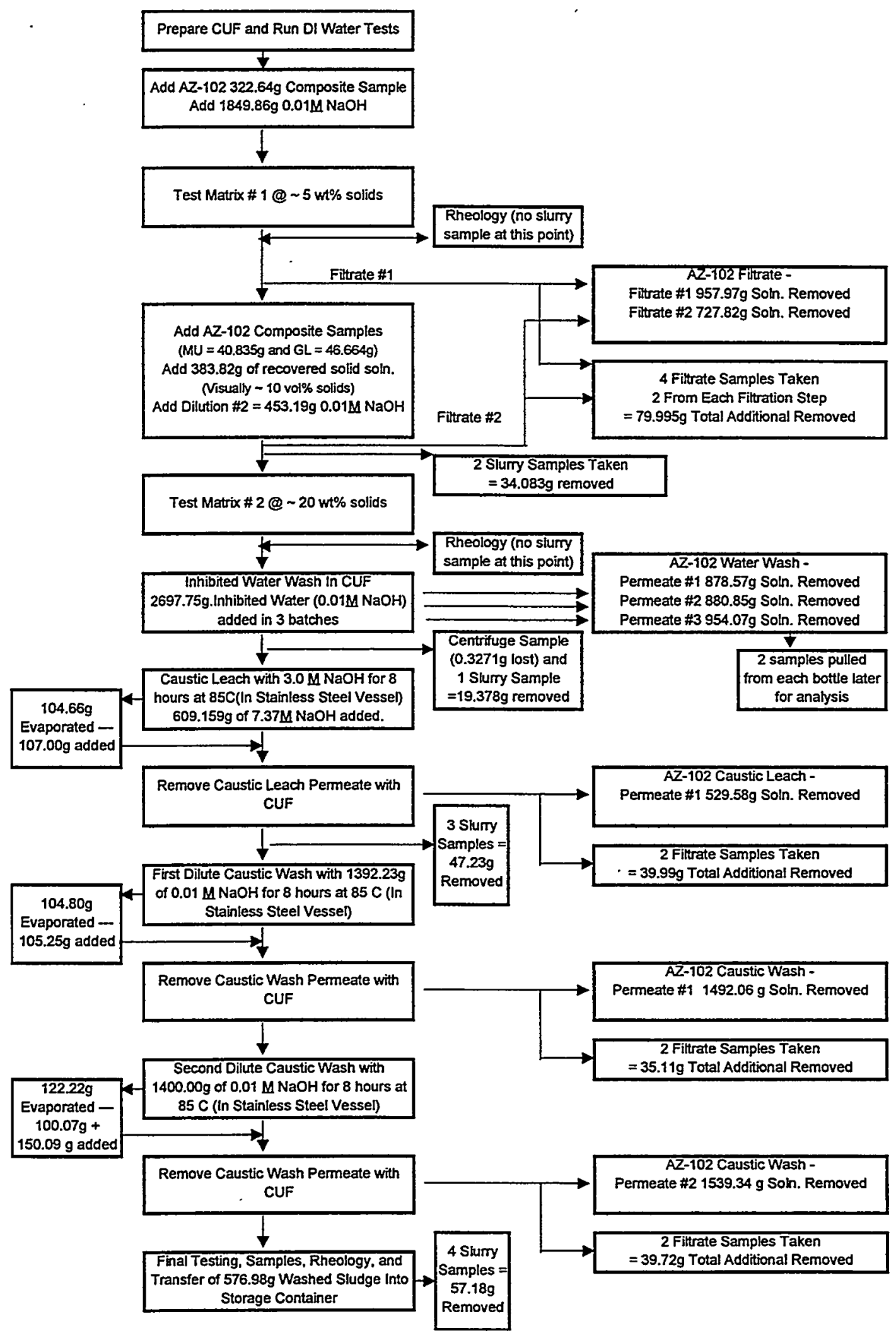

Figure 2.3. AZ-102 Crossflow Filtration Test Experimental Steps 
Table 2.2. Test Conditions for Low-Solids-Loading Matrix ${ }^{(a)}$

\begin{tabular}{|c|c|c|c|c|}
\hline Condition \# & $\begin{array}{c}\text { Target Flowrate } \\
(\mathbf{f t} / \mathbf{s})\end{array}$ & $\begin{array}{c}\text { Average Velocity } \\
\text { (ft/s) }\end{array}$ & $\begin{array}{c}\text { Target Pressure } \\
\text { (psid) }\end{array}$ & $\begin{array}{c}\text { Average Pressure } \\
\text { (psid) }\end{array}$ \\
\hline 1 & 12.2 & 9.47 & 50 & 49.11 \\
\hline 2 & 9.1 & 7.58 & 30 & 30.00 \\
\hline 3 & 15.2 & 7.11 & 70 & 70.29 \\
\hline 4 & 15.2 & 7.96 & 30 & 30.43 \\
\hline 5 & 9.1 & NA & 70 & NA \\
\hline 6 & 12.2 & 8.57 & 50 & 51.43 \\
\hline 7 & $13.1^{(0)}$ & 13.13 & $30^{(0)}$ & 29.50 \\
\hline
\end{tabular}

(a) Air Booster used to attain required pressure and flow.

(b) Determined to be the optimum condition.

An external air-booster was used originally for the test conditions, requiring both a high TMP and a high flow rate. However, since none of the targets could be reached with the AZ-102 even with the airbooster, it was used for all the conditions. Furthermore, Condition 5 was not performed during this testing matrix because it would have only been a replicate of Condition 3 , since higher than $7.1 \mathrm{ft} / \mathrm{s}$ axial velocity was not possible at 70 psid transmembrane pressure. The test was moved directly to Condition 6 .

After completion of the first test matrix, the slurry was de-watered, and the filtrate was collected in a bottle labeled AZ-102 Filtrate \#1. Samples AZ-102 GL, AZ-102 MU and the Recovered Solids were then added to the CUF. The recovered solids material was approximately $10 \mathrm{vol} \%$ settled solids. The slurry was again dewatered, and the filtrate from the second de-watering processes was collected in AZ102 Filtrate \#2. Representative samples of these filtrates and the final combined slurry were taken for analysis. The combined slurry filtered during this second dewatering step contained agglomerates that plugged the system. The system had to be manually pulsed by repeated stop and starts of the pump for almost $45 \mathrm{~min}$ before steady consistent operation of the CUF was possible. The slurry was allowed to mix for an additional $15 \mathrm{~min}$ before proceeding with this second de-watering step.

This concentrated slurry had an insoluble solids concentration calculated at $13.7 \mathrm{wt} \%$. It was run through a second test matrix to determine optimum de-watering conditions at these higher solids loading. Testing procedures for Matrix 2 were identical to the testing for Matrix 1. Since the target conditions could not be reached for Matrix 1, new achievable targets were decided upon for Matrix 2. The targeted and actual conditions are shown in Table 2.3. Once again, Condition 5 was not performed due to the difficulty in attaining high axial velocities at 70-psid transmembrane pressure.

Twenty minutes into Condition 6 , the transmembrane pressure suddenly increased to $>100$ psid. Upon adjusting back to the original pressure setpoint, it was discovered that the maximum flowrate was up by about $20 \%$. While this increase did not bring the flowrate up to the target, it was higher than had been achievable for any of the previous conditions. Therefore, after the completion of Condition 6 , another condition was added with the pressure at $30 \mathrm{psid}$ and the flowrate as high as possible. The sudden spike in pressure and corresponding jump in maximum attainable flowrate may indicate that a partial plug may have existed in the system, which was restricting flowrate throughout the previous testing. This plug may have broken loose 20 min into Condition 6, increasing the flow rate and the quantity of small particles to foul the filter. It is also possible that during Condition 6 , air was suddenly entrained into the 
sample, thus increasing the flowrate and blinding the filter with air bubbles. These hypotheses cannot be tested, but would be consistent with the previously noted nature of this material and observation of its performance in the CUF during the course of the test.

Table 2.3. Test Conditions for High-Solids-Loading Matrix ${ }^{(a)}$

\begin{tabular}{|c|c|c|c|c|c|}
\hline Condition \# & $\begin{array}{c}\text { Original Target } \\
\text { Flowrate (ft/s) }\end{array}$ & $\begin{array}{c}\text { Altered - Target } \\
\text { Flowrate } \\
(\mathrm{ft} / \mathrm{s})\end{array}$ & $\begin{array}{c}\text { Average } \\
\text { Flowrate } \\
(\mathrm{ft} / \mathrm{s})\end{array}$ & $\begin{array}{c}\text { Target } \\
\text { Pressure } \\
(\mathrm{psid})\end{array}$ & $\begin{array}{c}\text { Average } \\
\text { Pressure }\end{array}$ \\
\hline 1 & 12.2 & 7.55 & 7.87 & 50 & 51.07 \\
\hline 2 & 9.1 & 6.39 & 6.59 & 30 & 29.00 \\
\hline 3 & 15.2 & 5.81 & 5.96 & 70 & 67.74 \\
\hline 4 & 15.2 & $\begin{array}{c}\text { As High As } \\
\text { Possible }\end{array}$ & 8.45 & 30 & 30.29 \\
\hline 5 & 9.1 & NA & NA & 70 & NA \\
\hline 6 & 12.2 & $\begin{array}{c}\text { As High As } \\
\text { Possible }\end{array}$ & 8.98 & 50 & 47.83 \\
\hline 7 & $\begin{array}{l}\text { NA-Added } \\
\text { Test }\end{array}$ & $\begin{array}{c}\text { As High As } \\
\text { Possible }\end{array}$ & 11.53 & $30^{\text {(0) }}$ & 29.36 \\
\hline
\end{tabular}

(a) Air Booster used to attain required pressure and flow.

(b) Determined to be the optimum condition.

The slurry was washed three times with dilute caustic following the second test matrix. The total wash volume was divided into three parts and added batch-wise to the CUF. Each wash volume was approximately $900 \mathrm{~mL}$. After each addition, the system was de-watered into a labeled bottle until a similar volume was removed. The wash water was added directly into the mixing tank.

After completion of the water-washing steps, the slurry was removed from the CUF and leached at 3 $\mathrm{M} \mathrm{NaOH}$ in a separate vessel at $85^{\circ} \mathrm{C}$ for $8 \mathrm{~h}$. To reach the $3 \mathrm{M} \mathrm{NaOH}$ target, $609.16 \mathrm{~g}$ of $7.37 \mathrm{M} \mathrm{NaOH}$ was added the slurry.

To rinse residual solids from the CUF, the slurry was pumped into the leaching beaker, and then the $\mathrm{NaOH}$ was added to the CUF and allowed to mix. This solution was then pumped into the leaching beaker to mix with the slurry. This resulted in a slurry with a calculated value of $5.9 \mathrm{wt} \%$ insoluble solids in the leaching beaker. The temperature of the slurry was raised to $85 \pm 5^{\circ} \mathrm{C}$ and maintained there for $8 \mathrm{~h}$. The slurry was continuously stirred with a mixer blade throughout the caustic leaching. Approximately $15 \mathrm{~min}$ before the end of the leaching period, the heat tape on the CUF was activated to pre-warm the system so that slurry could be maintained at $85 \pm 5^{\circ} \mathrm{C}$ for the de-watering process. After $8 \mathrm{~h}$, the slurry was weighed, and the amount of liquid lost through evaporation was determined. The slurry was then transferred back into the CUF for de-watering back to original solids concentration ( $10 \mathrm{wt} \%$ solids). The amount of liquid lost through evaporation was used to rinse remaining solids out of the leach container into the CUF.

The slurry was pumped around in the CUF and heated to return its temperature to $85 \pm 5^{\circ} \mathrm{C}$ before the de-watering process was started. Filtrate flux, TMP, temperature, and flow rate data were taken every 10 min during all de-watering steps when possible. 
Following the caustic leaching steps, the solids were washed twice with $0.01 \mathrm{M} \mathrm{NaOH}$. Each dilute caustic wash was conducted in the same manner as the caustic leach. Dilute Caustic Wash \#1 consisted of $1390 \mathrm{~g}$ of $0.01 \mathrm{M} \mathrm{NaOH}$ added to the slurry. This produced a calculated solids concentration of $\sim 4$ $\mathrm{wt} \%$ in the leaching beaker. The solution was heated to $\sim 85^{\circ} \mathrm{C}$ and stirred for a period of $8 \mathrm{~h}$, then dewatered to the pre-wash concentration. Dilute Caustic Wash $\# 2$ consisted of $1400.00 \mathrm{~g}$ of $0.01 \mathrm{M} \mathrm{NaOH}$ added to the slurry. The solution was heated to $85 \pm 5^{\circ} \mathrm{C}$ and held for a period of $8 \mathrm{~h}$, then de-watered at $85 \pm 5^{\circ} \mathrm{C}$ to the pre-wash concentration. For both washes, the amount of liquid lost through evaporation was used to rinse remaining solids out of the leach container into the CUF. After the final wash, an additional $\sim 130 \mathrm{~mL}$ of water was added to the system in an attempt to remove all the solids from the leaching vessel. Duplicate sub-samples of each permeate were taken and analyzed for soluble components removed.

Approximately $577 \mathrm{~g}$ of final washed and leached AZ-102 sludge was drained from the CUF and collected into a 1-L bottle. The CUF was rinsed once with $500 \mathrm{~mL}$ of DI water, and the solids were collected to be settled and recovered. The CUF was then rinsed four more times with $1000 \mathrm{~mL}$ of DI water, and the solids from these rinse steps were recovered to the extent possible.

It was noted in both the rheology testing and in the final collection of the material that this sludge has the capacity to retain large amounts of trapped gases (assumed to be air) when mixed in the CUF. The bottle that contained the "Final Washed Sludge" was visually full after transfer from the CUF. After settling overnight, the bottle was a little less than $2 / 3$ full. This indicates that at the time of transfer, the material consisted of approximately $33-\mathrm{vol} \%$ entrained air, which was not easily removed in a short period of time.

The CUF was rinsed multiple times with water to remove all of the remaining solids and to recover the initial clean water fluxes. To assist in cleaning the filter, the water was added to the back-pulse chamber and forced backward through the filter. The wash water continued to come out of the CUF brown in color, indicating the presence of fine particles. An external cartridge filter with a $0.05-\mu \mathrm{m}$ rating was attached to the system. Roughly $2 / 3$ of the flow continued through the CUF, and the remaining $1 / 3$ of the flow was circulated through the cartridge filter in an attempt to remove the remaining solids. This recirculation continued for several hours while intermittently back-pulsing. At the conclusion of this cleaning step, the filtrate flux was measured with clean water. The filtrate flux was significantly below that measured before the AZ-102 test, and it was determined that acid cleaning would be required.

One liter of 1-M HNO $\mathrm{H}_{3}$ was added to the CUF (about $600 \mathrm{~mL}$ of that was back-pulsed in) and pumped through the system. The nitric acid was then drained from the CUF and found to be very dark and full of solids. A second batch of $\sim 600 \mathrm{~mL}$ of $1 \mathrm{M} \mathrm{HNO}_{3} / .2 \mathrm{M}$ Citric acid was added to the CUF and allowed to re-circulate through the system. This second batch of nitric acid was lighter, but still brown. The system was then rinsed until a neutral $\mathrm{pH}$ was obtained. The external cartridge filter with a $0.05-\mu \mathrm{m}$ rating was reattached and run before attempting to get clean water fluxes.

The clean water flux was measured again at 20,10 , and 30 psid. The resultant fluxes over 20 -min tests showed a decrease in flux with time, indicating that the system was not yet free of fines. The fluxes averaged $0.3517,0.2259$, and $0.7352 \mathrm{gpm} / \mathrm{ft}^{2}$, respectively. Comparing these values to the pre- $\mathrm{AZ}-102$ water-test values of $1.25,0.55$, and $1.54 \mathrm{gpm} / \mathrm{ft}^{2}$, respectively, it is obvious that pre-test conditions were 
not achieved. Since this was the last test planned for the CUF, it was decided not to attempting further cleaning. However, it is expected that further cleaning would have eventually been able to achieve about an $80 \%$ recovery of pre-AZ-102 test flux capacity, based on the C-104 testing. Further cleaning in the full-scale plant may be required to maintain a high clean-water flux. In the CUF system, the acid can damage the pump stator, so less extensive cleaning is possible.

\subsection{Sample Analyses}

The samples and associated analyses are shown in Table 2.4. For both permeates and slurry samples, analyses included

- total organic carbon (TOC) and total inorganic carbon (TIC)

- ion chromatography (IC) (for soluble anions)

- inductively coupled plasma-atomic emission spectroscopy (ICP-AES) (for metals)

- gamma energy analysis (GEA) $\left({ }^{137} \mathrm{Cs},{ }^{241} \mathrm{Am}\right)$

- strontium chemical separation followed by beta counting $\left({ }^{90} \mathrm{Sr}\right)$

- alpha emission analysis (AEA) (for $\left.{ }^{241} \mathrm{Am},{ }^{239} \mathrm{Pu}\right)$

- total cyanide $\left(\mathrm{CN}^{-}\right)$.

The slurry samples were prepared by both acid digestion and $\mathrm{KOH}$ fusion to obtain complete dissolution as well as measure the $\mathrm{K}$ and $\mathrm{Ni}$ concentration.

Table 2.4. Samples and Analyses Performed

\begin{tabular}{|c|c|c|c|}
\hline Sampling Step & Sampling Number & Sample Type & Analysis \\
\hline \multirow{3}{*}{$\begin{array}{l}\text { Initial Sludge } \\
\text { Composite }\end{array}$} & $\mathrm{AZ}-102 \mathrm{MU}$ & \multirow{3}{*}{ Sludge } & PSD \\
\hline & $\overline{A Z}-102 \mathrm{MU}$ & & Physical Properties \\
\hline & $\mathrm{AZ}-102 \mathrm{MU}$ & & Chemical and Radiochemical \\
\hline $\begin{array}{l}\text { Initial Decanted } \\
\text { Supernatant }\end{array}$ & AZ-102 MU SUP & Supernatant & Chemical and Radiochemical \\
\hline $\begin{array}{l}\text { First De-Watering } \\
\text { After Matrix } 1\end{array}$ & CUF-AZ-102-001 & Permeate & Chemical and Radiochemical \\
\hline $\begin{array}{l}\text { Second De-Watering } \\
\text { After Matrix } 1\end{array}$ & CUF-AZ-102-003 & Permeate & Chemical and Radiochemical \\
\hline \multirow{2}{*}{$\begin{array}{l}\text { Dewatered Slurry } \\
\text { (Before Matrix 2) }\end{array}$} & CUF-AZ-102-005 & \multirow{2}{*}{ Slurry } & Physical Properties \\
\hline & CUF-AZ-102-006 & & PSD \\
\hline $\begin{array}{l}\text { Dewatered Slurry } \\
\text { (After Matrix 2) }\end{array}$ & NA & Slurry & Rheology \\
\hline Water Wash 1 & CUF- AZ-102-015 & Permeate & Chemical and Radiochemical \\
\hline Water Wash 2 & CUF- AZ-102-017 & Permeate & Chemical and Radiochemical \\
\hline Water Wash 3 & CUF-AZ-102-019 & Permeate & Chemical and Radiochemical \\
\hline Washed Slurry & CUF- AZ-102-007 & Slurry & Chemical and Radiochemical \\
\hline
\end{tabular}




\begin{tabular}{|c|c|c|c|}
\hline Sampling Step & Sampling Number & Sample Type & Analysis \\
\hline Caustic Leach & CUF- AZ-102-009 & Permeate & Chemical and Radiochemical \\
\hline \multirow{2}{*}{ After Caustic Leach } & $\begin{array}{l}\text { CUF- AZ-102-010 } \\
\text { CUF- AZ-102-011 }\end{array}$ & \multirow{2}{*}{ Slurry } & Chemical and Radiochemical \\
\hline & CUF- AZ-102-012 & & Physical Properties \\
\hline Caustic Wash 1 & CUF- AZ-102-013 & Permeate & Chemical and Radiochemical \\
\hline Caustic Wash 2 & CUF-AZ-102-022 & Permeate & Chemical and Radiochemical \\
\hline \multirow{3}{*}{ Final Slurry } & CUF-AZ-102-024 & \multirow{3}{*}{ Slurry } & PSD \\
\hline & $\begin{array}{l}\text { CUF- AZ-102-023 } \\
\text { CUF- AZ-102-026 }\end{array}$ & & Chemical and Radiochemical \\
\hline & $\begin{array}{l}\text { CUF- AZ-102-025 } \\
\text { and Final Rheology }\end{array}$ & & $\begin{array}{l}\text { Rheology \& Physical } \\
\text { Properties }\end{array}$ \\
\hline $\begin{array}{l}\text { Final Decanted } \\
\text { Supernatant }\end{array}$ & CUF- AZ-102-027 & Permeate & $\begin{array}{l}\text { Acid Digest/ICP-AES } \\
\text { (for } \mathrm{Na} \text { ) }\end{array}$ \\
\hline
\end{tabular}

In addition to the above analysis, several additional analyses were performed on the composited initial and final slurry. For these two slurries, a precious metals group (PMG) fusion was also performed to obtain the Pt concentration in the slurry. The additional analysis for these slurry samples included

- inductively coupled plasma-mass spectrometry (ICP-MS) (for ${ }^{237} \mathrm{~Np},{ }^{126} \mathrm{Sn},{ }^{129} \mathrm{I},{ }^{99} \mathrm{Tc}, \mathrm{Pr}, \mathrm{Rb}, \mathrm{Ta}, \mathrm{Pt}$ )

- extraction and Beta Count for ${ }^{3} \mathrm{H}$

- combustion release and beta count (for ${ }^{14} \mathrm{C}$ )

- cold vapor atomic adsorption spectroscopy (for $\mathrm{Hg}$ )

- ammonia concentration.

In addition to the analysis performed with the permeates, the original sample decanted supernatant analysis included the following:

- ICP-MS (for ${ }^{237} \mathrm{~Np},{ }^{129} \mathrm{I},{ }^{99} \mathrm{Tc}$ )

- cold vapor atomic adsorption spectroscopy (for $\mathrm{Hg}$ )

- separations and beta counting for ${ }^{99} \mathrm{Tc}$

- ammonia concentration.

The physical analyses of the slurries included density, weight percent dissolved and total solids, and volume percent settled and centrifuged solids. The results of these analyses, along with a further description of the experimental steps, are provided in Section 4.0. The rheological work measured shear stress as a function of shear rate. The particle size distribution (PSD) measurements were performed for selected samples using Microtrac X-100 and Microtrac UPA particle analyzers. The results of this work along with further description of the experimental steps are provided in Section 5.0. 


\subsection{Ultrafiltration and Washing Results}

This section is divided into two subsections: crossflow filtration results, and dilute caustic-washing and caustic-leaching results. The physical property and rheological results, and the particle size distribution results are presented in Sections 4.0 and 5.0, respectively

\subsection{Crossflow Filtration Results}

Two crossflow filtration matrices were conducted at low and high solids loading. During these matricies, filtrate fluxes were measured. Filtrate fluxes were also measured during the washing and leaching steps. These results are presented in the sections below.

\subsubsection{Low Solids Loading Matrix Results}

The low solids loading matrix consisted of six conditions. All were performed at 5.1-wt\% insoluble solids concentration, and each was 1 hour in duration. The average filtrate fluxes from these conditions are shown in Table 3.1. As mentioned in Section 2.5, Condition 5 was not performed for this matrix. A - graph of the filtrate flux as a function of time for all seven conditions is shown in Figure 3.1. The high initial flux rates drop within a few minutes to a lower, more consistent flux rate that slowly decreases over time. For comparison of test conditions, the flux rate was averaged over the 1-h run time, except for the first $10 \mathrm{~min}$ of operation. All the flux data presented in this section have been corrected to $25^{\circ} \mathrm{C}$ using the following formula provided by BNFL to correct for viscosity and surface tension changes:

$$
\text { Flux }_{25 C}=\text { Flux }_{T} e^{2500\left(\frac{1}{273+T}-\frac{1}{298}\right)}
$$

where Flux ${ }_{25 \mathrm{C}}$ is the corrected filtrate flux, and $\mathrm{T}$ is the temperature $\left(\right.$ in ${ }^{\circ} \mathrm{C}$ ) at the flux measurement $\left(\right.$ Flux $\left._{\mathrm{T}}\right)$. All of the raw data for the filtrate flux measurements are included in Appendix D.

Table 3.1. Average Filtrate Flux for Low Solids Matrix ( $-5.1 \mathrm{wt} \%)$

\begin{tabular}{|c|c|c|c|}
\hline Condition \# & $\begin{array}{c}\text { Average } \\
\text { Velocity (ft/s) }\end{array}$ & $\begin{array}{c}\text { Average Pressure } \\
\text { (psid) }\end{array}$ & $\begin{array}{c}\text { Average Filtrate } \\
\text { Flux (gpm/ft' }\end{array}$ \\
\hline 1 & 9.5 & 49.1 & 0.126 \\
\hline 2 & 7.6 & 30.0 & 0.082 \\
\hline 3 & 7.1 & 70.3 & 0.046 \\
\hline 4 & 8.0 & 30.4 & 0.055 \\
\hline 5 & NA & NA & NA \\
\hline 6 & 8.6 & 51.4 & 0.071 \\
\hline 7 & 13.1 & 29.5 & 0.078 \\
\hline
\end{tabular}

NA $=$ Not performed 


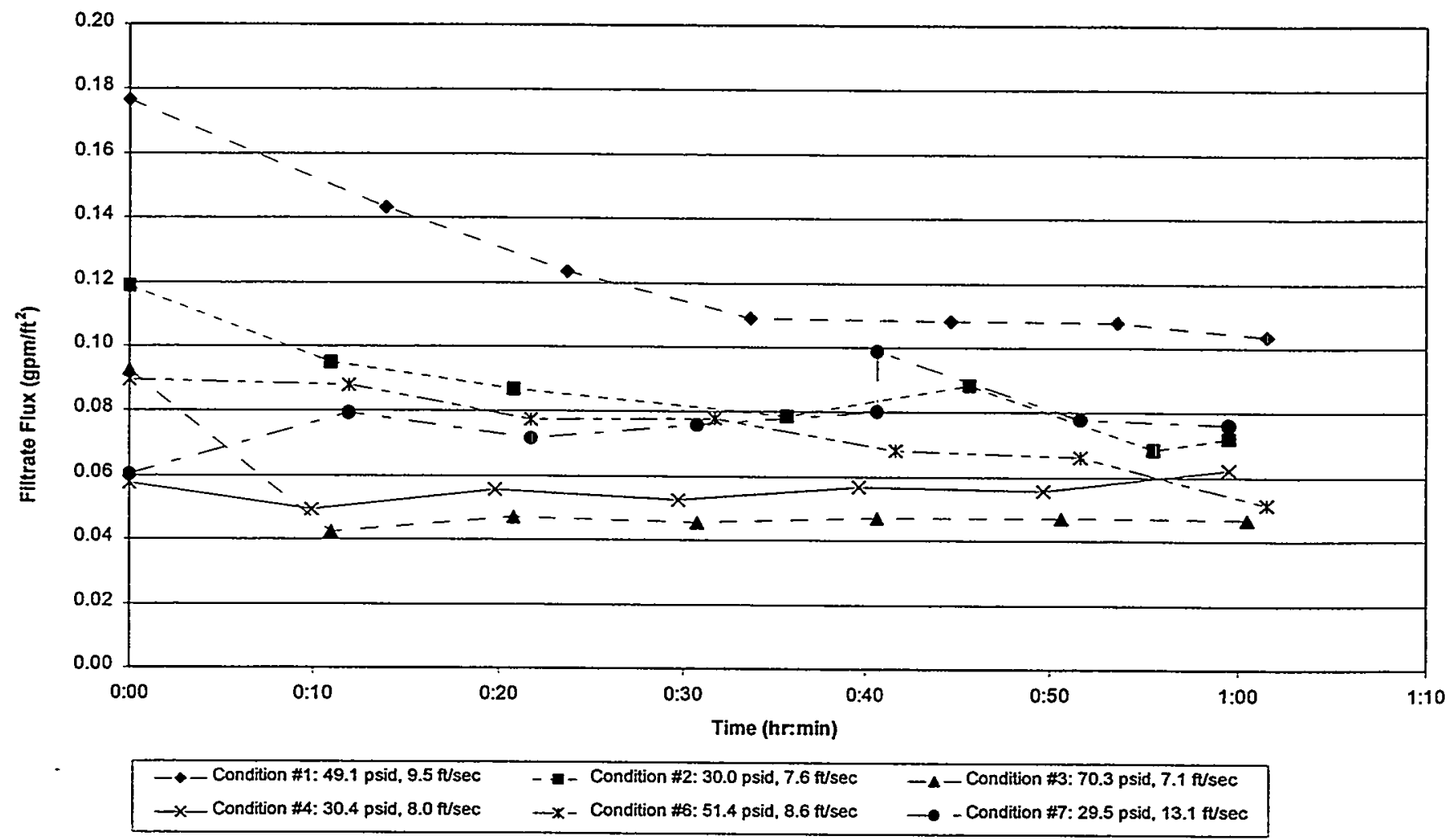

Figure 3.1. Filtrate Flux as a Function of Time for the Low Solids Matrix

The initial condition (49.1 psid, $9.5 \mathrm{ft} / \mathrm{s}$ ) had the highest average filtrate flux. As with previous crossflow filtration studies (Brooks et al. 1999; Brooks et al. 2000; Geeting and Reynolds 1997) on Hanford tank wastes, during each condition and between conditions, the filtrate flux steadily decreases over time. This was evidenced by the decrease in filtrate flux that was observed in Conditions \#1 and \#6 and Conditions \#2 and \#4. With similar pressure and slightly lower velocity, Condition \#6 (51.4 psid, 8.6 $\mathrm{ft} / \mathrm{s})$ had a filtrate flux $44 \%$ lower than Condition \#1. Condition $\# 2(30.0 \mathrm{psid}, 7.6 \mathrm{ft} / \mathrm{s})$ and Condition \#4 ( $30.4 \mathrm{psid}, 8.0 \mathrm{ft} / \mathrm{s}$ ) were also nearly identical in pressure and velocity. In this case, there was a $32 \%$ decrease in filtrate flux from Condition \#2 to Condition \#4.

The initial, final, and average filtrate flux results are shown in Figure 3.2. The first four conditions show a linear decrease in initial filtrate flux in spite of backpulsing and varied TMPs. A similar linear decrease in average filtrate flux was seen with the first three conditions. This decrease was probably related more to filter fouling and the influence of particle break-up than from changes in TMP. Thus, no trend in TMP can be seen from the first three data points over the range of 30 to $70 \mathrm{psid}$. This result may indicate the need for higher backpulsing pressure and frequency to prevent this irreversible fouling. 
In comparing the initial, average, and final flux values for all conditions, it can be concluded that after approximately 2-3 hours of slurry circulation in the CUF, the solids are eroded to a stable finer particle size distribution (See Section 5.1). The evidence for this assumption is determined by the rate at which equilibrium is established during one hour of circulation. During Conditions $1 \& 2$, the flux declines slowly over time. For Conditions 3-7, the equilibrium flux is reached more quickly. Thus in the later cases, the resistance of the deposited layer on the membrane surface is relatively unchanged during the one hour of circulation (Tarleton and Wakeman 1994).

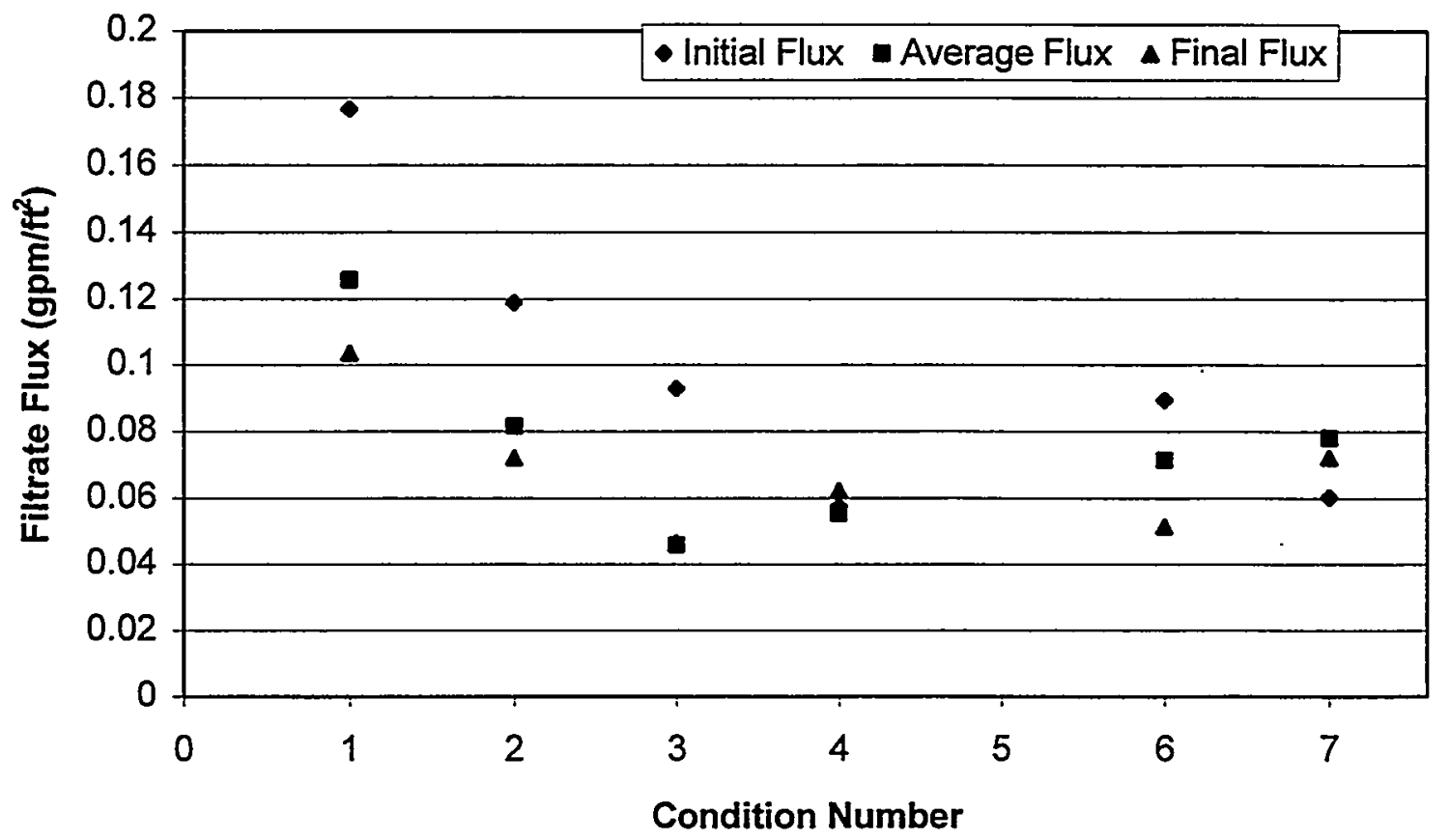

Figure 3.2. Initial, Average, and Final Filtrate Flux for Each Condition in the Low Solids Matrix

Conditions \#4, \#6, and \#7 better illustrate the influence of pressure and velocity. The lower pressure and velocity of Condition \#4 (30.4 psid, $8.0 \mathrm{ft} / \mathrm{s})$ yielded a lower filtrate flux than Conditions \#6 and \#7, with their higher pressure or axial velocity, respectively. The high pressure and low velocity of Condition \#6 (51.4 psid, $8.6 \mathrm{ft} / \mathrm{s}$ ) appeared to offset the high velocity and lower pressure of Condition \#7 (29.5 psid, $13.1 \mathrm{ft} / \mathrm{s}$ ) for nearly identical average filtrate fluxes. The increase seen between Condition \#4 and \#6 with higher transmembrane pressure would indicate a possible small, but measurable, influence of pressure on filtrate flux.

\subsubsection{De-Watering from Low to High Solids Loading}

The slurry was de-watered in two steps, once on the initial slurry containing AZ-102 Comp (the initial feed), and again on the slurry after it contained all AZ-102 sludge material to be used, including AZ-102 $\mathrm{MU}, \mathrm{AZ}-102 \mathrm{GL}$, and the recovery jar. The initial de-watering removed approximately $950 \mathrm{~mL}$ of supernatant at a filtrate flux of $0.094 \mathrm{gpm} / \mathrm{ft}^{2}$. These filtrate flux measurements were performed at $48 \mathrm{psid}$ and $10.2 \mathrm{ft} / \mathrm{s}$. The results were approximately $30 \%$ higher than those seen for similar material during 
Condition \#6. The solids concentration varied from $5.1 \mathrm{wt} \%$ to approximately $9.2 \mathrm{wt} \%$ solids during the dewatering step. This increase in filtrate flux in spite of the higher solids loading may be the result of the higher axial velocity $(10.2 \mathrm{ft} / \mathrm{s}$ vs. $8.6 \mathrm{ft} / \mathrm{s})$. The second de-watering step removed an additional $730 \mathrm{~mL}$ of supernatant. The TMP was very similar to the first dewatering step, but the average axial velocity was much lower (5.7 vs. $10.2 \mathrm{ft} / \mathrm{s}$ ) and decreased over time (from 7.3 to $4.3 \mathrm{ft} / \mathrm{s}$ ). The filtrate flux for this step decreased from 0.067 to $0.024 \mathrm{gpm} / \mathrm{ft}^{2}$. During this de-watering, the solids concentration increased from an estimated 8.7 - to 13.7 -wt $\%$ solids.

\subsubsection{High-Solids-Loading Matrix Results}

The second filtration matrix was performed after the slurry had been de-watered to a calculated solids concentration of $13.7 \mathrm{wt} \%$ solids. This matrix consisted of six conditions. As mentioned in Section 2.5, Condition 5 was not performed for this matrix. The first and sixth conditions were repeated to evaluate filter fouling during the course of the testing. The average filtrate fluxes for this matrix are shown in Table 3.2. The filtrate fluxes as a function of time are shown in Figure 3.3. As done previously, each condition was performed over the course of $1 \mathrm{~h}$ with 3 to 4 backpulses between each condition.

Table 3.2. Average Filtrate Flux for High-Solids Matrix ( $13.7 \mathrm{wt} \%)$

\begin{tabular}{|c|c|c|c|}
\hline Condition \# & $\begin{array}{c}\text { Average Velocity } \\
(\mathbf{f t} / \mathbf{s})\end{array}$ & $\begin{array}{c}\text { Average Pressure } \\
(\mathbf{p s i d})\end{array}$ & $\begin{array}{c}\text { Average Filtrate } \\
\text { Flux }\left(\mathbf{g p m} / \mathbf{f t}^{2}\right)\end{array}$ \\
\hline 1 & 7.9 & 51.1 & 0.032 \\
\hline 2 & 6.6 & 29.0 & 0.028 \\
\hline 3 & 6.0 & 67.7 & 0.030 \\
\hline 4 & 8.4 & 30.3 & 0.038 \\
\hline 6 & 9.0 & 47.8 & 0.020 \\
\hline 7 & 11.5 & 29.4 & 0.050 \\
\hline
\end{tabular}

Unlike the previous matrix, the highest average flux did not occur at the first condition. Instead, it occurred at the condition of highest axial velocity (Condition 7). Once again, the average filtrate flux appeared to decrease over the entire matrix as evidenced in the decrease in filtrate flux that was observed in Conditions \#1 and \#6. With nearly identical pressure and increased velocity in Condition \#6, there was a $38 \%$ decrease between the two conditions. Some of this decrease could be associated with a sudden change that occurred to the testing apparatus $23 \mathrm{~min}$ into the Condition. There was a spike in the pressure and then immediately the flow increased from $7.8 \mathrm{ft} / \mathrm{s}$ to $10.2 \mathrm{ft} / \mathrm{s}$. The filtrate flux decreased by approximately $50 \%$. It is postulated that build-up of particles somewhere in the system suddenly broke free, allowing an increase in flow and further coating the filter. This in turn resulted in a decrease in filtrate flux. A second postulate is that a sudden increase in entrained air in the slurry blinded the filter, resulting in a decrease in filtrate flux, although entrained air or its effects were noted only at the conclusion of testing. 


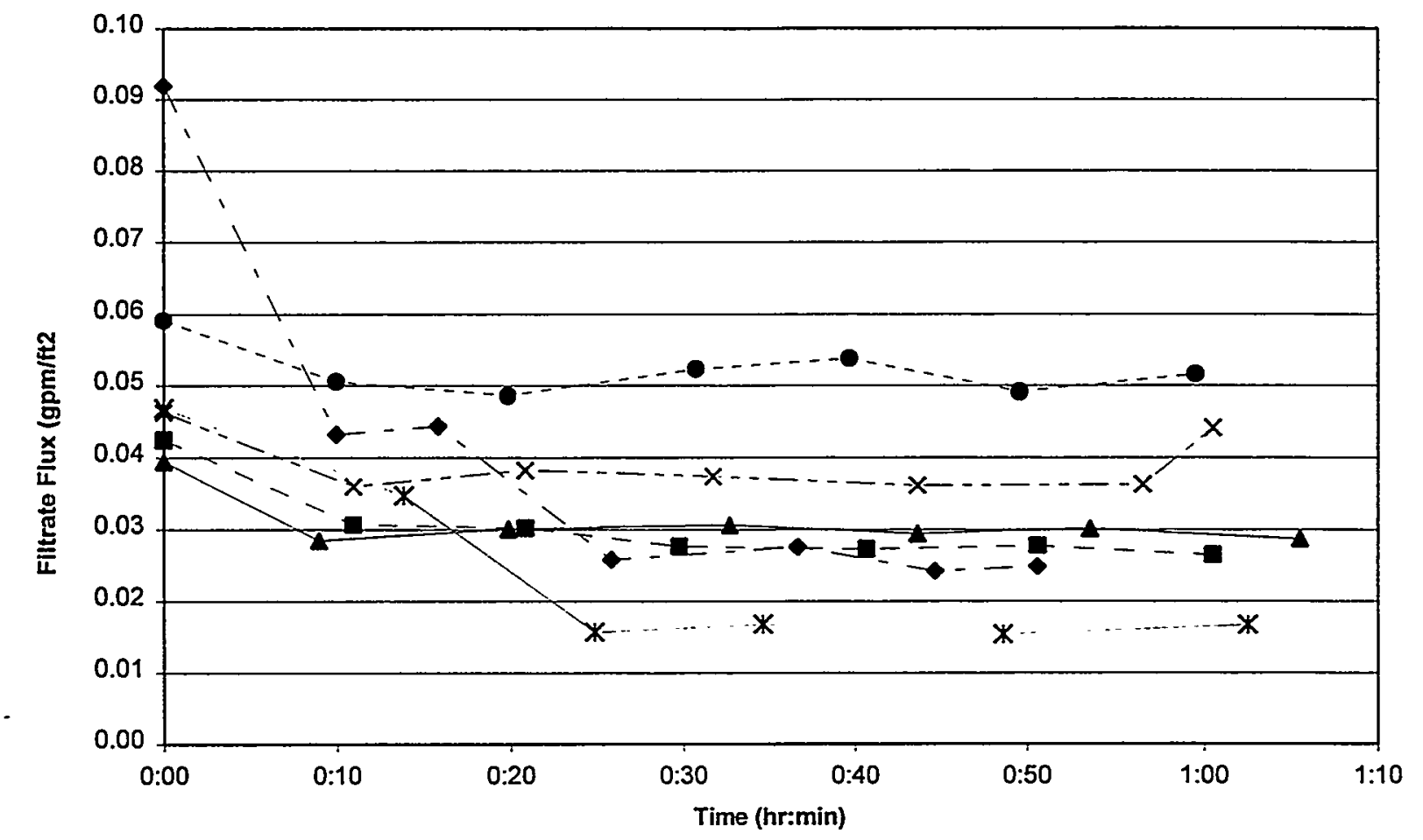

\begin{tabular}{|c|c|c|c|}
\hline - Condition \#1: 51.1 psid, $7.9 \mathrm{ft} / \mathrm{sec}$ & $-m$ & Condition \#2: 29.0 psid, $6.6 \mathrm{ft} / \mathrm{sec}$ & _ Condition \#3: 67.8 psid, $6.0 \mathrm{ft} / \mathrm{sec}$ \\
\hline$\rightarrow \times-$ Condition \#4: 30.3 psid, $8.4 \mathrm{ft} / \mathrm{sec}$ & $\mathbf{x}$ & Condition \#6: $47.8 \mathrm{psid}, 9.0 \mathrm{ft} / \mathrm{sec}$ & - - Condition \#7: $29.4 \mathrm{psid}, 11.5 \mathrm{ft} / \mathrm{sec}$ \\
\hline
\end{tabular}

Figure 3.3. Filtrate Flux as a Function of Time for the High Solids Matrix

The first three data points provide some indication as to the effect of TMP at constant axial velocity. The nearly constant filtrate flux seems to indicate that the filtrate flux was not impacted by TMP over the range from 30 to 70 psid.

A comparison between Conditions \#2, \#4, and \#7 provides an indication of the effect of axial velocity at nearly constant TMP. With increased axial velocity, there was a significant increase in filtrate flux. This trend can best be seen in Figure 3.4 where filtrate flux was plotted as a function of axial velocity. The resulting graph is nearly linear. Overall, for the high solids matrix, the optimum condition was achieved at low pressures and high axial velocities. 


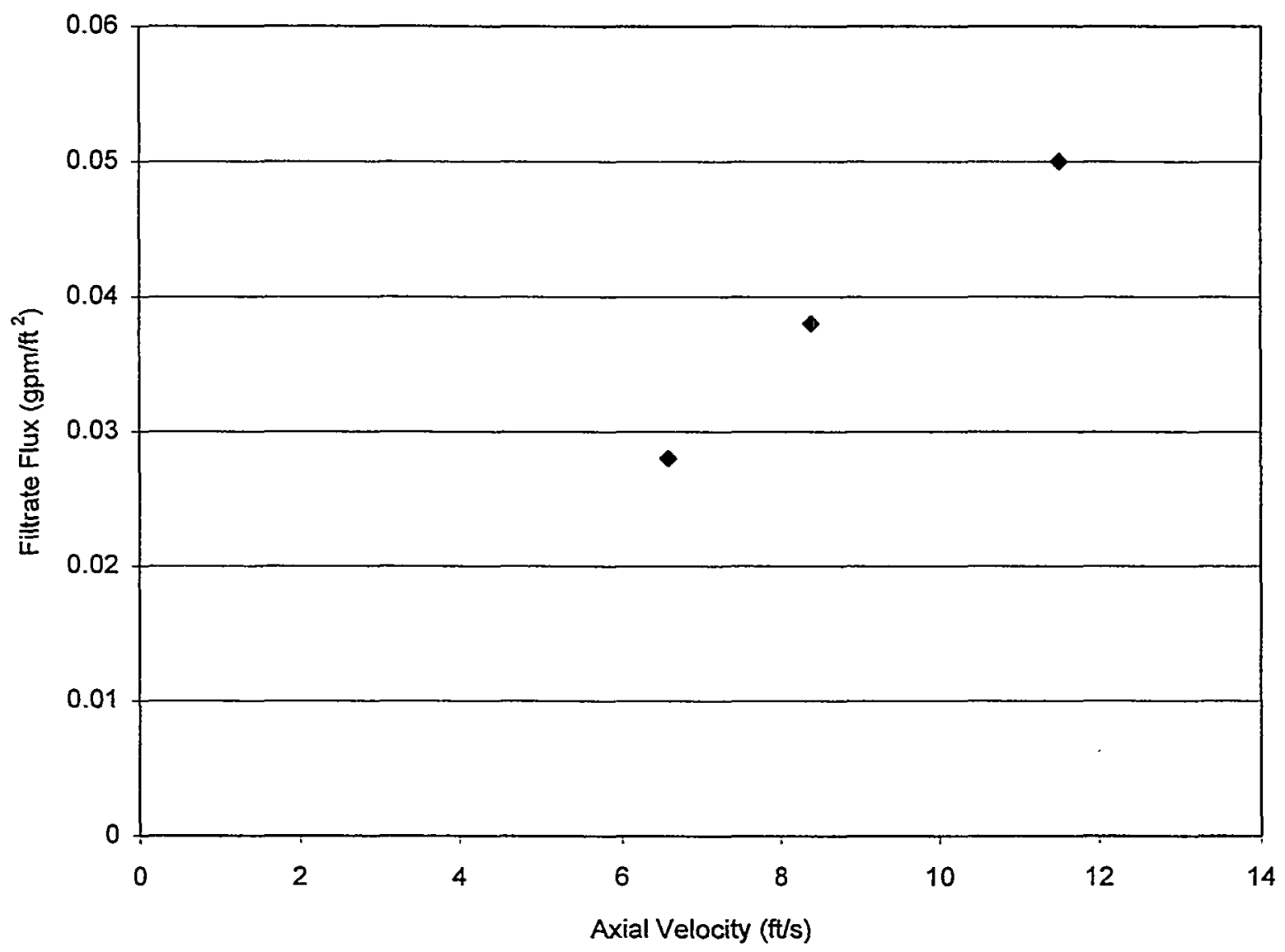

Figure 3.4. Filtrate Flux as a Function of Axial Velocity for the High Solids Matrix at -30 psid TMP 
The initial, final, and average filtrate-flux results are shown in Figure 3.5. The initial filtrate flux for the first condition was significantly higher than all subsequent conditions. Condition 7 also has a slightly higher initial filtrate flux, possibly due to the significantly higher axial velocity, which removes more material during backpulsing. The remaining conditions were relatively constant in initial filtrate flux.

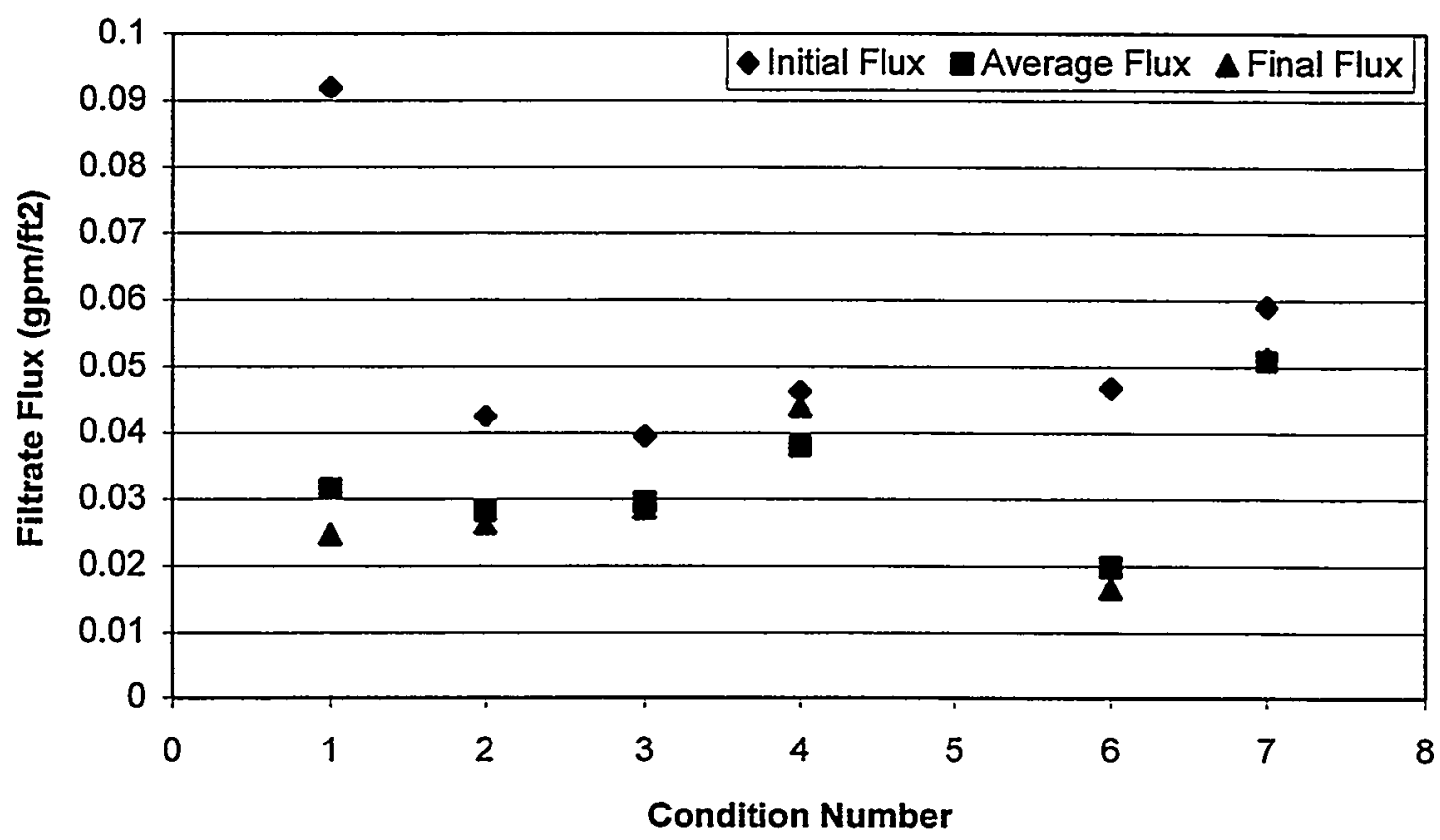

Figure 3.5. Initial, Average, and Final Filtrate Flux for Each Condition in the High-Solids Matrix

The filtrate fluxes for this high solids loading test matrix were lower than those seen in the previous matrix. With the 2.7-fold increase in solids concentration, the filtration flux decreased by an average of 2.3-fold (see Figure 3.6). In the case of Conditions \#1, \#2, and \#6, the differences were larger.

\subsubsection{Filtration Results During the Washing and Caustic Leaching Steps}

Washing with dilute caustic was performed in three steps. In each step, approximately $900 \mathrm{~mL}$ was added to the CUF, and then an equal quantity of filtrate was removed. During each of the steps, the solids concentration should increase from approximately $7 \%$ up to $11 \%$, assuming minimal solids dissolution during washing. The average filtrate fluxes for these washing steps are presented in Table 3.3. 


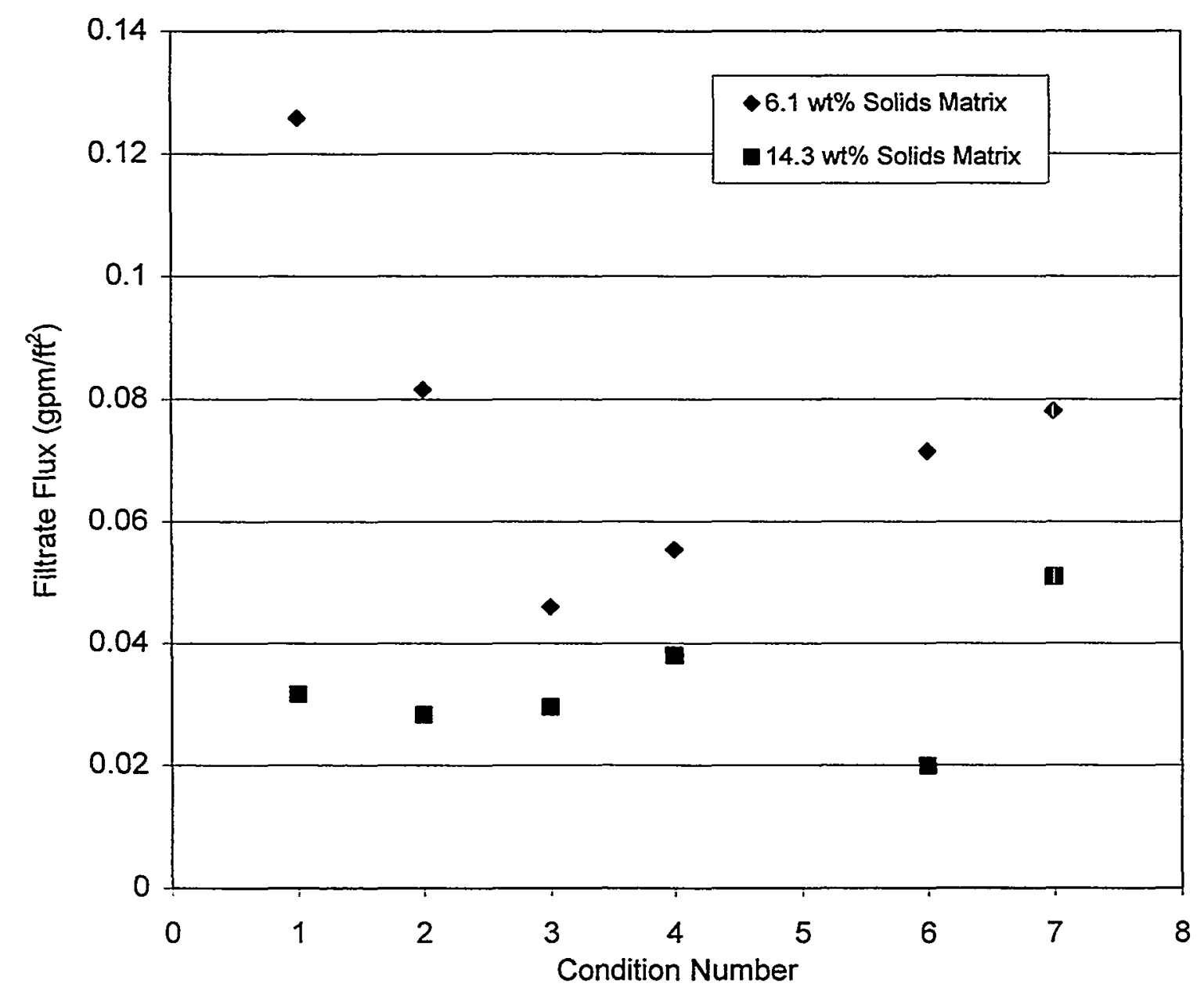

Figure 3.6. Average Filtrate Flux Comparison between High and Low Solids Loading Matrices 
Table 3.3. Average Filtrate Flux for Dewatering During Washing and Caustic Leach

\begin{tabular}{|l|c|c|c|c|}
\hline \multicolumn{1}{|c|}{ Step } & $\begin{array}{c}\text { Average Velocity } \\
(\mathrm{ft} / \mathrm{s})\end{array}$ & $\begin{array}{c}\text { Average Pressure } \\
(\mathrm{psid})\end{array}$ & $\begin{array}{c}\text { Average Filtrate } \\
\text { Flux (gpm/ft' }\end{array}$ & $\begin{array}{c}\text { High T Filtrate } \\
\text { Flux Corrected } \\
\text { for Temperature }\end{array}$ \\
\hline Wash 1 & 7.4 & 53.2 & 0.038 & (b) \\
\hline Wash 2 & 7.3 & 49.8 & 0.028 & (b) \\
\hline Wash 3 & 4.0 & 48.2 & 0.014 & (b) \\
\hline $\begin{array}{l}\text { Caustic } \\
\text { Leach }\end{array}$ & 8.8 & 31.0 & $0.17^{(\mathrm{a})}$ & 0.042 \\
\hline $\begin{array}{l}\text { Caustic } \\
\text { Wash 1 }\end{array}$ & 8.4 & 29.5 & $0.17^{(\mathrm{a})}$ & 0.042 \\
\hline
\end{tabular}

(a) Performed at $85^{\circ} \mathrm{C}$. Filtrate flux was not corrected for temperature using Equation 3.1.

(b) Performed near $25^{\circ} \mathrm{C}$ and corrected for temperature using Equation 3.1.

Each washing step required 20 to $40 \mathrm{~min}$ to remove the $900 \mathrm{~mL}$ of filtrate. With each washing step, the average filtrate flux decreased. In the case of Wash 3, this was the highest the pump would operate. . The larger reduction in filtrate flux for this case was probably due to the significant reduction in average velocity.

Filtrate flux data were also taken during the caustic leach and first caustic wash de-watering steps. During these tests, the filtration was performed at elevated temperatures. The filtrate flux rates at $85^{\circ} \mathrm{C}$, not corrected for the elevated temperature, are shown in Table 3.3. Overall, the insoluble solids concentration was increased from $\sim 5.9$ to $\sim 8.3 \mathrm{wt} \%$ solids in the case of the caustic leach and from $\sim 4.0$ to $\sim 8.8 \mathrm{wt} \%$ in the case of the first caustic wash. In both cases, the filtrate flux was much higher than matrices and de-watering done previously, indicating a possible significant increase in plant throughput as a result of higher operational temperatures. Elevated temperatures may, however, dissolve some solids that would reprecipitate in the filtrate after it is cooled. Using the correction in Equation 3.1, the filtrate flux was normalized to adjust the flux value on the same temperature basis. The resultant flux was reduced by approximately $75 \%$ and became more in line with the filtrate flux of Condition \#1 in the lowsolids test matrix.

\subsubsection{Statistical Analysis}

The goal of the statistical analysis is to estimate the error associated with these tests and to develop a model that adequately predicts the average flux for $\mathrm{AZ}-102$ over the range of conditions studied.

The standard deviation estimate for the overall test was calculated by assuming that the change in flux with respect to time was constant after the first $10 \mathrm{~min}$ of each condition and calculating the standard deviation for each run. While this is not entirely true since the filtrate flux continues to decline slowly over time, it does provide a means of estimating the error associated with testing while the process is at steady-state operation. These individual condition standard deviations were then pooled over all 12 conditions using the formulas: 


$$
s_{p}=\sqrt{\frac{\sum_{j=1}^{k} \sum_{i=1}^{n_{i}}\left(y_{i j}-\bar{y}_{i}\right)^{2}}{\sum_{j=1}^{k}\left(n_{j}-1\right)}} \quad \text { or } \quad s_{p}=\sqrt{\frac{\sum_{j=1}^{k}\left(n_{j}-1\right) s_{j}^{2}}{\sum_{j=1}^{k}\left(n_{j}-1\right)}}
$$

where the $y$ 's are the filtrate flux values, s's are the standard deviations for an individual condition, the n's are the number of observations in each run condition, and in our case, $k=12$ since there were 12 sludge/run conditions. Using the above formula with all 77 data points taken, the pooled standard deviation was calculated to be $0.00786 \mathrm{gpm} / \mathrm{ft}^{2}$.

There were 10 filtrate-flux determinations made for Condition \#7 at the $5.1 \%$ sludge concentration level. Of these, 2 were taken at the 41 -min mark, and 4 were taken at the 60 -min mark. In contrast to the previous data, these data points should provide a reasonable estimate of the standard deviation with a reduced effect of decline due to time. A pooled estimate for standard deviation was calculated using these points and was found to be $0.00681 \mathrm{gpm} / \mathrm{ft}^{2}$.

A statistical model can be used to understand the important factors, predict filtrate-flux performance, and control for the effects particular to the CUF test and equipment that would not be seen in actual operation (i.e., run number). Four possible factors were evaluated: linear velocity in $\mathrm{ft} / \mathrm{s}$ (Velocity), pressure in psid (Pressure), time or run order in hours (Run), solids concentration given as fraction of insoluble solids (Solids), or any combination of those variables. Since the Conditions for Matrix \#1 and \#2 were run in series, the value of "Run" ranges from 1 (Condition 1, Matrix 1) to 12 (Condition 7, Matrix 2).

A model was developed that incorporated both the low and high solids loading matrix. The regression analysis was conducted using the average flux of the 12 conditions studied in the high and low solids loading matricies. Multicollinearities were found among the regressor terms, so model selection followed an effort to eliminate redundant terms from the model and ultimately establish a model that fit the data well and provided reliable indicators of the effect of each term remaining in the model. The model with the best fit with only statistically significant terms took on the following form:

$$
\text { Average Flux }=0.0326+0.00734 \cdot \text { Velocity }(\mathrm{ft} / \mathrm{s})-0.00645 \cdot \mathrm{Run}
$$

For this model, the root mean square error was $0.01364 \mathrm{gpm} / \mathrm{ft}^{2}$ with an $\mathrm{R}$-square of 0.8079 .

The model shows that axial velocity has a positive relationship, and run number has a negative relationship with filtrate flux. These results were not unexpected since higher velocities remove more solids from the surface of the filter and improve filtrate fluxes while continued operation tends to foul the filter and reduce the filtrate flux. 
Transmembrane pressure was not included in the model because it was found to be collinear with velocity and did not contribute to the model. Transmembrane pressure may in fact be significant to the filtrate flux. Part of the reason for this may also be that no data were taken at high pressures and high velocities (due to equipment limitations); most of the data were taken either at high pressure and low velocity or low pressure and high velocity. Thus the two parameters were related in this data set.

Similarly, solids concentration was not included in the model because solids concentration and run number were also collinear. Since all low solids load data were taken during Runs 1-6 while all high solids loading data were taken during Runs 7-12, these two effects cannot be statistically separated from each other.

One of the purposes of these models was to determine the optimum conditions without the effect of run order for both solids concentrations. In the case of both the low and high solids loading matrix, the optimum filtration condition was the highest axial velocity. Higher solids loading, of course, reduces filtrate flux, although it was not included in the model.

\subsection{Sludge-Washing and Caustic-Leaching Results}

The chemical and radiochemical analyses obtained from the slurry-washing and caustic-leaching tests are presented in this section. Slurry samples were taken on the initial feed before the material was added to the CUF, following the three water washes, following the caustic leach, and at the conclusion of the tests following the two caustic washes. As discussed in Section 2, a sample of decanted supernatant was taken for analysis before the material was added to the CUF. Liquid samples were taken on all permeates removed throughout the course of the wash/leach steps. The results of these analyses for non-radioactive species are shown in Table 3.4. Slurry samples are presented here on a dry basis and permeate samples on a wet basis. When a sample is dried, it is done so by holding the sample at $105^{\circ} \mathrm{C}$ for 24 hours.

Table 3.4 shows that the primary metals in the initial slurry were, from highest to lowest concentration, iron, aluminum, sodium, uranium, cadmium, zirconium, nickel, and calcium. Significant soluble anions present in the slurry were nitrite, sulfate, and nitrate. Comparing the initial sample and intermediate Sample \#1, the initial dewatering steps as well as dilute caustic washing appear to have removed a majority of the sodium, potassium, and the anions.

During the caustic leaching, aluminum, phosphorus, silicon and chromium were removed, as well as additional potassium. The concentration of metals in the final slurry remained roughly in the same order as in the initial slurry (for the top eight components). During the course of washing and leaching, most of the soluble anions measured by IC were washed from the solids, with small amounts of chloride, phosphate, sulfate, and fluoride remaining.

The radioactive component concentrations are shown in Table 3.5. Of the major radioactive isotopes, only ${ }^{137} \mathrm{Cs}$ was significantly removed during leaching and washing. As would be expected, the ${ }^{90} \mathrm{Sr}$ and transuranic (TRU) isotopes remained with the slurry. 
Table 3.4. Non-Radioactive Component Concentrations

\begin{tabular}{|c|c|c|c|c|c|c|c|c|c|c|c|}
\hline & $\begin{array}{c}\text { Initial } \\
\text { Sample }^{(a)}\end{array}$ & $\begin{array}{c}\text { Initial } \\
\text { Sample } \\
\text { Supernate } \\
\end{array}$ & $\begin{array}{c}\text { Water } \\
\text { Wash } \\
\text { Permeate } \\
\text { No. } 1 \\
\end{array}$ & $\begin{array}{c}\text { Water Wash } \\
\text { Permeate } \\
\text { No. } 2 \\
\end{array}$ & $\begin{array}{c}\text { Water Wash } \\
\text { Permeate } \\
\text { No. } 3\end{array}$ & $\begin{array}{c}\text { Intermediate } \\
\text { Sample No. } 1^{(\mathrm{a})}\end{array}$ & $\begin{array}{c}\text { Caustic Leach } \\
\text { Permeate }\end{array}$ & $\begin{array}{c}\text { Intermediate } \\
\text { Sample No. } 2^{(n)}\end{array}$ & \begin{tabular}{|c|} 
Caustic \\
Wash \\
Permeate \\
No. 1 \\
\end{tabular} & $\begin{array}{c}\text { Caustic } \\
\text { Wash } \\
\text { Permeate No. } \\
2\end{array}$ & $\begin{array}{c}\text { Final } \\
\text { Sample }^{(\mathrm{a})}\end{array}$ \\
\hline Analyte & $\mu \mathrm{g} / \mathrm{g}$ & $\mu \mathrm{g} / \mathrm{mL}$ & $\mu \mathrm{g} / \mathrm{mL}$ & $\mu \mathrm{g} / \mathrm{mL}$ & $\mu \mathrm{g} / \mathrm{mL}$ & $\mu \mathrm{g} / \mathrm{g}$ & $\mu \mathrm{g} / \mathrm{mL}$ & $\mu \mathrm{g} / \mathrm{g}$ & $\mu \mathrm{g} / \mathrm{mL}$ & $\mu \mathrm{g} / \mathrm{mL}$ & $\mu \mathrm{g} / \mathrm{g}$ \\
\hline Ag & 352 & $<0.61$ & $<0.25$ & $<0.12$ & $<0.1$ & 390 & $<0.62$ & 235 & $<0.25$ & $<0.25$ & 470 \\
\hline Al & $1.25 \mathrm{E}+5$ & 217 & 146 & 108 & 93. & $1.85 \mathrm{E}+5$ & $1.04 \mathrm{E}+4$ & $1.01 \mathrm{E}+5$ & $4.91 \mathrm{E}+3$ & $2.18 \mathrm{E}+3$ & $1.07 \mathrm{E}+5$ \\
\hline As & $<1 \mathrm{E}+3$ & $<6.1$ & $<2.5$ & $<1.2$ & $<1$ & $<1 \mathrm{E}+3$ & 9.60 & $<2 \mathrm{E}+3$ & 5.80 & 2.60 & $<1 \mathrm{E}+3$ \\
\hline $\mathbf{B}$ & 125 & 44.6 & 14.9 & 15.0 & 11. & 230.0 & 23.9 & 250.0 & 10.00 & 10.5 & 225.0 \\
\hline $\mathbf{B a}$ & 550 & 0.260 & $<0.098$ & $<0.05$ & $<0.0$ & 808 & $<0.25$ & 521 & $<0.10$ & $<0.10$ & 958 \\
\hline $\mathrm{Be}$ & 13.5 & $<0.24$ & $<0.098$ & $<0.05$ & $<0.0$ & 20.00 & 0.250 & 12.00 & $<0.10$ & $<0.10$ & 22.50 \\
\hline $\mathbf{B i}$ & $<596$ & $<2.4$ & $<0.98$ & $<0.48$ & $<0.5$ & $<574$ & $<2.5$ & $<606$ & $<0.99$ & $<0.99$ & $<592$ \\
\hline $\mathrm{Ca}$ & $7.20 \mathrm{E}+3$ & 9.30 & 5.00 & 4.60 & 4.2 & $1.00 \mathrm{E}+4$ & 14.0 & $8.15 \mathrm{E}+3$ & 3.90 & 4.20 & $1.10 \mathrm{E}+4$ \\
\hline Cd & $2.07 E+4$ & $<0.37$ & $<0.15$ & $<0.07$ & $<0.0$ & $2.84 E+4$ & 15.0 & $1.79 \mathrm{E}+4$ & 0.870 & $<0.15$ & $3.30 \mathrm{E}+4$ \\
\hline $\mathrm{Ce}$ & $<1 \mathrm{E}+3$ & $<4.9$ & $<2.0$ & $<0.96$ & $<1$ & $1.30 \mathrm{E}+3$ & $<4.9$ & $<1 \mathrm{E}+3$ & $<2.0$ & $<2.0$ & $1.55 \mathrm{E}+3$ \\
\hline Co & 69.0 & $<1.2$ & $<0.49$ & $<0.24$ & $<0.2$ & 100.0 & $<1.2$ & 63.0 & $<0.50$ & $<0.50$ & 120.0 \\
\hline $\mathrm{Cr}$ & $2.14 \mathrm{E}+3$ & 826.5 & 36.3 & 20.6 & 11. & $1.58 \mathrm{E}+3$ & 43.8 & 969 & 17.4 & 8.82 & $1.64 \mathrm{E}+3$ \\
\hline $\mathrm{Cu}$ & 306 & 0.840 & $<0.25$ & $<0.12$ & $<0.1$ & 488 & $<0.62$ & 301 & $<0.25$ & $<0.25$ & 585 \\
\hline Dy & $<298$ & $<1.2$ & $<0.49$ & $<0.24$ & $<0.2$ & $<287$ & $<1.2$ & $<303$ & $<0.50$ & $<0.50$ & $<296$ \\
\hline Eu & $<596$ & $<2.4$ & $<0.98$ & $<0.48$ & $<0.5$ & $<574$ & $<2.5$ & $<606$ & $<0.99$ & $<0.99$ & $<592$ \\
\hline $\mathrm{Fe}$ & $1.40 \mathrm{E}+5$ & 0.685 & 0.320 & 0.200 & 0.35 & $1.87 \mathrm{E}+5$ & 3.70 & $1.20 \mathrm{E}+5$ & 1.000 & 0.810 & $2.21 \mathrm{E}+5$ \\
\hline $\mathrm{Hg}$ & 19.1 & 0.212 & na & \begin{tabular}{l|l} 
na \\
\end{tabular} & na & \begin{tabular}{l|} 
na \\
\end{tabular} & na & na & \begin{tabular}{l|} 
na \\
\end{tabular} & na & 26.6 \\
\hline $\mathbf{K}$ & $6.40 \mathrm{E}+3$ & $3.74 \mathrm{E}+3$ & 190 & 115 & 69. & $<1 \mathrm{E}+4$ & 190 & $<1 E+4$ & 61.0 & 27.0 & $<1 E+4$ \\
\hline $\mathrm{La}$ & $4.19 E+3$ & $<1.2$ & $<0.49$ & $<0.24$ & $<0.2$ & $6.33 E+3$ & $<1.2$ & $4.04 \mathrm{E}+3$ & $<0.50$ & $<0.50$ & $7.41 \mathrm{E}+3$ \\
\hline $\mathbf{L i}$ & $<179$ & $<0.73$ & $<0.29$ & $<0.14$ & $<0.1$ & $<172$ & $<0.74$ & $<182$ & $<0.30$ & $<0.30$ & $<177$ \\
\hline $\mathrm{Mg}$ & 805 & $<2.4$ & $<0.98$ & $<0.48$ & $<0.5$ & $1.60 \mathrm{E}+3$ & $<2.5$ & $1.05 \mathrm{E}+3$ & $<0.99$ & $<0.99$ & $1.95 \mathrm{E}+3$ \\
\hline $\mathbf{M n}$ & $3.37 \mathrm{E}+3$ & $<1.2$ & $<0.49$ & $<0.24$ & $<0.2$ & $4.50 \mathrm{E}+3$ & $<1.2$ & $2.90 \mathrm{E}+3$ & $<0.50$ & $<0.50$ & $5.38 \mathrm{E}+3$ \\
\hline
\end{tabular}




\begin{tabular}{|c|c|c|c|c|c|c|c|c|c|c|c|}
\hline & $\begin{array}{c}\text { Initial } \\
\text { Sample }^{(a)}\end{array}$ & $\begin{array}{c}\text { Initial } \\
\text { Sample } \\
\text { Supernate }\end{array}$ & $\begin{array}{l}\text { Water } \\
\text { Wash } \\
\text { Permeate } \\
\text { No. } 1\end{array}$ & $\begin{array}{c}\text { Water Wash } \\
\text { Permeate } \\
\text { No. } 2\end{array}$ & $\begin{array}{c}\text { Water Wash } \\
\text { Permeate } \\
\text { No. } 3\end{array}$ & $\begin{array}{c}\text { Intermediate } \\
\text { Sample No. } 1^{(\mathrm{a})}\end{array}$ & $\begin{array}{c}\text { Caustic Leach } \\
\text { Permeate }\end{array}$ & $\begin{array}{c}\text { Intermediate } \\
\text { Sample No. } 2^{(\mathrm{a})}\end{array}$ & \begin{tabular}{|c|} 
Caustic \\
Wash \\
Permeate \\
No. 1
\end{tabular} & \begin{tabular}{|c|} 
Caustic \\
Wash \\
Permeate No. \\
2
\end{tabular} & $\begin{array}{c}\text { Final } \\
\text { Sample }^{(a)}\end{array}$ \\
\hline Analyte & $\mu \mathrm{g} / \mathrm{g}$ & $\mu \mathrm{g} / \mathrm{mL}$ & $\mu \mathrm{g} / \mathrm{mL}$ & $\mu \mathrm{g} / \mathrm{mL}$ & $\mu \mathrm{g} / \mathrm{mL}$ & $\mu \mathrm{g} / \mathrm{g}$ & $\mu \mathrm{g} / \mathrm{mL}$ & $\mu \mathrm{g} / \mathrm{g}$ & $\mu \mathrm{g} / \mathrm{mL}$ & $\mu \mathrm{g} / \mathrm{mL}$ & $\mu \mathrm{g} / \mathrm{g}$ \\
\hline Mo & 90.0 & 61.4 & 3.00 & 1.70 & 0.970 & $<287$ & 2.30 & $<303$ & 1.30 & 2.50 & $<296$ \\
\hline $\mathrm{Na}$ & $1.17 \mathrm{E}+5$ & $7.02 E+4$ & $3.71 \mathrm{E}+3$ & $2.22 \mathrm{E}+3$ & $1.43 \mathrm{E}+3$ & $2.52 \mathrm{E}+4$ & $5.41 \mathrm{E}+4$ & $2.53 \mathrm{E}+5$ & $2.06 \mathrm{E}+4$ & $8.70 \mathrm{E}+3$ & $8.33 \mathrm{E}+4$ \\
\hline Nd & $2.94 \mathrm{E}+3$ & $<2.4$ & $<0.98$ & $<0.48$ & $<0.50$ & $4.46 \mathrm{E}+3$ & $<2.5$ & $2.83 E+3$ & $<0.99$ & $<0.99$ & $5.22 \mathrm{E}+3$ \\
\hline $\mathrm{Ni}$ & $9.31 \mathrm{E}+3$ & $<0.73$ & $<0.29$ & $<0.14$ & $<0.15$ & $1.37 \mathrm{E}+4$ & $<0.74$ & $8.71 \mathrm{E}+3$ & $<0.30$ & $<0.30$ & $1.62 \mathrm{E}+4$ \\
\hline $\mathbf{P}$ & $1.25 \mathrm{E}+3$ & 144 & 6.60 & 6.52 & 6.63 & $2.50 \mathrm{E}+3$ & 163 & $1.65 \mathrm{E}+3$ & 69.9 & 28.4 & $2.80 \mathrm{E}+3$ \\
\hline $\mathbf{P b}$ & $1.35 \mathrm{E}+3$ & $<2.4$ & $<0.98$ & $<<0.48$ & $<0.50$ & $1.87 \mathrm{E}+3$ & 6.10 & 1,155 & 2.40 & $<0.99$ & $2.25 \mathrm{E}+3$ \\
\hline Pd & $<4 \mathrm{E}+3$ & $<18$ & $<7.4$ & $<3.6$ & $<3.8$ & $<4 \mathrm{E}+3$ & $<19$ & $<5 \mathrm{E}+3$ & $<7.4$ & $<7.4$ & $<4 E+3$ \\
\hline $\mathbf{R h}$ & $<2 \mathrm{E}+3$ & $<7.3$ & $<2.9$ & $<1.4$ & $<1.5$ & $<2 \mathrm{E}+3$ & $<7.4$ & $<2 \mathrm{E}+3$ & $<3.0$ & $<3.0$ & $<2 \mathrm{E}+3$ \\
\hline $\mathbf{R u}$ & $<7 \mathrm{E}+3$ & $<27$ & $<11$ & $<5.3$ & $<5.5$ & $<6 \mathrm{E}+3$ & $<27$ & $<7 \mathrm{E}+3$ & $<11$ & $<11$ & $<7 \mathrm{E}+3$ \\
\hline $\mathbf{S b}$ & $<3 E+3$ & $<12$ & $<4.9$ & $<2.4$ & $<2.5$ & $<3 \mathrm{E}+3$ & $<12$ & $<3 \mathrm{E}+3$ & $<5.0$ & $<5.0$ & $<3 \mathrm{E}+3$ \\
\hline Se & $<1 E+3$ & $<6.1$ & $<2.5$ & $<1.2$ & $<1.3$ & $<1 \mathrm{E}+3$ & $<6.2$ & $<2 \mathrm{E}+3$ & $<2.5$ & $<2.5$ & $<1 \mathrm{E}+3$ \\
\hline Si & $4.95 \mathrm{E}+3$ & 302 & 33.0 & 33.7 & 28.7 & $5.50 \mathrm{E}+3$ & 120 & $1.63 E+4$ & 56.9 & 45.0 & $7.10 \mathrm{E}+3$ \\
\hline Sn & $<9 \mathrm{E}+3$ & $<37$ & $<15$ & $<7.2$ & $<7.5$ & $<9 \mathrm{E}+3$ & $<37$ & $<9 \mathrm{E}+3$ & $<15$ & $<15$ & $<9 \mathrm{E}+3$ \\
\hline $\mathbf{S r}$ & 265 & $<0.37$ & $<0.15$ & $<0.07$ & $<0.08$ & 393 & $<0.37$ & 255 & $<0.15$ & $<0.15$ & 473 \\
\hline Te & $<9 \mathrm{E}+3$ & $<37$ & $<15$ & $<7.2$ & $<7.5$ & $<9 \mathrm{E}+3$ & $<37$ & $<9 \mathrm{E}+3$ & $<15$ & $<15$ & $<9 \mathrm{E}+3$ \\
\hline Th & 720 & $<24$ & $<9.8$ & $<4.8$ & $<5.0$ & $<6 \mathrm{E}+3$ & $<25$ & $<6 \mathrm{E}+3$ & $<9.9$ & $<9.9$ & $<6 \mathrm{E}+3$ \\
\hline $\mathbf{T i}$ & 58.5 & $<0.61$ & $<0.25$ & $<0.12$ & $<0.13$ & 84.00 & $<0.62$ & 54.50 & $<0.25$ & $<0.25$ & $\mathbf{1 8 5}$ \\
\hline $\mathbf{T I}$ & $<3 E+3$ & $<12$ & $<4.9$ & $<2.4$ & $<2.5$ & $<3 E+3$ & $<12$ & $<3 \mathrm{E}+3$ & $<5.0$ & $<5.0$ & $<3 \mathrm{E}+3$ \\
\hline $\mathbf{U}$ & $2.70 \mathrm{E}+4$ & $<48.8$ & 38.0 & 18.0 & $<10.00$ & $3.68 \mathrm{E}+4$ & $<49.4$ & $2.32 \mathrm{E}+4$ & 24.0 & $<19.8$ & $4.24 \mathrm{E}+4$ \\
\hline $\mathrm{V}$ & $<298$ & $<1.2$ & $<0.49$ & $<0.24$ & $<0.25$ & $<287$ & 1.40 & $<303$ & 0.700 & $<0.50$ & $<296$ \\
\hline 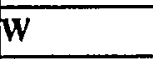 & $<1 E+4$ & $<49$ & $<20$ & $<9.6$ & $<10$ & $<1 \mathrm{E}+4$ & $<49$ & $<1 E+4$ & $<20$ & $<20$ & $<1 \mathrm{E}+4$ \\
\hline $\mathbf{Y}$ & $<298$ & $<1.2$ & $<0.49$ & $<0.24$ & $<0.25$ & $<287$ & $<1.2$ & $\begin{array}{c}<03 \\
\end{array}$ & 0.50 & $<0.50$ & 310 \\
\hline $\mathbf{Z n}$ & 340 & $<1.2$ & $<0.49$ & $<0.24$ & 0.330 & 500 & 3.40 & 475 & 3.70 & 0.980 & 970 \\
\hline $\mathbf{Z r}$ & $1.59 \mathrm{E}+4$ & $<1.2$ & $<0.49$ & $<0.24$ & $<0.25$ & $2.18 \mathrm{E}+4$ & $<1.2$ & $1.42 \mathrm{E}+4$ & 0.50 & $<0.50$ & $3.27 \mathrm{E}+4$ \\
\hline
\end{tabular}




\begin{tabular}{|c|c|c|c|c|c|c|c|c|c|c|c|}
\hline & $\begin{array}{c}\text { Initial } \\
\text { Sample }^{(a)}\end{array}$ & $\begin{array}{c}\text { Initial } \\
\text { Sample } \\
\text { Supernate }\end{array}$ & $\begin{array}{c}\text { Water } \\
\text { Wash } \\
\text { Permeate } \\
\text { No. } 1\end{array}$ & $\begin{array}{c}\text { Water Wash } \\
\text { Permeate } \\
\text { No. } 2\end{array}$ & \begin{tabular}{|c|} 
Water Wash \\
Permeate \\
No. 3
\end{tabular} & $\begin{array}{c}\text { Intermediate } \\
\text { Sample No. } 1^{(\mathrm{a})}\end{array}$ & $\begin{array}{c}\text { Caustic Leach } \\
\text { Permeate }\end{array}$ & $\mid \begin{array}{c}\text { Intermediate } \\
\text { Sample No. } 2^{(\mathrm{a})}\end{array}$ & $\begin{array}{c}\text { Caustic } \\
\text { Wash } \\
\text { Permeate } \\
\text { No. } 1\end{array}$ & \begin{tabular}{|c|} 
Caustic \\
Wash \\
Permeate No. \\
2
\end{tabular} & $\begin{array}{r}\text { Final } \\
\text { Sample }\end{array}$ \\
\hline Analyte & $\mu \mathrm{g} / \mathrm{g}$ & $\mu \mathrm{g} / \mathrm{mL}$ & $\mu \mathrm{g} / \mathrm{mL}$ & $\mu \mathrm{g} / \mathrm{mL}$ & $\mu \mathrm{g} / \mathrm{mL}$ & $\mu \mathrm{g} / \mathrm{g}$ & $\mu \mathrm{g} / \mathrm{mL}$ & $\mu \mathrm{g} / \mathrm{g}$ & $\mu \mathrm{g} / \mathrm{mL}$ & $\mu \mathrm{g} / \mathrm{mL}$ & $\mu \mathrm{g} / \mathrm{g}$ \\
\hline $\mathbf{F}$ & $1.70 \mathrm{E}+3$ & 750 & 50 & 30 & 2 & 230 & $<10$ & 590 & $<25$ & $<25$ & \\
\hline $\mathrm{Cl}$ & $<250$ & $<100$ & $<10$ & $<10$ & $<1$ & 400 & 890 & $4.15 E+3$ & 370 & 370 & 1.35 \\
\hline $\mathrm{NO}_{2}$ & $6.61 \mathrm{E}+4$ & $4.17 \mathrm{E}+4$ & $1.93 \mathrm{E}+3$ & $1.12 \mathrm{E}+3$ & 66 & $5.50 \mathrm{E}+3$ & 420 & $1.75 \mathrm{E}+3$ & 180 & 180 & $<$ \\
\hline $\mathrm{Br}$ & $<250$ & $<100$ & $<10$ & $<10$ & $<1$ & $<27$ & $<10$ & $<250$ & $<25$ & $<25$ & $\overline{<}$ \\
\hline $\mathrm{NO}_{3}$ & $2.14 \mathrm{E}+4$ & $1.38 \mathrm{E}+4$ & 740 & 380 & 22 & $1.60 \mathrm{E}+3$ & 160 & $<490$ & 100 & 100 & \\
\hline $\mathrm{PO}_{4}$ & 569 & 435 & $<20$ & $<20$ & 3 & 960 & 210 & $2.05 \mathrm{E}+3$ & 160 & 160 & \\
\hline $\mathrm{SO}_{4}$ & $2.93 E+4$ & $2.11 \mathrm{E}+4$ & $1.13 \mathrm{E}+3$ & 600 & 35 & $2.80 \mathrm{E}+3$ & 220 & 995 & 110 & 110 & \\
\hline $\mathrm{C}_{2} \mathrm{O}_{4}$ & $3.90 \mathrm{E}+3$ & $3.29 \mathrm{E}+3$ & 160 & 130 & 8 & 420 & 30 & $<490$ & $<50$ & $<50$ & \\
\hline $\mathrm{CN}$ & 13.5 & 9.60 & 3.10 & 2.40 & 2.3 & 8.80 & 1.70 & 5.00 & 1.80 & 1.00 & \\
\hline TIC & $7.99 \mathrm{E}+3$ & $8.62 \mathrm{E}+3$ & 790 & 430 & 42 & 560 & 900 & $1.12 \mathrm{E}+4$ & $3.13 \mathrm{E}+3$ & 645 & 2.871 \\
\hline TOC & 760 & $1.07 \mathrm{E}+3$ & 50 & 40 & $<4$ & 610 & $<40$ & $1.79 \mathrm{E}+3$ & 580 & 60 & 2.751 \\
\hline TC & $8.75 \mathrm{E}+3$ & $9.69 \mathrm{E}+3$ & 840 & 470 & 42 & $1.17 \mathrm{E}+3$ & 900 & $1.20 \mathrm{E}+4$ & $3.71 \mathrm{E}+3$ & 705 & $\overline{5.62]}$ \\
\hline
\end{tabular}


Table 3.5. Radioactive Component Concentrations

\begin{tabular}{|c|c|c|c|c|c|c|c|c|c|c|c|}
\hline & $\begin{array}{c}\text { Initial } \\
\text { Sample }^{(a)}\end{array}$ & $\begin{array}{c}\text { Initial Sample } \\
\text { Supernate }\end{array}$ & $\begin{array}{c}\text { Water Wash } \\
\text { Permeate } \\
\text { No. } 1\end{array}$ & $\begin{array}{c}\text { Water Wash } \\
\text { Permeate } \\
\text { No. } 2\end{array}$ & \begin{tabular}{|c|} 
Water Wash \\
Permeate \\
No. 3
\end{tabular} & $\begin{array}{c}\text { Intermediate } \\
\text { Sample } \\
\text { No. } 1^{(a)}\end{array}$ & $\begin{array}{c}\text { Caustic } \\
\text { Leach } \\
\text { Permeate }\end{array}$ & \begin{tabular}{|} 
Intermediate \\
Sample \\
No. $2^{(a)}$
\end{tabular} & \begin{tabular}{|c|} 
Caustic \\
Wash \\
Permeate \\
No. 1
\end{tabular} & $\begin{array}{c}\text { Caustic } \\
\text { Wash } \\
\text { Permeate } \\
\text { No. } 2\end{array}$ & $\begin{array}{c}\text { Final } \\
\text { Sample }^{(a)}\end{array}$ \\
\hline Analyte & $\mu \mathrm{Ci} / \mathrm{g}$ & $\mu \mathrm{Ci} / \mathrm{mL}$ & $\mu \mathrm{Ci} / \mathrm{mL}$ & $\mu \mathrm{Ci} / \mathrm{mL}$ & $\mu \mathrm{Ci} / \mathrm{mL}$ & $\mu \mathrm{Ci} / \mathrm{g}$ & $\mu \mathrm{Ci} / \mathrm{mL}$ & $\mu \mathrm{Ci} / \mathrm{g}$ & $\mu \mathbf{C i} / \mathbf{m L}$ & $\mu \mathbf{C i} / \mathbf{m L}$ & $\mu \mathrm{Ci} / \mathrm{g}$ \\
\hline${ }^{00} \mathrm{Sr}$ & $1.64 \mathrm{E}+4$ & 2.04 & $3.26 \mathrm{E}-2$ & $1.30 \mathrm{E}-2$ & $1.85 \mathrm{E}-2$ & $2.17 \mathrm{E}+4$ & 0.136 & $1.27 \mathrm{E}+4$ & $3.42 \mathrm{E}-2$ & $2.56 \mathrm{E}-2$ & $2.49 E+4$ \\
\hline${ }^{239,240} \mathrm{Pu}$ & 6.33 & $3.02 \mathrm{E}-2$ & $3.53 \mathrm{E}-5$ & $1.75 \mathrm{E}-5$ & $2.10 \mathrm{E}-5$ & 7.63 & $9.77 \mathrm{E}-5$ & 4.69 & $1.67 \mathrm{E}-5$ & $1.69 \mathrm{E}-5$ & 9.83 \\
\hline${ }^{238} \mathrm{Pu}$ & 0.767 & $3.36 \mathrm{E}-3$ & $5.15 \mathrm{E}-5$ & $4.08 \mathrm{E}-5$ & $5.61 \mathrm{E}-5$ & 1.21 & $5.05 \mathrm{E}-5$ & 0.712 & $4.45 \mathrm{E}-5$ & $4.25 \mathrm{E}-5$ & 1.57 \\
\hline${ }^{236} \mathrm{Pu}$ & $<0.05$ & $3.32 \mathrm{E}-5$ & $<3 \mathrm{E}-7$ & $<1 \mathrm{E}-6$ & $<2 \mathrm{E}-7$ & $<0.06$ & $<1 \mathrm{E}-7$ & $<0.05$ & $<3 E-7$ & $<2 \mathrm{E}-7$ & $<0.3$ \\
\hline${ }^{241} \mathrm{Am}$ (AEA) & 113 & $2.09 \mathrm{E}-4$ & $1.53 \mathrm{E}-4$ & $3.41 \mathrm{E}-5$ & $4.99 \mathrm{E}-5$ & 135 & $3.24 \mathrm{E}-5$ & 90.0 & $3.36 \mathrm{E}-5$ & $1.32 \mathrm{E}-4$ & 175 \\
\hline${ }^{243,244} \mathrm{Cm}$ & 0.300 & $2.82 \mathrm{E}-5$ & $4.90 \mathrm{E}-5$ & $4.81 \mathrm{E}-5$ & $6.54 \mathrm{E}-5$ & 0.25 & $4.33 \mathrm{E}-5$ & $<0.3$ & $5.30 \mathrm{E}-5$ & $4.91 \mathrm{E}-5$ & 0.281 \\
\hline${ }^{242} \mathrm{Cm}$ & $9.67 \mathrm{E}-2$ & $<1.5 \mathrm{E}-5$ & $<2 \mathrm{E}-7$ & $<2 \mathrm{E}-7$ & $<2 \mathrm{E}-7$ & $7.95 \mathrm{E}-2$ & $<1 \mathrm{E}-7$ & $<0.07$ & $<2 \mathrm{E}-7$ & $<3 E-7$ & $<0.06$ \\
\hline Total Alpha & 143.3 & na & na & na & \begin{tabular}{l|} 
na \\
\end{tabular} & na & na & na & na & na & \\
\hline${ }^{80} \mathrm{Co}$ & 4.71 & $<6 \mathrm{E}-3$ & $<4 \mathrm{E}-4$ & $<5 E-4$ & $<4 \mathrm{E}-4$ & 5.55 & $<5 E-4$ & 2.03 & $<5 \mathrm{E}-4$ & $<6 \mathrm{E}-4$ & $\overline{7.40}$ \\
\hline${ }^{106} \mathbf{R u R h}$ & na & na & $<1 \mathrm{E}-1$ & $<7 \mathrm{E}-2$ & $<6 \mathrm{E}-2$ & 5.71 & $<9 \mathrm{E}-2$ & 1.18 & $<6 \mathrm{E}-2$ & $<4 \mathrm{E}-2$ & 11.8 \\
\hline${ }^{125} \mathrm{Sb}$ & 24.1 & $<7 \mathrm{E}-1$ & $<6 \mathrm{E}-2$ & $<5 \mathrm{E}-2$ & $<4 \mathrm{E}-2$ & 19.6 & $<6 \mathrm{E}-2$ & 11.0 & $<4 \mathrm{E}-2$ & $<3 \mathrm{E}-2$ & 40.3 \\
\hline${ }^{134} \mathrm{Cs}$ & 1.98 & 1.20 & $5.29 \mathrm{E}-2$ & $3.05 \mathrm{E}-2$ & $1.85 \mathrm{E}-2$ & $<0.6$ & $4.36 \mathrm{E}-2$ & $<0.1$ & $2.18 \mathrm{E}-2$ & $9.95 \mathrm{E}-3$ & $<7 \mathrm{E}-1$ \\
\hline${ }^{137} \mathrm{Cs}$ & $1.80 \mathrm{E}+3$ & $1.12 \mathrm{E}+3$ & 48.0 & 29.1 & 17.8 & 546 & 42.6 & 160 & 20.8 & 9.09 & 169 \\
\hline${ }^{194} \mathrm{Eu}$ & 44.7 & $<3 \mathrm{E}-2$ & $<3 \mathrm{E}-3$ & $<2 \mathrm{E}-3$ & $<2 \mathrm{E}-3$ & 57.1 & $<2 \mathrm{E}-3$ & 19.2 & $<2 \mathrm{E}-3$ & $<2 \mathrm{E}-3$ & 72.8 \\
\hline${ }^{155} \mathrm{Eu}$ & 83.4 & $<5 \mathrm{E}-1$ & $<4 \mathrm{E}-2$ & $<3 \mathrm{E}-2$ & $<3 \mathrm{E}-2$ & 105 & $<4 \mathrm{E}-2$ & 35.6 & $<3 \mathrm{E}-2$ & $<2 \mathrm{E}-2$ & 134 \\
\hline${ }^{241} \mathrm{Am}$ (GEA) & 126 & $<5 \mathrm{E}-1$ & $<4 \mathrm{E}-2$ & $<3 \mathrm{E}-2$ & $<3 \mathrm{E}-2$ & 156 & $<4 E-2$ & 57.1 & $<3 E-2$ & $<2 \mathrm{E}-2$ & 203 \\
\hline${ }^{14} \mathrm{C}$ & $1.51 \mathrm{E}-3$ & na & na & na & na & na & na & na & na & na & $2.36 \mathrm{E}-3$ \\
\hline
\end{tabular}




\begin{tabular}{|c|c|c|c|c|c|c|c|c|c|c|c|}
\hline & $\begin{array}{c}\text { Initial } \\
\text { Sample }^{(\mathfrak{a})}\end{array}$ & \begin{tabular}{c|} 
Initial Sample \\
Supernate
\end{tabular} & \begin{tabular}{|c} 
Water Wash \\
Permeate \\
No. 1
\end{tabular} & $\begin{array}{c}\text { Water Wash } \\
\text { Permeate } \\
\text { No. } 2\end{array}$ & \begin{tabular}{|c} 
Water Wash \\
Permeate \\
No. 3
\end{tabular} & $\begin{array}{c}\text { Intermediate } \\
\text { Sample } \\
\text { No. } 1^{(a)}\end{array}$ & $\begin{array}{c}\text { Caustic } \\
\text { Leach } \\
\text { Permeate }\end{array}$ & \begin{tabular}{|c|} 
Intermediate \\
Sample \\
No. 2
\end{tabular} & \begin{tabular}{|c|} 
Caustic \\
Wash \\
Permeate \\
No. 1 \\
\end{tabular} & $\begin{array}{c}\text { Caustic } \\
\text { Wash } \\
\text { Permeate } \\
\text { No. } 2 \\
\end{array}$ & $\begin{array}{c}\text { Final } \\
\text { Sample }^{(\mathrm{a})}\end{array}$ \\
\hline & $\mu \mathrm{g} / \mathrm{g}$ & $\mathrm{ng} / \mathrm{mL}$ & $\mathrm{ng} / \mathrm{mL}$ & $\mathrm{ng} / \mathrm{mL}$ & $\mathrm{ng} / \mathrm{mL}$ & $\mathrm{ng} / \mathrm{mL}$ & $\mathrm{ng} / \mathrm{mL}$ & $\mathrm{ng} / \mathrm{mL}$ & $\mathrm{ng} / \mathrm{mL}$ & $\mathrm{ng} / \mathrm{mL}$ & $\mu \mathrm{g} / \mathrm{g}$ \\
\hline Cs & 23.6 & 20.1 & na & $\mathrm{na}$ & na & na & na & na & na & na & 2.37 \\
\hline $\mathrm{Pr}$ & 481 & na & na & na & na & na & na & na & $\mathrm{na}$ & na & 796 \\
\hline Ta & 2.21 & na & na & $\mathrm{na}$ & na & na & na & na & na & na & 20.3 \\
\hline${ }^{237} \mathrm{~Np}$ & 103 & 0.140 & na & na & na & na & na & na & na & na & 175 \\
\hline $\mathbf{R b}$ & 232 & na & na & na & na & na & na & na & na & na & 228 \\
\hline${ }^{99} \mathrm{Tc}$ & 22.7 & 13.8 & na & na & na & na & na & na & na & na & 1.55 \\
\hline${ }^{126} \mathrm{Sn}$ & $<0.7$ & na & na & na & na & na & na & na & na & na & $<0.9$ \\
\hline 127 & 20.5 & $6.34 \mathrm{E}-2$ & na & na & na & na & na & na & na & na & $\overline{19.4}$ \\
\hline${ }^{229} 1$ & $<3.1$ & $1.53 \mathrm{E}-2$ & na & na & na & na & na & na & na & na & $<2.5$ \\
\hline${ }^{135,137} \mathrm{Cs}$ & 0.443 & 0.505 & na & na & na & na & na & na & na & na & 0.423 \\
\hline Tritium & $4.09 \mathrm{E}-2^{(0)}$ & na & na & na & na & $\mathrm{na}$ & na & na & na & na & $1.61 \mathrm{E}-2^{(6)}$ \\
\hline
\end{tabular}


Table 3.6. Distribution of Non-Radioactive Analytes in the Wash Steps

\begin{tabular}{|c|c|c|c|c|c|}
\hline Analyte & $\begin{array}{c}\text { Water Wash } \\
\text { Efficiency }^{(b)} \\
(\%)^{(\mathbf{b})}\end{array}$ & $\begin{array}{l}\text { Caustic Leach } \\
\text { Efficiency (\%) }\end{array}$ & $\begin{array}{c}\text { Caustic Wash No. } 1 \\
\text { Efficiency (\%) }\end{array}$ & $\mid \begin{array}{c}\text { Caustic Wash No. } 2 \\
\text { Efficiency (\%) }\end{array}$ & Residue (\%) \\
\hline $\mathbf{A g}$ & $<0$ & $<1$ & $<1$ & $<1$ & $>96.9$ \\
\hline$\overline{A l}$ & 2.5 & 59.3 & 1.9 & $<0.003$ & 36.3 \\
\hline As & $<12$ & 81.1 & 18.9 & $<19$ & 0 \\
\hline$\overline{\mathbf{B}}$ & 62.5 & 20.8 & $<1$ & 16.7 & 0 \\
\hline$\overline{\mathbf{B a}}$ & $<0.1$ & $<0.3$ & $<0.1$ & $<0.1$ & $>99.4$ \\
\hline $\mathrm{Be}$ & $<3$ & 13.9 & $<5$ & $<5$ & 86.0 \\
\hline $\mathbf{C a}$ & 60.4 & 39.6 & $<8$ & $<8$ & 0 \\
\hline$\overline{C d}$ & $<0.00$ & 0.66 & $<0.01$ & $<0.01$ & 99.3 \\
\hline $\mathrm{Ce}$ & $<1$ & $<3$ & $<2$ & $<2$ & $>92.4$ \\
\hline $\mathrm{Co}$ & $<3$ & $<10$ & $<5$ & $<5$ & 100.0 \\
\hline $\mathbf{C r}$ & 44.1 & 13.6 & $<0.1$ & 0.54 & 41.7 \\
\hline$\overline{\mathbf{C u}}$ & $<0.4$ & $<1$ & $<0.5$ & $<0.6$ & $>97.5$ \\
\hline Fe & 0.006 & 0.02 & $<0.001$ & $<0.001$ & 99.97 \\
\hline$\overline{\mathbf{K}}$ & 80.9 & 19.1 & $<2$ & $<2$ & 0 \\
\hline$\overline{\mathrm{La}}$ & $<0.1$ & $<0.2$ & $<0.1$ & $<0.1$ & $>99.6$ \\
\hline$\overline{M g}$ & $<0$ & $<1$ & $<1$ & $<1$ & $>97.0$ \\
\hline $\mathbf{M n}$ & $<0.1$ & $<0.2$ & $<0.1$ & $<0.1$ & $>99.5$ \\
\hline$\overline{M o}$ & 65.9 & 11.6 & 2.9 & 19.6 & 0 \\
\hline $\mathbf{N a}$ & 80.2 & nd & nd & nd & 11.2 \\
\hline Nd & $<0.2$ & $<0.5$ & $<0.2$ & $<0.3$ & $>98.9$ \\
\hline$\overline{\mathbf{N i}}$ & $<0.02$ & $<0.0$ & $<0.02$ & $<0.02$ & $>99.9$ \\
\hline $\mathbf{P}$ & 6.7 & 44.5 & $<0.2$ & 0.7 & 47.7 \\
\hline$\overline{\mathbf{P b}}$ & $<0.4$ & 3.8 & $<0.5$ & $<0.6$ & $<96.2,>94.7$ \\
\hline $\mathbf{S i}$ & 16.1 & 14.0 & $<1$ & 4.5 & $<65.3,>64.7$ \\
\hline $\mathbf{S r}$ & $<0.3$ & $<1$ & $<0.4$ & $<0.4$ & $>98.1$ \\
\hline$\overline{\mathbf{T}} \mathbf{i}$ & $<1$ & $<3$ & $<2$ & $<2$ & $>92.0$ \\
\hline$\overline{\mathbf{U}}$ & 1.8 & $<1$ & 1.22 & $<1$ & $<96.5,>95.8$ \\
\hline $\bar{\nabla}$ & $<19$ & 93.1 & 6.9 & $<30$ & \\
\hline$\overline{\mathbf{Y}}$ & $<1$ & $<4$ & $<2$ & $<2$ & $>90.5$ \\
\hline $\mathbf{Z n}$ & 0.6 & $4 . \overline{3}$ & 4.5 & $<1$ & $<90.6,>90.0$ \\
\hline $\mathbf{Z r}$ & $<0.01$ & $<0.04$ & $<0.02$ & $<0.02$ & $>99.9$ \\
\hline $\mathbf{F}$ & 77.5 & $<12$ & $<44$ & $<43$ & $<22.5$ \\
\hline CI & $<2$ & 73.9 & 0 & 26.1 & 0 \\
\hline $\mathrm{NO}_{2}$ & 94.1 & 0 & 0 & 5.9 & 0 \\
\hline $\mathrm{NO}_{3}$ & 87.2 & 0 & 4.3 & 8.5 & 0 \\
\hline $\mathrm{PO}_{4}$ & 8.5 & 40.6 & 21.5 & 29.4 & 0 \\
\hline $\mathrm{SO}_{4}$ & 92.5 & $\cdot 0$ & 1.11 & 6.4 & $\overline{0}$ \\
\hline $\mathrm{C}_{2} \mathrm{O}_{4}$ & 100 & 0 & $<30$ & $<29$ & 0 \\
\hline $\mathrm{CN}$ & 75.5 & 0.19 & 20.3 & 4.2 & 0 \\
\hline
\end{tabular}




\begin{tabular}{|l|r|r|r|r|r|}
\hline Analyte & $\begin{array}{c}\text { Water Wash } \\
\text { Efficiency } \\
\mathbf{( \% )}^{(\mathbf{b})}\end{array}$ & $\begin{array}{r}\text { Caustic Leach } \\
\text { Efficiency (\%) }\end{array}$ & $\begin{array}{r}\text { Caustic Wash No. 1 } \\
\text { Efficiency (\%) }\end{array}$ & $\begin{array}{l}\text { Caustic Wash No. 2 } \\
\text { Efficiency (\%) }\end{array}$ & Residue (\%) \\
\hline \hline IIC & 20.0 & 9.9 & 70.1 & 0 & 0 \\
\hline TOC & 4.3 & $<4$ & 81.5 & 0 & $<14.2,>10.4$ \\
\hline TC & 18.0 & 8.5 & 73.4 & 0 & 0 \\
\hline
\end{tabular}

(a) Accounts for carry-over of interstitial liquid.

(b) Accounts for material removed in the initial dewatering steps.

Note: $\mathrm{nd}=$ Not determined due to large amount of sodium added as wash steps.

The removal efficiencies both for the initial dilute washing and the caustic leaching of the nonradioactive and radioactive components are shown in Table 3.6 and Table 3.7. The results indicate that $80.2 \%$ of the sodium was removed from the slurry during the water-washing steps. Nearly all of the soluble fluoride, nitrite, nitrate, sulfate, oxalate, and cyanide were removed during the first water washes. Chloride and phosphate were the only exceptions, with phosphate having only $8.5 \%$ removal, and no measurable chloride was removed during the water washes. Other non-radioactive components with significant removal efficiencies during the water wash were boron with $63 \%$ removal, calcium with $60 \%$ removal, chromium with $44 \%$ removal, potassium with $81 \%$ removal, and molybdenum with $66 \%$ removal.

The TIC and TOC concentrations and removal efficiencies are somewhat suspect. The highest concentrations of TIC and TOC were found in the first caustic-wash solution, where 70 and $82 \%$ of the total was removed. It would seem unlikely that both TIC and TOC would be removed in this particular step. Analytical error was possibly the culprit.

In terms of radioactive components, $61 \%$ of the ${ }^{137} \mathrm{Cs}$ was removed during the initial water-wash steps.

The caustic-leach and subsequent caustic-washing steps were performed at estimated $2.4,0.9$, and $0.38 \mathrm{M} \mathrm{NaOH}$ concentrations. The leaching efficiencies of these steps are also shown in Tables 3.6 and 3.7. While only $1.9 \%$ of the aluminum was removed during the dilute caustic washing, $59.3 \%$ was removed during the caustic-leaching step. 
Table 3.7. Distribution of Radioactive Analytes in the Wash Steps

\begin{tabular}{|c|c|c|c|c|c|}
\hline Analyte & $\begin{array}{l}\text { Water Wash } \\
\text { Efficiency } \\
(\%)^{(b)}\end{array}$ & $\begin{array}{l}\text { Caustic Leach } \\
\text { Efficiency (\%) }\end{array}$ & $\begin{array}{c}\text { Caustic Wash No. } 1 \\
\text { Efficiency (\%) }\end{array}$ & $\begin{array}{c}\text { Caustic Wash No. } 2 \\
\text { Efficiency (\%) }\end{array}$ & $\begin{array}{c}\text { Residue } \\
(\%)\end{array}$ \\
\hline${ }^{90} \mathrm{Sr}$ & 0.003 & 0.007 & 0 & 0.001 & 99.99 \\
\hline${ }^{239,240} \mathbf{P u}$ & 0.008 & 0.01 & 0 & 0.002 & 99.98 \\
\hline${ }^{238} \mathbf{P u}$ & 0.11 & 0.01 & 0.03 & 0.033 & 99.81 \\
\hline${ }^{241} \mathrm{Am}$ (AEA) & 0.001 & 0 & 0.0002 & 0.001 & 99.997 \\
\hline${ }^{243,244} \mathrm{Cm}$ & 0.69 & 0 & 0.27 & 0.20 & 98.8 \\
\hline${ }^{60} \mathrm{Co}$ & $<0.2$ & $<0.1$ & $<0.2$ & $<0.2$ & $>99.4$ \\
\hline${ }^{106} \mathbf{R u R h}$ & $<20$ & $<11$ & $<11$ & $<7$ & $>49.7$ \\
\hline${ }^{125} \mathrm{Sb}$ & $<4$ & $<2$ & $<2$ & $<2$ & $>90.1$ \\
\hline${ }^{134} \mathrm{Cs}$ & 65.2 & 30.1 & 3.8 & 0.81 & 0 \\
\hline${ }^{137} \mathrm{Cs}$ & 61.2 & 29.6 & 3.0 & 0.17 & 6.1 \\
\hline${ }^{154} \mathbf{E u}$ & $<0.1$ & $<0.04$ & $<0.06$ & $<0.06$ & $>99.7$ \\
\hline${ }^{155} \mathbf{E u}$ & $<0.8$ & $<0.4$ & $<0.5$ & $<0.3$ & $>97.9$ \\
\hline${ }^{241}$ Am (GEA) & $<0.5$ & $<0.3$ & $<0.3$ & $<0.2$ & $>98.6$ \\
\hline
\end{tabular}

The quantity of HLW glass produced from the as-received AZ-102 waste would have been limited by the high aluminum oxide concentration. With a DOE limit of $21 \%$ for the $\mathrm{Al}_{2} \mathrm{O}_{3}+\mathrm{Fe}_{2} \mathrm{O}_{3}+\mathrm{ZrO}_{2}$ and a mass of $207 \mathrm{~g}$ of dried initial sample going into the CUF, $450 \mathrm{~g}$ of HLW glass would be produced with the initial sludge. Even with almost $64 \%$ removal of $\mathrm{Al}$ from the sample after washing and leaching, $\mathrm{Al}_{2} \mathrm{O}_{3}+\mathrm{Fe}_{2} \mathrm{O}_{3}+\mathrm{ZrO}_{2}$ are still the limiting constituents in the glass. However, with the aluminum reduction, approximately 100-130 $\mathrm{g}$ of dried material would remain after caustic leaching, producing 315$345 \mathrm{~g}$ of $\mathrm{HLW}$ glass. Assuming no material was lost or removed during the process, this would be a glass mass reduction of $23-30 \%$.

Other non-radioactive constituents significantly removed during the caustic-leaching process were arsenic, boron, calcium, potassium, and vanadium. Additionally, greater than $50 \%$ of the aluminum, chromium, phosphorus, and greater than $75 \%$ of the sodium, IC measured anions, TOC, and TIC were removed during the combined washing and leaching steps. Of the radioactive components, only ${ }^{134} \mathrm{Cs}$, ${ }^{137} \mathrm{Cs}$, and possibly tritium were removed in significant quantities during the caustic-leaching process.

Table 3.8 shows the percentage recovery. The mass recovery is the comparison of the total mass of analyte recovered throughout the test (what is removed in each process step plus what remains in the sludge residue) to the mass of analyte present in the initial sludge. The mass recovery can be represented as

$$
\text { Re covery }=\frac{\sum \text { Analyte }_{\text {leach } / \text { wash }}+\text { Analyte }_{\text {resitue }}}{\text { Analyte }_{\text {initial sludge }}} \cdot 100
$$


Table 3.8. Mass Recovery

\begin{tabular}{|r|c|}
\hline \multicolumn{1}{|c|}{ Analyte } & Recovery \\
\hline $\mathrm{Ag}$ & $81 \%$ \\
$\mathrm{Al}$ & $120 \%$ \\
$\mathrm{As}$ & - \\
$\mathrm{B}$ & $532 \%$ \\
$\mathrm{Ba}$ & $106 \%$ \\
$\mathrm{Be}$ & $106 \%$ \\
$\mathrm{Ca}$ & $97 \%$ \\
$\mathrm{Cd}$ & $97 \%$ \\
$\mathrm{Ce}$ & - \\
$\mathrm{Co}$ & $105 \%$ \\
$\mathrm{Cr}$ & $102 \%$ \\
$\mathrm{Cu}$ & $116 \%$ \\
$\mathrm{Fe}$ & $96 \%$ \\
$\mathrm{Hg}$ & $81 \%$ \\
$\mathbf{K}$ & $88 \%$ \\
$\mathrm{La}$ & $107 \%$ \\
$\mathbf{M g}$ & $146 \%$ \\
$\mathrm{Mn}$ & $97 \%$ \\
$\mathrm{Mo}$ & $115 \%$ \\
$\mathrm{Na}$ & $114 \%$ \\
$\mathrm{Nd}$ & $108 \%$ \\
$\mathrm{Ni}$ & $105 \%$ \\
\hline
\end{tabular}

\begin{tabular}{|rc|}
\hline Analyte & Recovery \\
\hline $\mathbf{P}$ & $238 \%$ \\
$\mathrm{~Pb}$ & $103 \%$ \\
$\mathrm{Si}$ & $134 \%$ \\
$\mathrm{Sr}$ & $108 \%$ \\
$\mathrm{Th}$ & $0 \%$ \\
$\mathrm{Ti}$ & $186 \%$ \\
$\mathbf{U}$ & $98 \%$ \\
$\mathbf{V}$ & - \\
$\mathbf{Y}$ & - \\
$\mathrm{Zn}$ & $183 \%$ \\
$\mathbf{Z r}$ & $123 \%$ \\
$\mathbf{F}$ & $81 \%$ \\
$\mathrm{Cl}$ & - \\
$\mathrm{NO}_{2}$ & $78 \%$ \\
$\mathrm{NO}_{3}$ & $78 \%$ \\
$\mathrm{PO}_{4}$ & $631 \%$ \\
$\mathrm{SO}_{4}$ & $86 \%$ \\
$\mathrm{C}_{2} \mathrm{O}_{4}$ & $102 \%$ \\
$\mathrm{CN}$ & $674 \%$ \\
$\mathrm{TIC}$ & $269 \%$ \\
$\mathrm{TOC}$ & $455 \%$ \\
$\mathrm{TC}$ & $285 \%$ \\
\hline &
\end{tabular}

\begin{tabular}{|rr|}
\hline Radionuclide & Recovery \\
${ }^{90} \mathrm{Sr}$ & $90 \%$ \\
${ }^{239,}{ }^{240} \mathrm{Pu}$ & $92 \%$ \\
${ }^{238} \mathrm{Pu}$ & $121 \%$ \\
${ }^{241} \mathrm{Am}(\mathrm{AEA})$ & $92 \%$ \\
${ }^{243,}, 244 \mathrm{Cm}$ & $54 \%$ \\
${ }^{242} \mathrm{Cm}$ & $1 \%$ \\
${ }^{60} \mathrm{Co}$ & $91 \%$ \\
${ }^{125} \mathrm{Sb}$ & $97 \%$ \\
${ }^{134} \mathrm{Cs}$ & $79 \%$ \\
${ }^{137} \mathrm{Cs}$ & $88 \%$ \\
${ }^{154} \mathrm{Eu}$ & $95 \%$ \\
${ }^{155} \mathrm{Eu}$ & $93 \%$ \\
${ }^{241} \mathrm{Am} \mathrm{(GEA)}$ & $94 \%$ \\
${ }^{14} \mathrm{C}$ & $88 \%$ \\
$\mathrm{Tritium}$ & $95 \%$ \\
$\mathbf{C s}$ & $6 \%$ \\
$\mathbf{P r}$ & $93 \%$ \\
$\mathrm{Ta}$ & $517 \%$ \\
${ }^{237} \mathrm{~Np}$ & $95 \%$ \\
$\mathbf{R b}$ & $55 \%$ \\
${ }^{99} \mathrm{Tc}$ & $4 \%$ \\
${ }^{127} \mathrm{I}$ & $53 \%$ \\
${ }^{135,137} \mathrm{Cs}$ & $54 \%$ \\
\hline &
\end{tabular}

This value provides a means of evaluating the closure of the mass balance (i.e., how much of each component was not accounted for). In general, the recoveries were reasonably close to $100 \%$. There were some cases where the recoveries were very much larger or much smaller than $100 \%$. These generally occur for analytes at very low concentrations throughout the process. These deviations also occur when there is significant error in one or more of the analyses (e.g., TOC, TIC). The major constituent recoveries indicate that very little of the total slurry mass was unaccounted for during the process.

Recoveries for the radionuclides also appear reasonably close to $100 \%$, especially with the major radionuclides. In some cases, analysis was performed on the starting and final material, but not on the permeate samples removed throughout the washing and leaching process. In this case, the recovery provides an estimate of the removal efficiency during the washing and leaching. For example, the recovery indicates that $>96 \%$ of the ${ }^{99} \mathrm{Tc}, 47 \%$ of the ${ }^{127} \mathrm{I}$, and only $5 \%$ of the tritium were removed during processing. Without the full data set, it is not possible, however, to distinguish poor mass recoveries from high removal efficiencies. 
The insoluble radioactive-component concentrations provide a means of measuring the capability of the filter to separate the insoluble solids from the liquids. The isotope ${ }^{241} \mathrm{Am}$ is basically insoluble in caustic solutions and its concentration was measured for all permeates and slurries so it was used to measured filter removal efficiency. This can be done in terms of a decontamination factor (DF) for each step of the process using the following equation:

$$
D F=\frac{C_{A m, \text { solids }} w t \%_{\text {solids }}}{100 C_{\text {Am,permeate }}}
$$

where $C_{A m \text {,permeate }}$ is the ${ }^{241} \mathrm{Am}$ concentration in a given permeate sample, $C_{A m \text {,solids }}$ is the ${ }^{241} \mathrm{Am}$ concentration in the dried slurry taken during that time, and wt\% slurry is the weight percent solids in the dried slurry. The ${ }^{241} \mathrm{Am}$ water-wash DFs were between 100,000 and 450,000, and the caustic-leach DFs were 400,000. These high DFs indicate good solid/liquid separations using the Mott $0.1-\mu \mathrm{m}$ sintered metal filter. 


\subsection{Physical-Properties and Rheological-Properties Testing}

This section describes physical and rheological analyses conducted on samples of AZ-102 slurry. The physical and rheological analyses included density, weight percent (wt\%) and volume percent (vol\%) solids, and shear stress as a function of shear rate.

Physical measurement samples were taken three times during the course of testing: 1) before the second filtration test matrix but after the material had been dewatered to approximately $13.7 \mathrm{wt} \%$ solids (concentrated slurry-CUF-AZ102-006);2) after the caustic leaching step and the caustic permeate had been removed from the slurry to approximately $9 \mathrm{wt} \%$ solids (caustic leached slurry-CUF-AZ102-012); and 3) at the end of testing, after washing and caustic leaching the slurry at approximately $9.2 \mathrm{wt} \%$ solids (final slurry--CUF-AZ102-025).

Rheological measurements were taken three times during the course of testing: 1) after the first filtration test matrix at approximately $5.1-w t \%$ solids (initial slurry); 2) after the second filtration test matrix at approximately $13.7 \mathrm{wt} \%$ solids (concentrated slurry); and 3) at the end of testing, after washing and caustic leaching the slurry at approximately $9.2 \mathrm{wt} \%$ solids (final slurry). Each of these subsamples

- were taken directly from the ultrafiltration loop and immediately characterized by shear stress versus shear rate. Following rheological measurements, the material was returned to the CUF for continued testing, thus no sample number applies for these measurements.

\subsection{Physical-Properties Analysis}

The above-described AZ-102 physical property samples were analyzed for density of the bulk slurries, settled solids, centrifuged solids, and centrifuged supernatant. The density results are listed in Table 4.1. The weight percent ( $w t \%$ ) and volume percent (vol\%) settled solids (on a wet basis), wt $\%$ and vol\% centrifuged solids (on a wet basis), and wt $\%$ total solids (on a dry basis) were measured for these samples as well. The wt\% and vol\% solids results are listed in Table 4.2.

For this testing, a known mass of each slurry was placed in duplicate in volume-graduated centrifuge cones. The duplicates were then allowed to settle for 3 days. The total mass $\left(M_{B}\right)$ and volume $\left(V_{B}\right)$ of the slurry after it was allowed to settle were recorded and the density of the bulk slurry was calculated $\left(D_{B}=M_{B} / V_{B}\right)$. These results appeared to be biased low and had a high relative percent difference, probably because of entrained gas as well as an inability to clearly measure the total sample volume due to material smeared on the sides of the centrifuge tubes. Therefore, the bulk slurry densities were recalculated later in the work using volumes recorded following centrifugation. Following settling, the volume of the settled solids $\left(\mathrm{V}_{\mathrm{ss}}\right)$ and volume of clarified supernatant $\left(\mathrm{V}_{\mathrm{st}}\right)$ were recorded. The vol\% settled solids were then calculated $\left(\mathrm{Vol} \%_{\mathrm{ss}}=\mathrm{V}_{\mathrm{ss}} / \mathrm{V}_{\mathrm{B}} \times 100 \%\right)$. For previous samples in the BNFL project, a portion of the clarified supernatant was then transferred to a graduated cylinder to determine supernatant density. For these samples of AZ-102, there was insufficient liquid to make this determination. 
Table 4.1. Density Measurements for Samples of AZ-102

\begin{tabular}{|l|c|c|c|c|}
\hline \multirow{2}{*}{ Average Values } & \multicolumn{4}{|c|}{ Bulk Density, g/mL } \\
\cline { 2 - 5 } & $\begin{array}{c}\text { Centrifuged } \\
\text { Slurry }\end{array}$ & $\begin{array}{c}\text { Settled } \\
\text { Solids }\end{array}$ & $\begin{array}{c}\text { Centrifuged } \\
\text { Solids }\end{array}$ & $\begin{array}{c}\text { Centrifuged } \\
\text { Supernatant }\end{array}$ \\
\hline $\begin{array}{l}\text { Concentrated Slurry } \\
\text { CUF-AZ102-006 }\end{array}$ & 1.09 & 1.07 & 1.36 & 1.016 \\
\hline $\begin{array}{l}\text { Relative \% } \\
\text { Difference }\end{array}$ & $2 \%$ & $6 \%$ & $2 \%$ & $0.1 \%$ \\
\hline $\begin{array}{l}\text { Caustic Leached } \\
\text { Slurry } \\
\text { CUF-AZ102-012 }\end{array}$ & 1.16 & 1.15 & 1.35 & 1.108 \\
\hline $\begin{array}{l}\text { Relative \% } \\
\text { Difference }\end{array}$ & $1 \%$ & $2 \%$ & $1 \%$ & $4 \%$ \\
\hline $\begin{array}{l}\text { Final Slurry } \\
\text { CUF-AZ102-025 }\end{array}$ & 1.05 & 1.07 & 1.20 & 1.040 \\
\hline $\begin{array}{l}\text { Relative \% } \\
\text { Difference }\end{array}$ & $0 \%$ & NA & $6 \%$ & $0 \%$ \\
\hline
\end{tabular}

(a) The relative \% difference is between the sample and its duplicate and provides a means for showing sample variability.

Table 4.2. Wt\% and Vol\% Solids Measurements for Samples of AZ-102

\begin{tabular}{|l|c|c|c|c|c|}
\hline Average Values & $\begin{array}{c}\text { Wt\% } \\
\text { Settled } \\
\text { (wet basis) }\end{array}$ & $\begin{array}{c}\text { Wt\% } \\
\text { Centrifuged } \\
\text { (wet basis) }\end{array}$ & $\begin{array}{c}\text { Vol\% } \\
\text { Settled } \\
\text { (wet basis) }\end{array}$ & $\begin{array}{c}\text { Vol\% } \\
\text { Centrifuged } \\
\text { (wet basis) }\end{array}$ & $\begin{array}{c}\text { Wt\% Total } \\
\text { (dry basis) }\end{array}$ \\
\hline $\begin{array}{l}\text { Concentrated } \\
\text { Slurry } \\
\text { CUF-AZ102-006 }\end{array}$ & 95 & 33 & 96 & 26 & 14.8 \\
\hline $\begin{array}{l}\text { Relative \% } \\
\text { Difference }\end{array}$ & $2 \%$ & $0 \%$ & $5 \%$ & $4 \%$ & $0 \%$ \\
\hline $\begin{array}{l}\text { Caustic Leached } \\
\text { Slurry } \\
\text { CUF-AZ102-012 }\end{array}$ & 96 & 32 & 96 & 28 & 16.0 \\
\hline $\begin{array}{l}\text { Relative \% } \\
\text { Difference }\end{array}$ & $1 \%$ & $3 \%$ & $3 \%$ & $4 \%$ & $39 \%$ \\
\hline $\begin{array}{l}\text { Final Slurry } \\
\text { CUF-AZ102-025 }\end{array}$ & $1 \%$ & 30 & 93 & 26 & 9.8 \\
\hline $\begin{array}{l}\text { Relative \% } \\
\text { Difference }\end{array}$ & 94 & NA & $8 \%$ & $5 \%$ \\
\hline
\end{tabular}


The samples were then centrifuged at approximately 1000 times the force of gravity for $1 \mathrm{~h}$. All of the centrifuged supernatant was then transferred to a graduated cylinder, its mass $\left(M_{\mathrm{cl}}\right)$ and volume were $\left(\mathrm{V}_{\mathrm{cl}}\right)$ recorded, and the density was calculated $\left(\mathrm{D}_{\mathrm{cl}}=\mathrm{M}_{\mathrm{cl}} / \mathrm{V}_{\mathrm{cl}}\right)$. The mass $\left(\mathrm{M}_{\mathrm{cs}}\right)$ and volume $\left(\mathrm{V}_{\mathrm{cs}}\right)$ of the centrifuged solids were then recorded, and the density was calculated $\left(D_{c s}=M_{c s} / V_{c s}\right)$. In addition, the wt\% centrifuged solids ( $\left.\mathrm{Wt} \% \%_{c s}=\mathrm{M}_{\mathrm{cs}} / \mathrm{M}_{\mathrm{B}} \times 100 \%\right)$, and vol\% centrifuged solids $\left(\mathrm{Vol} \%_{\mathrm{cl}}=\mathrm{V}_{\mathrm{cl}} / \mathrm{V}_{\mathrm{B}} \times 100 \%\right)$ were also calculated.

Before centrifugation, the supernatant following solids settling could not be removed from the centrifuge cone without disturbing the settled solids; therefore, the mass of the settled solids $\left(\mathrm{M}_{\mathrm{ss}}\right)$ could not be measured directly. The mass of the settled solids was calculated. This was done by first calculating the mass of the settled supernatant in the centrifuge cone using the measured centrifuged supernatant following solids settling density and volume $\left(M_{\mathrm{sl}}=\mathrm{D}_{\mathrm{cl}} \times \mathrm{V}_{\mathrm{sl}}\right)$, then subtracting this mass for the mass of the bulk slurry to get the mass of the settled solids $\left(M_{s s}=M_{B}-M_{s l}\right)$. The density of the settled solids was then calculated $\left(D_{s s}=M_{s s} / V_{s s}\right)$ as well as the wt\% settled solids $\left(W t \%_{s s}=M_{s s} / M_{B} \times 100 \%\right)$.

The centrifuged solids and supernatants were then each dried at $105^{\circ} \mathrm{C}$ for $24 \mathrm{~h}$. The mass of the dried centrifuged supernatant $\left(\mathrm{M}_{\mathrm{dcl}}\right)$ and dried centrifuged solids $\left(\mathrm{M}_{\mathrm{dcs}}\right)$ were then measured. Assuming that all mass lost during the drying process was water and not another volatile component, the weight percent total solids in the bulk slurry was calculated (Wt\% total solids $\left.=\left[\mathrm{M}_{\mathrm{des}}+\mathrm{M}_{\mathrm{dcl}}\right] /\left[\mathrm{M}_{\mathrm{cs}}+\mathrm{M}_{\mathrm{cl}}\right] \times 100 \%\right)$.

The density of the centrifuged supernatant for the concentrated slurry was $1.016 \mathrm{~g} / \mathrm{mL}$. As would be expected, this value increased to $1.108 \mathrm{~g} / \mathrm{mL}$ following addition of the $3 \mathrm{M} \mathrm{NaOH}$ leach solution. Following the final water wash, the supernatant density was down to $1.040 \mathrm{~g} / \mathrm{mL}$.

The wt $\%$ settled solids were between 94 and $96 \%$ and the vol\% settled solids were between 93 and $96 \%$ for all three samples analyzed. Similarly, the wt $\%$ and vol\% centrifuged solids for all three samples were between 30 and $33 \%$ and 26 and $28 \%$, respectively. Based on the similarity between the wt $\%$ and vol\% settled and centrifuged solids over the course of testing, it would seem that the CUF test matrix and leaching did not significantly effect the solids packing characteristics of this sludge.

An additional calculation was performed to determine the $w t \%$ solids in the samples, excluding all interstitial liquid (wt\% undissolved solids). This can also be thought of as the solids left if all the supernatant could be removed from the bulk slurry. The following equation was used:

$$
\text { Wt } \% \text { undissolved solids }=\left(1-\frac{1-\frac{M_{d s c}}{M_{c s}}}{1-\frac{M_{d c l}}{M_{c l}}}\right) \times \frac{M_{c s}}{M_{B}} \times 100 \%
$$

This calculation assumes 1) that the supernatant and the interstitial liquid have the same composition, and 2) that all mass loss during the drying of the centrifuged solids was water loss from interstitial liquid. The results of this calculation are listed in Table 4.3 along with the wt\% dried residue from the centrifuged solids (Solids Residue $=\mathrm{M}_{\mathrm{des}} \mathrm{M}_{\mathrm{cs}} \times 100 \%$ ), and dried centrifuged supernatant (Supernatant Residue $=\mathrm{M}_{\mathrm{dcl}} / \mathrm{M}_{\mathrm{cl}} \times 100 \%$ ). 
Table 4.3. Results of Wt\% Residual Solids and Undissolved Solids Calculation Following Drying at $105^{\circ} \mathrm{C}$ for $24 \mathrm{~h}$ for Samples of $\mathrm{AZ}-102$

\begin{tabular}{|l|c|c|c|}
\hline \multicolumn{1}{|c|}{ Sample } & \multicolumn{1}{|c|}{$\begin{array}{c}\text { Wt\% Residual } \\
\text { Centrifuged Solids }\end{array}$} & $\begin{array}{c}\text { Wt\% Residual } \\
\text { Centrifuged } \\
\text { Supernatant }\end{array}$ & $\begin{array}{c}\text { Wt\% } \\
\text { Undissolved } \\
\text { Solids }\end{array}$ \\
\hline $\begin{array}{l}\text { Concentrated Slurry } \\
\text { CUF-AZ102-006 } \\
\text { Average }\end{array}$ & 41.65 & 1.55 & 13.6 \\
\hline $\begin{array}{l}\text { Relative \% } \\
\text { Difference }\end{array}$ & 0.2 & 6 & 1 \\
\hline $\begin{array}{l}\text { Caustic Leached } \\
\text { Slurry } \\
\text { CUF-AZ102-012 } \\
\text { Average }\end{array}$ & 37.4 & 10.45 & 9.5 \\
\hline $\begin{array}{l}\text { Relative\% } \\
\text { Difference }\end{array}$ & 1 & 10 & 2 \\
\hline $\begin{array}{l}\text { Final Slurry } \\
\text { CUF-AZ102-025 } \\
\text { Average }\end{array}$ & 32.6 & 1.7 & 9.2 \\
\hline $\begin{array}{l}\text { Relative \% } \\
\text { Difference }\end{array}$ & NA & NA & NA \\
\hline
\end{tabular}

NA - Not applicable, the centrifuged liquid from CUF-AZ102-025 was spilled so no duplicate was available. A relative percent difference requires two values.

\subsection{Rheological and Flow Properties}

The AZ-102 initial diluted feed, dewatered slurry (similar to CUF-AZ102-006), and final slurry (same as CUF-AZ102-025) were analyzed for shear stress as a function of shear rate from approximately 0.1 to $500 \mathrm{~s}^{-1}$ or $1000 \mathrm{~s}^{-1}$. The slurries were analyzed at $25^{\circ} \mathrm{C}$ using a Haake M5 measuring head modified for hot cell operations. An MVI measuring geometry was used on the Haake. A $49.9 \mathrm{cP}$ standard, Brookfield lot 102298 , was used to check the calibration of the instrument before samples were analyzed.

Samples of the initial diluted slurry and the dewatered slurry were collected directly from the ultrafiltration test loop and immediately analyzed. The final slurry sample was collected in a $125-\mathrm{mL}$ wide-mouth jar and analyzed approximately 1 day later. Before analyzing the final slurry sample, the sample in the jar was shaken to combine the separated liquid and solid layers. Shear stress as a function of shear rate data was obtained by measuring the shear stress produced at a specific shear rate. 
As requested by the client, samples were allowed to sit in the system for 5 minutes before analysis. The shear rate was then gradually increased from 0 to either $500 \mathrm{~s}^{-1}$ or $1000 \mathrm{~s}^{-1}$, generating the increasing shear rate curve, and then back down to $0 \mathrm{~s}^{-1}$ generating the decreasing curve. For analysis conducted to $1000 \mathrm{~s}^{-1}$, the shear rate was increased to $1000 \mathrm{~s}^{-1}$ over $5 \mathrm{~min}$. The shear rate was then held at $1000 \mathrm{~s}^{-1}$ for $5 \mathrm{~min}$, and then decreased to $0 \mathrm{~s}^{-1}$ over $5 \mathrm{~min}$. In general, analyses of this duration can exhibit solids settling problems. Shorter duration runs from 0 to $500 \mathrm{~s}^{-1}$ over 2 min followed by a decreasing curve from 500 to $0 \mathrm{~s}^{-1}$ over $2 \mathrm{~min}$ were used to look for settling behavior. As will be discussed, no evidence of settling in the slurries was observed during these analyses.

Rheograms for the standards, samples, and duplicates are presented in Figures 1 through 15 in Appendix F. The measured viscosity at $33 \mathrm{~s}^{-1}$ for both the increasing and decreasing curve are presented in Table 4.4. The first sample of the initial diluted feed was analyzed from 0 to $1000 \mathrm{~s}^{-1}$ two times without removing the sample from the instrument. The viscosity of the sample was near the lower limit for the instrument, roughly $2 \mathrm{cP}$. This sample displayed a low viscosity, between 12 and $2.5 \mathrm{cP}$, between 33 and $430 \mathrm{~s}^{-1}$. A yield point was detected, but below the quantification limit of $1 \mathrm{~Pa}$. A decrease in viscosity with increasing shear rate above a yield point is referred to as yield pseudoplastic behavior. All AZ-102 samples displayed yield pseudoplastic behavior. The initial slurry samples showed a decrease in viscosity between the increasing shear rate curve and the decreasing shear-rate curve as well as between runs. This decrease in viscosity with increasing shear history is referred to as thixotropic behavior.

Above approximately $430 \mathrm{~s}^{-1}$, a sharp rise in shear stress with shear rate was observed for the initial slurry. This represents the onset of Taylor Vortices. Taylor Vortices are the result of a secondary flow that occurs as the inner cylinder of the concentric-cylinder instrument rotates. Taylor Vortices result from analyzing a material at too high a shear rate. All data collected above the onset of Taylor vortices is invalid. Taylor vortices are expected when the following two equations are satisfied:

$\operatorname{Re}>41.3\left[R_{2} /\left(R_{2}-R_{1}\right)\right]^{1 / 2}$

$\operatorname{Re}=\gamma\left(\mathrm{R}_{2}-\mathrm{R}_{1}\right)^{2} \rho / \mu$

Where $R_{1}=$ Radius of Inner Cylinder (0.02004 $\mathrm{m}$ for MVI)

$\mathrm{R}_{\mathbf{2}}=$ Radius of Outer Cylinder $(0.02100 \mathrm{~m}$ for MVI)

$\gamma=$ Shear Rate $\left(\mathrm{s}^{-1}\right)$

$\rho=$ density $(g / m L)$

$\mu=$ Apparent viscosity (Paøs)

For the initial slurry, the density was $1.09 \mathrm{~g} / \mathrm{mL}$ and the apparent viscosity of the slurry at the onset of Taylor Vortices was approximately $2.5 \mathrm{cP}(0.0025 \mathrm{~Pa} \bullet \mathrm{s})$. Applying the above equations, Taylor Vortices would be expected at $480 \mathrm{~s}^{-1}$. This value of $480 \mathrm{~s}^{-1}$ is within $12 \%$ of the observed value of $430 \mathrm{~s}^{-1}$. Several analyses of the initial slurry were conducted only to $500 \mathrm{~s}^{-1}$ to provide better resolution of the onset. These analyses show an onset of $460 \mathrm{~s}^{-1}$, which is within $4 \%$ of the predicted value. 
Table 4.4. Results for Yield Stress and Viscosity at $33 \mathrm{sec}^{-1}$ for Samples of AZ-102 Slurry Along with Observed Onset of Taylor Vortices

\begin{tabular}{|c|c|c|c|c|c|c|}
\hline \multirow[b]{2}{*}{ Sample } & \multirow[b]{2}{*}{ Analysis } & \multirow[b]{2}{*}{$\begin{array}{c}\text { Yield } \\
\text { Stress } \\
(\mathrm{Pa}) \\
\end{array}$} & \multirow[b]{2}{*}{$\begin{array}{c}\text { Upper } \\
\text { Shear } \\
\text { Rate }\left(s^{-1}\right)\end{array}$} & \multicolumn{2}{|c|}{ Viscosity (cP) } & \multirow[b]{2}{*}{$\begin{array}{c}\text { Taylor } \\
\text { Vortices } \\
\text { Onset }\left(\mathrm{s}^{-1}\right)\end{array}$} \\
\hline & & & & $\begin{array}{c}\text { Increasin } \\
\text { g Curve } \\
\text { At } 33 \mathrm{~s}^{-1}\end{array}$ & $\begin{array}{c}\text { Decreasing } \\
\text { Curve } \\
\text { At } 33 \mathrm{~s}^{-1}\end{array}$ & \\
\hline \multirow[t]{5}{*}{ Initial Slurry } & $\begin{array}{l}\text { Sample 1 } \\
\text { Run 1 }\end{array}$ & $<1$ & 1000 & 12 & $\mathrm{BD}$ & 430 \\
\hline & $\begin{array}{l}\text { Sample 1 } \\
\text { Run 2 }\end{array}$ & $<1$ & 1000 & 5 & $\mathrm{BD}$ & 430 \\
\hline & $\begin{array}{l}\text { Sample } 2 \\
\text { Run } 1\end{array}$ & $<1$ & 500 & 16 & 6 & 460 \\
\hline & $\begin{array}{l}\text { Sample } 2 \\
\text { Run } 2\end{array}$ & $<1$ & 500 & 13 & 4 & 460 \\
\hline & $\begin{array}{l}\text { Sample } 2 \\
\text { Run } 3\end{array}$ & $<1$ & 1000 & 11 & 5 & 430 \\
\hline \multirow[t]{6}{*}{$\begin{array}{l}\text { Concentrated } \\
\text { Slurry }\end{array}$} & $\begin{array}{l}\text { Sample 1 } \\
\text { Run 1 }\end{array}$ & 3 & 1000 & 100 & 29 & ND \\
\hline & $\begin{array}{l}\text { Sample 1 } \\
\text { Run } 2\end{array}$ & 1.2 & 1000 & 39 & 25 & 940 \\
\hline & $\begin{array}{l}\text { Sample 2 } \\
\text { Run } 1\end{array}$ & 2.6 & 500 & 82 & 47 & ND \\
\hline & $\begin{array}{l}\text { Sample } 2 \\
\text { Run } 2\end{array}$ & 1.8 & 500 & 58 & 40 & ND \\
\hline & $\begin{array}{l}\text { Sample } 2 \\
\text { Run } 3\end{array}$ & 1.5 & 1000 & 49 & 35 & 940 \\
\hline & $\begin{array}{l}\text { Sample } 2 \\
\text { Run } 4\end{array}$ & 1.3 & 1000 & 43 & 32 & 890 \\
\hline \multirow[t]{3}{*}{ Final Slurry } & $\begin{array}{l}\text { Sample 1 } \\
\text { Run 1 }\end{array}$ & 8 & 1000 & 172 & 171 & NA \\
\hline & $\begin{array}{l}\text { Sample } 2 \\
\text { Run } 1\end{array}$ & 6.5 & 1000 & 167 & 189 & NA \\
\hline & $\begin{array}{l}\text { Sample } 2 \\
\text { Run } 2\end{array}$ & 8 & 1000 & 205 & 209 & NA \\
\hline
\end{tabular}

$\mathrm{ND}-$ Not detected, analysis only conducted to $500 \mathrm{~s}^{-1}$.

NA - Not applicable, onset of Taylor Vortices above limit of viscometer.

$\mathrm{BD}-$ Below detection, detection limit for Haake with MVI is approximately $2 \mathrm{cP}$. 
The concentrated slurry displayed yield pseudoplastic and thixotropic behavior. This sample displayed a yield stress of approximately $2.5-3.5 \mathrm{~Pa}$. The initial sample displayed high viscosity on the increasing shear-rate curve along with a bump between 700 and $900 \mathrm{~s}^{-1}$. This behavior was not seen during the decreasing shear rate curve of this sample or any of the duplicate analyses. This behavior was probably the result of large solids or agglomerates that were broken up at the higher shear rates. The onset of Taylor vortices occurred at $940 \mathrm{~s}^{-1}$, and $890 \mathrm{~s}^{-1}$ for this sample. Using a density of $1.16 \mathrm{~g} / \mathrm{mL}$ and a viscosity of approximately $0.045 \mathrm{~Pa} \cdot \mathrm{s}$, the expected onset was $815 \mathrm{~s}^{-1}$. The expected value of $815 \mathrm{~s}^{-1}$ was within approximately $15 \%$ of the observed values. As with the initial slurry sample, all data collected above the onset of Taylor vortices is invalid.

The final slurry displayed yield pseudoplastic behavior, but no thixotropy was observed. This sample displayed a yield stress of approximately $6-8 \mathrm{~Pa}$. This sample was removed from the ultrafiltration unit and stored in a jar for approximately 1 day before the shear-stress versus shear-rate analysis was conducted. This sample was gently agitated in the jar and loaded into the rheometer. The level of material in the rheometer was monitored during the analysis. The level of material was observed to drop during the course of each analysis, $\sim 20 \mathrm{~min}$ in duration. This level drop appeared to be the result of gas entrained in the slurry. As the material was sheared, these entrained bubbles were released, decreasing the level of material in the instrument. The level did not drop sufficiently to cause analytical errors in the analyses.

The apparent viscosity of the final slurry decreased from approximately 200 to $12 \mathrm{cP}$ over the range of 33 to $1000 \mathrm{~s}^{-1}$. This appears unexpectedly high compared to the viscosity of the dewatered slurry which decreased from approximately 50 to $6 \mathrm{cP}$ over the range of 33 to $940 \mathrm{~s}^{-1}$. The concentrated slurry had slightly a higher solids content than the final slurry, 9.5 versus $9.2 \mathrm{wt} \%$ undissolved solids, and 32 versus $30 \mathrm{wt} \%$ centrifuged solids, respectively. Given the slightly higher solids content, one may anticipate that the viscosity of the two slurries would be similar or that the concentrated slurry would be higher. The higher viscosity of the final slurry must be the result of a change in the solids properties beyond just solids content and could be the result of entrained gas bubbles mentioned previously. Entrained gas bubbles generally increase the viscosity of a slurry. As discussed in Section 5.0, the final slurry also contained significantly more fine particles. These finer particles could also be responsible for the increase in viscosity of this sample over the concentrated slurry sample. 


\subsection{Particle Size Distribution}

The PSD of the initial sludge composite (Sample CUF-AZ-102 MU), the de-watered slurry before Matrix 2 (Sample CUF-AZ-102-005), and the final slurry (Sample CUF-AZ-102-024) is described below. The first sample was the initial composite AZ-102 sludge before it was diluted and fed into the CUF (initial sludge). The second sample was the slurry that was taken after Matrix 1 testing was completed and the slurry was de-watered (concentrated slurry). The third sample was the final slurry, which was caustic leached and was caustic washed twice (final slurry). The sample number associated with the process flowsheet step of crossflow filtration testing is presented in Table 2.3, and the experimental process is described in detail in Section 2.6.

\subsection{Experimental}

A Microtrac X-100 Particle Analyzer and a Microtrac Ultrafine Particle Analyzer (UPA) were both used to measure the PSD of these samples. The operation of the Mircotrac X-100 and Microtrac UPA analyzers was checked against National Institute of Standards and Technology (NIST)-traceable standards from Duke Scientific Corporation. The PSD results of NIST-traceable standards are documented in Appendix $\mathrm{H}$.

The Microtrac X-100 Particle Analyzer measures particle diameter by scattered light from a laser beam projected through a stream of the sample particles diluted in a suspending medium. The amount and direction of light scattered by the particles is measured by an optical detector array and then analyzed to determine the size distribution of the particles. This measurement is limited to particles with diameters between 0.12 and $700 \mu \mathrm{m}$. The Microtrac UPA measures particle diameter by Doppler-shifted scattered light. This method is limited to particles with diameters between $3 \mathrm{~nm}$ and $6.5 \mu \mathrm{m}$.

The PSD of these three samples and their duplicates was measured on the Microtrac X-100 after applying a variety of circulation time, circulation flow rate, and sonication treatments. The treatments in successive order included 1) circulation at $40 \mathrm{~mL} / \mathrm{s}, 2$ ) circulation at $60 \mathrm{~mL} / \mathrm{s}, 3$ ) circulation at $60 \mathrm{~mL} / \mathrm{s}$ with $40 \mathrm{~W}$ sonication for $90 \mathrm{sec}$, and 4) circulation at $60 \mathrm{~mL} / \mathrm{s}$ with $40 \mathrm{~W}$ sonication for $90 \mathrm{sec}$ for the second time. For each sample replicate, the PSD was measured three times and averaged. The PSD of the averaged data on a volume-weighted basis and on a number-weighted basis is reported. The PSD of these three samples and their duplicates was then repeated using the Microtrac UPA under conditions of Brownian motion. The results on a volume-weighted basis and on a number-weighted basis are reported.

The suspending medium for these analyses was surrogate supernatants based on the ICP-AES and IC data obtained for the applicable AZ-102 supernatant. The composition of these three supernatants is reported in Table 5.1. 
Table 5.1. Surrogate Supernatant Composition

\begin{tabular}{|l|c|c|c|}
\hline & Initial Sludge & Concentrated Slurry & Final Slurry \\
\hline Component & Concentration (M) & Concentration (M) & Concentration (M) \\
\hline $\mathrm{SiO}_{2}$ & $1.08 \mathrm{E}-02$ & $1.32 \mathrm{E}-03$ & $1.61 \mathrm{E}-03$ \\
\hline $\mathrm{NaNO}_{3}$ & $1.27 \mathrm{E}-01$ & $8.18 \mathrm{E}-03$ & $1.61 \mathrm{E}-03$ \\
\hline $\mathrm{NaOH}$ & $3.00 \mathrm{E}-01$ & $2.60 \mathrm{E}-02$ & $1.78 \mathrm{E}-01$ \\
\hline $\mathrm{KNO}_{3}$ & $9.59 \mathrm{E}-02$ & $8.44 \mathrm{E}-03$ & $6.92 \mathrm{E}-03$ \\
\hline $\mathrm{Al}(\mathrm{OH})_{3}$ & $8.00 \mathrm{E}-03$ & $6.04 \mathrm{E}-03$ & $8.07 \mathrm{E}-02$ \\
\hline $\mathrm{Na}_{2} \mathrm{C}_{2} \mathrm{O}_{4}$ & $3.74 \mathrm{E}-02$ & $3.41 \mathrm{E}-03$ & $5.68 \mathrm{E}-04$ \\
\hline $\mathrm{Na}_{2} \mathrm{SO}_{4}$ & $2.19 \mathrm{E}-01$ & $1.65 \mathrm{E}-02$ & $1.15 \mathrm{E}-03$ \\
\hline $\mathrm{Na}_{2} \mathrm{HPO}_{4}-7 \mathrm{H}_{2} \mathrm{O}$ & $4.58 \mathrm{E}-03$ & $5.26 \mathrm{E}-04$ & $1.68 \mathrm{E}-03$ \\
\hline $\mathrm{NaF}$ & $3.95 \mathrm{E}-02$ & $4.74 \mathrm{E}-03$ & $1.32 \mathrm{E}-03$ \\
\hline $\mathrm{NaNO}_{2}$ & $9.05 \mathrm{E}-02$ & $8.07 \mathrm{E}-02$ & $5.43 \mathrm{E}-04$ \\
\hline $\mathrm{Na}_{2} \mathrm{CO}_{3}$ & $7.18 \mathrm{E}-01$ & $9.25 \mathrm{E}-02$ & $5.38 \mathrm{E}-02$ \\
\hline
\end{tabular}

In Appendix $\mathrm{H}$, the PSD plots for the samples and their duplicates under all conditions measured are presented in volume-weighted distribution and number-weighted distribution form. The numberweighted PSD is computed by counting each particle and by weighting all the particle diameters equally. The volume-weighted PSD, however, is weighted by the volume of each particle measured, which is proportional to the cube of the particle diameter. In this case, larger particles are treated as more important in the distribution than the smaller particles. In general, the PSD plots show that under all conditions the samples were polydispersed, and as a result the mean size of the volume distribution is much larger than the mean size of the number.

\subsection{Particle Size Distribution Results}

In Figure 5.1, the averaged PSDs for the initial sludge, concentrated slurry, and final slurry in cumulative under-size-percentage form are presented for the Microtrac X-100 system. In Figure 5.2, these results are illustrated in a histogram on the volume-weighted PSD. The reproducibility of the two replicate PSD plots for the initial sludge and concentrated slurry samples suggest that the slurry was thoroughly homogenized, and each extracted sample was a representative specimen. A close examination of the two final slurry replicate plots (Figures 5.1 and 5.2) shows a well-defined peak at $6.5 \mu \mathrm{m}$ in the final slurry duplicate sample occupying $23 \%$ of the volume or mass particles. The final slurry sample, on the other hand, exhibits a less-defined peak at $6.5 \mu \mathrm{m}$ that occupied $9 \%$ of the volume-weighted distribution. Despite this slight difference, the overall distribution shape and the location of the peaks for both final slurry replicates compare very well and suggest that the replicates are reasonably reproducible. 


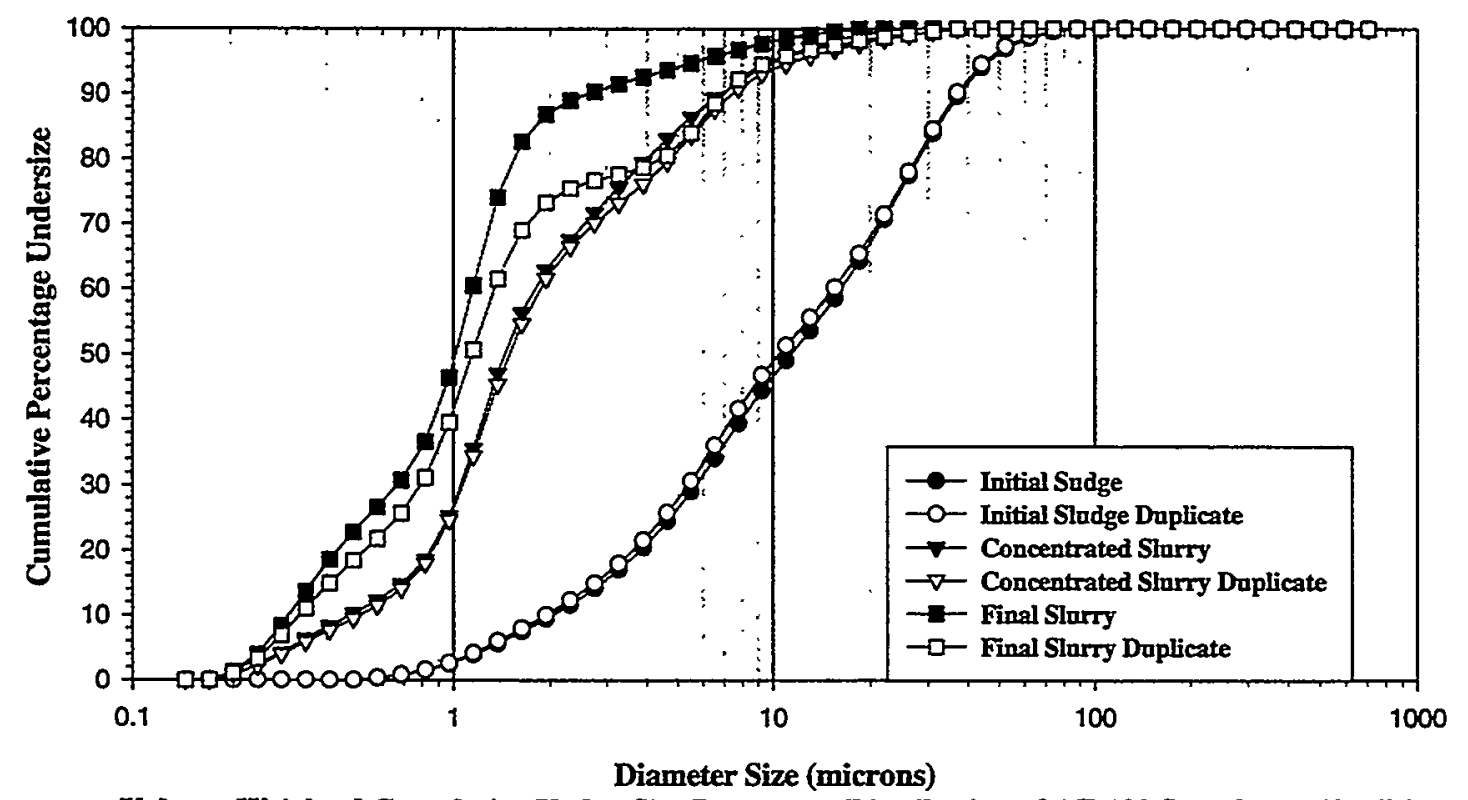

Volume-Weighted Cumulative Under-Size Percentage Distribution of AZ-102 Samples at $40 \mathrm{~mL} / \mathrm{s}$.

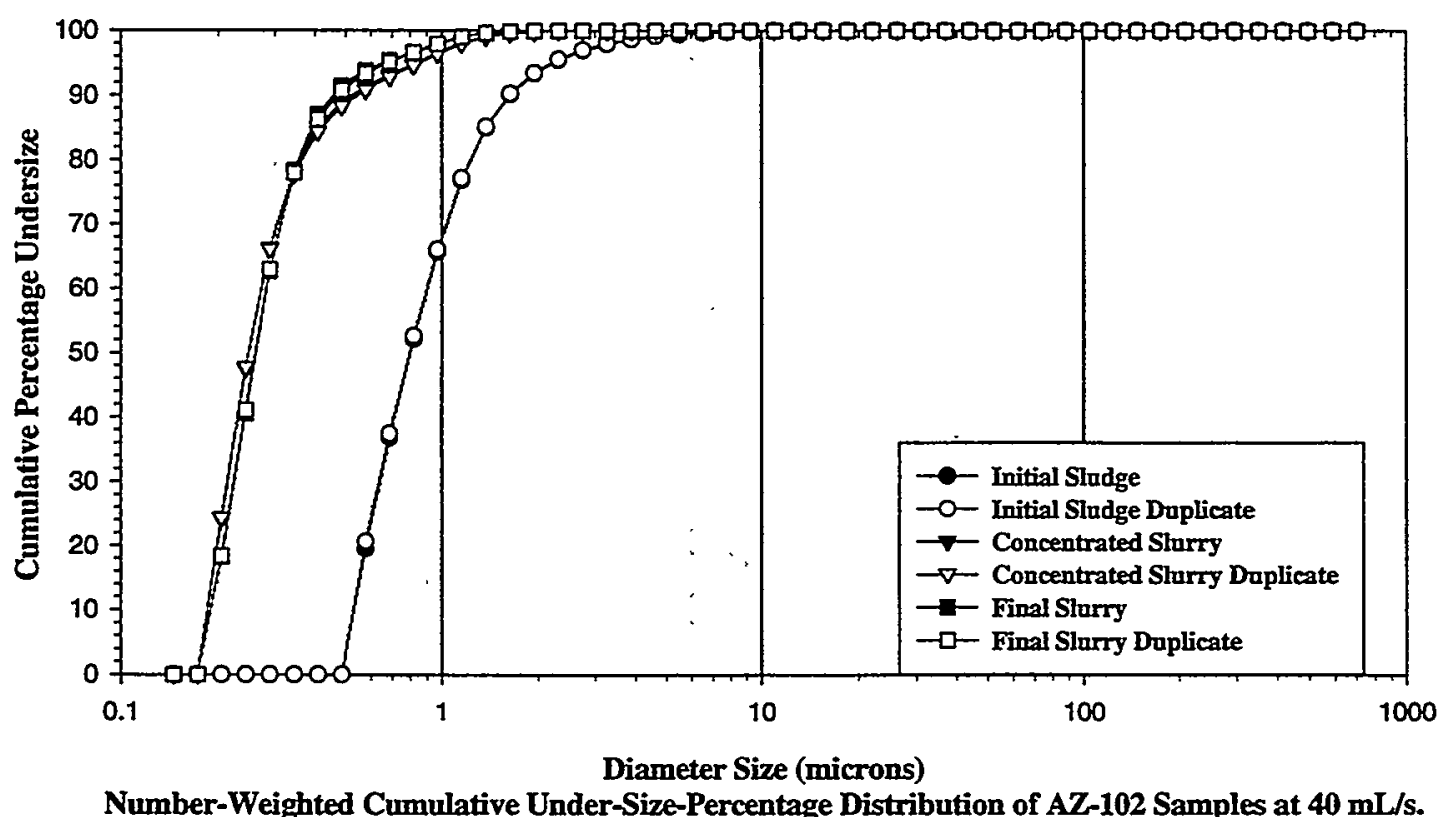

Figure 5.1. Cumulative Under-Size Percentage Distribution for AZ-102 Slurries Using the Microtrac X-100 


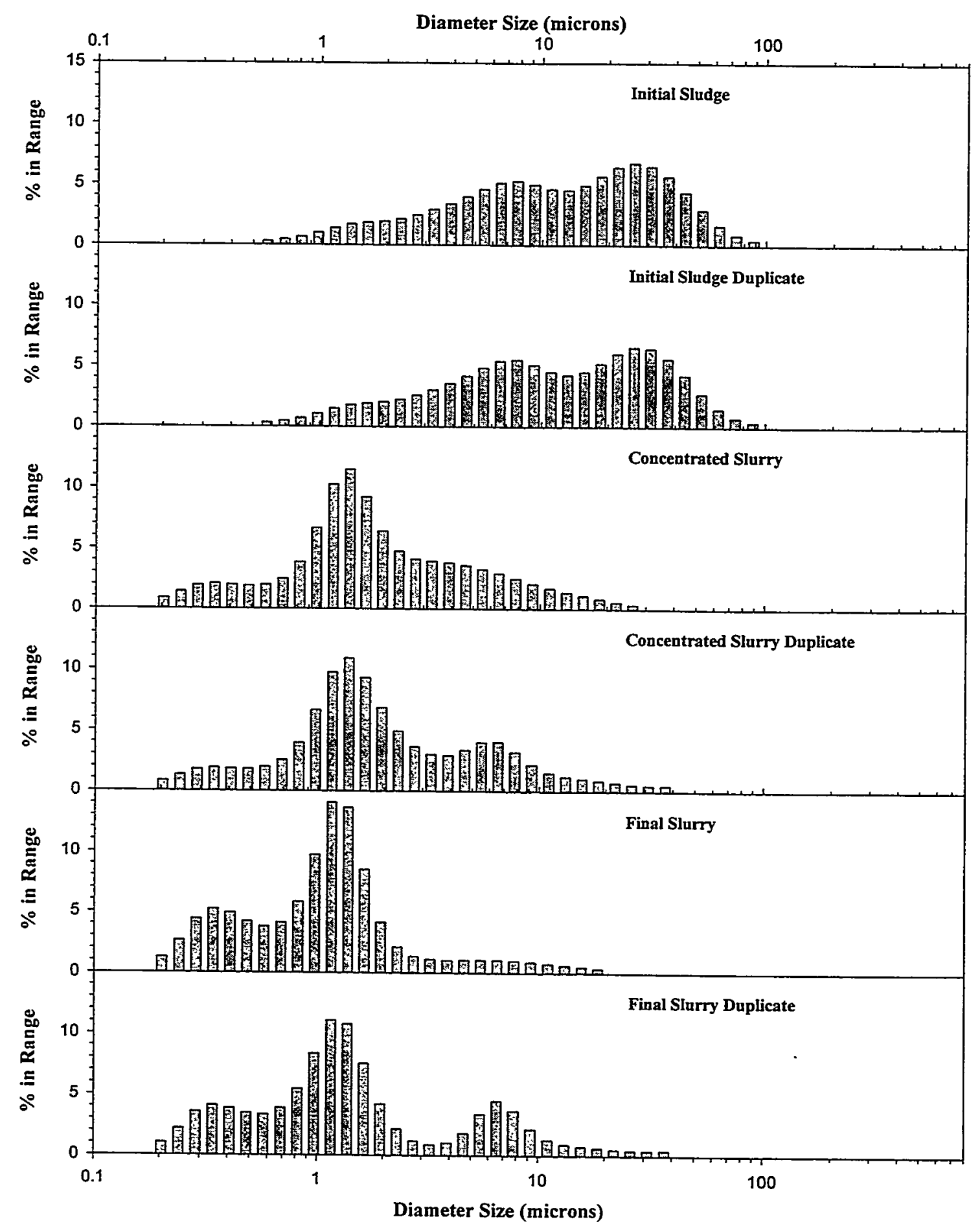

Figure 5.2. Volume-Weighted Distribution for AZ-102 Slurries Using the Microtrac X-100 
The cumulative under-sized-percentage plots using the UPA system (see Figure 5.3) show the samples and their duplicates. Once again the replicates are reasonably reproducible within experimental error. The PSD analysis (Figures 5.1 and 5.3 combined) of the concentrated slurry and the final slurry indicate that the large majority $(>90 \%)$ of the volume and number of the particles have diameters greater than 0.03 and less than $10 \mu \mathrm{m}$. The PSD of the initial slurry, on the other hand, indicates that $45 \%$ of the volume of particles are greater than 0.1 and less than $10 \mu \mathrm{m}$, and $55 \%$ of the volume of particles have diameters greater that 10 and less that $75 \mu \mathrm{m}$.

The volume-weighted distribution plots (see Figure 5.2) of the initial sludge show a bimodal distribution formed from overlapping two Gaussian distribution peaks while the concentrated slurry and the final slurry distribution plots show a trimodal distribution. The major particle-size peaks along with the relative volume or number percentage that each peak represents are summarized in Tables 5.2 and 5.3.

Table 5.2. Peak Mode Location for Volume-Weighted Particle Distribution of AZ-102 Samples

\begin{tabular}{|c|c|c|c|c|}
\hline \multirow[b]{2}{*}{ Sample } & \multicolumn{2}{|c|}{$\underline{X-100}(40 \mathrm{~mL} / \mathrm{sec})$} & \multicolumn{2}{|c|}{ UPA (Brownian Motion) } \\
\hline & $\begin{array}{c}\text { Mode } \\
\text { Diameter } \\
(\mu \mathbf{m})\end{array}$ & Vol \% & $\begin{array}{c}\text { Mode } \\
\text { Diameter } \\
(\mu \mathrm{m})\end{array}$ & Vol \% \\
\hline \multirow{2}{*}{$\begin{array}{c}\text { Initial Sludge } \\
\text { (CUF-AZ102 MU) }\end{array}$} & 24.280 & 51 & \multirow{2}{*}{1.174} & \multirow{2}{*}{100} \\
\hline & 4.647 & 49 & & \\
\hline \multirow{2}{*}{$\begin{array}{l}\text { Initial Sludge Duplicate } \\
\text { (CUF-AZ102 MU DUP) }\end{array}$} & 24.590 & 49 & 5.537 & 2 \\
\hline & 4.604 & 51 & 1.412 & 98 \\
\hline \multirow{2}{*}{$\begin{array}{l}\text { Concentrated Slurry } \\
\text { (CUF-AZ-102-005) }\end{array}$} & 1.561 & 92 & \multirow{2}{*}{1.794} & \multirow{2}{*}{100} \\
\hline & 0.287 & 8 & & \\
\hline \multirow{3}{*}{$\begin{array}{c}\text { Concentrated Slurry } \\
\text { Duplicate } \\
\text { (CUF-AZ-102-005 DUP) }\end{array}$} & 6.236 & 27 & 1.683 & 96 \\
\hline & 1.271 & 66 & \multirow{2}{*}{0.346} & \multirow{2}{*}{4} \\
\hline & 0.286 & 7 & & \\
\hline \multirow{3}{*}{$\begin{array}{c}\text { Final Slurry } \\
\text { (CUF-C104-024) }\end{array}$} & 6.525 & 9 & 2.826 & 83 \\
\hline & 1.112 & 69 & \multirow{2}{*}{0.411} & \multirow{2}{*}{17} \\
\hline & 0.319 & 22 & & \\
\hline \multirow{4}{*}{$\begin{array}{l}\text { Final Slurry Duplicate } \\
\text { (CUF-C104-024 DUP) }\end{array}$} & 6.505 & 23 & 1.614 & 89 \\
\hline & 1.103 & 58 & 0.163 & 3 \\
\hline & \multirow{2}{*}{0.319} & \multirow{2}{*}{19} & 0.078 & 4 \\
\hline & & & 0.034 & 4 \\
\hline
\end{tabular}



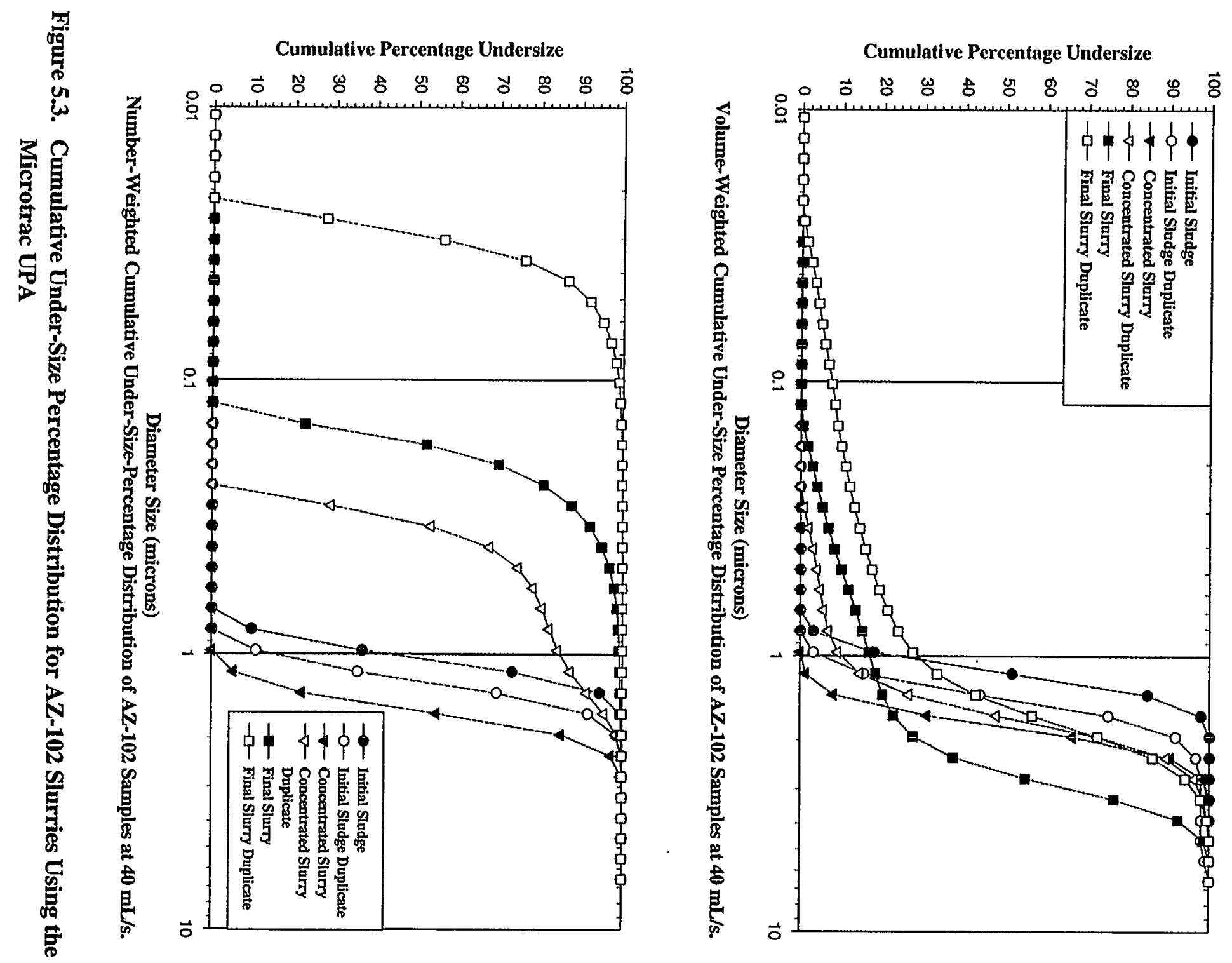
Table 5.3. Peak Mode Location for Number-Weighted Particle Distribution of AZ-102 Samples

\begin{tabular}{|c|c|c|c|c|}
\hline \multirow[b]{2}{*}{ Sample } & \multicolumn{2}{|c|}{$\underline{X-100}(40 \mathrm{~mL} / \mathrm{sec})$} & \multicolumn{2}{|c|}{ UPA (Brownian Motion) } \\
\hline & $\begin{array}{c}\text { Mode } \\
\text { Diameter } \\
(\mu \mathbf{m})\end{array}$ & Num \% & $\begin{array}{c}\text { Mode } \\
\text { Diameter } \\
(\mu \mathrm{m})\end{array}$ & Num \% \\
\hline $\begin{array}{c}\text { Initial Sludge } \\
\text { (CUF-AZ102 MU) }\end{array}$ & 0.798 & 100 & 1.035 & 100 \\
\hline $\begin{array}{l}\text { Initial Sludge Duplicate } \\
\text { (CUF-AZ102 MU DUP) }\end{array}$ & 0.793 & 100 & 1.245 & 100 \\
\hline \multirow{2}{*}{$\begin{array}{l}\text { Concentrated Slurry } \\
\text { (CUF-AZ-102-005) }\end{array}$} & 0.979 & 7 & \multirow[t]{2}{*}{1.598} & \multirow[t]{2}{*}{100} \\
\hline & 0.241 & 93 & & \\
\hline \multirow{2}{*}{$\begin{array}{c}\text { Concentrated Slurry } \\
\text { Duplicate } \\
\text { (CUF-AZ-102-005 DUP) }\end{array}$} & \multirow{2}{*}{0.284} & \multirow{2}{*}{100} & 1.310 & 20 \\
\hline & & & 0.311 & 77 \\
\hline $\begin{array}{c}\text { Final Slurry } \\
\text { (CUF-C104-024) }\end{array}$ & 0.261 & 100 & 0.169 & 100 \\
\hline $\begin{array}{l}\text { Final Slurry Duplicate } \\
\text { (CUF-C104-024 DUP) }\end{array}$ & 0.260 & 100 & 0.029 & 100 \\
\hline
\end{tabular}

The significant decrease in the volume-weighted distribution histogram from the initial sludge to the concentrated slurry shown in Figure 5.2 represents the extent of solids de-agglomeration after the solids were re-circulated in the CUF line for 6 hours at various crossflow-velocity and TMP conditions described in Table 3.1. The production of finer particles exhibited in the concentrated slurry PSD confirms that particle break-up is a significant factor in reducing filtration flux from Conditions 1 to 7 (see Figure 3.1). A possible explanation for reduction in flux can be described in terms of forming higher resistance "cakes" (deposited layer on the membrane surface) as the solids deposited at or near the membrane surface are enriched progressively with finer particles. In crossflow filtration, a slight decrease in the filtrate flux is caused by the formation of a porous filter cake as the particles are deposited on the membrane surface. However, as small fine particles begin to plug the filter cake, the filtrate flux could decrease very rapidly and necessitate back flushing to regenerate the membrane. Upon each backpulsing and progressive de-agglomeration, the dispersed fine particles are capable of penetrating the pores of the membrane and reducing the filtration flux further. 
Figures 5.4 and 5.5 compare the volume- and number-weighted histograms of the three samples for the Microtrac X-100 at 40 and $60 \mathrm{~mL} / \mathrm{s}$ circulation flow rate. Figure 5.6 and 5.7 compare the volume-weighted and number-weighted distribution of these samples before and after sonication. It can be seen from these plots (Figures 5.4, 5.5, and 5.6) that after the slurry was caustic leached and caustic washed, the nature of agglomerate compaction was changed. The final slurry solids are more shear sensitive and are easier to de-agglomerated compared to the concentrated slurry (same agglomeration compaction nature as initial slurry) under identical variation in the circulation flowrate and sonication treatments as the concentrated slurry.

Furthermore, the comparison of the volume-weighted distribution plots (see Figure 5.6 and 5.7) of the concentrated slurry and the final slurry before sonication show that the overall distribution shape and the location of the peaks in both samples (concentrated slurry and final slurry) are almost the same and similar, respectively. 


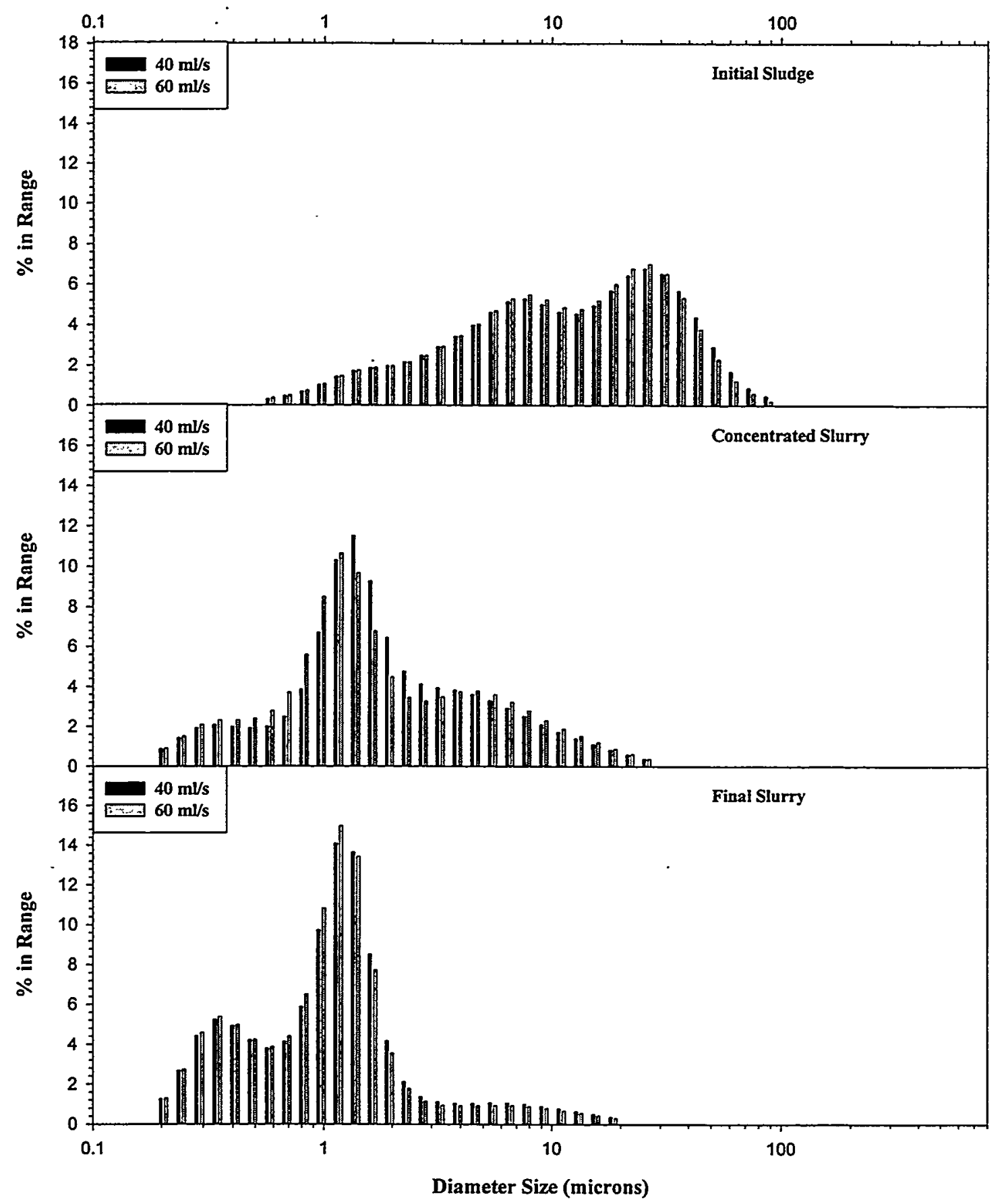

Figure 5.4. Histogram of the Volume- Weighted AZ-102 Slurries Using the Microtrac X-100 at 40 and $60 \mathrm{~mL} / \mathrm{s}$ Circulation Flow Rate 


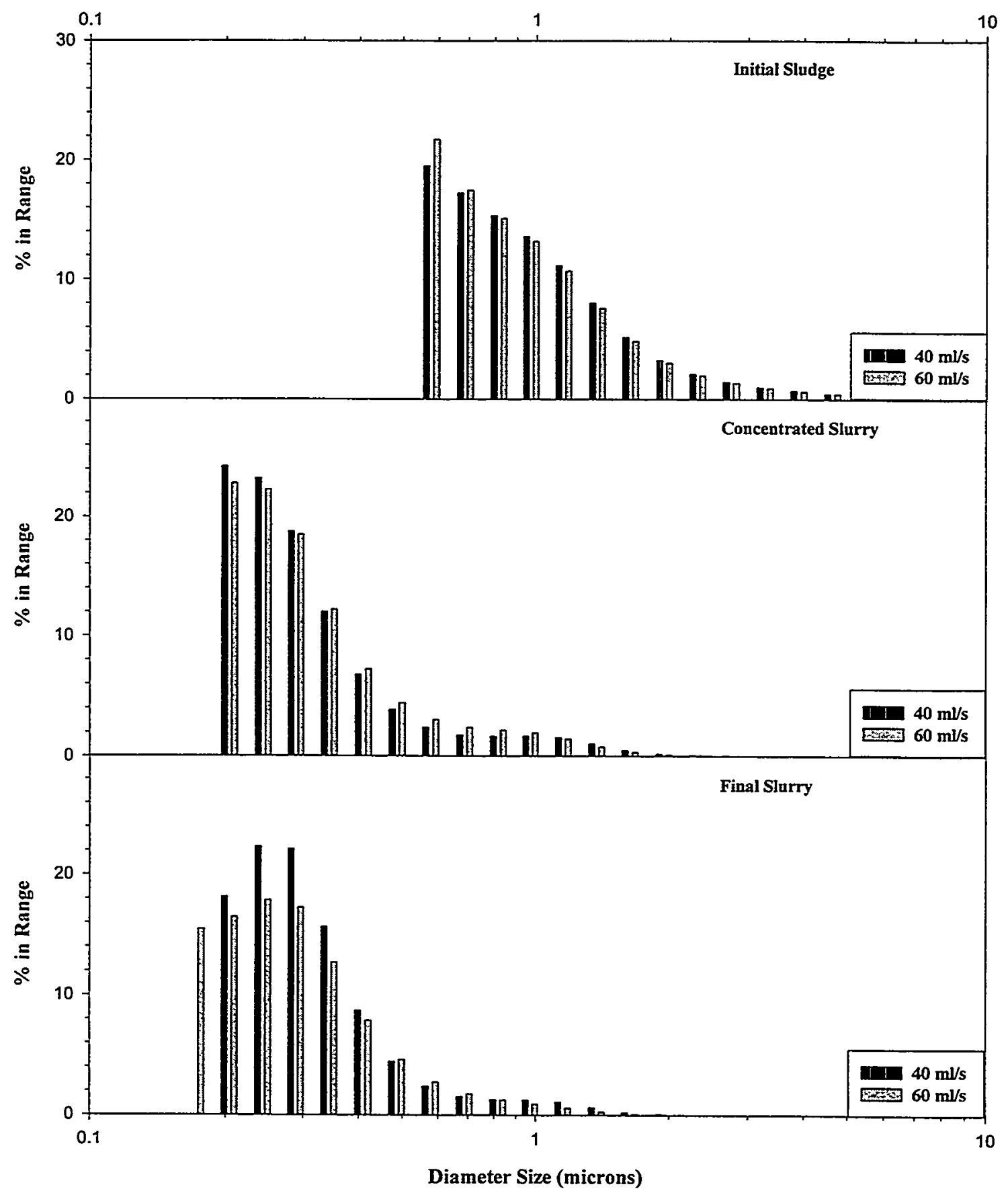

Figure 5.5. Histogram of the Number-Weighted AZ-102 Slurries Using the Microtrac X-100 at 40 and $60 \mathrm{~mL} / \mathrm{s}$ Circulation Flow Rate 


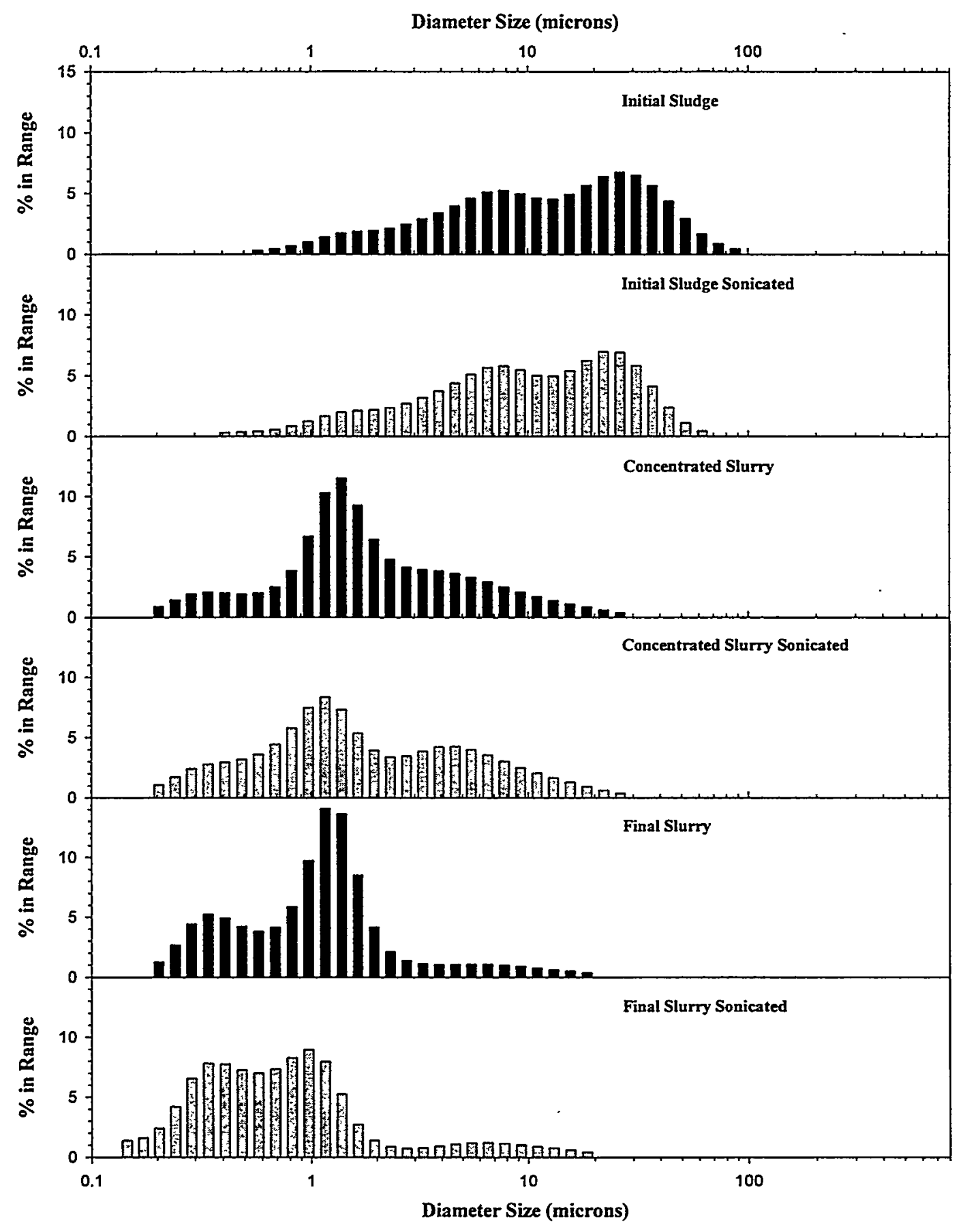

Figure 5.6. Histogram of the Volume Weighted AZ-102 Slurries before and after Sonication Using the Microtrac X-100 


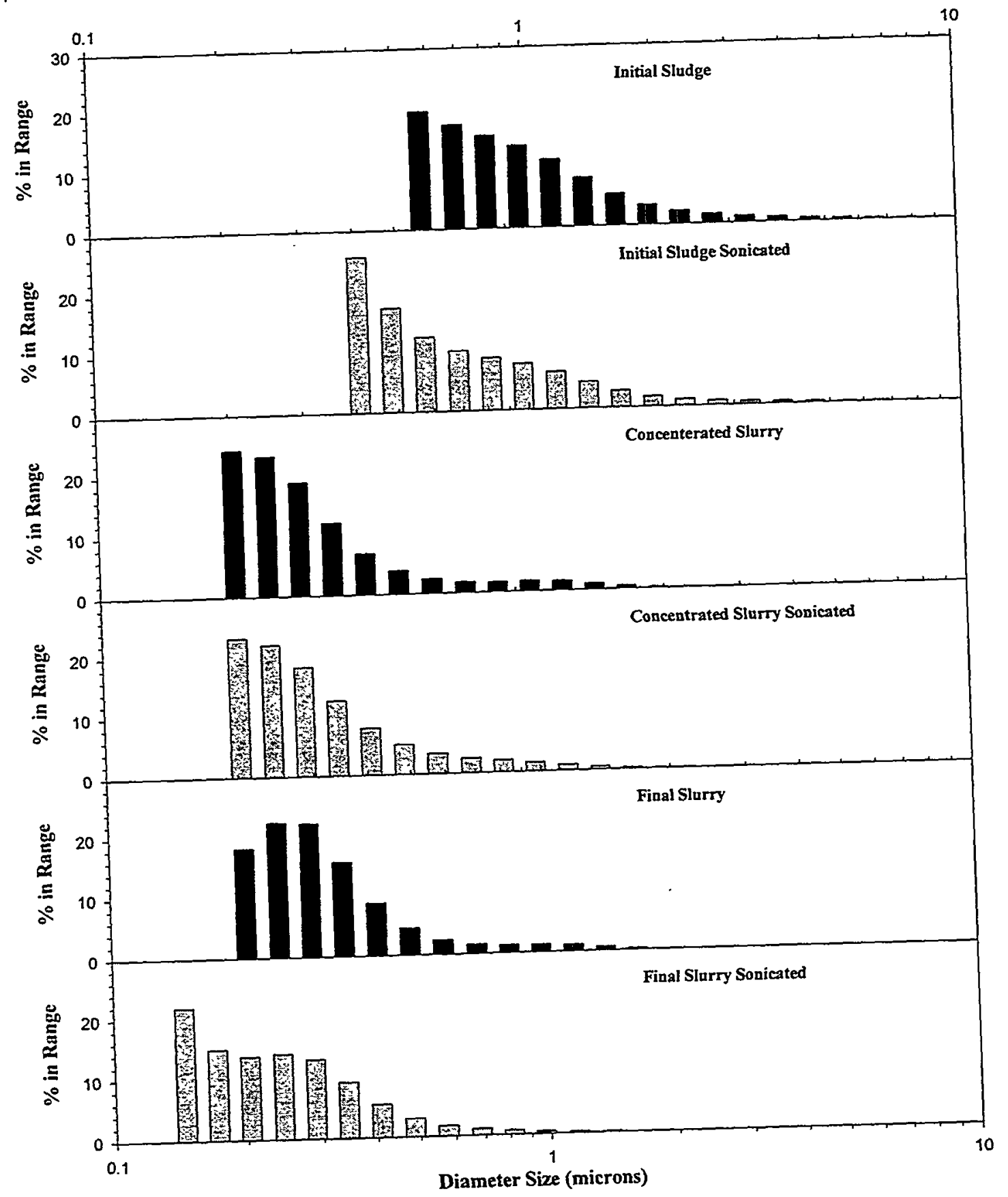

Figure 5.7. Histogram of the Number Weighted AZ-102 Slurries before and after Sonication Using the Microtrac X-100 


\subsection{Conclusions}

Based on the testing and analysis performed on AZ-102 sludge described in this document, the following conclusions have been obtained. They have been divided into categories for clarity.

\section{AZ-102 Crossflow Filtration}

- For a slurry at $5.1 \mathrm{wt} \%$ insoluble solids, the average filtrate flux over $50 \mathrm{~min}$ of operation ranged from 0.046 to $0.126 \mathrm{gpm} / \mathrm{ft}^{2}$. The dominant variable affecting the filtrate flux data during the first three conditions appears to be operating time. During these conditions, there was a steady decline in filtrate flux. Changes in the TMP appeared to have little effect. For the three subsequent runs, the axial velocity and TMP may have slightly increased the flux rate.

- For a slurry at $13.7 \mathrm{wt} \%$ insoluble solids, the average filtrate fluxes ranged from 0.020 to $0.051 \mathrm{gpm} / \mathrm{ft}^{2}$ over $50 \mathrm{~min}$ of operation. This filtrate flux is $\sim 2.3$ times less than the low solids matrix, and $\sim 2.7$ times higher in solids concentration. Over the range of conditions studied, higher axial velocities improve filtrate flux. Once again, TMPs appear to have little effect.

- The filtrate DFs for ${ }^{241} \mathrm{Am}$ (ratio of concentrations in the slurry to the concentration in the filtrate) were between 100,000 and 450,000 for the filtrates collected, indicating excellent solid-liquid separations.

- A statistical model of filtrate flux was developed and found to be a function of axial velocity and run order. Based on this modeling effort, the optimum condition for both low and high solids loading is to maximize the axial velocity. Due to collinearities between pressure and velocity, and run order and solids concentration in the current data set, from a statistical standpoint, it is not possible to determine the effect of TMP and solids concentration on filtrate flux.

- Even after two cleanings with ( $1 \mathrm{M})$ nitric acid, the CUF was not capable of recovering the clean water filtrate flux. In full-scale operation, higher temperatures and longer cleaning times may be required. Acid cleaning at temperatures greater than ambient was not possible in the CUF due to the potential for corrosion of the CUF material.

\section{AZ-102 Wash and Caustic Leach Testing}

- Dilute caustic washing removed $80.4 \%$ of the sodium and $>90 \%$ of the soluble anions, including nitrate, nitrite, and sulfate. Significant quantities of fluoride and cyanide were also removed. The only radioactive isotopes significantly removed by washing were ${ }^{137} \mathrm{Cs}$ and possibly ${ }^{99} \mathrm{Tc}$, and ${ }^{127} \mathrm{I}$.

- The first caustic leach removed $60 \%$ of the aluminum, but only $1.2 \%$ was removed during the subsequent caustic wash steps. Caustic leaching also increased the removal of $P$ as well as the watersoluble components, such as $\mathrm{K}$ and ${ }^{137} \mathrm{Cs}$.

- $\mathrm{Fe}, \mathrm{Al}$, and $\mathrm{Na}$ were the analytes of highest concentration, respectively, in the final composition of the final leached/washed sludge.

- The total mass of solids was reduced by approximately $44 \%$ during the course of water washing and caustic leaching, and the mass of $\mathrm{HLW}$ glass (assuming $\mathrm{Al}+\mathrm{Fe}+\mathrm{Zr}$ limiting the glass) was reduced by potentially $\sim 27 \%$. 
- The initial slurry exhibited significant plugging in the CUF during the start of operations. After several hours of operations, the plugging effects were reduced. The final slurry was found to entrain significant quantities of air that remained in the material for hours. This entrained air may have impacted the pumpability and filterability of the material, although entrained air and its effects were only observed on the final slurry.

- The initial dilute slurry, concentrated slurry, and final slurry were found to be yield pseudoplastic and thixotropic.

- There was a significant decrease in particle size from the initial as-received sludge to the concentrated slurry. This decrease is attributed to particle deagglomeration during pumping in the CUF. In contrast, there is less difference in particle size between the concentrated slurry and the final washed and leached material.

- The slurry exhibited increased shear sensitivity after washing and leaching as evidenced by its large reduction in number distribution after sonication. 


\subsection{References}

Brooks, K. P., P. R. Bredt, G. R. Golcar, S. A. Hartley, M. W. Urie, J. M. Tingey, K. G. Rappe, and L. K. Jagoda. 1999. Ultrafiltration and Characterization of AW-101 Supernatant and Entrained Solids, BNFL-RPT-002 Rev. 0, PNWD-3000, Battelle Northwest, Richland, Washington.

Brooks, K. P., P. R. Bredt, G. R. Golcar, S. A. Hartley, M. W. Urie, K. G. Rappe, L. K. Jagoda, and M. W. Urie. 2000. Characterization, Washing, Leaching and Filtration of C-104 Sludge, BNFL-RPT-030 Rev. 0, PNWD-3024, Battelle Northwest, Richland, Washington.

Geeting, J.G.H., and B. A. Reynolds. 1997. Bench-Scale Crossflow Filtration of Hanford Tank C-106, $C-107, B-110$, and U-110 Sludge Slurries, PNNL-11652. Pacific Northwest National Laboratory, Richland, Washington.

Hallen, R. T., P. R. Bredt, K. P. Brooks, and L. K. Jagoda. 2000. Combined Entrained Solids and Sr/TRU Removal from AN-107 Diluted Feed, PNWD-3035, Battelle Northwest, Richland, Washington.

Tarleton, E. S. and R. J. Wakeman. 1994. Understanding Flux Decline in Crossflow Microfiltration: Part II-Effects of Process Parameters. Trans IchemE, Vol 72, Part A, May 1994. pp. 431-439.

U.S. Department of Energy, Richland Operations (DOE-RL). 1996. River Protection Project Waste Treatment Plan (RPP-WTP) (formerly TWRS) Privatization Contract, DE-RP06-96RL13308, Richland, Washington. 


\section{Appendix A: CUF Filtration, Washing and Leaching Test Instructions and Laboratory Record Book}




\section{Appendix A: CUF Filtration, Washing and Leaching Test Instructions and Laboratory Record Book}




\section{PNNL Test Instruction}

Document No.: BNFL-TP-29953-076

Rev. No.: 0

Title: HLW Filtration and Caustic Leaching of AZ-102

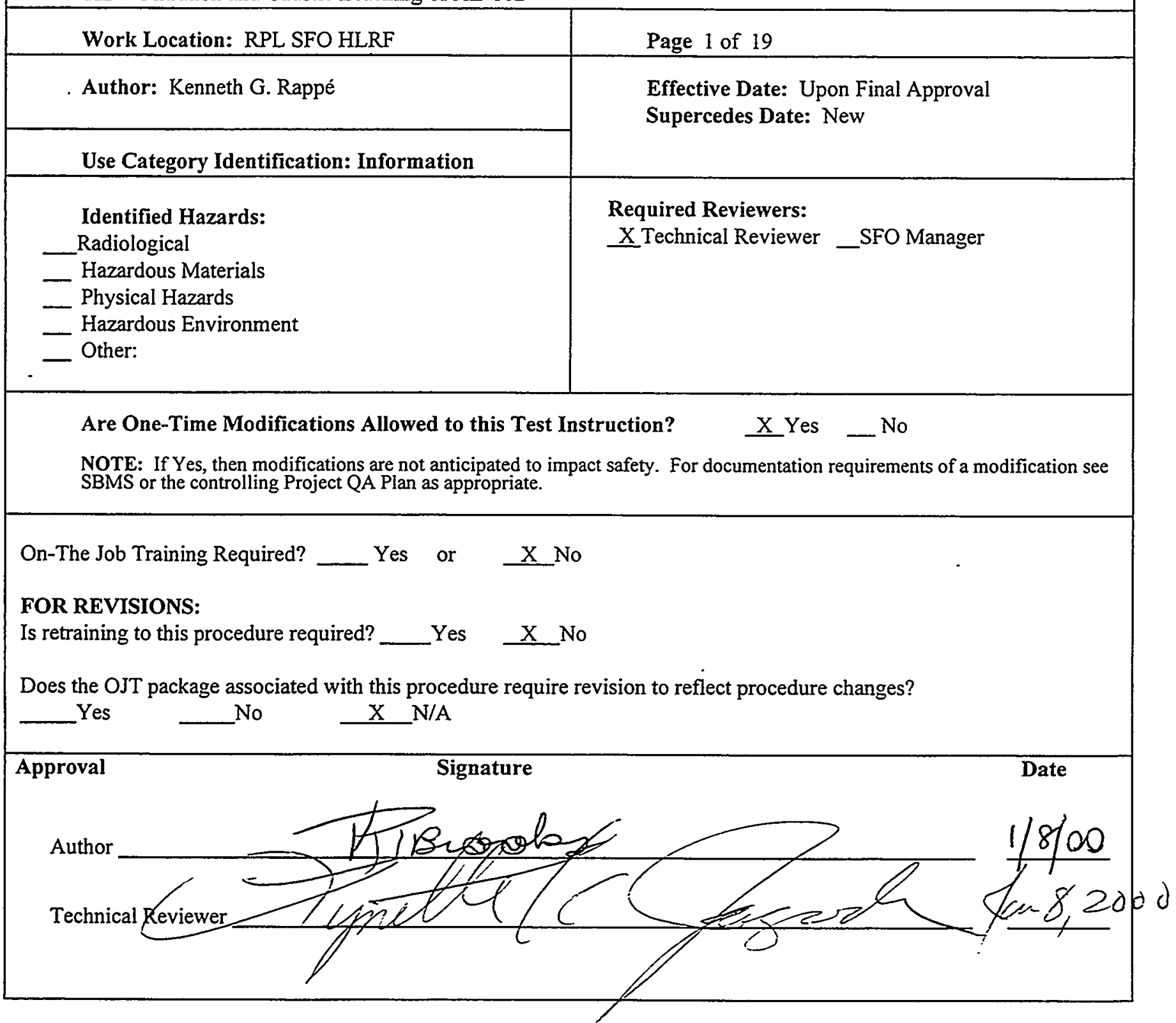




\subsection{Applicability}

This test instruction is to be used to perform the testing of the Cell Unit Filter (CUF) in the HLRF A-cell with 381 grams of AZ-102 slurry, which contains approximately 127.6 grams of undissolved solids.

\subsection{Supporting Documents}

This test instruction is not a stand-alone document. It will be used in conjunction with PNNL Operating Procedure BNFL-TP-29953-020, which contains the necessary procedural information for the safe operation of the CUF. It is also linked to PNNL Test Plan No. BNFL-TP-29953-069, which contains an overall description of the project, ES\&H compliance, emergency response, and the hazards assessment and mitigation.

\subsection{Responsible Staff}

The staff responsible for executing this test plan are:

- Task Manager - Kriston Brooks

- SFO Manager - Randy Thornhill

- Test Engineers - Kriston Brooks, Ken Rappé, Lynette Jagoda

- Hot Cell Technician - Mac Zumhoff, Ralph Lettau, Don Rinehart

- Radiological Control Technician

\subsection{Materials, Equipment, Supplies and Reagents Needed}

\subsection{Materials Required}

- AZ-102 Samples “A," "MU," and "GL." AZ-102 Recovery Jar.

- One $250 \mathrm{~mL}$ glass jar labelled "AZ-102 Initial Feed"

- Twenty-seven 20-mL glass scintillation vials for filtrate and slurry samples, prelabeled as follows:

CUF-AZ102-001 through CUF-AZ102-027.

- Two 1-L bottles, labeled "AZ-102 Filtrate\#1" and "AZ-102 Filtrate\#2" with mark(s) indicating 970 milliliters.

- Two 1-L polyethylene bottle labeled "CUF AZ-102 First Wash." It should be marked with a line for 1-L volume.

- Three 1-L polyethylene bottles labeled "AZ-102 WW permeate\#1" through "AZ-102 WW permeate\#3". Each bottle should have a mark indicating a volume of $900-\mathrm{mL}$.

- One 1-L polyethylene bottle labeled "AZ-102 CL permeate."

- Two 1-L polyethylene bottles labeled "AZ-102 CW permeate\#1" and "AZ-102 CW permeate\#2."

- Two 1-L plastic-coated glass bottles labeled "AZ-102 final sample" and "AZ-102 decant."

- Three graduated centrifuge tubes.

- Tubing for de-watering mode.

- Two 10 liter containers, one labeled for the alkaline rinses and the other labeled for the acidic rinses.

- Containers for draining from the bottom of the pump and from the sample valve.

- One 2-L bottle labeled "tank overflow container." 
- Tubing to go from valve V-10 to the caustic leaching/washing vessel.

- 10 liters of 0.2-micron filtered DI water for washing the CUF upon completion of AZ-102 processing.

\subsection{Equipment}

- 4000 gram balance

- Video tape

- $\mathrm{pH}$ paper

- Hand held camera. Used for making difficult readings and volume estimations.

- Stopwatch

- Calculator

- CUF Ultrafiltration system with $100 \mathrm{~mL}$ plug in place

- 1000 watt Chiller

\subsection{Reagents Needed}

All containers that will be put into the cell should be labeled with "AZ-102" and "CUF testing."

- 1-L of filtered, distilled water labeled "start-up water."

- 1.62 liters of $0.01-\mathrm{M} \mathrm{NaOH}_{a q}$ labeled "5 wt \% dilution 1." - TBD $\mathrm{mL}$ ( $837 \mathrm{~g}$ - recovery jär liquid r." of $0.01-\mathrm{M} \mathrm{NaOH}_{a q}$ labeled "5 wt \% dilution

- 2.7 liters of $0.01-\mathrm{M} \mathrm{NaOH}_{a q}$ labeled "water wash solution" split up into three separate 1-L containers containing $900-\mathrm{mL}$ of solution in each.

- $\mathrm{NaOH}_{a q}$ labeled "caustic leach solution." Amount and molarity to be determined. Will be approximately $600 \mathrm{~mL}$.

- $100 \mathrm{~mL}$ bottle of $3 \mathrm{M} \mathrm{NaOH}_{a q}$ labeled "3M caustic rinse." Determine mass of caustic in bottle.

- Two containers of 0.01-M NaOH $a q$ labeled "caustic wash solution\#1" and "caustic wash solution\#2." Amount to be determined. Will be approximately $1600 \mathrm{~mL}$ of solution in each container.

- 1 liter of filtered, distilled water labeled "AZ-102 CUF rinse."

- 1 liter of 1-M HNO $\mathrm{Haq}_{3}$ labeled "AZ-102 CUF wash acid."

- 1 liter of filtered, distilled water labeled "shut-down water."

\subsection{Other Supplies}

1. Workplace Copy of Operating Procedure BNFL-TP-29953-020

2. Extra Copies of Data Sheets 1, 2, and 3

3. Laboratory Record Book

4. DAS disk for recording data

\subsection{Test Instructions}

The laboratory record book (LRB) shall be used to record other testing information as required by this procedure and all test conditions not stated by this procedure. 
Cross-contamination between samples and contamination of samples from outside sources must be minimized at each step. Use new tools and bottles for each sample as much as possible. Those tools that are reused should be washed and rinsed prior to reuse.

Keep all test materials in sealed containers as much as possible to prevent them from drying. Due to the shortage of test sample, do not remove any additional slurry other than what is specifically requested for in this test instruction.

\subsection{Pre-start}

5.1.1 Inventory materials, equipment, supplies, and reagents to ensure all required items are available. Assure that all materials have been modified for remote handling.

5.1.2 Do the following and initial and date when each item is completed. $\checkmark \quad$ Review PNNL Operating Procedure BNFL-TP-29953-020. $\checkmark \quad$ Review the work instructions in this document.

5.1.3 Weight AZ-102 Sample A and tare weigh the bottle labeled "AZ-102 Initial Feed"

AZ-102 Sample A

Total $\frac{788.56}{\text { w/ cap a w/o motol clamp }}$
Tare AZ-102 Initial Feed

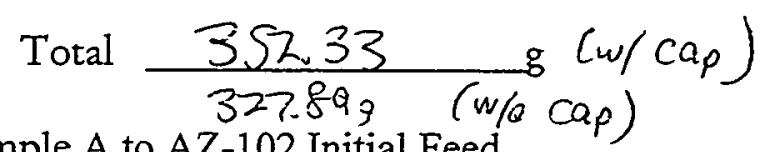

5.1.4 Transfer $284 \mathrm{~g}$ of AZ-102 from AZ-102 Sample A to AZ-102 Initial Feed.

Reweigh both containers. Any solids remaining on the tools used for the transfer should be saved and will be rinsed into the CUF.

Not performed. See LRB.

AZ-102 Sample A

Total

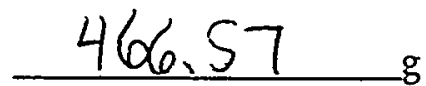

AZ-102 Initial Feed

Total g

5.1.5 Conduct the "0.0 Pre-Start" operations in BNFL-TP-29953-020. Replace the overflow container with the bottle labeled "tank overflow container."

** Steps 5.1.6 through 5.1.12 have already been completed. They will remain in the instruction for reference purposes only. Operations should begin with step 5.1.13.

5.1.6 Perform "1.0 Start-Up" operations in BNFL-TP-29953-020 with lay-up solution currently in CUF with one variation: V4 the filtrate control valve should be closed. Run CUF for 5 minutes between 4 and 6 gallons per minute (gpm).

5.1.7 Conduct the "10.0 Draining the system" operation in BNFL-TP-29953-020. 
5.1.8 Perform "1.0 Start-Up" operations in BNFL-TP-29953-020 with 1.0 liter of filtered, distilled water.

5.1.9 Perform "6.0 Back-pulsing" operations in BNFL-TP-29953-020.

5.1.10 Shut off the system and conduct the "10.0 Draining the system" operation in BNFL-TP-29953-020.

5.1.11 Perform "1.0 Start-Up" operations in BNFL-TP-29953-020 using the liquid in the bottle labeled "start-up water".

5.1.12 Conduct the "3.0 Operation during Ultrafilter Recycle Mode" operations in BNFL-TP-29953-020 using the conditions below. Filtrate flow rate should be monitored and data collected in the operating procedure. Each test should be performed for only 20 minutes and the system should be back-pulsed. After each condition, the test engineer should initial and date the table below.

\begin{tabular}{|c|c|c|c|}
\hline Condition & Flowrate (gpm) & $\begin{array}{c}\text { Transmembrane } \\
\text { Pressure (psig) }\end{array}$ & $\begin{array}{c}\text { Initial and date } \\
\text { when complete }\end{array}$ \\
\hline 1 & 4.20 & 30 & \\
\hline 2 & 4.20 & 55 & \\
\hline 3 & 4.20 & 70 & \\
\hline
\end{tabular}

5.1.13 Shut off the system and conduct the "10.0 Draining the system" operation in BNFL-TP-29953-020.

\subsection{Start-Up}

5.2.1 Obtain the following information:

M\&TE List:

$\checkmark$ Balance 1: $\left(S_{m, 311}\right)$

Calib ID

Location

$326-06-01-06.1$

Calib Exp Date 8/2000

$\checkmark$ Balance 2: (large

Calib ID

Location A-cell Sauth.

Calib Exp Date $8 / 2000$

TC 1 Calib ID/Date 3003/8/20 P-201 Calib ID/Date 325-JD-2 $/ \begin{gathered}E_{k p} \\ \% / 2000\end{gathered}$

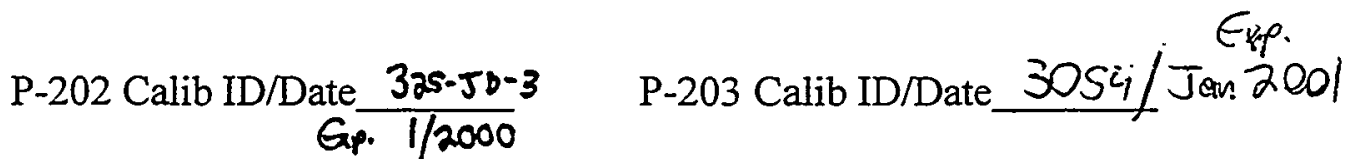

5.2.2 Weigh the jars containing the AZ-102 samples and the " $5 \mathrm{wt} \%$ dilution $1 . "$

Record their weights below. 
AZ-102 Sample MU

Total

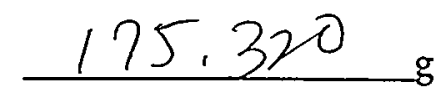

“5 wt\% dilution $1 "$

Total
AZ-102 Sample GL

Total $180,833 \quad \mathrm{~g}$

5.2.3 Conduct the "1.0 Start-Up" operations in BNFL-TP-29953-020 staring with approximately one-half of the material in " $5 \mathrm{wt} \%$ dilution $1 . "$ Once that is pumping, add the contents of AZ-102 Initial Feed. Shake the jar containing the AZ-102 sample thoroughly before adding it to the slurry reservoir. Use the remaining " $5 \mathrm{wt} \%$ dilution" material to recover any solids left in the sample jar that cannot be transferred by shaking. Pay close attention to the level of material in the CUF.

5.2.4 Record the weights of the empty jars and lids in the spaces provided below. Calculate the amount of material remaining in the sample jar. If the difference is greater than $\sim 2 \mathrm{~g}$ or significant solids are visible, further solids recovery is warranted. Record the method of recovery in the LRB.

Az-102 Sample A

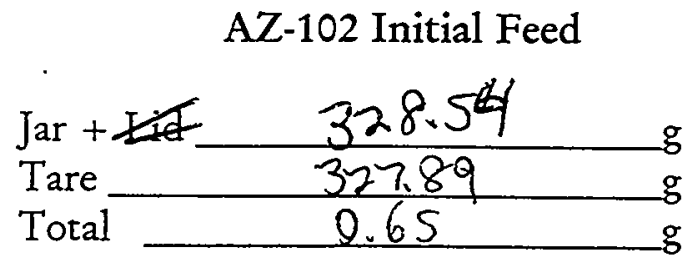

$321.99 \mathrm{~g}$

5.2.5 Record the level in the slurry reservoir.

Height inches “5wt\% dilution"

Jar + Lid $\frac{\operatorname{See} L R B}{\operatorname{See} L R B} \mathrm{~g}$
Tare $\frac{\mathrm{g}}{1849.86 \quad \mathrm{~g}}$
Total 189.8

\subsection{Operation}

\section{First Test Matrix}

5.3.1 Conduct the "3.0 Operation during Ultrafilter Recycle Mode" operations in BNFL-TP-29953-020 using the conditions below. Filtrate flow rate should be monitored and data collected as specified in the operating procedure. After each condition, the test engineer should initial and date the table below.

\begin{tabular}{|c|c|c|c|}
\hline Condition & Flow rate (gpm) & $\begin{array}{l}\text { Transmembrane } \\
\text { Pressure (psig) }\end{array}$ & $\begin{array}{l}\text { Initial and date } \\
\text { when complete }\end{array}$ \\
\hline 1 & 4.20 & 50 & $T_{1 B} 1 / 10100$ \\
\hline
\end{tabular}




\begin{tabular}{|c|c|c|c|}
\hline 2 & 3.13 & 30 & KRe $1 / 10 / 00$ \\
\hline 3 & 5.23 & 70 & $4 / 1060$ \\
\hline 4 & 5.23 & 30 & KGR 1/10/00 \\
\hline 5 & 3.13 & 70 & - \\
\hline 6 & 4.20 & 50 & KGR / $/ 10$ \\
\hline 7 & Op̃timum from $1-6$ & Optimum from $1-6$ & QICC) 1110100 \\
\hline
\end{tabular}

5.3.2 Using the rheometer sample cup, obtain $40 \mathrm{~mL}$ of slurry material for rheological L6 measurements following "7.0 Slurry Sampling" in BNFL-TP-29953-020. This may require as many as eight samplings to obtain this material. Perform rheological measurement per Table 4 in BNFL-TP-29953-069.

Viscometer

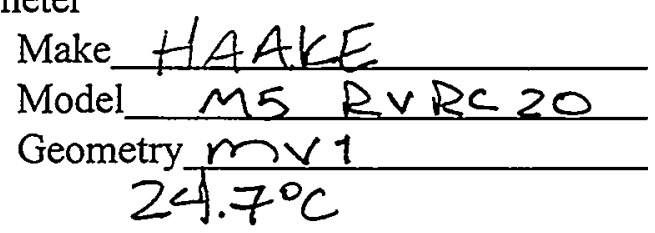

* colded -30 mis if PI to UF i insing ievfogy

5.3.3 Tare-weigh the 1-L bottle labeled "AZ-102 Filtrate\#1. 2. if

$18: 29 \mathrm{pm}$ Weight of empty "AZ-102 Filtrate\#1" with lid $\frac{102.626}{1 \mathrm{~A}} \mathrm{~g}$
4 Pre-weigh two of the labeled $20-\mathrm{mL}$ glass scintillation" vials and record its

5.3.4 Pre-weigh two of the labeled 20 -mL glass scintillation vials and record its -\# - - $1901 \$-02$ weights. Mid-way through the following step (5.3.5), obtain two filtrate samples of at $19: 0(\mathrm{pm})$ least 20 grams following "8.0 Filtrate Sampling" in BNFL-TP-29953-020. If required, more than two sample vials may be used. Record the weights and sample numbers in Data Sheet 3. These will be used for chemical and radiochemical analyses.

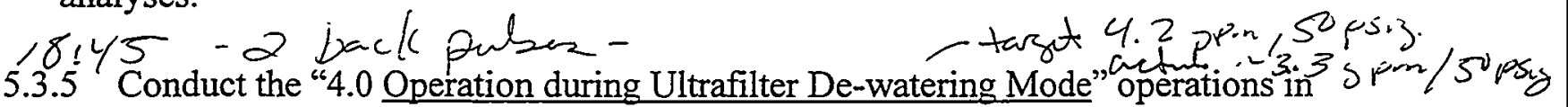
BNFL-TP-29953-020 using the optimum conditions from step 5.3.1. Fill "AZ-102 Filtrate\#1" to the $970 \mathrm{~mL}$ mark, or as high 2 possible if this mark in unattainable. ing possible if this mark in unattain

5.3.6 Replace the lid on the bottle and weigh.

$$
\begin{aligned}
& \text { Total weight of material removed in } \\
& A z-102 \text { F tiotem l }
\end{aligned}
$$

5.3.7 Record the level in the slurry reservoir.

Height $n /-2^{\prime \prime}$ inches $19 / 4$ vidro

5.3.8 Weigh the bottle labeled " 5 wt\% dilution 2" and the AZ-102 recovery jar.

Calculate the weight of liquid/slurry in the recovery jar. 


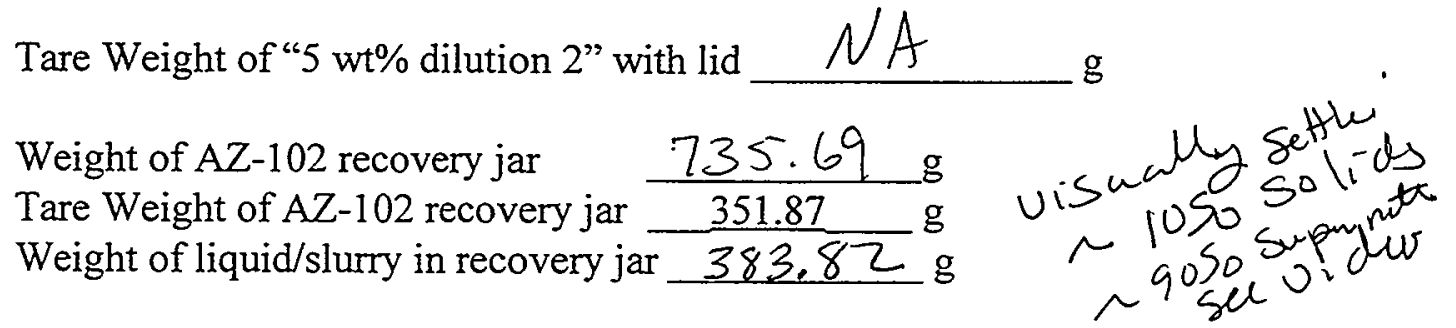

5.3.9 Calculate and add the proper weight of $0.01 \mathrm{M} \mathrm{NaOH}$ to the bottle labeled " $5 \mathrm{wt} \%$ dilution 2."

Weight required to be added to CUF

Weight of liquid/slurry in recovery jar

Weight needed in " $5 \mathrm{wt} \%$ dilution 2 "

$$
\frac{837}{453.18 \mathrm{~g} 3.82} \mathrm{~g} g
$$$$
\text { . OIM NaOH }
$$

Actual weight of " $5 \mathrm{wt} \%$ dilution $2 "$ added $453.19 \mathrm{~g}$

Pre - $m_{u}=175.3205 .3 .10$ Add the remaining slurry material from "AZ-102 Sample A", "AZ-102 Sample "re - $G L=180.83$ 3 MU," and "AZ-102 Sample GL" to the CUF.

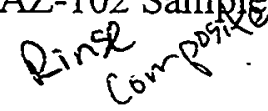

5.3.11 Use the AZ-102 recovery jar and $5 \mathrm{wt} \%$ dilution 2 liquids to rinse out the three AZ-102 sample jars. Pour this material into the CUF. finished @ 2030 When looked in CUF no slwrry

5.3.12 Weigh the empty containers.

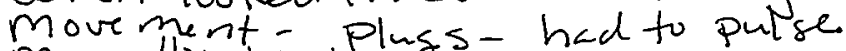

Weight of "AZ-102 Sample A"

Weight of "AZ-102 Sample MU"

Weight of "AZ-102 Sample GL"

Weight of recovery jar

Weight added to CUF

movement - Pluss - had to pulse

Weight of "AZ-102 Sample A"

Weight of "AZ-102 Sample MU"

Weight of "AZ-102 Sample GL"

Weight of recovery jar

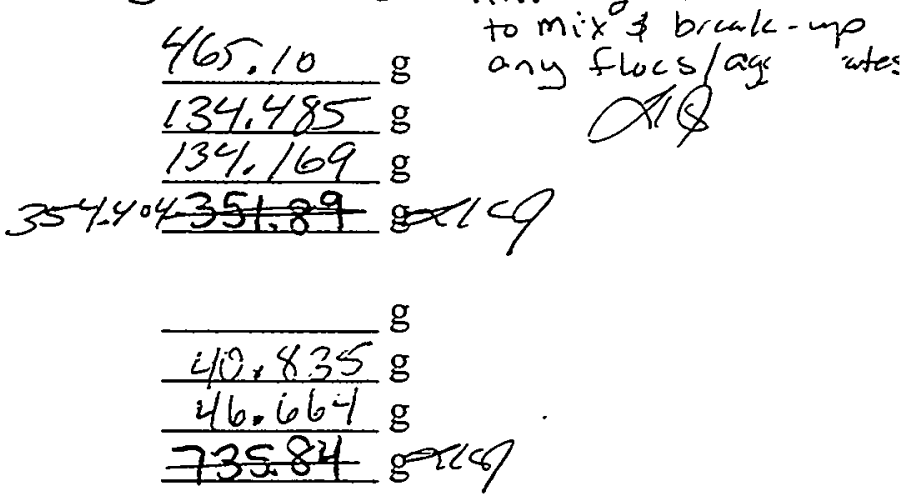

5.3.13 Tare-weigh the 1-L bottle labeled "AZ-102 Filtrate\#2."

Weight of empty "AZ-102 Filtrate\#2" with lid 100,36/_g

5.3.14 Pre-weigh two of the labeled 20-mL glass scintillation vials and record its weights. Mid-way through the following step (5.3.15), obtain two filtrate samples of at least 20 grams following "8.0 Filtrate Sampling" in BNFL-TP-29953-020. If required, more than two sample vials may be used. Record the weights and sample numbers in Data Sheet 3. These will be used for chemical and radiochemical analyses.

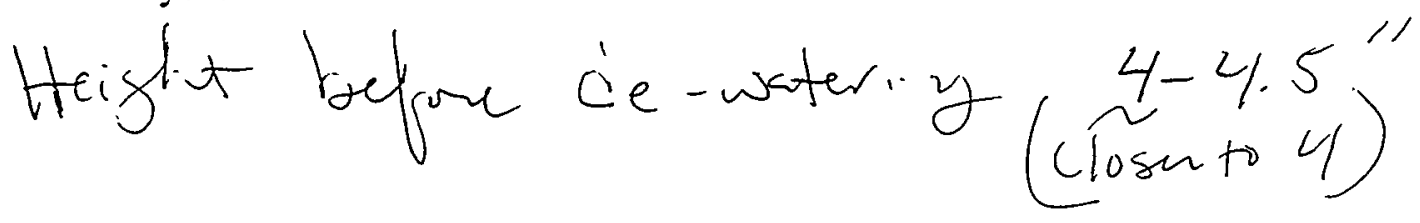

* thaving lots of plugsing problens. 
5.3.15 Conduct the "4.0 Operation during Ultrafilter De-watering Mode" operations in BNFL-TP-29953-020 using the optimum conditions from step 5.3.1. Fill "AZ-102 Filtrate\#2" to the $970 \mathrm{~mL}$ mark, or as high as possible if this mark in unattainable.

5.3.16 Replace the lid on the bottle and weigh.

Weight of "AZ-102 Filtrate\#2" with lid Total weight of material removed

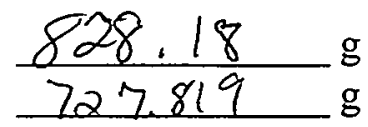

5.3.17 Record the level in the slurry reservoir.

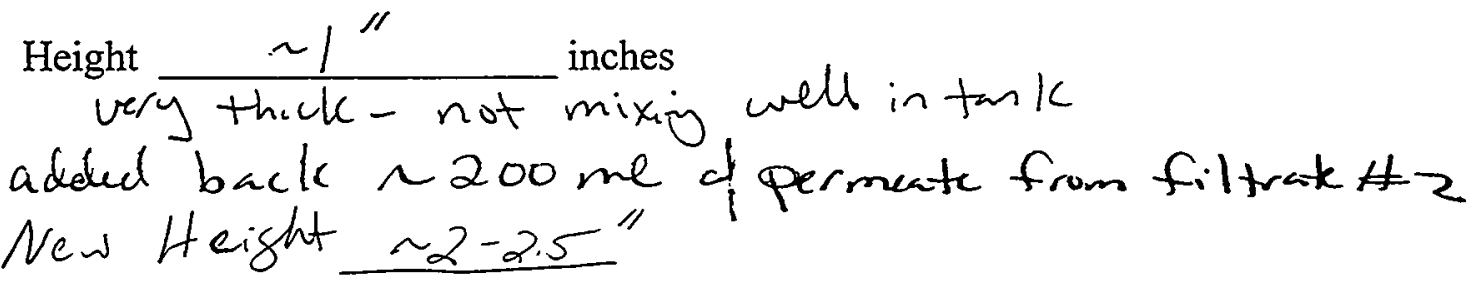

Second Test Matrix

5.3.18 Conduct the "3.0 Operation during Ultrafilter Recycle Mode" operations in BNFL-TP-29953-020 using the conditions below. Filtrate flow rate should be monitored and data collected as specified in the operating procedure. After each condition, the test engineer should initial and date the table below, and check the level in the slurry reservoir (video-taping periodically, as necessary).

\begin{tabular}{|c|c|c|c|}
\hline Condition & Flowrate (gpm) & $\begin{array}{l}\text { Transmembrane } \\
\text { Pressure (psig) }\end{array}$ & $\begin{array}{l}\text { Initial and date } \\
\text { when complete }\end{array}$ \\
\hline 1 & $420 \quad 2.6$ & 50 & R/B $1 / 11 / 00$ \\
\hline 2 & 3.132 .2 & 30 & $1 / 11 / 00$ \\
\hline 3 & 5.2320 & 70 & Re 1/11/00 \\
\hline 4 & 5.23 & 30 & $1 / 11 / 00$ \\
\hline 5 & 3.13 & 70 & Nonformed \\
\hline 6 & 4.20 & 50 & The 1/N/00 \\
\hline
\end{tabular}

5.3.19 Obtain two slurry samples of 20 and 10 grams each, respectively, following "7.0 Slurry Sampling" in BNFL-TP-29953-020 and using the pre-labeled sample vials. These will be used for physical property and particle size distribution analyses. $\sim 11: 45 \mathrm{pm}^{\mathrm{m}}$ Record the weights and sample numbers in Data Sheet 3.

5.3.20 Using the rheometer sample cup, obtain $40 \mathrm{~mL}$ of slurry material for rheological measurements following "7.0 Slurry Sampling" in BNFL-TP-29953-020. This may require as many as eight samplings to obtain this material. See Table 4 in BNFL-TP29953-069 for a description of this process. T) Vis y/10/00 
5.3.21 Adjust the flow to $<2 \mathrm{gpm}$ and the pressure to $<10$ psig while the rheology of the material is measured. Pour the $40-\mathrm{mL}$ used for rheological measurements back into the CUF. Perform rheological measurement per Table 4 in BNFL-TP-29953-069.

5.3.22 Increase the flow and pressure to its optimal value and repeat step 5.3.20 and 5.3.21 for a second $40-\mathrm{mL}$ slurry sample.

\section{Three Water Washes}

5.3.23 Weigh all three one-liter bottles labeled "water wash solution."

Bottle

with solution

(Solutionanly)

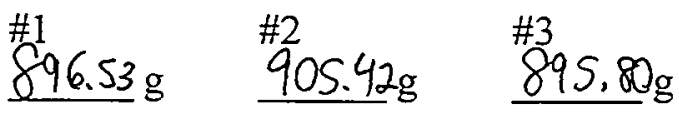

5.3.24 Obtain the tare weight of the three empty two-liter bottles labeled "AZ-102 WW permeate\#1" through "AZ-102 WW permeate\#3."

Empty bottle

$$
\text { permeate\#1 permeate\#2 permeate\#3 }
$$

$100.00 \mathrm{~g} \quad 100.29 \mathrm{~g} \quad 100.58 \mathrm{~g}$

5.3.25 Add the first bottle of "water wash solution" to the slurry reservoir.

\subsubsection{Conduct the "4.0 Operation during Ultrafilter De-watering Mode" sperations in}

BNFL-TP-29953-020 using the optimum conditions from step 5.3,12, dcquing flux measurements periodically. Fill "AZ-102 WW permeate\#1" to the 900-mL mark. Add the second bottle of "water wash solution", and begin filling "AZ-102 WW permeate\#2." Add the third bottle of "water wash solution" once the $900-\mathrm{mL}$ mark is reached in the second permeate bottle. Continue dewatering into "AZ-102 water wash permeate\#3," filling it to its $900-\mathrm{mL}$ mark, or as high as possible if the $900-\mathrm{mL}$ mark in unattainable. Following each dewatering (after each $900-\mathrm{mL}$ mark is reached), check the slurry height. Video tape if necessary.

5.3.27 Weigh the three empty one-liter bottles labeled "water wash solution."

\begin{tabular}{|c|c|c|c|}
\hline $\begin{array}{l}\text { Bottle } \\
\text { without solution }\end{array}$ & $\begin{array}{l}\# 1 \\
\mu / \Lambda \quad g\end{array}$ & $\begin{array}{l}\# 2 \\
N / A\end{array}$ & $\begin{array}{l}\# 3 \\
N / A\end{array}$ \\
\hline & $896.53 \mathrm{~g}$ & $905.42 \mathrm{~g}$ & $895.80 \mathrm{~g}$ \\
\hline
\end{tabular}

5.3.28 Weight the three one-liter bottles labeled "AZ-102 WW permeate\#1" through "AZ-102 WW permeate\#3." 

with permeate
permeate\#1
permeate\#2
permeate\#3
$978.57 \mathrm{~g} \quad 981.14 \mathrm{~g} \quad 105 \% .65 \mathrm{~g}$
Total permeate
$878.57 \mathrm{~g} \quad 580.85 \mathrm{~g}$
$954,01 \mathrm{~g}$

5.3.29 Obtain the tare weight of a graduated centrifuge tube.

Tare weight of centrifuge tube $=$

$$
6.4899
$$

5.3.30 Obtain 1 slurry sample of at least 10 grams following "7.0 Slurry Sampling" in

BNFL-TP-29953-020 and using the graduated centrifuge tube. Determine the weight of the sample $\left(\mathrm{Wt}_{\text {sample }}\right)$ and the total sample volume $\left(\mathrm{V}_{\text {sample }}\right)$. Centrifuge for 5

minutes, remove, and determine volume of centrifuged solids $\left(\mathrm{V}_{\text {solids }}\right)$.

Weight (tube and sample) $=15.91 \quad \mathrm{~g}$

$\mathrm{Wt}_{\text {sample }}=$

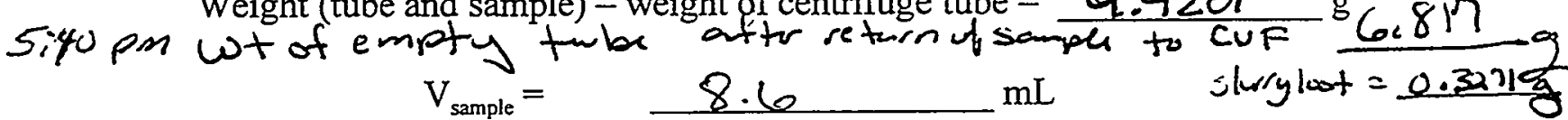

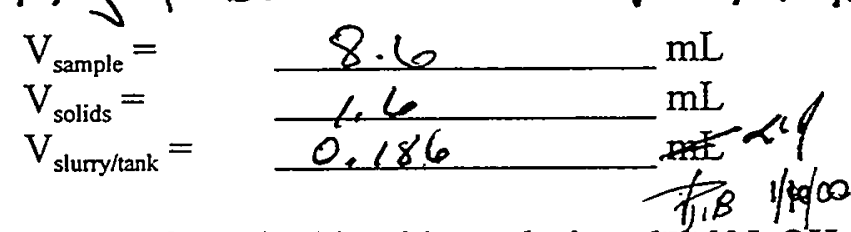

5.3.31 Calculate the volume of required leaching solution, $\mathrm{NaOH}_{a q}$ and place in "caustic leach solution." Place a mark indicating this volume on the bottle labeled

"AZ-102 CL permeate\#1". $\mathrm{V}_{\text {slury }}$ represents the volume of the slurry.

Volume of $\mathrm{NaOH}_{a q}$ to be used $=$ $3 * \mathrm{~V}_{\text {slurrytank }} *\left(\mathrm{~V}_{\text {solids }} / \mathrm{V}_{\text {sample }}\right)=$ $\mathrm{mL}$

5.3.32 Record the.level in the slurry reservoir.

Height $\sim / 1,5$ inches

5.3.33 Obtain one slurry sample of at least 20 grams following "7.0 Slurry Sampling" in BNFL-TP-29953-020 and using the pre-labeled sample vials. This will be used for physical analyses. Record the weight and sample number in Data Sheet 3. of 6 1/11/00

\section{Caustic Leach}

5.3.34 Measure the Tare of the empty caustic leach container. -No lid / No baflez ete. Tare container 1124.41

5.3.35 Drain the system of slurry following "10.0 Draining the System" with the following changes: rather than placing a container underneath sample port V10 to 
collect slurry, tubing will be connected to the sample port and flow directed into the caustic leaching/washing container. - Rinsed scimple (Dot in to Caust ic Leach $c$.

5.3.36 Prepare the $\mathrm{NaOH}_{a q}$ solution. The volume of this solution was determined above. The concentration is to be sufficient to create a $3 \mathrm{M} \mathrm{NaOH}$ solution above the centrifuged solids layer.

$$
\begin{aligned}
& \text { Volume } \mathrm{NaOH} \text { solution required }=483 \mathrm{ml} g \\
& \text { Molarity of } \mathrm{NaOH} \text { solution }=7.37 \mathrm{M} \\
& \text { Bottle with }\left(\mathrm{M} \mathrm{NaOH}_{a q}=\frac{676.49 \mathrm{~g}}{-\mathrm{Empt}}\right. \\
& \rightarrow \rightarrow \text { Buth } \$ \text { sointon Bothtar } 66.93 \mathrm{~g}
\end{aligned}
$$

5.3.37 Add the above volume of solution to the slurry reservoir and pump through the system for five minutes. Drain as described above (5.3.35)into the caustic-leaching vessel. Determine the weight of $3-\mathrm{M} \mathrm{NaOH}_{a q}$ added.

\section{Leach \\ Container with $\not 3-\mathrm{M} \mathrm{NaOH}_{a q}=$}

Level in leaching container

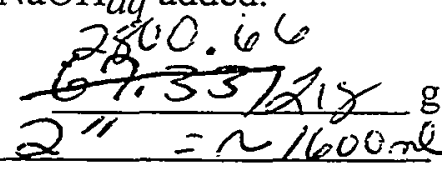

\section{4}

2114 pm gintsm

$$
21
$$$$
609.159 \mathrm{~g} \text { cod }
$$

5.3.38 Begin heating the slurry and set the controller temperature to $85^{\circ} \mathrm{C}$. Secure the top on the leaching/washing vessel along with the attached mixer. Initiate steady mixing. Wait until the slurry temperature reaches $85^{\circ} \mathrm{C}$ and note the time. Leaching will continue for 8 hours from this time.

Time $85^{\circ} \mathrm{C}$ is reached Estrintat Shutdown time (above time plus 8 hours) $\angle \frac{0}{6}: \frac{1}{6} \frac{5 \mathrm{AM} M}{6} \mathrm{SM} / 11 / 00$

Sint off CMF - 6:33 frr

5.3.39 Obtain the tare weight of the empty one-liter bottle labeled "AZ-102 CL permeate." Empty bottle
Rinsed 'Container w'

AZ 102 CL permeate

5.3.40 Begin heating the CUF at the end of the caustic leach. When leaching is complete, stop the heating/mixing the caustic leach. Measure weight and level of full container.

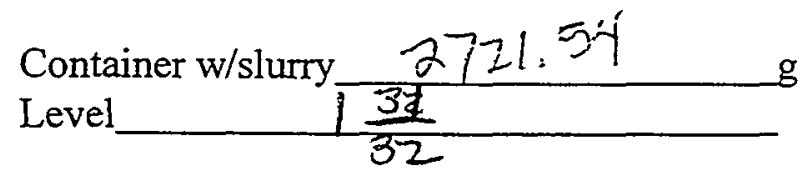

5.3.41 Add the slurry to the slurry reservoir. Pump until the temperature reaches $85 \pm 5^{\circ} \mathrm{C}$.

5.3.42 Calculate water lost during leaching.

Full container pre-leach

2800,66 g 
Full container post-leach

Amount of water lost

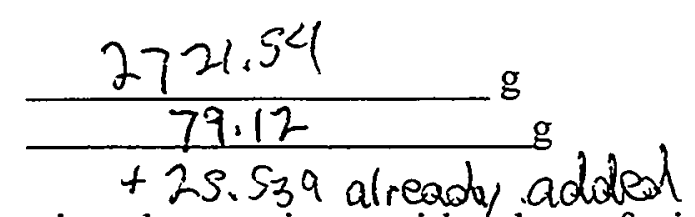

5.3.43 Add amount of water equal to that lost into the container, swirl ahd transfer into the slurry reservior.
Actual Water Added to CUF
81.46 g

Note if too many solids remain in the container, rinse the caustic leach vessel with an additional $100-\mathrm{mL}$ of $3-\mathrm{M} \mathrm{NaOH}_{a q}$ to remove any residual solids on the bottom or sides and add to the reservoir. Determine the weight of $3-\mathrm{M} \mathrm{NaOH}_{a q}$ added.

$\begin{array}{ll}\text { Container with 3-M NaOH} & \mathrm{Mq}_{a q}= \\ \text { Container without 3-M NaOH} & \text { Not formalg }\end{array}$

5.3.44 Pre-weigh two of the labeled 20-mL glass scintillation vials and record their weights. Mid-way through the following step (5.3.45), obtain two filtrate samples.

5.3.45 Conduct the "4.0 Operation during Ultrafilter De-watering Mode" operations in BNFL-TP-29953-020 using the optimum conditions from step 5.3.18. Obtain two filtrate samples of at least 20 grams following "8.0 Filtrate Sampling" in BNFL-TP29953-020. If required, more than two sample vials may be used. Record the weights and sample numbers in Data Sheet 3 . These will be used for chemical and radiochemical analyses. Fill "AZ-102 CL permeate" to the mark made in step 5.3.31, or as high as possible if mark is unattainable.

$$
\text { Cassici fald }
$$

5.3.46 Weight the full one-liter bottle labeled "AZ-102
With permeate
AZ-102 CL permeate
596.58 g

5.3.47 Record the level in the slurry reservoir.

Height not done inches

5.3.48 Obtain three slurry samples of at least 20 grams each following "7.0 Slurry

Sampling" in BNFL-TP-29953-020 and using the pre-labeled sample vials. These will be used for chemical and physical analyses. Record the weights and sample numbers in Data Sheet 3.

\section{First Caustic Wash}

5.3.49 Drain the system of slurry following " 10.0 Draining the System" with the following changes: rather than placing a container underneath sample port V10 to collect slurry, tubing will be connected to the sample port and flow directed into the caustic leaching/washing container. 
Level with slurry $\frac{13 / 16-i n d h}{702.3 \mathrm{ml}}$

5.3.50 Add sufficient volume of $0.01-\mathrm{M} \mathrm{NaOH}_{a q}$ to the slurry reservoir from "caustic wash solution\#1" to make $2400 \mathrm{~mL}$ total volume (slurry and and pump through the system for five minutes. Drain as described above (5.3.34) into the caustic-leaching $5 / 1 / 10 / 00$ vessel. Determine the weight of $0.01-\mathrm{M} \mathrm{NaOH}_{a q}$ added. Determine the weight of full leaching container.

labeled $\mathrm{cw}_{11} \quad$ Volume $0.01-\mathrm{M} \mathrm{NaOH}_{a q}$ required (2400-slurry volume) $\frac{1400 \mathrm{~mL}}{1401-\mathrm{M} \mathrm{NaOH}_{a q} \text { added }} \mathrm{mL}$ permeate Level in leaching container 2-7/8 mass inleaching container $\frac{3320.60}{2.288-1 \text {-iters }}$

5.3.51 Begin heating the sturry and set the controller temperature to $85^{\circ} \mathrm{C}$. Secure the top on the leaching/washing vessel along with the attached mixer. Initiate steady mixing. Wait until the slurry temperature reaches $85^{\circ} \mathrm{C}$ and note the time. Leaching will continue for 8 hours from this time.

Time $85^{\circ} \mathrm{C}$ is reached

Shutdown time (above time plus 8 hours) $0.8: 54$ AM/pM

5.3.52 Obtain the tare weight of the empty one-liter bottle labeled "AZ-102 CW permeate\#1."

\section{Empty bottle}

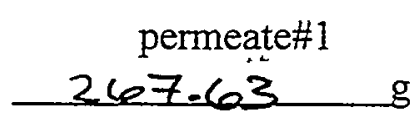

5.3.53 Begin heating the CUF at the end of the caustic wash. When washing is 2100 complete, stop the heating/mixing the caustic wash. Measure weight and level of full container.

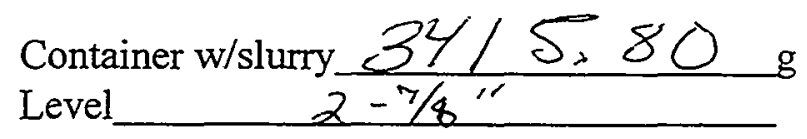

5.3.54 Add the slurry to the slurry reservoir. Pump until the temperature reaches $80^{\circ} \mathrm{C}$.

5.3.55 Calculate water lost during leaching.

Full container pre-leach Full container post-leach Amount of water lost

$\frac{\frac{3520.60}{3415.80}}{104.80} \mathrm{~g}$

5.3.56 Add an amount of water equal to that lost into the container, swirl, and transfer into the slurry reservior. 


\section{Actual water added to CUF $105,25 \quad \mathrm{~g}$}

Note if too many solids remain in the container, rinse with an addition $100 \mathrm{~mL}$ of $0.01 \mathrm{M}$ $\mathrm{NaOH}$ solution. Pour into the CUF. Determine the amount added.

$$
\text { Additional Water added to the CUF_Not performed g }
$$

4 5.3.57 Pre-weigh two of the labeled 20-mL glass scintillation vials and record their weights. Mid-way through the following step, obtain two filtrate samples.

7 5.3.58 Conduct the "4.0 Operation during Ultrafilter De-watering Mode" operations in BNFL-TP-29953-020 using the optimum conditions from step 5.3.18, recording flux measurements periodically. Obtain two filtrate samples of at least 20 grams following "8.0 Filtrate Sampling" in BNFL-TP-29953-020. If required, more than two sample vials may be used. Record the weights and sample numbers in Data Sheet 3. These will be used for chemical and radiochemical analyses. Fill "AZ-102 CW permeate\#1" to the amount added in step 5.3.48, or as high as possible if mark in unattainable.

50

$1 / 6 / \infty$

5.3.59 Record the level in the slurry reservoir.

$$
\text { Height Not Performed inches (videa taped) }
$$

\section{$\underline{\text { Second Caustic Wash }}$}

5.3.60 Drain the system of slurry following " 10.0 Draining the System" with the following changes: rather than placing a container underneath sample port V10 to collect slurry, tubing will be connected to the sample port and flow directed into the caustic leaching/washing container.

$\begin{array}{ll}\text { Tare container } & 1124.41 \quad \mathrm{~g} \\ \text { Level with slurry } & \text { Not performed-taken from weight \& volime betow } \\ \text { Volume of slurry } & \text { Not performed }\end{array}$

5.3.61 Add sufficient volume of $0.01-\mathrm{M} \mathrm{NaOH}_{a q}$ to the slurry reservoir from "caustic wash solution\#2" to make $2400 \mathrm{~mL}$ total volume (slurry and and pump through the system for five minutes. Drain as described above (5.3.34) into the caustic-leaching vessel. Determine the weight of $0.01-\mathrm{M} \mathrm{NaOH}_{a q}$ added. Determine the weight of the full leach container.

Volume $0.01-\mathrm{M} \mathrm{NaOH}_{a q}$ required (2400-slurry volume) $14 \mathrm{QO} \mathrm{mL}$ Volume $0.01-\mathrm{M} \mathrm{NaOH}_{a q}$ added Weight of Full Container with $0.01-\mathrm{M} \mathrm{NaOH}_{a q}$ Level in leaching container $2 \frac{111}{16}$ Werght of Full Leach Container

$$
\frac{3259 \cdot 25}{\operatorname{Losing} \sim 0.01 \mathrm{~g} / \mathrm{sec} \text { evaparation }}
$$


5.3.62 Begin heating the slurry and set the controller temperature to $85^{\circ} \mathrm{C}$. Secure the top on the leaching/washing vessel along with the attached mixer. Initiate steady mixing. Wait until the slurry temperature reaches $85^{\circ} \mathrm{C}$ and note the time. Leaching will continue for 8 hours from this time.

Time $85^{\circ} \mathrm{C}$ is reached

Shutdown time (above time plus 8 hours)

$$
1 \frac{4: 1}{2}: \frac{3}{3} \frac{\text { AMPM }}{\text { AMM }} \rightarrow 12: 13
$$

5.3.63 Obtain the tare weight of the empty one-liter bottle labeled "AZ-102 CW permeate\#2."

$$
\text { Empty bottle }
$$$$
\text { permeate\#2 }
$$$$
261.982 \mathrm{~g}
$$

5.3.64 Begin heating the CUF at the end of the caustic wash. When washing is complete, stop the heating/mixing the caustic leach.

$$
\begin{aligned}
& \text { Container w/slurry } 3237.10-100.068 \mathrm{~g} \\
& \text { Level not taken }
\end{aligned}
$$

5.3.65 Add the slurry to the slurry reservoir. Pump until the temperature reaches $80^{\circ} \mathrm{C}$.

5.3.66 Calculate the water lost during heating.

$$
\begin{aligned}
& \text { Full container pre-leach } \\
& \text { Full container post-leach } \\
& \text { Amount of water lost }
\end{aligned}
$$

$\frac{3259.25}{3137.032} \mathrm{~g}$
$\frac{122.218}{\mathrm{~g}} \mathrm{~g}$

5.3.67 Add an amount of water equal to that lost into the container, swirl, and transfer into the slurry reservoir.

$$
\text { Actual water added to CUF }
$$
100.068 g

Note if too many solids remain in the container, rinse with an addition $100 \mathrm{~mL}$ of $0.01 \mathrm{M}$ $\mathrm{NaOH}$ solution. Pour into the CUF. Determine the amount added.

$$
\text { Additional Water added to the CUF } 150.092 \quad \mathrm{~g}
$$

5.3.68 Pre-weigh two of the labeled 20-mL glass scintillation vials and record their weights. Mid-way through the following step, obtain two filtrate samples.

Measure filtrate fux initial, midille, end (over course of 10 minutes).

5.3.69 Conduct the "4.0 Operation during Ultrafilter De-watering Mode" operations in BNFL-TP-29953-020 using the optimum conditions from step 5.3.18, recording flux measurements periodically. Obtain two filtrate samples of at least 20 grams following "8.0 Filtrate Sampling" in BNFL-TP-29953-020. If required, more than 
two sample vials may be used. Record the weights and sample numbers in Data Sheet 3. These will be used for chemical and radiochemical analyses. Fill "AZ-102 CW permeate\#2" to the amount added in step 5.3.61, or as high as possible if mark in unattainable.

5.3.70 Record the level in the slurry reservoir.

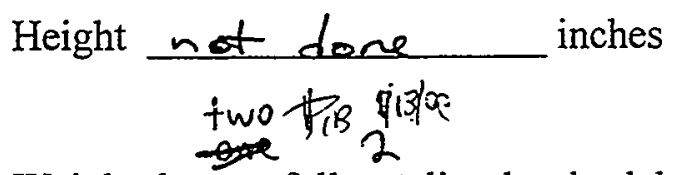

5.3.71 Weight the full gre-liter bottles labeled "AZ-102 CW permeate\#1" "AZ 102 permeatet2."

$\begin{array}{lll} & \text { permeate\#1 } & \text { permeate\#2 } \\ \text { With permeate } & 1759.69 \mathrm{~g} & 1801.32 \mathrm{~g} \\ \text { Tare } & 267.63 \mathrm{~g} & \frac{161.982 \mathrm{~g}}{1492.06} \\ & 1539.338\end{array}$

Testing Finale

(Call Paul- if he is avallable do this. If not, collect a $80 \mathrm{~g}$ sample for him.)

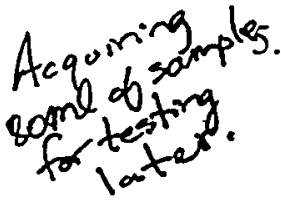

5.3.72 Using the rheometer sample cup, obtain $40 \mathrm{~mL}$ of slurry material for rheological measurements following "7.0 Slurry Sampling" in BNFL-TP-29953-020. This may require as many as eight samplings to obtain this material.

5.3.73 Adjust the flow to $<2 \mathrm{gpm}$ and the pressure to $<10$ psig or turn off the pump while the rheology of the material is measured. The $40-\mathrm{mL}$ of material will be recovered at a later time. Determine weight of material used.

5.3.74 Increase the flow and pressure to its optimal value and repeat step 5.3.62 and

5.3.6z for a second $40-\mathrm{mL}$ slurry sample.

43 i/10/09

5.3.75 Obtain four slurry samples of at least 10 (1) \& 20 (3) grams each, respectively, following "7.0 Slurry Sampling" in BNFL-TP-29953-020 and using the pre-labeled sample vials. These will be used for chemical and physical analyses, and particle size $6: 33$ PM distribution. Record the weights and sample numbers in Data Sheet 3.

Draining and Rinsing the System, ic glass (w/ plostic coating)

$$
\text { IL glass (w/ plostic coating) }
$$

5.4.1 Tare-weigh the 2-L, bottle labeled "AZ-102 final sample."

Weight of empty "AZ-102 final sample" with lid $520.37 \mathrm{~g}$

5.4.2 Drain the system of slurry following "10.0 Draining the System" into "AZ-102 final sample." Weight of full "AZ-102 final sample" with lid

1092.35

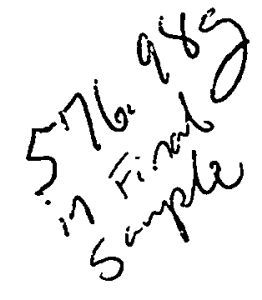

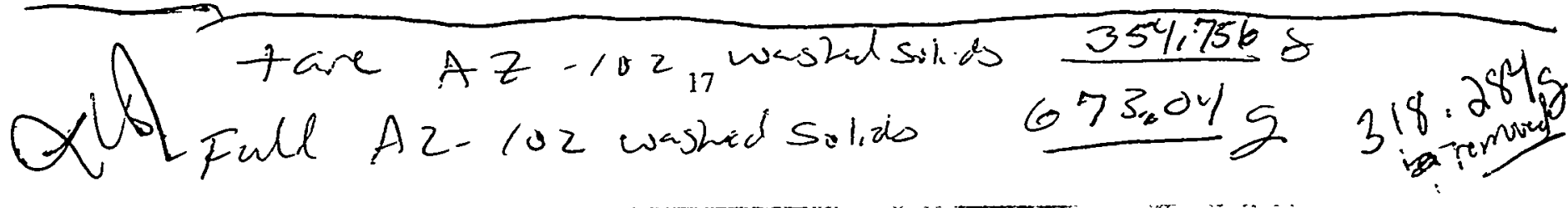


5.4.3 Add the 1-L of filtered, distilled water in "AZ-102 CUF rinse" to the reservoir. Open V4 and pump through the entire system for 5 minutes.

Weight of full "AZ-102 CUF rinse"

Weight of empty "AZ-102 CUF rinse"

Weight of "AZ-102 CUF rinse"

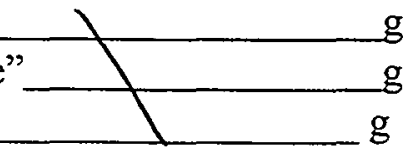

See $L R B$

for details

5.4.4 Back-pulse the system once following " 6.0 Back-Pulsing."

5.4.5 Shut off pump and drain the system following "10.0 Draining the System."

Weight of full "CUF rinse" See $L R B \quad \mathrm{~g}$

5.4.6 Conduct the "9.0 Rinsing the system" operation in BNFL-TP-29953-020 for the second and third rinses. The second rinse should be done with 2-L of filtered, distilled water, and the third rinse with 1-L of filtered, distilled water. The second and third rinses should be collected separately from the first in the alkaline rinse storage container. Filtrate flow rates should be checked with the third rinse to determine if an acidic rinse is required. The acidic solutions, if necessary, should be placed in a separate container.

$\rightarrow$ Back quisub durng $2^{\text {nd }} \rightarrow$ Rinse / None fur IStRinse.

5.4.7 Conduct the "3.0 Operation during Ultrafilter Recycle Mode" operations in BNFL-TP-29953-020 using the conditions below and the 1- $\mathrm{L}$ of filtered, distilled water in "shut-down water." Filtrate flow rate should be monitored and data collected in the operating procedure. Each test should be performed for only 20 minutes and the system should be back-pulsed. After each condition, the test engineer should initial and date the table below.

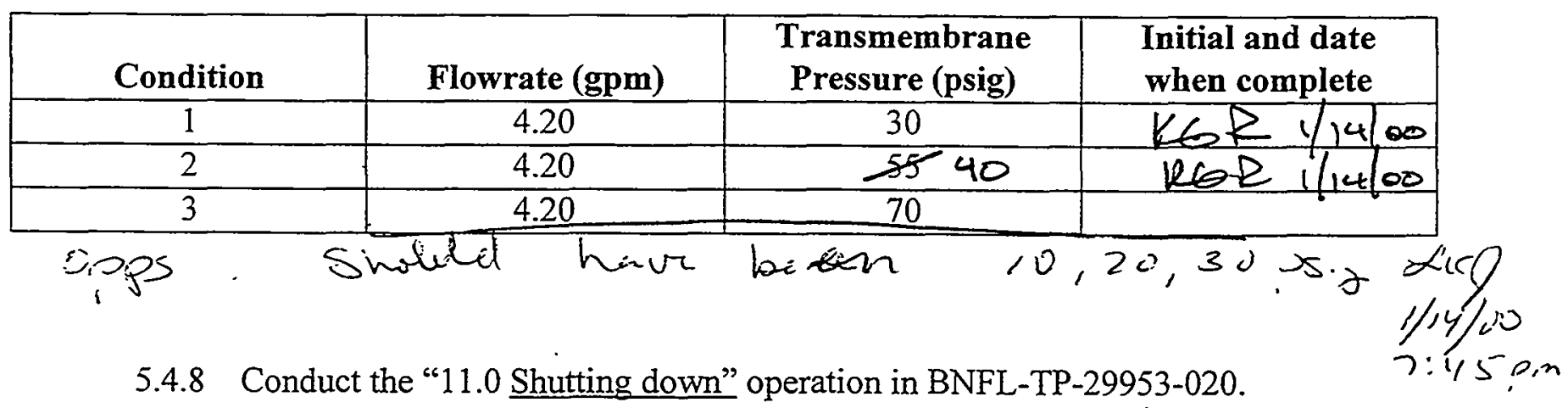

5.4.9 Conduct the "12.0 Lay Up" operation in BNFL-TP-29953-020.

$$
\text { "A2-102 Final Sample" }
$$

5.4.10 Allow the slurry to settle in the 2-L bottle्र. Analysis of the permeate from the second caustic wash, "AZ-102 caustic wash permeate\#2," will determine if further washing is required. If no further washing is required, decant off the liquid on top of 
the settled slurry into "AZ-102 decant" until 1 to 2 inches of liquid remain. Weigh the amount of liquid removed.

Weight of empty "AZ-102 decant" with lid

Weight of full "AZ-102 decant" with lid $\mathrm{g}$ $\mathrm{g}$

5.4.11 Remove and weigh all appropriate samples from all permeate bottles.

\subsection{Sample Analysis}

The point of contact for physical property sample analysis of the slurry samples is Paul Bredt. The point of contact for the sample analysis of the filtrate, wash, and filtered solids samples is Mike Urie and Rick Steele.

\subsection{Slurry Sample Physical Analysis}

The slurry samples taken for physical testing (except for particle size distribution analysis samples, which will go to Lab 312) will remain in the HLRF. These samples will be used for obtaining the following information: bulk density, supernatant density, particle size distribution, volume percent settled and centrifuged solids, and suspended solids loading. Each of these analyses will be done in duplicate. The viscosity of these samples was performed previously during testing in Section 5.0. 


\subsection{Chemical and Radiochemical Analysis}

The following samples should be transferred to the SAL hot cells for prep work and analysis.

Liquid Samples

- One sample from the first de-watering step.

- One sample from the second de-watering step.

- One sample taken from the bottle labeled "AZ-102 water wash permeate\#1"

- One sample taken from the bottle labeled "AZ-102 water wash permeate\#2"

- One sample taken from the bottle labeled "AZ-102 water wash permeate\#3"

- One sample taken during the AZ-102 caustic leach

- One sample taken during the first AZ-102 caustic wash \#1

- One sample taken during the second AZ-102 caustic wash \#2

- One sample taken from the bottle labeled "AZ-102 decant"

Slurry Samples

- One sample after three water washes

- Two samples after the caustic leach

- Two samples after the final dilute caustic wash

- The following will be performed on these samples: TOC/TIC and IC on the original sample and acid digestion followed by GEA, Sr-90 analysis, ICP-MS for Tc-99, total alpha and ICPAES. See BNFL-TP-29953-069 for further details. 
32

A2-102 Test

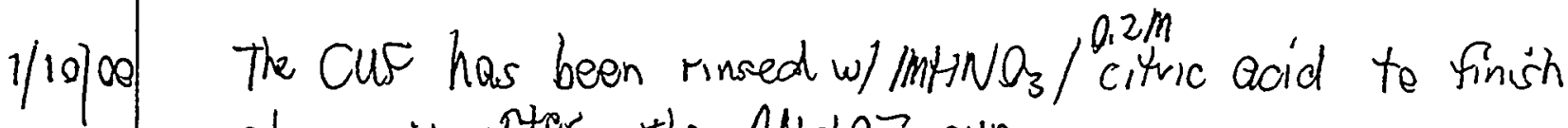
cleaning it after the AN -107 run.

It has been rinsed te neutral pt t and the clean water flux measured. A new pressure gauge on permeate side was needed of the leak on the chilled water is fixed. We are concerned about whether the water we insert in the tank outside the cell all ends up in the Clair

Weight of water $\left(0.01 \mathrm{~m} \mathrm{~N}^{\mathrm{O}} \mathrm{OM}\right)$.

Tare weight of container inside $=243.51 \mathrm{~g}$

Weigh of full container inside $=323.8449$

Weigh of $0.01 \mathrm{M} \mathrm{NalH}$ inside 221.52 ,

Delta

2) 9

$$
\begin{aligned}
& \text { Weight of water outside }=688.07 \mathrm{~g}\left({ }_{(1)}\right) \\
& \text { Weight of }(0.01 \mathrm{~m}) \mathrm{NaOH} \text { outside } 711.95 \mathrm{~g} \text { (*2) }
\end{aligned}
$$

We attempted to transfer the solids to a different Container. In the process, material was being last, dried on and getting spread everywhere. Instead we will send all of the material both in A2-102 A and the other new container Into the CUF.

We may have lost $2-3 \mathrm{~g}$ dried solid on the cloths where we set the spatulas. We may have lost an additional $3-4 \mathrm{~g}$ on the spatulas.

Flow $M \times+B$ settings:

$$
\begin{aligned}
& m=1.9901 \\
& B=-1.9987
\end{aligned}
$$

Project No 29953

Entered By RP Brooks

Date of Work 1/10/00

Disclosed To and Understood By Dato 1/10/00

Signed

Date

2.

Date 
A2-102

2:10 ain Attracted hew pressure gauge.

$9.3^{\circ}$

Drained eves

Turned on DAS

Added $106.09 \mathrm{~g}$ of $0.01 \mathrm{~m} \mathrm{NaOH}$ to

the Az-102 Initial feed container (maybe $10_{3}$ went to Az -102 Sample $A$ ) - (from existing squirt battle)

Added, $221.52 \mathrm{~g}$ of $0.01 \mathrm{~m} \mathrm{NaOH}$ to Az-102 sample A Weight of $78.858 \mathrm{~g} \rightarrow 686.26 \mathrm{~g}$

Poured Az-102 Initial feed into CUp (w/ 106.099 water)

$$
\begin{aligned}
& \text { weight of } 815.20 \mathrm{~g} \\
& \text { container }+0.01 \mathrm{~m} \mathrm{NaOH}
\end{aligned} \rightarrow 712.88 \mathrm{~g}
$$

Poured into Az-102 Sample A to clean bottle.

4:02 Repeated as needed. Cleanedup spatulas as well as. could.

Az -102 Sample A has a hid that says

"A 2-102 Recovered Solids Rind"

Side says "Az-10z".

4:35 started CUF

- Initially no flew a pressure built up in the inlet pressure gauge but nat the outlet. Lots of flow variation/ pressure variation-

Added

$123.11 \mathrm{~g}$ of $0.01 \mathrm{~m} \mathrm{NaOH}$ additional to get it $49 \mathrm{~S}_{4}+\mathrm{H}_{\mathrm{C}}$

4:52 Opened V4 and began flux measurements.

Needed air stepper to get to 50 psi \& still cant get to $4.2 \mathrm{gpm}$.

Project No. 4.2 g pm. 29953 Date of Work $1 / 10 / 00$ Entered By KP Brants Disclosed To and Understood By Dado- 1/10/00 Signed 1.

Date

Date 
A2-102

4

\$:20 Continues to creep up in pressure over time. It also appears that the flow rate is increasing over time. The flux is decreasing over time.

6:06 Started condition $\$ 2$

6:16 Adjusted velocity down Since 4.2 gp wasn't achieved, we need to run the matrix at lower axial veloaties.

$7: 23$ System plugs at condition $\$ 3$ such that pressure $200 \mathrm{~ms}$ up to 100 psi \& then yo have to back way down to get it to equilibrate. 30 psi. Readjust \& the pressure jumps to tOO psi again.

$7: 28$ finally holding mare or less steady at $\sim 70$ psi 7:37 still bouncing around \& plugging.

12ioupn - V3 toggle switch came off.

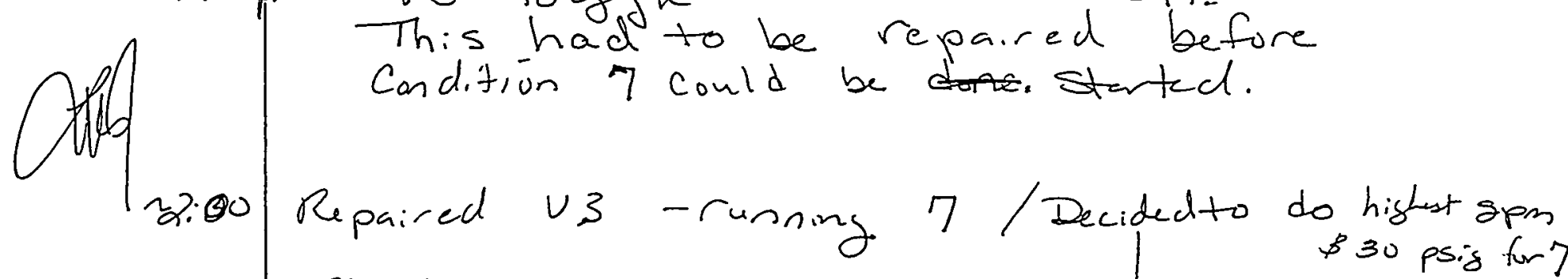

23:30 Rheology taken - Because optimum was

* When rinsing Cup added 130 extra but had already keen dou e 23:x ml DI to CUF

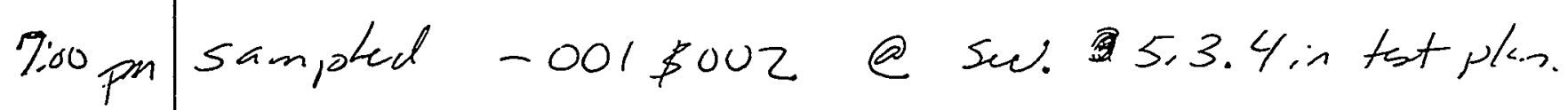

6:45 pm back pulsed 2 tiries/started De wafer ing

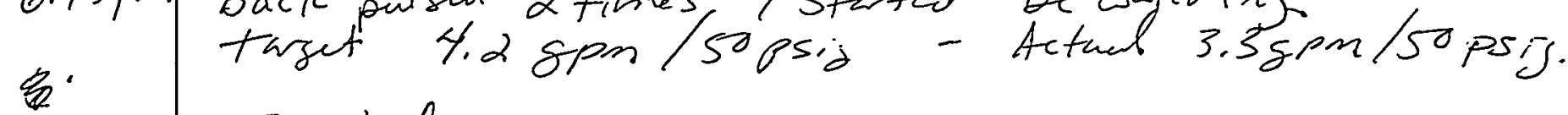

7!llopp Finished De watering

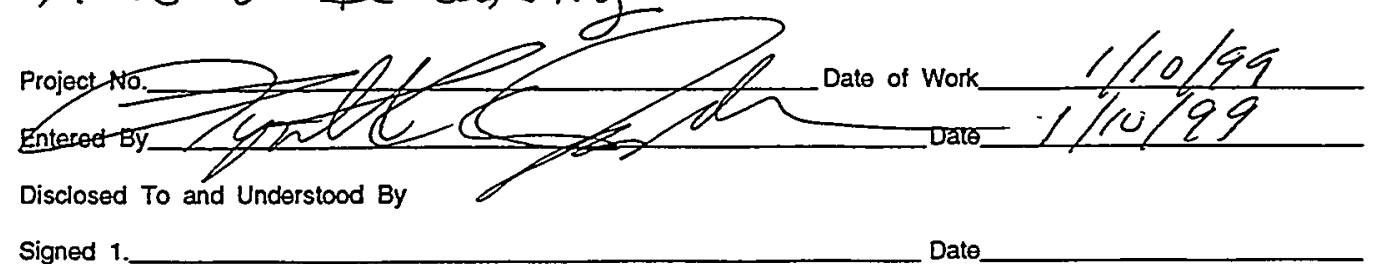

Signed 1

Date

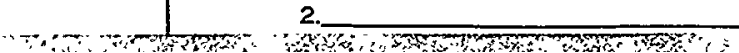

Date

काष 
A2-102 HOT CUE

8i30pn finished adding all addition d material to the CUF. Recovery solids visuals r co so solelel solids roost supinate

Ralph e used supernate to rinse other samples into CUF.

When addition was complete noted no movement in the CUF and no flow rate -

The system was plugged.

- 9:30 fr 45 minutes of manual start and stop (bum pore pump) action was required before the system would run continuously. An additional $4 \mathrm{gmin}$ of crossing and bumping where needed before di -watering could be started.

* See notes from Composite sampling. from this date.

10:50 De watering Complete - Slurry is too thick and stagnate in zones - See videoAdder a so. me permute back - Still stagnate then added 2 100-110 me permeate back - mostly flown g but nut then added a 50 more back. Smooth flown (uniform) uniform

dod to slurry samples

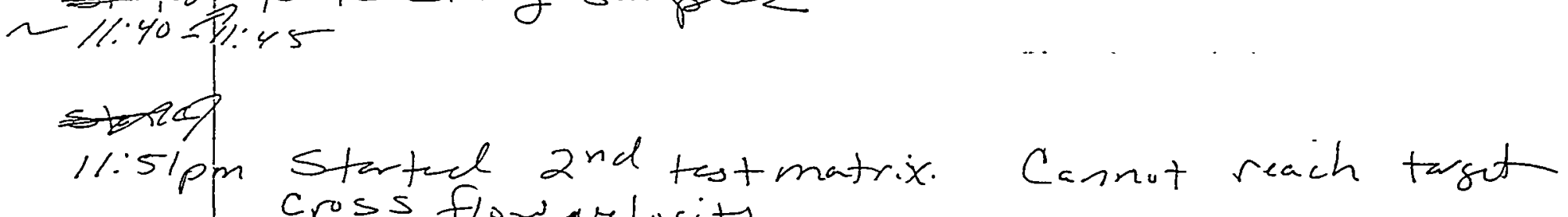
cross flow velocity.

1/1100 lii am Started condition 2

235 am The slurry appears to not be mixing - added 102,3g DI water to improve mixing. Volume may be lower than before -hard to tell. (co is

Project No.

Entered By

Disclosed To and Understood By

Signed 1
Date of work_ $1 / 10100$

Dario $1 / 10 /(90$

Date 
96

2:50

The flow appears to be a constant. Higher pressures (up to 30-40) down to 0 psi all produce $\sim 2.5 \mathrm{gpm}$. Increased air flow doesn't appear to help.

At 60 psi air feed a 30 psi $\Delta P$, we achieved $2.4 \mathrm{gpm}$ w/ Air booster at $\sim 80(70-90$ psi pulsing), math 30 psi 45 we achieved $2.4 \mathrm{gpm}$.

Tare weights of sample seals.

$$
\begin{aligned}
& 7-16.926 g \\
& 8-16.893 g \\
& 9-17.004 g
\end{aligned}
$$

3:30 Took filter off back end of CuR air motor to increase flow. Maybe 0.3 gum increase.

4:14 Started condition 4

S.2.2 Skipped condition 5

S:24 Started condition 6

S:47 Something happened. Pressure jumped to cleo psi momentarily we then reduced the pressure and the flow rate jumped to $1 \mathrm{gpm}$ mare. The filtrate flux decreased by mare than half. The pressure drop across the filter went from $2-4$ to 27-8 psi. The flow rate is $3.3 \mathrm{gpm}$ as compared to $25-2.7 \mathrm{gpm}$ before.

$6: 43$ Running test at 30 psi $\$ 3.7$ gpo since suddenly we can get there.

$$
\begin{array}{cccc}
\text { Az-10z ww Permeate } & & \text { Tare Ur } \\
" 100.009 & 100.299 \\
" & " 100.589
\end{array}
$$

Project No Date of Work

Entered By Date

Disclosed To and Understood By

Signed 1

Date

2.

Date 
KoR $A z-102$

10: to Washing Paul's appartas.

I

11:45a Finished washing viscometer. Added 1 st water wash solution. Beginning permeate removal of wash. Lost $\sim 10 \mathrm{~m} 1$ total.

Il:55a Added oil to oiler for pump.

$12: 00$ gro ing to 50 psi t max flow.

Back pulsing. Twice.

12:35p beginning ww 2. Backpulsing twice.

Add water. Initiate permeate removal. Back pulse. Take flow rate. $1: 35 p$ done w/ wwi.

Added wows. Badkpulsing.

$3: 15$ done water

3:30p centrifuge tube. $6.4899 \mathrm{~g}$

Empty water wash bottles.

\#102.8602g.

\#2. $102.9535 \mathrm{~g}$

$\# 3102.9225 \mathrm{~g}$.

Centrifuged sample $8.6 \mathrm{ml}$

Centrifuge solids $1.6 \mathrm{ml}$

N Volume of slurry calculated to be $865 \mathrm{ml} e$ this point (Ka neg)

See next + page for NaH calculations

* Large vessel Calibration (Kp Brooks)

$$
\begin{aligned}
& <750-\text { not sear } \\
& 7 / 8 "=750 \mathrm{ml} \\
& 13 / 4 "=1400 \mathrm{ml} \\
& 21 / 2 "=2000 \mathrm{ml}
\end{aligned}
$$

Project No Date of Work

Entered By Date

Disclosed To and Understood By

Signed 1

Date

2. 
98

$A Z-102$

Caustic Leach Calculations

$$
\begin{aligned}
& 3 \times \frac{V \text { solids }}{V \text { total }} \times V_{\text {slurry }}=x \text { volume } \mathrm{NaOH} \\
& 3 \times \frac{1.6}{816} \times 865=483 \mathrm{ml} \\
& \text { slurry }-\frac{v_{\text {solid }}}{v+i t a l} \times V_{\text {slurry }}=Y \text { volume liquid target e } 3 M \mathrm{MaOH} \\
& 865-160.9=704 \mathrm{ml} \\
& \frac{3 M \mathrm{NaOH}}{1 \mathrm{~L}}\left(\begin{array}{c}
X+Y) L \\
1187
\end{array}=\right.\text { moles NaH seeded } \\
& =3.561 \text { moles } \mathrm{NaOH}
\end{aligned}
$$

$\therefore 483 \mathrm{me}$ of $7.3 .7 \mathrm{M} \mathrm{NaOH}$ needed to add $\mathrm{NaOH}$ make up (KP Brooks)

142. $50 \mathrm{~g} \mathrm{NaOH}$ powder

$483 \mathrm{ml} \mathrm{H}_{2} \mathrm{O}$

Tare bottle lid $=66.93 \mathrm{~g}$

Bottle, lid o Sol $=676.49 \mathrm{~g}$

$609.56 \mathrm{~g}$ of $7.37 \mathrm{M} \mathrm{NaOH}$ were prepared

for Caustic Leach in CUF.

6:25 pm Slurry Sample CUF-AZ-102-007 taken

The Sample port. was removed from the CUF to attach the hose for transfer the story to the Leaching vessel. It It was ringed with a 10 ne DI into * Problem ar rose with vessel lid-it is too small before Slurry transfer to vessel.

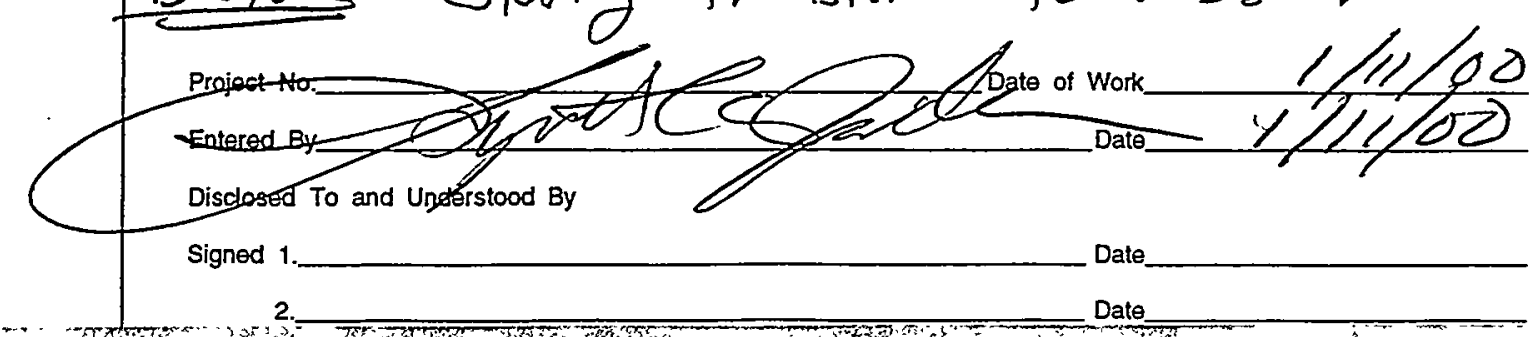


$\frac{A Z-102}{2152|A| l \text { is set and stating of leach/heat cycle. }}$

Time $=2157 \quad$ Temp $=34^{\circ} \mathrm{C}$

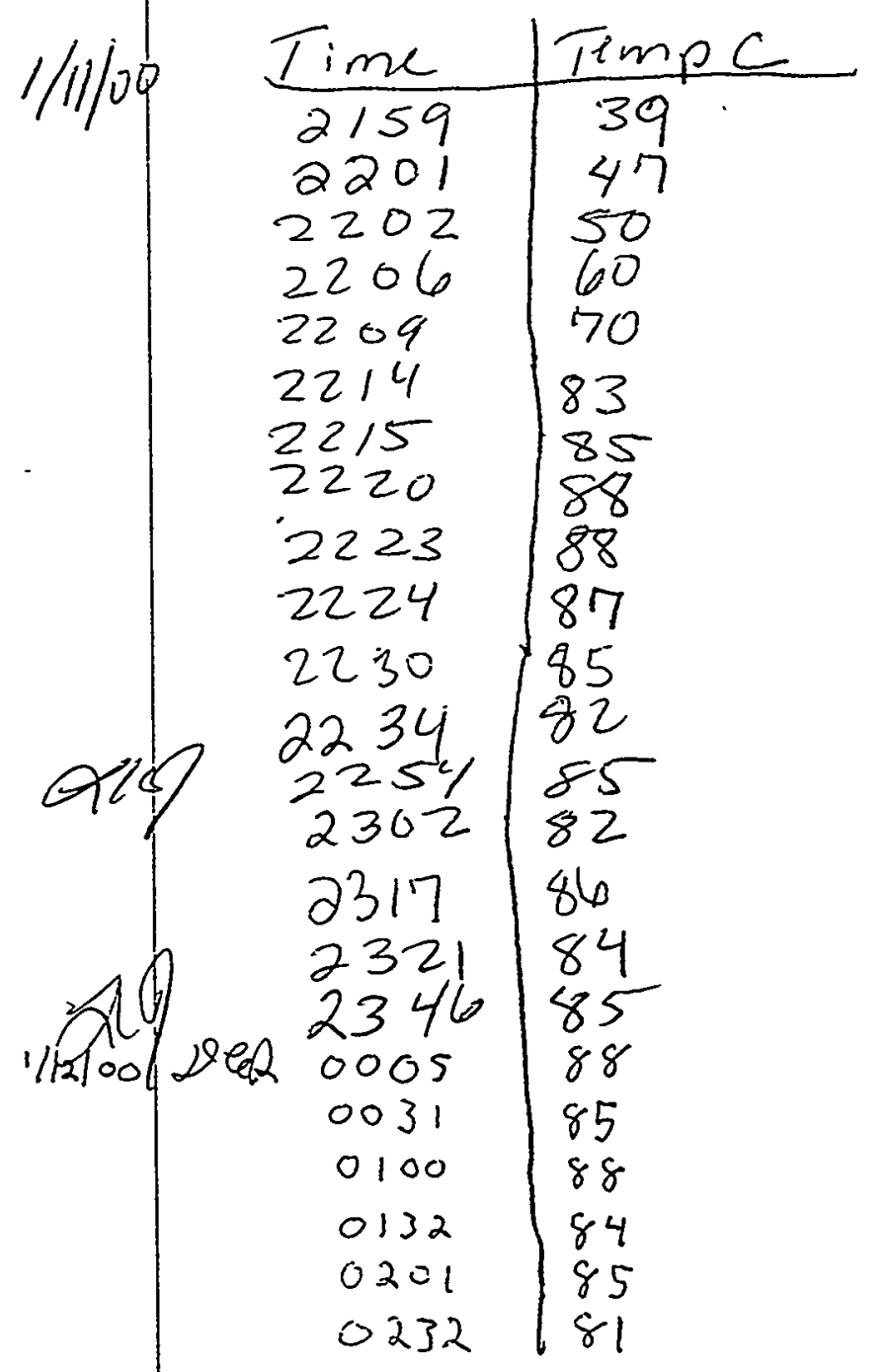

Pat TC TC-325-426- 8/00 Gaines

\begin{tabular}{l|l} 
Time & Temp C \\
\hline get 0305 & 88 \\
030 & 85 \\
0405 & 87 \\
0431 & 86 \\
0500 & 84 \\
0530 & 82 \\
0600 & 83 \\
0628 & 86 \\
&
\end{tabular}

Controller Calibration Expires 8/2001 $S / N \quad 2013$

Rinsed out "Az-102 Caustic Add" it will replace

"A2-10z CL permeate".

387.3219 DI water container initial

Project No Date of Work

Entered By

Date

Disclosed To and Understood By

Signed 1

Date

2

Date 
100

$361.282 \mathrm{~g}$ DI waver after rinsing off the impeller $25.539 \mathrm{~g}$ DII water added

6:55 Weighed $\neq$ measured level on container 7:01 Added slurry to CUF. Turned on heat tape 7:27 Rinsed with DI water

$$
\begin{array}{ll}
7: 30 & T_{\text {cur }}=58^{\circ} \mathrm{C} \\
7: 35 & T_{\text {cur }}=67^{\circ} \mathrm{C} \\
7: 42 & T_{\text {cur }}=75{ }^{\circ} \mathrm{C} \\
7: 46 & T_{\text {cur }}=79^{\circ} \mathrm{C} \\
7: 50 & T_{\text {cur }}=83^{\circ} \mathrm{C} \\
8: 00 & T_{\text {cur }}=88^{\circ} \mathrm{C}
\end{array}
$$

8:22 Aewatered caustic leach.

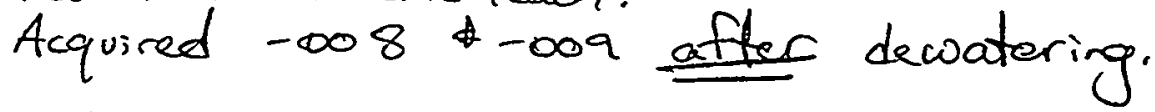

09:17 Tare wo's

$$
\begin{array}{rr}
\text { CuF-AZ-102-010 } & 16.988 \mathrm{~g} \\
-011 & 17.008 \mathrm{~g} \\
-012 & 17.023 \mathrm{~g}
\end{array}
$$

$10: 27 a 596.58 \mathrm{~g}$ - ut. of caustic leach permeate removed. Total! Bottle solution,

wt. of cow. solution wo bottle.

$1659.86 \mathrm{~g}$

bottle $267.63 \mathrm{~g}$

Project No Date of Work

Entered By. Dato $1 / 13 / 00$

Disclosed To and Understood By

Signed 1.

Date

2. Date 
$\frac{A Z 1.02}{16 R} \frac{1100}{\text { Drained slurry. } 10: 55 a \text {. level in washing vessel. 13/16 -inch } 101}$ Tare uts.

$$
\begin{array}{rr}
\text { CuF-A2702-013 } & 16.861 \mathrm{~g} \\
-014 & 16.969 \mathrm{~g} \\
-017 & 16.913 \mathrm{~g} \\
-016 & 16.803 \mathrm{~g}
\end{array}
$$

1l:40p Drained caustic wash solution into vessel. Dreaming pump housing \& blowing out upper loop. Braining pump housing again.

Rinsing out drain container. Determining how much rinse we add, tare wt. $145.000 \mathrm{~g} \mathrm{w} /$ wash $154.500 \mathrm{~g}$ added $9.500 \mathrm{~g}$ wash

Level 2-7/8-inches in leaching container.

$$
3520.6 \mathrm{gg} \text { slurry in teaching vessel. }
$$

12:30p Heating caustic wash vessel. Now $Q 40^{\circ} \mathrm{C}$.

$\begin{array}{ll}\text { Time } & \frac{\operatorname{Im} 7}{43}(-C) \\ 12: 30 p & 62 \\ 12: 40 P & 82 \\ 12: 50 P & 82 \\ 12: 54 P & 85 \\ 13: 25 & 86 \\ 13: 56 & 87 \\ 14: 26 & 88 \\ 19: 42 & 87 \\ 21: 00 & 84\end{array}$

quo pr that tire complete * Manipulator hand/band snapped - Working with Cannot pull samples from "nide "of de watering.

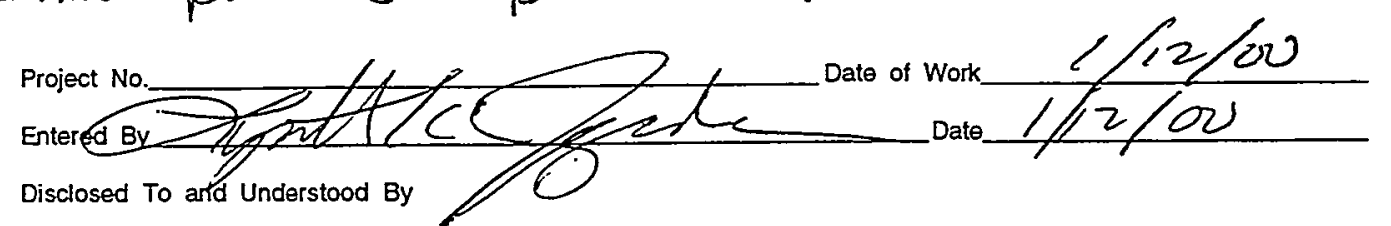

Disclosed To and Understood By

Signed 1

Date

Date 
102

$A z-102$

Slurry success filly transpired in to COF Started e $65^{\circ} \mathrm{C}$

2153 Ti mp up to 74.3

2225 - Tempe $\& 88$ - Working on Maniphenen rainClimbed to 92 - twa on chiller for <lain disport buckle to 85

$2328 . T=79.7 \cdots$ still cook lg on manipulu

gQ54) Started dewatering

1:03. Stopped dewatering. "g pulled samples.

Transferee the sherry to the pot

Made up some more QQ M Na OA - needed 300 w

Added O. I $2 \mathrm{~g}$ of $\mathrm{NaQH}$ pellets to container to make $1400.7 \mathrm{~g}$ total weight of liquid. (already had

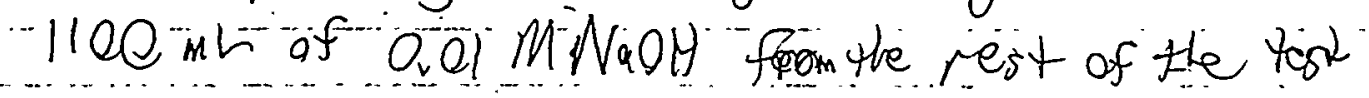
$0.010 \mathrm{M} \mathrm{NaOH}$

$10 \times$ dilution of standardized $0.1 \mathrm{M} \mathrm{NaOH}$ 7.0 Liters prepared Expiration da ie 1/1/2001 RE: Chemre=37-rgs $\angle B 357359.102$

Thu label -was for all of the other 0.01 in NOB used during the Washes, of W

2:35 Add water to. CUF a mixed around :

0.52 Transferred liquid into pot

Project No.

Date of Work

Entered By

Date

Disclosed

Da te

2

Date 
Discovered that the heat tape was mining continuously

103 during the last run- last ones to start it hook it directly to power.

Pot- has been uncovered for the last 30 minutes losing $\sim 0.01 \mathrm{~g} / \mathrm{sec}$ te evaporation

Put on lid

402 Started Stirring

4:13 Reached $85^{\circ} \mathrm{C}$

see

$$
\begin{array}{ll}
4: 30 & 84^{\circ} \mathrm{C} \\
5: 00 & 83^{\circ} \mathrm{C} \\
5: 35 & 83^{\circ} \mathrm{C} \\
6: 02 & 83^{\circ} \mathrm{C} \\
6: 30 & 82^{\circ} \mathrm{C} \\
7: 01 & 85^{\circ} \mathrm{C} \\
7: 30 & 84^{\circ} \mathrm{C} \\
8: 00 & 83^{\circ} \mathrm{C} \\
08: 30 & 86^{\circ} \mathrm{C} \\
09: 00 & 87^{\circ} \mathrm{C} \\
09: 30 \text { os } 1: 300 & 88^{\circ} \mathrm{C} \\
10: 00 & 87^{\circ} \mathrm{C} \\
10: 30 & 84^{\circ} \mathrm{C} \\
11: 00 & 82^{\circ} \mathrm{C} \\
11: 30 & 82^{\circ} \mathrm{C} \\
12: 00 & 83^{\circ} \mathrm{C} \\
12: 12 & \text { shat } \text { dow h }
\end{array}
$$

$166^{2}$

$1 / 13 \mid 100$
Date of Work

Project No. Date $1 / 13 / 00$

Disclosed To and Understood By

Signed

Date

2. Date 
104

1100

* significant solids also stuck to mixer.

Will attempt to rinse of 0 .

Squirt bottle before rinse: 432.51

after rinse: $\frac{332.442}{100.068} \mathrm{~g}$

Rinsing appeared successful aside from some crksted-on material on stem of impeller.

Weighing pot. $3237.10 \mathrm{~g}$

Rinsing pot. Twice. Large chunks did not come ont of ter initial pot dump.

Additional water added: bottle $182.35 \mathrm{~g}$

$$
332.442-182.35 \mathrm{~g}=150.092 \mathrm{~g}
$$

01:30 f everything in cut, heating.

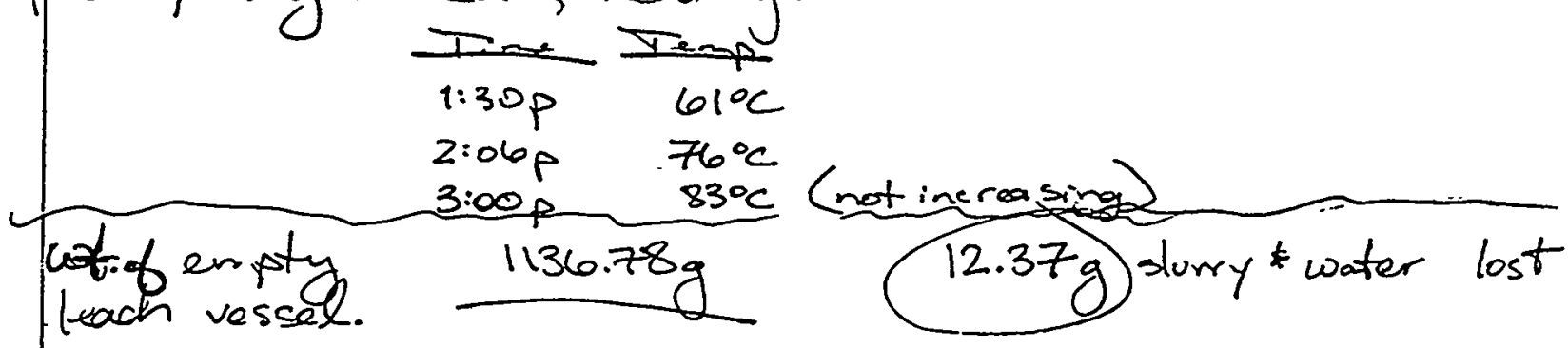

Nard weights of: Empty caustic wash permeate \#2 bottle Tore wit of CUF-AZ-102-015

Heed samples of water wash Bereneates $\# 1, \# 2, \# 3$. 2 each.

Tare ut of $\mathrm{CW}$ permeate \#2 bottle: $261.982 \mathrm{~g}$

Tare uh of:

$$
\begin{array}{rr}
\text { CUF-AZ-102-015 } & 16.714 \\
-018 & 16.951 \\
-019 & 16.846 \\
-020 & 16.924
\end{array}
$$

Project No Date of Work

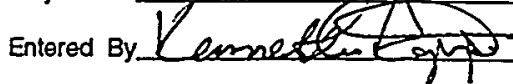

Disclosed To and Understood By

Signed 1 Date $1 / 13 / 00$

Date

2. Date 
KG

$1 / 13100$
Tare cuts.

$$
\begin{array}{r}
C U F-A Z \cdot 102- \\
021 \\
022 \\
023 \\
024 \\
025 \\
026
\end{array}
$$

16.8810

95

16.9507

16.9559

17.0717

17.0804

17.1539441

3:05p Setting cut to 30 psi * make cross -flow.

Flow rate initial

3:12p $1 / 13 / 00 \quad 4.59$ sec. $20 \mathrm{ml} \quad 1.9 \mathrm{gpm} 28-30 \mathrm{psi}$

$3: 30 \mathrm{p} 85 \propto$ reached Beginning de-watering.
talf-complete

3:45p Acquired samples Cuf-AZ-102-021 $\neq-022$.

3:50p Resume dewatering. Done. filing $100 \mathrm{ml}$ extra due to Sample weigh os.

additional water added for rinsing

$$
\begin{array}{rr}
C U F-A z-102-021 & 35.402 \mathrm{~g} \\
-022 & 37.734 \mathrm{~g}
\end{array}
$$$$
\text { wash vessel. }
$$

* Filtrate appears quite bubbly, like possibly getting a lot of foaming Rheology via for Paul's final sample. 5.3.72.

filling with -80 ml of slur y

* Heat tape controller has been going screwy. Realized slurry temp. had dropped to $\angle 70^{\circ} \mathrm{C}$. Treating back up. Saw T.C. line was getting slightly charred by the heat tape.

4:30p Pump shat down - no f low.

Looked in slurry tank, no mixing, way too thick. Got 440 mo of sample For Paul's rheology.

Project No. Date of Work

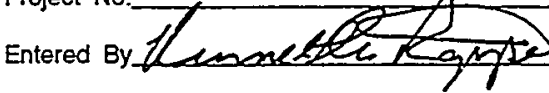
Date $1 / 13 / 00$ Disclosed To and Understood By

Signed Date

2. Dato 


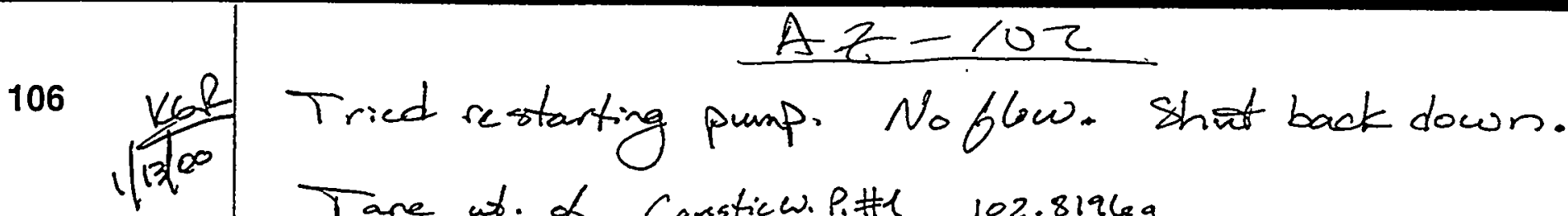

Tare at. of Caustic. P.\#l $102.8196 \mathrm{gg}$ bottle. $\quad 303.6576 \mathrm{~g}$

Adding $200.8374 \mathrm{~g} \Delta \mathrm{w}$.

Ala 5iapplurry is show a thick elating of Solids all

Q19 5iapplurry is show a thick equating of Solids all

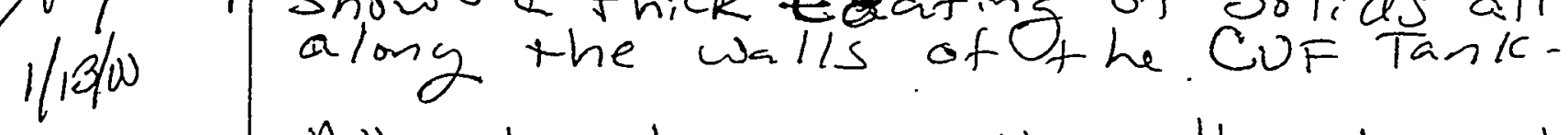

A tempting to Scrape the walls down before Proceeding, Temp slurry was $\sim 43 C$. Turned
on chiller.

$5: 35 T=20.6 \mathrm{C}$

Sent in 3 bottles. "Lay plastic coated ( 1 quant) "A z-102 Final Simple" $\Rightarrow$ Tore N300 me plastic Coated $\Rightarrow 354.756 \mathrm{~g}$ "Az-102 pijashed sol .dos /st Pings" $1<$ plastic polyethylene $A z-102$ CUF, st Rinse $\Rightarrow 105,575 \mathrm{~g}$

5:55 Scraping sides did not return onysolids to slurry
but recur er some fo be resorjin Rinse.. Taking Rheology Sample Final wt. $192.5 \% \mathrm{~g}$

lost $\sim 5 \mathrm{~g}$ from spout -

4 Slurry 5 samples taken

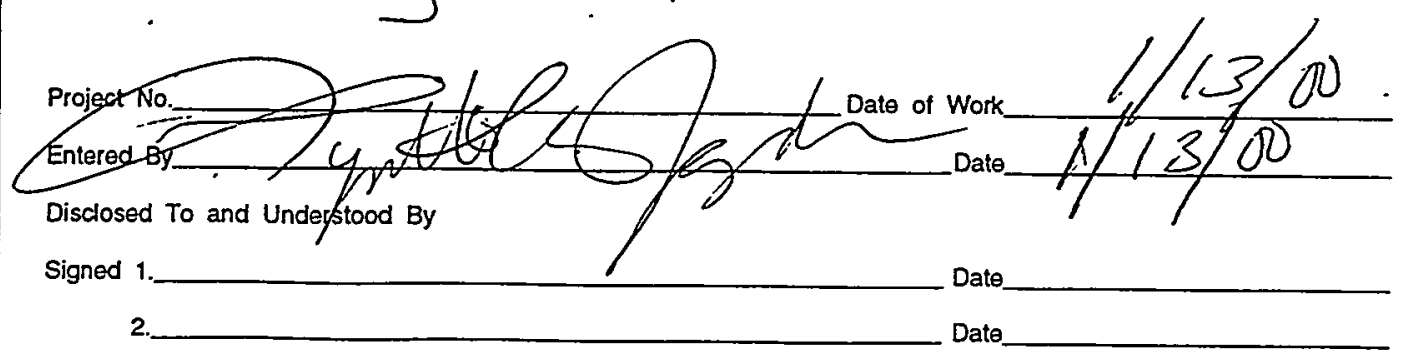


$A z-102$

Trapfered washed sludge from CUF to

1 Az-102 Final sample - $576.98 \mathrm{~g}$ transfer

0:50 Firstringe Barth stat $54293 \mathrm{~g}$ washing down tank sids.

DI bottle after washin $03.129 \mathrm{~g}$

miro- Cup on allowing to mix. DI $439.7502 z$ ad bled

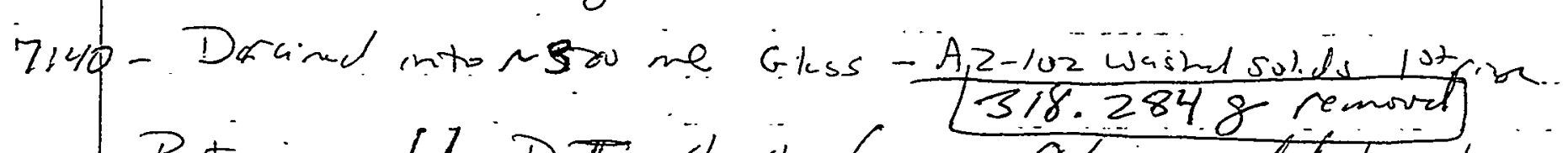

Put in IL DI Hz oi from Chem add tank.

Az 102-CUF Rust $1040.26 \mathrm{~g}=\mathrm{full}$ tare $\frac{105.5255}{1054604}$

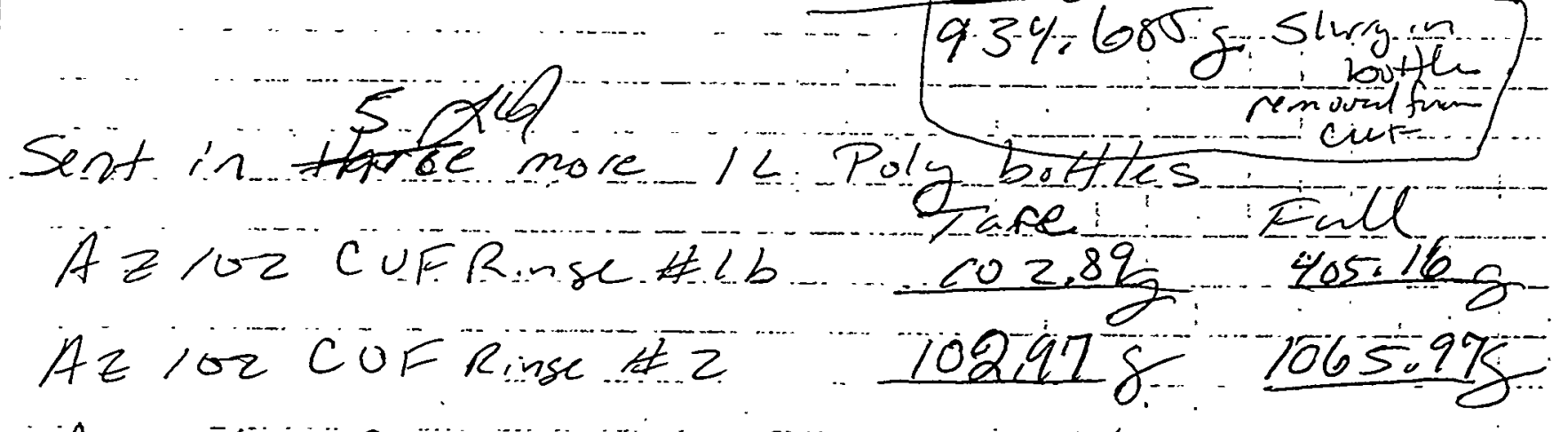

$A z-102 C U F$ Rinse zzz $\mathrm{b}$. $102.94 \mathrm{~g}-714.54 \mathrm{~g}$

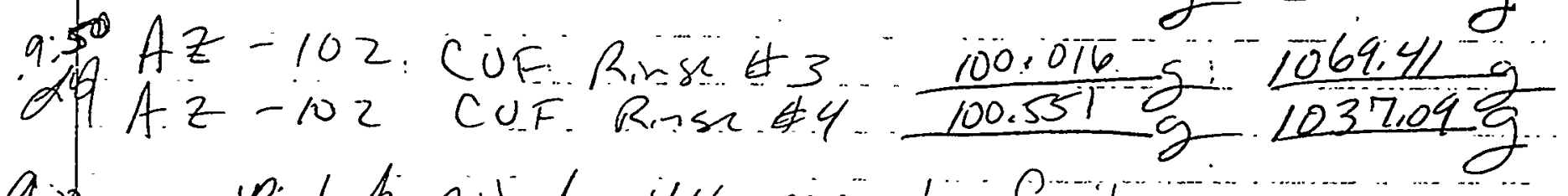

9.00pm - Ralph noted U4 maybe failing...

1/30 -Hooking up cartridge:

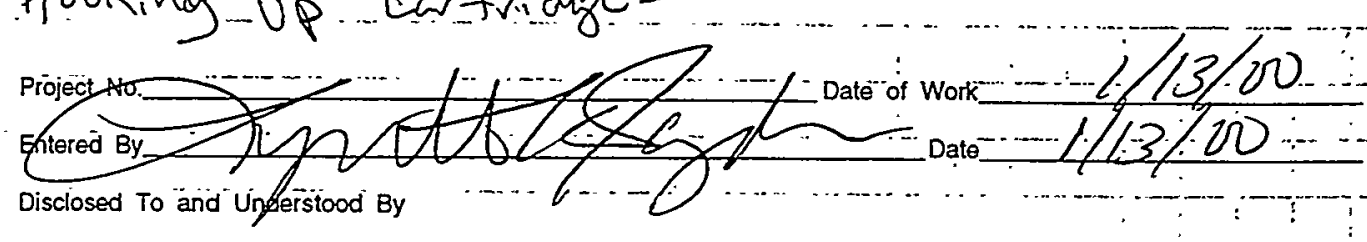

Signed 1.

Date-.-

2

Date 

$1081 / 14 / 00$ 1:03 $a_{m}$ started the 0.0Sam fitter cleaning the CVF
(external filter)

2:21 Backpulsed twice - very Slow!

Back pulsed again

2:30 Drained System - still kind of brown

2:40 Refilled w/ water (il) attached filter gran

Checked water exiting filter very clear

Checked water out of va- Still very yellow

Filtrate flow rate is very slow - clean water fluxes not recovered. Pulled off supernate from AZ-iOz final material. Picked up some solids - will have to filter.

4:45 Backipulsed $2600 \mathrm{ml}$ of $\mathrm{HNO}_{3}$ thru the top S:06 Turned on CUF w/ / $l$ of / M MO H

6: Do Drain $1 \mathrm{M} \mathrm{HNO}_{3}$ - muddy brown colored Put $\sim 600 \mathrm{~mL}$ of $1 \mathrm{MAN}_{3} / 0.2 \mathrm{~m}$ Citric into CUF

6:30 Removed acid \& replaced w/ 1.SL of DF water

The aced is lighter this time, but still fairly brown 7:00 Badpulsed several times and drained liquid. Still fairly brown.

7:12 Backpulsed 3 thru the top \& drained the liquid 7:20 Added second batch of water - running thru 0.05 um filter

Project No. Date of Work

Entered By Date

Disclosed To and Understood By

Signed 1

Date

2.

Date 
$1 / 14 / 00$

KGR 12:00p rinsing rhedosy equipment.

109

Everything to go into 'AZ-102 Final Sample' jar.

DI water bottle weight.

Before rinsing: $509.62 \mathrm{~g}$

After rinsing: $399.22 \mathrm{~g}$.

Rinsed with $110.40 \mathrm{~g}$ DI water.

Good recovery of sample!!

Find sample jor weight:

'Az-102 Find Sample' $=1254.17 \mathrm{~g}$

Checking pitt of second rinse. Done. have no standards, so leaving checking water filtrate flux measurement.

* Mas pressure attainable, just $<40$ prigs, Therefore, just ruming@30 prig to prig.

2:20p Backpulsed once upon completion of water tests. Opened V2 $\$$ vi to flow through external filter cartage. Ran pressure up to 25 pig for $\sim 15$ minutes. 2:35p Back pulsed twice. Brained.

* Looks clear.

1fH/los * Note Clean water fluxes not achieved OIQ 1/44/00 * Note Visually Solids have settled well in final sample $\$$ yet settled enough to recover. $\therefore$ leaving All till monday Additionally - based on the settling in the his L solids jar, a lot

slits

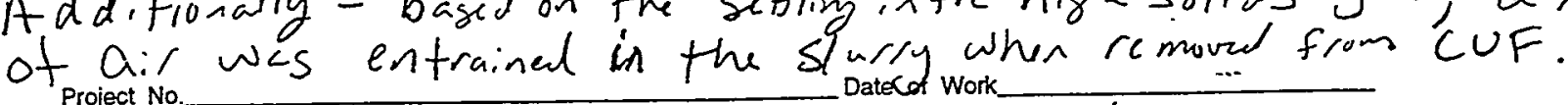
Entered By K Lo Rappee Dato 1/24/100 Disclosed To and Understood By Signed 1 . Date

2. Date 


\section{Appendix B: Testing Mass Balance}




\section{Appendix B: Testing Mass Balance}

B.1 


\begin{tabular}{|c|c|c|c|c|c|c|c|}
\hline Date/Time & Description & $\begin{array}{l}\text { Volume } \\
\text { (mL) }\end{array}$ & Mass (g) & $\begin{array}{l}\text { Density } \\
\text { (g/mL) }\end{array}$ & $\begin{array}{c}\text { Caustic } \\
\text { Molarity } \\
\text { (M) }\end{array}$ & $\begin{array}{l}\text { Undissolved } \\
\text { Solids (g) }\end{array}$ & $\begin{array}{l}\text { Weight Percent } \\
\text { Undissolved Solids }\end{array}$ \\
\hline \multirow{24}{*}{$10-\operatorname{San}-00$} & Sample A & 197 & 315.64 & 1.60 & & 131.8 & $41.8 \%$ \\
\hline & 5 wt\% dilution \#1 & 1850 & 1849.86 & 1.00 & & 0.0 & $0.0 \%$ \\
\hline & Test Sample \#1 & 2047 & 2165.5 & 1.06 & & 110.4 & $5.1 \%$ \\
\hline & & & & & & & \\
\hline & First Test Matrix & & & & & & \\
\hline & \& Dewatering & & & & & & \\
\hline & Rheology equipment rinse & 30 & 30.0 & 1.00 & 0 & $\mathbf{0}$ & $0.0 \%$ \\
\hline & Dewatering \#1 & 951 & 957.97 & 1.008 & & 0 & $0.0 \%$ \\
\hline & Filtrate Sample -001 & 17 & 17.18 & 1.008 & 0 & 0 & $0.0 \%$ \\
\hline & Filtrate Sample -002 & 17 & 16.90 & 1.008 & 0 & 0 & $0.0 \%$ \\
\hline & Test Sample \#1 & 1092.3 & 1203.4 & 1.102 & & 110.4 & $9.2 \%$ \\
\hline & & & & & & & \\
\hline & Sample MU & 25 & 40.835 & 1.60 & & 17.1 & $41.8 \%$ \\
\hline & Sample GL & 29 & 46.664 & 1.60 & & 19.5 & $41.8 \%$ \\
\hline & Recovery Jar & 384 & 383.82 & 1.00 & & 38.4 & $10.0 \%$ \\
\hline & 5 wt\% dilution \#2 & 453 & 453.19 & 1.00 & 0.010 & 0 & $0 \%$ \\
\hline & Test Sample \#2 & 1983.9 & 2128.0 & 1.073 & & 185.4 & $8.7 \%$ \\
\hline & Dewatering $\# 2$ & 723 & 727.82 & 1.006 & & 0 & $0 \%$ \\
\hline & Filtrate Sample -003 & 23 & 22.89 & 1.006 & 0 & 0 & $0 \%$ \\
\hline & Filtrate Sample -004 & 19 & 19.03 & 1.006 & 0 & 0 & $0 \%$ \\
\hline & Test Sample \#2 & 1246 & 13582 & 1.090 & & 185.4 & $13.7 \%$ \\
\hline & Slurry Sample -005 & 13 & 14.133 & 1.090 & 0 & 1.9 & $13.7 \%$ \\
\hline & Slurry Sample -006 & 17 & 18.806 & 1.090 & 0 & 2.6 & $13.7 \%$ \\
\hline & Water for mixing assistance & 102 & 102.3 & 1.00 & 0 & 0 & $0 \%$ \\
\hline \multirow{12}{*}{ 11-Jan-00 } & Second Test Matrix & & & & & & \\
\hline & \& Water Washes & & & & & & \\
\hline & Water Wash \#1 Solution & 887 & 886.53 & 1.00 & 0.01 & $\begin{array}{ll}0 \\
0\end{array}$ & $0 \%$ \\
\hline & Water Wash \#2 Solution & 905 & 905.42 & 1.00 & 0.01 & 0 & $0 \%$ \\
\hline & Water Wash \#3 Solution & 896 & 895.80 & 1.00 & 0.01 & 0 & $0 \%$ \\
\hline & Water Wash \#1 Permeate & 871 & 875.71 & 1.006 & & 0 & $0 \%$ \\
\hline & Water Wash \#2 Permeate & 877 & 878.19 & 1.001 & & 0 & $0 \%$ \\
\hline & Water Wash \#3 Permeate & 956 & 951.73 & 0.995 & & 0 & $0 \%$ \\
\hline & Test Sample & 1287 & 1409.71 & 1.10 & & 159.77 & $11.3 \%$ \\
\hline & Centrifuge Sample & 0.3 & 0.327 & 1.10 & 0.00 & 0.04 & $11.3 \%$ \\
\hline & Slurry Sample -007 & 18 & 19.378 & 1.10 & 0.00 & 2.2 & $11.3 \%$ \\
\hline & Sample Port Rinse & 10 & 10 & 1.00 & 0 & 0 & $0 \%$ \\
\hline \multirow[t]{2}{*}{ 11-Jan-00 } & Caustic Leach & & & & & & \\
\hline & Caustic Leach Solution & 483 & 609.16 & 1.26 & 7.37 & 0 & $0 \%$ \\
\hline \multirow[t]{9}{*}{$12-\operatorname{Jan}-00$} & DI impeller rinse & 26 & 25.54 & 1.00 & 0.00 & 0 & $0 \%$ \\
\hline & Evaporation & 105 & 104.66 & 1.00 & 0.00 & 0 & $0.0 \%$ \\
\hline & DI impeller rinse & 81 & 81.46 & 1.00 & 0.00 & 0 & $0 \%$ \\
\hline & Caustic Leach Permeate & 485 & 529.58 & 1.092 & & 0 & $0 \%$ \\
\hline & Filtrate Sample -008 & 17 & 18.708 & 1.092 & 0 & 0 & $0 \%$ \\
\hline & Filtrate Sample -009 & 20 & 21.285 & 1.092 & 0 & 0 & $0 \%$ \\
\hline & Test Sample & 1238 & 1441.9 & 1.165 & & 136.98 & $9.5 \%$ \\
\hline & Slurry Sample -010 & 15 & 17.011 & 1.165 & 0 & 1.62 & $9.5 \%$ \\
\hline & Slurry Sample -011 & 13 & 14.846 & 1.165 & 0 & 1.41 & $9.5 \%$ \\
\hline
\end{tabular}




\begin{tabular}{|c|c|c|c|c|c|c|c|}
\hline Date/Time & Description & $\begin{array}{l}\text { Volume } \\
\text { (mL) }\end{array}$ & Mass (g) & $\begin{array}{l}\text { Density } \\
\text { (g/mL) }\end{array}$ & $\begin{array}{c}\text { Caustic } \\
\text { Molarity } \\
\text { (M) }\end{array}$ & $\begin{array}{l}\text { Undissolved } \\
\text { Solids (g) }\end{array}$ & $\begin{array}{l}\text { Weight Percent } \\
\text { Undissolved Solids }\end{array}$ \\
\hline & Slurry Sample -012 & 13 & 15.377 & 1.165 & 0 & 1.46 & $9.5 \%$ \\
\hline & Drain container rinse & 10 & 9.50 & 1.00 & 0.00 & 0 & $0 \%$ \\
\hline \multirow{5}{*}{ 12-Jan-00 } & Caustic Washes & & & & & & \\
\hline & Caustic Wash \#1 Solution & 1392 & 1392.23 & 1.00 & 0.01 & 0 & $0 \%$ \\
\hline & Test Sample & 2598.89 & 2796.43 & 1.08 & & 132.5 & $4.7 \%$ \\
\hline & Evaporation & 105 & 104.80 & 1.00 & 0.00 & 0 & $4.7 \%$ \\
\hline & Water added & 105 & 105.25 & 1.00 & 0.00 & 0 & $0 \%$ \\
\hline \multirow[t]{8}{*}{ 13-Jan-00 } & Caustic Wash \#1 Permeate & 1435 & 1492.06 & 1.040 & & 0 & $0 \%$ \\
\hline & Filtrate Sample -013 & 19 & 19.898 & 1.040 & 0 & 0 & $0 \%$ \\
\hline & Filtrate Sample -014 & 15 & 15208 & 1.040 & 0 & 0 & $0 \%$ \\
\hline & Test Sample & 1130.6 & 1269.7 & 1.123 & & 116.8 & $9.2 \%$ \\
\hline & Caustic Wash \#2 Solution & 1400 & 1400.00 & 1.00 & 0.01 & 0 & $0 \%$ \\
\hline & Evaporation & 122 & 122.22 & 1.00 & 0.00 & 0 & $0.0 \%$ \\
\hline & Drain container rinse & 100 & 100.07 & 1.00 & 0.00 & 0 & $0 \%$ \\
\hline & Water added & 150 & 150.09 & 1.00 & 0.00 & 0 & $0 \%$ \\
\hline \multirow[t]{9}{*}{-} & Caustic Wash \#2 Permeate & 1508 & 1539.34 & 1.021 & & 0 & $0 \%$ \\
\hline & Filtrate Sample - 021 & 18 & 18.521 & 1.021 & 0 & 0 & $0 \%$ \\
\hline & Filtrate Sample -022 & 21 & 21.203 & 1.021 & 0 & 0 & $0 \%$ \\
\hline & Water added & 201 & 200.84 & 1.00 & 0.00 & 0 & $0 \%$ \\
\hline & Test Sample & 1048 & 1100.0 & 1.050 & & 101.2 & $9.2 \%$ \\
\hline & Siurry Sample -023 & 15 & 16.274 & 1.050 & 0 & 1.50 & $9.2 \%$ \\
\hline & Slurry Sample -024 & 10 & 10.823 & 1.050 & 0 & 1.00 & $9.2 \%$ \\
\hline & Siurry Sample -025 & 15 & 15.609 & 1.050 & 0 & 1.44 & $9.2 \%$ \\
\hline & Siurry Sample -026 & 14 & 14.472 & 1.050 & 0 & 1.33 & $9.2 \%$ \\
\hline 13-Jan-00 & Test Finale & & & & & & \\
\hline & Test Sample & 1352 & 1419.4 & 1.050 & & 1259.2 & $88.7 \%$ \\
\hline
\end{tabular}




\section{Appendix C: Analytical Results}


Appendix C: Analytical Results

C. 1 


\section{Battelle PNNL/RPG/Inorganic Analysis ... ICPAES Data Report}

Project:

Client:

29953

K. Brooks

ACL Number(s): 00-0902 through 00-0917

Client ID: "AZ-102 MU" through "CUF-AZ-102-027"

ASR Number: 5667,5668

Total Samples: 16

Procedure: PNL-ALO-211, "Determination of Elements by Inductively Coupled Argon Plasma Atomic Emission Spectrometry" (ICP-AES).

Analyst: $\quad$ D.R. Sanders

Analysis Date (Filename): $\quad$ 02-02-00 (A0579) [ALO-115 KOH/Ni fusion]

02-08-00 (A0582) [ALO-128 Acid Digestion - liquids]

02-24-00 (A0586) [ALO-129 Acid Leach - solids]

See Chemical Measurement Center 98620: ICP-325-405-1 File for Calibration and Maintenance Records.

M\&TE Number:

ICPAES instrument -- WB73520

Mettler AT400 Balance -- Ser.No. 360-06-01-029
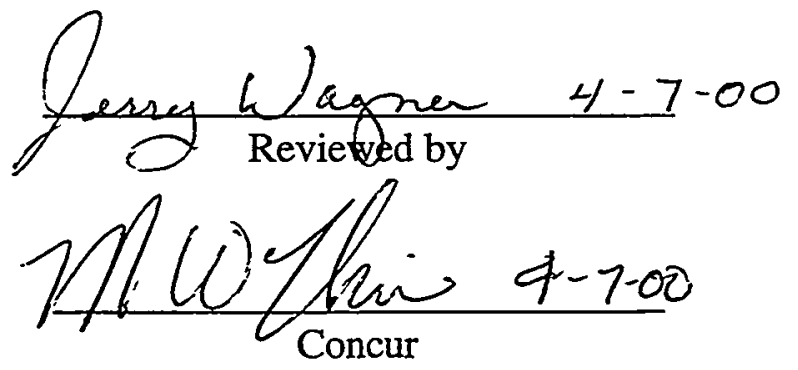

4/7/00 


\section{Battelle PNNL/RPG/Inorganic Analysis ... ICPAES Data Report}

\section{$\underline{\text { ASR-5667 }}$}

Sample AZ-102 MU (ACL\# 00-0902) was prepared in duplicate by the Shielded Analytic Lab (SAL) using ALO-115 KOH/Ni fusion procedure. About 0.19 grams dried slurry sample was fused and diluted to a final volume of $100 \mathrm{ml}$. Samples dissolved leaving a slightly cloudy mixture prior to adding $2 \%$ hydrochloric acid during dilution. An additional dilution (11.24-fold) was prepared by SAL prior to ICPAES analysis because of ALARA concerns. Measurement results are reported in $\mu \mathrm{g} / \mathrm{g}$ dry weight and corrected for all preparation and analytical dilution.

Sample AZ-102 MU (ACL\# 00-0902) was also prepared in duplicate by SAL using ALO-129 Acid Leach procedure. About $0.48 \mathrm{~g}$ of dried slurry sample was processed and diluted to a final volume of about $25 \mathrm{ml}$. The prepared samples did not completely dissolve leaving a 'light-gray' residue in the bottom of the digestion vessel. The samples were also diluted 11.20-fold because of ALARA concerns. ICPAES measurement results are reported as $\mu \mathrm{g} / \mathrm{g}$ dry weight. Comparing results of the fusion prepared samples with the acid leached samples, it appears that aluminum, iron and zirconium were incompletely dissolve by acid leach procedure. Analysis results should be based upon the fusion prepared sample data.

Sample AZ-102 M SUP (ACL\#00-0903) was prepared in duplicate, plus matrix-spike and blankspike by SAL using ALO-128 Acid Digestion procedures for liquids. About $5.1 \mathrm{ml}$ of supernatant was processed and diluted to a final volume of about $25 \mathrm{ml}$. No ALARA dilution was performed prior to ICPAES analysis. Measurement results are reported in $\mu \mathrm{g} / \mathrm{ml}$.

Silver recovery was low in the spiked blank (about 19\%) and sample ACL\# 00-0903 (about 13\%) because hydrochloric acid was used during sample preparation causing silver to precipitate.

Barium recovery was acceptable in the spiked blank (about 105\%) but very low in the matrix spiked sample (about 5\%). The low recovery of barium in the matrix-spiked sample is mainly due to high concentration of sulfate in the sample (ACL\# 00-0903).

Silver recovery is expected to be low for all samples since hydrochloric acid was used to prepare all samples. Barium concentration will be low in all samples that have high sulfate concentration. 


\section{Battelle PNNL/RPG/Inorganic Analysis ... ICPAES Data Report}

\section{ASR-5668}

Four dry-slurry samples plus one duplicate and one wet-slurry sample, CUF-AZ-102-007 to CUF-AZ-102-026 (ACL\# 00-0909 to 00-0916) were prepared by SAL using ALO-115 KOH/Ni fusion procedure. About 0.19g of dried slurry sample (except sample ACL\# 00-0912) was fused and diluted to a final volume of $100 \mathrm{ml}$. Samples dissolved leaving only a slightly cloudy mixture prior to adding 2\% hydrochloric acid during dilution. Sample ACL\# 00-0912 was prepared using about $0.95 \mathrm{~g}$ of wet slurry ( $18.5 \%$ solids) and processed similarly using ALO-115 fusion procedure. Sample weight for ACL\# 00-0912 was adjusted for percent solids. All samples were diluted 11.24-fold by SAL prior to ICPAES analysis because of ALARA concerns. Measurement results are reported in $\mu \mathrm{g} / \mathrm{g}$ dry weight corrected for all preparation and analytical dilution.

Five wet-slurry samples (same ACL\#'s as above) were prepared by SAL using ALO-129 Acid Leach procedure. About 1.1 to $1.5 \mathrm{~g}$ of wet-slurry material $(0.48 \mathrm{~g}$ dry-slurry) was processed and diluted to a final volume of about $25 \mathrm{ml}$. The prepared samples did not completely dissolve leaving a 'dark-brown' residue in the bottom of the digestion vessel. One ml of concentrated hydrochloric acid added to the leached samples did not appear to dissolve any of the residues. Samples were further diluted 11.20-fold because of ALARA concerns. ICPAES measurement results are reported as $\mu \mathrm{g} / \mathrm{g}$ dry weight (wet-slurry sample weights adjusted for percent solids). Comparing results of the fusion prepared samples with the acid leached samples, it appears that aluminum, iron and zirconium were incompletely dissolve by the acid leach procedure. Also, sodium concentration appears higher (up to about $25 \%$ higher) in the wet-slurry leached samples prepared using ALO-129 procedure than for the same dry-slurry fusion prepared samples except for sample ACL\# 00-0912. This sample was prepared by both ALO-129 and ALO-115 procedure using wet-slurry material. Except for potassium and nickel, all results should be based upon the fusion prepared sample data. Potassium and nickel concentration may need to be adjusted based upon sodium concentration between the acid leach and fusion results.

Nine supernatant samples, CUF-AZ-102-001 to CUF-AZ-102-027 (ACL\# 00-0904 to 00-0917) were prepared by SAL using ALO-128 Acid Digestion procedure for liquids. About $5.1 \mathrm{ml}$ of supernatant sample was processed and diluted to a final volume of about $25 \mathrm{ml}$. No ALARA dilution was performed prior to ICPAES analysis. ICPAES measurement results are reported as $\mu \mathrm{g} / \mathrm{ml}$. Supernatant aliquot weights were recorded during sample preparation and later used to convert to volume based upon original sample density information. Measurement results are reported in $\mu \mathrm{g} / \mathrm{ml}$ corrected for all preparation and analytical dilution.

\section{$\underline{4 / 7 / 00}$}




\section{Battelle PNNL/RPG/Inorganic Analysis ... ICPAES Data Report}

Volumes and weights have been recorded on bench sheets and included with this report. Values reported earlier have been changed from $\mu \mathrm{g} / \mathrm{g}$ to $\mu \mathrm{g} / \mathrm{ml}$ in this report for supernatant samples only. Values reported earlier for acid leached slurries have been changed to reflect percent solids content of the samples.

For ICPAES analytes of interest (22 analytes) see attached table 3A in ASR-5667/5668.

Quality control check-standard results met tolerance requirements for all analytes except as noted below. Following is a list of quality control measurement results relative to ICPAES analysis tolerance requirements

Five fold serial dilution:

(Solid \& liquid samples) Results were within tolerance limit of $\leq 10 \%$ for all analytes tested after correcting for dilution except as follows. Potassium was slightly low in 5-fold serial dilution in sample ACL\# 00-0903. Chromium was very high in the 5-fold dilution of sample ACL\# 00-0910. Two other analytes (not analytes of interest) were similarly high. The discrepancy is most likely due to pipetting error during preparation of the 5-fold dilution. Measurements reported for these analytes did not involve the serial dilution used for this test.

\section{Duplicate RPD (Relative Percent Difference):}

(Solid \& liquid samples) All analytes tested were recovered within tolerance limit of $\leq 20 \%$ relative percent difference (RPD) except as follows. RPD for aluminum and, although not an analyte of interest, zirconium were very different in sample ACL\# 00-0902 and 00-0902-D. Aluminum RPD for the duplicate samples measured 56\% ( $\mathrm{Zr}$ RPD was 26\%). The original sample had higher concentration for both analytes than the duplicate sample. The duplicate samples were prepared using ALO-129 acid leach procedure. Both aluminum and zirconium are more resistive to acid attack. Aluminum and zirconium in the fusion prepared sample ACL\# 00-0902 was about twice as high in concentration as the acid leach prepared sample. Less resistant analytes were similar in concentration for both fusion and acid leach prepared samples. 


\section{Battelle PNNL/RPG/Inorganic Analysis ... ICPAES Data Report}

\section{Post-Spiked Samples (Group A):}

(Solid \& liquid samples) All analytes of interest were recovered within tolerance of $75 \%$ to $125 \%$ except potassium in the acid digestion (ALO-128) prepared sample ACL\# 00-0903. Potassium recovery (134\%) was above the tolerance limit. All other analytes above EQL were within tolerance. The reason for the discrepancy is not known.

Post-Spiked Samples (Group B):

(Solid \& liquid samples) All analytes of interest were recovered within tolerance of $75 \%$ to $125 \%$.

Blank Spike:

(Solid \& liquid samples) A blank spike is not require for fusion prepared samples. All analytes of interest in solid and liquid prepared samples tested were recovered within tolerance limit of $80 \%$ to $120 \%$ recovery except as follows. Silver in the blank spike prepared using ALO-129 and ALO-128 procedure produced low recovery ( $27 \%$ and $19 \%$ respectively) because hydrochloric acid was used during sample preparation, causing silver to precipitate from solution.

Matrix Spiked Sample: (Solid \& liquid samples) A matrix spike is not require for fusion prepared samples. All analytes of interest in solid and liquid prepared samples tested were recovered within tolerance limit of $75 \%$ to $125 \%$ recovery, except as follows. Arsenic in the matrix-spiked sample ACL\# 00-0909, prepared using ALO-129 procedure, produced low recovery of $22 \%$. The reason for the low arsenic recovery is unclear but may be related to a high sulfate concentration in the sample. Silver and barium in the matrix-spiked sample ACL\# 00-0903 prepared using ALO-128 procedure were both low (13\% and 5\% respectively). Silver recovery is low because hydrochloric acid was used to prepare the sample. Barium recovery is low most likely because of high concentration of sulfate in the sample, which will precipitate barium from solution. 


\section{Battelle PNNLRPG/Inorganic Analysis ... ICPAES Data Report}

Quality Control Check Standards (solid and liquid samples):

Concentration of all analytes is within tolerance limit of $\pm 10 \%$ accuracy in standards: QC_MCVA, QC_MCVB, and QC_SSTMCV. Calibration Blank (ICP98.0) concentration is acceptable, less than two times IDL.

High Calibration Standard Check (solid and liquid samples):

Verification of the high-end calibration for all analytes is within tolerance limits of $\pm 5 \%$ accuracy except for potassium. Potassium was slightly high ( $6 \%$ to $8 \%$ ) during analysis of solids prepared using ALO-129 acid leach procedure.

Process Blank:

(solid and liquid samples) All analytes of interest were within tolerance limit of $\leq \mathrm{EQL}$ or $<5 \%$ of sample concentration in the prepared samples.

Laboratory Control Standard (LCS):

(Fusion prepared samples) All analytes measured at a concentration equal to or greater than EQL were recovered within tolerance limit of $75 \%$ to $125 \%$. SRM-2710 Montana Soil was used for the LCS in PNL-ALO-115 fusion preparations. Calcium was the only analyte that exceeded tolerance limits. Without blank correction calcium recovery was about $140 \%$. With blank correction calcium recovery was too low, about $28 \%$. Typically a blank correction is applied for calcium determination in the SRM-2710 using ALO-115 KOH/Ni fusion procedure since there calcium is known to be present in the $\mathrm{KOH}$ reagent. If a sample contaminated the fusion blank it would lead to low recovery, which may have occurred in this case.

Please note bracketed values listed in the data report are within ten times instrument detection limit and have a potential uncertainty much greater than $15 \%$. 


\section{Battelle PNNL/RPG/Inorganic Analysis ... ICPAES Data Report}

Comments:

1) "Final Results" have been corrected for all laboratory dilution performed on the sample during processing and analysis unless specifically noted.

2) Detection limits (DL) shown are for acidified water. Detection limits for other matrices may be determined if requested.

3) Routine precision and bias is typically $\pm 15 \%$ or better for samples in dilute, acidified water (e.g. $2 \% \mathrm{v} / \mathrm{v} \mathrm{HNO}_{3}$ or less) at analyte concentrations greater than ten times detection limit up to the upper calibration level. This also presumes that the total dissolved solids concentration in the sample is less than $5000 \mu \mathrm{g} / \mathrm{mL}$ ( 0.5 per cent by weight).

4) Absolute precision, bias and detection limits may be determined on each sample if required by the client.

5) The maximum number of significant figures for all ICP measurements is 2. 


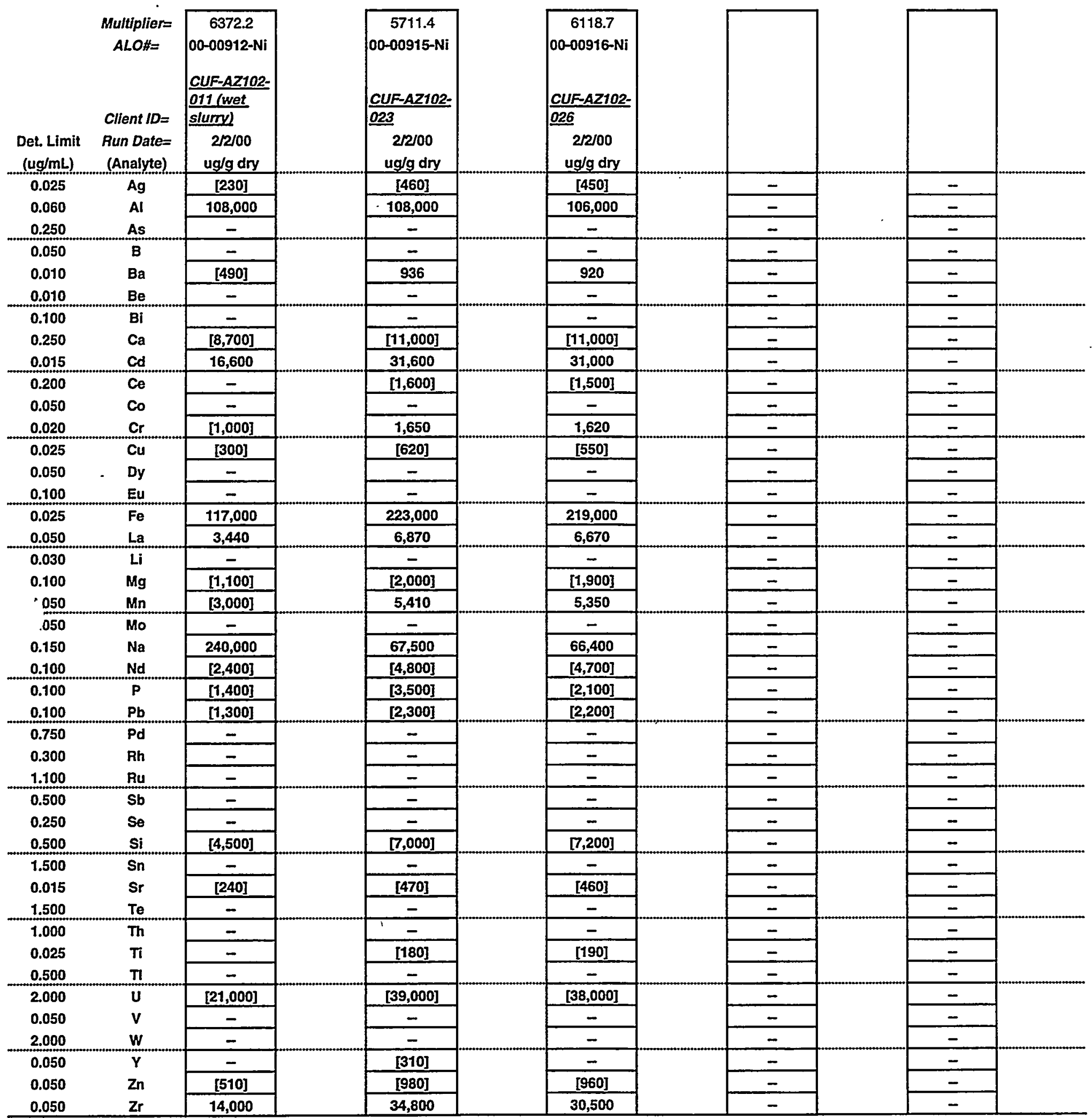

Note: 1) Overall error greater than 10-times detection limit is estimated to be within $+1-15 \%$.

2) Values in brackets $\square$ are within 10-times detection limit with errors likely to exceed $15 \%$.

3) ".-." indicate measurement is below detection. Sample detection limit may be found by

multiplying "det. limit" (far left column) by "multiplier" (top of each column). 
Battelle PNNL/RPG/Inorganic Analysis ... ICPAES Data Report Page 1 of 3

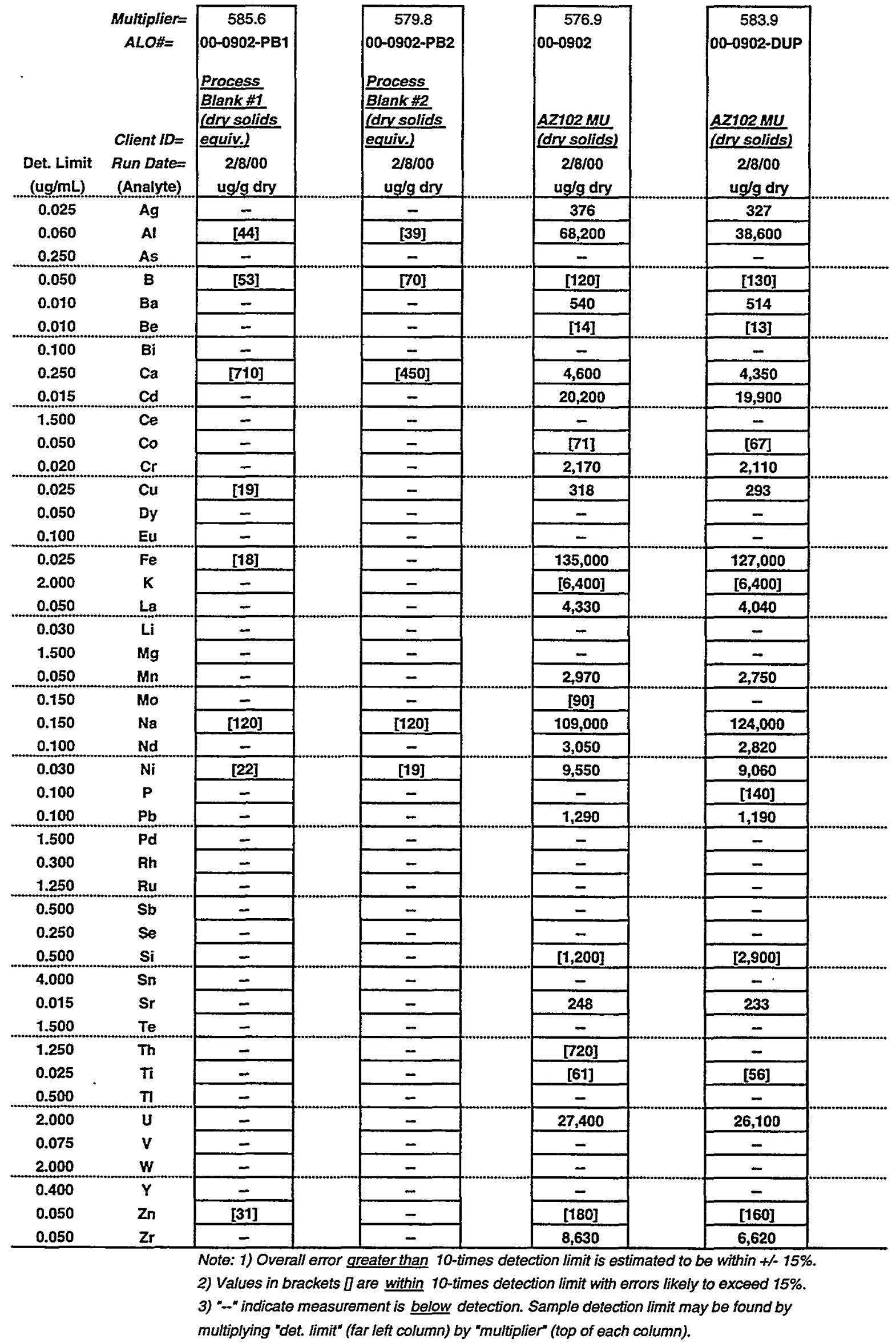


Battelle PNNL/RPG/Inorganic Analysis ... ICPAES Data Report Page 2 of 3

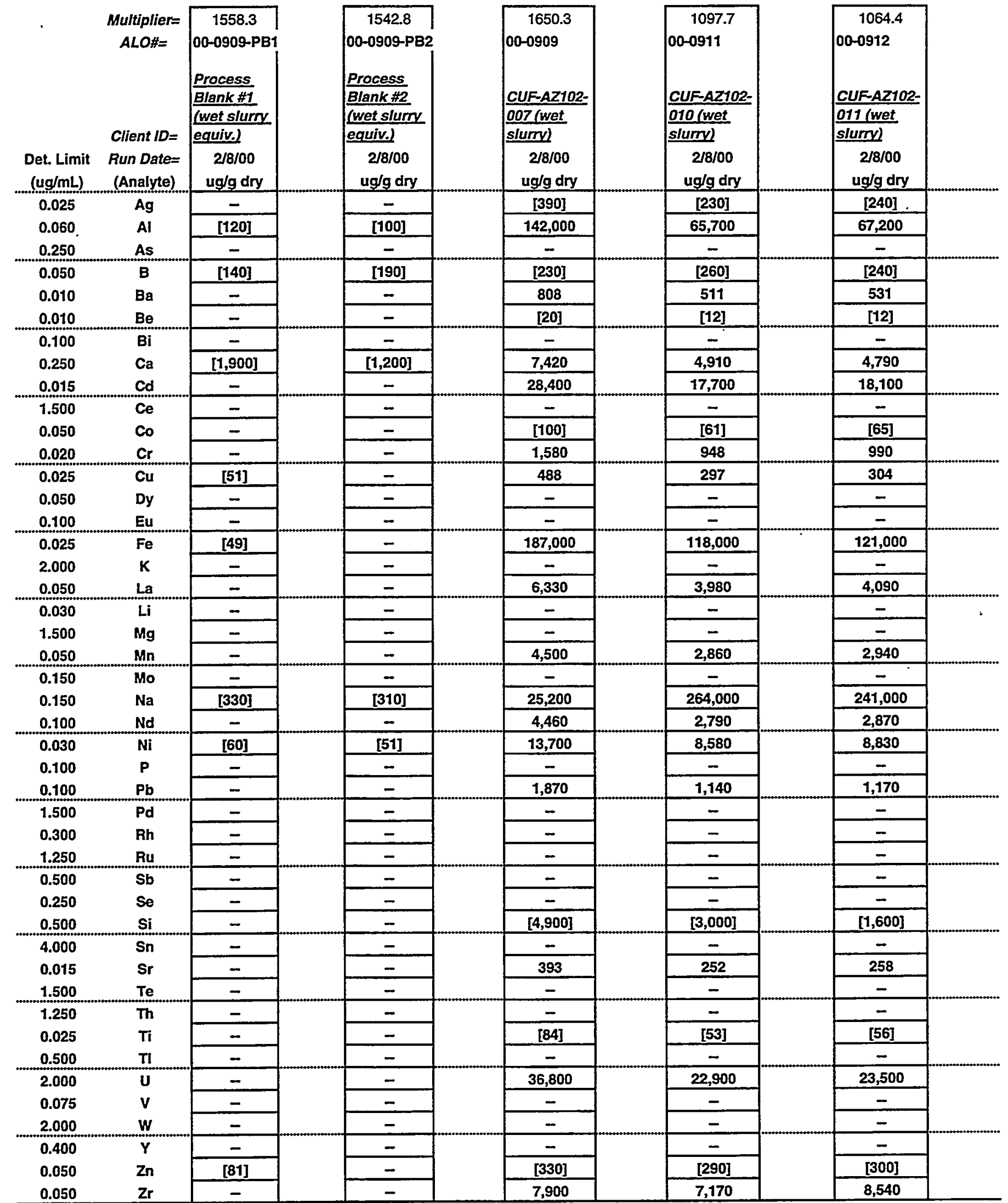

Note: 1) Overall error greater than 10-times detection limit is estimated to be within $+1-15 \%$.

2) Values in brackets $\square$ are within 10-times detection limit with errors likely to exceed $15 \%$.

3) "-." indicate measurement is below detection. Sample detection limit may be found by

multiplying "det. limit" (far left column) by "multiplier" (top of each column). 


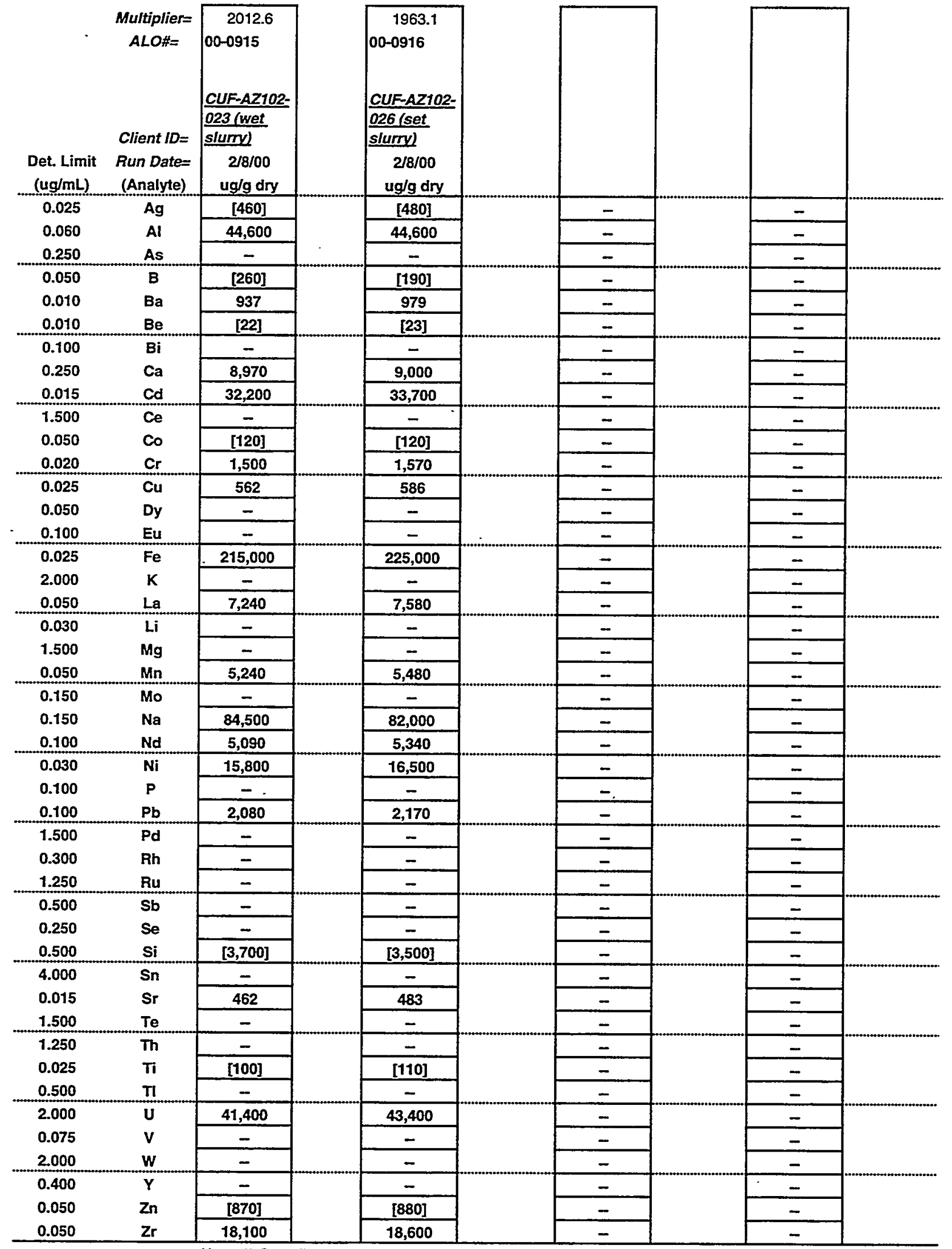

Note: 1) Overall error greater than 10-times detection limit is estimated to be within $+1-15 \%$.

2) Values in brackets $\square$ are within 10-times detection limit with errors likely to exceed $15 \%$.

3) "--" indicate measurement is below detection. Sample detection limit may be found by

multiplying "det. limit" (far left column) by "multiplier" (top of each column). 
Battelle PNNL/RPG/Inorganic Analysis ... ICPAES Data Report Page 1 of 3

\begin{tabular}{|c|c|c|c|c|c|c|}
\hline $\begin{array}{c}\text { Det. Limit } \\
(u g / m L)\end{array}$ & $\begin{array}{c}\text { Multiplier= } \\
\text { ACLA= } \\
\text { Client ID= } \\
\text { Run Date= } \\
\text { (Analyte) }\end{array}$ & \begin{tabular}{|c}
\multicolumn{1}{c}{4.8} \\
00-0903-PB \\
Process \\
Blank \\
$\begin{array}{c}2 / 24 / 00 \\
\mathrm{ug} / \mathrm{mL}\end{array}$ \\
\end{tabular} & $\begin{array}{c}24.5 \\
00-0903 \text { Q5 } \\
\frac{A Z 102 M}{S \underline{S U P}} \\
\begin{array}{c}2 / 24 / 00 \\
u g / m L\end{array} \\
\end{array}$ & \begin{tabular}{|c|}
24.3 \\
$00-0903-D U P$ \\
AZ102M \\
$\frac{S U P}{2 / 24 / 00}$ \\
$u g / m L$ \\
\end{tabular} & $\begin{array}{c}9.8 \\
00-0904 \text { Q2 } \\
\text { CUF-AZ102- } \\
001 \\
2 / 24 / 00 \\
u g / \mathrm{mL} \\
\end{array}$ & $\begin{array}{c}9.8 \\
00-0905 \text { Q2 } \\
\text { CUF-AZ102- } \\
003 \\
\begin{array}{c}003 \\
u \mathrm{~g} / \mathrm{mL}\end{array} \\
\end{array}$ \\
\hline \multirow{3}{*}{$\begin{array}{l}0.025 \\
0.060 \\
0.250\end{array}$} & \multirow{3}{*}{$\begin{array}{l}\text { Ag } \\
\text { Al } \\
\text { As }\end{array}$} & - & - & \begin{tabular}{|c|}
- \\
\end{tabular} & \multirow{2}{*}{\begin{tabular}{|c|}
- \\
184
\end{tabular}} & \multirow{2}{*}{\begin{tabular}{|c|}
- \\
163 \\
\end{tabular}} \\
\hline & & 4.50 & 214 & \multirow{2}{*}{$\frac{219}{-}$} & & \\
\hline & & - & - & & - & - \\
\hline \multirow{3}{*}{$\begin{array}{l}0.050 \\
0.010 \\
0.010 \\
\end{array}$} & \multirow{3}{*}{$\begin{array}{l}\mathrm{B} \\
\mathrm{Ba} \\
\mathrm{Be}\end{array}$} & 7.44 & 43.3 & 45.8 & 17.6 & 13.5 \\
\hline & & - & [0.26] & - & - & - \\
\hline & & - & - & - & - & - \\
\hline 0.100 & \multirow{3}{*}{$\begin{array}{l}\mathrm{Bi} \\
\mathrm{Ca} \\
\mathrm{Cd}\end{array}$} & - & - & - & - & - \\
\hline 0.250 & & {$[4.8]$} & {$[8.8]$} & {$[9.8]$} & {$[5.8]$} & {$[6.1]$} \\
\hline 0.015 & & - & - & - & - & - \\
\hline 0.200 & $\mathrm{Ce}$ & - & - & - & - & - \\
\hline 0.050 & co & - & - & - & - & - \\
\hline 0.020 & $\mathrm{Cr}$ & - & 822 & 831 & 66.2 & 66.9 \\
\hline 0.025 & $\mathrm{Cu}$ & - & {$[0.84]$} & - & - & - \\
\hline 0.050 & Dy & - & - & - & - & - \\
\hline 0.100 & Eu & - & - & - & - & - \\
\hline 0.025 & $\mathrm{Fe}$ & [0.18] & [0.70] & {$[0.67]$} & [0.25] & {$[0.25]$} \\
\hline 2.000 & $\mathbf{K}$ & - & 3,650 & 3,830 & 325 & 329 \\
\hline 0.050 & La & - & - & - & - & - \\
\hline 0.030 & $\mathrm{Li}$ & - & $=$ & - & - & - \\
\hline 0.100 & Mg & - & - & - & - & - \\
\hline 0.050 & $\mathrm{Mn}$ & - & - & - & - & - \\
\hline 750 & Mo & - & 61.0 & 61.7 & 5.10 & 5.12 \\
\hline .50 & Na & 15.7 & 67,600 & 72,700 & 5,980 & 6,020 \\
\hline 0.100 & Nd & - & - & - & - & - \\
\hline 0.030 & $\mathrm{Ni}$ & [0.35] & - & - & - & - \\
\hline 0.100 & $\mathbf{P}$ & - & 143 & 145 & {$[8.8]$} & [7.2] \\
\hline 0.100 & $\mathrm{~Pb}$ & - & - & - & - & - \\
\hline 0.750 & Pd & - & - & - & - & - \\
\hline 0.300 & Rh & - & $=$ & - & - & - \\
\hline 1.100 & Ru & - & - & - & - & - \\
\hline 0.500 & Sb & - & - & - & - & - \\
\hline 0.250 & Se & - & - & - & - & - \\
\hline 0.500 & $\mathrm{Si}$ & [21] & 299 & 304 & [43] & [37] \\
\hline 1.500 & Sn & - & - & - & - & - \\
\hline 0.015 & $\mathrm{Sr}$ & - & - & - & - & - \\
\hline 1.500 & $\mathrm{Te}$ & - & - & - & - & - \\
\hline 1.000 & Th & - & - & - & - & - \\
\hline 0.025 & $\pi i$ & - & - & - & - & - \\
\hline 0.500 & $T$ & - & - & - & - & - \\
\hline 2.000 & $\mathbf{U}$ & - & - & - & [23] & [29] \\
\hline 0.050 & $v$ & - & - & - & - & - \\
\hline 2.000 & $w$ & - & - & - & - & - \\
\hline 0.050 & $Y$ & - & - & $=$ & - & - \\
\hline 0.050 & $Z n$ & $=$ & - & - & - & - \\
\hline 0.050 & $\mathrm{Zr}$ & - & - & - & - & - \\
\hline
\end{tabular}

Note: 1) Overall error greater than 10-times detection limit is estimated to be within $+/-15 \%$.

2) Values in brackets $\square$ are within 10-times detection limit with errors likely to exceed $15 \%$.

3) :-.- indicate measurement is below detection. Sample detection limit may be found by

multiplying "det. limit" (far left column) by "multiplier" (top of each column). 
Battelle PNNL/RPG/Inorganic Analysis ... ICPAES Data Report Page 2 of 3

\begin{tabular}{|c|c|c|c|c|c|c|c|c|}
\hline $\begin{array}{c}\text { Det Limit } \\
\text { (ug/ml) }\end{array}$ & $\begin{array}{c}\text { Multiplier= } \\
\text { ACL\#= } \\
\text { Client } 1 D= \\
\text { Run Date= } \\
\text { (Analyte) }\end{array}$ & $\begin{array}{c}9.8 \\
00-0906 \text { @2 } \\
\text { CUF-AZ102- } \\
\underline{015} \\
2 / 24 / 00 \\
u g / m L\end{array}$ & \begin{tabular}{|c|}
$\begin{array}{c}4.8 \\
00-0907\end{array}$ \\
CUE-AZ102- \\
$\underline{017}$ \\
$2 / 24 / 00$ \\
$u g / m L$ \\
\end{tabular} & $\begin{array}{c}\quad 5.0 \\
00-0908 \\
\text { CUF-AZ102- } \\
\underline{019} \\
2 / 24 / 00 \\
\mathrm{ug} / \mathrm{mL}\end{array}$ & . & $\begin{array}{c}24.7 \\
00-0910 @ 5 \\
\text { CUF-AZ102- } \\
\underline{009} \\
2 / 24 / 00 \\
\mathrm{ug} / \mathrm{mL}\end{array}$ & $\begin{array}{c}9.9 \\
00-0913 @ 2 \\
\text { CUF-AZ102- } \\
\underline{013} \\
2 / 24 / 00 \\
u g / m L\end{array}$ & \\
\hline 0.025 & Ag & - & - & - & & - & - & \\
\hline 0.060 & Al & 146 & 108 & 93.8 & & 10,400 & 4,910 & \\
\hline 0.250 & As & - & - & - & & [9.6] & {$[5.8]$} & \\
\hline 0.050 & $\mathbf{B}$ & 14.9 & 15.0 & 11.3 & & 23.9 & 10.0 & \\
\hline 0.010 & $\mathbf{B a}$ & - & - & - & & - & $=$ & \\
\hline 0.010 & $\mathbf{B e}$ & $=$ & - & - & & {$[0.25]$} & - & \\
\hline 0.100 & $\mathbf{B i}$ & - & $=$ & - & & - & - & \\
\hline 0.250 & $\mathrm{Ca}$ & [5.0] & [4.6] & [4.2] & & [14] & [3.9] & \\
\hline 0.015 & Cd & - & - & - & & 15.0 & {$[0.87]$} & \\
\hline 0.200 & $\mathrm{Ce}$ & - & - & - & & - & - & \\
\hline 0.050 & Co & - & - & - & & - & - & \\
\hline 0.020 & $\mathrm{Cr}$ & 36.3 & 20.6 & 11.8 & & 43.8 & 17.4 & \\
\hline 0.025 & $\mathrm{Cu}$ & - & - & - & & - & - & \\
\hline 0.050 & Dy & - & - & - & & - & - & \\
\hline 0.100 & Eu & - & - & - & & - & - & \\
\hline 0.025 & $\mathrm{Fe}$ & {$[0.32]$} & {$[0.20]$} & [0.35] & & {$[3.7]$} & {$[1.0]$} & \\
\hline 2.000 & $\mathbf{K}$ & [190] & 115 & [69] & & [190] & [61] & \\
\hline 0.050 & La & - & - & - & & - & - & \\
\hline 0.030 & $\mathrm{Li}$ & - & - & - & & - & - & \\
\hline 0.100 & $\mathbf{M g}$ & - & - & - & & - & - & \\
\hline 0.050 & Mn & - & - & - & & - & - & \\
\hline 0.050 & Mo & [3.0] & {$[1.7]$} & {$[0.97]$} & & [2.3] & [1.3] & \\
\hline 0.150 & $\mathrm{Na}$ & 3,710 & 2,220 & 1,430 & & 54,100 & 20,600 & \\
\hline 0.100 & Nd & - & - & - & & - & - & \\
\hline 0.030 & $\mathrm{Ni}$ & - & - & - & & - & $=$ & \\
\hline 0.100 & $\mathbf{P}$ & [6.6] & 6.52 & 6.63 & & 163 & 69.9 & \\
\hline 0.100 & $\mathrm{~Pb}$ & - & - & - & & [6.1] & {$[2.4]$} & \\
\hline 0.750 & $P d$ & - & - & $=$ & & - & - & \\
\hline 0.300 & $\mathbf{R h}$ & - & - & $=$ & & - & - & \\
\hline 1.100 & Ru & - & $=$ & - & & - & - & \\
\hline 0.500 & $\mathbf{S b}$ & - & - & - & & - & - & \\
\hline 0.250 & Se & - & - & - & & - & - & \\
\hline 0.500 & Si & [33] & 33.7 & 28.7 & & [120] & 56.9 & \\
\hline 1.500 & Sn & - & - & - & & - & - & \\
\hline 0.015 & Sr & - & - & - & & - & - & \\
\hline 1.500 & Te & - & - & - & & - & - & \\
\hline 1.000 & Th & - & $=$ & $=$ & & - & - & \\
\hline 0.025 & $\pi$ & - & - & - & & - & - & \\
\hline 0.500 & $\pi$ & - & - & - & & - & - & \\
\hline 2.000 & $\mathbf{U}$ & [38] & [18] & - & & - & [24] & \\
\hline 0.050 & $\mathbf{V}$ & - & - & - & & [1.4] & {$[0.70]$} & \\
\hline 2.000 & $W$ & - & - & - & & - & - & \\
\hline 0.050 & $\mathbf{Y}$ & - & $=$ & - & & - & - & \\
\hline 0.050 & Zn & $=$ & - & [0.33] & & [3.4] & {$[3.7]$} & \\
\hline 0.050 & $\mathrm{Zr}$ & - & - & - & & - & - & \\
\hline
\end{tabular}

Note: 1) Overall emror greater than 10-times detection limit is estimated to be within $+1-15 \%$.

2) Values in brackets $\square$ are within 10-times detection limit with errors likely to exceed $15 \%$.

3) "--" indicate measurement is below detection. Sample detection limit may be found by

multiplying "det. limit" (far left column) by "multiplier" (top of each column). 
Battelle PNNL/RPG/Inorganic Analysis ... ICPAES Data Report Page 3 of 3

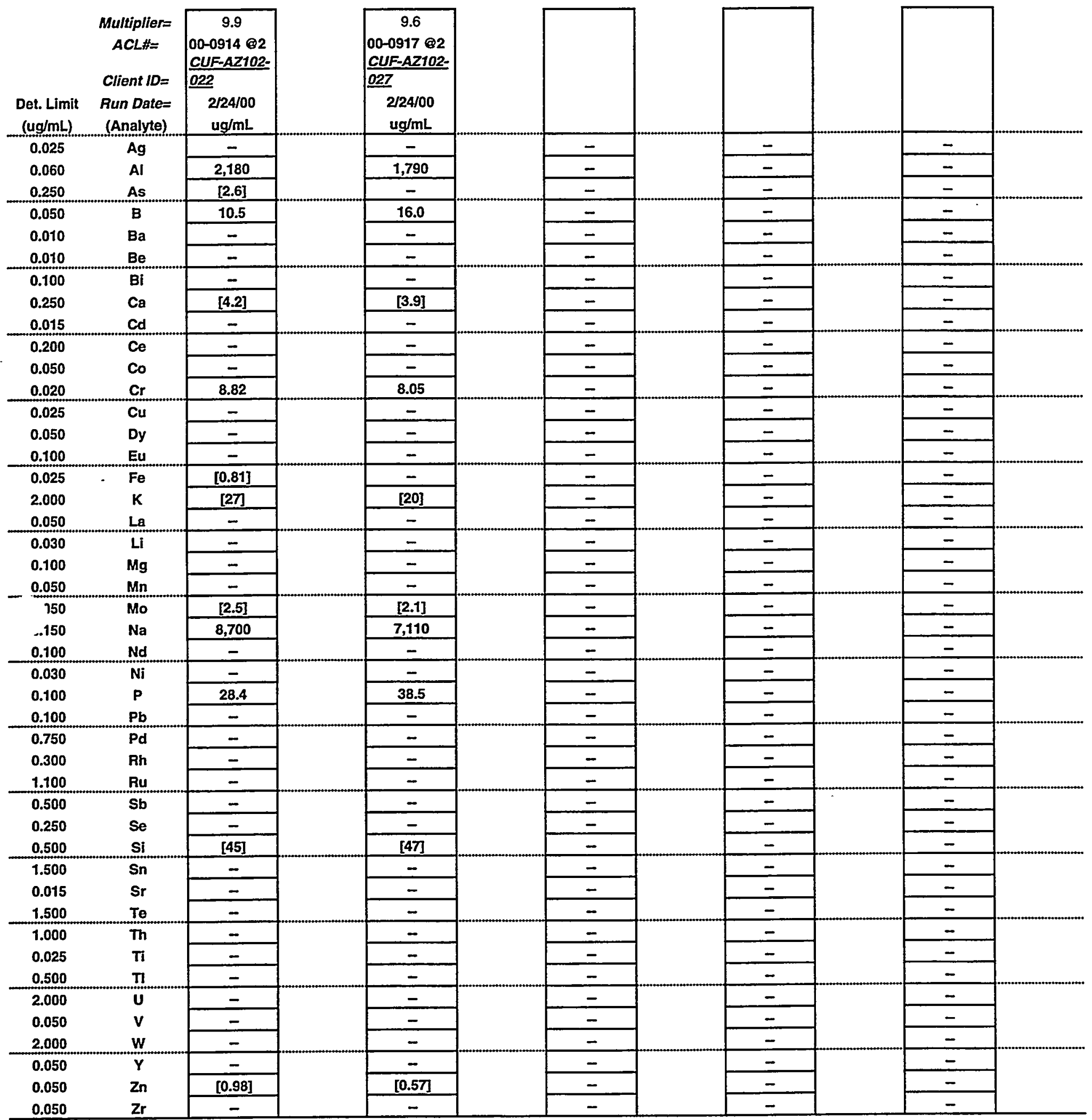

Note: 1) Overall enor greater than 10-times detection limit is estimated to be within $+1-15 \%$.

2) Values in brackets $\square$ are within 10-times detection limit with errors likely to exceed $15 \%$.

3) "--" indicate measurement is below detection. Sample detection limit may be found by

multiplying "det. limit" (far left column) by "multiplier" (top of each column). 


\section{Battelle PNNL/RPG/Inorganic Analysis --- IC Report}

$\begin{array}{lllr}\text { Client: } & \text { K Brooks } & \text { Charge Code/Project: } & \text { W45577/29953 } \\ \text { ACL Numbers: } & \text { 00-0902 to 00-0916 } & \text { ASR Number: } & 5667 \text { and 5668 } \\ \text { Analyst: } & \text { MJ Steele } & \text { Analysis Date: } & 2 / 11 / 00 \text { and 3/15/00 }\end{array}$

Procedure: PNL-ALO-212, "Determination of Inorganic Anions by Ion Chromatography" M\&TE: IC system (WD25214); Balance (360-06-01-031) --- See Chemical Measurement Center 98620 RIDS IC File for Calibration, Standards Preparations, and Maintenance Records.

\section{Final Results:}

The AZ-102 as received samples (ASR 5667) and the AZ-102 CUF samples (ASR 5668) were analyzed by ion chromatography (IC) for inorganic anions as specified in the governing ASR. The final results are presented in Tables 1 through 3 below. Table 1 presents the slurry anion results in $\mu \mathrm{g} / \mathrm{g}$ on a dry weight basis (i.e., corrected for weight percent solids) and Table 2 presents the liquid samples (supernatant, filtrates, washes, and leaches) in $\mu \mathrm{g} / \mathrm{ml}$. Although not requested by the ASR, Table 3 presents the slurry concentration in $\mu \mathrm{g} / \mathrm{g}$ of wet slurry. All sample were diluted at the IC workstation to appropriate levels to ensure that all anions reported were measured within the calibration range. The diluted slurry samples were analyzed (after filtering) on February 11 and the liquids on March 15.

\begin{tabular}{|c|c|c|c|c|c|c|c|c|c|c|c|}
\hline \multirow{2}{*}{\multicolumn{2}{|c|}{ Table 1: Slurry Results on a Dry Weight Basis }} & \multirow{3}{*}{\begin{tabular}{|c|} 
Solidss \\
Dil Fetr \\
\end{tabular}} & \multirow{3}{*}{$\begin{array}{l}\text { Wt } \% \\
\text { Solids } \\
\end{array}$} & \multirow{3}{*}{$\begin{array}{r}\mathbf{F} \\
\mathrm{ug} / \mathrm{g} \\
\end{array}$} & \multirow{3}{*}{$\begin{array}{c}\mathrm{Cl} \\
\mathrm{ug} / \mathrm{g}\end{array}$} & \multirow{3}{*}{$\begin{array}{l}\mathrm{NO}_{2} \\
\mathrm{ug} / \mathrm{g}\end{array}$} & & & & & \\
\hline & & & & & & & \multirow{2}{*}{$\begin{array}{c}\mathrm{Br} \\
\mathrm{ug} / \mathrm{g}\end{array}$} & \multirow{2}{*}{$\begin{array}{l}\mathrm{NO}_{3} \\
\mathrm{ug} / \mathrm{g}\end{array}$} & \multirow{2}{*}{$\begin{array}{l}\mathrm{PO}_{4} \\
\mathrm{ug} / \mathrm{g}\end{array}$} & \multirow{2}{*}{$\begin{array}{l}\mathrm{SO}_{4} \\
\mathrm{ug} / \mathrm{g}\end{array}$} & \multirow{2}{*}{$\begin{array}{r}\mathrm{C}_{2} \mathrm{O}_{4} \\
\mathrm{ug} / \mathrm{g}\end{array}$} \\
\hline Lab ID & \begin{tabular}{|c|} 
Sample ID \\
\end{tabular} & & & & & & & & & & \\
\hline $00-00902 \mathrm{~PB}$ & Process Blank (equiv Dil) & 103.3 & 41.8 & $<25$ & 41 & $<50$ & $<25$ & $<50$ & $<50$ & $<50$ & $<50$ \\
\hline $00-00902$ & AZ-102 MU As Rec Slurry & 103.0 & 41.8 & 1,400 & $<250$ & 63,300 & $<250$ & 20,400 & 660 & 27,400 & 3,500 \\
\hline \multirow[t]{3}{*}{ 00-00902 Dup } & AZ-102 MU As Rec Slurry dup & 103.6 & 41.8 & 2,000 & $<250$ & 68,800 & $<250$ & 22,300 & 470 & 31,100 & 4,300 \\
\hline & $\mathrm{RPD}$ & & & $35 \%$ & $\mathrm{n} / \mathrm{a}$ & $8 \%$ & $\mathrm{n} / \mathrm{a}$ & $9 \%$ & $34 \%$ & $13 \%$ & $21 \%$ \\
\hline & Matrix SpikeTrue@10x & & & 0.4 & 0.4 & 1.2 & 0.4 & 1.2 & 1.2 & 1.2 & 1.2 \\
\hline \multirow[t]{2}{*}{$00-00902 \mathrm{MS}$} & AZ-102 As Rec Slurry MS Rec & & & $121 \%$ & $205 \%$ & $-48 \%$ & $87 \%$ & $6 \%$ & $97 \%$ & $85 \%$ & $93 \%$ \\
\hline & Matrix Spike True & & & 4.0 & 4.0 & 12.0 & 4.0 & 12.0 & 12.0 & 12.0 & 12.0 \\
\hline $00.00902 P S$ & AZ-102 As Rec Slurry PS Rec & & & $107 \%$ & $104 \%$ & $114 \%$ & $95 \%$ & $110 \%$ & $102 \%$ & $98 \%$ & $106 \%$ \\
\hline $00-00902 B S$ & AZ-102 As Rec Slurry BS Rec & & & $103 \%$ & $195 \%$ & $95 \%$ & $96 \%$ & $105 \%$ & $82 \%$ & $104 \%$ & $98 \%$ \\
\hline $00.00902 B S$ & AZ-102 As Rec Slurry BS Rec & & & $106 \%$ & $197 \%$ & $98 \%$ & $94 \%$ & $105 \%$ & $101 \%$ & $109 \%$ & $106 \%$ \\
\hline $00-00909 \mathrm{VB}$ & Dil Blank -(equiv. Dil/wt\%) & 13.9 & 13.3 & $<30$ & $<30$ & $<60$ & $<30$ & $<60$ & $<60$ & $<60$ & $<60$ \\
\hline $00-00909$ & CUF-AZ-102-007 Slurry Wash \#3 & 12.6 & 11.3 & 230 & 400 & 5,500 & $<30$ & 1,600 & 960 & 2,800 & 420 \\
\hline $00-00911$ & CUF-AZ-102-010 Slurty Caustic Leach & 17.9 & 18.0 & 590 & 4,200 & 1,500 & $<250$ & $<500$ & 2,200 & 1,000 & $<500$ \\
\hline $00-00912$ & CUF-AZ-102-011 Slurry Caustic Leach & 18.0 & 18.5 & $<250$ & 4,100 & 2,000 & $<250$ & $<500$ & 1,900 & 990 & $<500$ \\
\hline $00-00915$ & CUF-AZ-102-023 Final Slurry & 11.0 & 10.4 & 300 & 1,500 & $<550$ & $<300$ & $<550$ & 850 & 690 & $<550$ \\
\hline $00-00916$ & CUF-AZ-102-026 Final Slurry & 11.5 & 10.7 & $<300$ & 1,200 & $<550$ & $<300$ & $<550$ & 870 & $<550$ & $<550$ \\
\hline \multirow[t]{2}{*}{ 00-00916 Rep } & CUF-AZ-102-026 Final Slurry Rep & 11.5 & 10.7 & $<300$ & 1,200 & $<550$ & $<300$ & $<550$ & 970 & $<550$ & $<550$ \\
\hline & $\mathrm{RPD}$ & & & $\mathrm{n} / \mathrm{a}$ & $0 \%$ & $\mathrm{n} / \mathrm{a}$ & $\mathrm{n} / \mathrm{a}$ & $\mathrm{n} / \mathrm{a}$ & $11 \%$ & $\mathrm{n} / \mathrm{a}$ & $\mathrm{n} / \mathrm{a}$ \\
\hline
\end{tabular}

RPD $=$ Relative Percent Difference (between sample and duplicate/replicate)

MS Rec = Matrix Spike Standard \% Recovery, PS Rec = Post Spike \% Recovery, BS Rec = Blank Spike Standard \% Recovery 


\section{Battelle PNNL/RPG/Inorganic Analysis --- IC Report}

\begin{tabular}{|c|c|c|c|c|c|c|c|c|c|}
\hline \multirow{2}{*}{\multicolumn{2}{|c|}{ Table 2: Liqud Samples }} & \multirow{3}{*}{$\begin{array}{c}F \\
\text { ug/ml }\end{array}$} & \multirow{3}{*}{$\begin{array}{c}\mathrm{Cl} \\
\mathrm{ug} / \mathrm{ml}\end{array}$} & \multirow{3}{*}{$\begin{array}{c}\mathrm{NO2} \\
\mathrm{ug} / \mathrm{ml}\end{array}$} & \multirow{3}{*}{$\begin{array}{c}\mathrm{Br} \\
\mathrm{ug} / \mathrm{ml} \\
\end{array}$} & \multirow{3}{*}{$\begin{array}{c}\text { NO3 } \\
\text { ug/ml }\end{array}$} & \multirow{3}{*}{$\begin{array}{c}\text { PO4 } \\
\mathrm{ug} / \mathrm{ml}\end{array}$} & \multirow{3}{*}{$\begin{array}{c}\mathrm{SO4} \\
\mathrm{ug} / \mathrm{ml}\end{array}$} & \multirow{3}{*}{$\begin{array}{l}\mathrm{C} 204 \\
\mathrm{ug} / \mathrm{ml}\end{array}$} \\
\hline & & & & & & & & & \\
\hline Lab ID & Sample ID & & & & & & & & \\
\hline $00-00903$ & AZ-102 (M Sup) As Received & 720 & $<100$ & 41,600 & $<100$ & 14,000 & 440 & 21,300 & 2,890 \\
\hline \multirow[t]{2}{*}{$00-00903 \mathrm{D}$} & AS-102 (M Sup) As Received Dup & 780 & $<100$ & 41,700 & $<100$ & 13,600 & 430 & 20,800 & 3,690 \\
\hline & $\mathrm{RPD}$ & $8 \%$ & $n / a$ & $0 \%$ & $\mathrm{n} / \mathrm{a}$ & $3 \%$ & $2 \%$ & $2 \%$ & $24 \%$ \\
\hline 00-00903 MS & AZ-102 (M Sup) As Received MS Rec & $98 \%$ & $94 \%$ & $99 \%$ & $120 \%$ & $118 \%$ & $106 \%$ & $101 \%$ & $106 \%$ \\
\hline $00-00903 \mathrm{MS}$ & AZ-102 (M Sup) As Received MS Rec & $108 \%$ & $109 \%$ & $105 \%$ & $107 \%$ & $I 06 \%$ & $105 \%$ & $106 \%$ & $105 \%$ \\
\hline Woring Spike & Recovery & $98 \%$ & $94 \%$ & $98 \%$ & $118 \%$ & $119 \%$ & $106 \%$ & $101 \%$ & $106 \%$ \\
\hline Woring Spike & Recovery & $109 \%$ & $109 \%$ & $105 \%$ & $107 \%$ & $106 \%$ & $106 \%$ & $106 \%$ & $105 \%$ \\
\hline $00-00904$ & CUF-AZ-102-001 Filtrate I & 90 & $<25$ & 3,820 & $<25$ & 1,080 & $<50$ & 1,630 & 250 \\
\hline $00-00905$ & CUF-AZ-102-003 Filtrate 2 & 90 & $<25$ & 3,710 & $<25$ & 1,030 & $<50$ & 1,580 & 300 \\
\hline $00-00906$ & CUF-AZ-102-015 Wash 1 & 50 & $<10$ & 1,930 & $<10$ & 740 & $<20$ & 1,130 & 160 \\
\hline 00.00907 & CUF-AZ-102-017 Wash 2 & 30 & $<10$ & 1,120 & $<10$ & 380 & $<20$ & 600 & 130 \\
\hline $00-00908$ & CUF-AZ-102-019 Wash 3 & 20 & $<10$ & 660 & $<10$ & 220 & 30 & 350 & 80 \\
\hline $00-00910$ & CUF-AZ-102-009 Caustic Leach & $<10$ & 890 & 420 & $<10$ & 160 & 210 & 220 & 30 \\
\hline $00-00913$ & CUF-AZ-102-013 Caustic Wash 1 & $<25$ & 370 & 180 & $<25$ & 100 & 160 & 110 & $<50$ \\
\hline $00-00914$ & CUF-AZ-102-022 Caustic Wash 2 & $<25$ & 370 & 180 & $<25$ & 100 & 160. & 110 & $<50$ \\
\hline
\end{tabular}

RPD $=$ Relative Percent Difference (between sample and duplicate/replicate)

MS Rec = Matrix Spike Standard \% Recovery, PS Rec = Post Spike \% Recovery, BS Rec= Blank Spike Standard \% Recovery

Table 3: Slurry Results on a Wet Weight Basis

\section{Q.C. Comments for Slurry Analyses (February 11, 2000) :}

Duplicates: Duplicate samples were extracted from the AZ-102 as received slurry sample (00-0902) and diluted in the hot cells. These dilution were than transferred to the IC Workstation and treated as duplicate for the IC analysis. At the IC Workstation, the CUF-AZ-102-026 final slurry sample (00-0916) which was diluted in the hot cell was split and analyzed in replicate. For anions above the estimated quantitation level (EQL; i.e., the lowest calibration standard), the Relative Percent Difference (RPD) is within the acceptance criteria of $20 \%$, except for fluoride, phosphate and oxalate on the duplicate processed in the hot cell. Oxalate is not an analyte of 


\section{Battelle PNNL/RPG/Inorganic Analysis --- IC Report}

interest stated on the ASR and the phosphate results are just marginally above the EQL. Interferences from suspected organic anion significantly affect the ability to accurately quantify the fluoride peak and the fluoride results should be considered qualitative.

Matrix Spike: A matrix spike of the AZ-102 as received sample (00-0902) were prepared in the hot cells. Unfortunately the spiking level was insufficient to recover the spike after the required analytical dilutions at the IC Workstation. Recoveries are reported for this MS; however, the spike level is right at the EQL following dilutions. Since no Matrix Spike results could be obtained, the sample was post-spike at the IC Workstation. All post-spike recoveries were within the spiking acceptance criteria of $75 \%$ to $125 \%$.

Blank Spike: A blank spike was prepared in the hot cells. Except for chloride which has a recovery about double (i.e., 195\%) that anticipated and phosphate which recovered low (i.e., $82 \%$ ), the blank spike recoveries were within the acceptance criteria of $90 \%$ to $110 \%$. The reason for the phosphate low recovery is unknown. Since all verification standard phosphate recoveries are acceptable, it is unlikely that the low phosphate recovery is due to column degradation. The high chloride results are suspected to be from a chloride contamination introduced during processing in the hot cell. Reanalysis of the blank spike produced good recovery for phosphate (i.e., 101\%), but produced the same high chloride recovery (i.e., 197\%). Since the source of the blank spike contamination can not be determined, the reported chloride results may be higher than the actual chloride sample concentration.

System Blank/Processing Blanks: Four system blanks were process during the analysis of the slurry samples. No anions were detected in the system blanks above the estimate quantitation level.

Quality Control Calibration Verification Check Standards: Four mid-range verification standards were analyzed throughout the analysis runs. Except for two chloride, one nitrite, and one nitrate result, the reported results for all anions of interest were recovered within the acceptance criteria of $90 \%$ to $110 \%$ for the verification standard. For those result outside the acceptance criteria, no results had recovery less than $88 \%$, and therefore these results should have little, if any, effect on the reported slurry sample results.

\section{Q.C. Comments for Liquids Analyses (March 15, 2000):}

Duplicates: Although there is only one AZ-102 as received supernatant sample (00-0902), two samples were extracted from the supernatant sample in the hot cells and transferred to the IC workstation for analysis. The samples were treated as duplicates. The RPDs for the measured anion are less than $10 \%$ and are well within the acceptance criteria of $20 \%$.

Matrix Spike: Two matrix spikes were prepared from the AZ-102 as received sample (00-0902) after the sample was delivered to the IC Workstation. No attempt to spike the supernatant in the 


\section{Battelle PNNL/RPG/Inorganic Analysis --- IC Report}

hot cells was made. All anion recoveries for all anions were within the $75 \%$ to $125 \%$ recovery acceptance criteria.

Blank Spike: No blank spikes were prepared in the hot cells. However, the working spike (i.e., the spike solution used to prepare the matrix spike samples) was measured at the same time as the Matrix Spike samples. One working spike analysis produced higher than expected recoveries for bromide and nitrate. Repeating the working spike analysis produced recoveries within the acceptance criteria of $90 \%$ to $110 \%$ recovery.

System Blank/Processing Blanks: Thirteen system blanks were processed during the analysis of the liquid samples. Other than three oxalate system blanks, no anions were detected in the system blanks above the estimate quantitation level. The low level of oxalate detected in the system blank has not affect on the reported oxalate values.

Quality Control Calibration Verification Check Standards: Eleven mid-range verification standards were analyzed throughout the analysis runs. For most of the anions recoveries were within the acceptance criteria from $90 \%$ to $110 \%$ for the verification standard. Two nitrite results, two phosphate results and one fluoride result recovered below the $90 \%$ lower limit; however these recoveries were all greater than $85 \%$. A single fluoride result recovered at about $60 \%$, well below the acceptance criteria. In general the reported fluoride results should be considered qualitative. Not only do the samples appear to adversely affect the column, there appears to be significant interferences in the fluoride region of the chromatograms (possibly from organic anions).

\section{General Comments:}

- The reported "Final Results" have been corrected for all dilution performed on the sample during processing or analysis.

- The low calibration standards are defined as the estimated quantitation limit (EQL) for the reported results and assume non-complex aqueous matrices. Actual detection limits or quantitation limits for specific sample matrices may be determined, if requested.

- Routine precision and bias are typically $\pm 15 \%$ or better for non-complex aqueous samples that are free of interference and have similar concentrations as the measured anions.

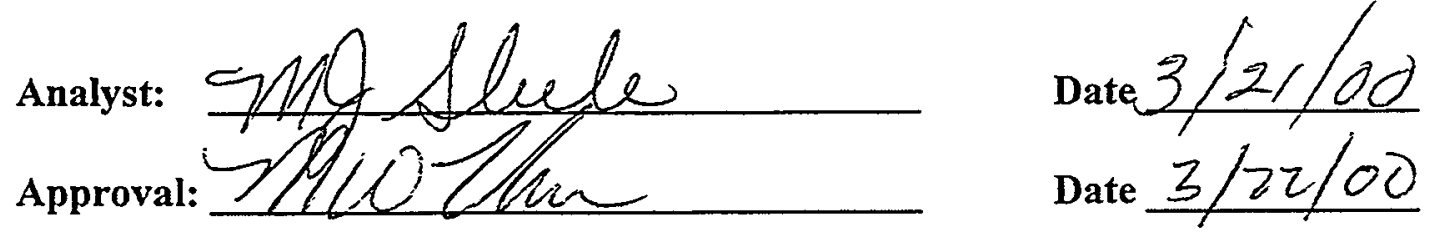

Archive Information: 


\section{Battelle PNNL/RPG/Inorganic Analysis -.- TOC/TIC Report}

Client: $\quad$ K. Brooks

ACL Numbers: 00-0902 to 00-0916

Analyst:

MJ Steele
Charge Code/Project:

ASR Number:

Analysis Date:
W45577 / 29953

5667 and 5668

April 5 and 7,2000

Procedure: PNL-ALO-381, "Direct Determination of TC, TOC, and TIC in Radioactive Sludges and Liquids by Hot Persulfate Method"

M\&TE: $\quad$ Carbon System (WA92040); Balance (360-06-01-023).

\section{Final Results:}

\begin{tabular}{|c|c|c|c|c|c|c|c|c|}
\hline \multicolumn{9}{|c|}{ SIurry Samples } \\
\hline Lab Number & Sample ID & $\begin{array}{c}\mathbf{W t} \\
\mathrm{g}\end{array}$ & $\begin{array}{c}\mathrm{TIC} \\
\mu \mathrm{g} \mathrm{C} / \mathrm{g}\end{array}$ & $\begin{array}{c}\text { TIC RPD } \\
\%\end{array}$ & $\begin{array}{c}\text { TOC } \\
\mu \mathrm{g} \mathrm{C/g}\end{array}$ & $\begin{array}{c}\text { TOC RPD } \\
\%\end{array}$ & $\begin{array}{c}\mathrm{TC} \\
\mu \mathrm{g} \mathrm{C} / \mathrm{g}\end{array}$ & $\begin{array}{c}\text { TC RPD } \\
\%\end{array}$ \\
\hline 00-0902 Dup & AZ-102 MU (As Received) Dup & 0.1254 & 7,240 & & 760 & & 8,000 & \\
\hline $00-0902$ & AZ-102 MU (As Received) & 0.2004 & 8,740 & 19 & 760 & 1 & 9,500 & 17 \\
\hline $00-0909$ & CUF-AZ102-007 & 0.1875 & 560 & & 610 & & 1,170 & \\
\hline $00-0911$ & CUF-AZ102-010 & 0.1041 & 11,200 & & 780 & & 11,980 & \\
\hline $00-0912$ & CUF-AZ102-011 & 0.1368 & lost & & 2,790 & & $n / a$ & \\
\hline $00-0915$ & CUF-AZ102-023 & 0.1441 & 2,910 & & 2,710 & & 5,620 & \\
\hline $00-0915 \mathrm{MS}$ & CUF-AZ102-023 MS & 0.1150 & $94.4 \%$ & & $96.2 \%$ & & $95.1 \%$ & \\
\hline $00-0916$ & CUF-AZ102-026 & 0.1663 & 2,820 & & 2,790 & & 5,610 & \\
\hline
\end{tabular}

\section{Liquid Samples}

\begin{tabular}{|c|c|c|c|c|c|c|c|c|}
\hline Lab Number & Sample ID & $\begin{array}{l}\text { Vol } \\
\mathrm{ml}\end{array}$ & $\begin{array}{c}\text { TIC } \\
\mu \mathrm{g} \mathrm{C} / \mathrm{ml}\end{array}$ & $\begin{array}{c}\text { TIC RPD } \\
\%\end{array}$ & $\begin{array}{c}\text { TOC } \\
\mu \mathrm{g} \mathrm{C} / \mathrm{ml}\end{array}$ & $\begin{array}{c}\text { TOC RPD } \\
\%\end{array}$ & $\begin{array}{c}\mathrm{TC} \\
\mu \mathrm{g} \mathrm{C} / \mathrm{ml}\end{array}$ & {$\left[\begin{array}{c}\text { TC RPD } \\
\%\end{array}\right.$} \\
\hline $00-0903$ & AZ-102 M Sup (As Received) & 0.10 & 8,670 & & 1,200 & & 9,870 & \\
\hline 00-0903 Dup & AZ-102 M Sup (As Received) Dup & 0.20 & 8,570 & 1 & 930 & 25 & 9,500 & 4 \\
\hline $00-0903 \mathrm{MS}$ & AZ-102 M Sup (As Received) MS & 0.10 & $99.4 \%$ & & $87.6 \%$ & & $93.7 \%$ & \\
\hline $00-0904$ & CUF-AZ102-001 Filtrate 1 & 0.50 & 1,070 & & 120 & & 1,190 & . \\
\hline 00-0904 Dup & CUF-AZ102-001 Filtrate 1 Dup & 0.30 & 1,070 & 0 & $<60$ & $\mathrm{n} / \mathrm{a}$ & 1,070 & 11 \\
\hline $00-0905$ & CUF-AZ102-003 Fitrate 2 & 0.50 & 1,100 & & 140 & & 1,240 & \\
\hline 00-0905 Dup & CUF-AZ102-003 Fitrate 2 Dup & 0.30 & 1,120 & 2 & 60 & $\mathrm{n} / \mathrm{a}$ & 1,180 & 5 \\
\hline 00-0906 & CUF-AZ102-015 Wash 1 & 0.50 & 790 & & 50 & & 840 & \\
\hline 00-0906 Dup & CUF-AZ102-015 Wash 1 Dup & 0.20 & 510 & 42 & $<90$ & $\mathrm{n} / \mathrm{a}$ & 510 & 48 \\
\hline $00-0907$ & CUF-AZ102-017 Wash 2 & 0.50 & 430 & & 40 & & 470 & \\
\hline 00-0907 Dup & CUF-AZ102-017 Wash 2 Dup & 0.30 & 430 & 1 & $<60$ & $n / a$ & 430 & 9 \\
\hline $00-0908$ & CUF-AZ102-019 Wash 3 & 0.50 & 420 & & $<40$ & & 420 & \\
\hline 00-0908 Dup & CUF-AZ102-019 Wash 3 Dup & 0.18 & 430 & 2 & $<100$ & $\mathrm{n} / \mathrm{a}$ & 430 & 2 \\
\hline $00-0910$ & CUF-AZ102-009 Caustic Leach & 0.50 & 890 & & $<40$ & & 890 & \\
\hline 00-0910 Dup & CUF-AZ1 02-009 Caustic Leach Dup & 0.20 & 910 & 1 & $<90$ & $n / a$ & 910 & 1 \\
\hline $00-0913$ & CUF-AZ102-013 Caustic Wash 1 & 0.50 & 3,090 & & 570 & & 3,660 & \\
\hline 00-0913 Dup & CUF-AZ102-013 Caustic Wash 1 Dup & 0.10 & 3,160 & 2 & 590 & $\mathrm{n} / \mathrm{a}$ & 3,750 & 2 \\
\hline $00-0914$ & CUF-AZ102-022 Caustic Wash 2 & 0.50 & 640 & & 50 & & 690 & \\
\hline 00-0914 Dup & CUF-AZ102-022 Caustic Wash 2 Dup & 0.30 & 650 & 3 & 70 & $\mathrm{n} / \mathrm{a}$ & 720 & 5 \\
\hline
\end{tabular}

$\mathrm{RPD}=$ Relative Percent Difference (between sample and duplicate/replicate); calculated from unrounded data. 


\section{Battelle PNNL/RPG/Inorganic Analysis --- TOC/TIC Report}

The analyses of the samples submitted under ASRs 5667 and 5668 were performed by the hot persulfate wet oxidation method. The hot persulfate method uses acid decomposition for TIC and acidic potassium persulfate oxidation at $92-95^{\circ} \mathrm{C}$ for $\mathrm{TOC}$, all on the same sample, with $\mathrm{TC}$ being the sum of the TIC and TOC.

The table above shows the results, rounded to two to three significant figures. The raw data bench sheets and calculation work sheets showing all calculations are attached. All sample results are corrected for average percent recovery of system calibration standards and are also corrected for contribution from the blank.

\section{Q.C. Comments:}

The TIC standard is calcium carbonate and TOC standard is $\alpha$-Glucose (the certificates of purity are attached). The standard materials were used in solid form for system calibration standards as well as matrix spikes. TIC and TOC percent recovery are determined using the appropriate standard (i.e., calcium carbonate for TIC or glucose for TOC) in either solid or liquid form.

The QC for the methods involves calibration blanks, system calibration standards, sample duplicates, and one matrix spike per matrix type.

April 5, 2000 QC

Calibration Standards: The QC system calibration standards were all within acceptance criteria of $90 \%$ to $110 \%$, with the average recovery being about $95 \%$ for TIC and $95 \%$ for TOC.

Calibration Blanks: The four calibration blanks run at the beginning, middle, and end of the analysis run were acceptable, averaging about $11 \mu \mathrm{gC}$ TIC and $33 \mu \mathrm{gC} \mathrm{TOC}$. These calibration/system blanks are considered good and the standard deviations for the TIC and TOC blanks is within the historical pooled standard deviation used to establish the method detection limits.

Duplicates: The precision between the duplicates, as demonstrated by the Relative Percent Difference (RPD), is acceptable. The RPDs for sample 00-0902 (AZ-102 as received) are within the acceptance criteria of $20 \%$. However, the relatively high RPDs (i.e., $19 \%$ for TIC and $17 \%$ for TOC) most likely indicate difficulties in obtaining representative "slurry" samples.

Matrix Spike: The accuracy of the carbon measurements can be estimated by the recovery results from the matrix spike. A matrix spike was prepared from sample 00-0915 (CUF-AZ102-023). The matrix spike demonstrated recoveries of about $94 \%$ for TIC and $96 \%$ for TOC; well within the acceptance criteria of $75 \%$ to $125 \%$ recovery.

April 7, 2000 QC

Calibration Standards: The QC system calibration standards were all within acceptance criteria, with the average recovery being about $99 \%$ for TIC and $97 \%$ for TOC. This is well within the acceptance criteria of $90 \%$ to $110 \%$.

Calibration Blanks: The four calibration blanks run at the beginning, middle, and end of the analysis run were acceptable, averaging about $18 \mu \mathrm{gC}$ TIC and $58 \mu \mathrm{gC}$ TOC. These 


\section{Battelle PNNL/RPG/Inorganic Analysis --- TOC/TIC Report}

calibration/system blanks are considered good and the standard deviations for the TIC and TOC blanks is within the historical pooled standard deviation used to establish the method detection limits.

Duplicates: The precision between the duplicates, as demonstrated by the Relative Percent Difference (RPD), is very good except for sample 00-0906 (CUF-AZ102-015). The RPDs for most samples are within the acceptance criteria of 20\%. Sample 00-0906 demonstrated an RPD of $42 \%$ to $48 \%$. Other than sample heterogeneity or undetected analysis error, no explanation can be offered for the poor precision.

Matrix Spike: The accuracy of the carbon measurements can be estimated by the recovery results from the matrix spike. A matrix spike was prepared from sample 00-0902 (AZ-102 as received). The matrix spike demonstrated recoveries of about $99 \%$ for TIC and $88 \%$ for TOC; well within the acceptance criteria of $75 \%$ to $125 \%$ recovery.

\section{General Comments:}

- The reported "Final Results" have been corrected for all dilution performed on the sample during processing or analysis.

- Routine precision and bias are typically $\pm 15 \%$ or better for non-complex samples that are free of interferences.

- The estimated quantitation limit (EQL) is defined as 5 times the MDL. Results less than 5 times the MDL have higher uncertainties, and RPDs are not calculated for any results less than 5 times the MDL.

- Some results may be reported as less than ("<") values. These less than values represent the sample MDL (method detection limit), which is the system MDL adjusted for the volume of sample used for the analysis. The system MDL is based on the attached pooled historical blank data. The evaluation and calculation of the system MDL is included in the data package.

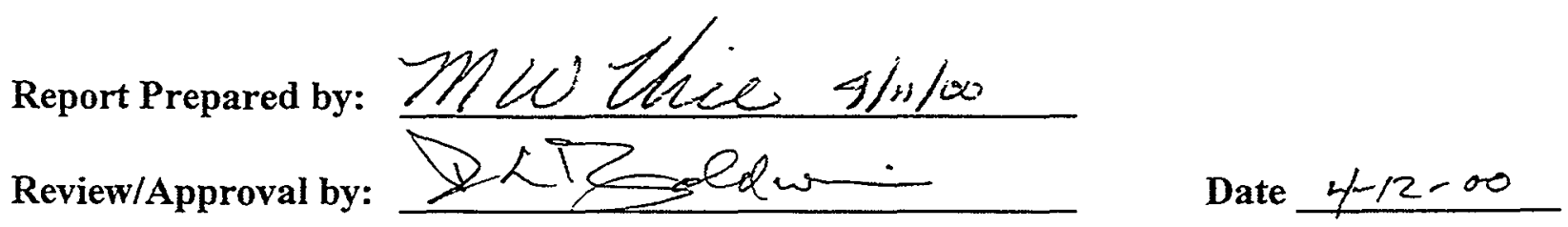

Archive Information:

Files: ASR 56675668 Brooks.doc ASR 5644566756685744 Liq + Solids.xls 
Project No. 29953

Internal Distribution

Date March 17, 2000

To Kriston Brooks

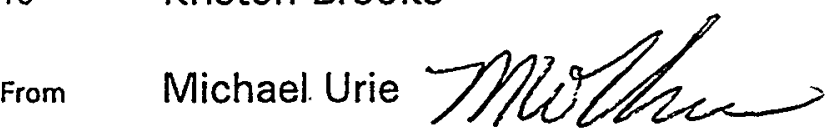

Subject Cyanide Results for As Received AZ-102 Samples and CUF-AZ102 Samples

Table 1: Slurry Samples

\begin{tabular}{|c|c|c|c|c|c|c|c|}
\hline \multirow[b]{2}{*}{ Lab \# } & \multirow[b]{2}{*}{ Client ID } & \multicolumn{2}{|c|}{ ( $\mu \mathrm{g} \mathrm{CN} / \mathrm{g}$ Slurry) } & \multirow{2}{*}{$\begin{array}{c}\text { RPD } \\
\operatorname{Rec}(\%)\end{array}$} & \multirow{2}{*}{$\begin{array}{l}\text { Rec. } \\
(\%)\end{array}$} & \multicolumn{2}{|c|}{ ug CN / g dry solids } \\
\hline & & Sample & Dup & & & Sample & Dup \\
\hline $00-0902 \mathrm{CB}$ & Hot Cell Blank & $<0.2$ & -- & - & -- & $\cdots$ & - \\
\hline $00-0902$ & AZ102 As Rec Slurry & 5.6 & 5.7 & 2.6 & -- & 13.4 & 13.6 \\
\hline $00-0909$ & CUF-AZ-102-007 & 1.0 & 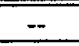 & -- & - & 8.8 & - \\
\hline $00-0911$ & CUF-AZ-102-010 & 0.90 & -- & - & -- & 5.0 & - \\
\hline $00-0912$ & CUF-AZ-102-011 & 0.92 & - & - & - & 5.0 & - \\
\hline $00-0915$ & CUF-AZ-102-023 & 0.87 & -- & - & - & 8.3 & - \\
\hline $00-0916$ & CUF-AZ-102-026 & 0.89 & - & - & -- & 8.3 & - \\
\hline 00-0916 Spike & CUF-AZ-102-026 Spike & - & -- & - & 68 & - & - \\
\hline
\end{tabular}

Table 2: Supernate, Filtrate and Wash Samples

\begin{tabular}{|c|c|c|c|c|c|}
\hline \multirow[b]{2}{*}{ Lab \# } & \multirow[b]{2}{*}{ Client ID } & \multicolumn{2}{|c|}{$(\mu \mathrm{g} \mathrm{CN} / \mathrm{mL})$} & \multirow{2}{*}{$\begin{array}{c}\text { RPD } \\
\operatorname{Rec}(\%)\end{array}$} & \multirow{2}{*}{$\begin{array}{l}\operatorname{Rec} \\
(\%) \\
\end{array}$} \\
\hline & & Sample & Dup & & \\
\hline $00-0903 \mathrm{CB}$ & Hot Cell Blank & $<0.03$ & $\therefore$ & -- & -- \\
\hline $00-0903$ & AZ102 As Rec Supernate & lost & 9.6 & $n / a$ & - \\
\hline 00-0903 Spike & AZ102 As Rec Supernate Spike & - & -- & -- & 94 \\
\hline $00-0904$ & CUF-AZ-102-001 & 3.3 & -- & - & - \\
\hline $00-0905$ & CUF-AZ-102-003 & 3.2 & - & - & - \\
\hline $00-0906$ & CUF-AZ-102-015 & 3.1 & -- & -- & -. \\
\hline $00-0907$ & CUF-AZ-102-017 & 2.4 & - & - & -- \\
\hline $00-0908$ & CUF-AZ-102-019 & 2.3 & -- & - & -- \\
\hline 00.0910 & CUF-AZ-102-009 & 1.7 & - & $-\cdots$ & -- \\
\hline $00-0913$ & CUF-AZ-102-013 & 1.8 & - & 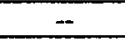 & -- \\
\hline $00-0914$ & CUF-AZ-102-022 & 1.0 & - & - & -- \\
\hline
\end{tabular}

The $C N$ results for $A Z-102$ As Received samples and the CUF AZ-102 samples analyzed on March 9-10, 2000 per ASR 5667 (as received) and ASR 5668 (CUF) are reported in the Tables 1 and 2 above. The samples were weighed in the Shielded Analytical Laboratory and delivered, ready for distillation, to Laboratory 400 in the Radiochemical Processing Laboratory. The samples were distilled with the addition of sulfamic acid to ensure there would be no interference if nitrates were present in the sample. The samples were analyzed using a Lachat QuickChem AE Autoanalyzer (WC36517). The reporting limits are estimated to be approximately $0.2 \mu \mathrm{g} \mathrm{CN} / \mathrm{g}$ (for solids/slurries) or $0.03 \mu \mathrm{g} \mathrm{CN} / \mathrm{mL}$ (for liquids). 


\section{Kriston Brooks}

March 17, 2000

Page 2

An independent mid-range calibration check solution run at the beginning, middle, and end of the analysis batches gave an average recovery of $99 \%$ over the two days of analysis. These calibration check standards ranged from $92 \%$ recovery to $106 \%$ recovery which is within the $85 \%$ to $115 \%$ acceptance criteria. A solid laboratory control standard (ERA-LSC) was analyzed at $178 \mu \mathrm{g} / \mathrm{g}$, well within the certified advisory range of 77 to $301 \mu \mathrm{g} / \mathrm{g}$.

A liquid sample (00-0903 AZ-102 As Received) and a slurry sample (00-0916

CUF-AZ-102-026) were spiked with CN. The spike recovery for the liquid sample was within the acceptance criteria of $75 \%$ to $125 \%$; however, the spike recovery for the slurry sample did not meet this criterion. Since the $\mathrm{CN}$ concentration of the slurry is reasonably low, the poor recovery is not due to sampling heterogeneity. The slurry concentration is less than $10 \%$ of the expected concentration of the spiked slurry sample and sampling heterogeneity should have little effect on the measured spike concentration. A blank spike at the same concentration as the slurry matrix spike measured $92 \%$. Other than potential matrix interferences or reactions, no explanation is offered for the poor slurry spike recovery.

One liquid sample and one slurry sample per batch were analyzed in duplicate. The Relative - Percent Difference (RPD, precision) could not be calculated for the liquid sample since one of the samples was inadvertently lost. The RPD for the slurry samples was $2.6 \%$, well within the acceptance criteria of $20 \%$.

All sample preparation sheets, standard preparation information, and analytical data are included with this report. 
WO/Project:

Client:
W45577/29953

K. Brooks

\section{ACL Numbers: 00-00902, 00-00903, 00-00915 \& 00-00916 \\ ASR Number 5667, 5668}

Procedure: PNNL-ALO-131, "Mercury Digestion"

PNNL-ALO-201, "Mercury Analysis"

Analyst: J. J. Wagner

Digestion Date: March 14, $2000 \quad$ Analysis Date: March 15, 2000

M\&TE: Hg system (WD14126); Mettler AT400 Balance (360-06-01-029).

See Chemical Measurement Center 98620 RIDS for Hg File for Calibration, Standards

Preparations, and Maintenance Records.

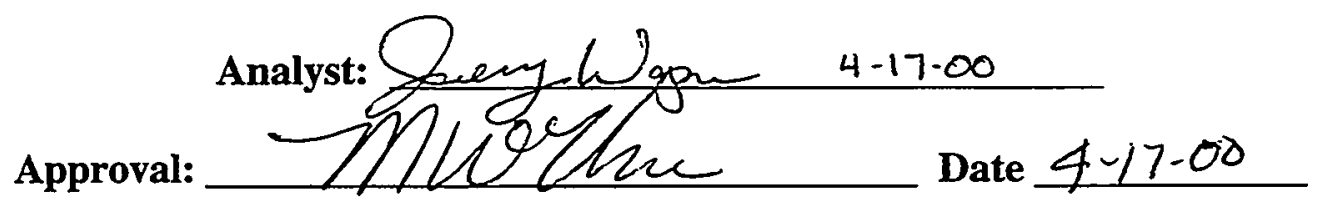

\section{Final Results:}

The samples were analyzed by cold vapor atomic absorption spectrophotometry for inorganic mercury as specified in ASR 5667,5668. Approximately 0.09 to $0.19 \mathrm{~g}$ weight of wet slurry and approximately $0.1 \mathrm{~g}$ weight of supernatant liquid samples were processed and diluted to a final volume of $25 \mathrm{ml}$ per procedure ALO-131. Additional analytical dilution of 3 to 10 -fold was necessary for some samples. The mercury concentration results are presented in the table below. 


\begin{tabular}{|c|c|c|c|c|c|c|c|c|}
\hline Faform, i & Solfig ample fo & 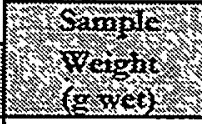 & Figeston & 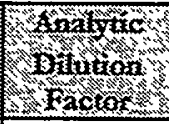 & 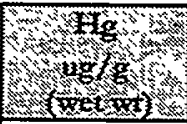 & 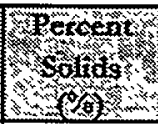 & 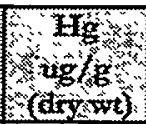 & $\begin{array}{l}\mathrm{KPD} \\
\mathrm{q}\end{array}$ \\
\hline $00-00902 \mathrm{CB}$ & Cell Blank & 0.1650 & 151.5 & 1 & $<0.02$ & & & \\
\hline $00-00902$ & AZ102 MU & 0.1947 & 128.4 & 10 & 7.56 & 41.76 & 18.1 & \\
\hline $00-00902 \mathrm{D}$ & AZ102 MU & 0.1299 & 192.5 & 10 & 8.37 & 41.76 & 20.0 & 10 \\
\hline $00-00915^{*}$ & CUF-AZ102-023 & 0.0905 & 276.2 & 3 & 2.78 & 10.44 & 26.6 & \\
\hline $00-00916^{*}$ & CUF-AZ102-026 & 0.1101 & 227.1 & 5 & 2.83 & 10.69 & 26.5 & 0.4 \\
\hline
\end{tabular}

\begin{tabular}{|c|c|c|c|c|c|c|}
\hline Gam & 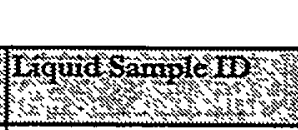 & Ko stiple & Afgesforl & 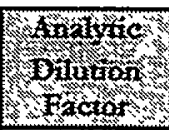 & 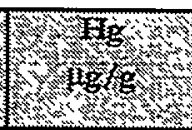 & $\begin{array}{l}\text { RPD } \\
(x) \\
(\alpha)\end{array}$ \\
\hline $00-00903 \mathrm{CB}$ & Cell Blank & 0.0974 & 256.7 & 1 & 0.08 & \\
\hline $00-00903$ & AZ102 M SUP & 0.1120 & 223.2 & 1 & 0.21 & \\
\hline 00-00903D & AZ102 M SUP & 0.1089 & 229.6 & 1 & 0.16 & $\mathrm{~N} / \mathrm{A}$ \\
\hline
\end{tabular}

RPD $=$ Relative Percent Difference (between sample and duplicate/replicate)

N/A $=$ RPD is not calculated when results are less than $5 \times$ IDL

“*” Field duplicate samples

\section{Notes:}

1) "Final Results" have been corrected for all dilution performed on the sample during processing or analysis.

2) The low calibration standard is defined as the estimated detection limit (IDL) for the reported results and assumes non-complex aqueous matrices. Actual detection limits or quantitation limits for specific sample matrices may be determined, if requested.

3) Routine precision and bias is typically $\pm 15 \%$ or better for non-complex aqueous samples that are free of interference.

\section{Q.C. Comments:}

Following are results of quality control checks performed during $\mathrm{Hg}$ analyses. In general, quality control checks met the requirements of the governing QA Plan.

Working Blank Spike/Process Blank Spike: Process Blank Spike recovery is $96 \%$ and $95 \%$, well within the acceptance criteria of $80 \%$ to $120 \%$.

Matrix Spiked Sample: A matrix spike was prepared for the slurry and supernatant samples submitted under ASR-5667 and ASR-5668. However, recovery of the matrix spike (45\% \& 55\%) fell below the acceptance criteria of $75 \%$ to $125 \%$. Failure of the matrix spike recover may have been caused by excess organic material present which would requiring more oxidizing reagent than specified in the digestion procedure.

Duplicate: Relative percent difference for duplicate wet slurry samples is within acceptance criteria of $\leq 20 \%$ RPD for RPL\# 00-00902, 00-00902D (10\% RPD) and RPL\# 00-00915 and 00-00916 field duplicate samples (0.4\%RPD). 
Laboratory Control Sample (solids): Sample recovery of mercury in SRM-2709 San Joaquin Valley Soil certified by NIST to contain $1.40 \pm 0.08 \mu \mathrm{g} / \mathrm{g}$ was recovered within acceptance criteria of $75 \%$ to $125 \%$.

Laboratory Control Sample (liquids): Sample recovery of mercury in SRM-1641c "Mercury in $\mathrm{H}_{2} \mathrm{O}$ " certified by NIST to contain $1.47 \mu \mathrm{g} / \mathrm{ml}$ was recovered (35\% and $49 \%$ ) below acceptance criteria of $75 \%$ to $125 \%$. NIST originally specified an expiration date of 1 year from date of delivery (Dec. 1, 1997) but had extended the expiration date until May 4, 2000. Perhaps the standard was too old resulting in poor recovery. However, two blank spikes were processed similarly to the samples at the same time using NIST traceable certified standards from an alternate vendor, different than the calibration standards. The blank spike recoveries ( $96 \%$ and 95\%) were well within acceptance tolerance of $80 \%$ to $100 \%$ recovery indicating that sample preparation and analysis were acceptable.

Cell Blanks/Processing Blanks: A cell blank, consisting of an aliquot of water used in the hot cell, was processed at the same time as the samples. The concentration measured was less than two times detection limit. Some samples were about the same concentration as the process blank and other samples were many times this level.

Quality Control Calibration Verification Check Standards: Six mid-range verification standards were analyzed throughout the analysis run. All were within the acceptance criteria of $80 \%$ to $120 \%$ recovery for the verification standard. 
Date March 17, 2000

To K.P.Books

From

Subject

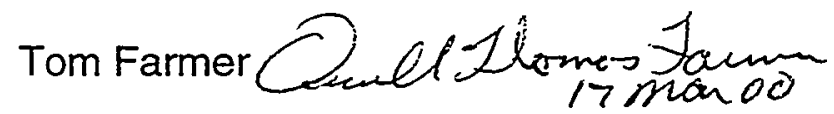

17 man 00
329/4 File

LSO Project File

Mike Urie

Pursuant to your request, the $6 \mathrm{Ni} / \mathrm{KOH}$ fusion samples that you submitted for analysis were analyzed by ICPMS for selected elements. The results of this analysis are reported on the attached page.

Johnson-Matthey standards for $\mathrm{Rb}, \mathrm{Ta}, \mathrm{Pr}$, and $\mathrm{Sn}$, an Amersham ${ }^{99} \mathrm{Tc}$ standard and Isotope Products ${ }^{129} \mathrm{I}$ and ${ }^{237} \mathrm{~Np}$ standards wereused to generate the calibration curves. Independent standards were used as the continuing calibration verification (CCV) standards.

Values for tin were obtained using the response of a natural tin standard. Interference corrections for ${ }^{126} \mathrm{Xe}$ and ${ }^{126} \mathrm{Te}$ were calculated. Because ${ }^{126} \mathrm{Sn}$ standards were not used and the concentrations were determined indirectly, these results shoud be considered semiquantitative.

The ${ }^{99} \mathrm{Tc}$ values reported assume that the Ru present is exclusively fission-product $R u$, and therefore does not have an isotope at $\mathrm{m} / \mathrm{z} 99$; i.e., everything observed at $\mathrm{m} / \mathrm{z} 99$ is due to ${ }^{99} \mathrm{Tc}$. The fingerprint we're seeing for Ru is obviously not natural, and is consistent with that observed in previous tank waste analyses.

No known cesium 135, 137 standard was available. Results reported are direct cesium ratios using natural barium standards for mass bias corrections.

If you have any questions regarding this analysis, feel free to call me at $372-0700$ or James Bramson at 372-0624 


\section{Brooks Analysis}

March 17, 2000

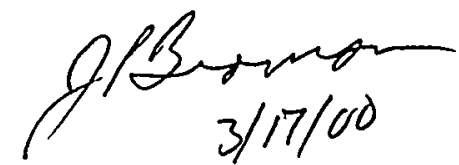

Results are reported in $\mu \mathrm{g}$ analyte/ $\mathrm{g}(\mathrm{ppm})$ of solid sample.

\begin{tabular}{|c|c|c|c|c|c|c|c|}
\hline $\begin{array}{l}\text { Sample } \\
\text { ID }\end{array}$ & $\begin{array}{l}\text { Client } \\
\text { ID }\end{array}$ & $\begin{array}{l}\text { ICP/MS } \\
\text { Number }\end{array}$ & $\begin{array}{l}\mathrm{Rb} \\
\mu \mathrm{g} / \mathrm{g} \quad \pm 1 \mathrm{SD}\end{array}$ & $\begin{array}{l}T C-99 \\
\mu \mathrm{g} / \mathrm{g} \pm 1 \mathrm{SD}\end{array}$ & $\begin{array}{c}\cdot S n-126 \\
\mu g / g\end{array}$ & $\begin{array}{c}+1-127 \\
\mu \mathrm{g} / \mathrm{g}\end{array}$ & $\begin{array}{c}+1-129 \\
\mu \mathrm{g} / \mathrm{g}\end{array}$ \\
\hline 00-00902-PB-Ni & PROCESS BLANK & $00208 b 16$ & $182 \pm 3$ & $1.0 \pm 0.1$ & $<0.9$ & $25 \pm 5$ & $<7.7$ \\
\hline $00-00902-\mathrm{Ni}$ & AZ102 MU & $00208 b 17$ & $244 \pm 3$ & $24.5 \pm 0.6$ & $<0.9$ & $23 \pm 4$ & $<3.9$ \\
\hline 00-00902-DUP-Ni & AZ102 MU & $00208 b 18$ & $219 \pm 4$ & $20.9 \pm 1.0$ & $<0.7$ & $18 \pm 1$ & $<3.1$ \\
\hline 00-00902 + spike & $A Z 102 \mathrm{MU}$ & $00210 a 16$ & & & & $41 \pm 10$ & $<4.0$ \\
\hline Spike Recovery & & & & & & $88 \%$ & \\
\hline $00-00915-\mathrm{Ni}$ & CUF-AZ102-023 & $00208 b 19$ & $230 \pm 6$ & $1.7 \pm 0.7$ & $<0.9$ & $14.7 \pm 0.1$ & $<2.5$ \\
\hline 00-00915-Ni Dup & CUF-AZ102-023 & $00208 b 20$ & $222 \pm 6$ & $1.7 \pm 0.2$ & $<0.9$ & & \\
\hline $00-00916-\mathrm{Ni}$ & CUF-AZ102-026 & $00208 b 21$ & $229 \pm 2$ & $1.4 \pm 0.1$ & $<0.9$ & $24 \pm 8$ & $<6.0$ \\
\hline $00-00916-\mathrm{Ni}+$ spike & CUF-AZ102-026 & $00208 b 22$ & $254 \pm 1$ & $4.8 \pm 0.6$ & & & \\
\hline Splike Recovery & & & $702 \%$ & $93 \%$ & & & \\
\hline SRM 2710 & LCS/00-00902/Ni & $00208 b 24$ & $334 \pm 9$ & $0.6 \pm 0.2$ & $<0.9$ & $11 \pm 1$ & $<2.4$ \\
\hline \multicolumn{8}{|c|}{ CCV and Blank results are reported in $n g / g(p p b)$} \\
\hline $\begin{array}{l}1 \% \text { HNO3 } \\
1 \% \text { HNO3 }\end{array}$ & & $\begin{array}{l}00208 b 1 \\
00208 b 15\end{array}$ & $\begin{array}{l}<0.03 \\
<0.02\end{array}$ & $\begin{array}{l}<0.02 \\
<0.02\end{array}$ & $\begin{array}{l}<0.06 \\
<0.06\end{array}$ & $\begin{array}{l}0.04 \pm 0.004 \\
0.04 \pm 0.02\end{array}$ & $\begin{array}{l}<0.2 \\
<0.1\end{array}$ \\
\hline $\begin{array}{l}\text { 5ppb Rb, Pr, Cs } \\
5 p p b \mathrm{Rb}, \mathrm{Pr}, \mathrm{Cs}\end{array}$ & & $\begin{array}{l}00208 \mathrm{~b} 12 \\
00208 \mathrm{~b} 27\end{array}$ & $\begin{array}{l}5.09 \pm 0.13 \\
5.12 \pm 0.12\end{array}$ & & & & \\
\hline $0.5 p p b$ Tc-99 & & $00208 b 14$ & & $0.515 \pm 0.049$ & & & \\
\hline $0.5 \mathrm{ppb}$ Tc-99 & & $00208 b 26$ & & $0.496 \pm 0.014$ & & & \\
\hline $1.0 p p b \quad 1-127$ & & $00210 a 15$ & & & & $0.87 \pm 0.02$ & \\
\hline $0.1 \mathrm{ppb} \mid-129$ & & $00210 a 11$ & & & & & $0.11 \pm 0.02$ \\
\hline 1ppb Ta/2ppb Np-237 & & $00209 a 3$ & & . & & & \\
\hline 1ppb Ta/2ppb Np-237 & & $00209 a 17$ & & & & & \\
\hline
\end{tabular}

${ }^{\star}$ Results are from procedure 00209a.

- Obtained using response of natural tin. Should be considered semiquantitative.

tResults are from procedure 00210a.

${ }^{*}$ Calculated value was greater than the detection limit, but less than the reporting limit.

$$
\begin{aligned}
& \text { Fic: } \quad 0 . T . J a m e r \\
& \text { Divi: } 17 \text { manoo, } \quad, \quad 10 / 3
\end{aligned}
$$




\section{Brooks Analysis}

March 17, 2000

Results are reported in $\mu \mathrm{g}$ analyte/ $\mathrm{g}(\mathrm{ppm})$ of solid sample

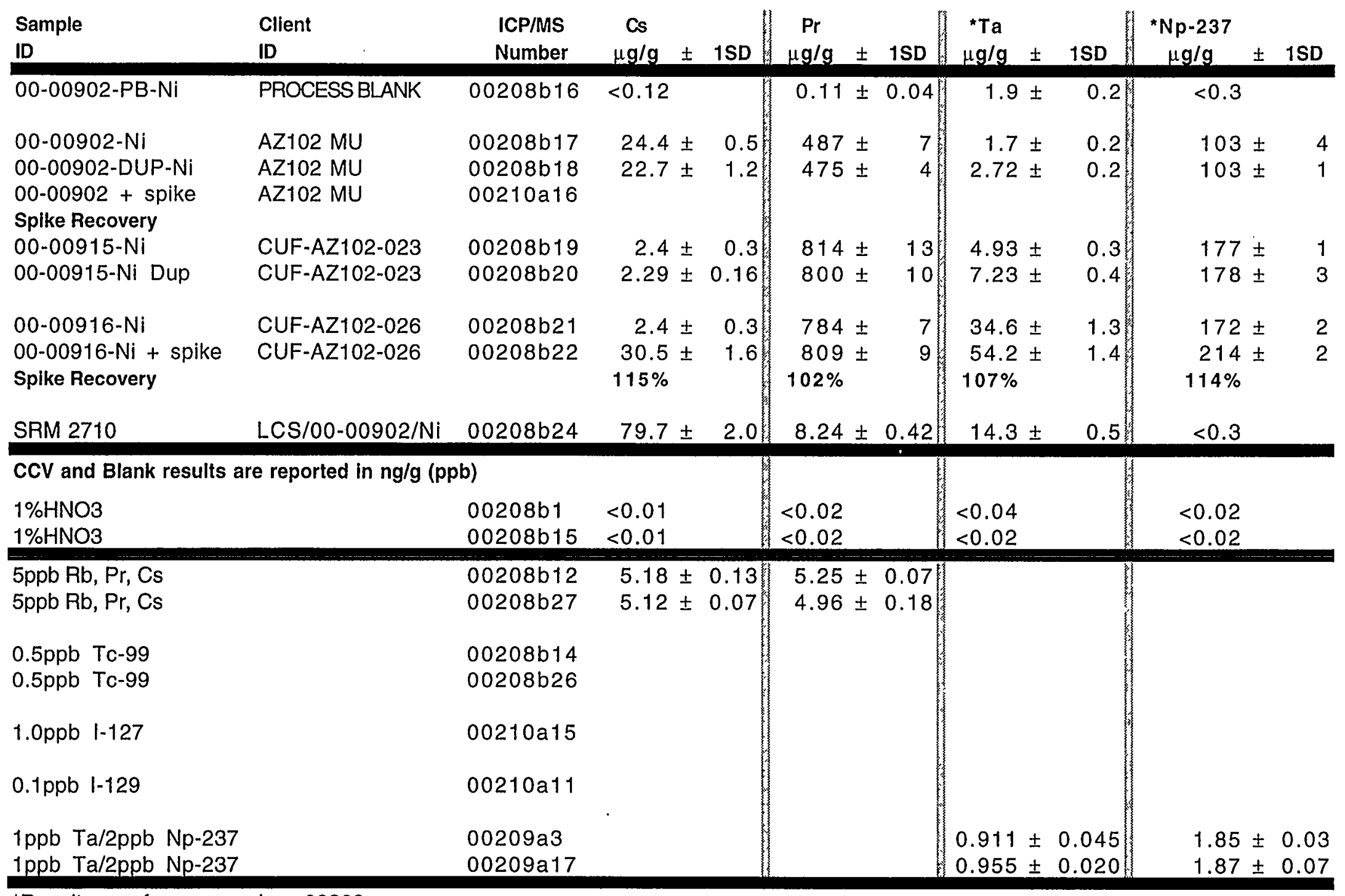

${ }^{\star}$ Results are from procedure 00209a.

-Obtained using response of natural tin. Should be conside

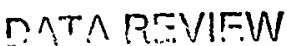

tResults are from procedure 00210a.

${ }^{\star \star}$ Calculated value was greater than the detection limit, bul

Fievis:. O.T. Formen__ 

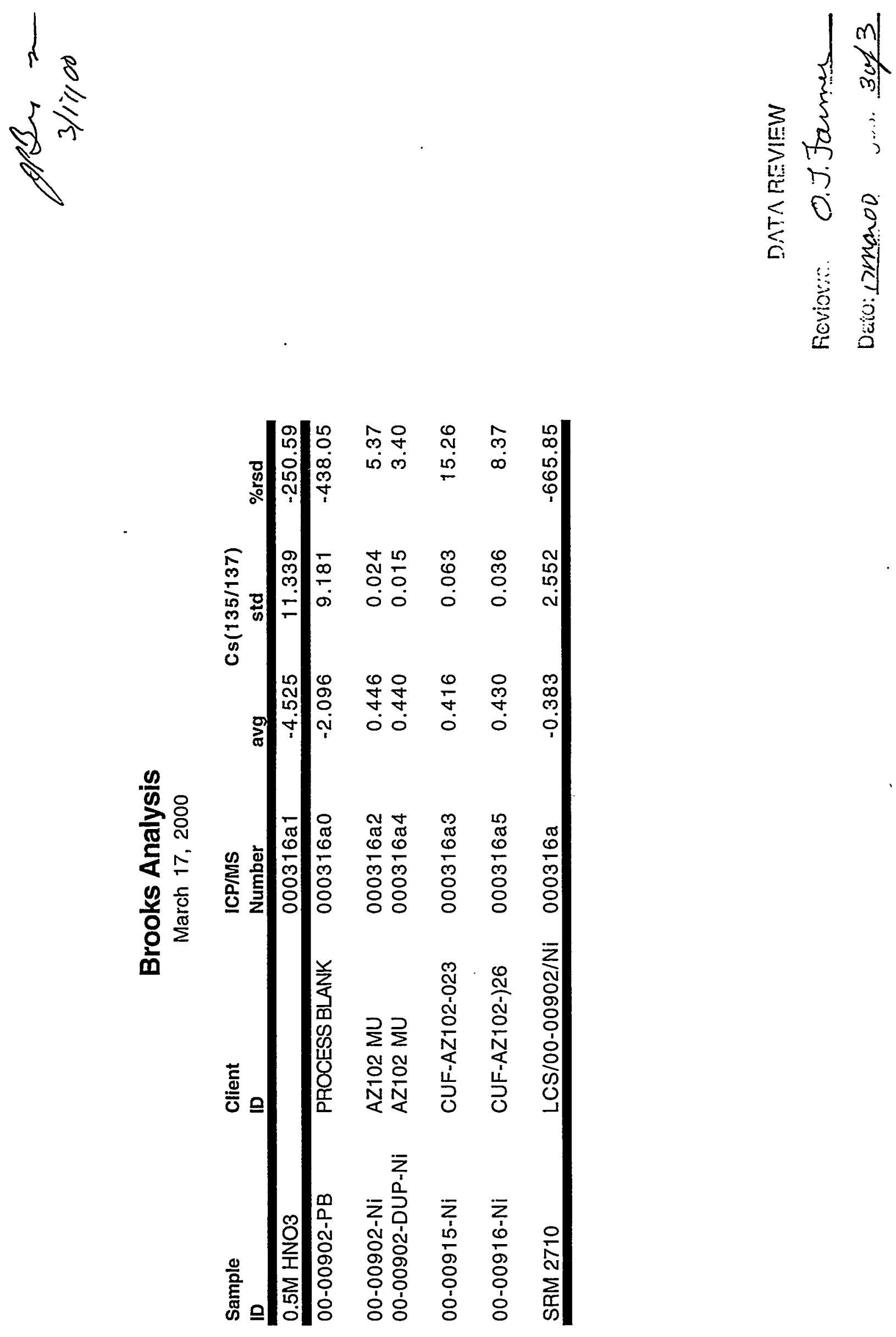


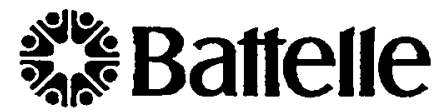

Project Number

Pacific Northwest Laboratories

Internal Distribution

Date March 31, 2000

329/4 File

To K.P.Books

LSO Project File

Mike Urie

From Tom FarmerC.J.Jamertr simawo

Subject $\quad$ ICP/MS Analysis of Submitted Samples

(ALO\#00-00903)

Pursuant to your request, the 5 acid digested samples that you submitted for analysis were analyzed by ICPMS for selected elements. The results of this analysis are reported on the attached page.

An Alfa Aesar cesium standard, Amersham ${ }^{99}$ Tc standard, Isotope Products ${ }^{129} \mathrm{I}$ and - ${ }^{237} \mathrm{~Np}$ standards and an ${ }^{127}$ I standard, prepared from Fisher potassium iodide (LOT\# 35260) were used to generate the calibration curves. Independent standards of each element were used as the continuing calibration verification (CCV) standards.

The ${ }^{99} \mathrm{Tc}$ values reported assume that the Ru present is exclusively fission-product $\mathrm{Ru}$, and therefore does not have an isotope at $\mathrm{m} / \mathrm{z} 99$; i.e., everything observed at $\mathrm{m} / \mathrm{z} 99$ is due to ${ }^{99} \mathrm{Tc}$. The fingerprint we're seeing for $\mathrm{Ru}$ is obviously not natural, and is consistent with that observed in previous tank waste analyses.

No known cesium 135, 137 standard was available. Results reported are direct cesium ratios using natural barium standards for mass bias corrections.

If you have any questions regarding this analysis, feel free to call me at 372-0700 or James Bramson at 372-0624 


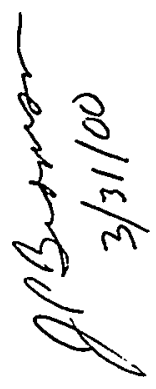

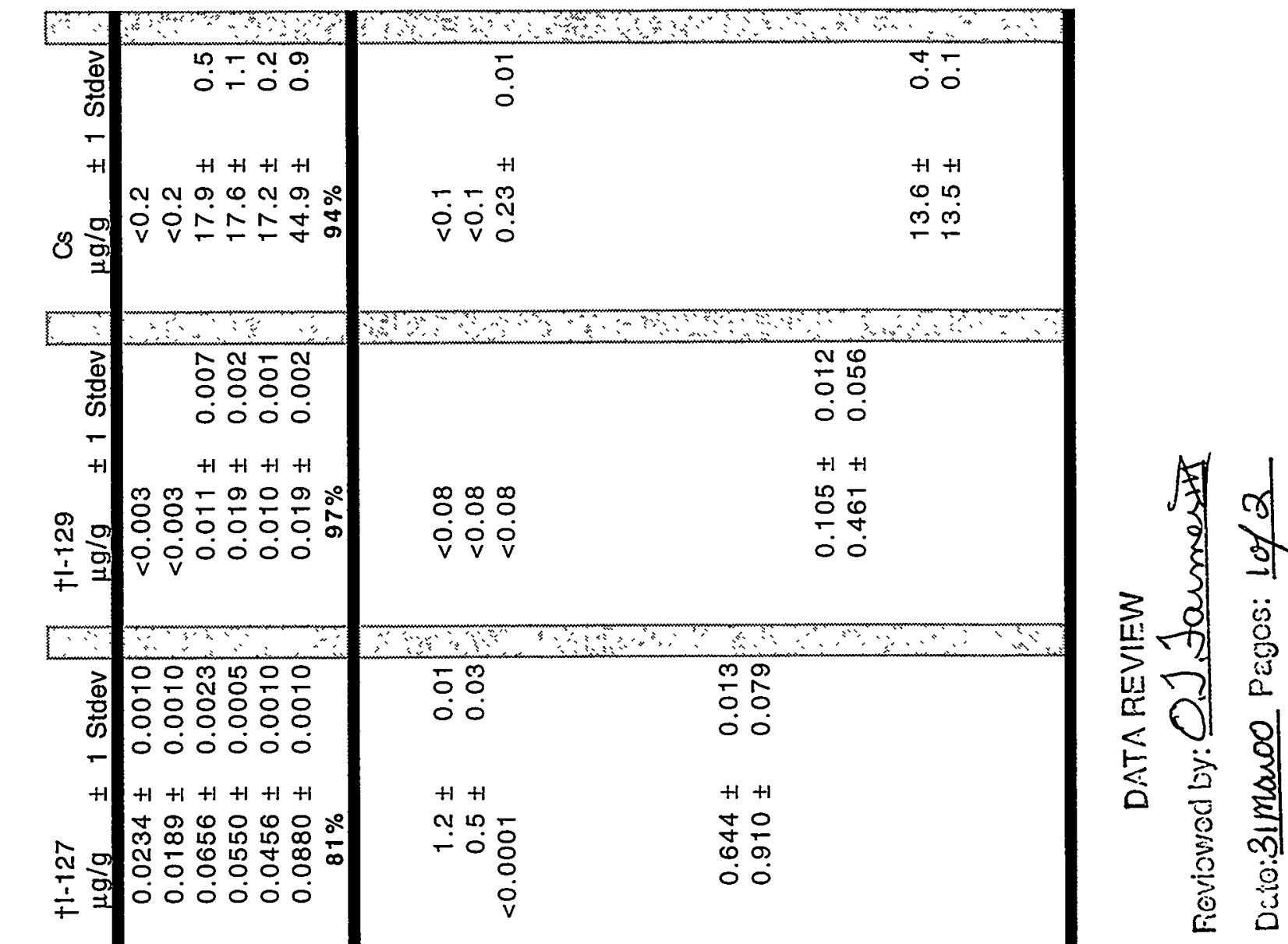




\section{K.P. Brooks Analysis}

March 30, 2000

Results are reported in $\mu \mathrm{g}$ analyte/g (ppm) of original sample.

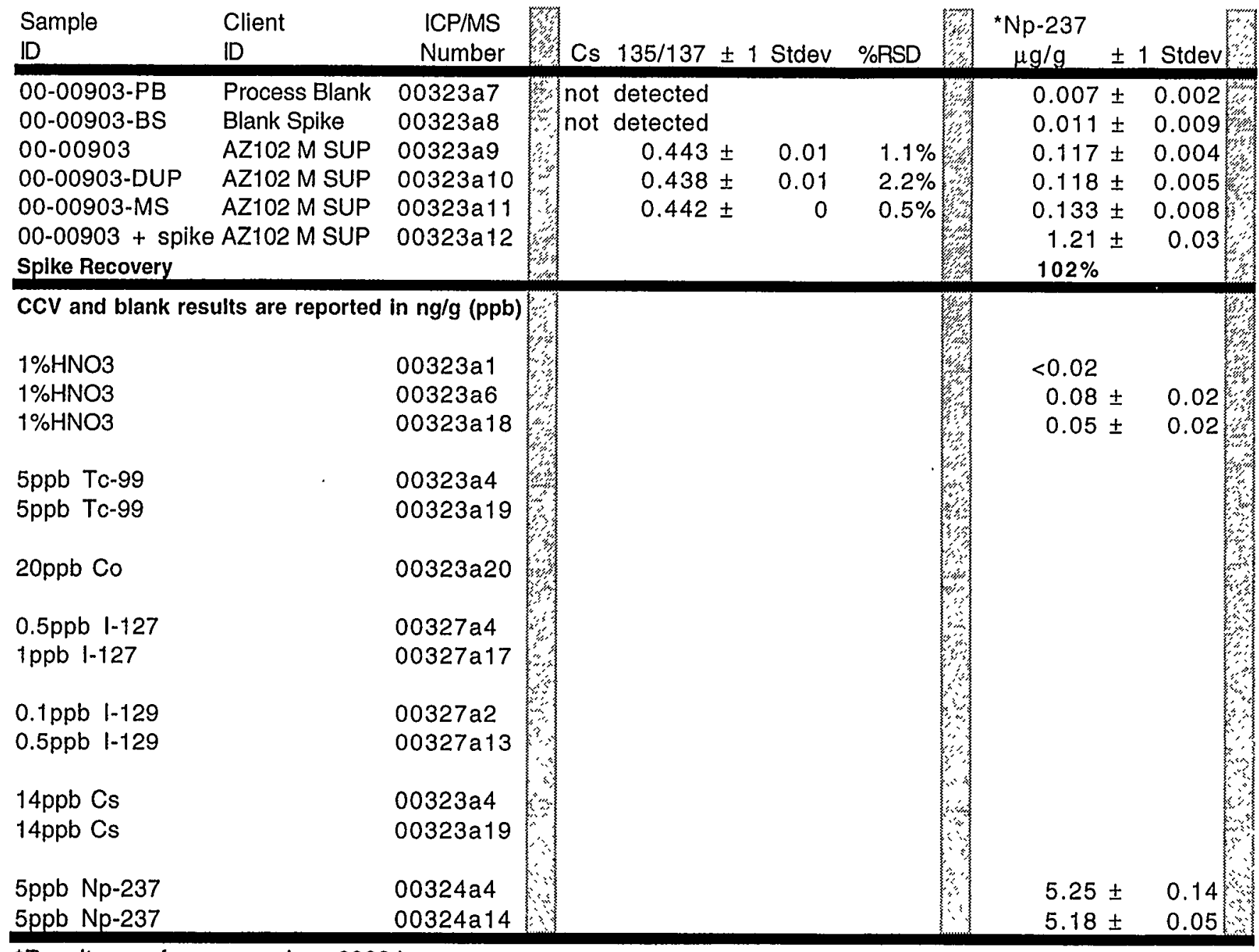

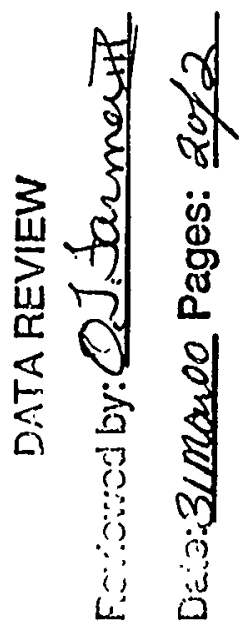

*Results are from procedure $00324 a$.

tResults are from procedure 00327 a. 
Date March 31, 2000

329/4 File

To K.P.Books

LSO Project File

Mike Urie

From Tom Farmer C. J Jarmestir 3imaroo

Subject ICP/MS Analysis of Submitted Samples

(ALO\#00-00902 PMG Fusions)

Pursuant to your request, the 6 fusion samples that you submitted for analysis were analyzed by ICPMS for platinum. The results of this analysis are reported on the attached page.

An Alfa Aesar platinum standard was used to generate the calibration curve and an - Independent CPI platinum standard was used as the continuing calibration verification (CCV) standard.

If you have any questions regarding this analysis, feel free to call me at 372-0700 or James Bramson at 372-0624 


\section{K.P. Brooks Platinum Analysis}

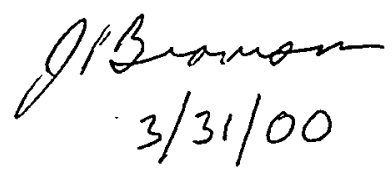

March 31, 2000

Results are reported in $\mu \mathrm{g}$ analyte/ $\mathrm{g}$ of original sample.

\begin{tabular}{|c|c|c|c|c|}
\hline $\begin{array}{l}\text { Sample } \\
\text { ID }\end{array}$ & $\begin{array}{l}\text { Client } \\
\text { ID }\end{array}$ & $\begin{array}{l}\text { ICPMS } \\
\text { Number }\end{array}$ & $\begin{array}{c}\mathrm{Pt} \\
\mu \mathrm{g} / \mathrm{g}\end{array}$ & \pm 1 Stdev \\
\hline $00-00902-\mathrm{PB}-\mathrm{Zr}$ & Process Blank & $00329 a 7$ & $<0.41$ & \\
\hline $00-00902-\mathrm{Zr}$ & AZ102 MU & $00329 a 9$ & $<0.41$ & \\
\hline 00-00902-DUP-Zr & AZ102 MU & $00329 a 10$ & $<0.39$ & \\
\hline $00-00915-\mathrm{Zr}$ & CUF-AZ102-023 & $00329 a 11$ & $<0.40$ & \\
\hline $00-00916-\mathrm{Zr}$ & CUF-AZ102-026 & $00329 a 12$ & $<0.38$ & \\
\hline $\begin{array}{l}\text { 00-00916 + spike } \\
\text { Spike Recovery }\end{array}$ & CUF-AZ102-026 & $00329 a 13$ & $\begin{array}{l}0.971 \pm \\
116 \%\end{array}$ & 0.036 \\
\hline
\end{tabular}

SRM 2710-Zr

LCS/00-00902/Zr

$00329 a 8$

$<0.34$

$\mathrm{CCV}$ and blank results are reported in $\mathrm{ng} / \mathrm{g}(\mathrm{ppb})$

$1 \%$ HNO3

$1 \% \mathrm{HNO} 3$

$1 \% \mathrm{HNO} 3$

$0.05 p p b P t$

$0.1 \mathrm{ppb} P \mathrm{Pt}$

$\begin{aligned} 00329 a 1 & <0.034 \\ 00329 a 6 & <0.030 \\ 00329 a 14 & <0.030\end{aligned}$

$00329 a 4$

0.0473

0.006 $00329 a 15$

0.005

\section{DATA REVIEW}

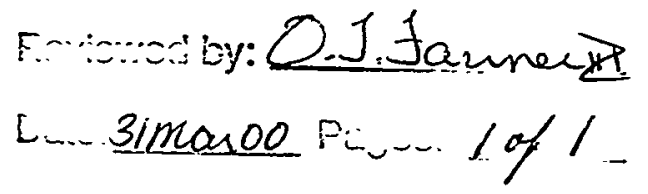


Battelle Pacific Northwest Laboratory

00-0902

Radiochemical Processing Group-325 Building

Chemical Measurements Center

$3 / 7 / 2000$

Client : Brooks

Cognizant Scientist:

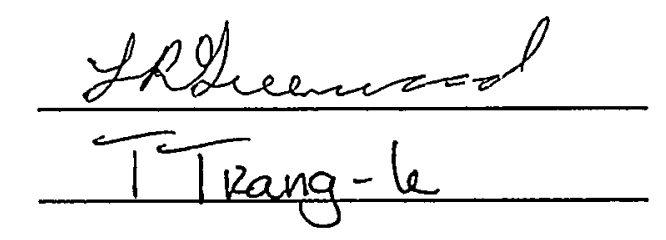

Date: $\quad 3-2-00$

Concur :

Date: $3 / 8 / 00$

Procedure: PNL-ALO-450

Equipment: Gamma detectors $\mathrm{G}$

Measured Activities ( $\mathrm{uCl} / \mathrm{g})$ with 1-sigma error

ALO ID

Client ID

00-0902 PB

Process Blank

00-0902

AZ102MU

00-0902 DUP

AZ102MU

00-0903 PB

Process Blank

00-0903

AZ102 M SUP

00-0903 DUP

AZ102 M SUP

\begin{tabular}{|c|c|c|c|c|c|c|}
\hline $\begin{array}{l}\text { Co-60 } \\
\text { Error \% }\end{array}$ & $\begin{array}{l}\text { Sb-125 } \\
\text { Error \% } \\
\end{array}$ & $\begin{array}{l}\text { Cs-134 } \\
\text { Error \% } \\
\end{array}$ & $\begin{array}{l}\text { Cs-137 } \\
\text { Error \% } \\
\end{array}$ & $\begin{array}{l}\text { Eu-154 } \\
\text { Error \% } \\
\end{array}$ & $\begin{array}{l}\text { Eu-155 } \\
\text { Error \% } \\
\end{array}$ & $\begin{array}{l}\text { Am-241 } \\
\text { Error \% } \\
\end{array}$ \\
\hline$<3 . E-2$ & $<7 . E-2$ & $<3 . E-2$ & $\begin{array}{c}6.10 \mathrm{E}-2 \\
22 \%\end{array}$ & $<7 . E-2$ & $<7 . E-2$ & $<7 . E-2$ \\
\hline $\begin{array}{c}4.73 E+0 \\
4 \%\end{array}$ & $\begin{array}{c}2.06 E+1 \\
8 \%\end{array}$ & $\begin{array}{c}2.13 E+0 \\
11 \%\end{array}$ & $\begin{array}{c}1.86 E+3 \\
2 \%\end{array}$ & $\begin{array}{c}4.45 E+1 \\
2 \%\end{array}$ & $\begin{array}{c}8.30 E+1 \\
3 \%\end{array}$ & $\begin{array}{c}1.22 E+2 \\
5 \%\end{array}$ \\
\hline $\begin{array}{c}4.68 E+0 \\
3 \%\end{array}$ & $\begin{array}{c}2.76 \mathrm{E}+1 \\
5 \%\end{array}$ & $\begin{array}{c}1.82 \mathrm{E}+0 \\
8 \%\end{array}$ & $\begin{array}{c}1.73 E+3 \\
2 \%\end{array}$ & $\begin{array}{c}4.48 \mathrm{E}+1 \\
2 \%\end{array}$ & $\begin{array}{c}8.37 E+1 \\
3 \%\end{array}$ & $\begin{array}{c}1.30 E+2 \\
4 \%\end{array}$ \\
\hline $1 \%$ & $29 \%$ & $16 \%$ & $7 \%$ & $1 \%$ & $1 \%$ & $6 \%$ \\
\hline$<3 . E-5$ & $<7 . E-5$ & $<3 . E-5$ & $\begin{array}{c}9.67 \mathrm{E}-4 \\
3 \%\end{array}$ & $<7$.E-5 & $<6 . E-5$ & $<6 . E-5$ \\
\hline$<6 . E-3$ & $<8 . E-1$ & $\begin{array}{c}1.03 E+0 \\
2 \%\end{array}$ & $\begin{array}{c}9.71 E+2 \\
2 \%\end{array}$ & $<3 . E-2$ & $<6 . E-1$ & $<5 . E-1$ \\
\hline$<5 . E-3$ & $<6 . E-1$ & $\begin{array}{c}1.06 E+0 \\
2 \%\end{array}$ & $\begin{array}{c}9.83 E+2 \\
2 \%\end{array}$ & $<3 . E-2$ & $<4 . E-1$ & $<4 . E-1$ \\
\hline & & $3 \%$ & $1 \%$ & & & \\
\hline
\end{tabular}




\section{Battelle Pacific Northwest Laboratory}

Radiochemical Processing Group-325 Building

Radioanalytical Applications Team

Client: Brooks

Cognizant Scientist:

Concur :

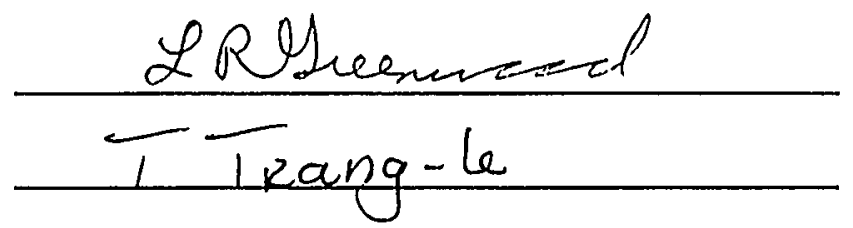

Rev. 1

$3 / 10 / 00$

Procedure: PNL-ALO-450

Equipment: Gamma detectors $G$

Measured Activities (uCi/g) with 1-sigma error

ALO ID
Client ID
00-0904
CUF-AZ-102-001
$00-0905$
CUF-AZ-102-003
00-0906
CUF-AZ102-015
00-0907
CUF-AZ-102-017
00-0908
CUF-AZ-102-019
00-0909
CUF-AZ-102-007

\begin{tabular}{|c|c|c|c|c|c|c|c|}
\hline $\begin{array}{c}\text { Co-60 } \\
\text { Error \% } \\
\end{array}$ & $\begin{array}{c}\text { RuRh-106 } \\
\text { Error \% } \\
\end{array}$ & $\begin{array}{l}\text { Sb-125 } \\
\text { Error \% } \\
\end{array}$ & $\begin{array}{l}\text { Cs-134 } \\
\text { Error \% } \\
\end{array}$ & $\begin{array}{l}\text { Cs-137 } \\
\text { Error \% } \\
\end{array}$ & $\begin{array}{l}\text { Eu-154 } \\
\text { Error \% } \\
\end{array}$ & $\begin{array}{l}\text { Eu-155 } \\
\text { Error \% } \\
\end{array}$ & $\begin{array}{l}\text { Am-241 } \\
\text { Error \% } \\
\end{array}$ \\
\hline$<5 . E-4$ & $<2 . E-1$ & $\cdot<8 . E-2$ & $\begin{array}{c}8.77 \mathrm{E}-2 \\
3 \%\end{array}$ & $\begin{array}{c}8.35 \mathrm{E}+1 \\
2 \%\end{array}$ & $<3 . E-3$ & $<5 . E-2$ & $<5 . E-2$ \\
\hline$<6 . E-4$ & $<2 . E-1$ & $<8 . E-2$ & $\begin{array}{c}9.04 \mathrm{E}-2 \\
3 \%\end{array}$ & $\begin{array}{c}8.58 \mathrm{E}+1 \\
2 \%\end{array}$ & $<4 . E-3$ & $<6 . E-2$ & $<5 . E-2$ \\
\hline$<4$.E-4 & $<1 . E-1$ & $<6 . E-2$ & $\begin{array}{c}5.29 \mathrm{E}-2 \\
3 \%\end{array}$ & $\begin{array}{c}4.80 \mathrm{E}+1 \\
2 \%\end{array}$ & $<3 . E-3$ & $<4 . E-2$ & $<4 . E-2$ \\
\hline$<5 . E-4$ & $<7 . E-2$ & $<5 . \mathrm{E}-2$ & $\begin{array}{c}3.05 \mathrm{E}-2 \\
4 \%\end{array}$ & $\begin{array}{c}2.91 \mathrm{E}+1 \\
2 \%\end{array}$ & $<2 . E-3$ & $<3 . E-2$ & $<3 . E-2$ \\
\hline$<4 . E-4$ & $<6 . E-2$ & $<4 . E-2$ & $\begin{array}{c}1.85 \mathrm{E}-2 \\
4 \%\end{array}$ & $\begin{array}{c}1.78 E+1 \\
2 \%\end{array}$ & $<2$.E-3 & $<3 . E-2$ & $<3$.E-2 \\
\hline $\begin{array}{c}5.55 \mathrm{E}+0 \\
4 \%\end{array}$ & $\begin{array}{c}5.71 E+0 \\
25 \%\end{array}$ & $\begin{array}{c}1.96 \mathrm{E}+1 \\
6 \%\end{array}$ & $<6 . E-1$ & $\begin{array}{c}5.46 \mathrm{E}+2 \\
2 \%\end{array}$ & $\begin{array}{c}5.71 \mathrm{E}+1 \\
2 \%\end{array}$ & $\begin{array}{c}1.05 E+2 \\
3 \%\end{array}$ & $\begin{array}{c}1.56 \mathrm{E}+2 \\
4 \%\end{array}$ \\
\hline
\end{tabular}


Measured Activities (uCi/g) with 1-sigma error

ALO ID
Client ID
$00-0910$
CUF-AZ-102-009
$00-0911$
CUF-AZ-102-010
$00-0912$
CUF-AZ-102-011
$00-0913$
CUF-AZ-102-013
00-0914
CUF-AZ-102-022
00-0915
CUF-AZ-102-023
00-0916
CUF-AZ-102-026

\begin{tabular}{cccccccc}
$\begin{array}{c}\text { Co-60 } \\
\text { Error } \%\end{array}$ & $\begin{array}{c}\text { RuRh-106 } \\
\text { Error } \%\end{array}$ & $\begin{array}{c}\text { Sb-125 } \\
\text { Error } \%\end{array}$ & $\begin{array}{c}\text { Cs-134 } \\
\text { Error } \%\end{array}$ & $\begin{array}{c}\text { Cs-137 } \\
\text { Error } \%\end{array}$ & $\begin{array}{c}\text { Eu-154 } \\
\text { Error } \%\end{array}$ & $\begin{array}{c}\text { Eu-155 } \\
\text { Error } \%\end{array}$ & $\begin{array}{c}\text { Am-241 } \\
\text { Error } \%\end{array}$ \\
\hline$<5 . E-4$ & $<9 . E-2$ & $<6 . E-2$ & $4.36 E-2$ & $4.26 E+1$ & $<2 . E-3$ & $<4 . E-2$ & $<4 . E-2$ \\
& & & $3 \%$ & $2 \%$ & & & \\
$3.34 E+0$ & $<5 . E 0$ & $1.67 E+1$ & $<5 . E-1$ & $2.64 E+2$ & $3.16 E+1$ & $5.88 E+1$ & $9.49 E+1$ \\
$4 \%$ & & $6 \%$ & & $2 \%$ & $2 \%$ & $3 \%$ & $5 \%$ \\
$3.86 E+0$ & $6.40 E+0$ & $2.86 E+1$ & $<5 . E-1$ & $2.98 E+2$ & $3.70 E+1$ & $6.72 E+1$ & $1.04 E+2$ \\
$4 \%$ & $22 \%$ & $4 \%$ & & $2 \%$ & $2 \%$ & $3 \%$ & $5 \%$ \\
$<5 . E-4$ & $<6 . E-2$ & $<4 . E-2$ & $2.18 E-2$ & $2.08 E+1$ & $<2 . E-3$ & $<3 . E-2$ & $<3 . E-2$ \\
& & & $4 \%$ & $2 \%$ & & & \\
$<6 . E-4$ & $<4 . E-2$ & $<3 . E-2$ & $9.95 E-3$ & $9.09 E+0$ & $<2 . E-3$ & $<2 . E-2$ & $<2 . E-2$ \\
$7.38 E+0$ & $<7 . E 0$ & $5.33 E+1$ & $<7 . E-1$ & $1.71 E+2$ & $7.37 E+1$ & $1.38 E+2$ & $2.01 E+2$ \\
$3 \%$ & & $3 \%$ & & $2 \%$ & $2 \%$ & $3 \%$ & $4 \%$ \\
$7.41 E+0$ & $1.18 E+1$ & $2.73 E+1$ & $<7 . E-1$ & $1.66 E+2$ & $7.19 E+1$ & $1.30 E+2$ & $2.04 E+2$ \\
$3 \%$ & $15 \%$ & $4 \%$ & & $2 \%$ & $2 \%$ & $3 \%$ & $4 \%$
\end{tabular}


Battelle Pacific Northwest Laboratory

Radiochemical Processing Group-325 Building

Chemical Measurements Center

Client: Brooks

Cognizant Scientist:

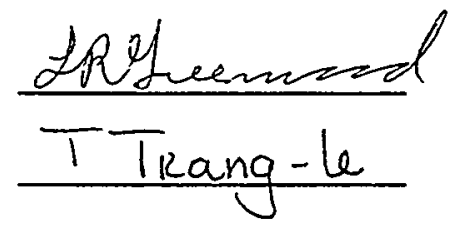

Concur :
00-0902

$3 / 23 / 00$

Procedure: PNL-ALO-496, 417, 476

Date: $3 / 23 / 00$

Date: $\quad 3 \mid 23100$

Measured Activities (uCi/g) with 1-sigma error

\begin{tabular}{|c|c|c|c|c|c|c|c|}
\hline $\begin{array}{l}\text { ALO ID } \\
\text { Client ID }\end{array}$ & $\begin{array}{c}\text { Sr-90 } \\
\text { Error +1- }\end{array}$ & $\begin{array}{l}\text { Pu-239+ } \\
\text { Pu-240 } \\
\text { Error +/- }\end{array}$ & $\begin{array}{l}\text { Pu-238 } \\
\text { Error +/- }\end{array}$ & $\begin{array}{l}\text { Pu-236 } \\
\text { Error +/- }\end{array}$ & $\begin{array}{l}\text { Am-241 } \\
\text { Error +1- }\end{array}$ & $\begin{array}{c}\mathrm{Cm}-243+ \\
\mathrm{Cm}-244 \\
\text { Error }+1-\end{array}$ & $\begin{array}{l}\text { Cm-242 } \\
\text { Error +1- }\end{array}$ \\
\hline 00-0902 PB & $4.09 E-1$ & $1.76 E-3$ & $<2 . E-3$ & $<5 . E-4$ & $<3 . E-3$ & $<7 . E-4$ & $<5 . E-4$ \\
\hline Process Blank & $29 \%$ & $40 \%$ & & & & & \\
\hline 00-0902 & $1.66 \mathrm{E}+4$ & $6.60 \mathrm{E}+0$ & $6.40 \mathrm{E}-1$ & $<2 . E-1$ & 1.11E+2 & $3.00 E-1$ & $<4 . E-2$ \\
\hline AZ102MU & $3 \%$ & $7 \%$ & $38 \%$ & & $5 \%$ & $28 \%$ & \\
\hline 00-0902 DUP & $1.61 E+4$ & $6.06 E+0$ & $8.94 \mathrm{E}-1$ & $<5 . E-2$ & $1.15 E+2$ & $<2 . E-1$ & 9.67E-2 \\
\hline AZ102MU & $3 \%$ & $7 \%$ & $21 \%$ & & $5 \%$ & & $50 \%$ \\
\hline RPD & $3 \%$ & $9 \%$ & $33 \%$ & & $4 \%$ & & \\
\hline 00-0903 PB & $3.24 E-3$ & $1.04 \mathrm{E}-5$ & 3.37E-5 & $<5 . E-7$ & $2.64 \mathrm{E}-5$ & $3.46 \mathrm{E}-5$ & $<4 . E-7$ \\
\hline Process Blank & $4 \%$ & $15 \%$ & $9 \%$ & & $11 \%$ & $9 \%$ & \\
\hline $00-0903$ & $1.83 E+0$ & $2.65 E-2$ & $2.90 \mathrm{E}-3$ & $2.90 E-5$ & $2.01 E-4$ & $2.46 E-5$ & $<9 . E-6$ \\
\hline AZ102 M SUP & $6 \%$ & $4 \%$ & $5 \%$ & $47 \%$ & $16 \%$ & $48 \%$ & \\
\hline 00-0903 DUP & $1.74 \mathrm{E}+0$ & $2.62 E-2$ & $2.97 E-3$ & $<2$.E-5 & $1.64 \mathrm{E}-4$ & $<5 . E-5$ & $<4 . E-5$ \\
\hline AZ102 M SUP & $6 \%$ & $4 \%$ & $5 \%$ & & $25 \%$ & & \\
\hline RPD & $5 \%$ & $1 \%$ & $2 \%$ & & $20 \%$ & & \\
\hline Matrix Spike & $96 \%$ & $104 \%$ & & & $90 \%$ & & \\
\hline Spike & $100 \%$ & $107 \%$ & & & $97 \%$ & & \\
\hline Blank & $<3 . E-3$ & $<8 . E-2$ & $<3 . E-1$ & $<2 . E-1$ & $<1 . E-1$ & $<6 . E-2$ & $<6 . E-2$ \\
\hline
\end{tabular}




\begin{tabular}{|c|c|c|c|c|c|c|c|}
\hline $\begin{array}{l}\text { ALO ID } \\
\text { Client ID }\end{array}$ & $\begin{array}{c}\text { Sr-90 } \\
\text { Error +1- }\end{array}$ & $\begin{array}{l}\text { Pu-240 } \\
\text { Error +/- }\end{array}$ & $\begin{array}{l}\text { Pu-238 } \\
\text { Error +/- }\end{array}$ & $\begin{array}{l}\text { Pu-236 } \\
\text { Error +/- } \\
\end{array}$ & $\begin{array}{l}\text { Am-241 } \\
\text { Error }+1- \\
\end{array}$ & $\begin{array}{l}\text { Cm-244 } \\
\text { Error +/- }\end{array}$ & $\begin{array}{l}\mathrm{Cm}-242 \\
\text { Error +1- }\end{array}$ \\
\hline $\begin{array}{l}00-0909 \\
\text { CUF-AZ-102-007 }\end{array}$ & $\begin{array}{c}2.17 E+4 \\
3 \%\end{array}$ & $\begin{array}{c}7.63 E+0 \\
5 \%\end{array}$ & $\begin{array}{c}1.21 E+0 \\
9 \%\end{array}$ & $<6 . E-2$ & $\begin{array}{c}1.35 E+2 \\
5 \%\end{array}$ & $\begin{array}{c}2.50 \mathrm{E}-1 \\
23 \%\end{array}$ & $\begin{array}{c}7.95 \mathrm{E}-2 \\
41 \%\end{array}$ \\
\hline $\begin{array}{l}00-0910 \\
\text { CUF-AZ-102-009 }\end{array}$ & $\begin{array}{c}1.36 \mathrm{E}-1 \\
3 \%\end{array}$ & $\begin{array}{c}9.77 \mathrm{E}-5 \\
4 \%\end{array}$ & $\begin{array}{c}5.05 E-5 \\
5 \%\end{array}$ & $<1 . E-7$ & $\begin{array}{c}3.24 \mathrm{E}-5 \\
6 \%\end{array}$ & $\begin{array}{c}4.33 \mathrm{E}-5 \\
6 \%\end{array}$ & $<1 . E-7$ \\
\hline $\begin{array}{l}00-0911 \\
\text { CUF-AZ-102-010 }\end{array}$ & $\begin{array}{c}1.15 E-4 \\
3 \%\end{array}$ & $\begin{array}{c}4.39 \mathrm{E}+0 \\
7 \%\end{array}$ & $\begin{array}{c}7.12 \mathrm{E}-1 \\
15 \%\end{array}$ & $<5 . E-2$ & $\begin{array}{c}9.00 \mathrm{E}+1 \\
5 \%\end{array}$ & $<3 . E-1$ & $<7 . E-2$ \\
\hline $\begin{array}{l}00-0912 \\
\text { CUF-AZ-102-011 }\end{array}$ & $\begin{array}{c}1.38 E+4 \\
3 \%\end{array}$ & $\begin{array}{c}4.98 \mathrm{E}+0 \\
6 \%\end{array}$ & $\begin{array}{c}5.01 \mathrm{E}-1 \\
19 \%\end{array}$ & $<3$.E-2 & $\begin{array}{c}9.32 E+1 \\
5 \%\end{array}$ & $\begin{array}{c}2.42 \mathrm{E}-1 \\
27 \%\end{array}$ & $<7 . E-2$ \\
\hline $\begin{array}{l}00-0913 \\
\text { CUF-AZ-102-013 }\end{array}$ & $\begin{array}{c}3.42 \mathrm{E}-2 \\
5 \%\end{array}$ & $\begin{array}{c}\text { 1.67E-5 } \\
7 \%\end{array}$ & $\begin{array}{c}4.45 E-5 \\
5 \%\end{array}$ & $<3 . E-7$ & $\begin{array}{c}3.36 \mathrm{E}-5 \\
6 \%\end{array}$ & $\begin{array}{c}5.30 \mathrm{E}-5 \\
6 \%\end{array}$ & $<2 . E-7$ \\
\hline $\begin{array}{l}00-0914 \\
\text { CUF-AZ-102-022 }\end{array}$ & $\begin{array}{c}2.56 \mathrm{E}-2 \\
6 \%\end{array}$ & $\begin{array}{c}1.69 \mathrm{E}-5 \\
7 \%\end{array}$ & $\begin{array}{c}4.25 E-5 \\
5 \%\end{array}$ & $<2 . E-7$ & $\begin{array}{c}1.32 \mathrm{E}-4 \\
5 \%\end{array}$ & $\begin{array}{c}4.91 \mathrm{E}-5 \\
6 \%\end{array}$ & $<3 . E-7$ \\
\hline $\begin{array}{l}00-0915 \\
\text { CUF-AZ-102-023 }\end{array}$ & $\begin{array}{c}2.53 E+4 \\
3 \%\end{array}$ & $\begin{array}{c}9.80 \mathrm{E}+0 \\
6 \%\end{array}$ & $\begin{array}{c}1.03 E+0 \\
26 \%\end{array}$ & $<3$.E-1 & $\begin{array}{c}1.71 E+2 \\
5 \%\end{array}$ & $\begin{array}{c}2.69 \mathrm{E}-1 \\
38 \%\end{array}$ & $<6 . E-2$ \\
\hline $\begin{array}{l}00-0916 \\
\text { CUF-AZ-102-026 }\end{array}$ & $\begin{array}{c}2.44 \mathrm{E}+4 \\
3 \%\end{array}$ & $\begin{array}{c}9.85 E+0 \\
6 \%\end{array}$ & $\begin{array}{c}2.11 E+0 \\
13 \%\end{array}$ & $<3 . E-1$ & $\begin{array}{c}1.79 E+2 \\
5 \%\end{array}$ & $\begin{array}{c}2.93 \mathrm{E}-1 \\
40 \%\end{array}$ & $<1 . E-1$ \\
\hline Matrix Spike & $96 \%$ & $104 \%$ & & & $90 \%$ & & \\
\hline Spike & $100 \%$ & $107 \%$ & & & $97 \%$ & & \\
\hline Blank & $<3 . E-3$ & $<3 . E-7$ & $<7 . E-7$ & $<6 . E-7$ & $<3 . E-7$ & $<2 . E-7$ & $<2 . E-7$ \\
\hline
\end{tabular}




\section{Battelle Pacific Northwest Laboratory}

Radiochemical Processing Group-325 Building

Radioanalytical Applications Team

Client: Brooks

Cognizant Scientist:

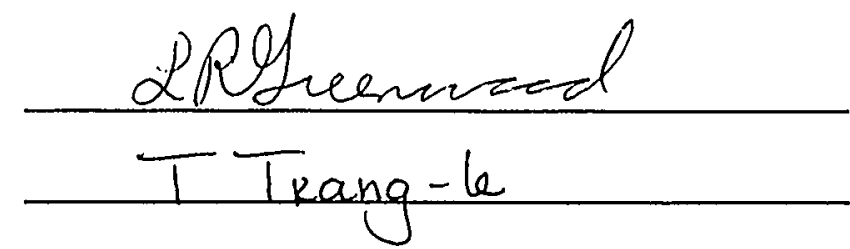

Date

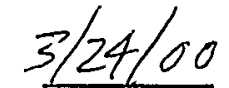

Date: $3 / 23100$

Procedure: PNL-ALO-476, 417, 496

Measured Activities (uCi/g) with 1-sigma error

\begin{tabular}{|c|c|c|c|c|c|c|c|}
\hline $\begin{array}{l}\text { ALO ID } \\
\text { Client ID }\end{array}$ & $\begin{array}{c}\text { Sr-90 } \\
\text { Error +/- }\end{array}$ & $\begin{array}{c}\text { Pu-239+ } \\
\text { Pu-240 } \\
\text { Error +1- }\end{array}$ & $\begin{array}{c}\text { Pu-238 } \\
\text { Error +1- }\end{array}$ & $\begin{array}{l}\text { Pu-236 } \\
\text { Error +1- }\end{array}$ & $\begin{array}{l}\text { Am-241 } \\
\text { Error +1- }\end{array}$ & $\begin{array}{l}\mathrm{Cm}-243+ \\
\mathrm{Cm}-244 \\
\text { Error +/- }\end{array}$ & $\begin{array}{l}\mathrm{Cm}-242 \\
\text { Error }+1-\end{array}$ \\
\hline $00-0904$ & $1.22 \mathrm{E}-2$ & $6.31 \mathrm{E}-5$ & $4.25 \mathrm{E}-5$ & $<2$.E-7 & 4.14E-5 & $4.42 \mathrm{E}-5$ & $<2 . E-7$ \\
\hline CUF-AZ-102-001 & $39 \%$ & $4 \%$ & $4 \%$ & & $6 \%$ & $6 \%$ & \\
\hline 00-0904 REP & $1.26 \mathrm{E}-2$ & $6.20 E-5$ & $4.66 \mathrm{E}-5$ & $<4 . E-7$ & $4.08 E-5$ & $4.74 \mathrm{E}-5$ & $<2 . E-7$ \\
\hline CUF-AZ-102-001 & $38 \%$ & $5 \%$ & $5 \%$ & & $6 \%$ & $6 \%$ & \\
\hline RPD & $3 \%$ & $2 \%$ & $9 \%$ & & $1 \%$ & $7 \%$ & \\
\hline 00-0905 & $3.65 \mathrm{E}-2$ & $4.68 E-5$ & $4.95 E-5$ & $<3 . E-7$ & $3.28 E-5$ & $5.28 \mathrm{E}-5$ & $<2 . E-7$ \\
\hline CUF-AZ-102-003 & $6 \%$ & $4 \%$ & $4 \%$ & & $7 \%$ & $6 \%$ & \\
\hline 00-0906 & 3.26E-2 & $3.53 \mathrm{E}-5$ & 5.15E-5 & $<3 . E-7$ & 1.53E-4 & $4.90 \mathrm{E}-5$ & $<2 . E-7$ \\
\hline CUF-AZ102-015 & $7 \%$ & $6 \%$ & $5 \%$ & & $5 \%$ & $6 \%$ & \\
\hline $00-0907$ & 1.30E-2 & $1.75 \mathrm{E}-5$ & $4.08 E-5$ & $<1 . E-6$ & $3.41 \mathrm{E}-5$ & $4.81 \mathrm{E}-5$ & $<2 . E-7$ \\
\hline CUF-AZ-102-017 & $8 \%$ & $8 \%$ & $6 \%$ & & $6 \%$ & $5 \%$ & \\
\hline 00-0908 & $1.85 \mathrm{E}-2$ & 2.10E-5 & $5.61 \mathrm{E}-5$ & $<2 . E-7$ & 4.99E-5 & $6.54 \mathrm{E}-5$ & $<2 . E-7$ \\
\hline CUF-AZ-102-019 & $4 \%$ & $5 \%$ & $4 \%$ & & $6 \%$ & $6 \%$ & \\
\hline \multicolumn{8}{|c|}{ Page 1} \\
\hline
\end{tabular}


Client: Brooks

Cognizant Scientist:

Concur :

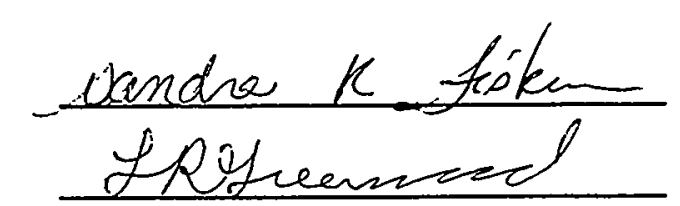

Date: $\quad 5 / 2 / 00$

Date: $5 / 2 / 60$

Procedure: PNL-ALO-432

Measured Activities (UCi/g) with 1-sigma error

\begin{tabular}{lc}
$\begin{array}{lc}\text { ALO ID } \\
\text { Client ID }\end{array}$ & $\begin{array}{c}\text { TC-99 } \\
\text { Error +/- }\end{array}$ \\
$\begin{array}{l}\text { 00-0903 PB } \\
\text { Prọcess Blank }\end{array}$ & $<3 . E-6$ \\
$00-0903$ & \\
AZ102 M SUP & $1.25 E-1$ \\
$00-0903$ DUP & $4 \%$ \\
AZ102 M SUP & $1.33 E-1$ \\
RPD & $4 \%$ \\
Standard & $6.2 \%$ \\
Matrix Spike & $99 \%$ \\
Blank & \\
\hline
\end{tabular}

Note: all QC parameters met specification per the QA plan in the PNNL standards-based management system except the matrix spike recovery. The Tc-99 spike was added as pertechnetate in sufficient quantity to be measured above the sample activity (two times the sample activity). The sample matrix may have been reducing causing some pertechnetate spike reduction. The procedure calls for the use of sodium dichromate to oxidize Tc species to Tc+7. However, for this matrix, this may not have been oxidizing enough. For a worst-case scenario, the sample Tc concentration may be biased low by about $25 \%$. 
Battelle Pacific Northwest Laboratory

00-0904

Radiochemical Processing Group-325 Building

Radioanalytical Applications Team

$3 / 21 / 00$

Client: Brooks

Cognizant Scientist:

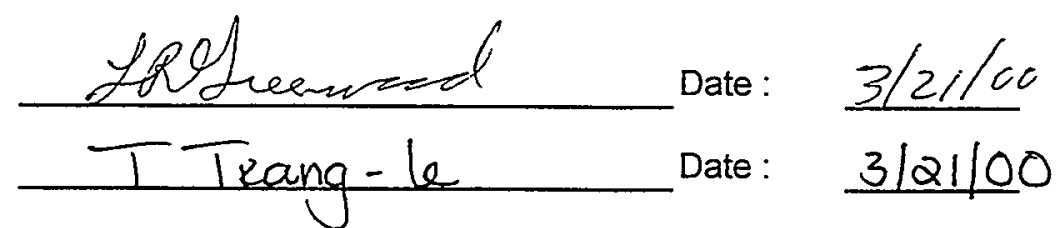

Procedure: PNL-ALO-4014

Equipment: Chemcheck KPA11R

Measured Concentration (ug/g) with 1- $\sigma$ error

\begin{tabular}{|c|c|c|c|}
\hline $\begin{array}{l}\text { ALO ID } \\
\text { Client ID }\end{array}$ & $\begin{array}{l}\text { Uranium } \\
\text { Error \% }\end{array}$ & Standards & Yield, \% \\
\hline $00-0904$ & $2.48 E+1$ & Pre 1 & $104 \%$ \\
\hline CUF-AZ-102-001 & $4 \%$ & Pre 2 & $101 \%$ \\
\hline 00-0904 Rep & $2.36 E+1$ & Post 1 & $98 \%$ \\
\hline CUF-AZ-102-001 & $4 \%$ & Post 2 & $100 \%$ \\
\hline $00-0905$ & $2.96 E+1$ & Blank & $<2$.E-5 \\
\hline CUF-AZ-102-003 & $4 \%$ & & \\
\hline $00-0906$ & $4.01 E+1$ & & \\
\hline CUF-AZ102-015 & $4 \%$ & & \\
\hline $00-0907$ & $1.92 E+1$ & & \\
\hline CUF-AZ-102-017 & $4 \%$ & & \\
\hline $00-0908$ & $8.44 \mathrm{E}+0$ & & \\
\hline CUF-AZ-102-019 & $4 \%$ & & \\
\hline $\begin{array}{l}00-0909 \\
\text { CUF-AZ-102-007 }\end{array}$ & $\begin{array}{c}2.87 E+4 \\
4 \%\end{array}$ & & \\
\hline $00-0910$ & 2. $12 E+1$ & & \\
\hline CUF-AZ-102-009 & $4 \%$ & & \\
\hline $00-0911$ & $1.74 E+4$ & & \\
\hline CUF-AZ-102-010 & $4 \%$ & & \\
\hline $00-0912$ & $1.91 \mathrm{E}+4$ & & \\
\hline CUF-AZ-102-011 & $4 \%$ & & \\
\hline $00-0913$ & $1.81 \mathrm{E}+1$ & & \\
\hline CUF-AZ-102-013 & $4 \%$ & & \\
\hline $00-0914$ & $1.29 E+1$ & & \\
\hline CUF-AZ-102-022 & $4 \%$ & & \\
\hline $00-0915$ & $3.63 E+4$ & & \\
\hline CUF-AZ-102-023 & $4 \%$ & & \\
\hline $00-0916$ & $3.52 E+4$ & & \\
\hline CUF-AZ-102-026 & $4 \%$ & & \\
\hline
\end{tabular}


Battelle Pacific Northwest Laboratory

00-0902

Radiochemical Processing Group-325 Building

Chemical Measurements Center

$3 / 21 / 00$

Client: Brooks

Cognizant Scientist:

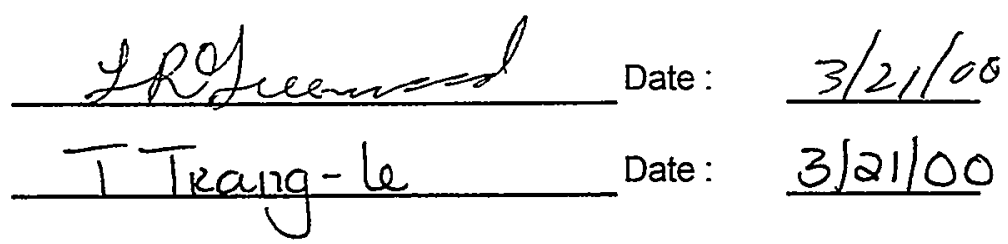

Procedure: PNL-ALO-4014

Equipment: Chemcheck KPA11R

Measured Concentration (ug/g) with 1- $\sigma$ error

ALO ID

Uranium

Client ID

Error $+1-$

00-0902 PB

$9.28 \mathrm{E}-1$

Process Blank

$3 \%$

00-0902

$2.26 \mathrm{E}+4$

AZ102MU

$4 \%$

00-0902 DUP

AZ102MU

$2.31 \mathrm{E}+4$

$4 \%$

RPD

$2 \%$

00-0903 PB

1.65E-2

Process Blank

$3 \%$

00-0903

AZ102 M SUP

1.69E+1

$3 \%$

00-0903 DUP

$1.69 E+1$

AZ102 M SUP

$3 \%$

RPD

$0 \%$

Pre Standard 1

$104 \%$

Pre Standard 2

$101 \%$

Post Standard 1

$98 \%$

Post Standard 2

$100 \%$

Blank

$<2$.E-5 
Battelle Pacific Northwest Laboratory

Radiochemical Processing Group-325 Building

Chemical Measurements Center

Client: Brooks

Cognizant Scientist:

Concur :

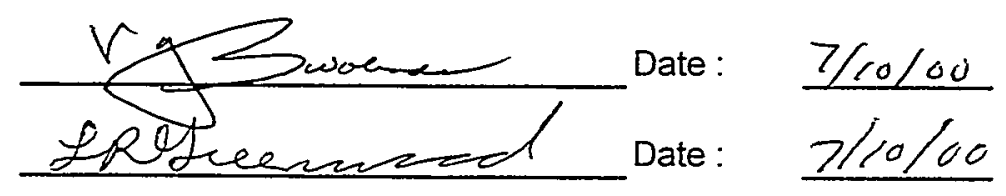

Measured Activity (uCi/g) with $1-\sigma$ error

ALO ID

Client ID

00-0902 PB

Process Blank

00-0902

AZ102MU

00-0902 DUP

$\mathrm{AZ} 102 \mathrm{MU}$

RPD
00-0902 H3

Rev. 1

$7 / 10 / 2000$

\begin{tabular}{c}
$\begin{array}{c}\text { Tritium } \\
\text { Error }+/-\end{array}$ \\
\hline $1.87 \mathrm{E}-3$ \\
$24 \%$ \\
$3.92 \mathrm{E}-2$ \\
$3 \%$ \\
$4.26 \mathrm{E}-2$ \\
$3 \%$ \\
$8 \%$
\end{tabular}

*Tritium values are reported per gram of wet slurry. 
Battelle Pacific Northwest Laboratory

Radiochemical Processing Group-325 Building

Radioanalytical Applications Team
00-0915 H3

$4 / 13 / 2000$

Client: Brooks

Cognizant Scientist:

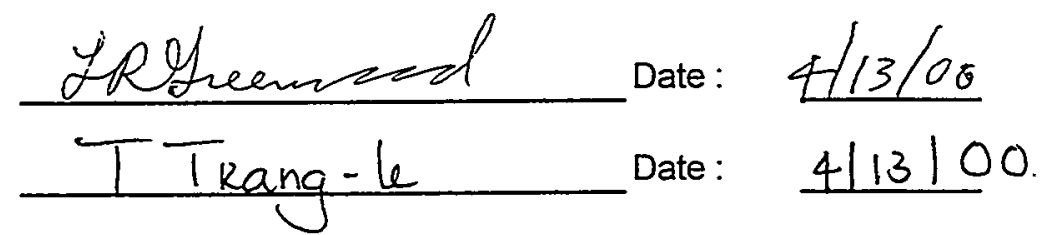

Measured Activities (uCi/g) with 1-sigma error

$\begin{array}{lc}\begin{array}{lc}\text { ALO ID } \\ \text { Client ID }\end{array} & \begin{array}{c}\text { Tritium* } \\ \text { Error } \%\end{array} \\ \begin{array}{lc}\text { 00-0915 } \\ \text { CUF-AZ-102-023 }\end{array} & 9.04 E-3 \\ \text { O0-0915 MS } & 4 \% \\ \text { CUF-AZ-102-023 } & 8.44 E-3 \\ \quad \text { RPD } & 4 \% \\ \text { O0-0916 } & 7 \% \\ \text { CUF-AZ-102-026 } & 2.35 E-2 \\ \text { Blank } & 3 \%\end{array}$

*Tritium is reported per gram of wet slurry.

**The MS refers to an inorganic matrix spike; hence, this sample is a duplicate for tritium. 
Client: Brooks

Procedure PNL-ALO-482

Cognizant Scientist:

Concur :

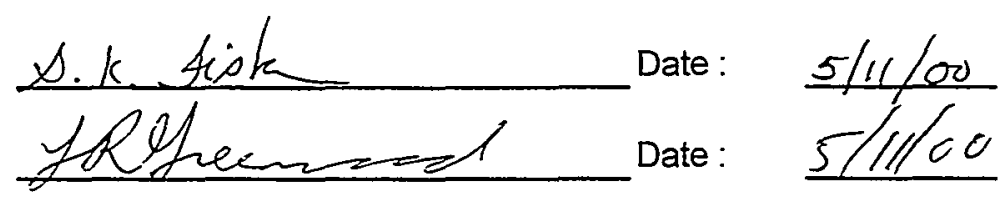

Measured Activity (uCi/g) with 1- $\sigma$ error

ALO ID

C-14

Client ID

Error +1

00-0902

$1.39 \mathrm{E}-3$

AZ102MU

$10 \%$

00-0902 DUP

1.62E-3

AZ102MU

$10 \%$

RPD

$15 \%$

Pre Run System Blank

$<3 . E-4$

Post Run System Blank

$<3 E-4$

Blank Spike

$106 \%$

Sample Spike

$106 \%$

C-14 was measured on direct aliquots of the wet slurry. The weight percent solids data were used to correct the results for dried weight, although it should be noted that some of the C-14 would of course be lost if the samples had actually been dried prior to analysis. The C-14 activity in the sample is slightly below the requested $M R Q$ limit of $1.8 \mathrm{E}-3 \mathrm{uCi} / \mathrm{g}$. 
Battelle Pacific Northwest Laboratory

Radiochemical Processing Group-325 Building

Radioanalytical Applications Team
00-0915 C14

$5 / 11 / 2000$

Client: Brooks

Cognizant Scientist:

Concur:

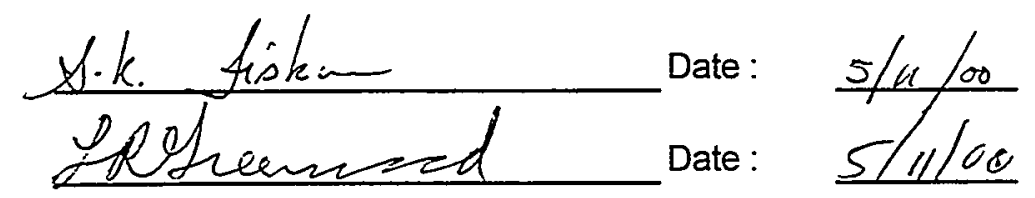

PNL-ALO-482

Measured Activities (uCi/g) with 1-sigma error

ALO ID

C-14

Client ID

Error \%

00-0915

$<1.2 \mathrm{E}-3$

CUF-AZ-102-023

00-0916

CUF-AZ-102-026

$2.36 \mathrm{E}-3$

$24 \%$

Pre Run System Blank

$<1.2 \mathrm{E}-3$

Post Run System Blank

$<1.2 \mathrm{E}-3$

Blank Spike

$106 \%$

Sample Spike

$106 \%$

C-14 was measured on direct aliquots of the wet slurry. The weight percent solids data were used to correct the results for dried weight, although it should be noted that some of the C-14 would of course be lost if the samples had actually been dried prior to analysis. The C-14 activity in the sample is slightly below the requested $M R Q$ limit of $1.8 \mathrm{E}-3 \mathrm{uCi} / \mathrm{g}$. 
Radiochemical Processing Laboratory

Shielded Facility Operations Team

\section{Shielded Analytical Laboratory Bench Sheet}

Client: KP BROOKS

TI\#/ASR: ASRS $5667 / 5668$

WP itünber: W45577

Procedure: Bench Instruction

\section{AZ102 DENSITIES \\ SAMPLE IDENTIFICATION}

\begin{tabular}{|c|c|c|c|c|c|}
\hline 4. & SAMPI & (9) & 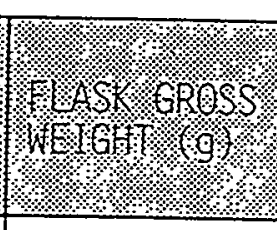 & Sist? & 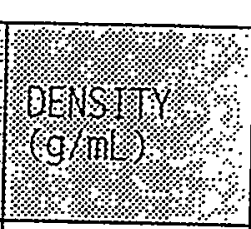 \\
\hline $00-00903$ & AZ102 M SUP & 4.3700 & $20.8 i c 1$ & 10 & 1.1446 \\
\hline $00-00904$ & CUF $-A Z-102-001$ & 438,22 & 19.4575 & & 1.0075 \\
\hline $00-00905$ & CUF-AZ-102-003 & 94674 & 145298 & & 1.0062 \\
\hline $00-00906$ & CUF-AZ-102-015 & 9.3444 & 14.528 & & 1.0058 \\
\hline $00-00907$ & CUF-AZ-102-017 & 9.3495 & 193605 & & 1.0011 \\
\hline $00-00908$ & CUF-AZ-102-019 & 94822 & 14.4344 & & $0.995 \%$ \\
\hline $00-00910$ & CUF -AZ-102-009 & 9.4853 & $\therefore 0.4000$ & & $1.0915^{-}$ \\
\hline $00-00913$ & CUF $-A Z-102-013$ & 9.4250 & 19.8241 & & 1.0398 \\
\hline $00-00914$ & CUF $-A Z-102-022$ & $9.37,8$ & 19.5814 & & 1.0206 \\
\hline $00-00917$ & CUF-AZ-102-027 & 10.6546 & 15.6959 & $4,5 \mathrm{mal}$ & 1.0073 \\
\hline
\end{tabular}

DENSITY $=\underline{\text { FLASK GROSS }(q)-\text { FLASK TARE }(q)}$ FLASK SIZE (mL)

M\&TE: $X$ Ce11 2 (360-06-01-016) Mettler AE160 Balance Other Cel1 5 (360-06-01-019) Sartorius LP4200S Balance Bench (510-06-01-014) Mettler AT201 Balance Bench (360-06-01-040) Denver A160 Balance

Analyst:

Date:

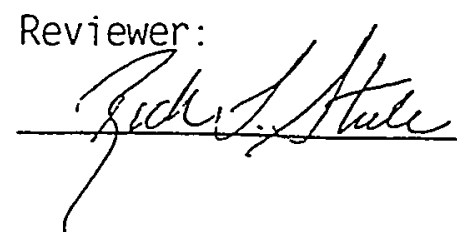

Date: $2 \cdot / f-00$ 
Shielded Analytical Laboratory

\section{WT\% SOLIDS DATA SHEET (325 SHIELDED ANALYTICAL LABORATORY)}
CLIENT:
Kriston Brooks
WORK PACKAGE:
W45577
QA PLAN: SBMS
IMPACT LEVEL:
AZ102 MU AND CUF-AZ102-XXXX SLURRIES SAMPLE IDENTIFICATION

ASRIARF/LOITI:

ASRs $5667 / 5668$

PROCEDURE NUMBER:

PNL-ALO-504

\begin{tabular}{|l|l|}
\hline \multicolumn{1}{|c|}{$\begin{array}{c}\text { NUCL. } \\
\text { NUMBER }\end{array}$} & \multicolumn{1}{c}{$\begin{array}{c}\text { CLIENT } \\
\text { IDENTIFICATION }\end{array}$} \\
\hline $00-00902$ & AZ102 MU \\
\hline $00-00902-D U P$ & AZ102 MU \\
\hline $00-00902-$ TRI & AZ102 MU \\
\hline $00-00909$ & CUF-AZ102-007 \\
\hline $00-00909-D U P$ & CUF-AZ102-007 \\
\hline $00-00909-T R I$ & CUF-AZ102-007 \\
\hline $00-00911$ & CUF-AZ102-010 \\
\hline $00-00911-D U P$ & CUF-AZ102-010 \\
\hline WT &
\end{tabular}

$W T \%$ SOLIDS $=\frac{B-\text { TARE }}{A-\text { TARE }} \times 100$

DATE/TIME IN: /-26-00 1500

DATE/TIME OUT: $/-27-00 \quad 0815$
(B) SAMPLE DRY WEIGHT PLUS TARE

\begin{tabular}{|l|l}
\hline 17.6915 & 42.01 \\
\hline 17.6479 & 41.89 \\
\hline 17.6700 & 41.38 \\
\hline 16.5316 & 11.40 \\
\hline 16.5049 & 11.31 \\
\hline 16.5797 & 11.29 \\
\hline 16.5548 & 17.91 \\
\hline 16.6479 & 17.88 \\
\hline
\end{tabular}
OVEN TEMPERATURE: $\angle 0.7{ }^{\circ}$ OVEN TEMPERATURE: $106^{\circ}$ BALANCE: CELL 2 (360-06-01-016) $X$ BALANCE: CELL. 5 (360-06-01-039)

THERMOCOUPLE: $2 / / 6$

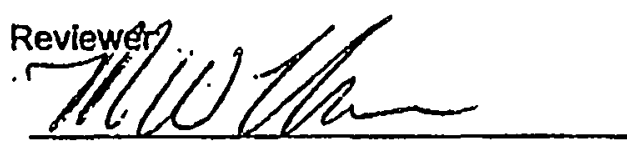

Date:

Analyst: Date:

$1-27-00$
$1-2 \cdot 7-00$ 


\section{WT\% SOLIDS DATA SHEET \\ (325 SHIELDED ANALYTICAL. LABORATORY)}

CLIENT:

Kriston Brooks

WORK PACKAGE:

W45577

ASRIARF/LOIT:

ASRs $5667 / 5668$

QA PLAN:

SBMS

IMPACT LEVEL:

PROCEDURE NUMBER:

PNL-ALO-504

AZ102 MU AND CUF-AZ102-XXX SLURRIES SAMPLE IDENTIFICATION

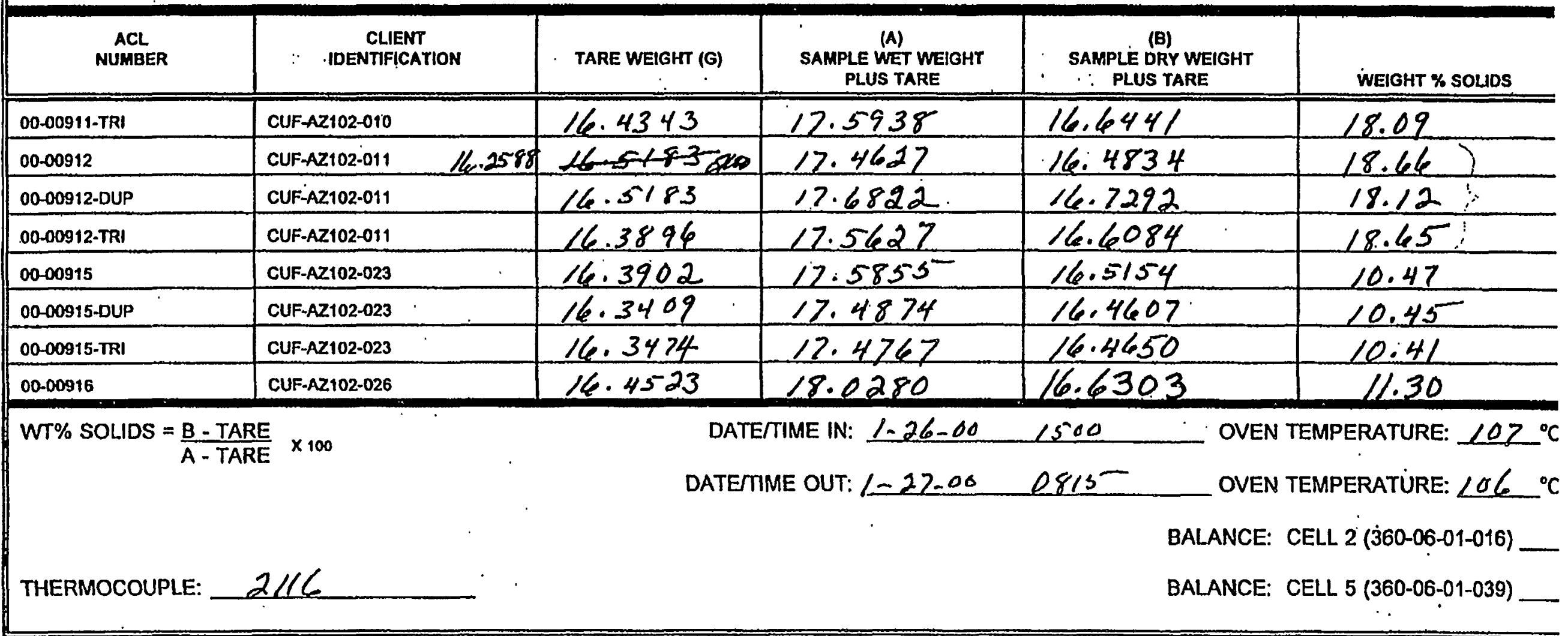

Date: L-27-00 Date:




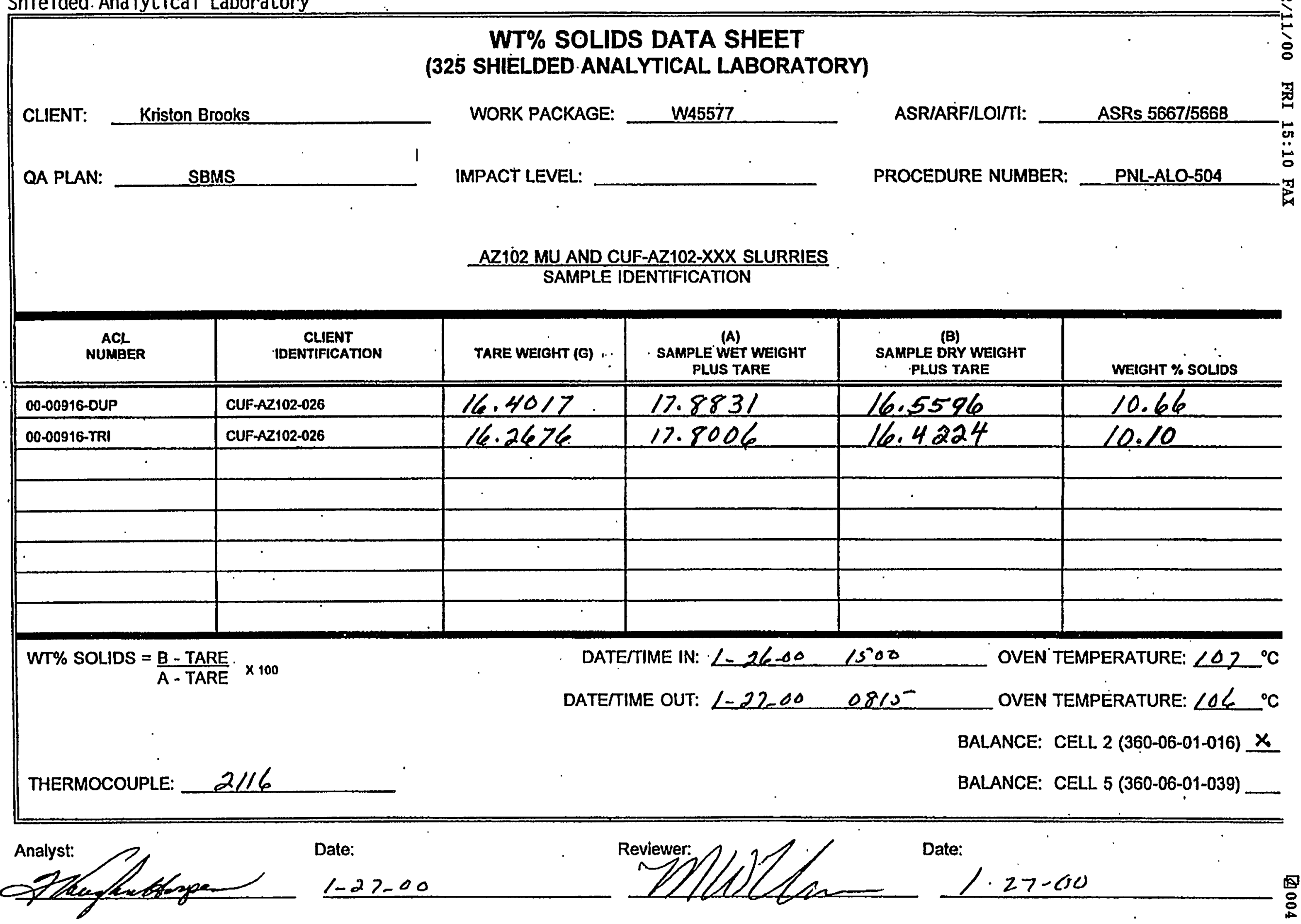


Appendix D: Crossflow Filtration Raw Data 


\section{Appendix D: Crossflow Filtration Raw Data}

D.1 


\begin{tabular}{|c|c|c|c|c|c|c|c|c|c|c|c|c|c|c|c|}
\hline $\begin{array}{l}\text { Condition } \\
\text { Number }\end{array}$ & Time & & $\begin{array}{l}\text { Total Time } \\
\text { Elapsed } \\
\text { (Min) }\end{array}$ & $\begin{array}{l}\text { Slurry } \\
\text { Loop Flow } \\
\text { Rate } \\
\text { (gpm) }\end{array}$ & $\begin{array}{l}\text { Filter } \\
\text { Outlet } \\
\text { Pressure } \\
\text { (psig) }\end{array}$ & $\begin{array}{l}\text { Filter Inlet } \\
\text { Pressue } \\
\text { (psig) }\end{array}$ & $\begin{array}{l}\text { Pressure } \\
\text { Drop } \\
\text { (psig) }\end{array}$ & $\begin{array}{l}\text { Filtrate } \\
\text { Sample } \\
\text { Volume } \\
\text { (mL) }\end{array}$ & $\begin{array}{l}\text { Time of } \\
\text { Collection } \\
\text { (Sec) }\end{array}$ & $\begin{array}{l}\text { Filtrate } \\
\text { Flow Rate } \\
\text { (mL/sec) }\end{array}$ & Slurry Temp C & $\begin{array}{l}\text { Filtrate Flux } \\
\text { (m3/m2/day) }\end{array}$ & $\begin{array}{l}\text { Permeability } \\
\text { (m/day/bar) }\end{array}$ & $\begin{array}{l}\text { Filtrate } \\
\text { Flux } \\
\text { (gpm/tt2) }\end{array}$ & $\begin{array}{l}\text { Permeability } \\
\text { (gpm/f2/psi) }\end{array}$ \\
\hline 1 & 1 & $4: 54$ & $0: 00$ & 3 & 48 & 51 & 3 & 40 & 18.69 & 2.140 & 24.2 & 10.368 & 3.038 & 0.176754 & 0.003568 \\
\hline & $i$ & $5: 08$ & $0: 14$ & 3.2 & 48.5 & 51 & 2.5 & 40 & 22.84 & 1.751 & 24.6 & 8.389 & 2.446 & 0.143012 & 0.002873 \\
\hline & 1 & $5: 18$ & $0: 24$ & 3 & 48 & 50 & 2 & 40 & 28.1 & 1.423 & 22.5 & 7.238 & 2.142 & 0.123393 & 0.002516 \\
\hline 1 & 1 & $5: 28$ & $0: 34$ & 3.3 & 48 & 52 & 4 & 40 & 26.87 & 1.489 & 28.5 & 6.397 & 1.856 & 0.109046 & 0.002179 \\
\hline 1 & 1 & $5: 39$ & $0: 45$ & 3.4 & 47 & 50 & 3 & 40 & 32.15 & 1.244 & 22.4 & 6.345 & 1.897 & 0.108158 & 0.002228 \\
\hline 1 & 1 & $5: 48$ & $0: 54$ & 3.5 & 47 & 51 & 4 & 40 & 30.59 & 1.308 & 24.3 & 6.317 & 1.870 & 0.107689 & 0.002196 \\
\hline 1 & 1 & $5: 56$ & $1: 02$ & 3.4 & 47 & 50 & 3 & 40 & 28.34 & 1.411 & 28.4 & 6.082 & 1.819 & 0.103674 & 0.002136 \\
\hline RAW & Avera & $g e S$ & lurry Flow = & $\begin{array}{r}\text { Average } \mathrm{Pr} \\
3.26\end{array}$ & ressure = & 49.17857 & & $\begin{array}{l}\text { Average Fic } \\
\text { Filtrate }\end{array}$ & low $=$ & 1.538 & $\begin{array}{l}\text { Average Flux = } \\
\text { With First Point }\end{array}$ & $\begin{array}{l}6.795 \\
\text { emoved }\end{array}$ & & & \\
\hline
\end{tabular}
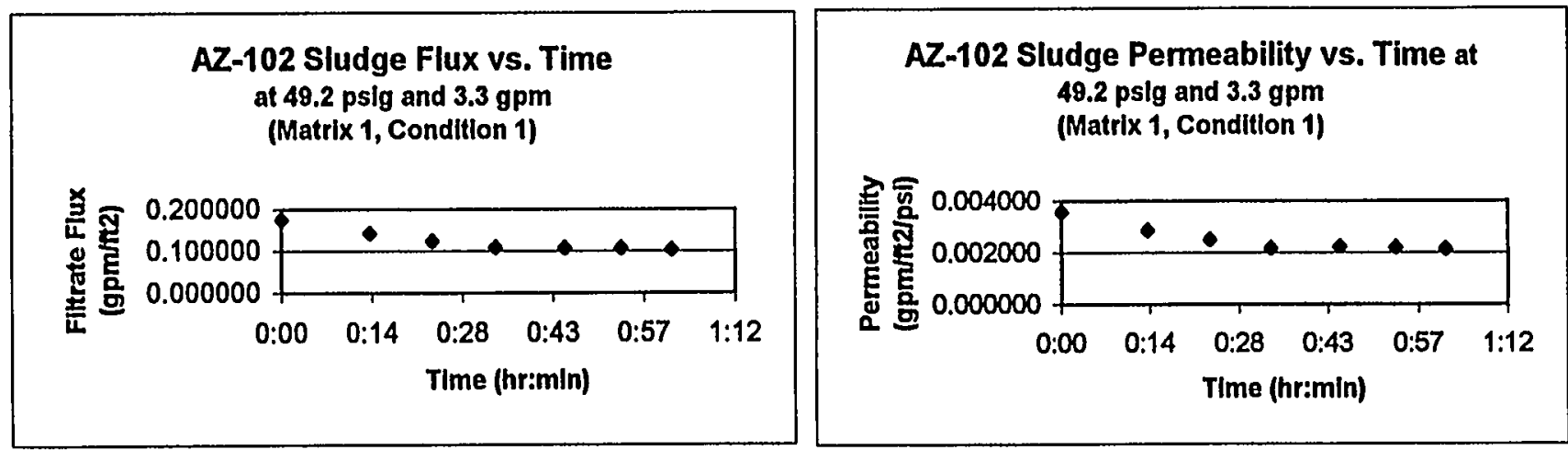


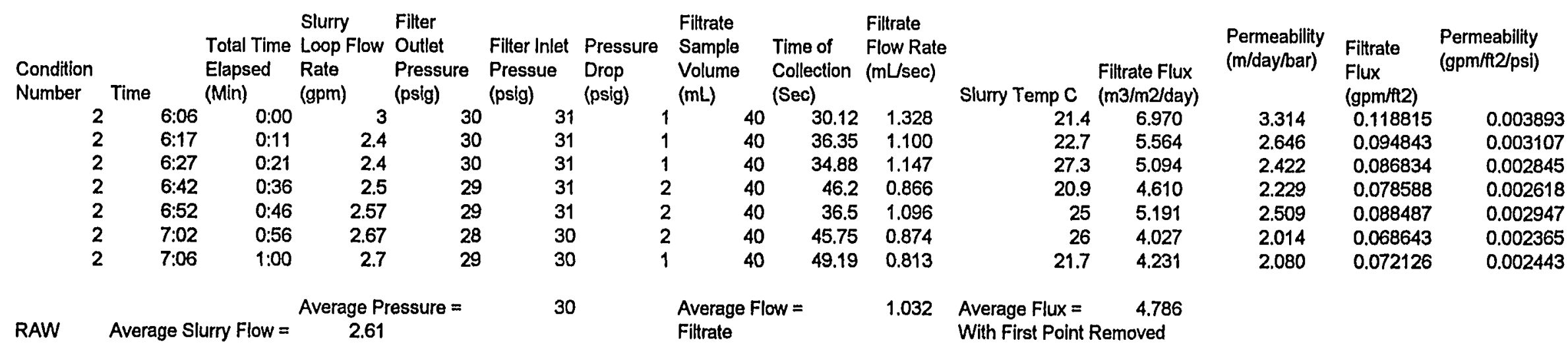
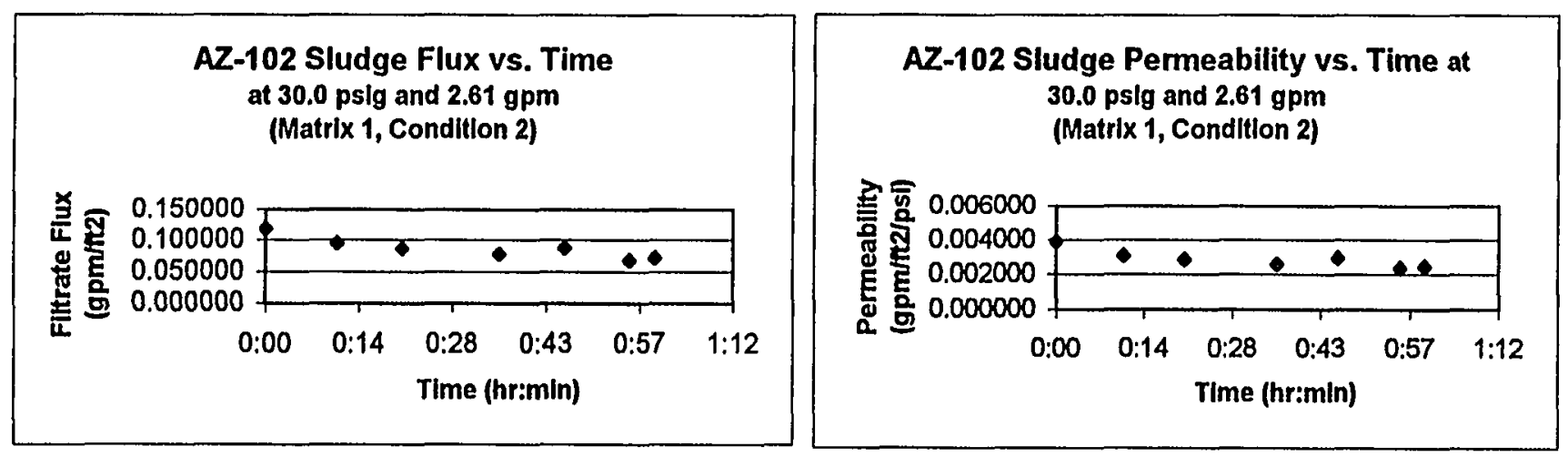


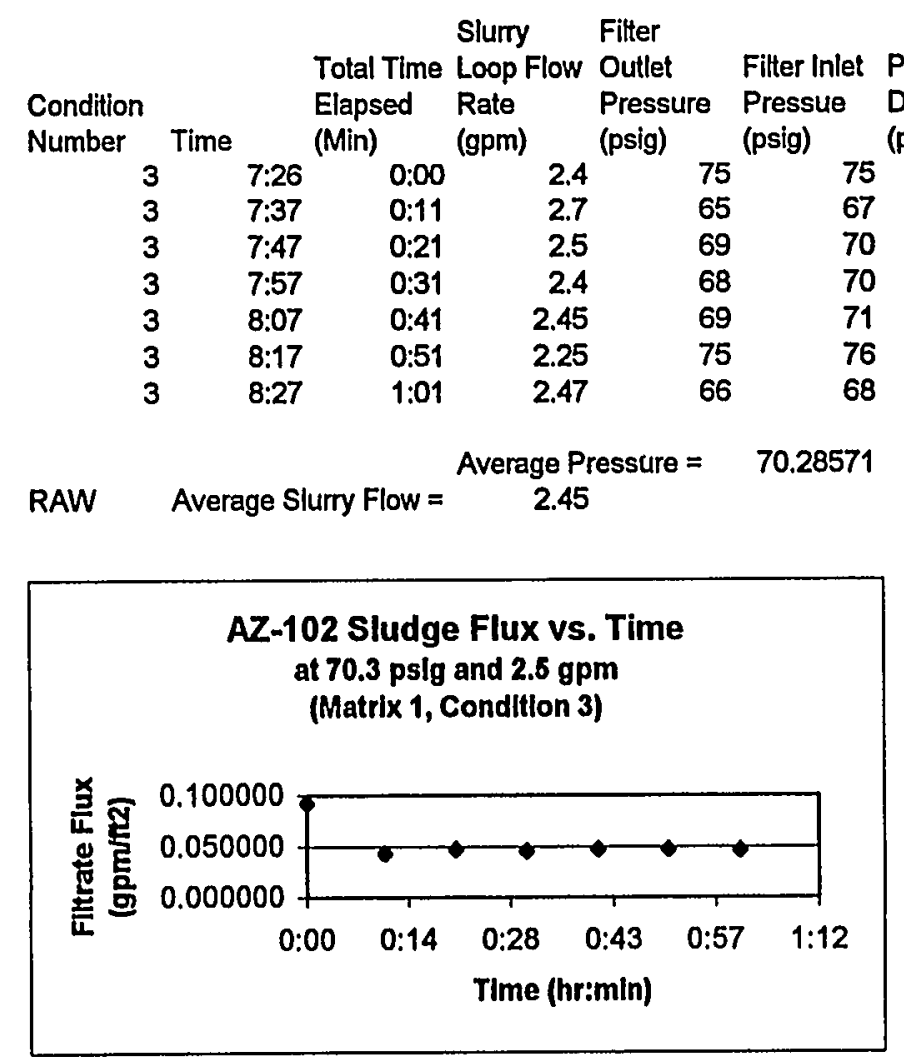

Filtrate Filtrate

Sample Time of Flow Rate Volume $(\mathrm{ml})$

\section{$a^{(\mathrm{mL})}$}

0
2
1

2

2
2

1

1
2

\section{Average Flow $=$}

Filtrate (Sec)

te

$\begin{array}{rr}32.19 & 1.243 \\ 40.03 & 0.500 \\ 35 & 0.571 \\ 32.75 & 0.611 \\ 37.03 & 0.540 \\ 32.69 & 0.612 \\ 34.47 & 0.580\end{array}$

Filtrate Flux

$\begin{array}{lr}27.8 & 5.443 \\ 23.1 & 2.497\end{array}$

$\begin{array}{ll}23.1 & 2.497 \\ 24.4 & 2.753\end{array}$

$28 \quad 2660$

$22.3 \quad 2.762$

$26.6 \quad 2.771$

$25.2 \quad 2.733$

0.665 Average Flux $=\quad 2.696$

With First Point Removed

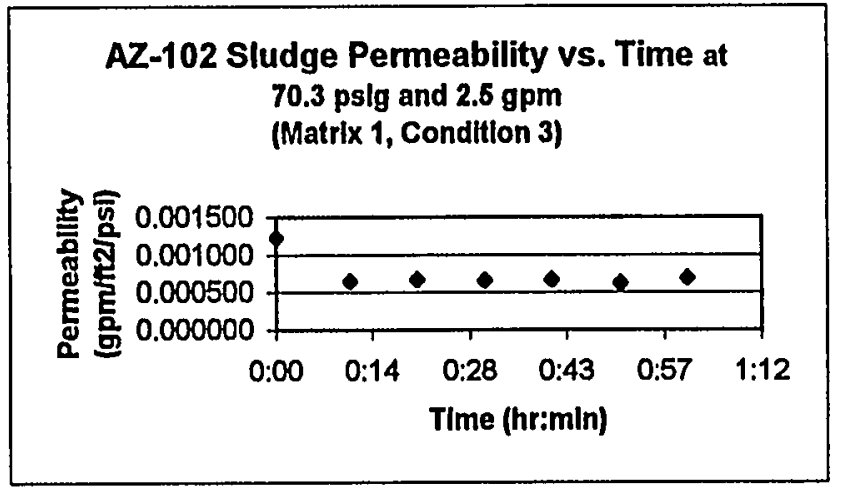

Permeability Fittrate Permeability

(m/day/bar) Flux (gpm/ft2/psi)

Flux

gpm/t2)

$\begin{array}{lll}1.053 & 0.092797 & 0.001236\end{array}$

$\begin{array}{lll}0.549 & 0.042573 & 0.000645\end{array}$

$\begin{array}{lll}0.574 & 0.046927 & 0.000675\end{array}$

$\begin{array}{lll}0.559 & 0.045354 & 0.000657\end{array}$

$\begin{array}{lll}0.572 & 0.047087 & 0.000672\end{array}$

$\begin{array}{lll}0.532 & 0.047236 & 0.000625\end{array}$

$\begin{array}{lll}0.592 & 0.046586 & 0.000695\end{array}$ 


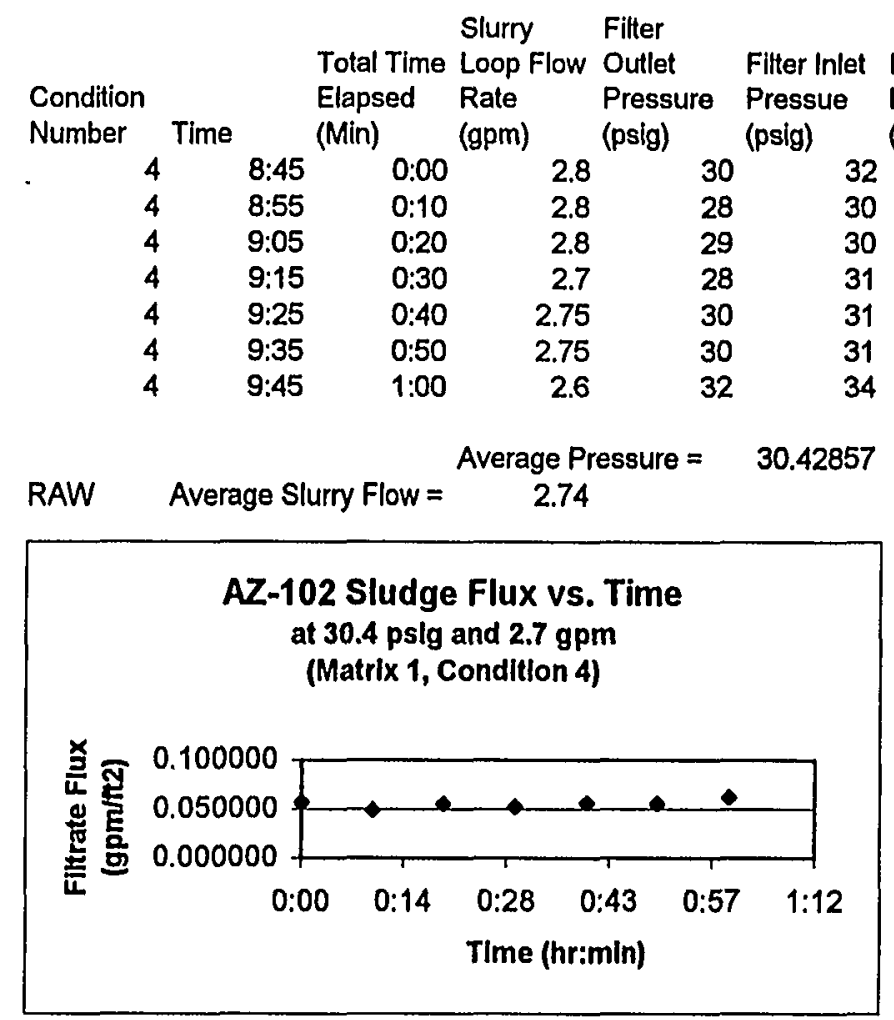

\section{Filtrate Filtrate}

Sample Time of Flow Rate

Volume Collection (mL/sec)

$(\mathrm{mL})$

$2^{20}$

(Sec)

$\begin{array}{ll}28.35 & 0.705\end{array}$

$31.1 \quad 0.643$

$31.91 \quad 0.627$

$29.38 \quad 0.681$

$\begin{array}{ll}27.5 & 0.727\end{array}$

$32.03 \quad 0.624$

$25.06 \quad 0.798$

Average Flow $=$

Filtrate
Permeability (m/day/bar)

Filtrate Flux

$24.7 \quad 3.370$

26.7

$21.6 \quad 3.270$

$26.6-3.083$

263

$21.6 \quad 3.258$

$26.2 \quad 3.655$

0.687 Average Flux $=\quad 3.249$

With First Point Removed

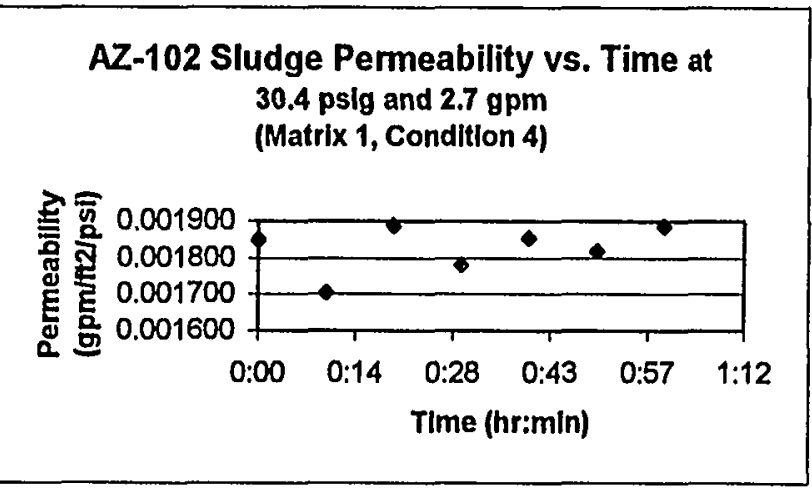




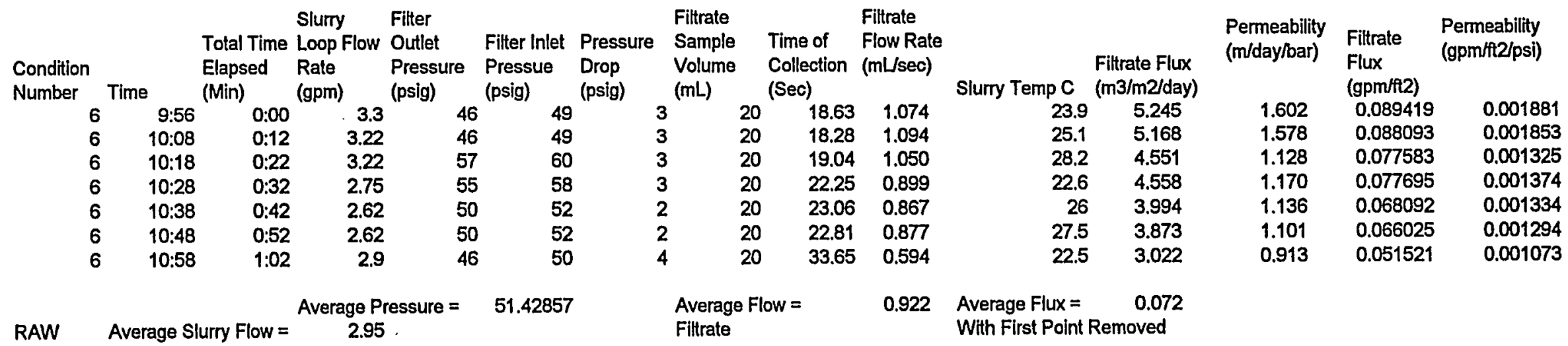
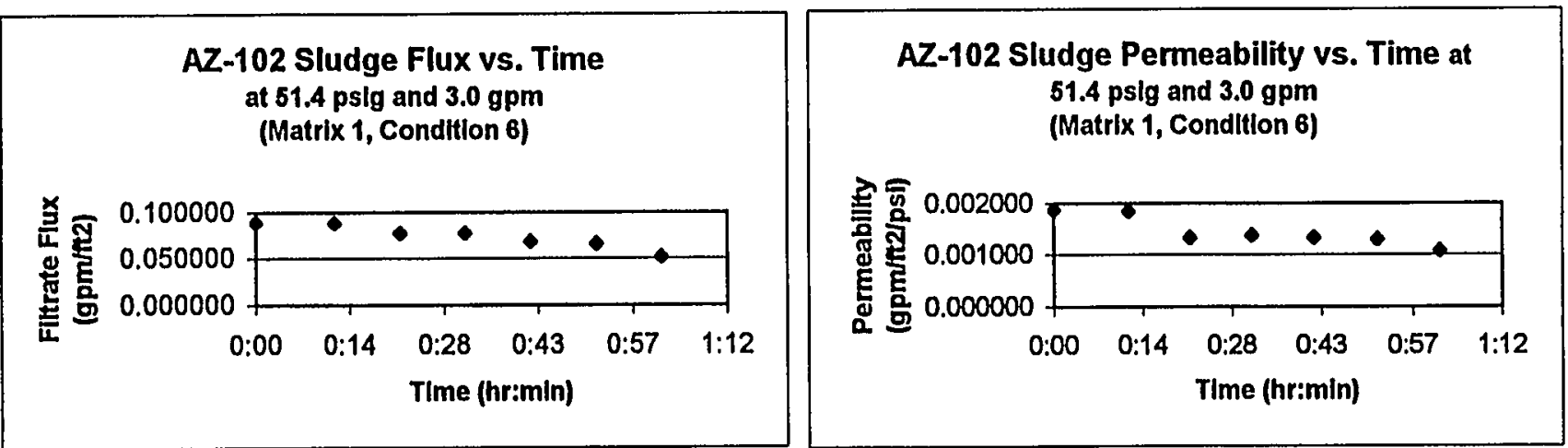


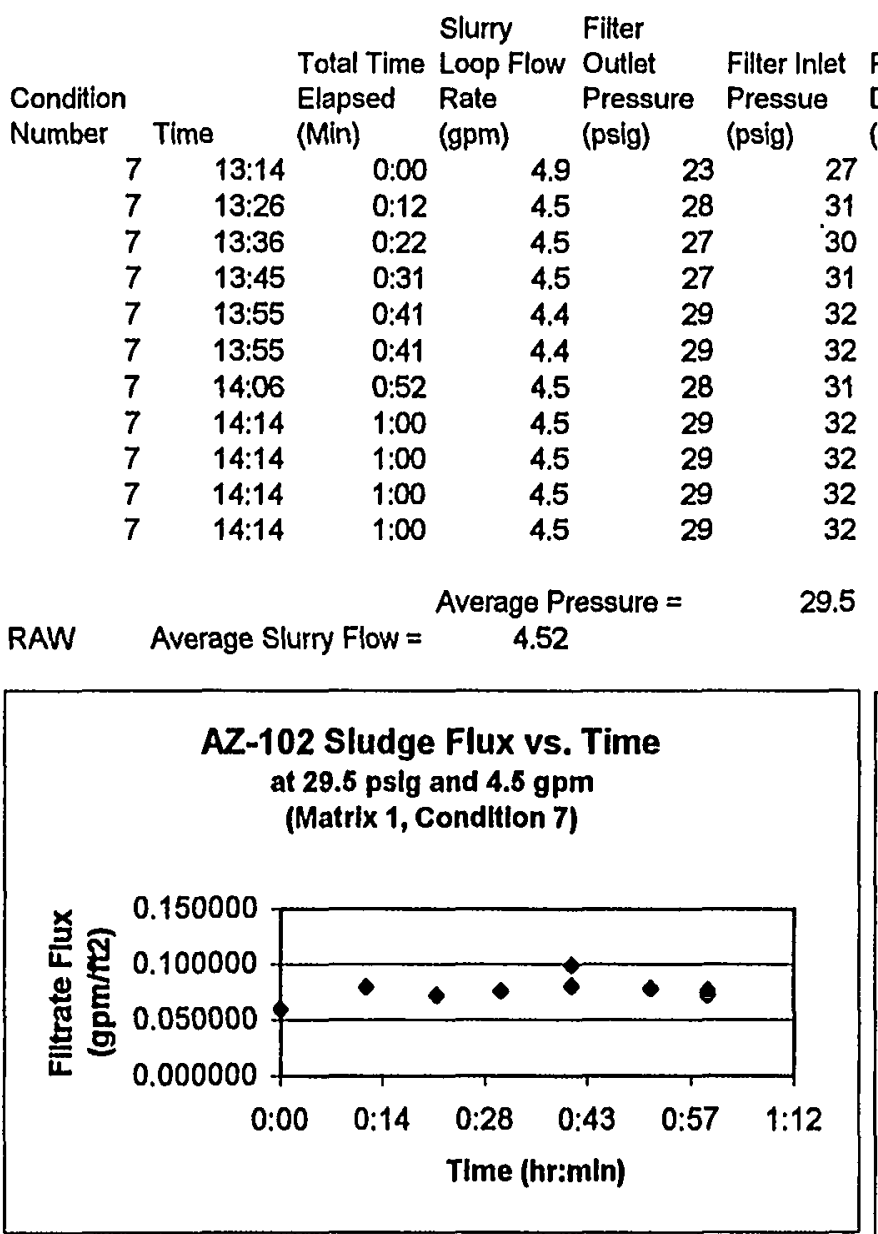

Filtrate

Sample

Volume

(ml)

4

$27^{\text {(psig) }}$

3

3

4

3

3

3

3

3

3

3

Average Flow =

Filtrate
Time of Fittrate

Collection (mL/sec) (Sec)

$20 \quad 25.35$

$\begin{array}{ll}21.37 & 0.936\end{array}$

$21.57 \quad 0.927$

$22.38 \quad 0.894$

$18.18 \quad 1.100$

\begin{tabular}{ll}
$19.56 \quad 1.022$ \\
\hline
\end{tabular}

$\begin{array}{ll}21.85 & 0.915\end{array}$

$23.04 \quad 0.868$

$22.03 \quad 0.908$

23.10 .866

0.919

Average Flux $=\quad 4.580$

With First Point Removed

$24.5 \quad 4.454$

$27.1 \quad 4.567$

$23.8 \quad 4.253$

$23.8 \quad 4.448$
Permeability

(m/day/bar)

Slurry Temp C (m3/m2/day)

$\begin{array}{rr}27 & 3.534 \\ 21.4 & 4.653\end{array}$

$\begin{array}{ll}21.4 & 4.653 \\ 26.9 & 4.203\end{array}$

$21.3 \quad 4.704$

$21.3 \quad 5.790$

$23.8 \quad 4.485$

4.242

AZ-102 Sludge Permeability vs. Time at

$28.6 \mathrm{psig}$ and $4.5 \mathrm{gpm}$

(Matrix 1, Condition 7)

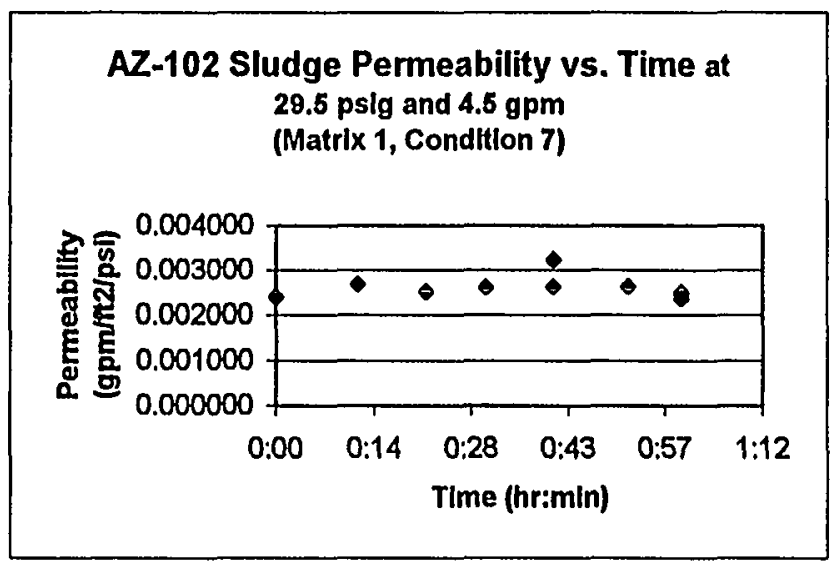

Permeability

(gpm/ft2/psi)

(gpm/ft2)

$0.060239 \quad 0.002408$

$0.079315 \quad 0.002687$

$0.071656 \quad 0.002512$

$0.075930 \quad 0.002616$

$0.080184 \quad 0.002627$

$0.098708 \quad 0.003234$

$0.077853 \quad 0.002637$

$0.076458 \quad 0.002505$

$0.072509 \quad 0.002376$

$0.075833 \quad 0.002485$

$0.072320 \quad 0.002369$ 


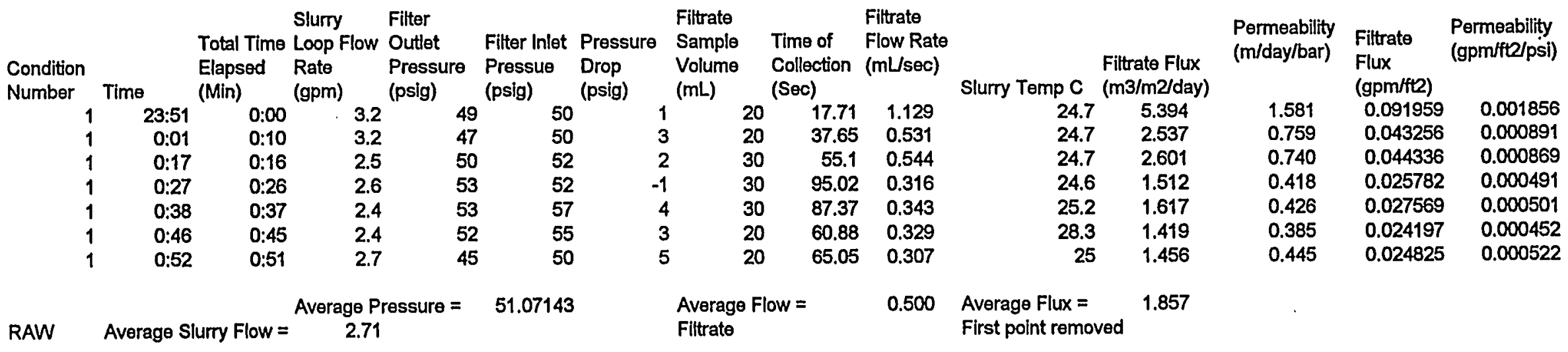
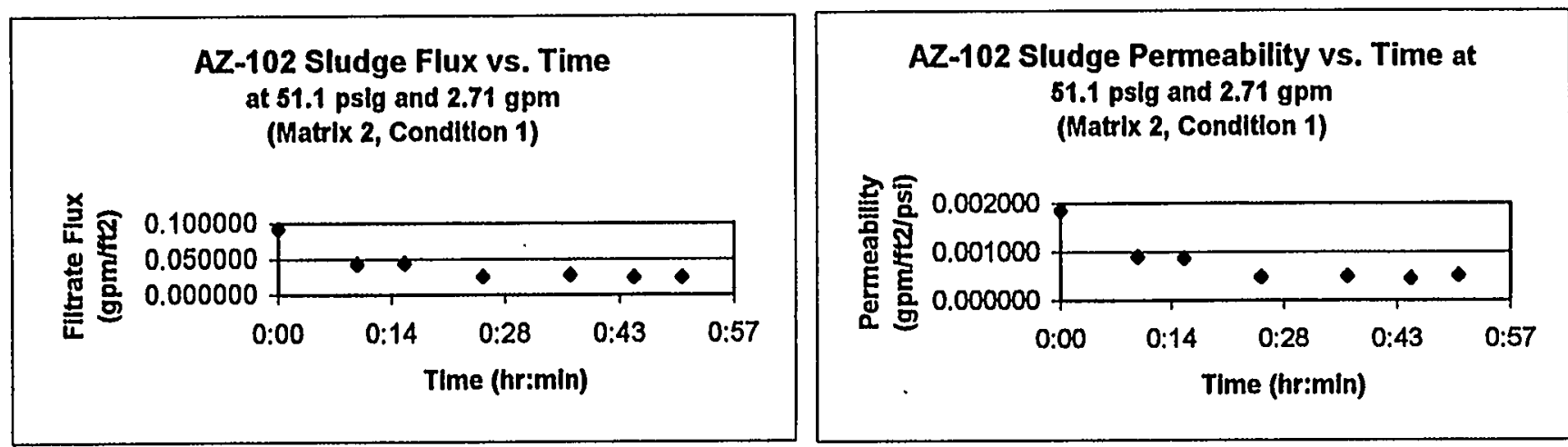


\begin{tabular}{|c|c|c|c|c|c|c|c|c|c|c|c|c|c|c|}
\hline $\begin{array}{l}\text { Condition } \\
\text { Number }\end{array}$ & Time & $\begin{array}{l}\text { Tolal Time } \\
\text { Elapsed } \\
\text { (Min) }\end{array}$ & $\begin{array}{l}\text { Slurry } \\
\text { Loop Flow } \\
\text { Rate } \\
\text { (gpm) }\end{array}$ & $\begin{array}{l}\text { Filter } \\
\text { Outlet } \\
\text { Pressure } \\
\text { (psig) }\end{array}$ & $\begin{array}{l}\text { Filter Inlet } \\
\text { Pressue } \\
\text { (psig) }\end{array}$ & $\begin{array}{l}\text { Pressure } \\
\text { Drop } \\
\text { (psig) }\end{array}$ & $\begin{array}{l}\text { Filtrate } \\
\text { Sample } \\
\text { Volume } \\
\text { (mL) }\end{array}$ & $\begin{array}{l}\text { Time of } \\
\text { Collection } \\
\text { (Sec) }\end{array}$ & $\begin{array}{l}\text { Filtrate } \\
\text { Flow Rate } \\
\text { (mL/sec) }\end{array}$ & 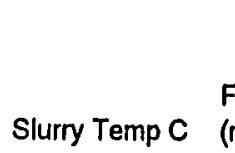 & $\begin{array}{l}\text { Filtrate Flux } \\
\text { (m3/m2/day) }\end{array}$ & $\begin{array}{l}\text { Permeability } \\
\text { (m/day/bar) }\end{array}$ & $\begin{array}{l}\text { Filtrate } \\
\text { Flux } \\
\text { (gpm/ft2) }\end{array}$ & $\begin{array}{l}\text { Permeability } \\
\text { (gpm/tt2/psi) }\end{array}$ \\
\hline 2 & $2 \quad 1: 15$ & $0: 00$ & 2.2 & 30 & 31 & 1 & 30 & 54.49 & 0.551 & 26.6 & 2.493 & 1.186 & 0.042507 & 0.001393 \\
\hline 2 & $1: 26$ & $0: 11$ & 2.18 & 28 & 30 & 2 & 30 & 84.17 & 0.356 & 22.8 & 1.797 & 0.899 & 0.030632 & 0.001056 \\
\hline 2 & $1: 36$ & $0: 21$ & 2.5 & 27 & 30 & 3 & 20 & 57.28 & 0.349 & 22.6 & 1.770 & 0.901 & 0.030180 & 0.001058 \\
\hline 2 & $1: 45$ & $0: 30$ & 2.1 & 28 & 30 & 2 & 20 & 55.35 & 0.361 & 26.9 & 1.623 & 0.812 & 0.027666 & 0.000953 \\
\hline 2 & $1: 56$ & $0: 41$ & 2.18 & 28 & 30 & 2 & 20 & 64.28 & 0.311 & 22.1 & 1.600 & 0.800 & 0.027282 & 0.000940 \\
\hline 2 & $2: 06$ & 0.51 & 2.3 & 27 & 30 & 3 & 20 & 62.45 & 0.320 & 22.6 & 1.624 & 0.826 & 0.027682 & 0.000971 \\
\hline 2 & $2: 16$ & $1: 01$ & 2.4 & 27 & 30 & 3 & 20 & 57.41 & 0.348 & 27.2 & 1.552 & 0.790 & 0.026452 & 0.000927 \\
\hline RAW & Average Slu & urry Flow = & $\begin{array}{c}\text { Average Pre } \\
2.27\end{array}$ & ressure $=$ & 29 & & $\begin{array}{l}\text { Average Flc } \\
\text { Filtrate }\end{array}$ & $o w=$ & 0.371 & $\begin{array}{l}\text { Average Flux = } \\
\text { First point removed }\end{array}$ & 1.661 & & . & \\
\hline
\end{tabular}
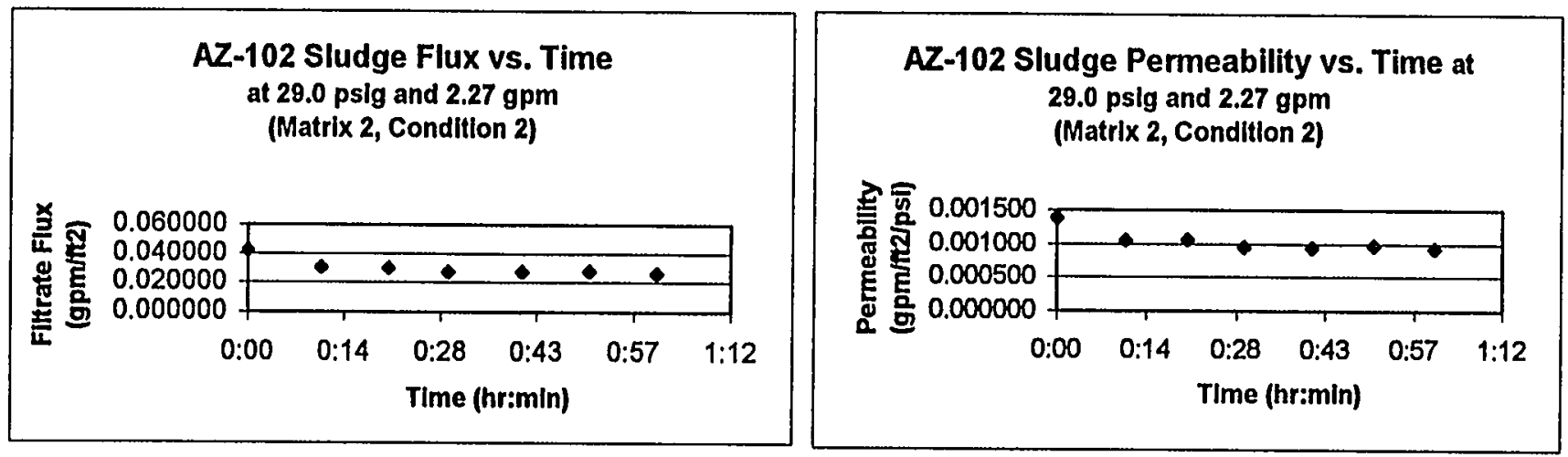
Slurry Filter

Total Time Loop Flow Outlet

Condition

Number Tim

Elapsed Rate

Rate

(psig)

$0: 00$

$0: 09$

$0: 20$

$0: 33$

$0: 44$

$0: 54$

1:06

2.05

1.86

1.9
1.83

1.83

2.34
2

Average Pressure

RAW Average Slurry Flow $=\quad 2.05$

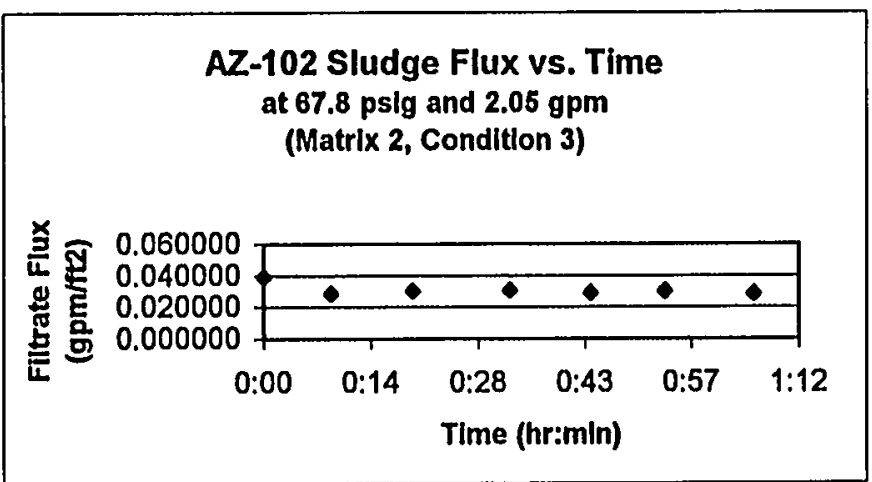

\begin{tabular}{ll}
\multicolumn{2}{c}{ (psig) } \\
65 & 70 \\
60 & 65 \\
65 & 68 \\
70 & 70 \\
68 & 68 \\
68 & 70 \\
70 & 7
\end{tabular}

67.78571
Filtrate Filtrate

Sample Time of Flow Rate

Volume Collection ( $\mathrm{mL} / \mathrm{sec}$ )

(mL)

(Sec)

(psig)
70
65
68
70
68
70
72

5
5
3
0
0
2
2

$\begin{array}{lll}21 & 41.81 & 0.502\end{array}$

$\begin{array}{lll}20 & 56.99 & 0.351\end{array}$

$20 \quad 53.53 \quad 0.374$

$\begin{array}{lll}20 & 52.62 & 0.380\end{array}$

$79.94 \quad 0.375$

$49.72 \quad 0.402$

$55.81 \quad 0.358$

Average Flow $=$

0.392

Filtrate

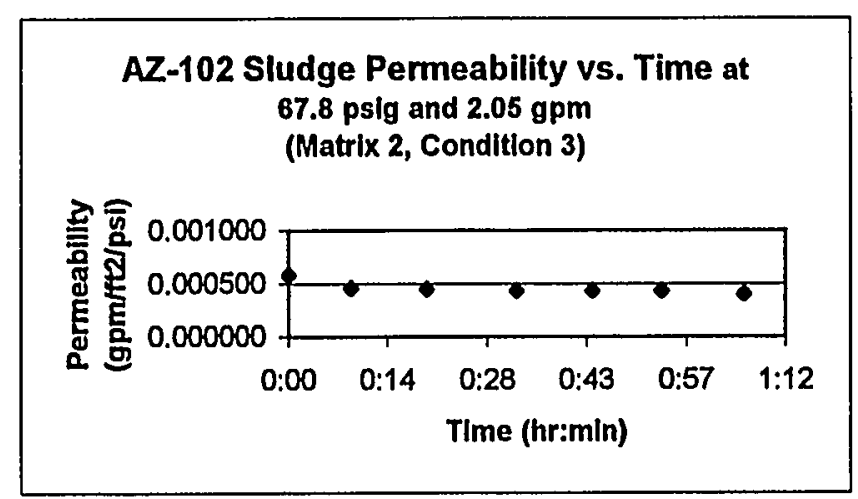

Permeability Filtrate Permeability

Filtrate Flux (m/day/bar) Flux (gpm/ft2/psi)

$\begin{array}{ll}\text { Filtrate Flux } \\ \text { Slurry Temp C } & (\mathrm{m} 3 / \mathrm{m} 2 / \text { day })\end{array}$

Flux

(gpm/ft2)

$\begin{array}{lllll}26 & 2.313 & 0.497 & 0.039434 & 0.000584\end{array}$

$\begin{array}{lll}0.387 & 0.028416 & 0.000454\end{array}$

$\begin{array}{lllll}25.1 & 1.765 & 0.385 & 0.030083 & 0.000452\end{array}$

$\begin{array}{lllll}25.1 & 1.795 & 0.372 & 0.030603 & 0.000437\end{array}$

$0.371 \quad 0.030123$

$\begin{array}{lll}0.371 & 0.030123 & 0.000436 \\ 0.344 & 0.028692 & 0.000404\end{array}$ 


\begin{tabular}{|c|c|c|c|c|c|c|c|c|c|c|c|c|c|c|c|}
\hline $\begin{array}{l}\text { Condition } \\
\text { Number }\end{array}$ & Time & & $\begin{array}{l}\text { Total Time } \\
\text { Elapsed } \\
\text { (Min) }\end{array}$ & $\begin{array}{l}\text { Slury } \\
\text { Loop Flow } \\
\text { Rate } \\
\text { (gpm) }\end{array}$ & $\begin{array}{l}\text { Filter } \\
\text { Outlet } \\
\text { Pressure } \\
\text { (psig) }\end{array}$ & $\begin{array}{l}\text { Filter Inlet } \\
\text { Pressue } \\
\text { (psig) }\end{array}$ & $\begin{array}{l}\text { Pressure } \\
\text { Drop } \\
\text { (psig) }\end{array}$ & $\begin{array}{l}\text { Filtrale } \\
\text { Sample } \\
\text { Volume } \\
\text { (mL) }\end{array}$ & $\begin{array}{l}\text { Time of } \\
\text { Collection } \\
\text { (Sec) }\end{array}$ & $\begin{array}{l}\text { Filltrate } \\
\text { Flow Rate } \\
\text { (mL/sec) }\end{array}$ & Slurry Temp C & $\begin{array}{l}\text { Filtrate Flux } \\
(\mathrm{m} 3 / \mathrm{m} 2 / \mathrm{dav})\end{array}$ & $\begin{array}{l}\text { Permeability } \\
\text { ( } \mathrm{m} / \text { day/bar) }\end{array}$ & $\begin{array}{l}\text { Filtrate } \\
\text { Flux } \\
\text { (gumffit) }\end{array}$ & $\begin{array}{l}\text { Permeability } \\
\text { (gpm/ft2/psi) }\end{array}$ \\
\hline 4 & 4 & $4: 14$ & $0: 00$ & 2.7 & 30 & 30 & 0 & $0 \quad 20$ & 32,66 & 0.612 & 27.4 & 2.712 & 1.311 & 0.046240 & 0.001540 \\
\hline & 4 & $4: 25$ & $0: 11$ & 2.9 & 28 & 30 & 2 & 20 & 46.8 & 0.427 & 23.5 & 2.112 & 1.056 & 0.036002 & 0.001241 \\
\hline 2 & 4 & $4: 46$ & $0: 32$ & 3 & 30 & 32 & & 20 & 40.88 & 0.489 & 27 & 2.191 & 1.025 & 0.037354 & 0.001204 \\
\hline & 4 & $4: 58$ & $0: 44$ & 3 & 28 & 32 & & 20 & 48.06 & 0.416 & 22.4 & 2.122 & 1.026 & 0.036176 & 0.001205 \\
\hline & 4 & $5: 11$ & $0: 57$ & 3 & 28 & 32 & 4 & 20 & 40.38 & 0.495 & 28.5 & 2.128 & 1.029 & 0.036281 & 0.001209 \\
\hline & 4 & $5: 15$ & $1: 01$ & 2.9 & 30 & 33 & 3 & 20 & 35.37 & 0.565 & 26.2 & 2.590 & 1.192 & 0.044146 & 0.001400 \\
\hline
\end{tabular}
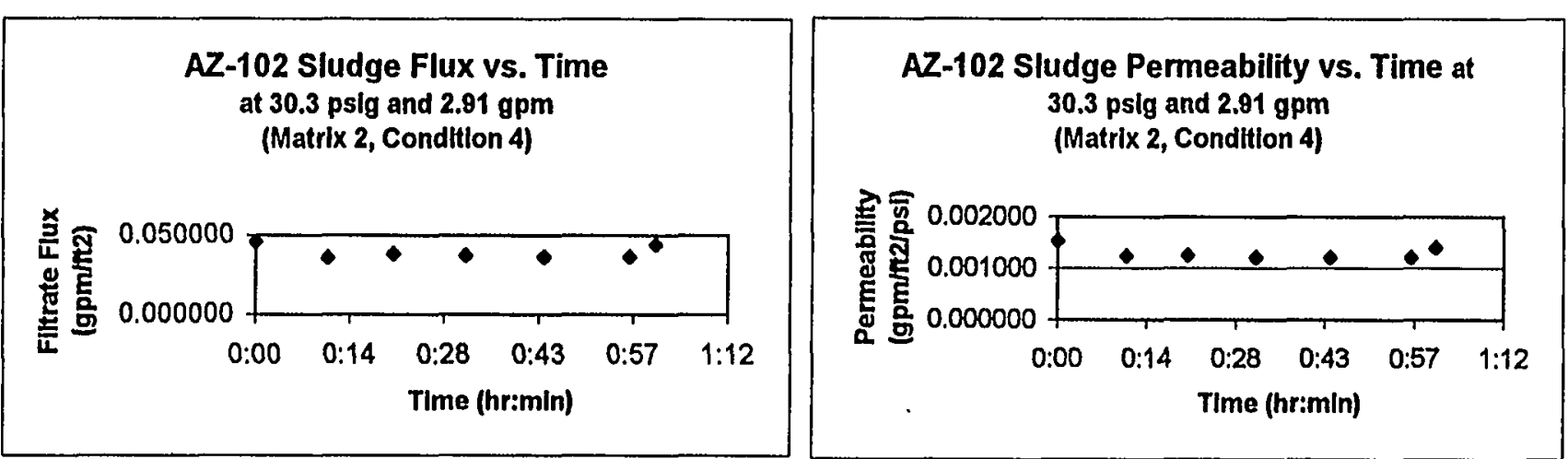


\begin{tabular}{|c|c|c|c|c|c|c|c|c|c|c|c|c|c|c|c|}
\hline $\begin{array}{l}\text { Condition } \\
\text { Number }\end{array}$ & Time & & $\begin{array}{l}\text { Total Time } \\
\text { Elapsed } \\
\text { (Min) }\end{array}$ & $\begin{array}{l}\text { Slumy } \\
\text { Loop Flow } \\
\text { Rale } \\
\text { (gpm) }\end{array}$ & $\begin{array}{l}\text { Filter } \\
\text { Outlet } \\
\text { Pressure } \\
\text { (psig) }\end{array}$ & $\begin{array}{l}\text { Filter Inlet } \\
\text { Pressue } \\
\text { (psig) }\end{array}$ & $\begin{array}{l}\text { Pressure } \\
\text { Drop } \\
\text { (psig) }\end{array}$ & $\begin{array}{l}\text { Filtrate } \\
\text { Sample } \\
\text { Volume } \\
\text { (mL) }\end{array}$ & $\begin{array}{l}\text { Time of } \\
\text { Collection } \\
\text { (Sec) }\end{array}$ & $\begin{array}{l}\text { Filtrate } \\
\text { Flow Rate } \\
\text { (mL/sec) }\end{array}$ & Slurry Temp C & $\begin{array}{l}\text { Filtrate Flux } \\
(\mathrm{m} 3 / \mathrm{m} 2 / \text { day })\end{array}$ & $\begin{array}{l}\text { Permeability } \\
\text { (m/day/bar) }\end{array}$ & $\begin{array}{l}\text { Filtrate } \\
\text { Flux } \\
\text { (gpm/ft2) }\end{array}$ & $\begin{array}{l}\text { Permeability } \\
\text { (gpm/t2/psi) }\end{array}$ \\
\hline & 65 & $5: 24$ & $0: 00$ & 2.5 & 49 & 51 & & $2 \quad 20$ & 37.02 & 0.540 & 22.5 & 2.747 & 0.797 & 0.046831 & 0.000936 \\
\hline & 6 & $5: 38$ & $0: 14$ & 2.7 & 47 & 52 & & 20 & 42.48 & 0.471 & 28.2 & 2.040 & 0.598 & 0.034774 & 0.000702 \\
\hline & 6 & $5: 49$ & $0: 25$ & 3.5 & 43 & 50 & & 20 & 107.76 & 0.186 & 23.4 & 0.920 & 0.287 & 0.015680 & 0.000337 \\
\hline & 6 & $5: 59$ & $0: 35$ & 3.3 & 45 & 50 & & 10 & 48.59 & 0.206 & 24.6 & 0.986 & 0.301 & 0.016806 & 0.000354 \\
\hline & 6 & $6: 13$ & $0: 49$ & 3.35 & 42 & 48 & & 10 & 51.75 & 0.193 & 25.5 & 0.902 & 0.291 & 0.015385 & 0.000342 \\
\hline & 6 & $6: 27$ & $1: 03$ & 3.2 & 45 & 52 & & 10 & 48.75 & 0.205 & 24.6 & 0.983 & 0.294 & 0.016751 & 0.000345 \\
\hline & Averao & & Flow $=$ & $\begin{array}{r}\text { Average } \mathrm{Pr} \\
3.09\end{array}$ & ressure = & 47.83333 & & $\begin{array}{l}\text { Average Fl } \\
\text { Fillrate }\end{array}$ & low $=$ & 0.300 & $\begin{array}{l}\text { Average Flux = } \\
\text { First point remove }\end{array}$ & 1.166 & & & \\
\hline
\end{tabular}
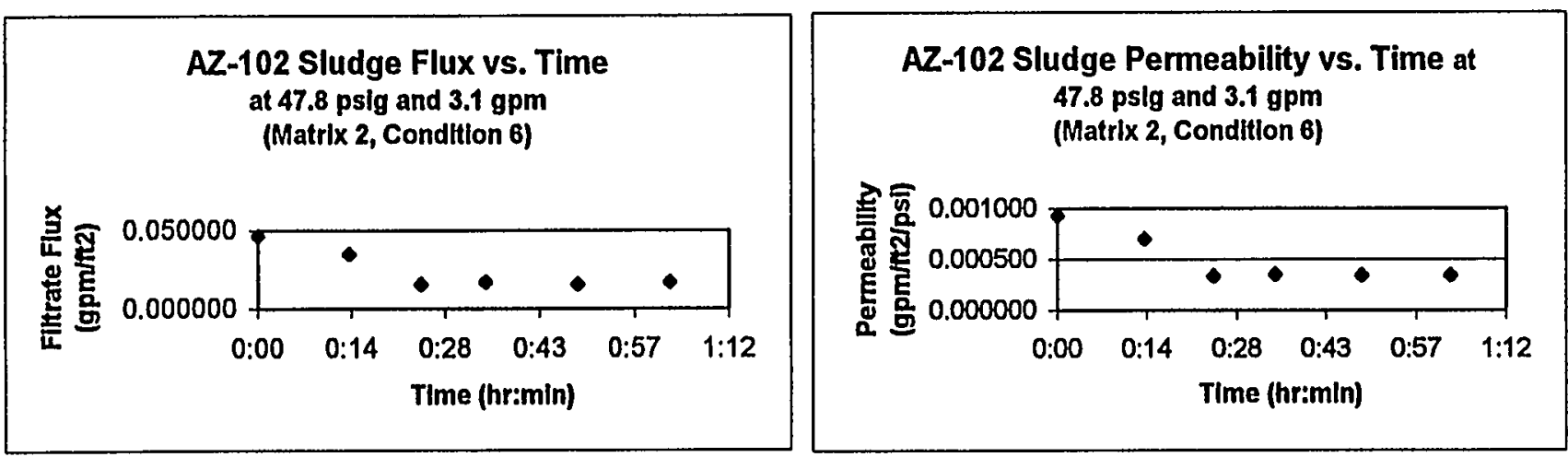


\begin{tabular}{|c|c|c|c|c|c|c|}
\hline $\begin{array}{l}\text { Condition } \\
\text { Number }\end{array}$ & Time & $\begin{array}{l}\text { Total Time } \\
\text { Elapsed } \\
\text { (Min) }\end{array}$ & $\begin{array}{l}\text { Slurry } \\
\text { Loop Flow } \\
\text { Rate } \\
\text { (gpm) }\end{array}$ & $\begin{array}{l}\text { Filter } \\
\text { Outlet } \\
\text { Pressure } \\
\text { (psig) }\end{array}$ & $\begin{array}{l}\text { Filter Inlet } \\
\text { Pressue } \\
\text { (psig) }\end{array}$ & $\begin{array}{l}\text { Pressur } \\
\text { Drop } \\
\text { (psig) }\end{array}$ \\
\hline 7 & $6: 43$ & $0: 00$ & 3.8 & 28 & 30 & \\
\hline 7 & $6: 53$ & $0: 10$ & 4 & 27 & 30 & \\
\hline 7 & $7: 03$ & $0: 20$ & 4.05 & 27 & 30 & \\
\hline 7 & $7: 14$ & $0: 31$ & 3.95 & 28 & 31 & \\
\hline 7 & $7: 23$ & $0: 40$ & 4 & 28 & 32 & \\
\hline 7 & $7: 33$ & $0: 50$ & 4.05 & 28 & 32 & \\
\hline 7 & $7: 43$ & 1:00 & 3.95 & 28 & 32 & \\
\hline
\end{tabular}

\section{Filtrate Filtrate}

$2^{(m L)} 20$

Average Pressure $=$

29.35714

RAW Average Slurry Flow $=\quad 3.97$

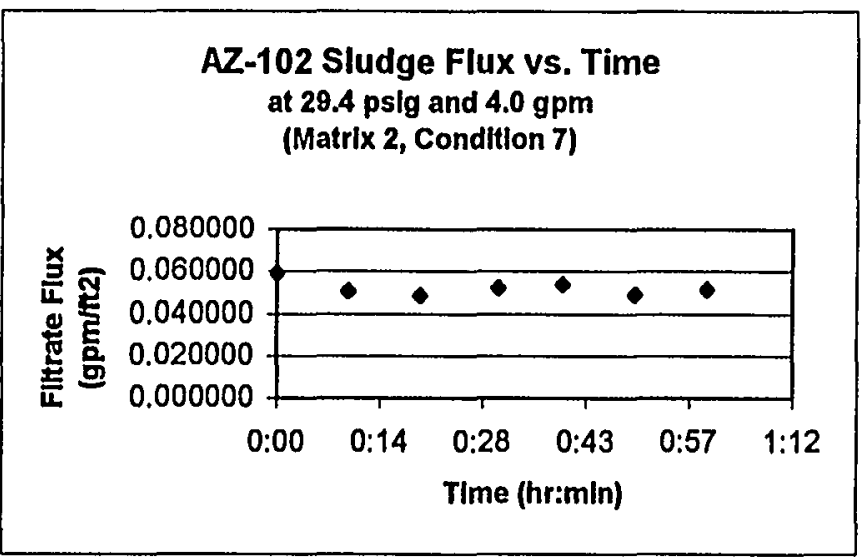

Sample Time of Flow Rate

Volume Collection (mL/sec)

$(\mathrm{mL})$

(Sec)

29.7

$29.77 \quad 0.672$

$32.59 \quad 0.614$

$31.59 \quad 0.633$

$33.84 \quad 0.591$

$42.5 \quad 0.706$

$\begin{array}{rr}49.74 & 0.603\end{array}$

$50.48 \quad 0.594$

Permeability

(m/day/bar)

Fitrate Flux

(m3/m2/day)

$\begin{array}{rr}22 & 3.465 \\ 24.3 & 2.965\end{array}$

$26.8 \quad 2.851$

$21.8 \quad 3.066$

$27.1 \quad 3.153$

$24.7 \quad 2.881$

$22.5 \quad 3.022$

0.630

Average Flow $=$

Filtrate
Filtrate

Flux

(gpm/ft2)

0.059076

0.050540

0.048609

0.052271

0.053746

0.049113

0.051515
Permeability

(gpm/ft2/psi)

\subsection{6}

0.001772

0.001704

0.001771

0.001790

0.001636

0.001716

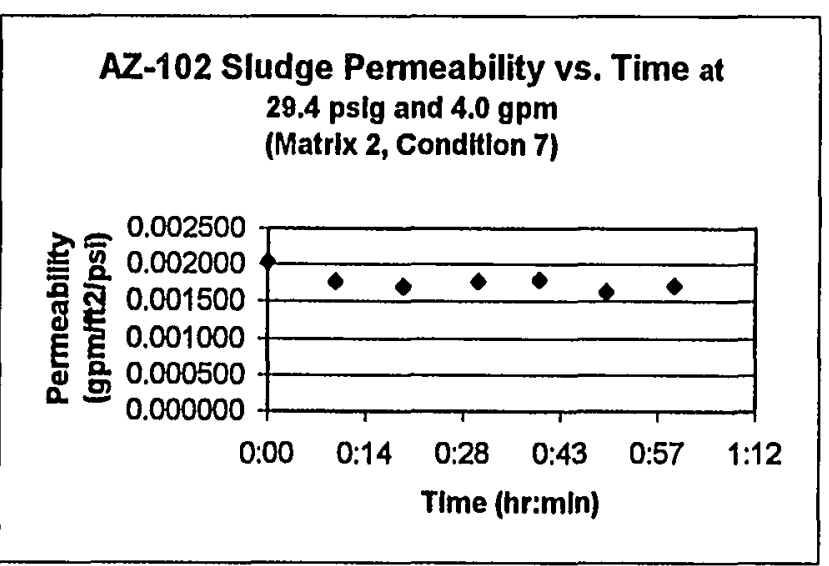




\section{Appendix E: Physical Properties Test Instruction}




\section{Appendix E: Physical Properties Test Instruction}

E.1 
NP\$ $w 4559$

\section{PNNL Test Instruction}

Document No.: BNFL-TP-29953-078

Rev. No.: 0

Title: BNFL Ultrafiltration Physical Testing: AZ-102

Work Location: Radiochemical Processing Laboratory

Author: Paul Bredt

Use Category Identification: Reference

Identified Hazards:

Radiological

Effective Date: Upon Final Approval

Supersedes Date: New

Required Reviewers:

X Technical Reviewer

Hazardous Materials

_ Physical Hazards

Hazardous Environment

- Other:

Are One-Time Modifications Allowed to this Test Instruction?

$\underline{X}$ Yes _ No

NOTE: If Yes, then modifications are not anticipated to impact safety. For documentation requirements of a modification see SBMS or the controlling Project QA Plan as appropriate.

On-The Job Training Required?

$$
\text { Yes or } \mathrm{X} \text { No }
$$

FOR REVISIONS:

Is retraining to this procedure required? ___ Yes $\mathrm{X}$ No

Does the OJT package associated with this procedure require revision to reflect procedure changes?

Yes

No

$\mathrm{X}$ N/A

Approval

Signature

Date

Author

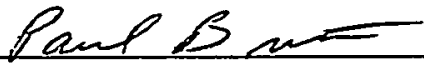

$1 / 17100$

Technical Reviewer

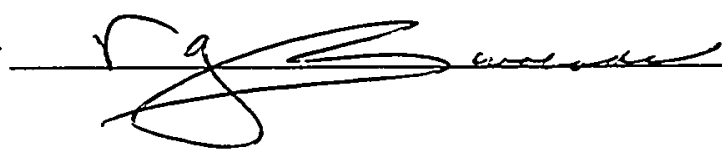

$i / i 700$ 


\section{BNFL Ultrafiltration Physical Testing: AZ-102}

\section{Scope:}

This test instruction defines work to be conducted on slurry samples collected during the ultrafiltration of materials from tanks 241-AZ-102. Under this test instruction, samples of the concentrated slurry (CUF-AZ102-006), caustic leached slurry (CUF-AZ102-012), and final slurry (CUF-AZ102-025) will be analyzed for select physical properties.

This test instruction provides details regarding the implementation of Technical Procedure 29953010. Client expectations for successful achievement of project data needs have already been established via the ultrafiltration test specifications provided to Battelle by BNFL. This test instruction is an internal mechanism for the cognizant scientist, to communicate to staff specifics on procedure implementation.

\section{General Instructions:}

1) Keep the sample in a sealed container as much as possible to prevent it from drying.

2) Sign and date the bottom of each page when the requested analyses are complete.

3) Cross-contamination between samples and contamination of samples from outside sources must be minimized at each step. Use new tools and bottles for each sample as much as possible. Those tools which are reused should be washed and rinsed prior to reuse.

\section{M\&TE List:}

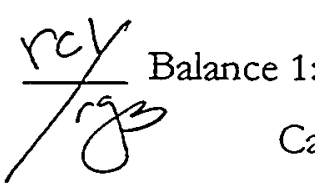

Calib ID $388-\phi 6-61-020$

Location $325 / 601 / C$ cell
Calib Exp Date $8 / 2000$

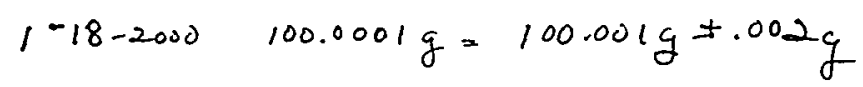

Balance 2

Calib ID

Calib Exp Date

Location
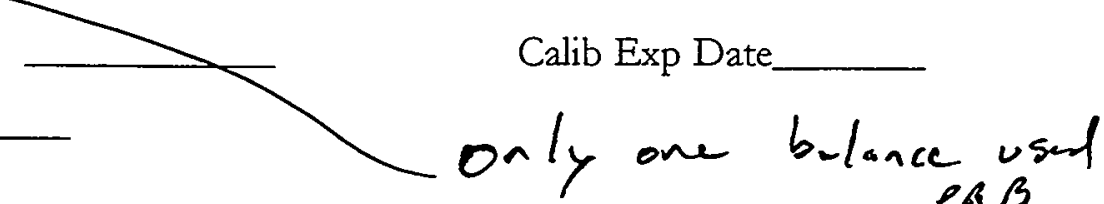

$\rho R B$

$6 / 9 / 00$

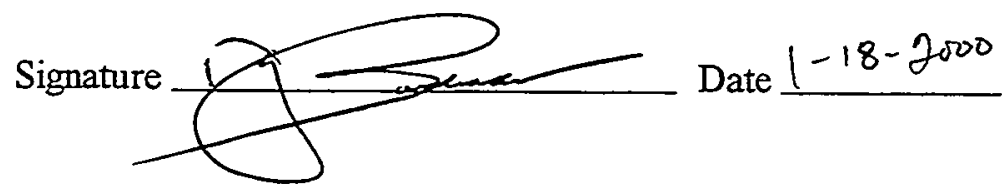


PR Bredt

January 17,2000
Test Instruction: TI-29953-078

Page 3 of 12

\section{Work Instructions}

1) Thoroughly agitate samples CUF-AZ102-006,CUF-AZ102-012, and CUF-AZ102-025 and transfer $\sim 8 \mathrm{ml}$ of each in duplicate into preweighed graduated $10 \mathrm{ml}$ centrifuge cones. These cones need to be rate for use at $\sim 105^{\circ} \mathrm{C}$. Weigh the loaded centrifuge cones.

$6 \mathrm{~A}$

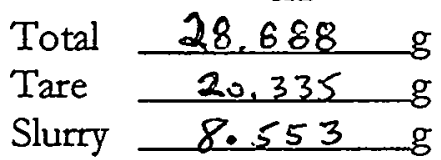

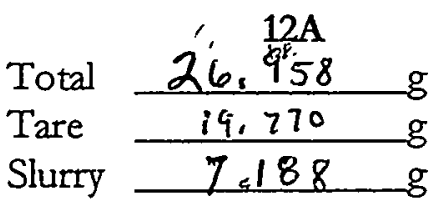

$\begin{array}{lc}\text { Total } & \frac{27.985}{19.98} \mathrm{~g} \\ \text { Tare } & \frac{19.992}{9.993} \mathrm{~g} \\ \text { Slurry } & \end{array}$ \begin{tabular}{lcr} 
& \multicolumn{1}{c}{$6 \mathbf{B}$} \\
Total & 28.739 & $\mathrm{~g}$ \\
Tare & 20.118 & $\mathrm{~g}$ \\
Slurry & 8.321 & $\mathrm{~g}$
\end{tabular}

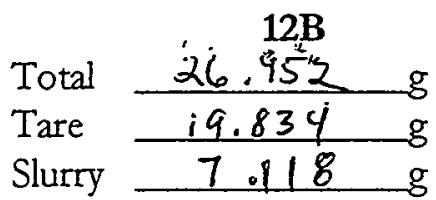

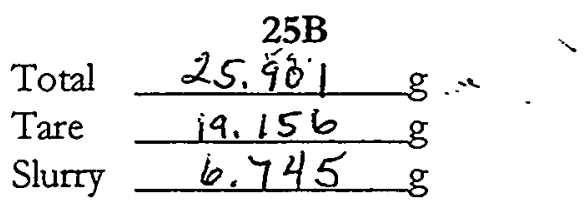

2) Agitate the cones and record the time and date. Not rearly secueny $(r y 3)$

Time $\beta: 3=19 \mathrm{~m}$ Date $1-19-2000$

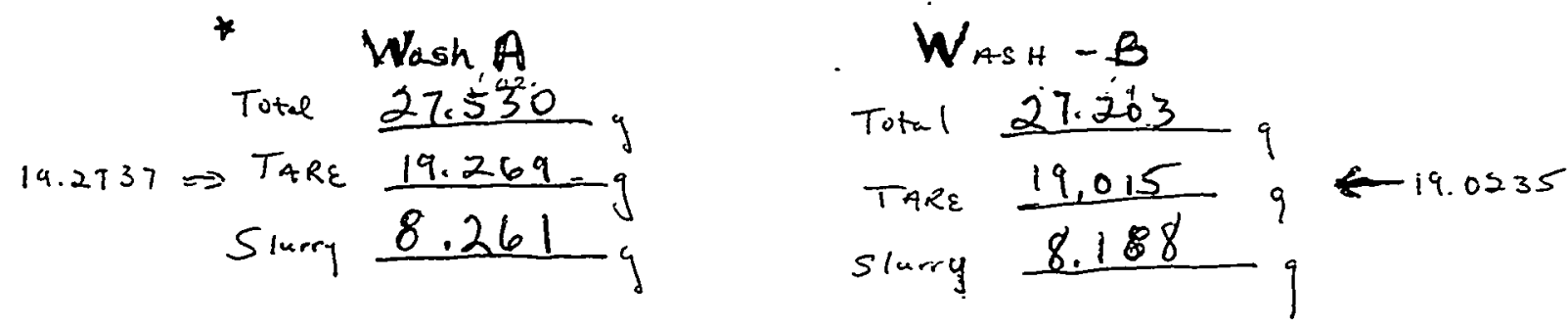

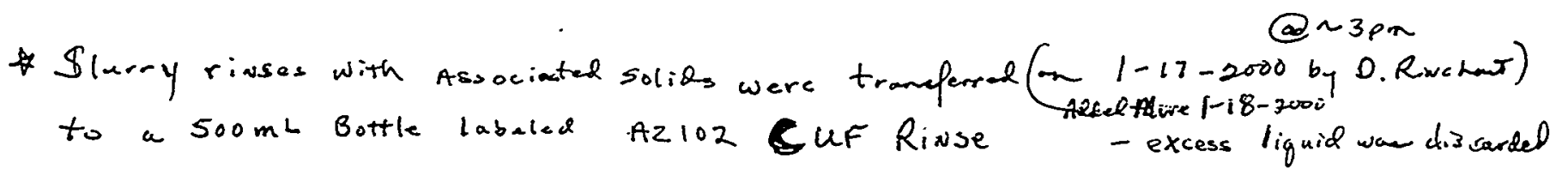
1-19-2000 The Liguid hayer wat removed tempormicly \& Solids were Ag.tuted prion to taking $228 \mathrm{~mL}$ Aligasts Above (See Attached Adedewean to this testplan ]

Signature

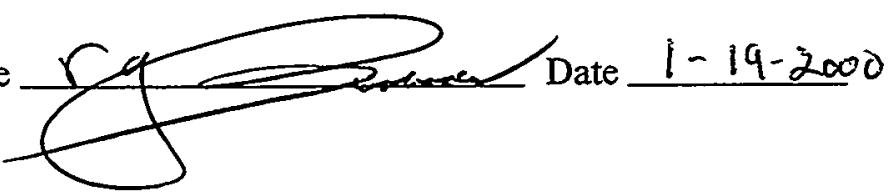


PR Bredt

January 17,2000
Test Instruction: TI-29953-078

Page 4 of 12

3) One hour after agitation, record the volume of the total sample and the volume of settled solids.

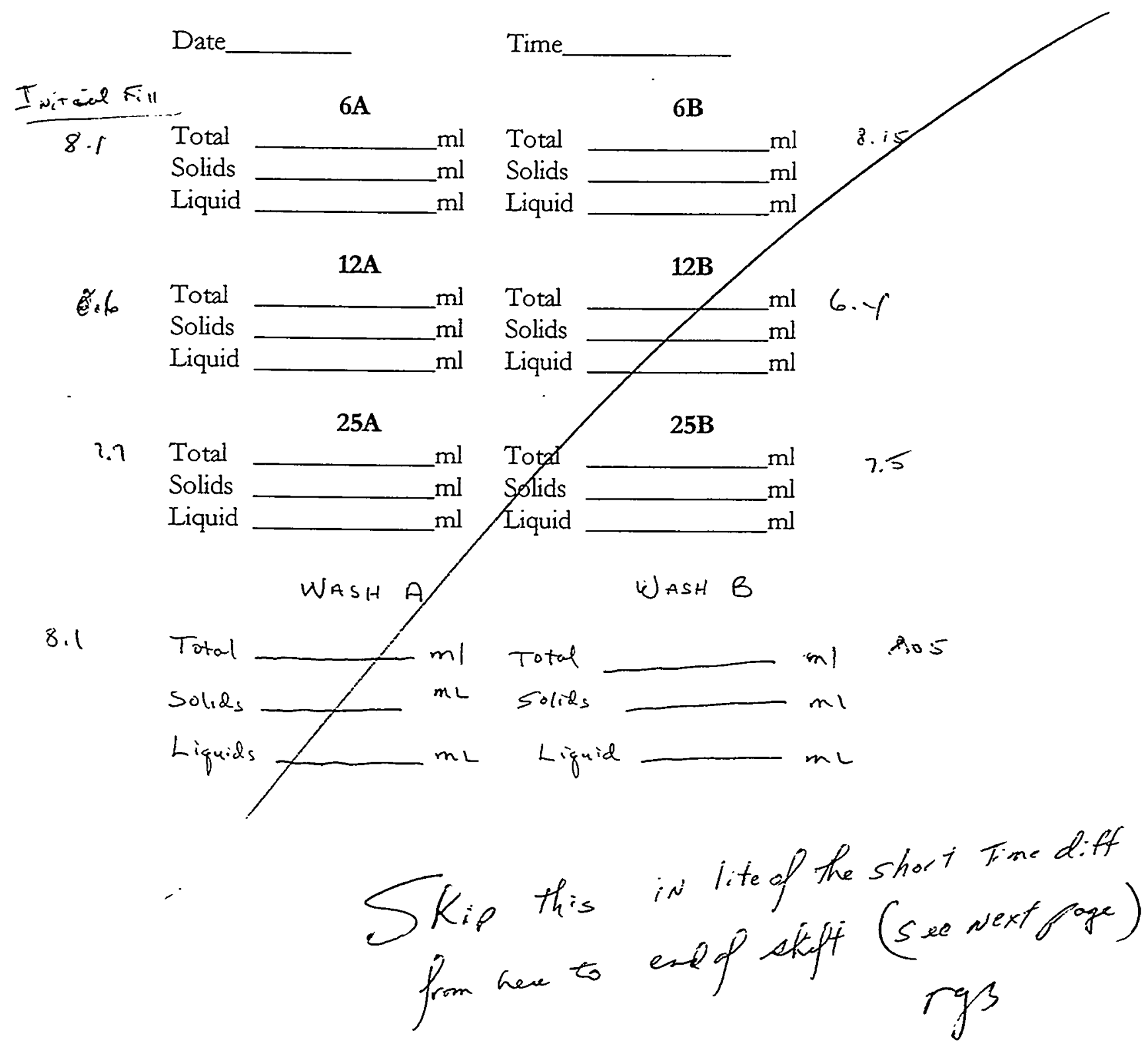

Signature 
PR Bred

January 17,2000
Test Instruction: TI-29953-078

Page 5 of 12

Note:

The following steps (4-9) are used to record data from the settling study. It is not necessary to record data in each step or at the specific time as stated, but data should be record as often as possible to document the stability of the final volume measurements in step 9.

4) Before the end of the shift (day 1), record the volume of the total sample and the volume of settled solids.

Date $1-19-2000 \quad$ Time $15: 30 \mathrm{~m}$.
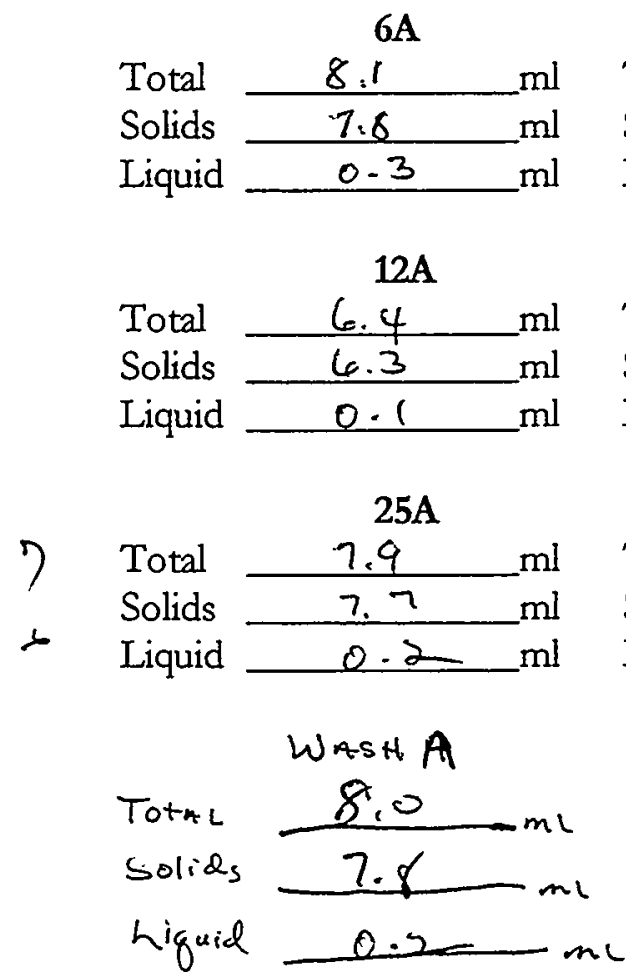
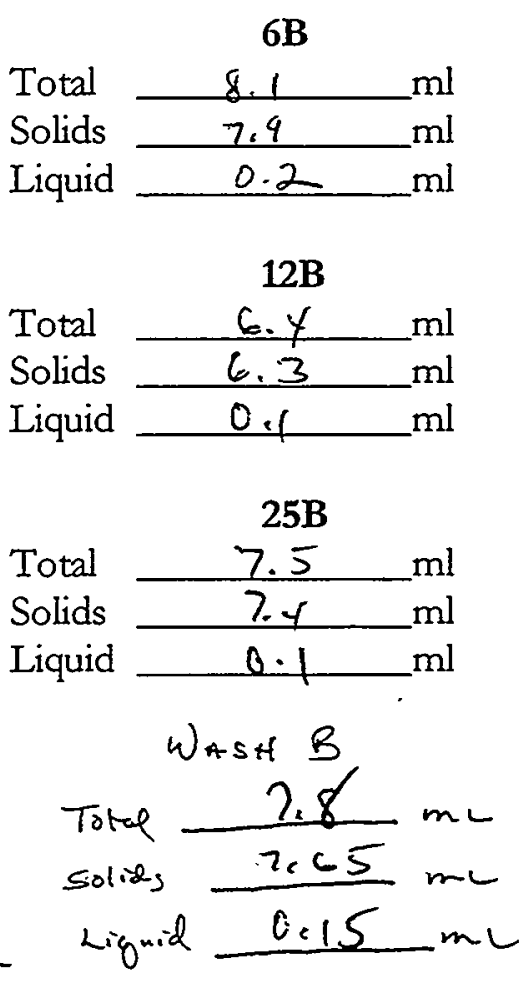

Signature 
5) At the start of the next day (day 2), record the volume of the total sample and the volume of settled solids.

$$
\begin{aligned}
& \text { Date } 1-20-00 \quad \text { Time } 8020-\text { ter }
\end{aligned}
$$

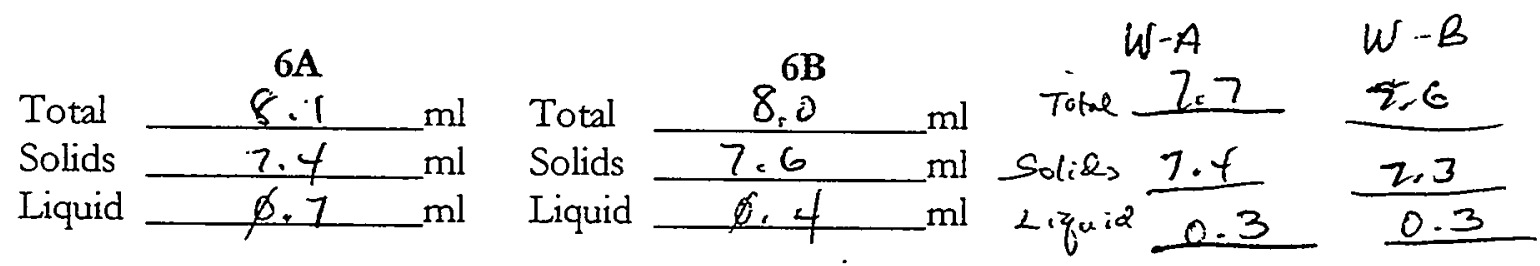

$$
\begin{aligned}
& 12 \mathrm{~A} 12 \mathrm{~B}
\end{aligned}
$$

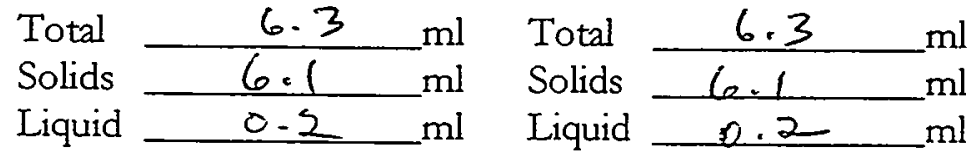

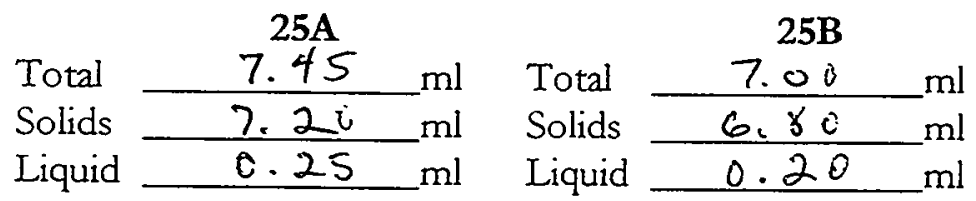

6) At the end of the day (day 2), record the volume of the total sample and the volume of settled solids.

Date $1-20-00$

$6 \mathrm{~A}$

Total $\frac{7.80}{7.35} \mathrm{ml}$
Solids $\mathrm{ml}$
Liquid
$\mathrm{ml}$

Total $\frac{6.3}{6.0} \mathrm{ml}$
Solids
Liquid
$\frac{0.3}{\mathrm{ml}}$

25A

Total $\frac{7.45}{7.2} \mathrm{ml}$
Solids $\frac{\mathrm{ml}}{0.25 \mathrm{ml}}$
Liquid
Time.15:00 hr

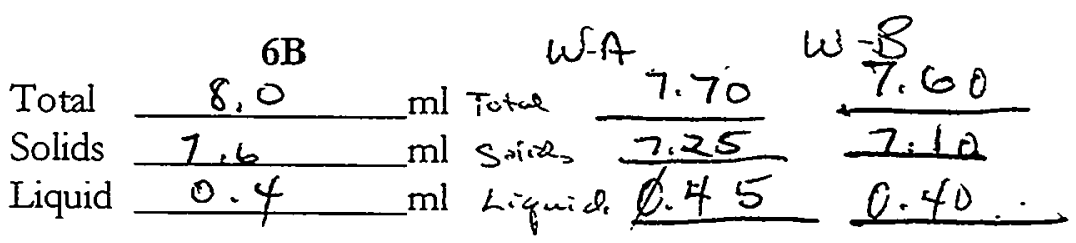

$12 B$

Total $\frac{6.3}{6.1} \mathrm{ml}$
Solids $\mathrm{ml}$
Liquid $\frac{0.2}{\mathrm{ml}}$

$25 B$

Total $7.0 \mathrm{ml}$

Solids $\frac{6.8}{6 l}$

Liquid $0.2 \mathrm{ml}$

Signature $r$ Sate $1-20-00$ 
7) At the start of the next day (day 3), record the volume of the total sample and the volume of settled solids.

Date $i-2 i-2000$

$6 \mathrm{~A}$

Total

Solids

Liquid

$\frac{7.7}{7.3} \mathrm{ml}$

\section{$0800 \mathrm{~h}$}

Time

\begin{tabular}{|c|c|c|c|c|}
\hline \multicolumn{3}{|c|}{$12 \mathrm{~A}$} & \multirow{4}{*}{$\begin{array}{l}\text { Total } \\
\text { Solids } \\
\text { Liquid }\end{array}$} & $12 B$ \\
\hline Total & 6.2 & $\mathrm{ml}$ & & $6-2$ \\
\hline Solids & 6.0 & $\mathrm{ml}$ & & 6.0 \\
\hline Liquid & 0.2 & $\mathrm{ml}$ & & $0.2 \mathrm{ml}$ \\
\hline & $25 \mathrm{~A}$ & & & $25 B$ \\
\hline Total & 7.50 & $\mathrm{ml}$ & Total & 7.00 \\
\hline Solids & 7.10 & $\mathrm{ml}$ & Solids & 6.60 \\
\hline Liquid & O. if & $\mathrm{ml}$ & Liquid & 0.4 \\
\hline
\end{tabular}

8) At the end of the day (day 3), record the volume of the total sample and the volume of settled solids.

Date $|-2|-2000$

$6 \mathrm{~A}$

\begin{tabular}{|c|c|}
\hline Total & 7.7 \\
\hline Solids & 2.3 \\
\hline Liquid & 0.4 \\
\hline
\end{tabular}

$\begin{array}{lc} & 12 \mathrm{~A} \\ \text { Total } & 6.2 \\ \text { Solids } & \frac{6.0}{0.2} \mathrm{ml} \\ \text { Liquid } & \mathrm{ml}\end{array}$
Time 25500

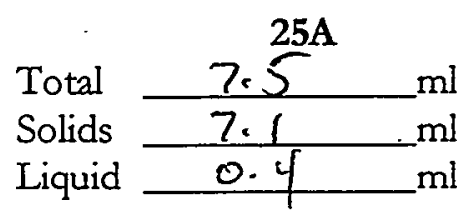

$\begin{array}{ll}\text { Total } & 8.0 \\ \text { Solids } & \mathrm{ml} \\ \text { Liquid } & \mathrm{ml}\end{array}$
ml l $\mathrm{ml}$ 
PR Bredt

January 17,2000

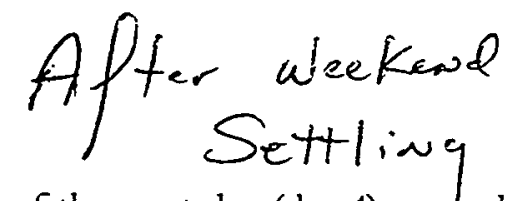

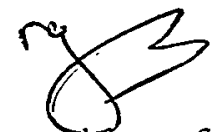

Test Instruction: TI-29953 078

Page 8 of 12

9) At the beginning of the next day (day 4), record the volume of the total sample and the volume of settled solids.
Date $1 / 2+/$ do
Time $10 \mathrm{Am}$

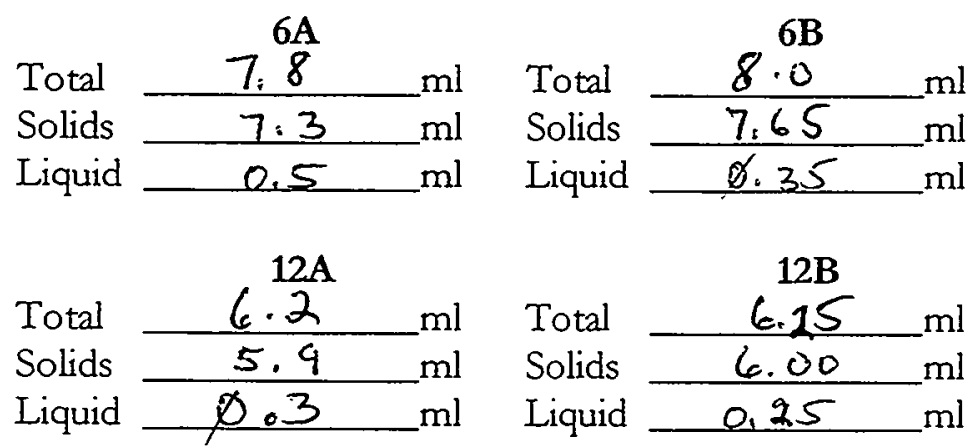

\begin{tabular}{|c|c|c|c|c|c|}
\hline & $25 \mathrm{~A}$ & & & $25 \mathrm{E}$ & \\
\hline Tota & 7.50 & _ml & Total & 7.0 & _ml \\
\hline Solids & 7.10 & _ml & Solids & 6.8 & $\mathrm{ml}$ \\
\hline Liquid & 0.40 & m $\mathrm{ml}$ & Liquid & 0.4 & m \\
\hline
\end{tabular}

10) Transfer a sample of the settled supernatant into a preweighed graduated cylinder and record the mass and volume of the supernatant. Return the supernatant to the centrifuge cone.

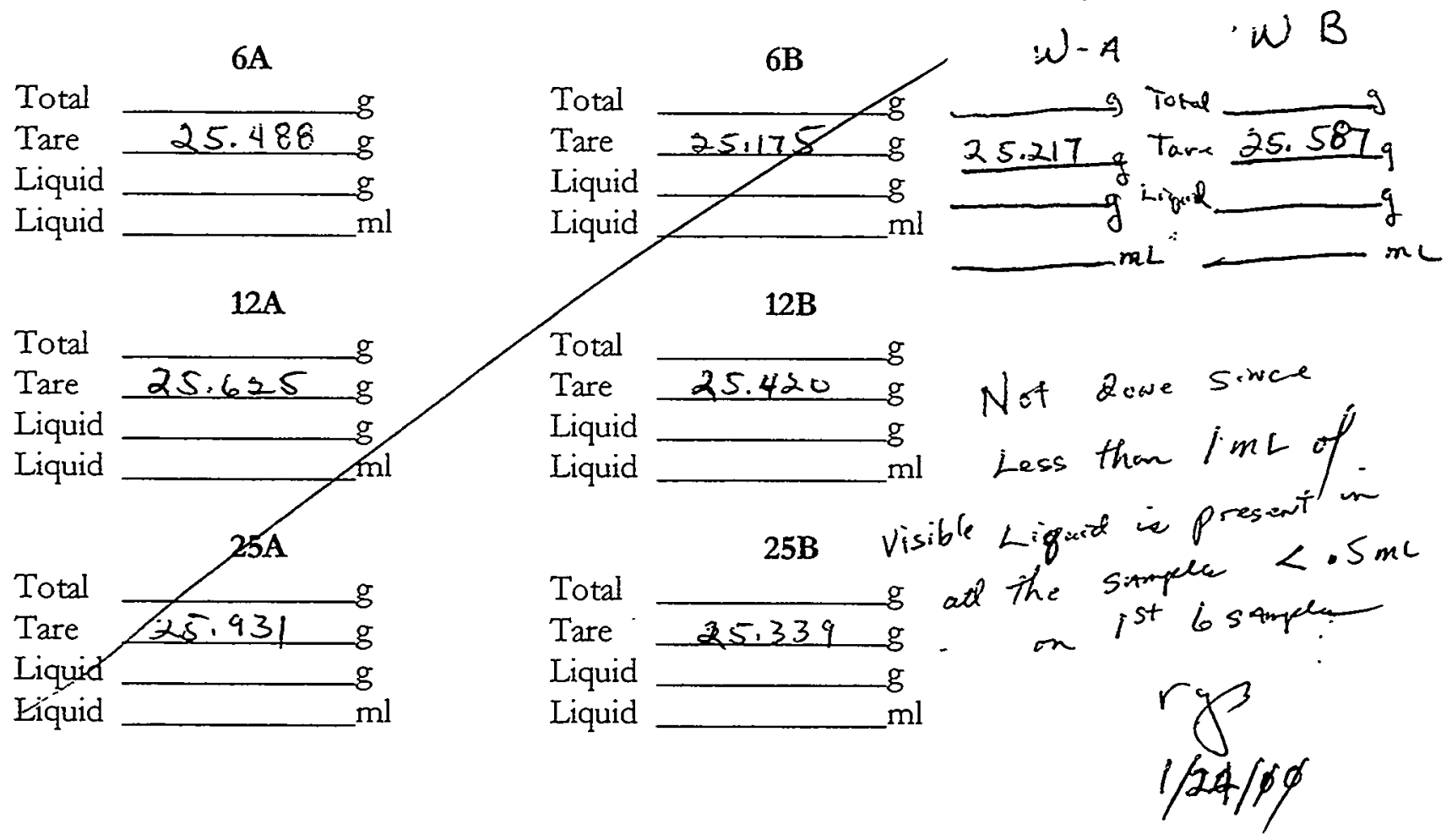

Signature $\frac{1 / 24 / 66}{1 / 5}$ Date $(/ 24 / \% \%$ 
Bazars Check $200 \mathrm{~g}=199.995 \mathrm{~g}$

$M T \notin 2 \# 388-06-4-220$ jog $=99.997 \mathrm{~g}$

PR Bred

Lac. $325 / 60 \%$ ceil

January 17,2000 .

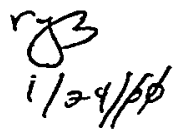

Test Instruction: TI-29953-078

Page 9 of 12

11) Centrifuge the cones at $\sim 1000 \mathrm{x} g$ for one hour. Reweigh the centrifuge cones and record the volume of the total sample and volume of centrifuged solids.

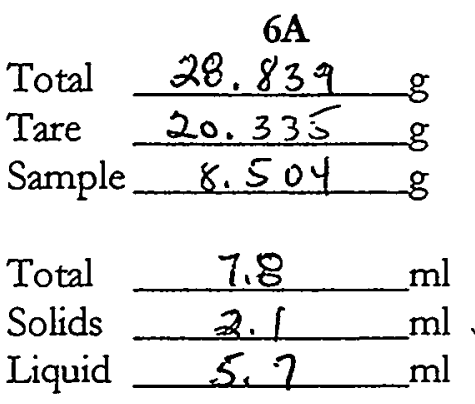

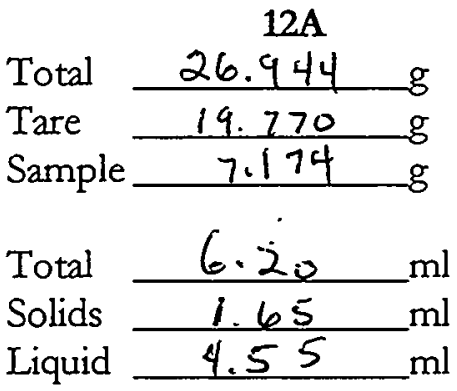

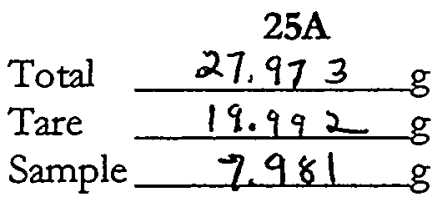

Total $\frac{2.60}{1.60} \mathrm{ml}$
Solids
Liquid
$\mathrm{ml}$

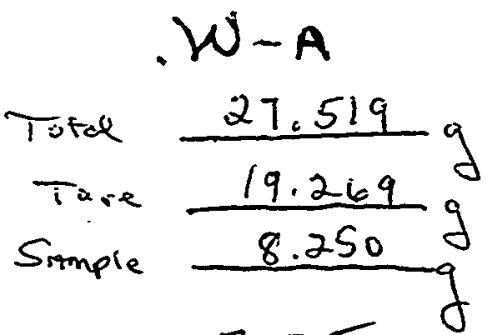

\begin{tabular}{lll} 
& \multicolumn{1}{c}{$6 \mathrm{~B}$} \\
Total & 28.432 & $\mathrm{~g}$ \\
\cline { 2 - 3 } & 20.118 & $\mathrm{~g}$ \\
Tare & 8.314 & $\mathrm{~g}$
\end{tabular}

$\begin{array}{ll}\text { Total } & \frac{7.7}{2.0} \mathrm{ml} \\ \text { Solids } & \mathrm{ml} \\ \text { Liquid } & \mathrm{5.1}\end{array}$

Total $\frac{26.916 \mathrm{~g}}{19.834 \mathrm{~g}}$
Tare
Sample $7.082 \mathrm{~g}$

$\begin{array}{ll}\text { Total } & \text { G. } 10 \\ \text { Solids } & 1.70 \\ \text { Liquid } & 4.40 \\ \end{array}$

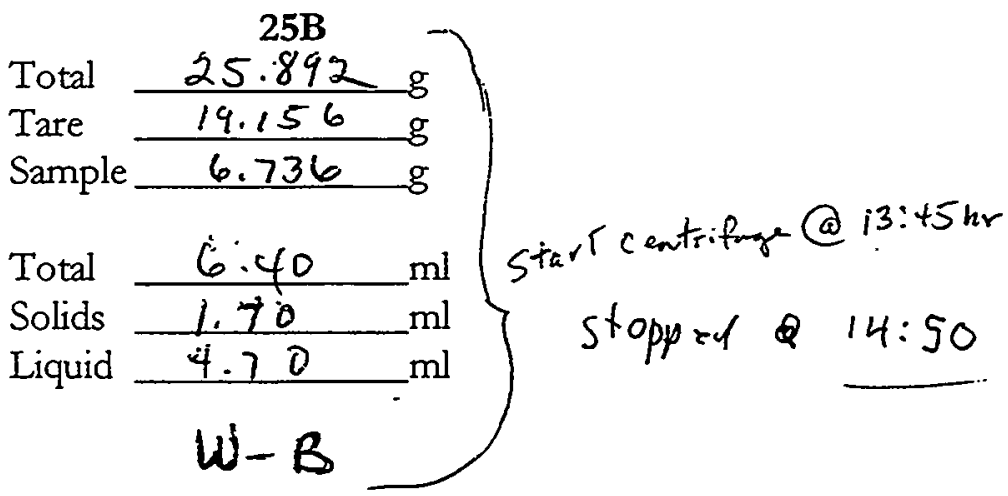

Total $\frac{27.188}{19.015} \mathrm{~g}$
Tore $\frac{19.173}{\text { S }} \mathrm{q}$

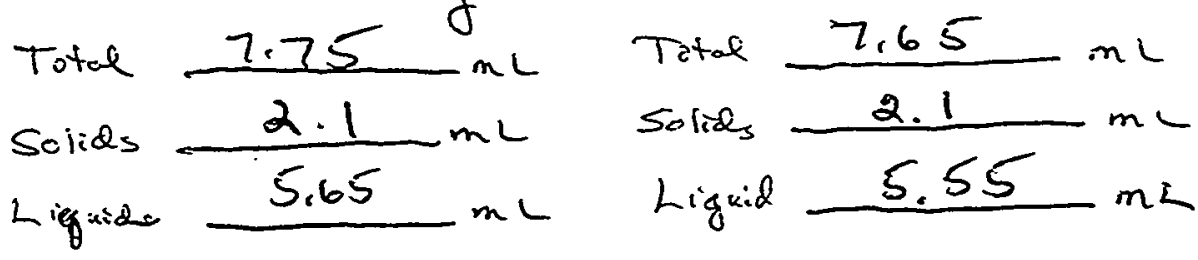

Signature

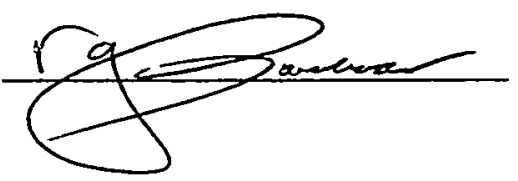

Date

Stat 1/2410\%

Stoppel@12:45 
PR Bredt

January 17,2000

Test Instruction: TI-29953-078

Page 10 of 12

12) Decant as much of the centrifuged supernatant as possible to a preweighed graduated cylinder and record the mass and volume of the supernatant. Weigh the solids left in the centrifuge cone.

$6 \mathrm{~A}$

$\begin{array}{lll}\text { Liquid+Grad } & \frac{31.128}{25.488} \mathrm{~g} & \text { Liquid+Grad } \\ \text { Grad } & \frac{5.64}{5} \mathrm{~g} & \text { Grad } \\ \text { Liquid } & \frac{5.55}{2} \mathrm{ml} & \text { Liquid } \\ \text { Liquid } & =1.0162 \mathrm{~g} / \mathrm{me} & \text { Liquid }\end{array}$

Solidstcone

Cone

Solids

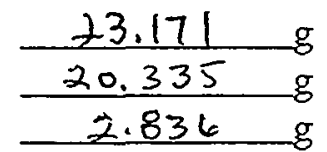

$12 \mathrm{~A}$

Spillel troperto

$S=-x$

Liquid + Grad

Grad

Liquid

Liquid

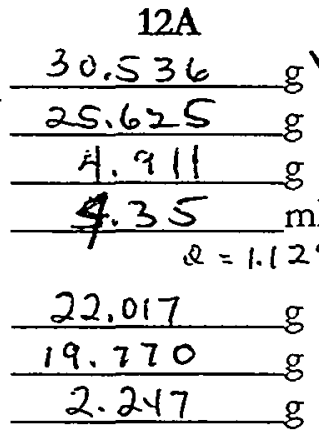

Solidst cone

Cone

Solids

$\begin{array}{ll} & 25 \mathrm{~A}<A l s o \\ \text { Liquid+Grad } & 28.271 \mathrm{~g} \\ \text { Grad } & \frac{25.931}{2.340} \mathrm{~g} \\ \text { Liquid } & \frac{2.340}{2.250} \mathrm{ml} \\ \text { Liquid } & \frac{2=1.040}{}\end{array}$

Solids+cone

Cone

Solids

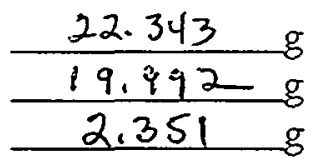

W-A

Liguiey Geno

Grad.

Liguid

Liguid

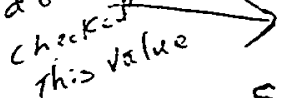

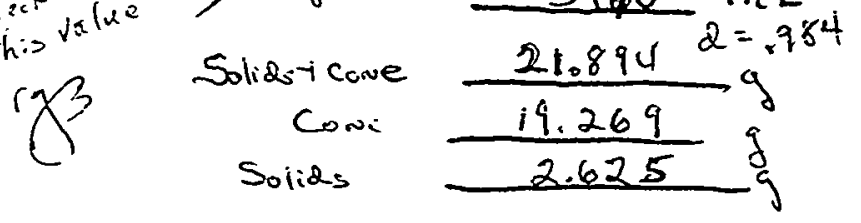

Signature

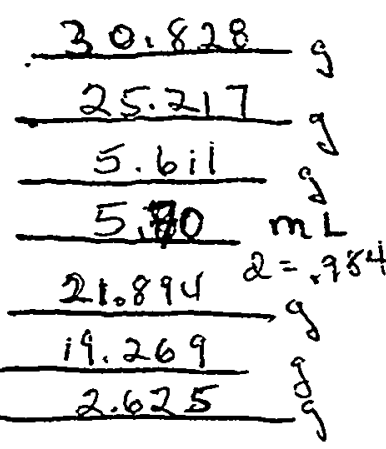

Solidstcone

Cone

Solids

$\begin{array}{ll}26.509 & \text { Liquid+Grad } \\ 25.655 & \text { Grad } \\ 0.884 & \text { Liquid } \\ \frac{0.80}{i .11} & \text { Liquid } \\ & \text { Solids+cone } \\ & \text { Cone } \\ & \text { Solids }\end{array}$

so spillek trumefer to grak. some in tron

Liquid+Grad

Grad

Liquid

Liquid

Solids+cone

Cone

Solids
$6 \mathrm{~B}$
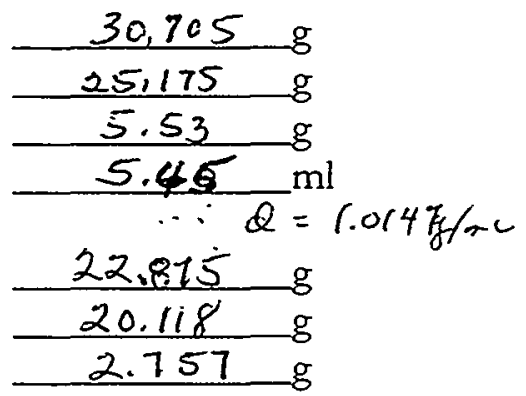

$12 B$

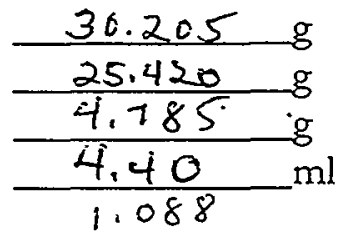

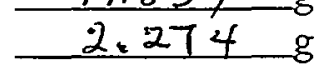
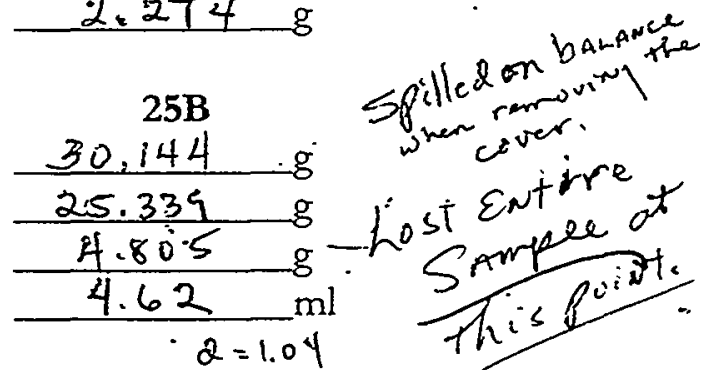

host Entire ot

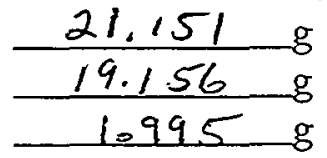

列

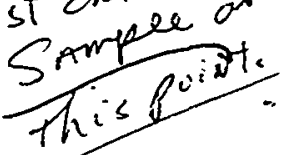


January 17,2000

Balance Check $\quad 100 \mathrm{~g}=99.998^{\circ}$ i

$m \& T E * 388-06-0 i-020$

13) Transfer the decanted supernatant to preweighed $20 \mathrm{ml}$ vials with lids rated to $105^{\circ} \mathrm{C}$. Weigh the loaded beakers.

6AL

Total

Tare

Supernatant

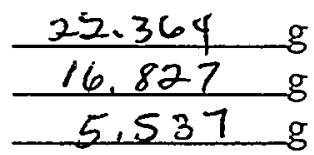

$12 \mathrm{AL}$

Total

Tare

Supernatant

$$
\begin{array}{r}
17.742 \\
\hline 17.012 \\
\hline 0.730 \\
\hline
\end{array}
$$

25AL

Total

Tare

Supernatant

\begin{tabular}{rr}
19.080 & $g$ \\
\hline 17.018 & $g$ \\
\hline 2.062 & $g$
\end{tabular}

Total

Tare

Supernatant

\begin{tabular}{rr}
22.267 & $g$ \\
16.882 & $g$ \\
\hline 5.385 & $g$
\end{tabular}

12BL

Total

Tare

Supernatant

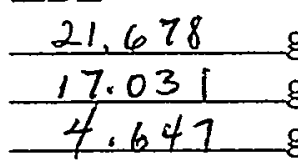

25BL

Total

Tare

Supernatant
W.AL

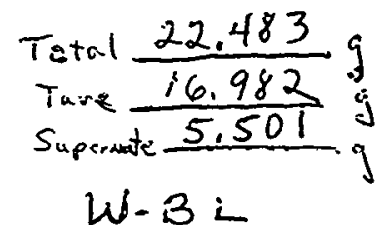

W. $3 i$

Page 11 of 12

14) Air dry the solids and liquids overnight to minimize splattering during the next drying step.

Consult the cognizant scientist on the use of a heat lamp or other drying technique to speed up this preliminary drying.

15) Transfer the solids and liquids to an oven at $105^{\circ} \mathrm{C}$ for 24 hours.

16) Remove the solids and liquids from the oven and cap the vials. Allow the vial to cool $\sim 1$ hour and reweigh.

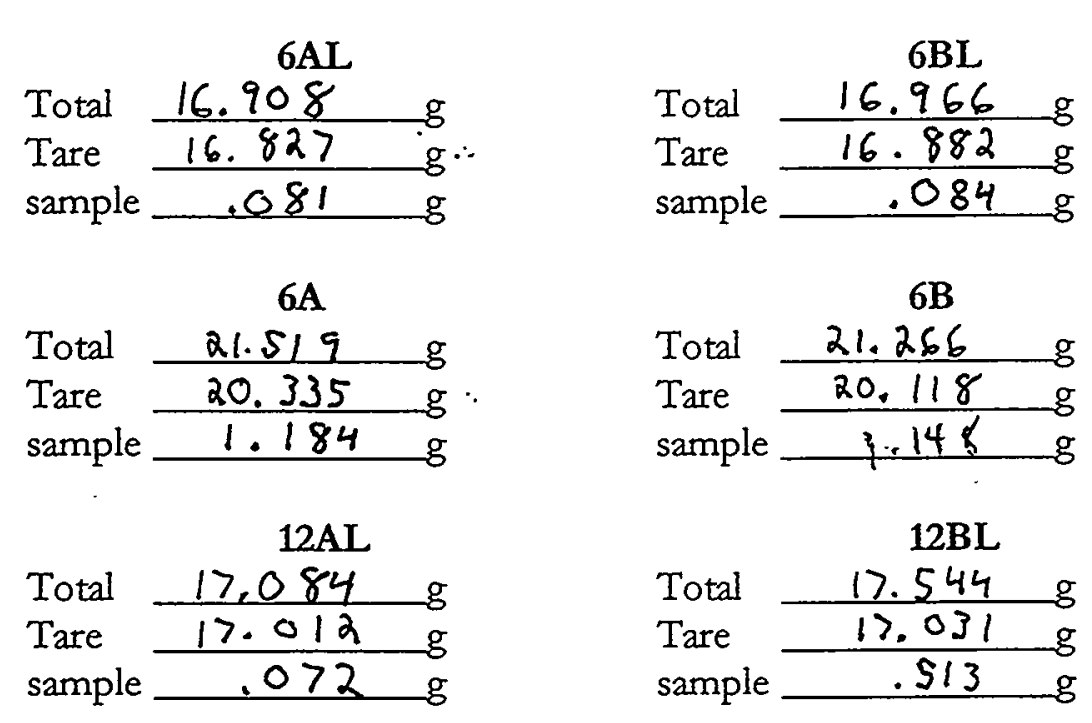

=W-AL $\quad W-B L$

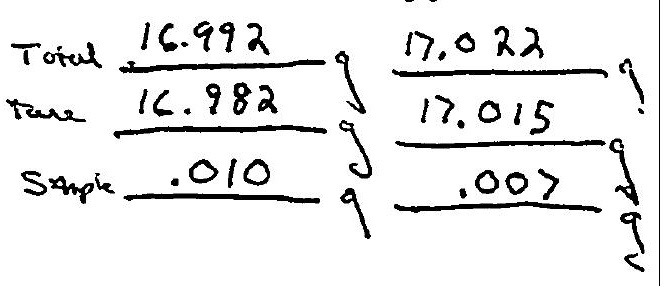

signature Xan thehas Date $2 / 2 / 00$ 
PR Bredt

Januairy 17, 2000
Test Instruction: TI-29953-078

Page 12 of 12

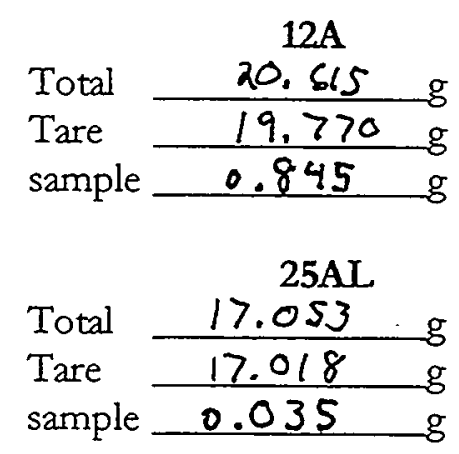

\begin{tabular}{|c|c|}
\hline Total & $\begin{array}{c}25 \mathrm{~A} \\
20.758\end{array}$ \\
\hline Tare & 19.992 \\
\hline & 0.766 \\
\hline
\end{tabular}

$$
W \cdot A
$$

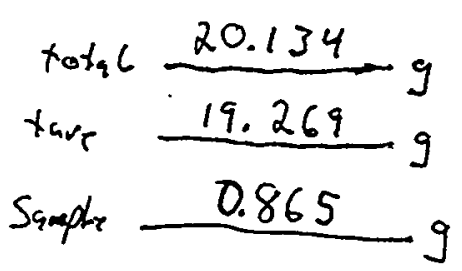

$12 B$
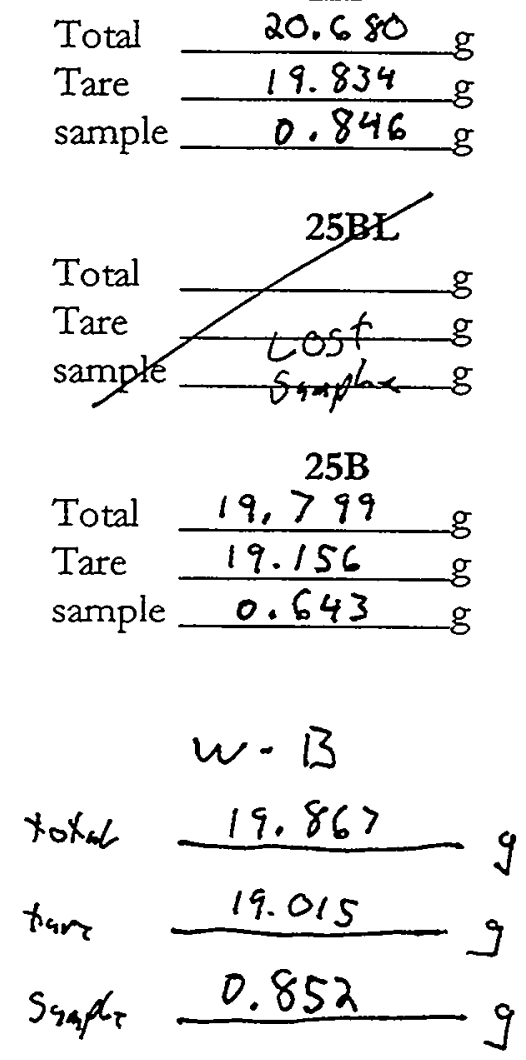

Signature Xa Y. Amahand Date 2/2/00 


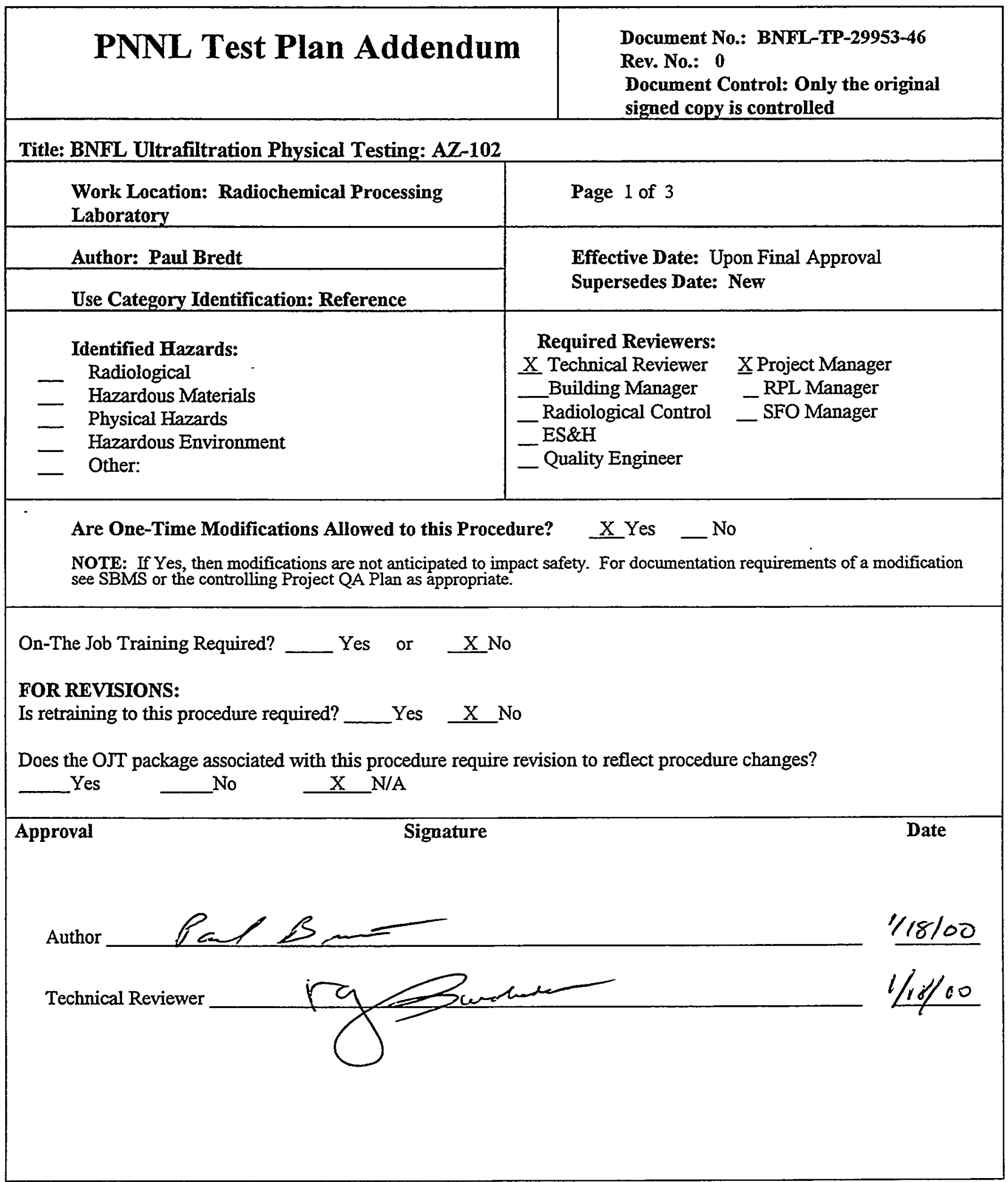




\section{BNFL Ultrafiltration Physical Testing: AZ-102}

\section{Scope}

This addendum define the preparation of sample AZ-102 CUF Rinse for physical properties testing under test instruction 29953-078. Sample AZ-102 CUF Rinse was generated by rinsing of the CUF unit after the AZ-102 run. AZ-102 CUF Rinse, in a $500 \mathrm{ml}$ glass jar, contains roughly 200 $\mathrm{ml}$ of solids. These solids need to be characterized prior to use in the HLW Vitrification task.

The liquid in AZ-102 CUF Rinse will be decanted. The density of this liquid will then be measured. The settled solids will then be mixed using a spatula and a $20 \mathrm{ml}$ subsample of the settled solids will then be collected. The liquid will then be added back to the settled solids in the $500 \mathrm{ml}$ jar. The $20 \mathrm{ml}$ of settled solids will then be analyzed for solids content under Test Instruction 29953-078 in parallel with samples CUF-AZ102-006, CUF-AZ102-012, and CUFAZ102-025.

Work Instructions

$$
\begin{aligned}
& \text { Bazarce mqTE 362-06-01-049 } \\
& \text { Truewi ioc0ici } \\
& \text { meas it } 1000.00 \text { okrys 1/19/2000 }
\end{aligned}
$$

1) Label a clean $500 \mathrm{ml}$ jar "AZ-102 WASH SUP". Record the mass of the empty jar.

\section{AZ-102 WASH SUP}

Tare ios.70

2) Record the mass of AZ-102 CUF RINSE.

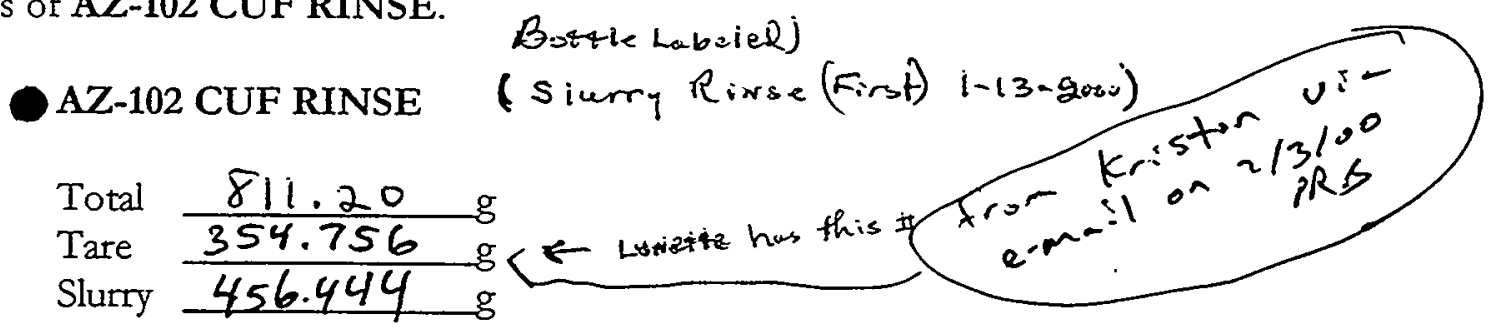

3) Decant as much supernatant as possible from AZ-102 CUF Rinse and transfer to AZ-102

WASH SUP. Record the new mass of AZ-102 WASH SUP and AZ-102 CUF RINSE.

AZ-102 WASH SUP

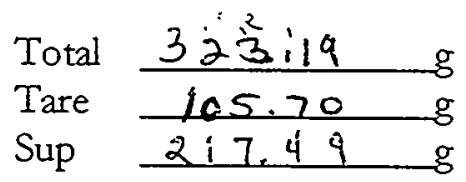

\begin{tabular}{|c|c|}
\hline Total & 593.70 \\
\hline Tare & 354.756 \\
\hline Solids & 238.94 \\
\hline
\end{tabular}

AZ-102 CUF RINSE 
4) Transfer $\sim 9 \mathrm{ml}$ of liquid from AZ-102 WASH SUP to a preweighed $10 \mathrm{ml}$ graduated cylinder (or a $5 \mathrm{ml}$ graduated cylinder may be used with $\sim 4 \mathrm{ml}$ of liquid). Record the mass and volume of liquid in the graduated cylinder. Discard this liquid after the mass and volume have been recorded.

\section{$\operatorname{Grad}(2 \sin c)$}

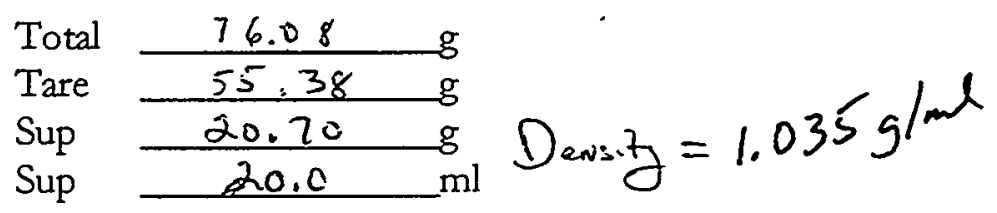

5) Label a clean $20 \mathrm{ml}$ vial AZ-102 RIN. Record the mass of the empty vial. I Lavech this

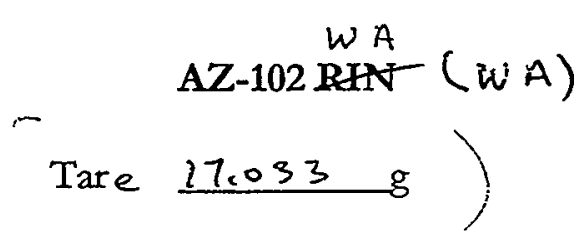
ar W.A

Tare $27.033 \mathrm{~g}$ )

6) Mix the solids in AZ-102 CUF Rinse with a spatula and transfer $\sim 20 \mathrm{ml}$ to AZ-102 RAN. Record the new mass of AZ-102 RIN.WA and AZ-102 CUF Rinse
$A$ Ther $2-8 \mathrm{~m} 2$
17.920
AZ-102 RIN
A $2-102$ CUFRinse

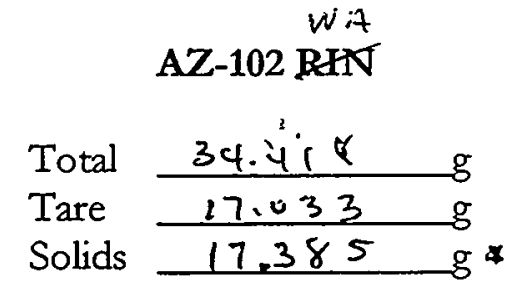

64

7) Transfer the liquid in AZ-102 WAS SUP back into AZ-102 CUF RINSE. Record the new mass of AZ-102 CUF RINSE.

\section{AZ-102 CUF RINSE}

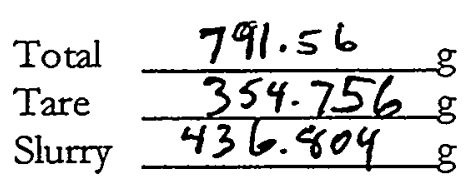

8) Perform solids analysis on AZ-102 CUF RINSE as defined under Test Instruction 29953-078.

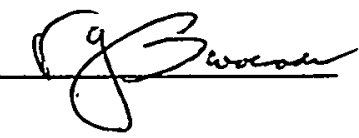

Date $i-19-2000$ 
\%22100 finish R.G. Swoboda

Step 1

Step 9

Step 10

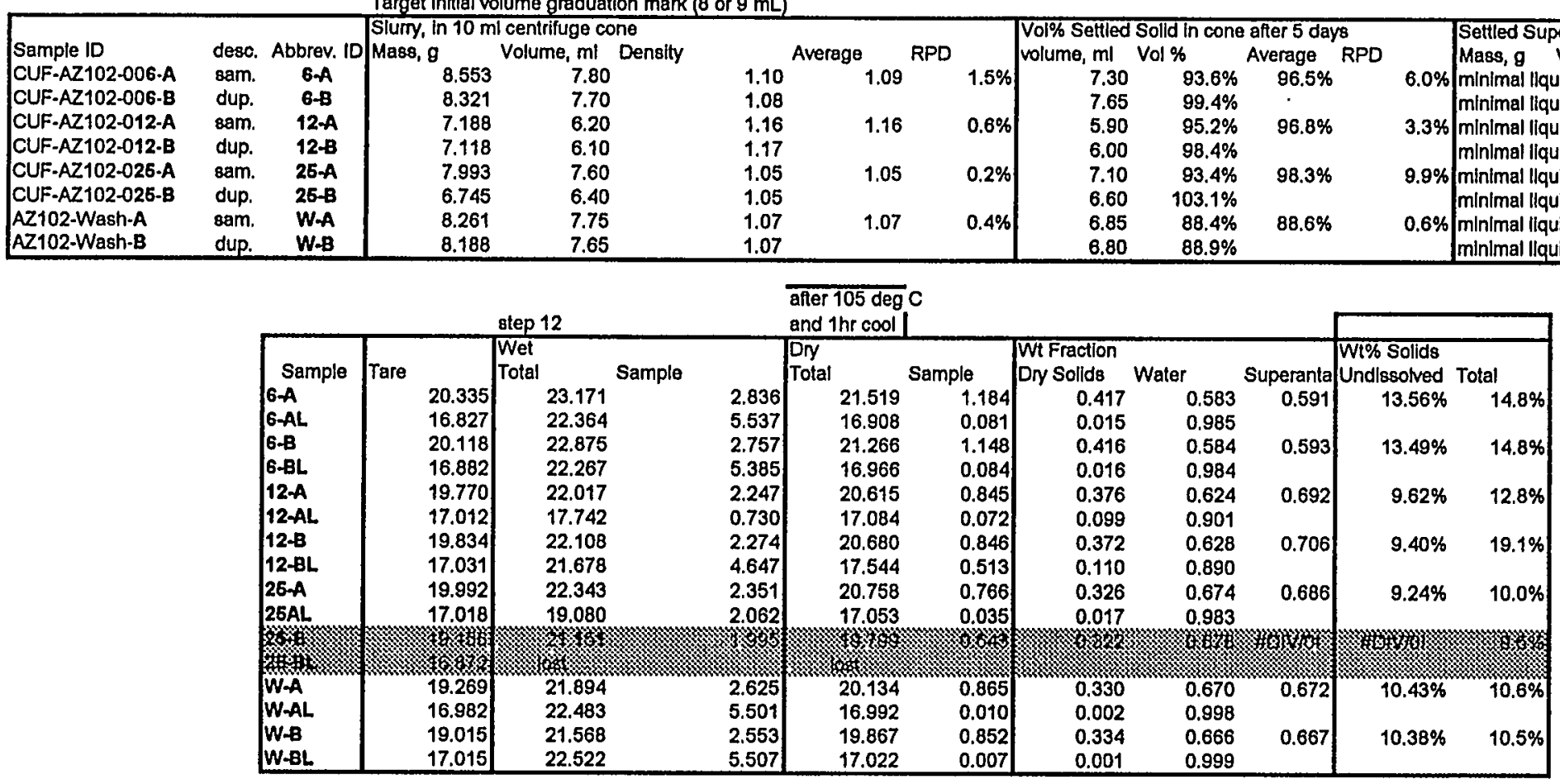

Table for Reportlng

\begin{tabular}{|c|c|c|c|c|c|c|c|c|c|c|c|}
\hline & & & $\begin{array}{l}\text { Density, } g^{\prime} \mathrm{ml} \\
\text { Slurv }\end{array}$ & & & Vol\% Sollds & & Wit Sollds & & & \\
\hline $\begin{array}{l}\text { Sample ID } \\
\text { CUF-AZ10: }\end{array}$ & $\begin{array}{l}\text { desc. } \\
\text { sam. }\end{array}$ & $\begin{array}{c}\text { Abbrev. ID } \\
G A\end{array}$ & $\begin{array}{l}\text { Sluryy } \\
1.10\end{array}$ & $\begin{array}{c}\text { Supernatant } \\
1.016\end{array}$ & $\begin{array}{c}\text { Centrifuged Sollds } \\
1.35\end{array}$ & $\begin{array}{l}\text { Settled } \\
93.6 \%\end{array}$ & $\begin{array}{c}\text { Centrifuged } \\
26.9 \%\end{array}$ & $\begin{array}{l}\text { Settled } \\
\quad 84,1 \%\end{array}$ & $\begin{array}{c}\text { Centrifuged } \\
33.2 \%\end{array}$ & $\begin{array}{l}\text { Total } \\
14.8 \%\end{array}$ & $\begin{array}{c}\text { Undissolved } \\
13.6 \%\end{array}$ \\
\hline CUF-AZ102-006-B & dup. & $6-B$ & 1.08 & 1.015 & 1.38 & $99.4 \%$ & 26. & $95.7 \%$ & & $14.8 \%$ & $13.5 \%$ \\
\hline 12-A & sam. & $12-A$ & 1.16 & 1.1 & 1.5 & 95. & & & & & \\
\hline 2-B & dup & $12+B$ & 1.17 & 1.088 & 1.3 & $98.4 \%$ & $27.9 \%$ & $96.2 \%$ & $31.9 \%$ & ( & $9.4 \%$ \\
\hline $102-025 . \mathrm{A}$ & & & 1.0 & & & & & & & & $9.2 \%$ \\
\hline$C U F-A Z 102-025-B$ & dup. & $26-8$ & 1.05 & 1.040 & 1.17 & $103.1 \%$ & $26.6 \%$ & $93.8 \%$ & & 9.5 & 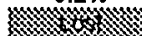 \\
\hline & sam. & WA & 1.07 & 0.984 & 1.25 & & 27. & $88.7 \%$ & & $10.6 \%$ & $10.4 \%$ \\
\hline AZ102-Wash-B & dup. & $W-B$ & 1.07 & 1.011 & 1.22 & $88.9 \%$ & $27.5 \%$ & $89.5 \%$ & $31.2 \%$ & $10.5 \%$ & $10.38 \%$ \\
\hline
\end{tabular}




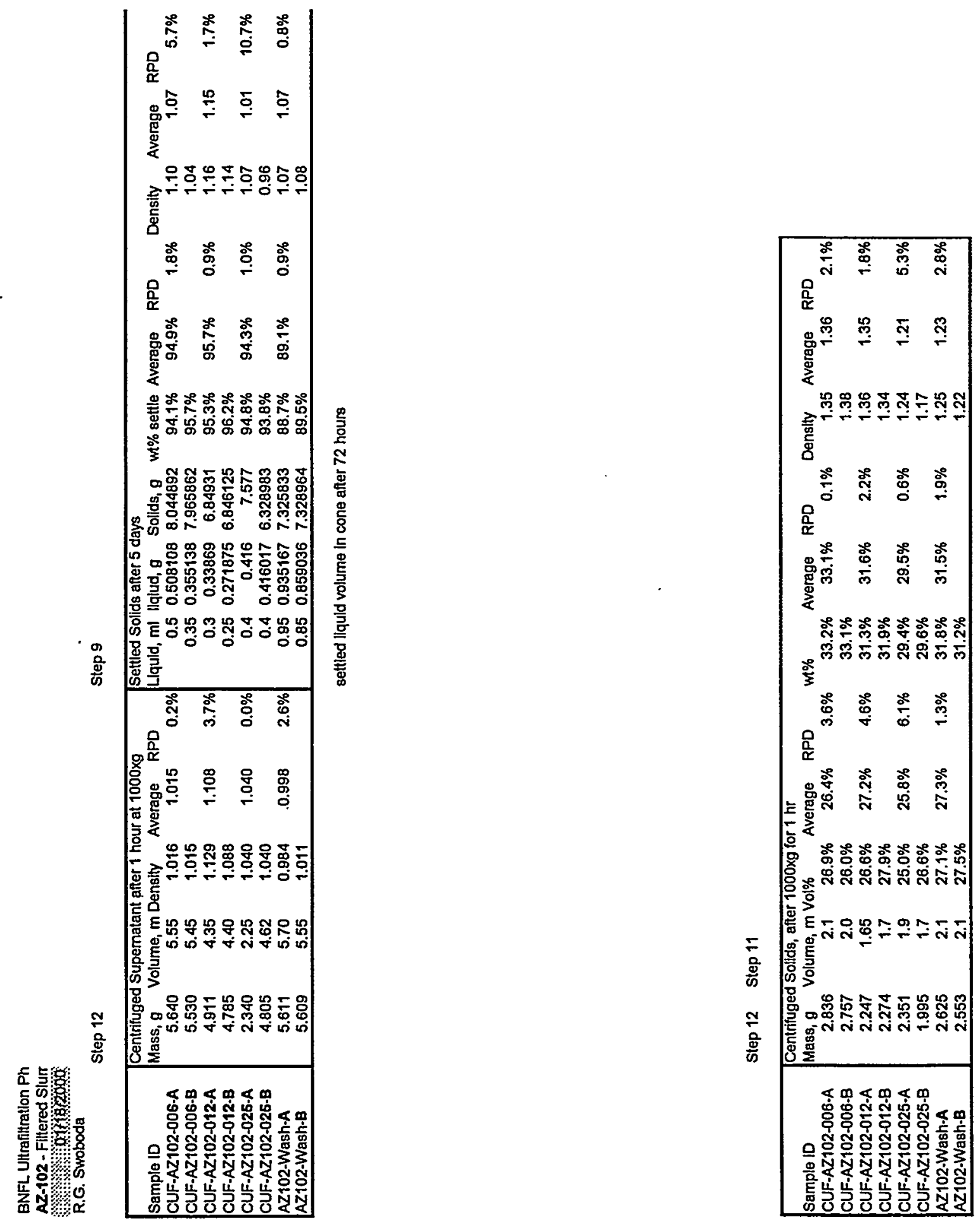




\section{Appendix F: Rheograms for AZ-102 and Standards}




\section{Appendix F: Rheograms for AZ-102 and Standards}


Figure 1. $50 \mathrm{cP}$ Brookfield Standard Lot 102298 Analyzed on 1/7/00 Using the In-Cell Remoted Haake M5

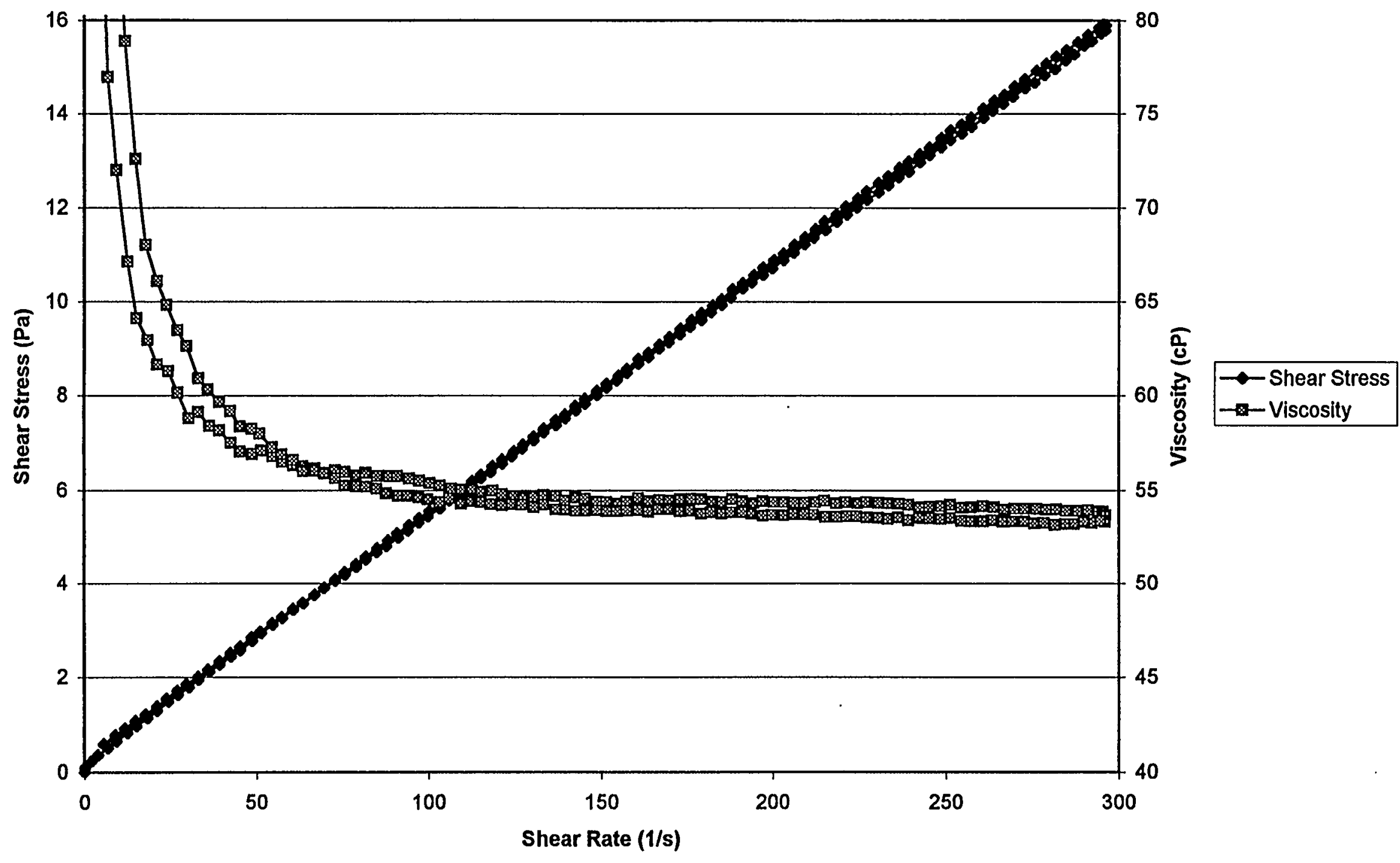




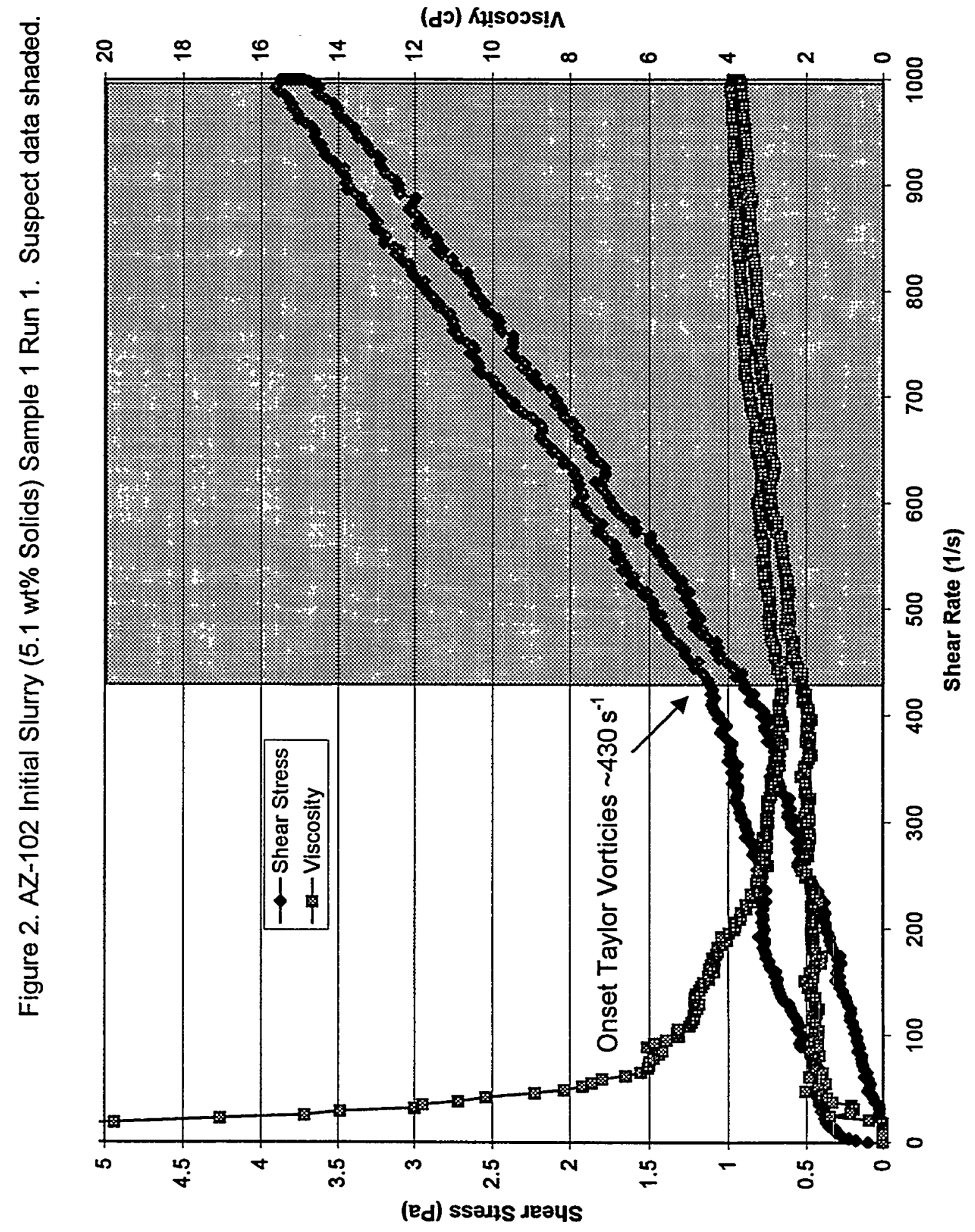


Figure 3. AZ-102 Initial Slurry (5.1 wt\% Solids) Sample 1 Run 2

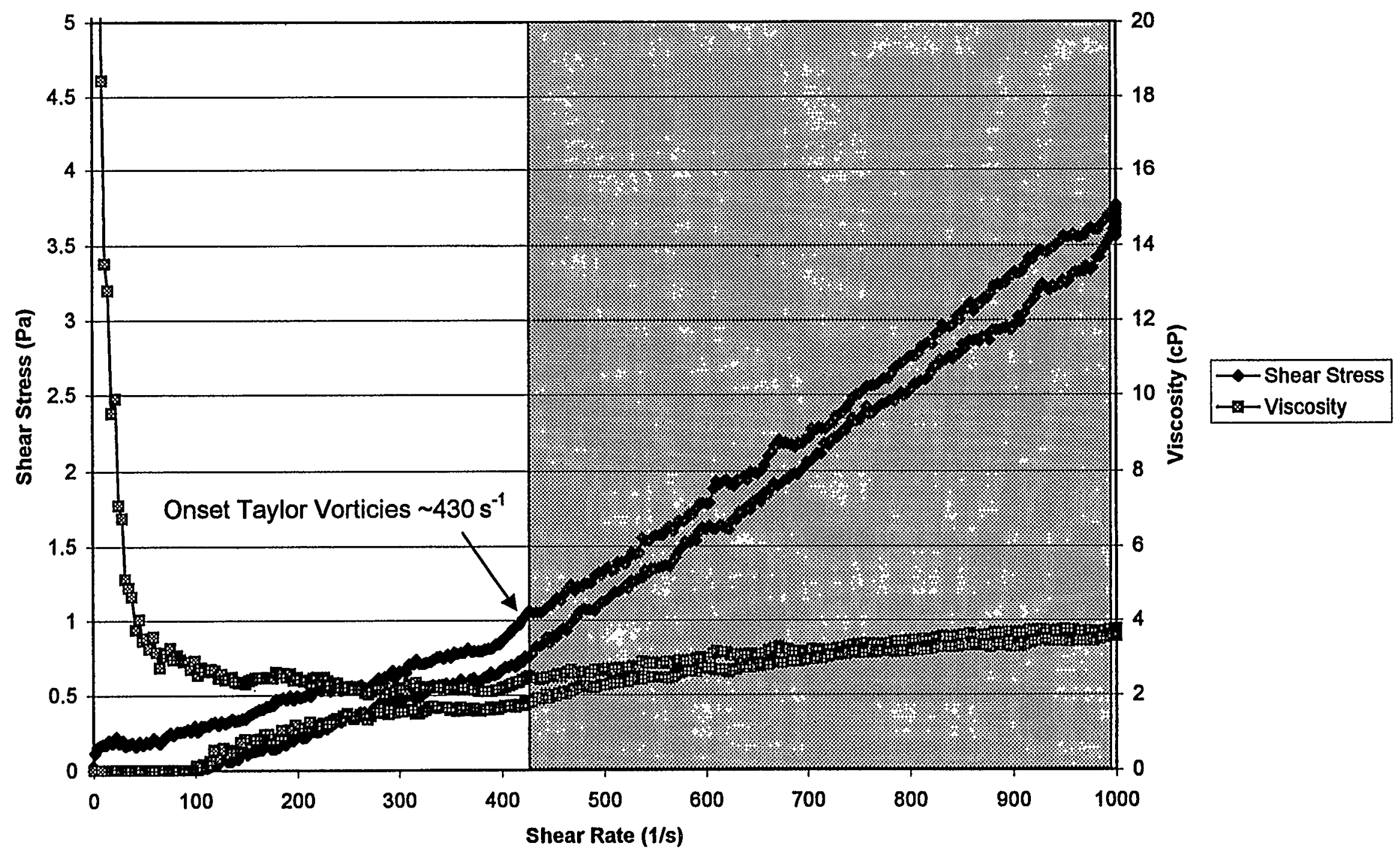


Figure 4. AZ-102 Initial Slurry (5.1 wt\% solids) Sample 2 Run 1

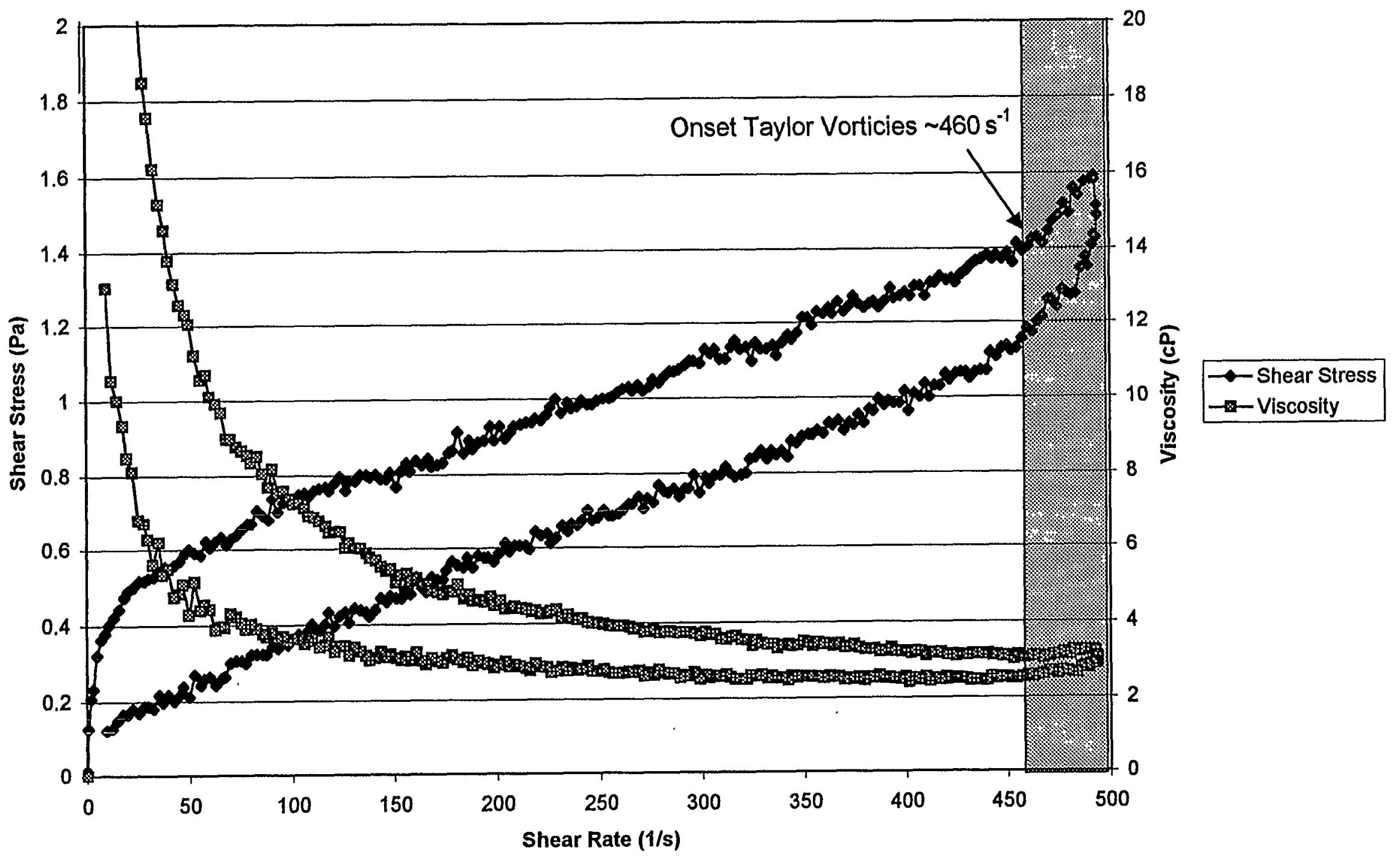


Figure 5. AZ-102 Initial Slurry (5.1 wt\% solids) Sample 2 Run 2

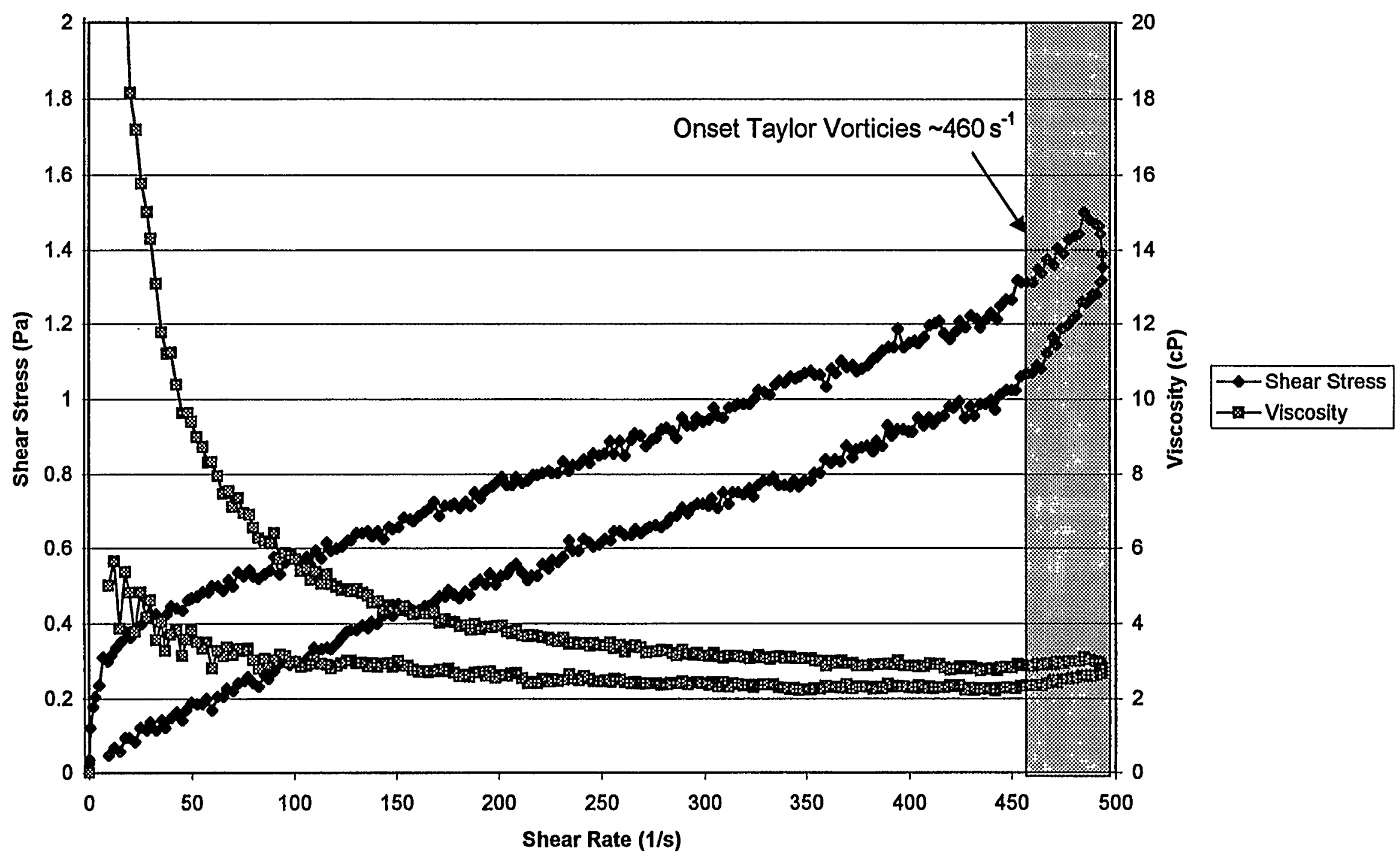


Figure 6. AZ-102 Initial Slurry (5.1 wt\% Solids) Sample 2 Run 3

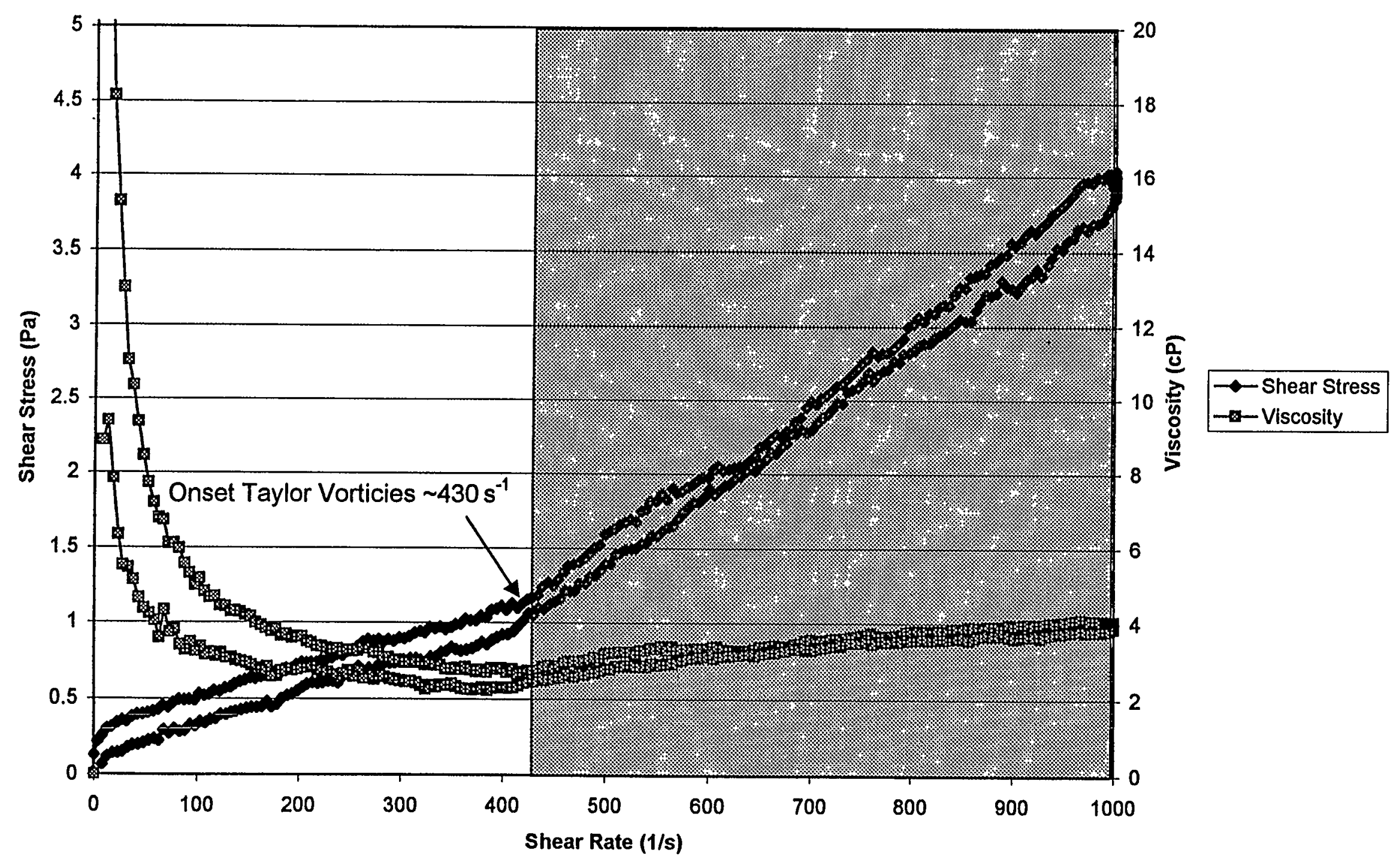


Figure 7. AZ-102 Concentrated Slurry (13.6 wt\% Solids) Sample 1 Run 1

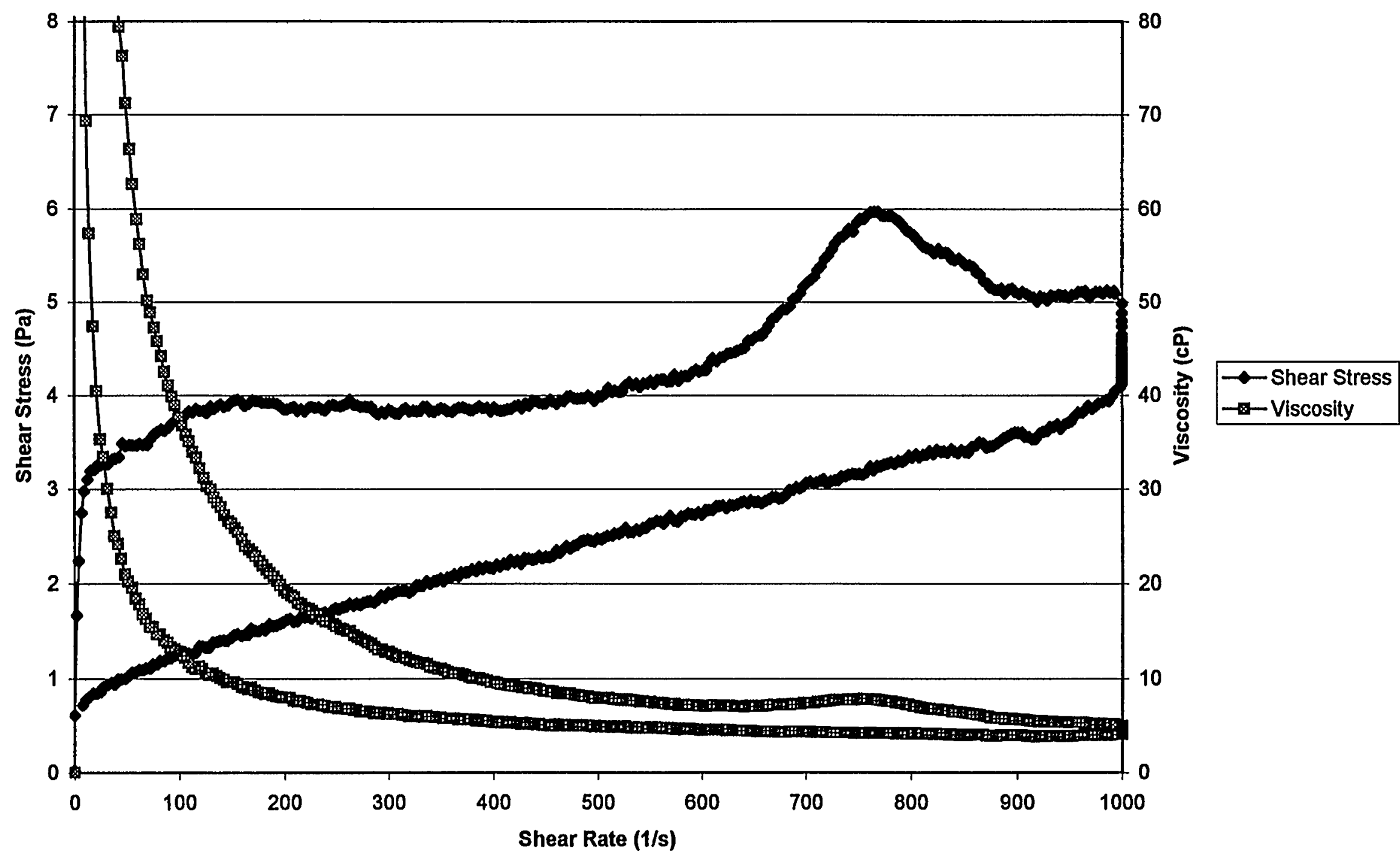


Figure 8. AZ-102 Concentrated Slurry (13.6 wt\% Solids) Sample 1 Run 2

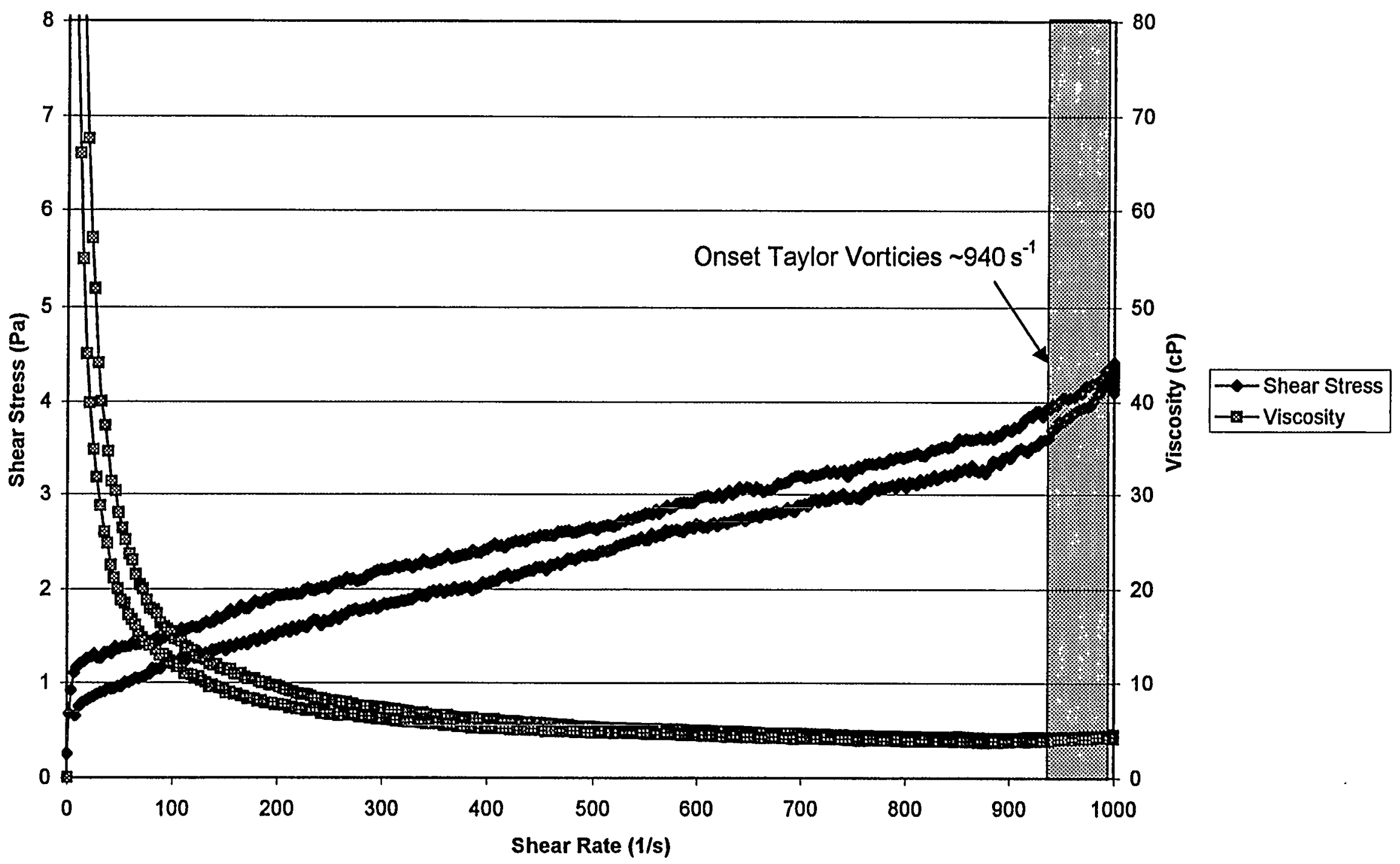


Figure 9. AZ-102 Concentrated Slurry (13.6 wt\% Solids) Sample 2 Run 1

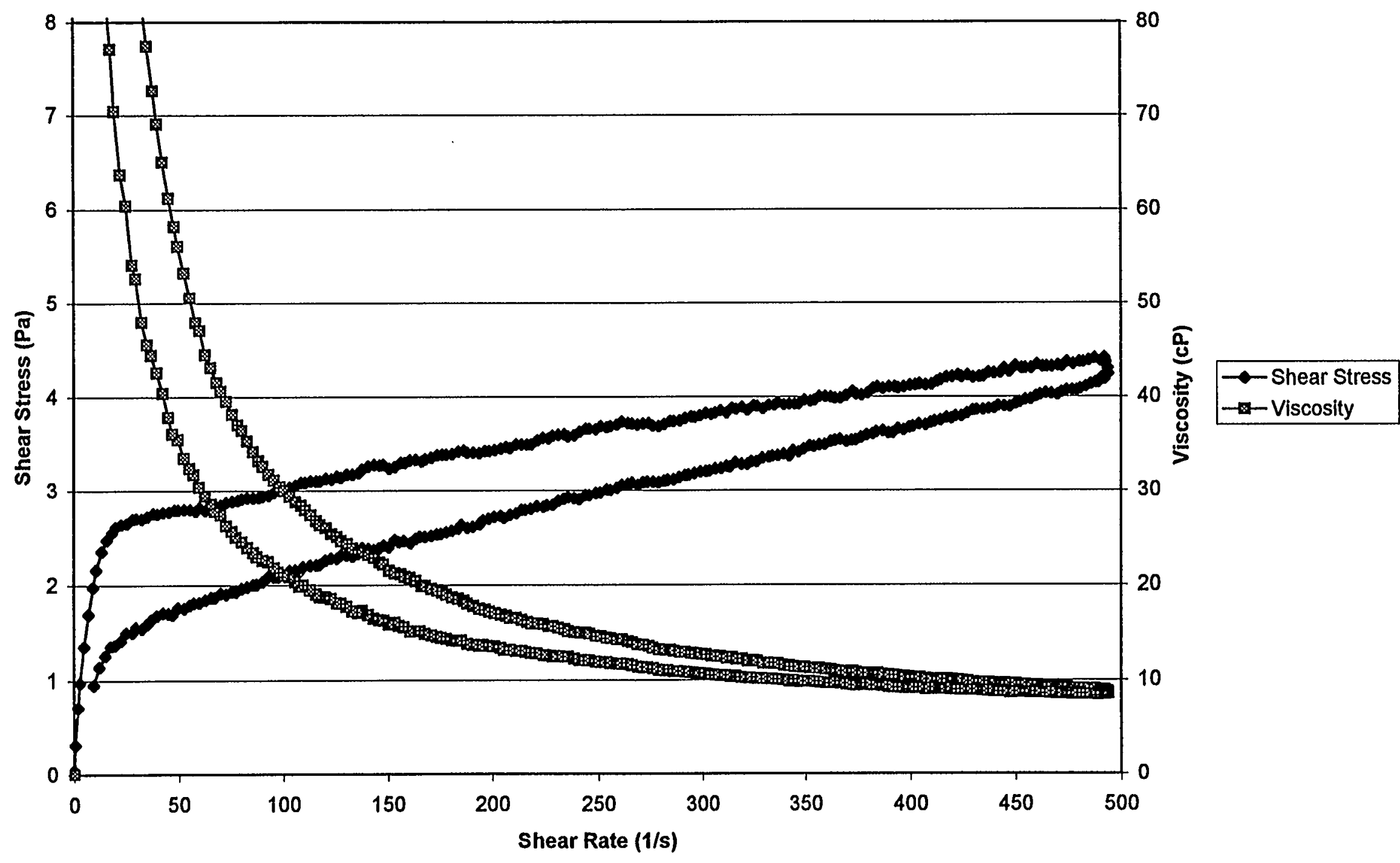


Figure 10. AZ-102 Concentrated Slurry (13.6 wt\% Solids) Sample 2 Run 2

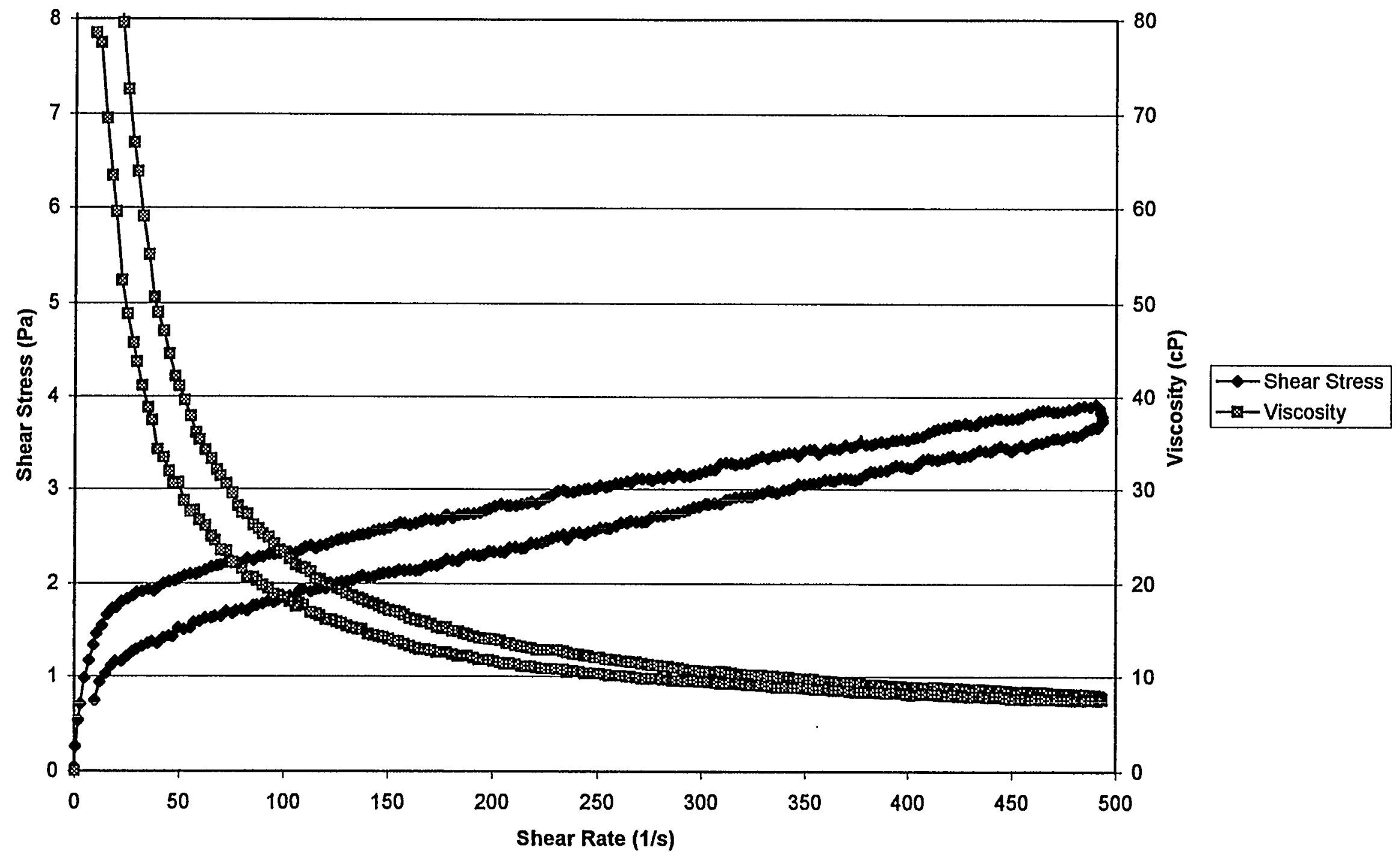


Figure 11. AZ-102 Concentrated Slurry (13.6 wt\% Solids) Sample 2 Run 3

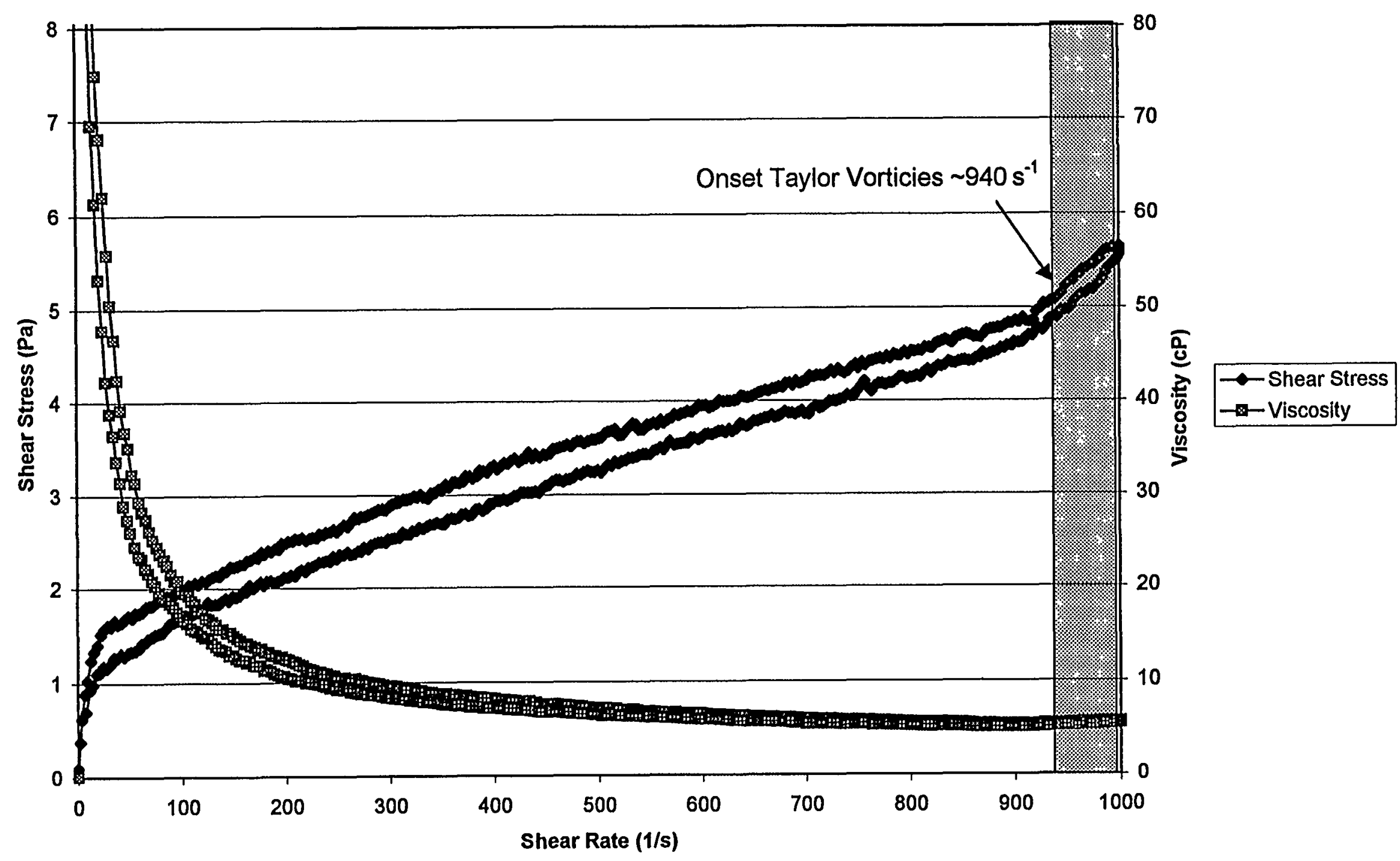




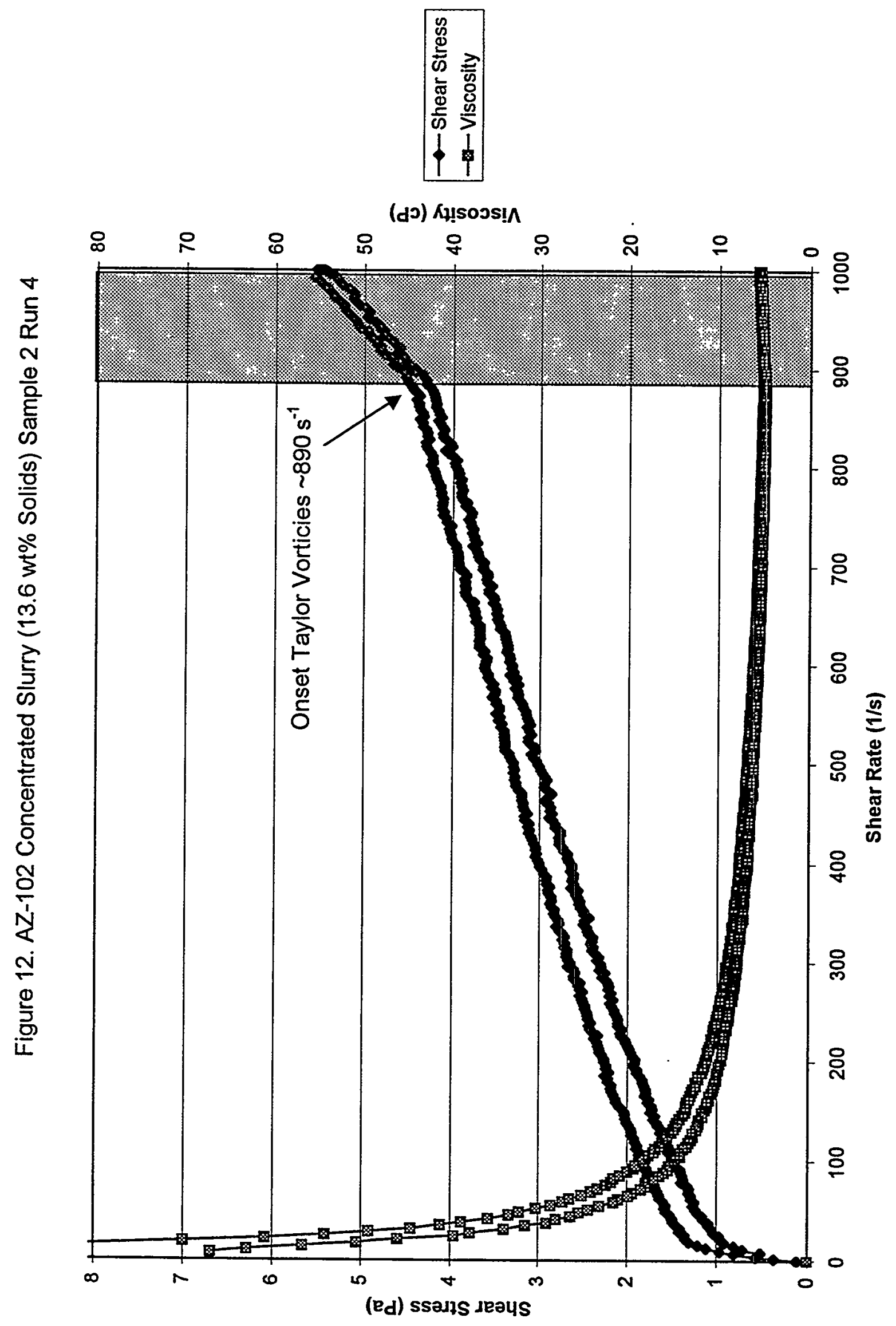


Figure 13. AZ-102 Final Slurry (9.2 wt\% Solids) Sample 1 Run 1

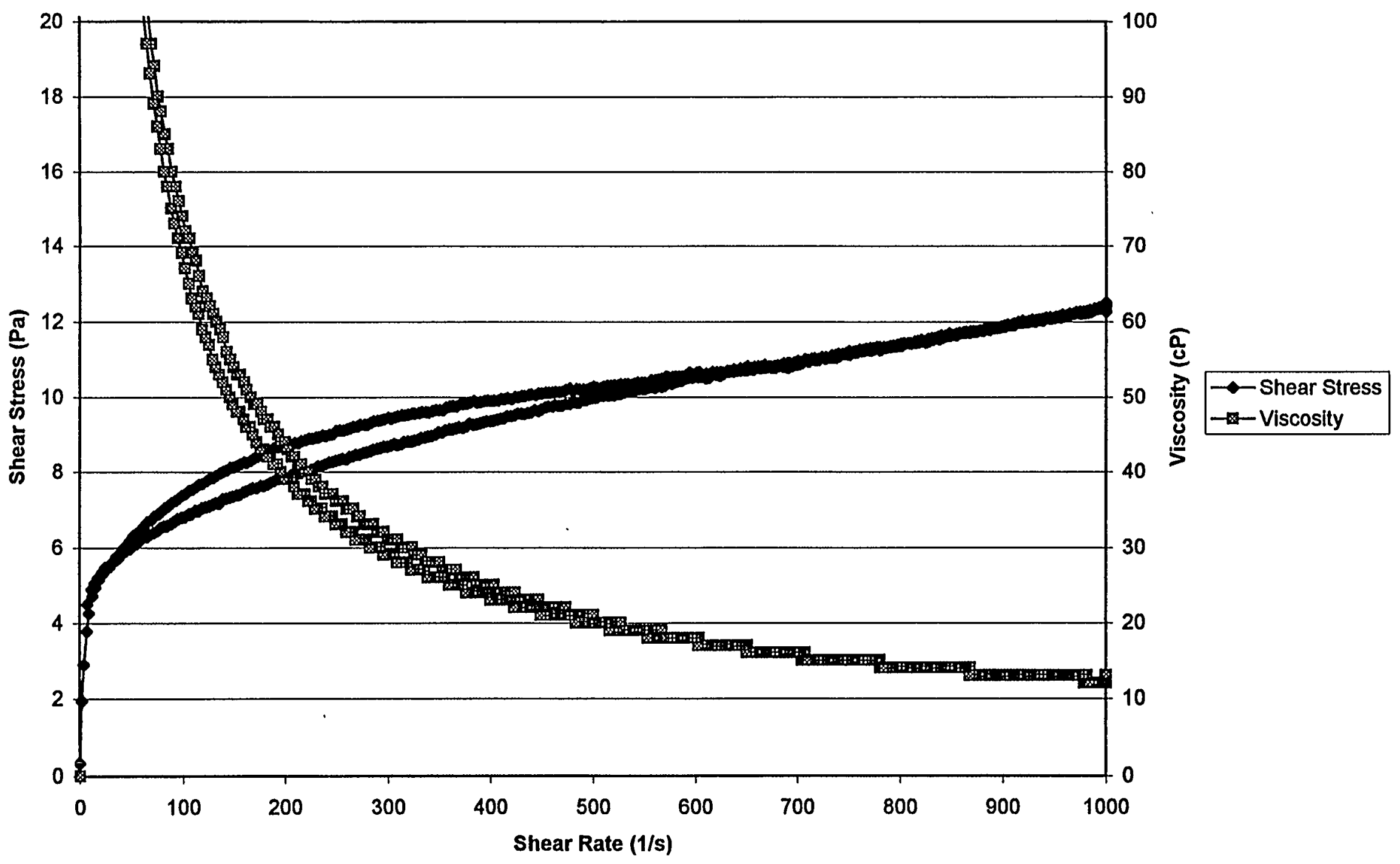




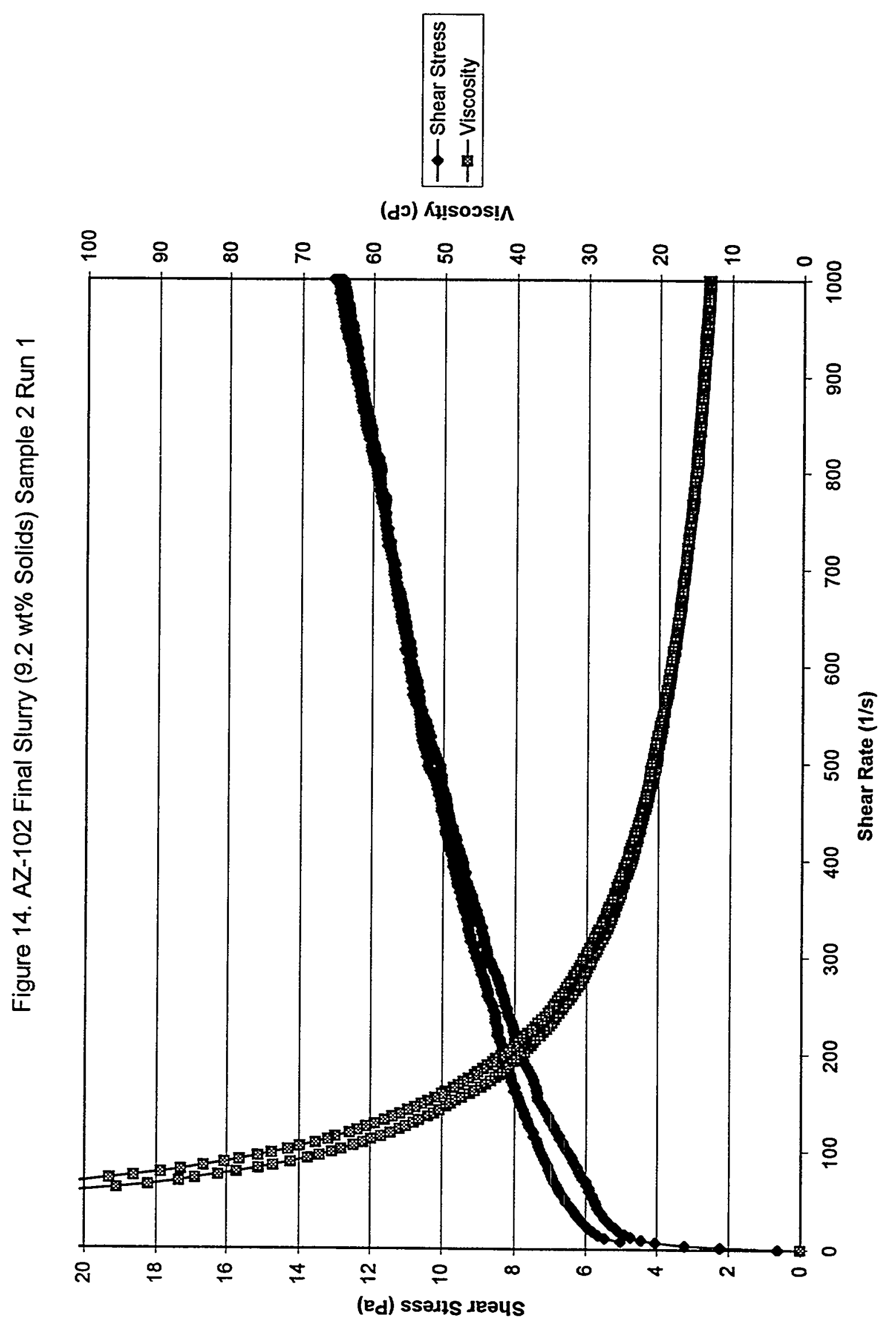


Figure 15. AZ-102 Final Slurry (9.2 wt\% Solids) Sample 2 Run 2

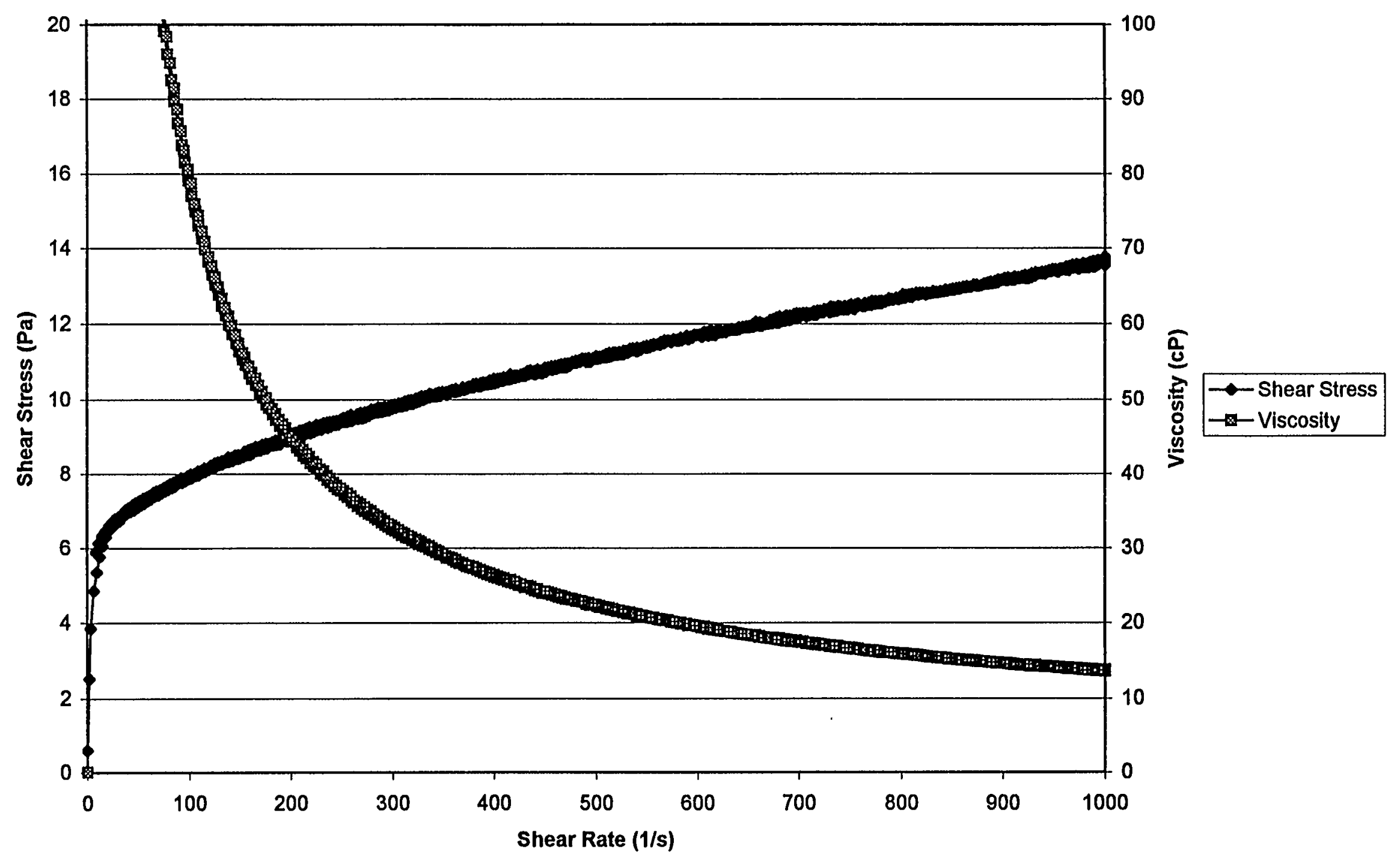




\section{Appendix G: Key Personnel Affiliated with AZ- 102 Testing}




\section{Appendix G: Key Personnel Affiliated with AZ-102 Testing}

\begin{tabular}{|l|l|l|}
\hline \multicolumn{1}{|c|}{ Name } & \multicolumn{1}{|c|}{ Responsibility } & \multicolumn{1}{c|}{ Telephone/email } \\
\hline Eugene Morrey & Battelle Project Manager & $\begin{array}{l}\text { (509)376-1982 } \\
\text { eugene.morrey@pnl.gov }\end{array}$ \\
\hline Dean Kurath & Battelle Project Engineer & $\begin{array}{l}\text { (509)376-6752 } \\
\text { dean.kurath@pnl.gov }\end{array}$ \\
\hline Kriston Brooks & $\begin{array}{l}\text { Ultrafiltration Task Manager, } \\
\text { Filtration and CUF Testing }\end{array}$ & $\begin{array}{l}\text { (509) 376-2233 } \\
\text { kriston.brooks@pnl.gov }\end{array}$ \\
\hline Paul Bredt & $\begin{array}{l}\text { Rheology and Physical Properties } \\
\text { Measurement }\end{array}$ & $\begin{array}{l}\text { (509)376-3777 } \\
\text { paul.bredt@pnl.gov }\end{array}$ \\
\hline Scott Cooley & Statistical Analysis & $\begin{array}{l}(509) 375-3604 \\
\text { scott.cooley@pnl.gov }\end{array}$ \\
\hline Mike Urie & $\begin{array}{l}\text { Chemical and Radiochemical } \\
\text { Analysis }\end{array}$ & $\begin{array}{l}(509) 376-9454 \\
\text { mike.urie@pnl.gov }\end{array}$ \\
\hline Ken Rappe & CUF Design and Testing & $\begin{array}{l}\text { (509) 372-3918 } \\
\text { ken.rappe@pnl.gov }\end{array}$ \\
\hline Gita Golcar & $\begin{array}{l}\text { (509)372-1967 } \\
\text { gr.golcar@pnl.gov }\end{array}$ \\
\hline Lynette Jagoda & Measurement & $\begin{array}{l}\text { (509)376-9951 } \\
\text { lynette.jagoda@pnl.gov }\end{array}$ \\
\hline Rick Steele & CUF Testing & $\begin{array}{l}(509) 372-0038 \\
\text { rick.steele@pnl.gov }\end{array}$ \\
\hline
\end{tabular}

G.1 


\section{Appendix H: Particle Size Distribution Experimental Raw Data}




\section{Appendix H: Particle Size Distribution Simulant Recipes and Experimental Raw Data}

H.1 


\begin{tabular}{|c|c|c|c|}
\hline Particle Size Analysis & $\begin{array}{l}\text { Duke Standal } \\
301 \text { um } \# 1913\end{array}$ & $\begin{array}{l}\text { Date: } 05 \\
\text { Time: } 10\end{array}$ & $\begin{array}{l}\text { 18/89 Meas \#: } 00004 \\
02 \quad \text { Pres \#: } 01\end{array}$ \\
\hline $\begin{array}{l}\text { NIST Duke Standard } \\
\text { 301um, Lot \#19136 } \\
\text { Slume Distribution; } x-100 \text { Syotem }\end{array}$ & $\begin{array}{l}\text { Summarv } \\
\mathrm{mv}=302.7 \\
\mathrm{mn}=287.2 \\
\mathrm{ma}=297.2 \\
\mathrm{cs}=0.020 \\
\mathrm{sd}=41.12\end{array}$ & $\begin{array}{l}\text { Percentiles } \\
10 \%=253.4 \quad 60 \%=309.4 \\
20 \%=266.0 \quad 70 \%=321.8 \\
30 \%=276.9 \quad 80 \%=336.3 \\
40 \%=287.490 \%=357.6 \\
50 \%=298.195 \%=378.4\end{array}$ & $\begin{array}{lll}\text { Dia } & \text { Vol\% } & \text { Width } \\
298.1 & 100 \% & 82.25\end{array}$ \\
\hline
\end{tabular}

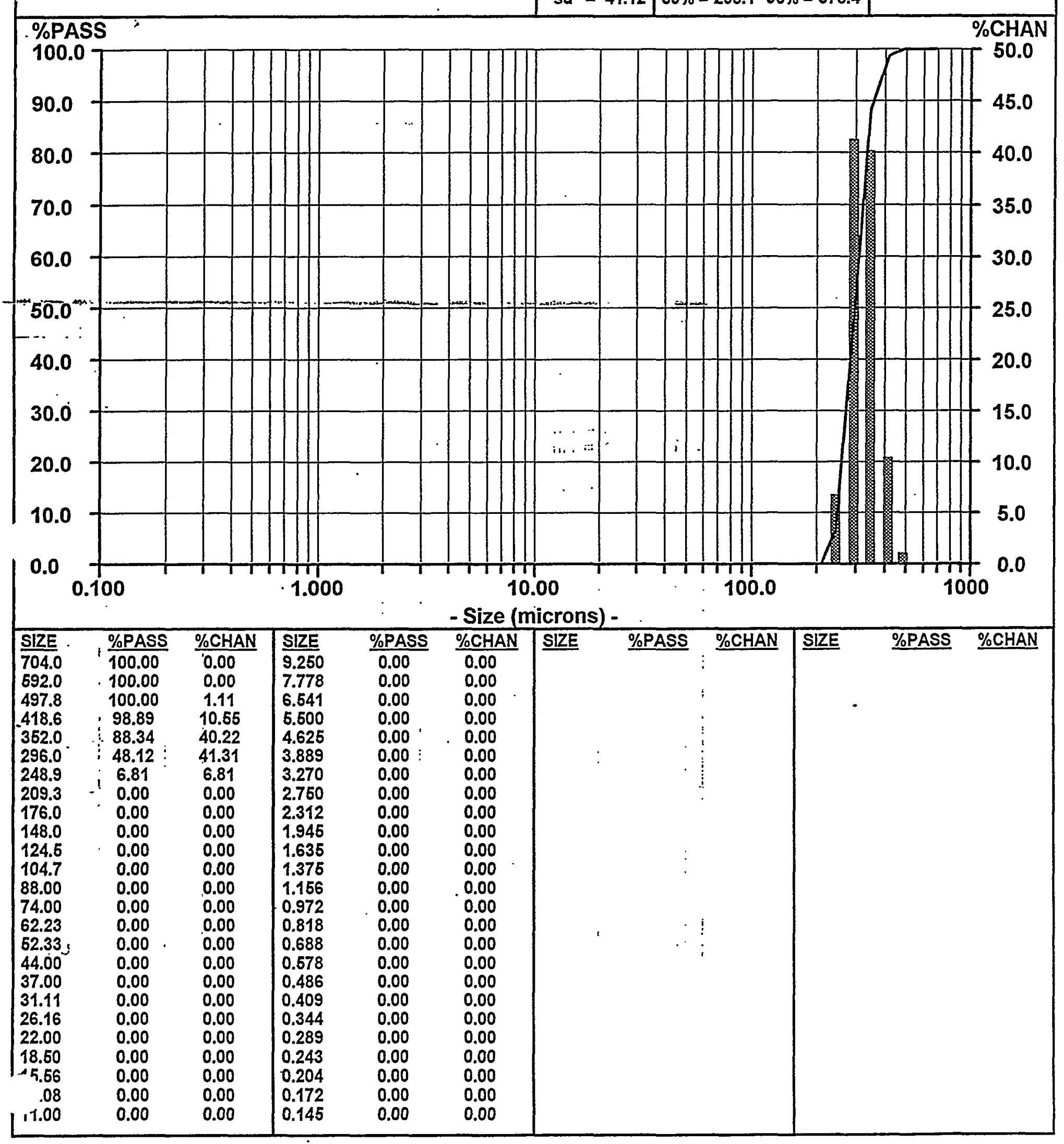




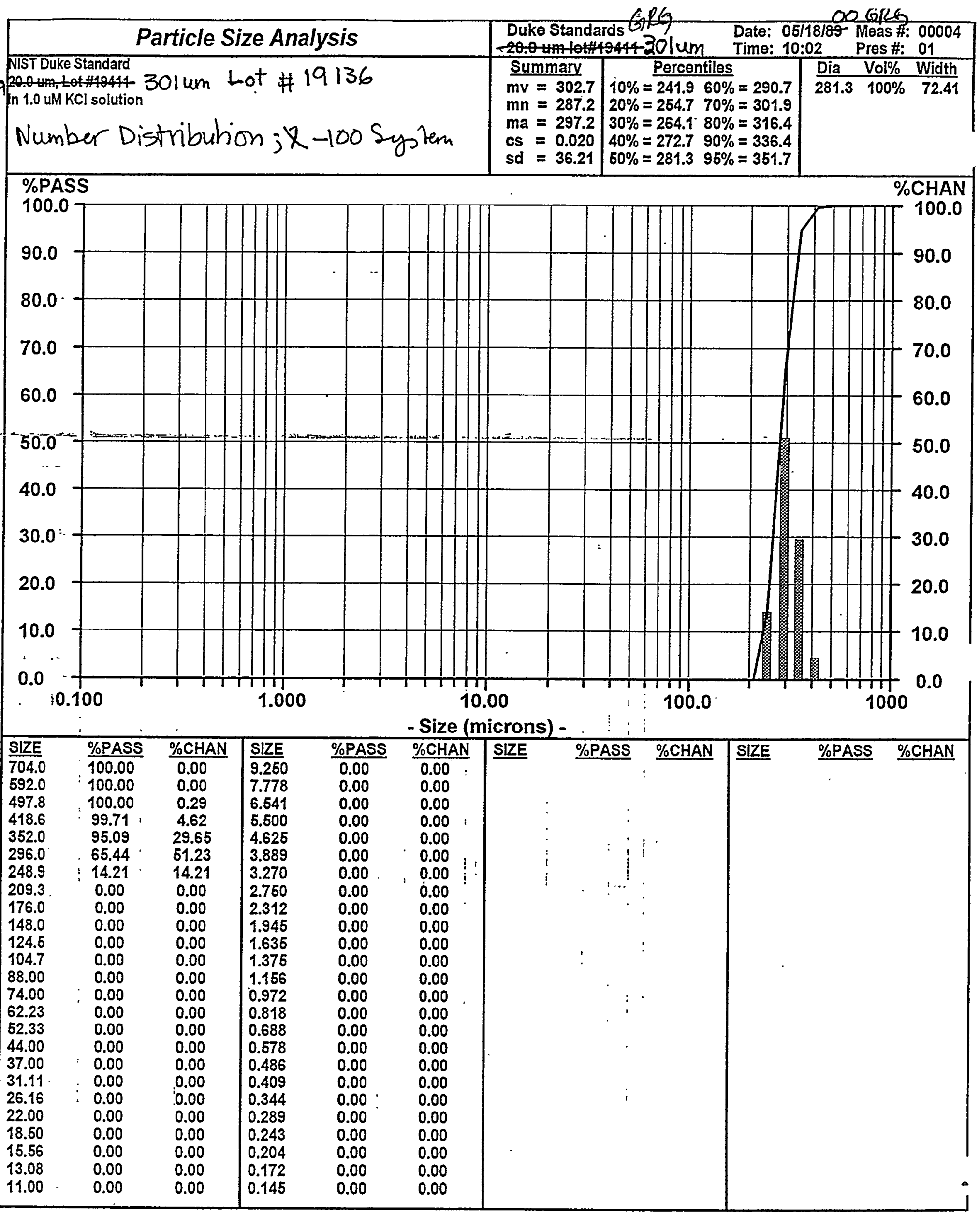




\section{Particle Size Analysis}

NIST Duke Standard 20.0 um, Lot $\# 19411$ In $1.0 \mathrm{uM} \mathrm{KCl}$ solution

ir nlume Distribution; $X-100$ System
Duke Standards 20.0 um lot\#19411

Summary $\quad$ Percentiles

$m v=21.20 \quad 10 \%=16.95 \quad 60 \%=21.45$

$m n=19.57 \quad 20 \%=18.10 \quad 70 \%=22.47$

$\mathrm{ma}=20.59 \quad 30 \%=19.0180 \%=23.85$

cs $=0.291 \quad 40 \%=19.80 \quad 90 \%=26.02$

sd $=3.454 \quad 50 \%=20.69 \quad 95 \%=28.24$

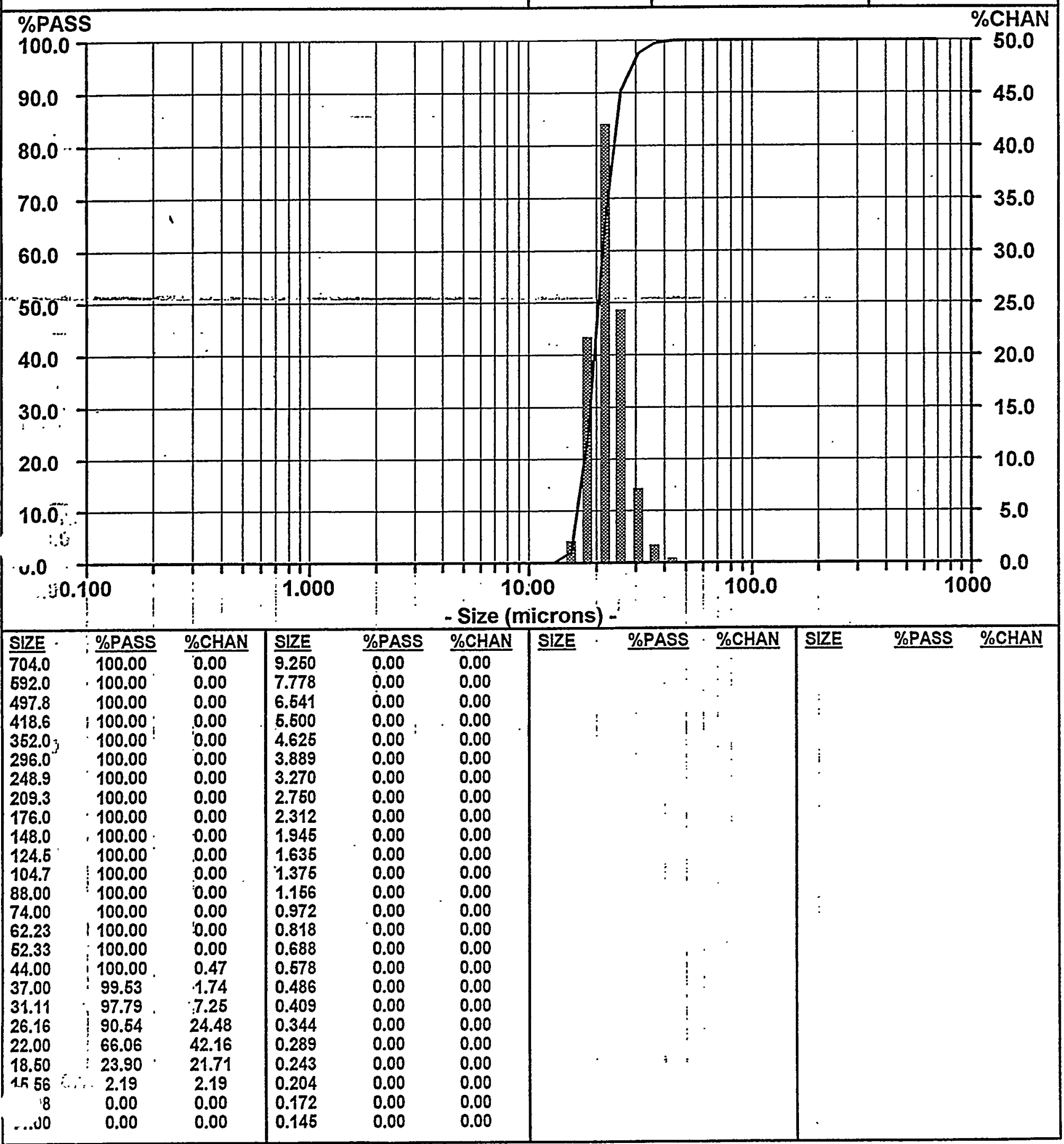




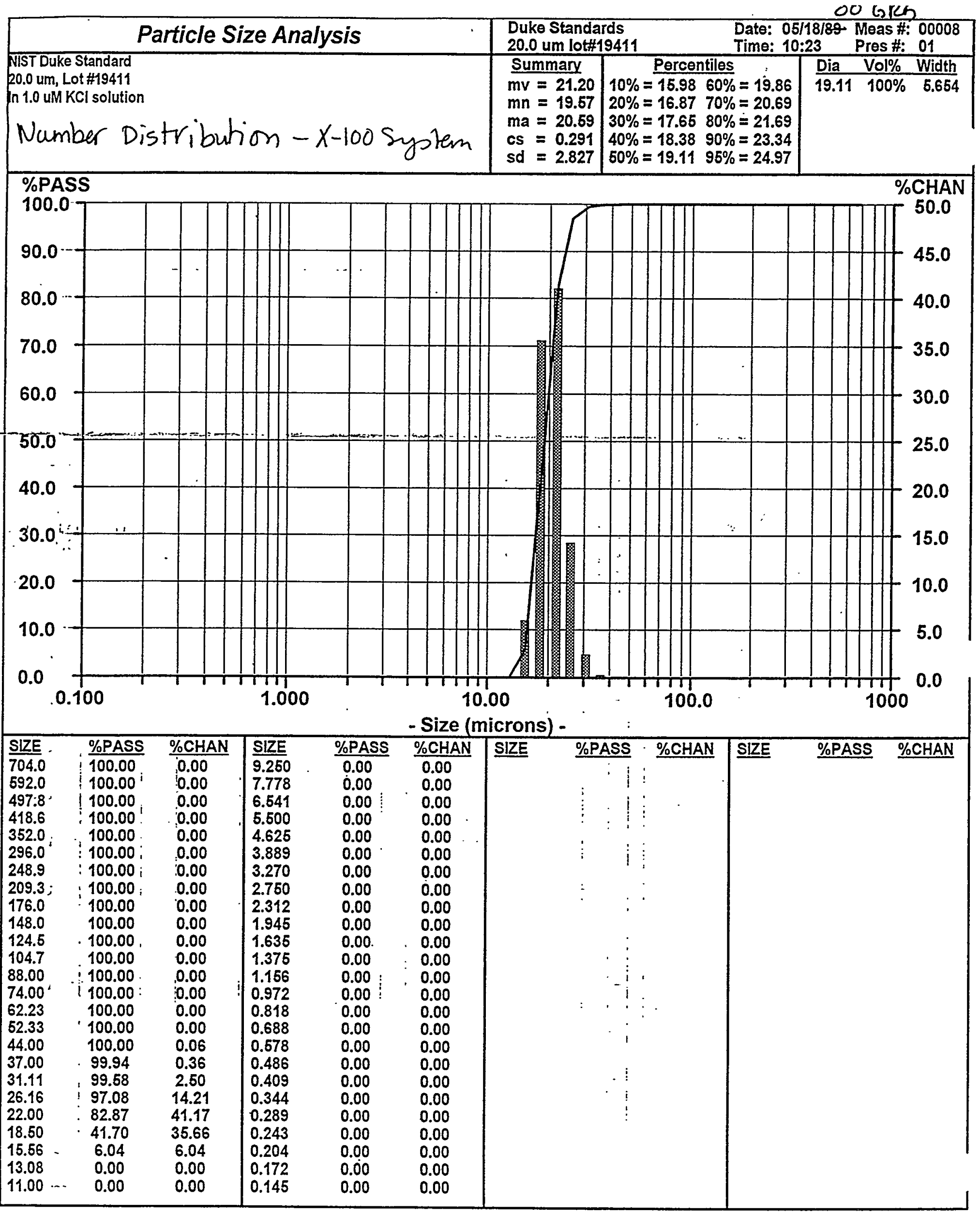




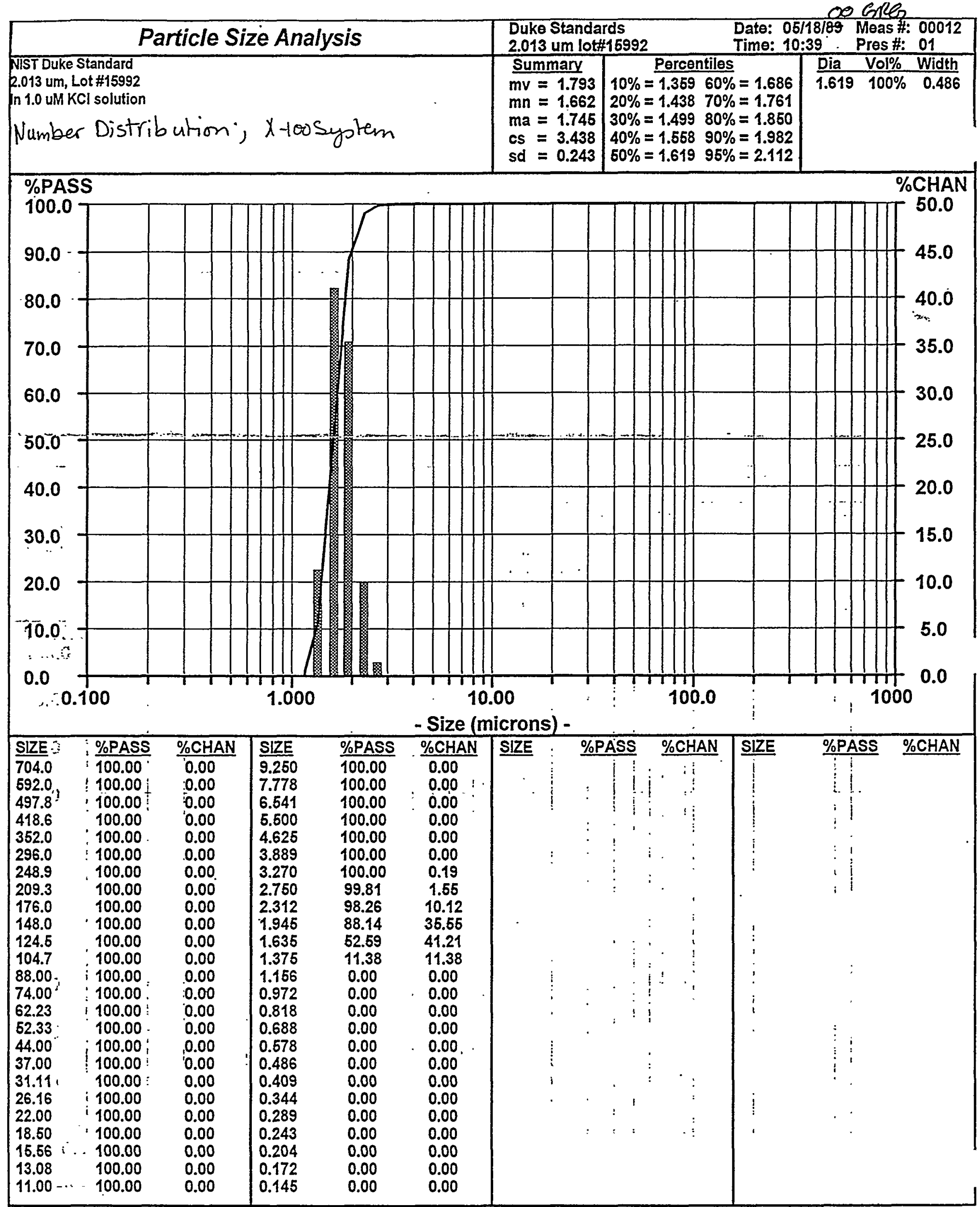




\section{Particle Size Analysis}

NIST Traceable Duke Standard

$304 \mathrm{~nm}$ Lot \#:15928

in $1.0 \mathrm{mM} \mathrm{KCl}$ Solution

PA-Sytem

volume Distribution

\%PASS

100.0

90.0

80.0

70.0

60.0

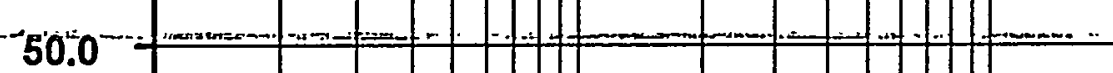

40.0

30.0

20.0

10.0

T

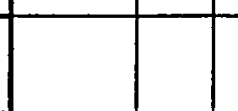

$-$

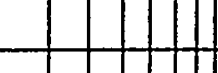

(1)
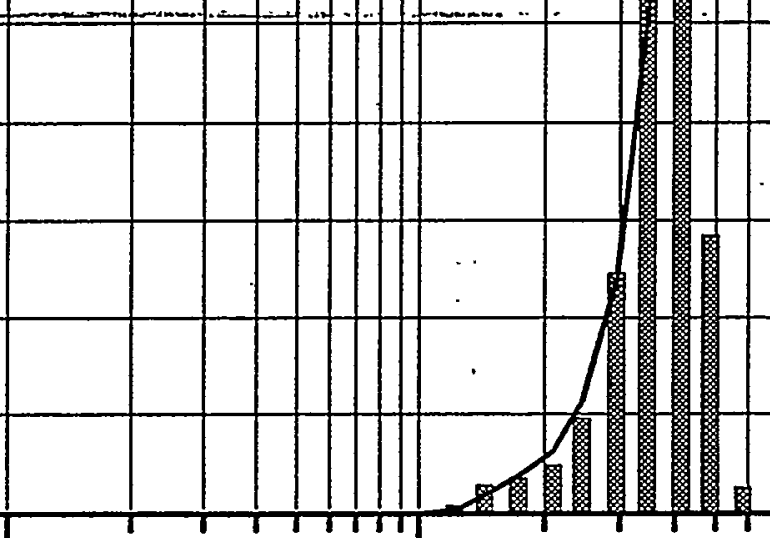

$\$ 0.0010 \quad 0.0100$

0.1000

DOGRG $\frac{m v=.3354}{m v} \quad 10 \%=\frac{\text { Percentiles }}{.2341 \quad 60 \%}=.3691 \quad \begin{array}{llll}\text { Dia } & \text { Vol\% } & \text { Width } \\ .3416 & 100 \% & .1435\end{array}$ $m n=.2445 \quad 20 \%=.2782 \quad 70 \%=.3773$

$m a=.3123 \quad 30 \%=.303380 \%=.3983$

cs $=19.22 \quad 40 \%=.3232 \quad 90 \%=.4279$

sd $=.0717 \quad 50 \%=.3416 \quad 95 \%=.4540$
\%CHAN

50.0

45.0

40.0

35.0

30.0

25.0

20.0

15.0

10.0

5.0 u.

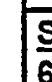

(4.) 
oOgR

Particle Size Analysis

NIST Duke Standard 304 nm Lot\#15928

Date: 05/19/89 Meas \#: 00001 Time: 18:26 - Pres \#: 01

NIST Traceable Duke Standard

304 nm Lot \#:15928

In $1.0 \mathrm{mM} \mathrm{KCl}$ Solution

Number Distribution; UPA Syptein

\begin{tabular}{|c|c|c|}
\hline Summary & Percentiles & Vol\% Width \\
\hline $\begin{array}{l}\mathrm{mv}=.3354 \\
\mathrm{mn}=.2445\end{array}$ & $\begin{array}{l}10 \%=.124460 \%=.2760 \\
20 \%=.1405 \quad 70 \%=.3051\end{array}$ & $\begin{array}{l}: 2942 \\
: 1340\end{array}$ \\
\hline
\end{tabular}

$\mathrm{ma}=.3123 \quad 30 \%=.164480 \%=.3344$

$c s=19.22 \quad 40 \%=.201890 \%=.3715$

sd $=.106960 \%=.242395 \%=.3990$

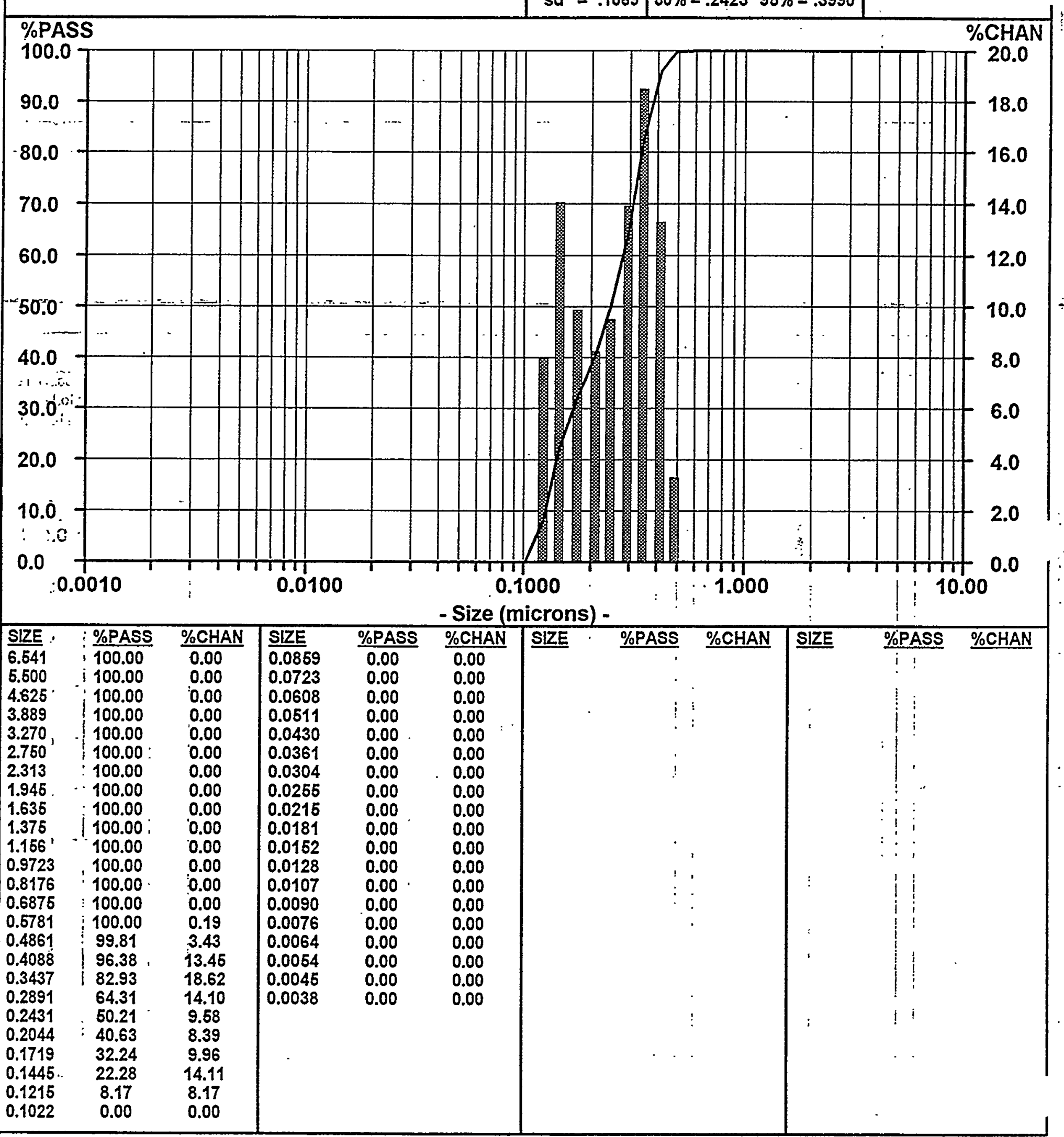




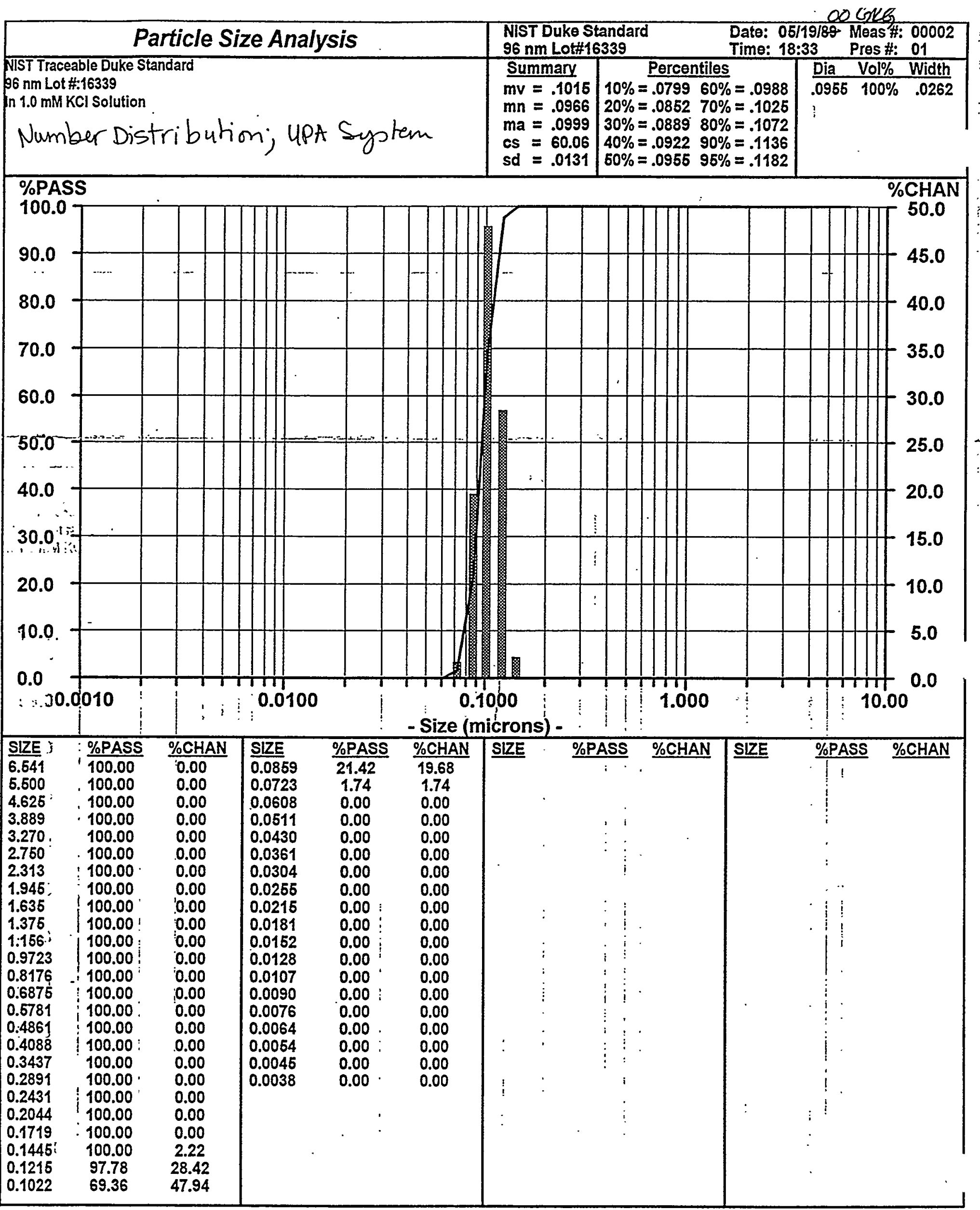


Particle Size Distribution Plots

For Initial Sludge: Sample CUF-AZ-102 MU R1D1

Replicate No: 1

40. 
. Particle Size Analysis

Hank CUFAZ102

SampleCUF-AZ102-MU-R2D1

In AZ-102-MU Simulated Supematant

60mis 'ume Distribution; $x-100$ Syptem

Date: 05/19/89 Meas \#: 00116 Time: 15:18 Pres \#: 01 CUF-AZ102-MU-R2D1

\begin{tabular}{crr} 
Dia & Vol\% & Width \\
\hline 23.35 & $48 \%$ & 22.33 \\
4.628 & $52 \%$ & 6.536 \\
& & \\
& & \\
\hline
\end{tabular}

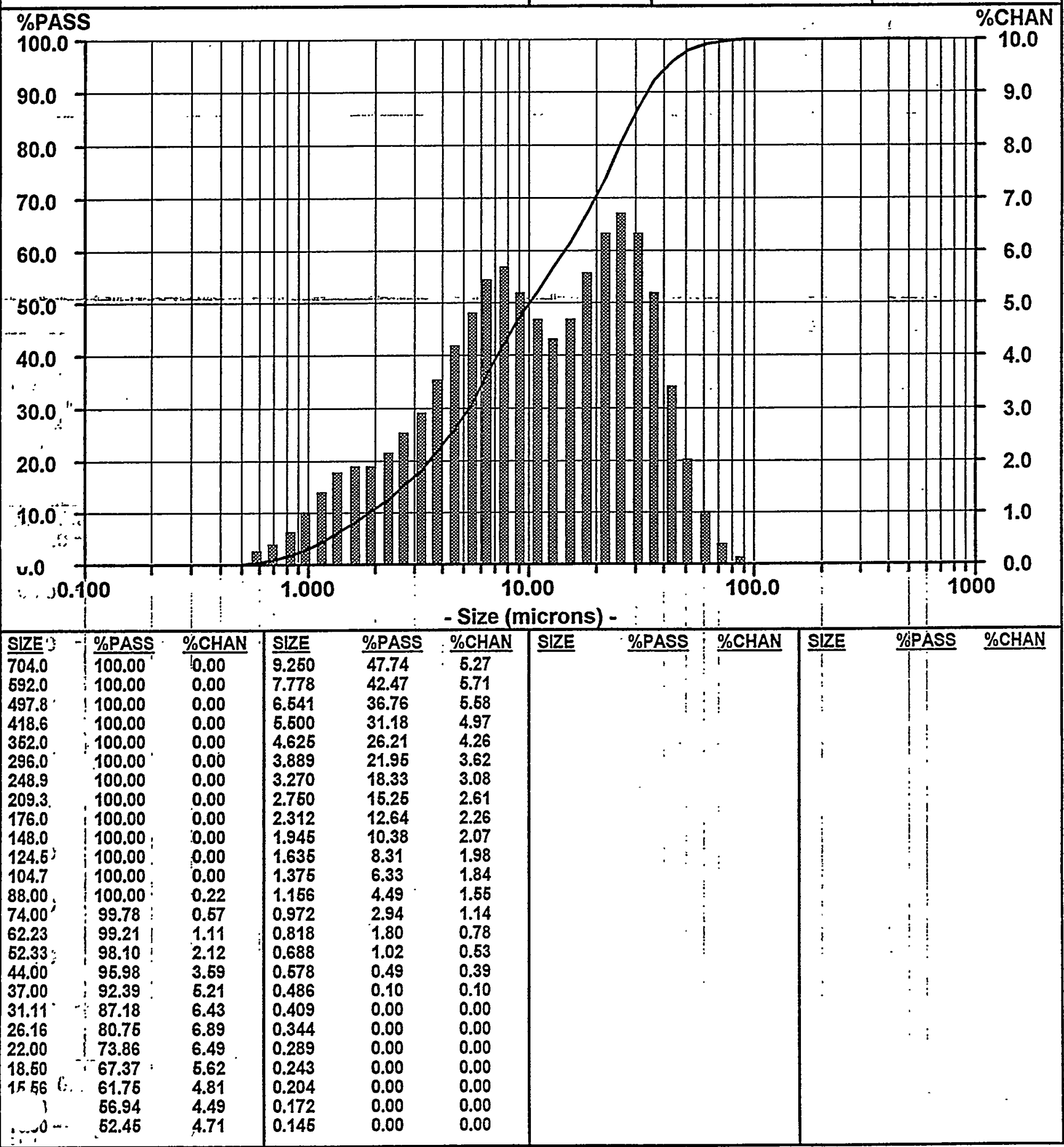

$m v=14.95 \quad 10 \%=1.886 \quad 60 \%=14.65$

$m n=0.955$

$\mathrm{ma}=4.844$

cS $=1.239$

$20 \%=3.55570 \%=19.89$

$30 \%=5.290 \quad 80 \%=25.67$

$40 \%=7.21390 \%=33.96$

$60 \%=10.0495 \%=41.64$

- Size (microns) -

704.0

418.6

248.9

209.3

176.0

148.0

104.7

88.00

74.00

62.23

62.33

31.11

1556

62.46

\begin{tabular}{l} 
\%CHAN \\
\hline 10.00 \\
0.00 \\
0.00 \\
0.00 \\
0.00 \\
0.00 \\
0.00 \\
0.00 \\
0.00 \\
0.00 \\
0.00 \\
0.00 \\
0.22 \\
0.57 \\
1.11 \\
2.12 \\
3.69 \\
6.21 \\
6.43 \\
6.89 \\
6.49 \\
5.62 \\
4.81 \\
4.49 \\
4.71 \\
\hline
\end{tabular}

1. 
$\infty \mathrm{G} / \mathrm{LQ}$

\section{Particle Size Analysis}

Panis CUFAZ102

SampleCUF-AZ102-MU-R2D1

In AZ-102-MU Simulated Supernatant

$60 \mathrm{ml} / \mathrm{s}$

Number Distribution; $x-100$ System
AZ-102 Waste CUF-AZ102-MU-R2D1

Summary

$m v=14.95$

$\mathrm{mn}=0.955$

$\mathrm{ma}=4.844$

$c s=1.239$

sd $=0.369$
Date: 06/19/89- Meas \#: 00116 Time: 15:18

Pres \#: 01

Dia Vol\% Width

$10 \%=0.49460 \%=0.838$

$20 \%=0.640 \quad 70 \%=0.966$

$30 \%=0.588 \quad 80 \%=1.151$

$40 \%=0.65490 \%=1.524$

$60 \%=0.736 \quad 96 \%=2.059$

$0.736: 100 \% \quad 0.739$

\section{\%PASS}

100.0

90.0

80.0
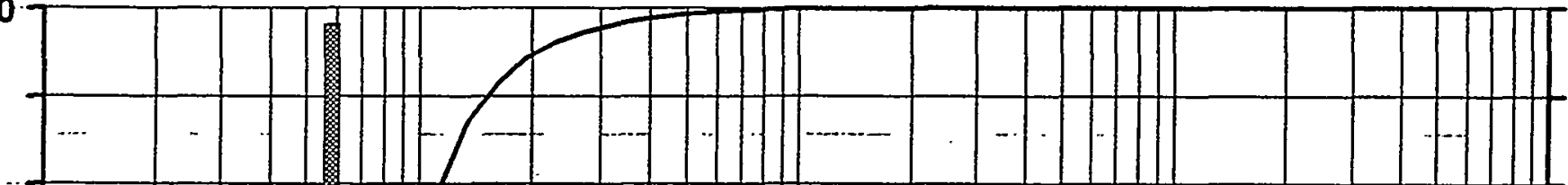

$\%$ CHAN

70.0

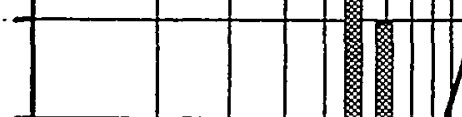

60.0
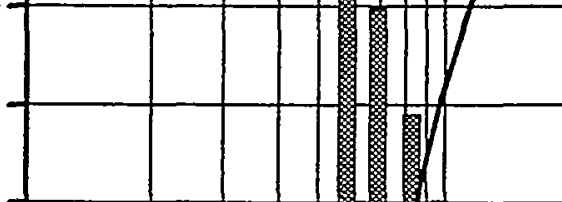

\begin{tabular}{llllll} 
& & & & \\
\hline & & & & \\
\hline
\end{tabular}
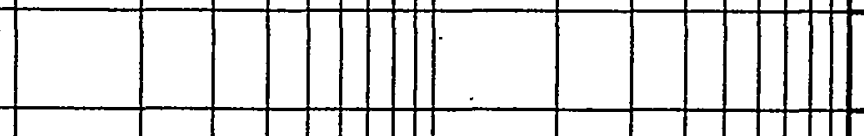

16.0

18.0 $-50.0$

40.0

30.0:

20.0

10.0

0.0
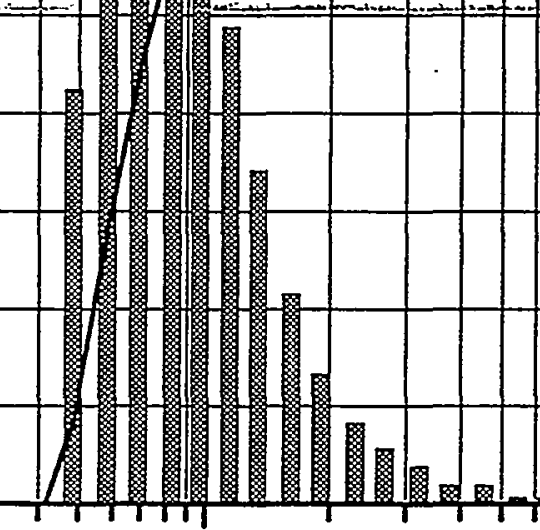

1.000

10.00

.100 .0

14.0

12.0

10.0

8.0

0.100

Size (microns) -

(

4

4

2

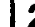

$$
2 \mathrm{C}
$$

\section{1.}

52.33

44.00

37.00

31.11 .

26.16

22.00

18.50

16.56

13.08

11.00

\begin{tabular}{|cc|c|}
\hline \%PASS & \%CHAN & SIZE \\
\hline 100.00 & $\frac{0.00}{9.250}$ \\
100.00 & 0.00 & 7.778 \\
100.00 & 0.00 & 6.541 \\
100.00 & 0.00 & 5.500 \\
100.00 & 0.00 & 4.625 \\
100.00 & 0.00 & 3.889 \\
100.00 & 0.00 & 3.270 \\
100.00 & 0.00 & 2.760 \\
100.00 & 0.00 & 2.312 \\
100.00 & 0.00 & 1.945 \\
100.00 & 0.00 & 1.635 \\
100.00 & 0.00 & 1.375 \\
100.00 & 0.00 & 1.156 \\
100.00 & 0.00 & 0.972 \\
100.00 & 0.00 & 0.818 \\
100.00 & 0.00 & 0.688 \\
100.00 & 0.00 & 0.678 \\
100.00 & 0.00 & 0.486 \\
100.00 & 0.00 & 0.409 \\
100.00 & 0.00 & 0.344 \\
100.00 & 0.01 & 0.289 \\
99.99 & 0.01 & 0.243 \\
99.98 & 0.01 & 0.204 \\
99.97 & 0.02 & 0.172 \\
99.95 & 0.03 & 0.146
\end{tabular}

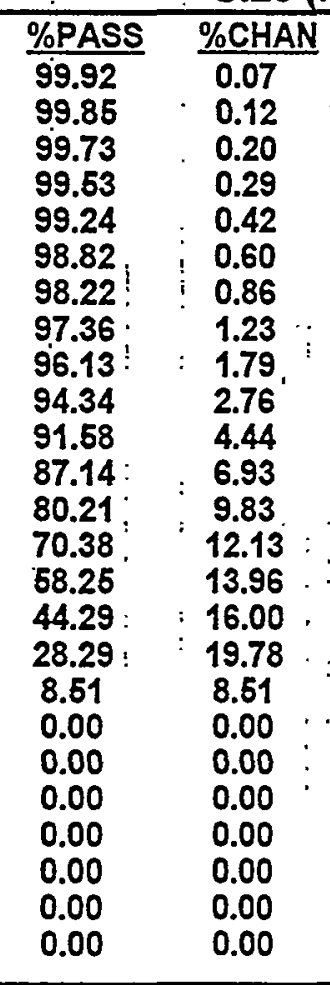




\section{. Particle Size Analysis}

CUF-AZ102

SampleCUF-AZ102-MU-R2D1

In AZ-102-MU Simulated Supematant

$60 \mathrm{ml} / \mathrm{s}$ 2nd Sonication 40 watts 90 seconds

lume Distribution $; x-100$ Syptem
AZ-102 Waste CUF-AZ102-MU-R2D1

Summary

$m v=12.37$

$m n=0.698$

$\mathrm{ma}=3.944$

$c s=1.621$

sd $=10.68$

00626

Date: 05/19/89 Meas \#: 00124 Time: 15:43

Pres \#: 01

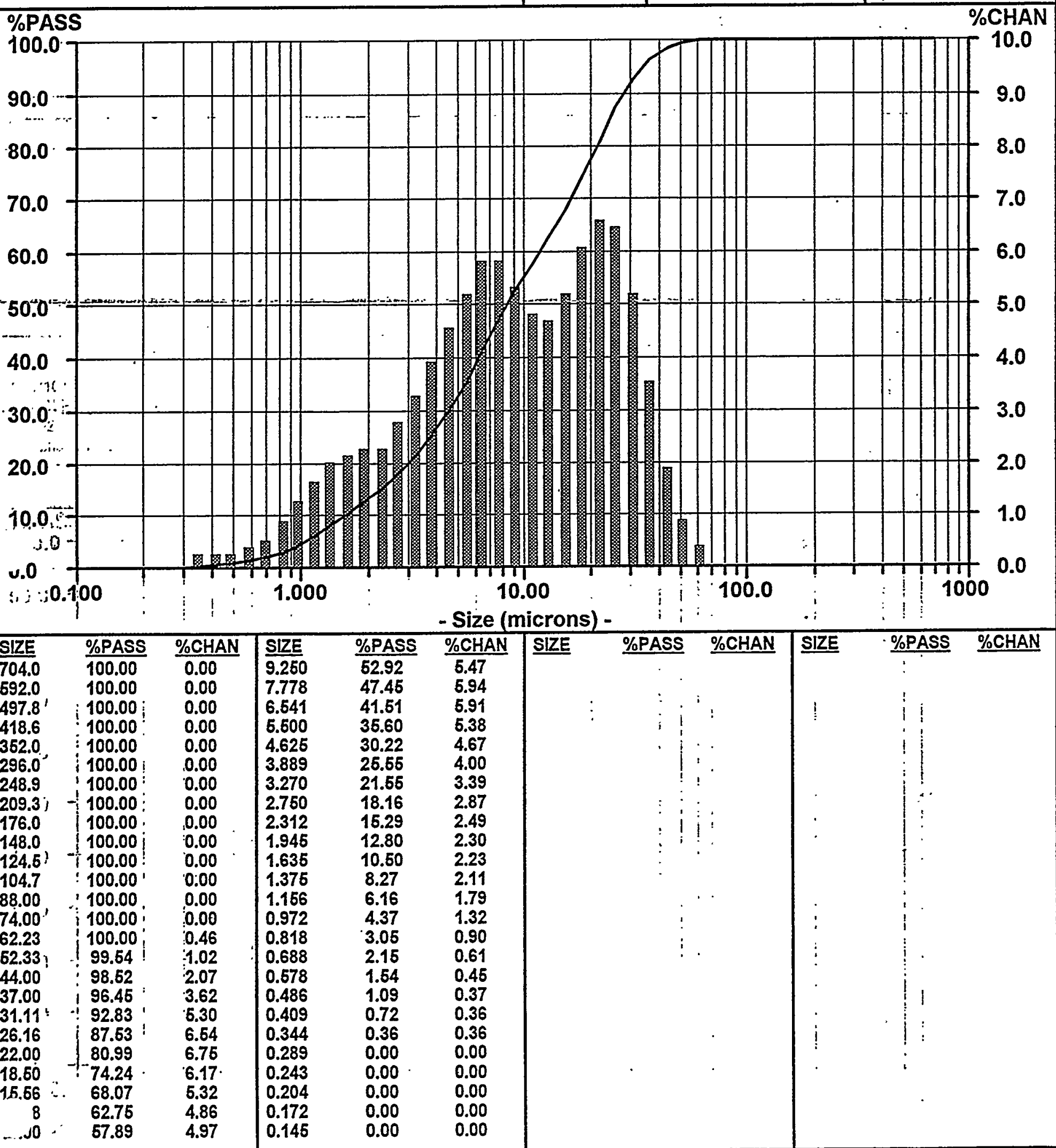


co seas

\section{Particle Size Analysis}

CUF AZ-102 Waste

UPA

Sample: CUF-AZ102-MU-R1D

Volume Distribution; UPA System
CUF AZ-102 Waste CUF-AZ102-MU-R1D

Summary . Percentiles

$\mathrm{mv}=1.164$

$m n=1.058$

$\mathrm{ma}=1.127$

$c s=5.323$

$\mathrm{sd}=.2054$
Date: 05/20/85 Meas f: 00019 Timo: 11:11 Pres \#: 01

$10 \%=.906560 \%=1.202$

$20 \%=.984670 \%=1.262$

$30 \%=1.04280 \%=1.334$

$40 \%=1.09590 \%=1.440$

$60 \%=1.14795 \%=1.639$

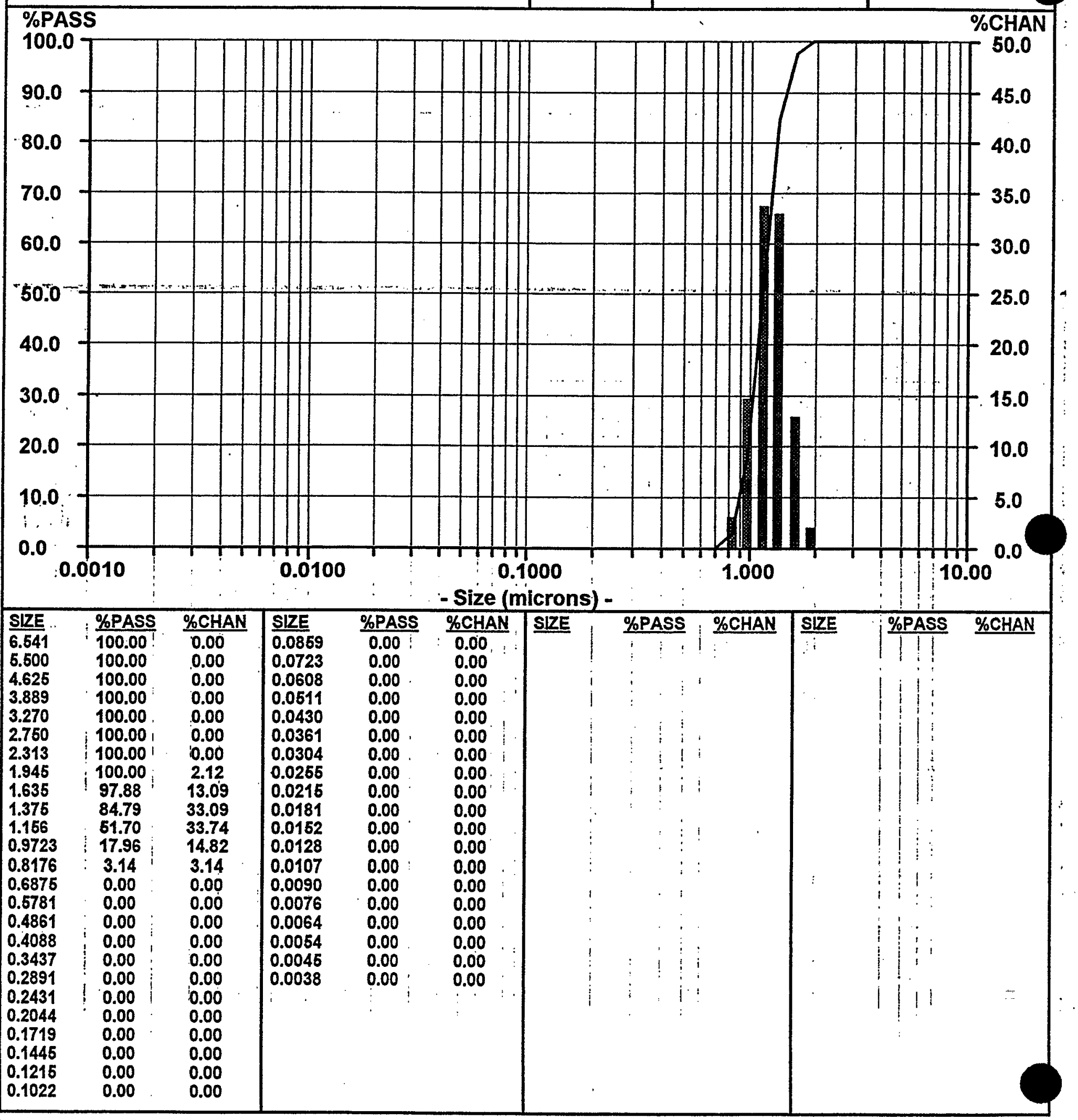


$\infty<k 67$

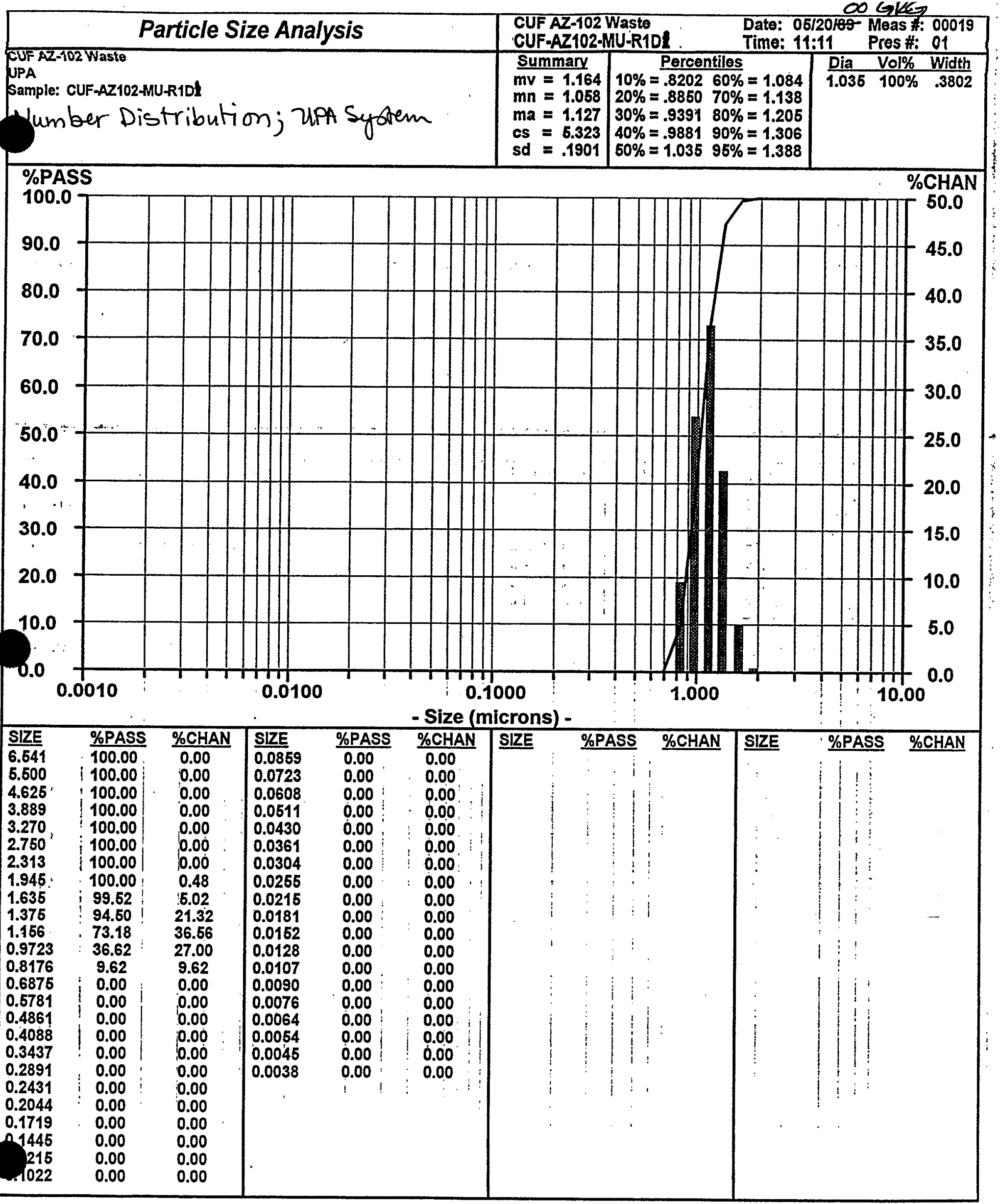




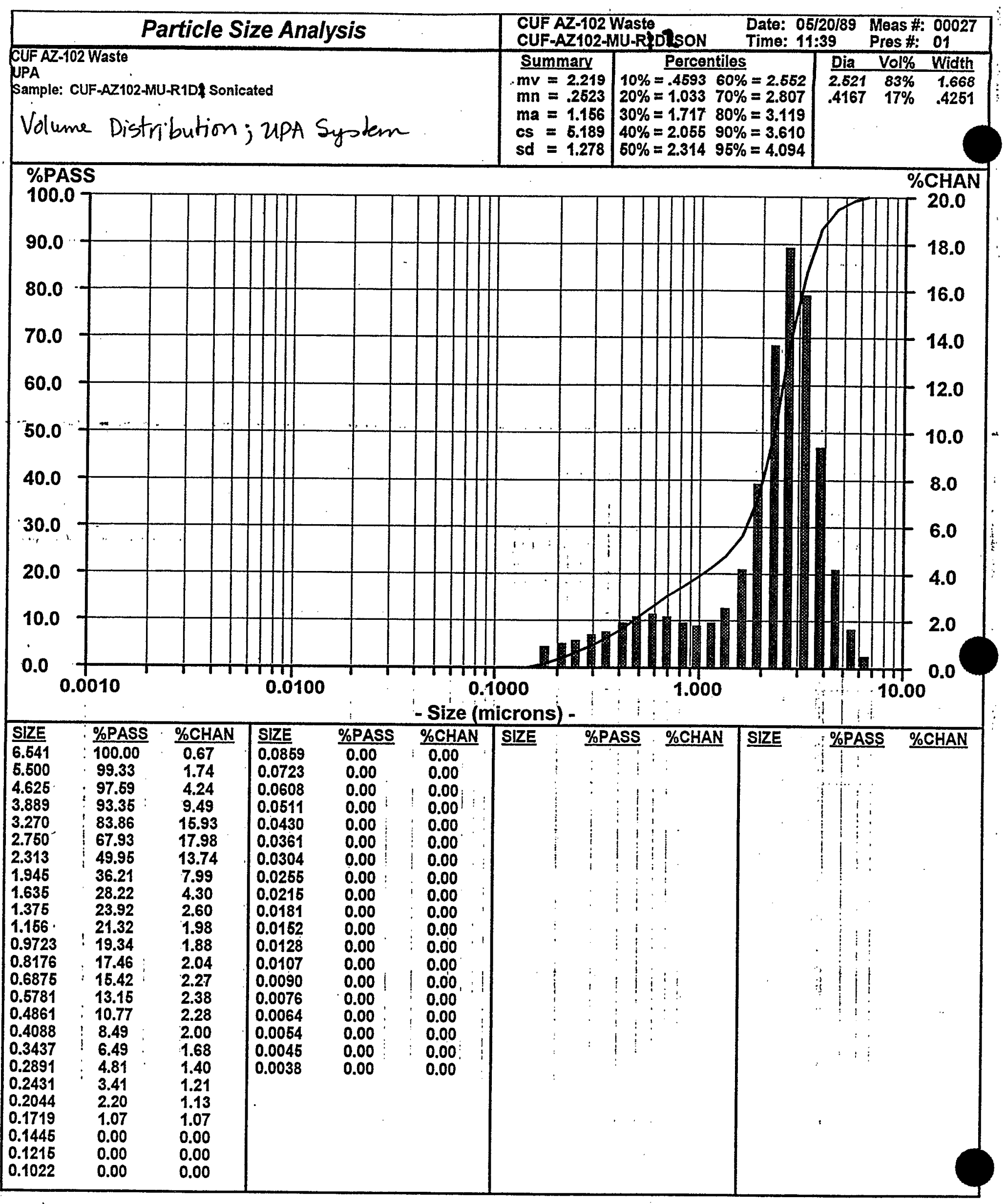


$00<1 / 5$

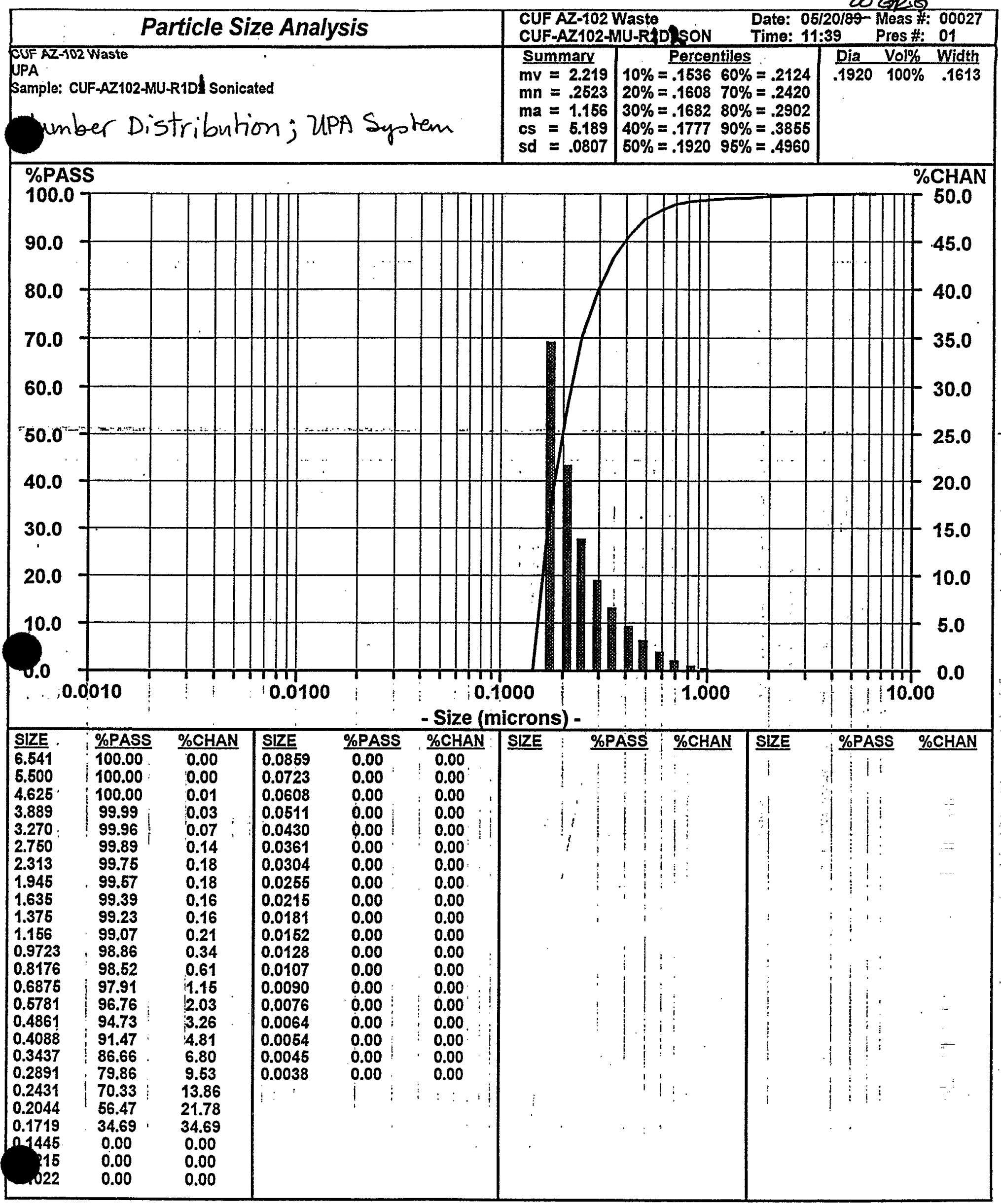


Particle Size Distribution Plots

For Initial Sludge: Sample CUF-AZ-102 MU R2D1

Replicate No: 2 
$00 \sin$

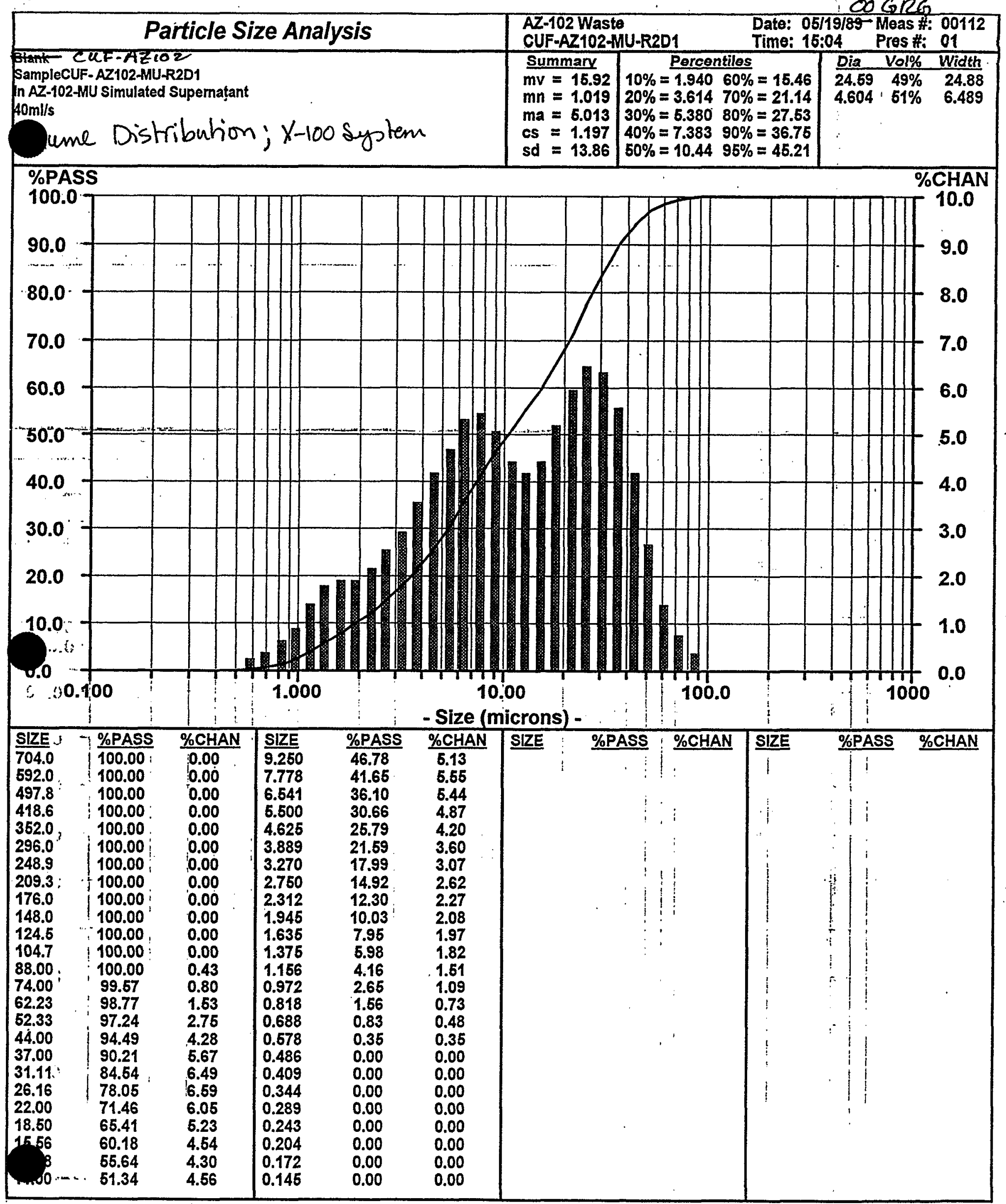




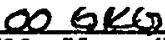

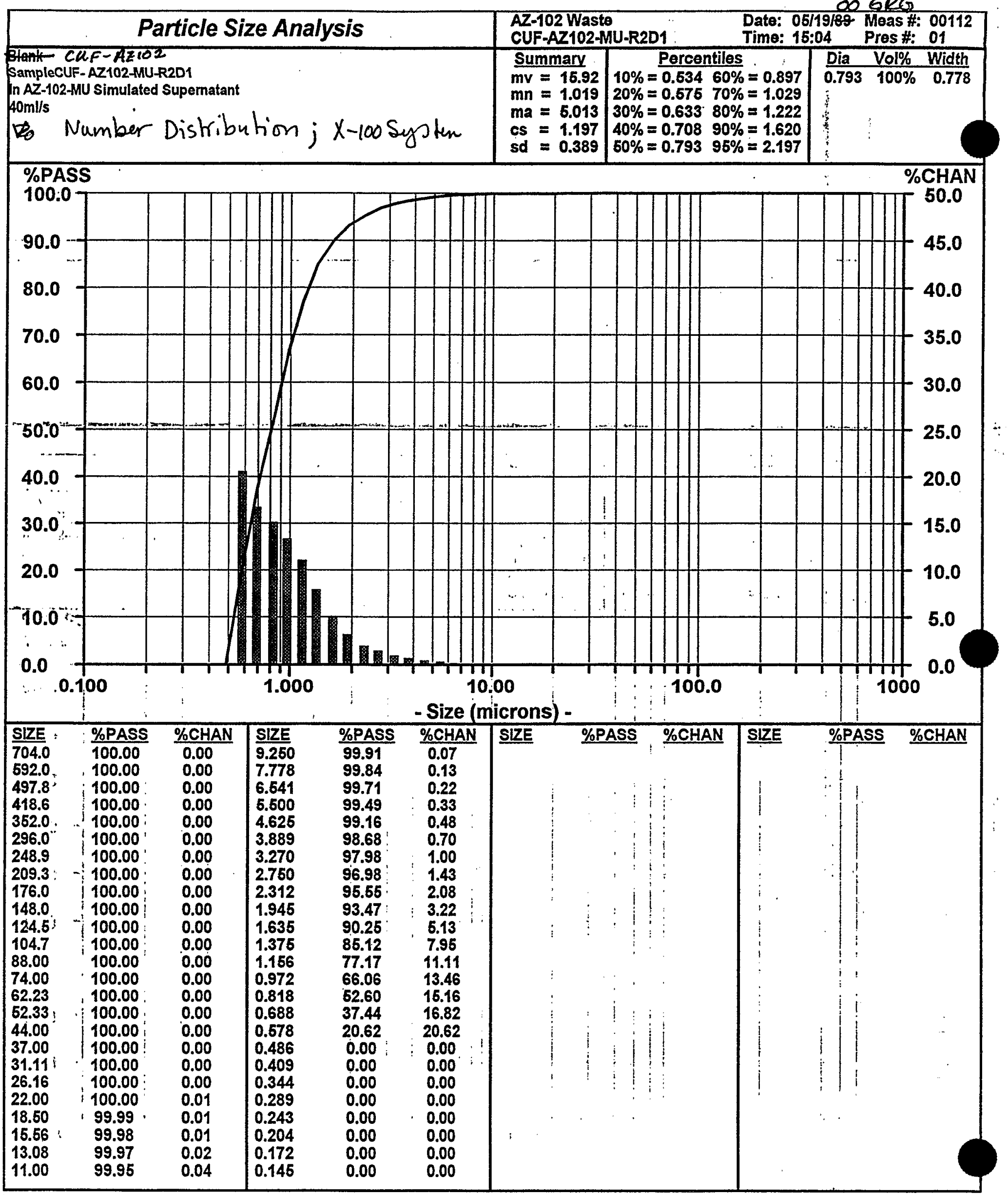


$00 \mathrm{GKG}$

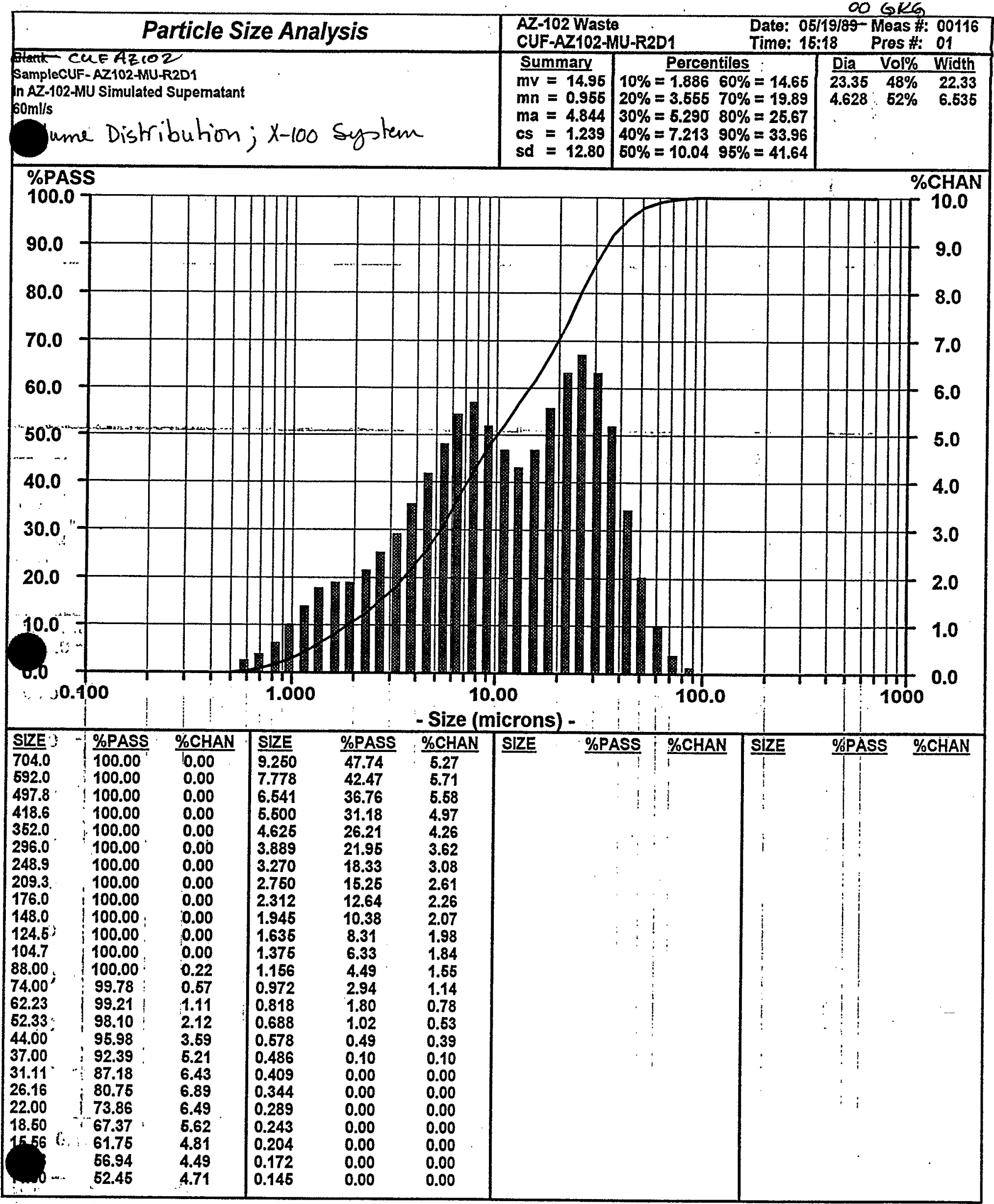


Particle Size Analysis

Famie CUFAZ102

SampleCUF-AZ102-MU-R2D1

In AZ-102-MU Simulated Supematant

$60 \mathrm{ml} / \mathrm{s}$

Number Distribution; $x-100$ System
AZ-102 Waste

CUF-AZ102-MU-R2D1

Summary

$m v=14.95$

$m n=0.955$

$\mathrm{ma}=4.844$

$c s=1.239$

sd $=0.369$

Percentiles
$10 \%=0.49460 \%=0.838$
$20 \%=0.54070 \%=0.966$
$30 \%=0.588 \quad 80 \%=1.161$
$40 \%=0.65490 \%=1.524$
$50 \%=0.73695 \%=2.059$

$\infty \mathrm{G}$

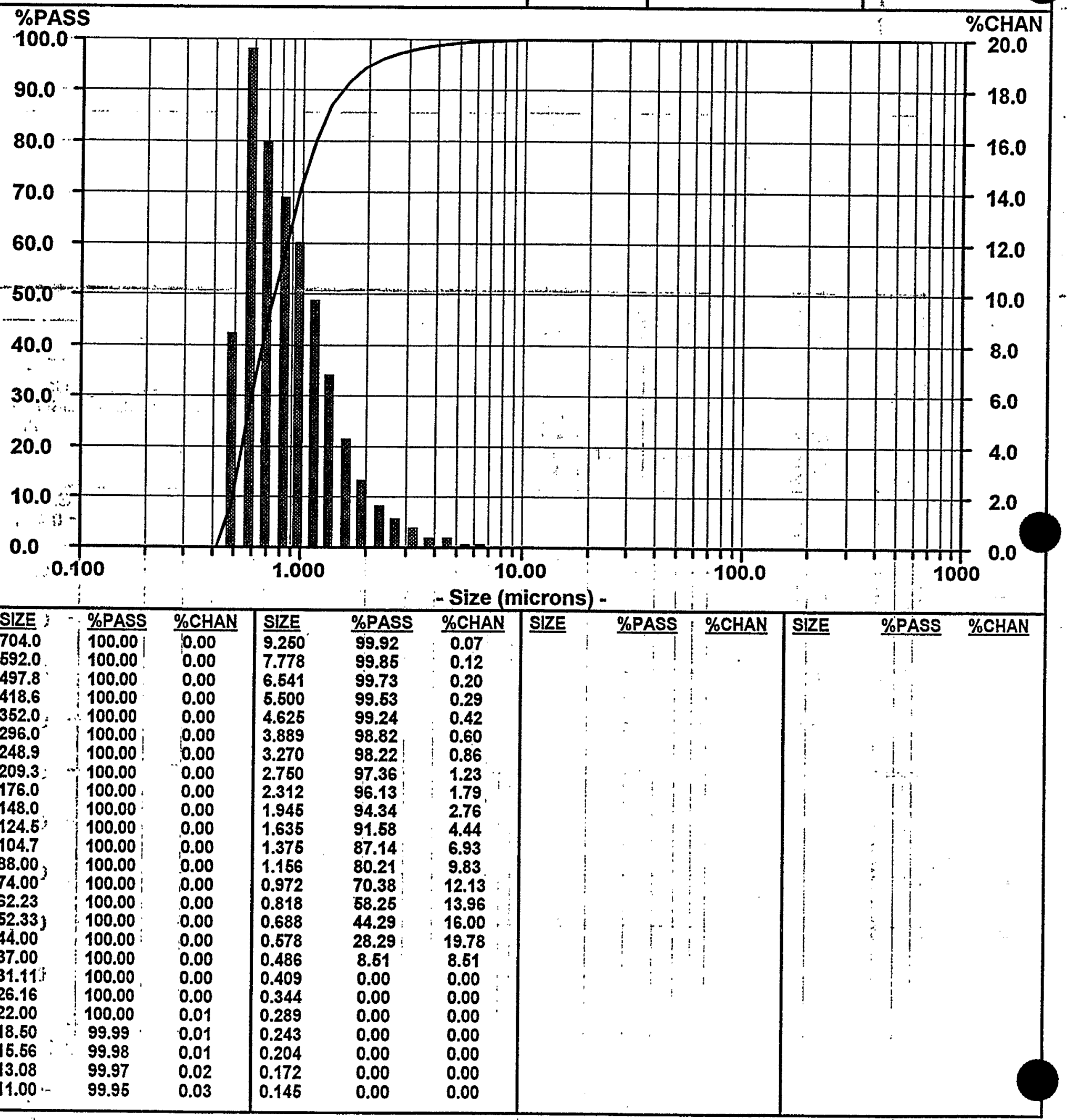


ookes

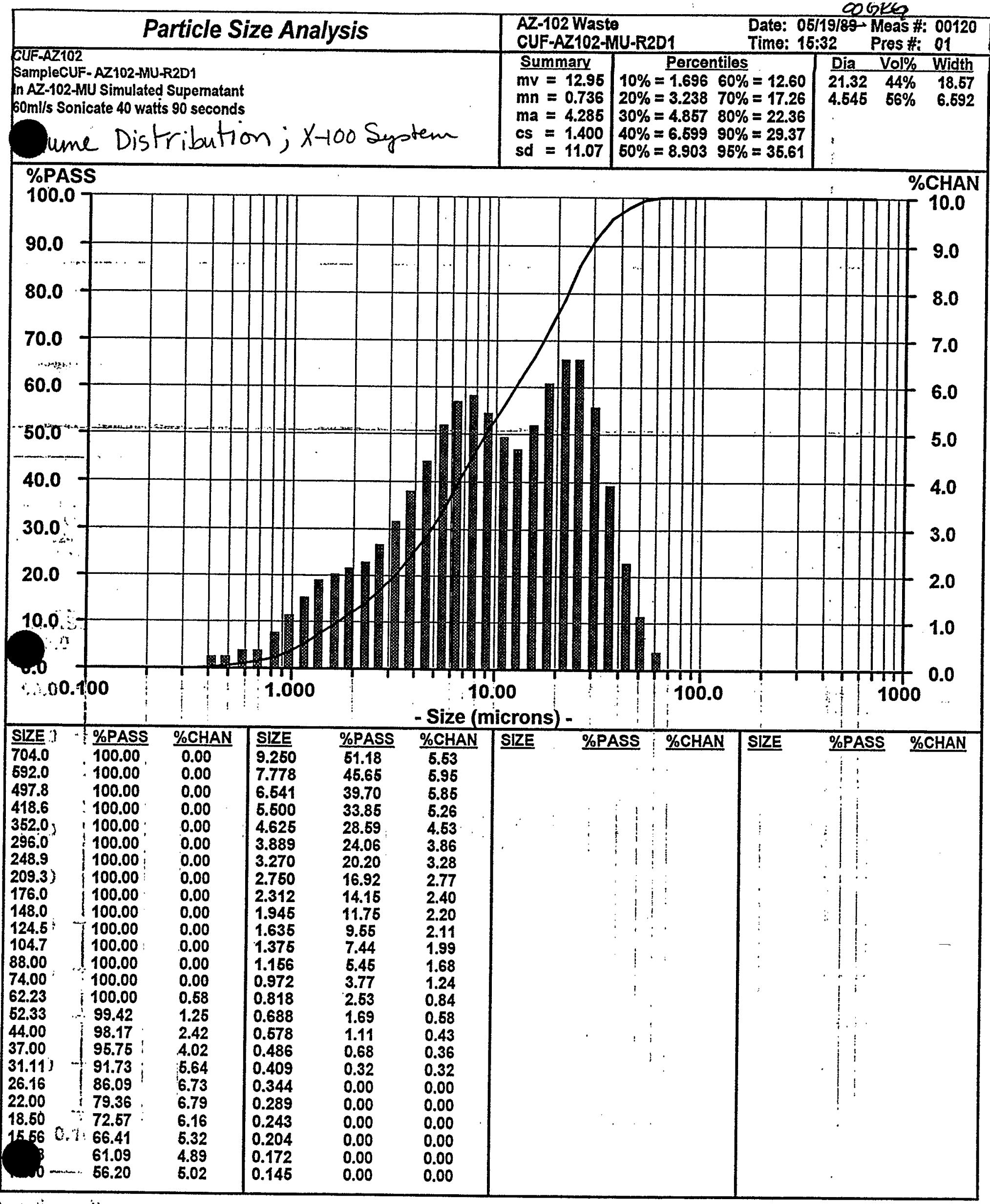


$\therefore \infty$ GRG

\section{Particle Size Analysis}

CUF-AZ102

SampleCUF-AZ102-MU-R2D1

In AZ-102-MU Simulated Supernatant

$60 \mathrm{ml} / \mathrm{s}$ Sonicate 40 watts 90 seconds

Number Distribution; $X-100$ SyAtem
AZ-102 Waste CUF-AZ102-MU-R2D1

Summary

$\mathrm{mv}=12.95$

$\mathrm{mn}=0.736$

$\mathrm{ma}=4.285$

cs $=1.400$

sd $=0.321$

Percentiles
$10 \%=0.371 \quad 60 \%=0.619$
$20 \%=0.393 \quad 70 \%=0.746$
$30 \%=0.422 \quad 80 \%=0.928$
$40 \%=0.467 \quad 90 \%=1.246$
$50 \%=0.629 \quad 95 \%=1.648$

\section{\%PASS}

100.0

90.0

80.0

$\square$

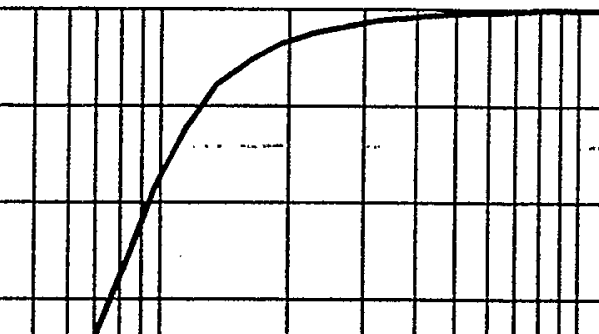

60.0

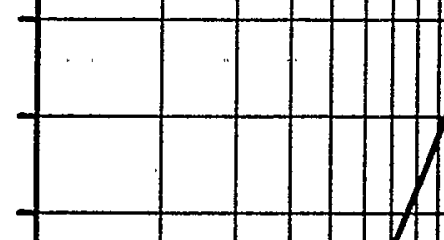

70.0

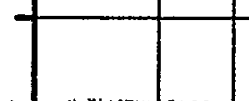

50.0

40.0

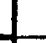

(n)

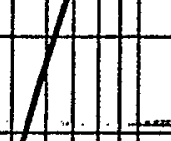

$2+110$
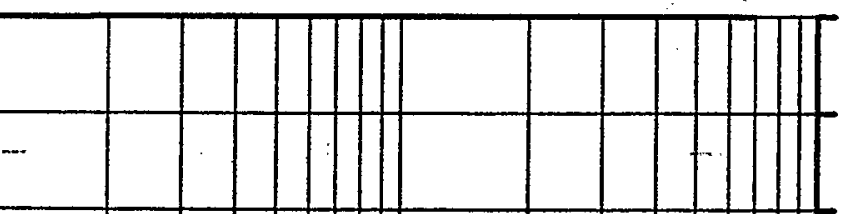

$\%$ CHAN

$\mathbf{3 0 . 0}$

i.
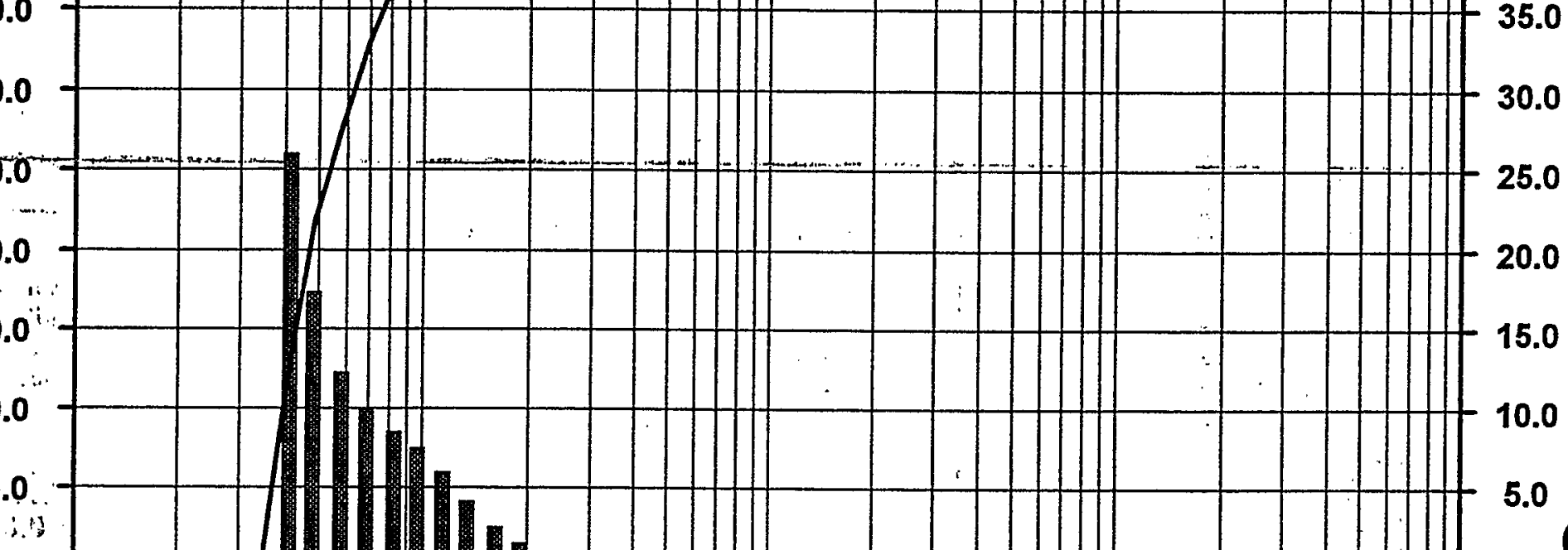

20.0

10.0

i.....

0.0700

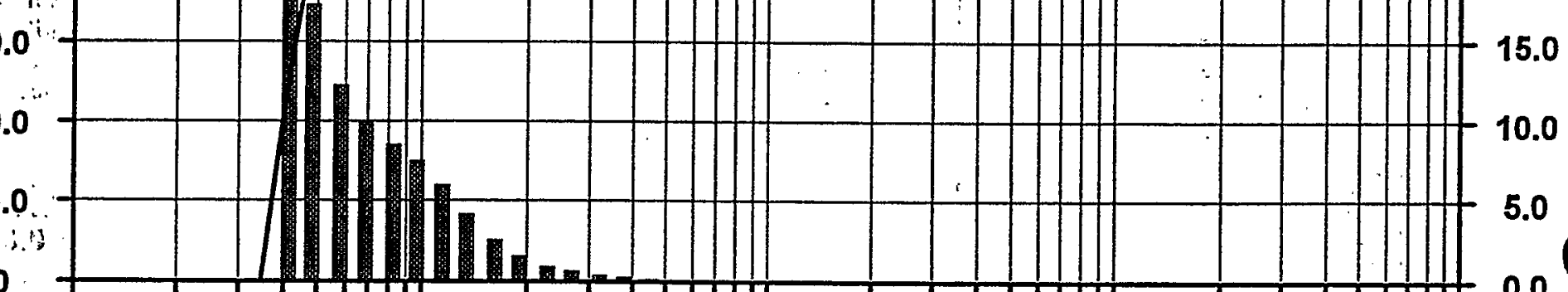

|

70

$$
41
$$

(1)

88.00

88.00

62.23

52.33

37.00

31.11

22.00

18.60

15.66

13.08

11.00

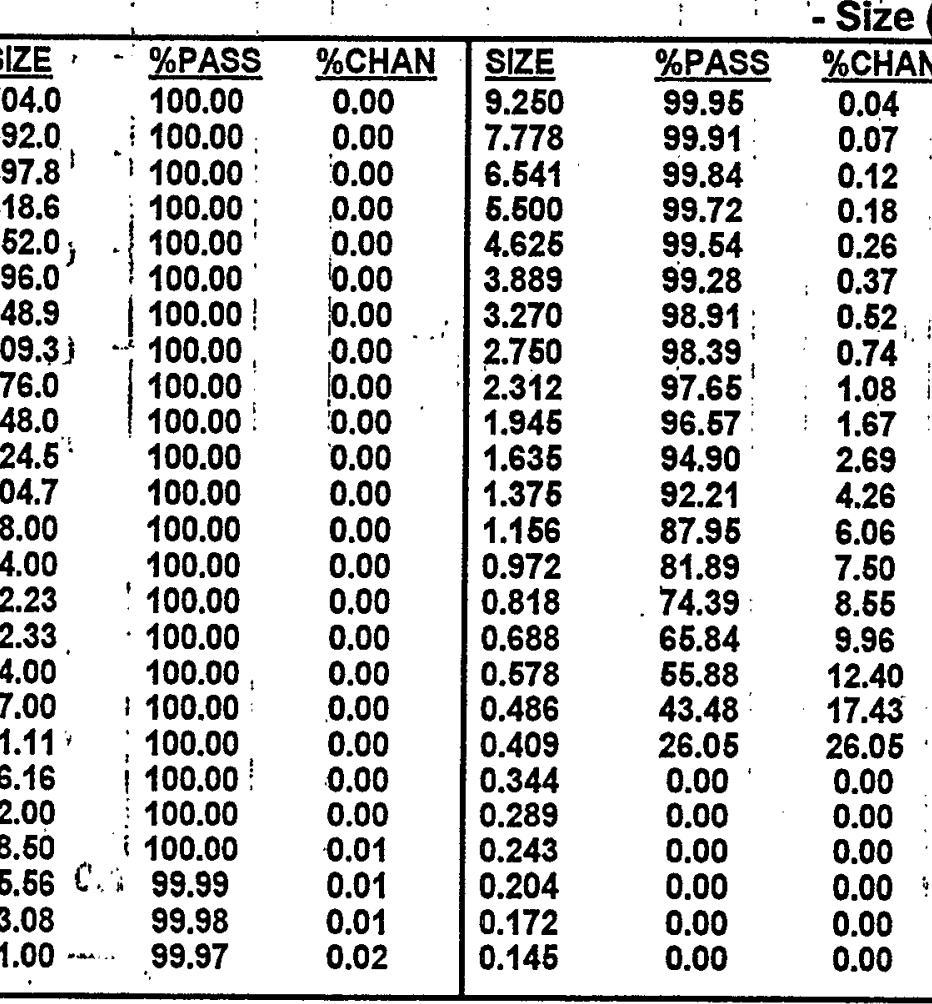
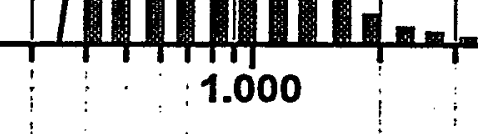

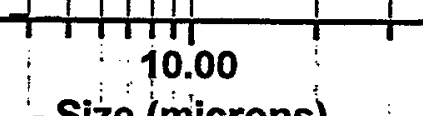

- Size (microns).

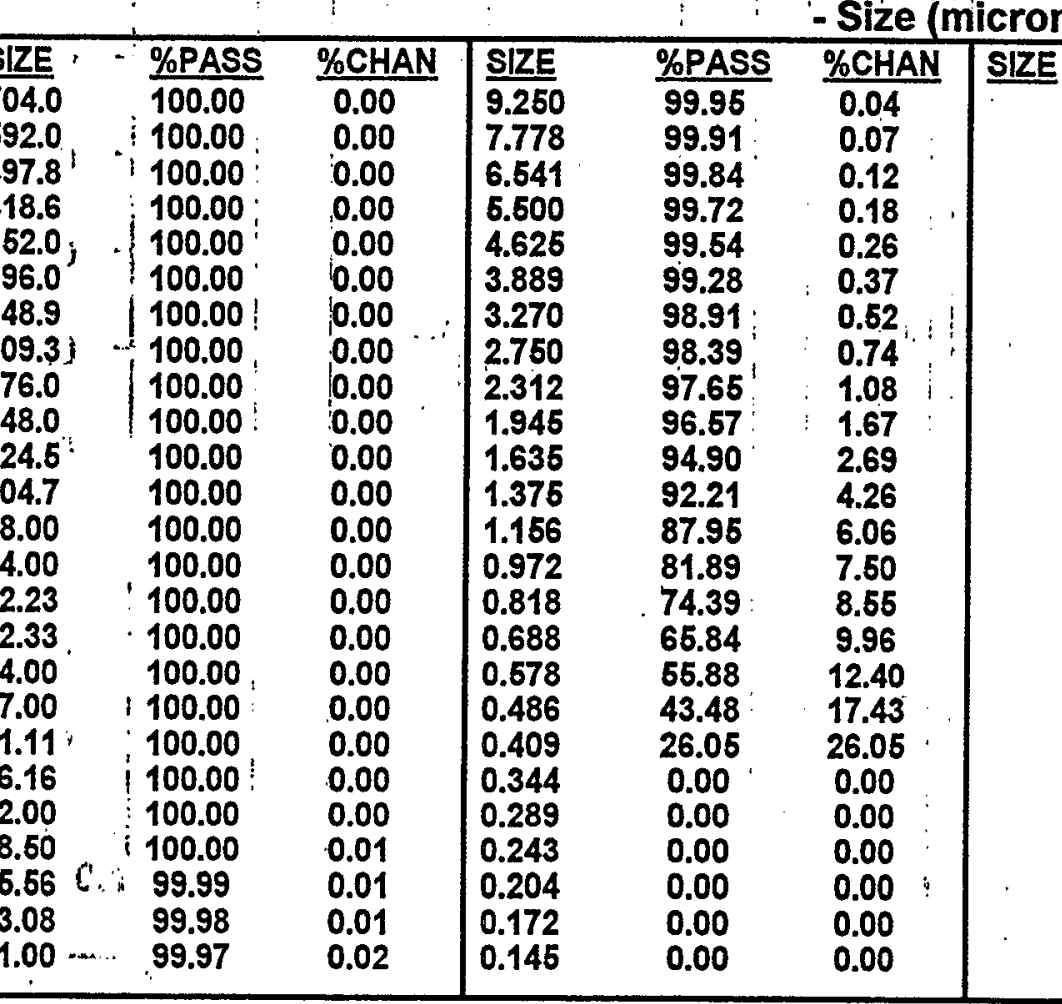

\begin{tabular}{|ccc|}
\hline Dia & Vol\% & Width \\
$0.629 \cdot 100 \%$ & 0.643 \\
$\vdots$ & & \\
$\vdots$ & & \\
\hline
\end{tabular}


$\infty 626$

\begin{tabular}{|l|l|ll|l|l|}
\hline \multicolumn{1}{|c|}{ Particle Size Analysis } & AZ-102 Waste & CUF-AZ102-MU-R2D1 & Date: $05 / 19 / 85$ & Time: $15: 43$ & Meas $\#: 00124$ \\
Pres \#: 01
\end{tabular}

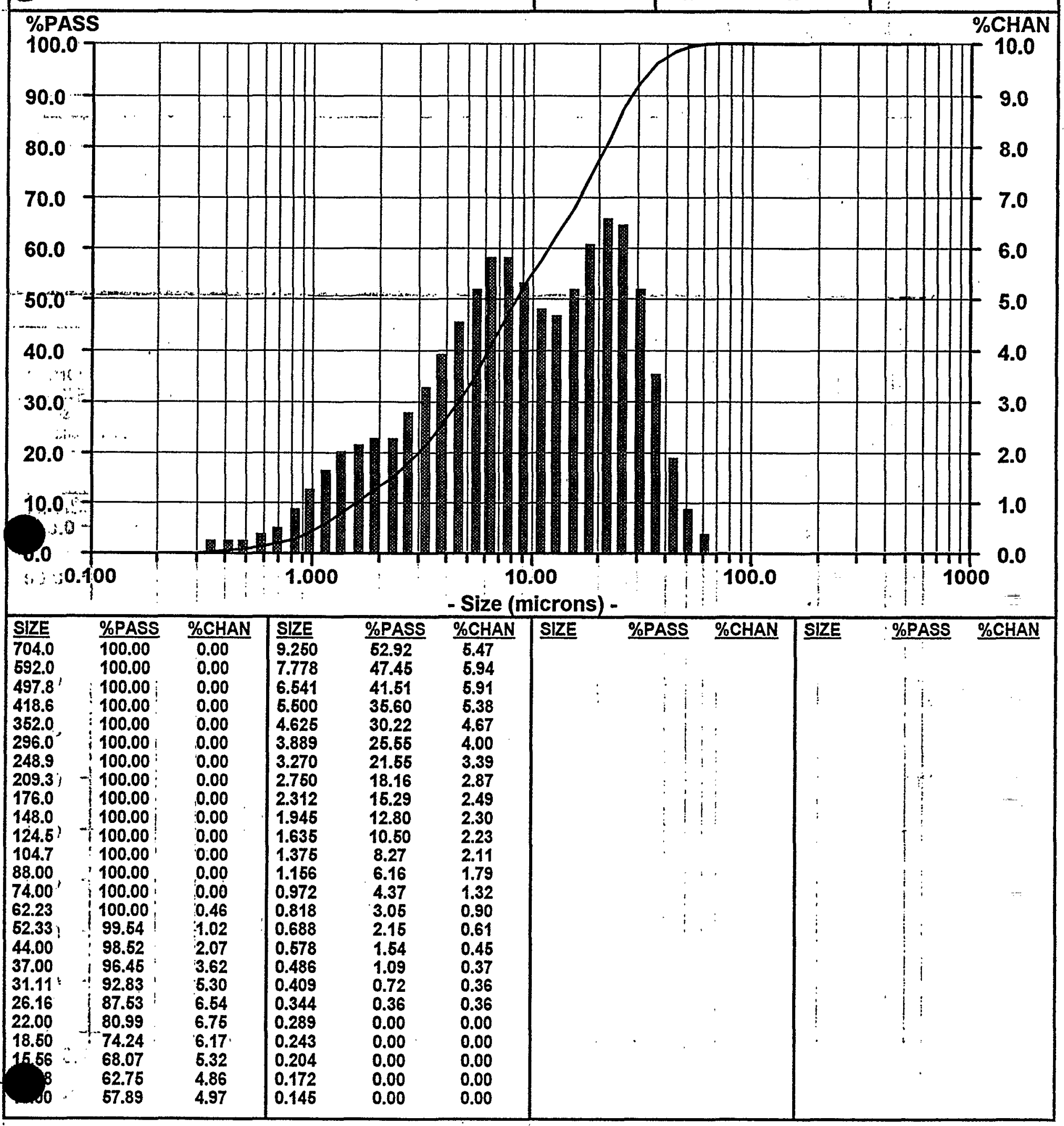




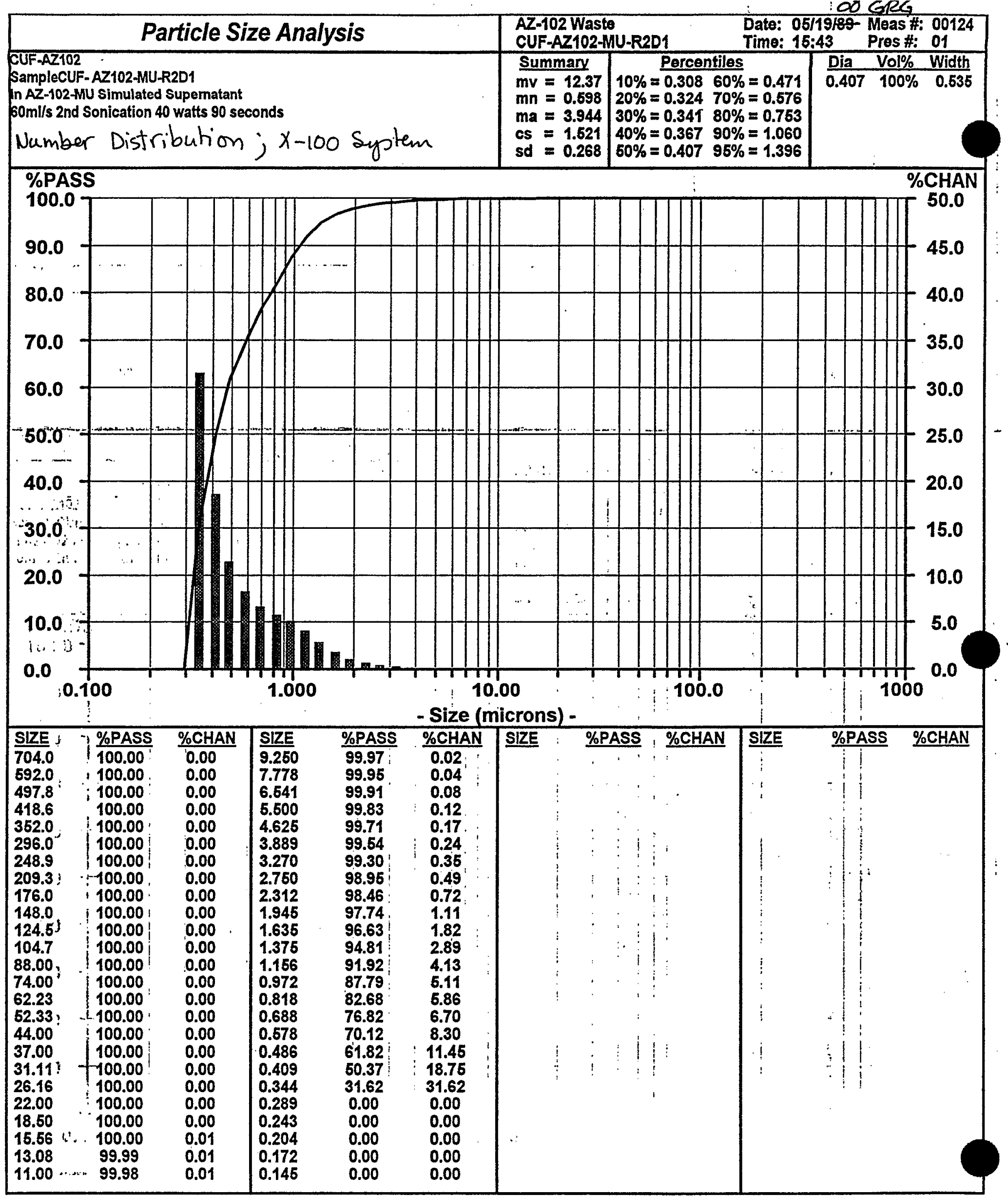




\section{Particle Size Analysis}

CUF AZ-102 Waste

JPA

Sample: CUF-AZ102-MU-R2D1

"rlume Distribution; UPA Syptem
CUF AZ-102 Waste CUF-AZ102-MU-R2D1

Summary

$\mathrm{mv}=1.632$

$m n=1.281$

$\mathrm{ma}=1.409$

$c s=4.259$

sd $=.3006$

Date: 05/20/89 Meas \#: 00021 Time: 11:18

Pres \#: 01

\begin{tabular}{ccc} 
Dia & Vol\% & Width \\
\hline 5.537 & $2 \%$ & 1.133 \\
1.412 & $98 \%$ & .5745 \\
& & \\
& &
\end{tabular}

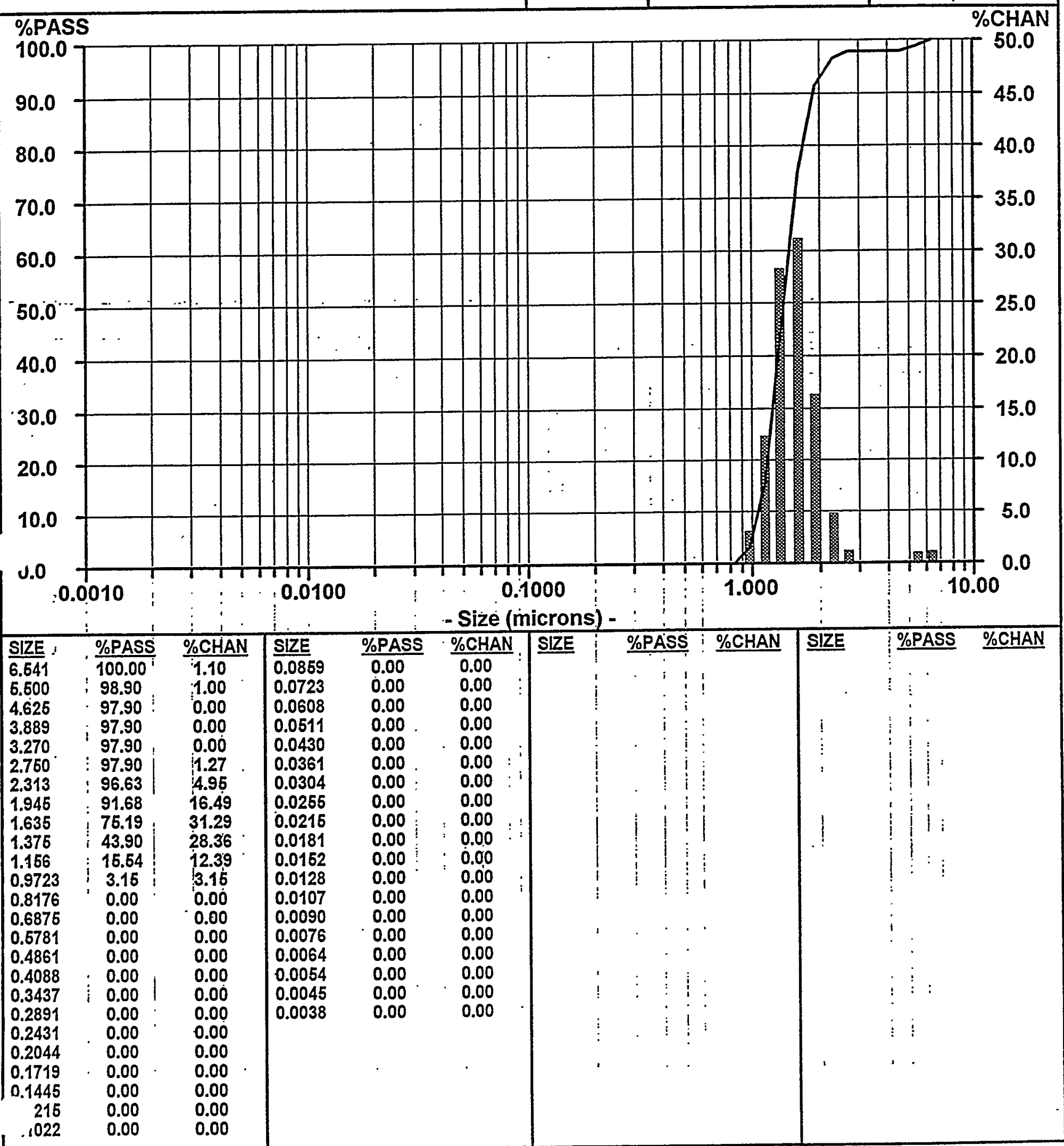


$10 \Leftrightarrow K G_{3}$

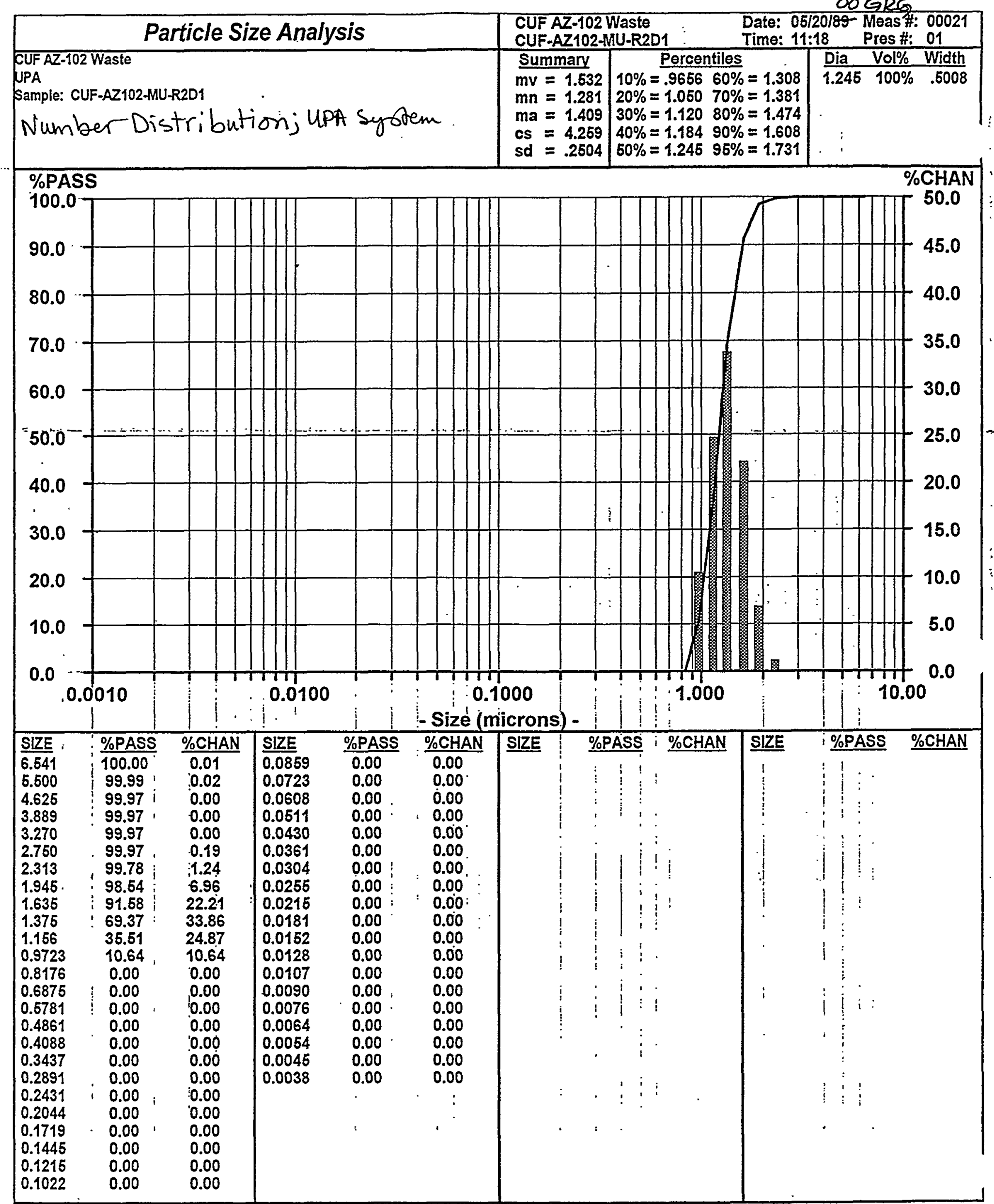




\section{Particle Size Analysis} CUF AZ-102 Waste

UPA

Sample: CUF-AZ102-MU-R1D2 Sonicated

R2DI

lume Distribution; UPA Syptem
CUF AZ-102 Waste Date: 05/20/89 Meas \#: 00027 CUF-AZ102-MU-R2D1SON Time: 11:39 Pres \#: 01 Summary Percentiles.

$\mathrm{ma}=1.156 \quad 30 \%=1.71780 \%=3.119$

sd $=1.278 \quad 60 \%=2.31495 \%=4.094$ $m v=2.219 \quad 10 \%=.459360 \%=2.552$

$m n=.2523 \quad 20 \%=1.033 \quad 70 \%=2.807$

$c s=5.189 \quad 40 \%=2.055 \quad 90 \%=3.610$

\begin{tabular}{ccc}
\hline Dia & Vol\% & Width \\
\hline 2.521 & $83 \%$ & 1.668 \\
.4167 & $17 \%$ & .4261 \\
& & \\
& &
\end{tabular}

$\%$ CHAN

20.0

18.0

16.0

70.0

60.0

50.0

40.0

30.0

20.0

10.0

v. 0

0.0010

\subsection{0}
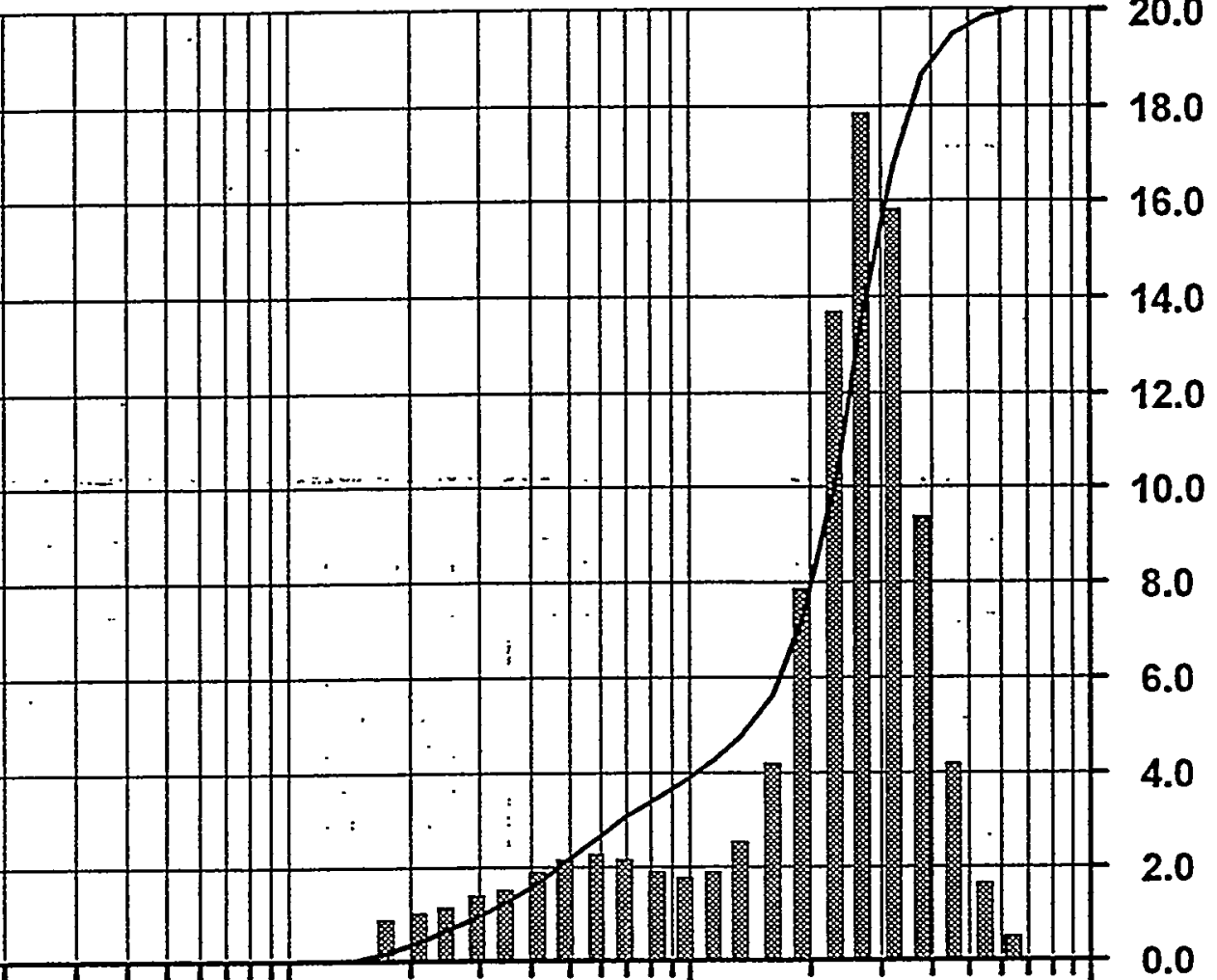

0.1000
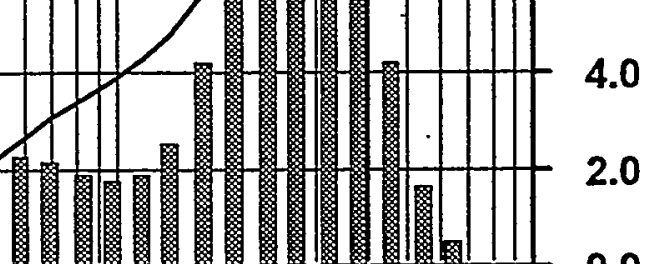

4.0

1.000

10.00

2.0

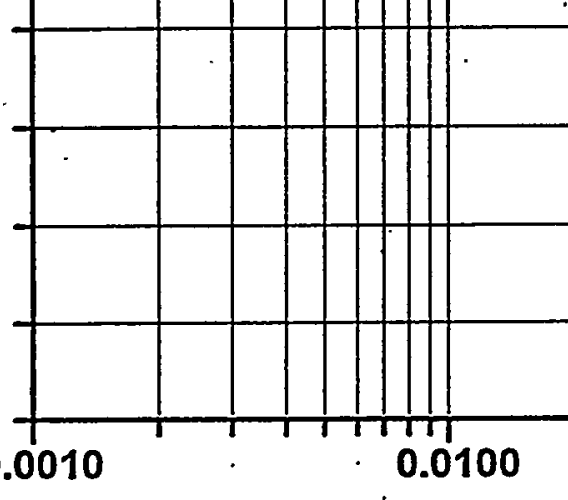

$$
\begin{aligned}
& \hline \text { SI } \\
& \hline 6 . \\
& 6 .
\end{aligned}
$$

S.

3.68

3.270

2.760

2.313

1.945

1.635

1.375

1.166

0.9723

0.8176

0.6875

0.5781

0.4861

0.4088

0.3437

0.2891

0.2431

0.2044

0.1719

0.1445 .

$\begin{array}{r}15 \\ -. J 22 \\ \hline\end{array}$
99.33

. 97.59

; 93.35

67.93

49.95

36.21

! 28.22

: 23.92

. 21.32

; 19.34

17.46

15.42

. 13.15

10.77

i 8.49

6.49

, 4.81

3.41

2.20

1.07

0.00

0.00

0.00
83.86

- Size (microns) -

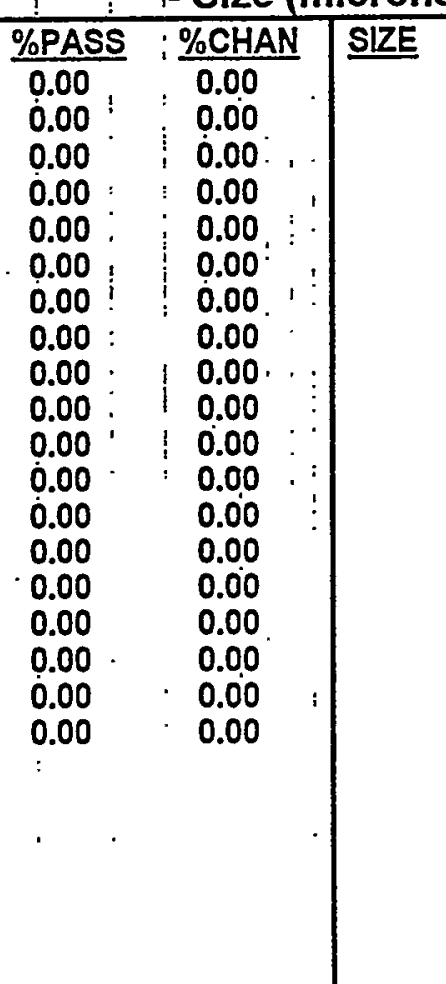

\begin{tabular}{ll}
0.00 & 0.00 \\
\hline
\end{tabular}


Particle Size Distribution Plots

For Concentrated Slurry: Sample CUF-AZ-102-005

Replicate No: 1 


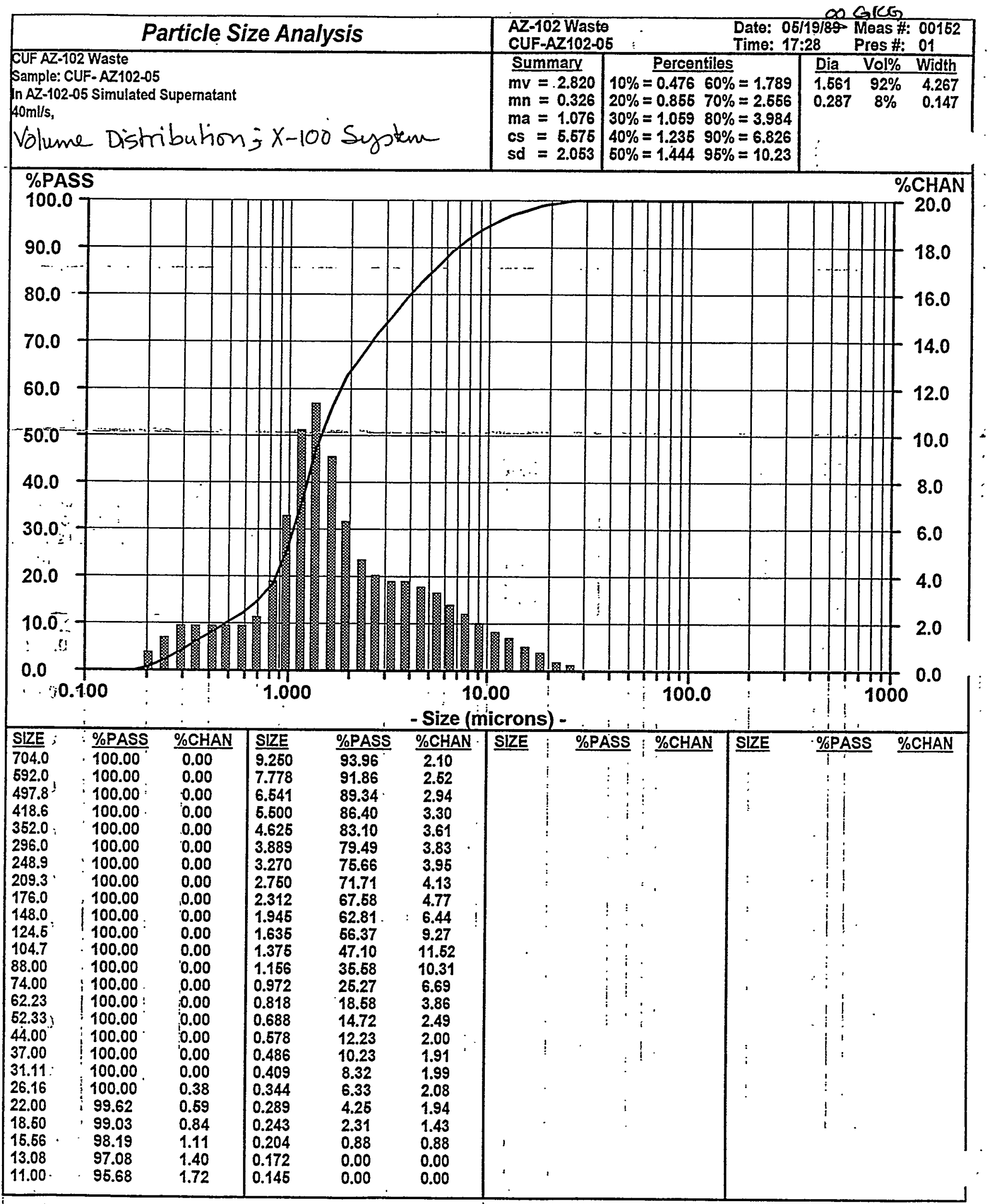




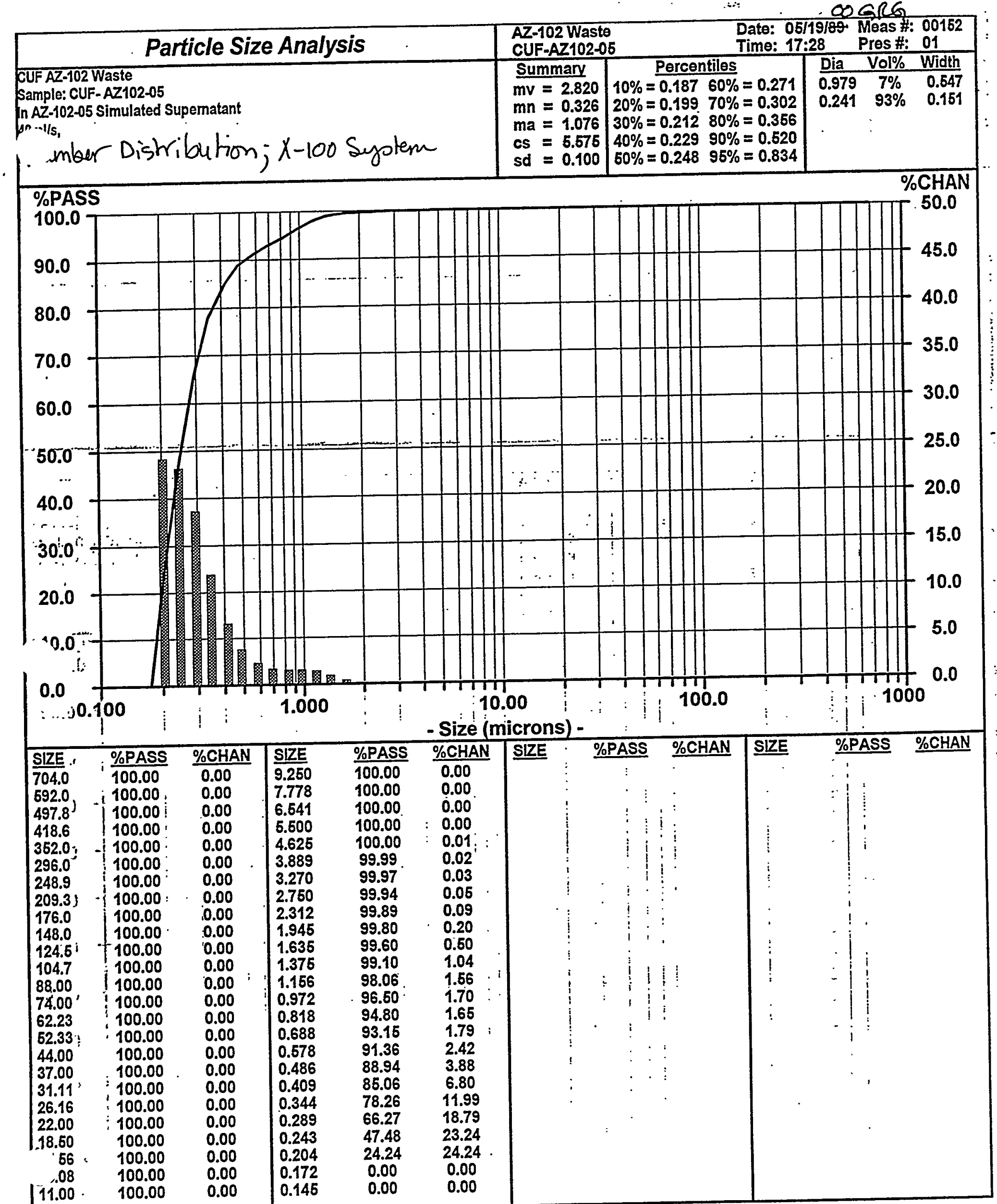




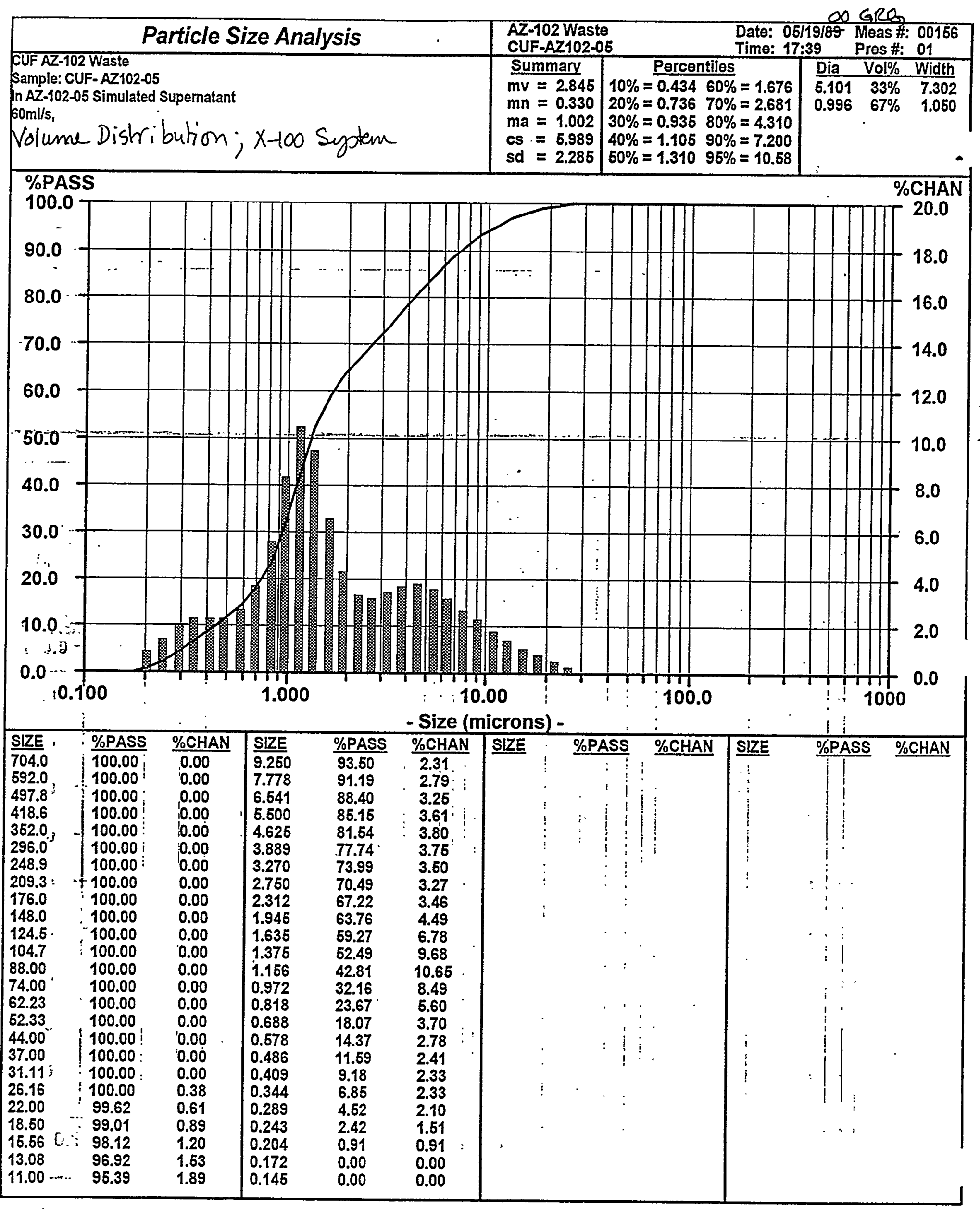


Particle Size Analysis

CUF AZ-102 Waste

Sample: CUF-AZ102-05

In AZ-102-05 Simulated Supematant

$60 \mathrm{ml} / \mathrm{s}$,

nber Distribution; $x-100$ System
AZ-102 Wasto

CUF-AZ102-05

Summary $\quad$ Percentiles

$m v=2.845 \quad 10 \%=0.188 \quad 60 \%=0.278$

$m n=0.330 \quad 20 \%=0.20170 \%=0.313$

$m a=1.002 \quad 30 \%=0.21580 \%=0.376$

cs $=5.989 \quad 40 \%=0.23390 \%=0.558$

sd $=0.113 \quad 60 \%=0.25495 \%=0.806$

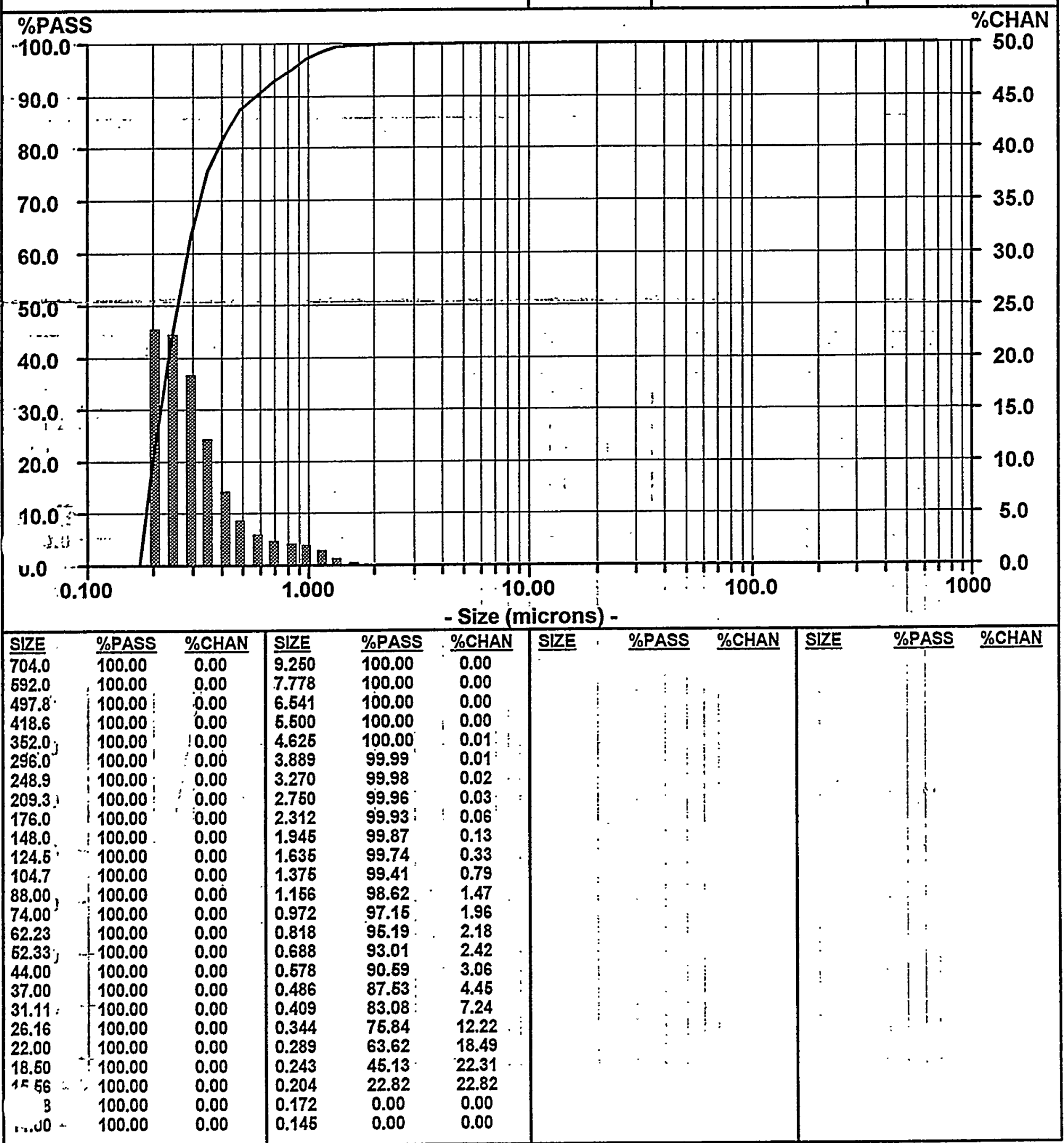




\begin{tabular}{|c|c|c|c|c|}
\hline Particle Size Analysis & $\begin{array}{l}\text { AZ-102 Wast } \\
\text { CUF-AZ102- }\end{array}$ & $\begin{array}{l}\text { Date: } 0 \\
\text { Time: } 18\end{array}$ & $\begin{array}{l}\text { 19/69 Meas \#: } \\
04 \quad \text { Pres H: }\end{array}$ & $\begin{array}{l}00164 \\
01\end{array}$ \\
\hline $\begin{array}{l}\text { CUFAZ-102 Waste } \\
\text { Sample: CUF-AZ102-05 } \\
\text { in AZ-102-05 Simulated Supernatant } \\
\text { snmlis, 2nd Sonication } 40 \text { watts } 90 \text { seconds } \\
\text { 1. vilume Distr ibution; X-100 System }\end{array}$ & $\begin{array}{l}\text { Summary } \\
\mathrm{mv}=2.971 \\
\mathrm{mn}=0.320 \\
\mathrm{ma}=0.951 \\
\mathrm{cs}=6.312 \\
\mathrm{sd}=2.509\end{array}$ & $\begin{array}{l}\text { Percentiles } \\
10 \%=0.386 \quad 60 \%=1.891 \\
20 \%=0.63270 \%=3.092 \\
30 \%=0.868 \quad 80 \%=4.667 \\
40 \%=1.06590 \%=7.574 \\
60 \%=1.33195 \%=10.98\end{array}$ & $\begin{array}{ll}\text { Dia } & \text { Vol\% } \\
4.724 & 39 \% \\
0.864 & 61 \% \\
\vdots & \end{array}$ & $\begin{array}{r}\text { Width } \\
7.126 \\
0.983\end{array}$ \\
\hline
\end{tabular}

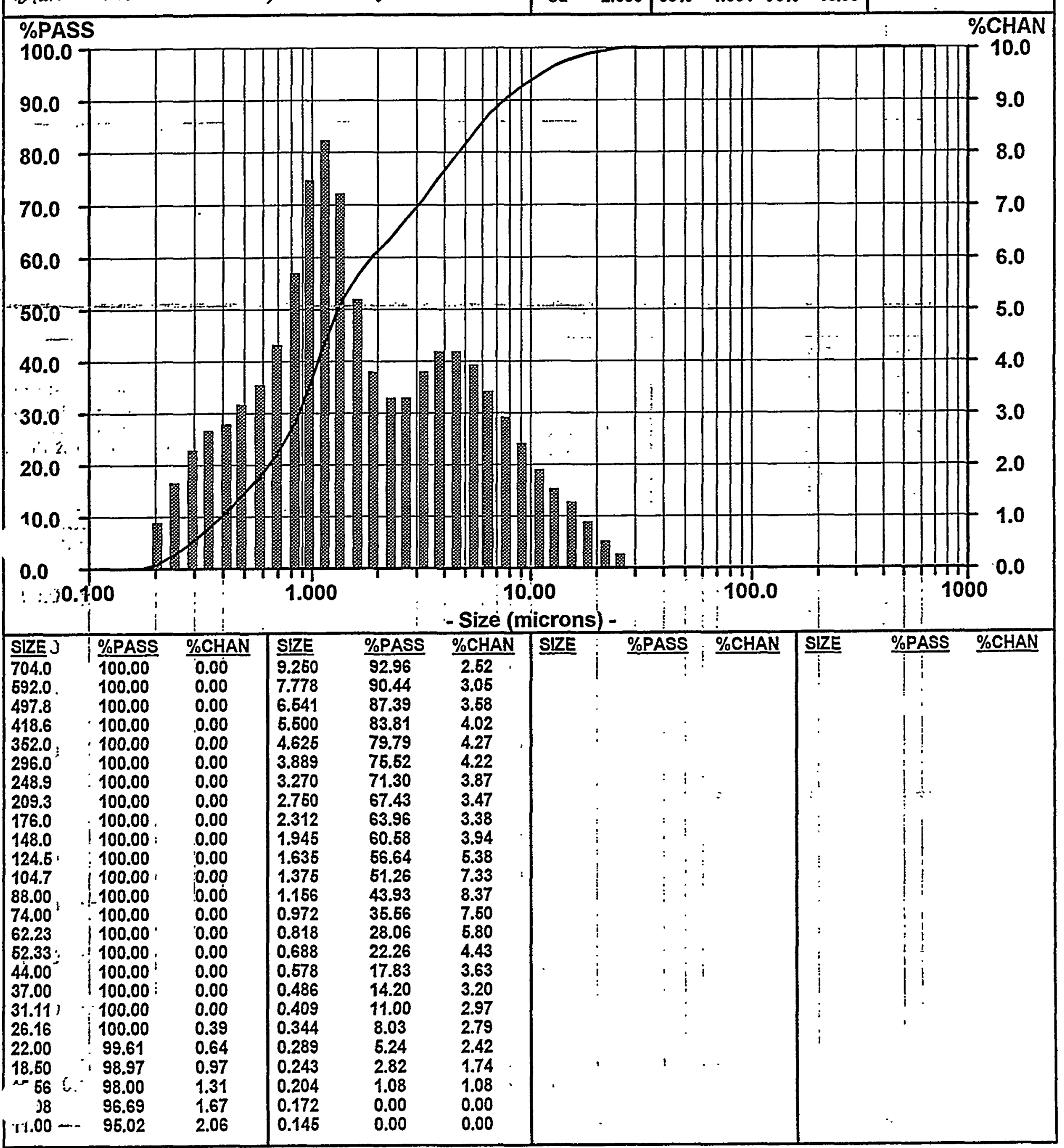




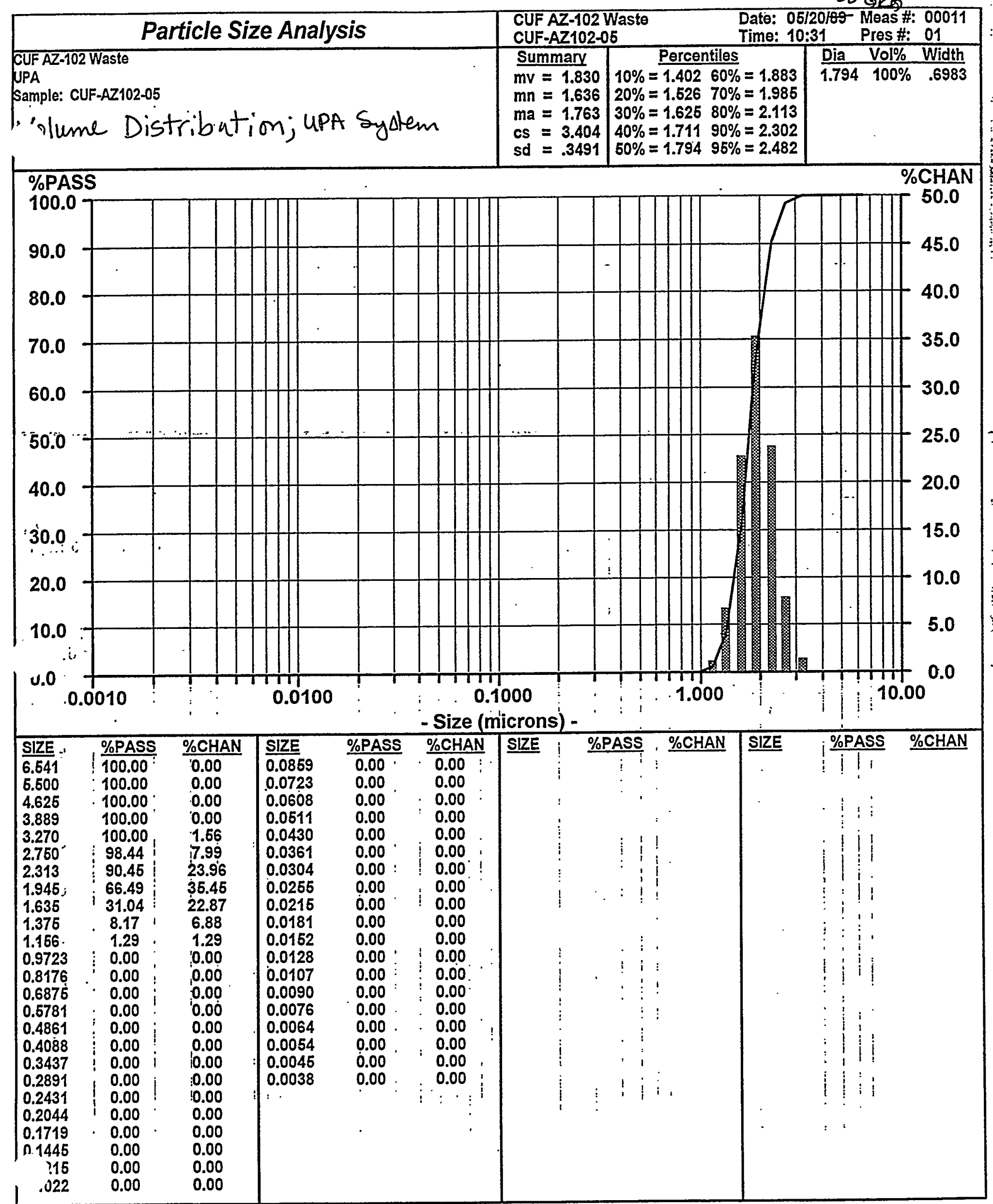




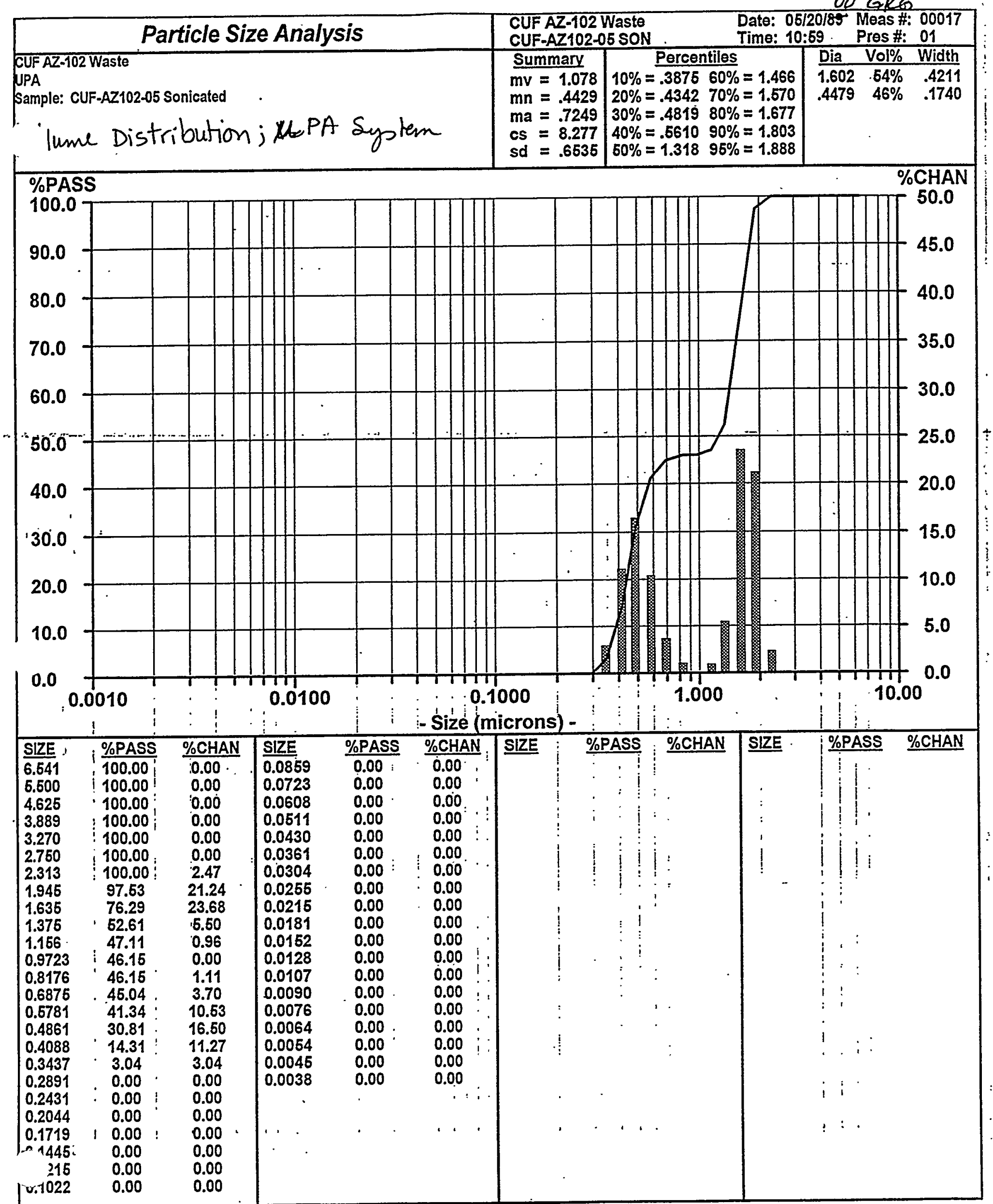




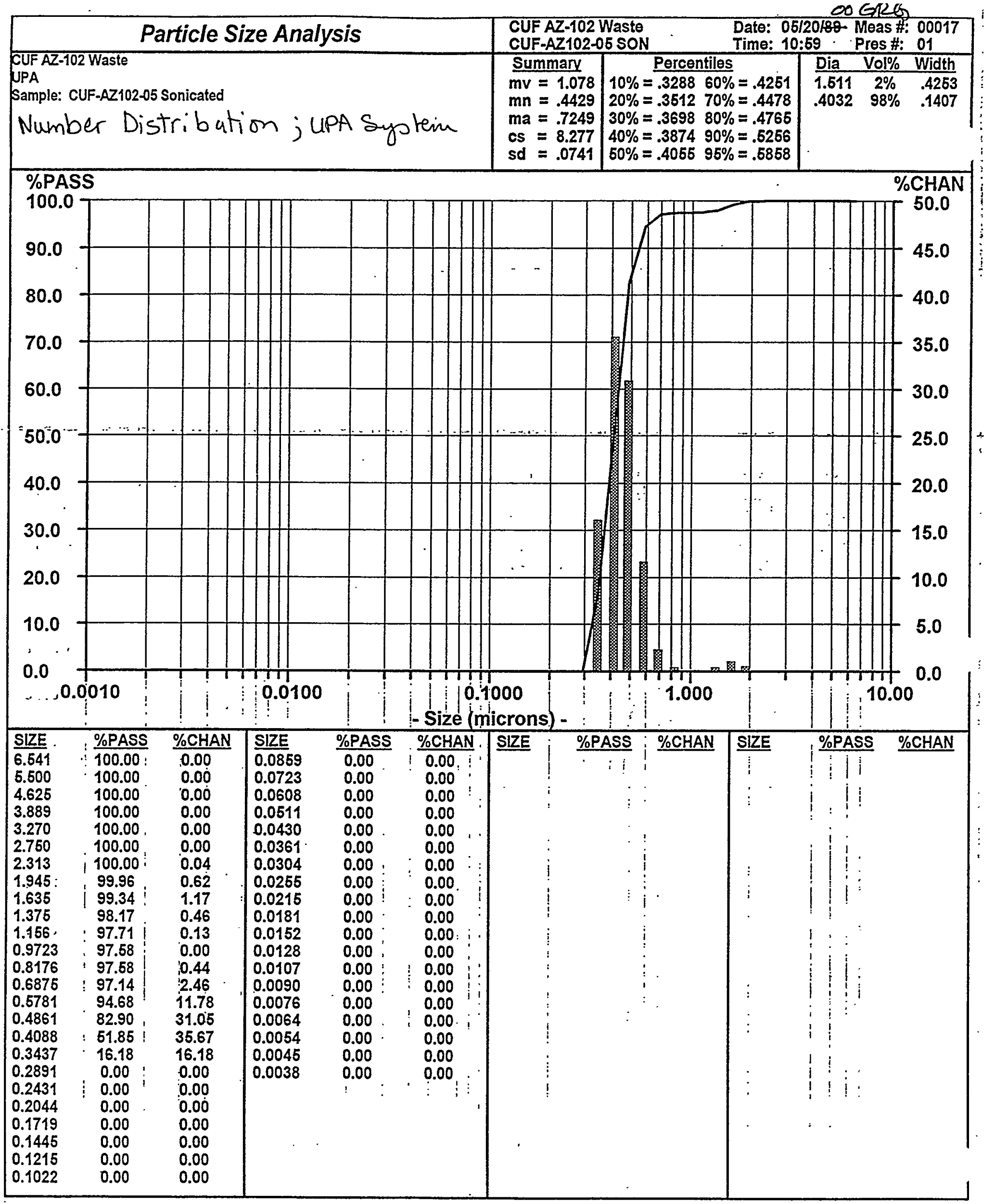


Particle Size Distribution Plots

For Concentrated Slurry: Sample CUF-AZ-102-005 DUP

Replicate No: 2 


\section{Particle Size Analysis}

\section{AZ-102 Waste}

SampleCUF. AZ102-05 DUP

in AZ-102-05 Simulated Supernatant

$40 \mathrm{~mL} / \mathrm{s}$

Volume Distribution; $x-100$ System
OSGRe

AZ-102 Waste Date: 05/18/89 Meas \#: 00036 CUF-AZ102-05 DUP

Time: 14:11

Pres \#: 01

\begin{tabular}{|l|l|l|l|}
\hline Summary & Percentiles & Dia Vol\% Width
\end{tabular}

$m v=3.237 \quad 10 \%=0.610 \quad 60 \%=1.860$

$m n=0.329 \quad 20 \%=0.869 \quad 70 \%=2.726$

$\mathrm{ma}=1.115 \quad 30 \%=1.074 \quad 80 \%=4.718$

$c s=6.380 \quad 40 \%=1.262 \quad 90 \%=7.374$

sd $=2.418 \quad 50 \%=1.491 \quad 95 \%=11.62$

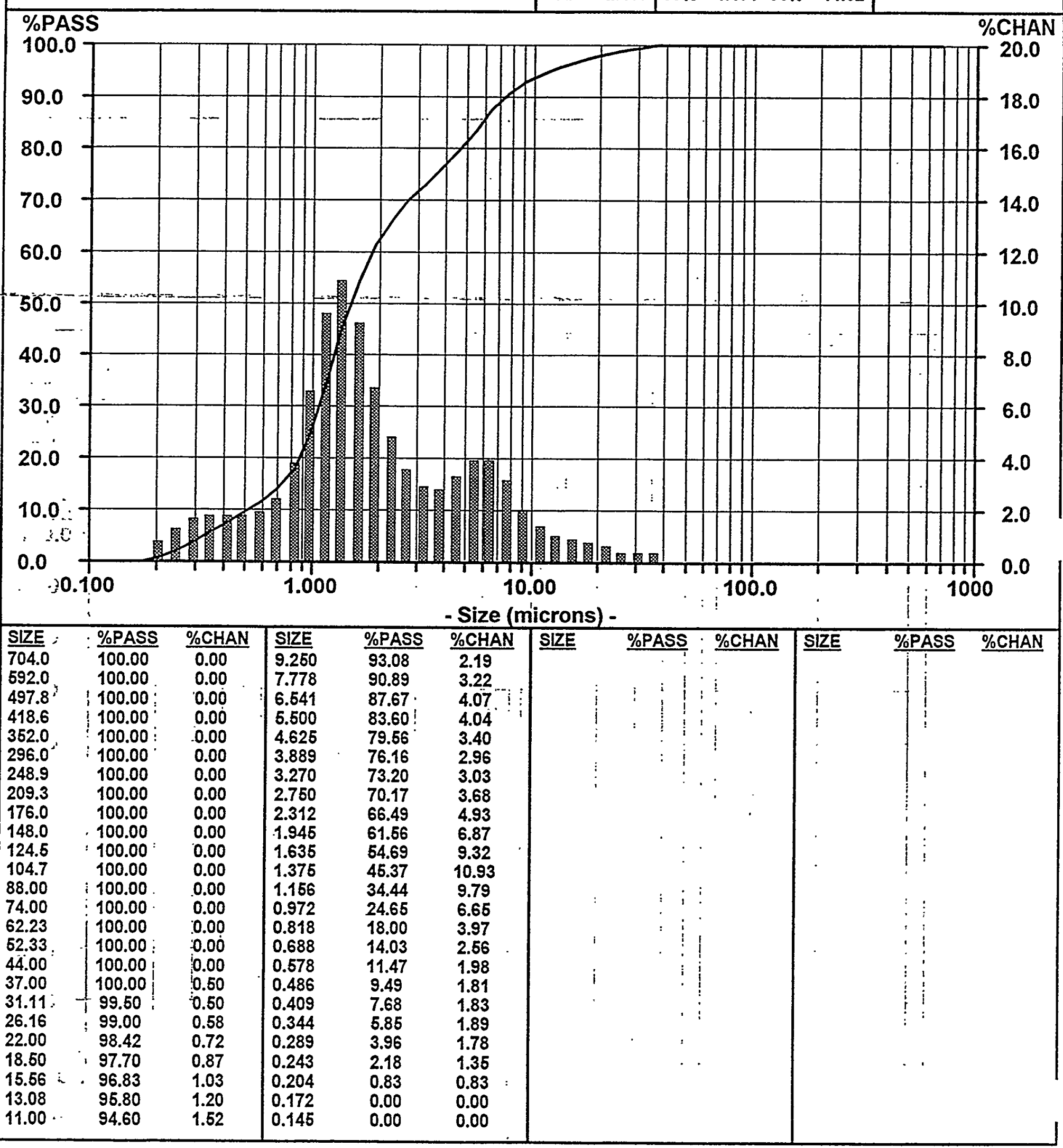




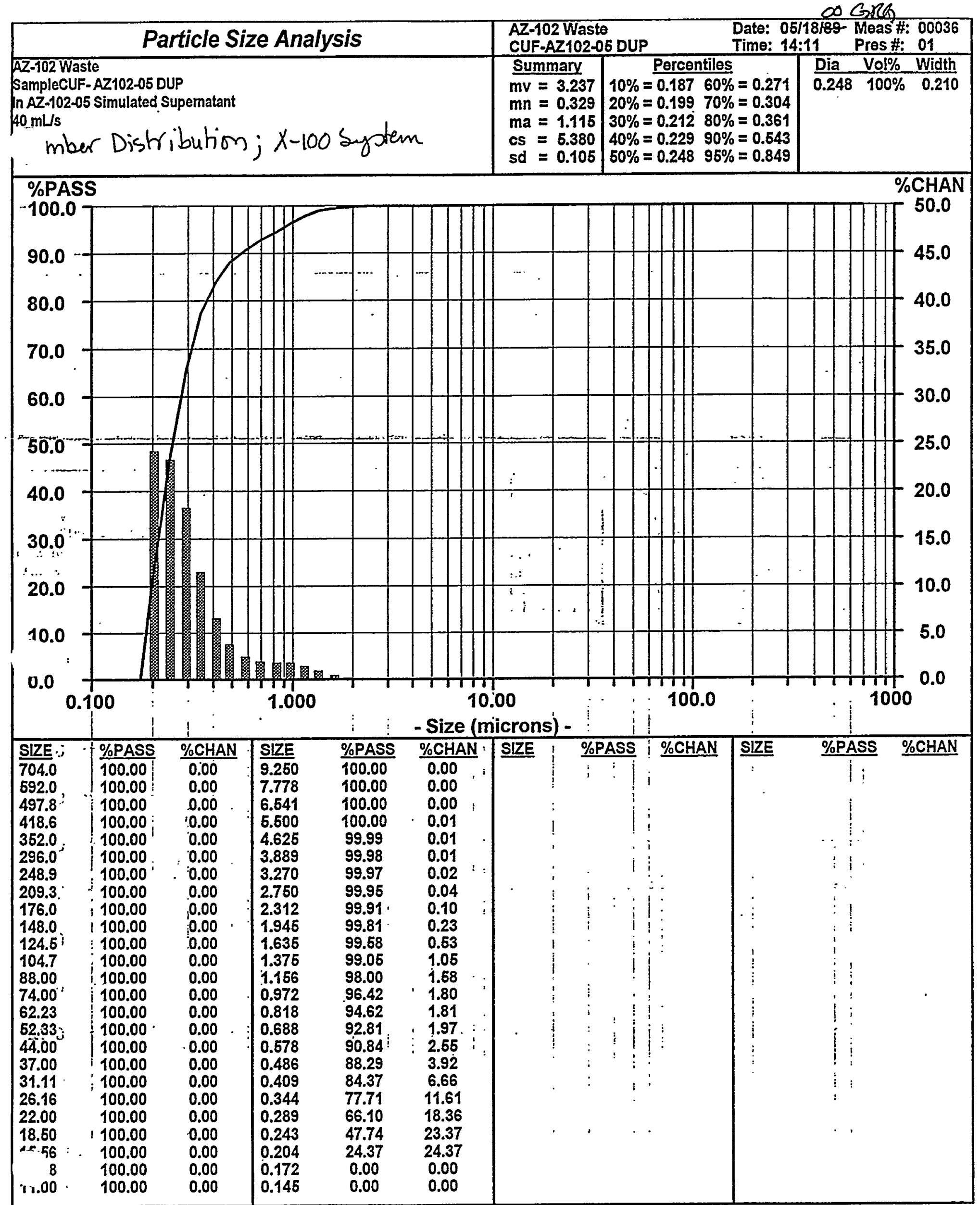


o GRe

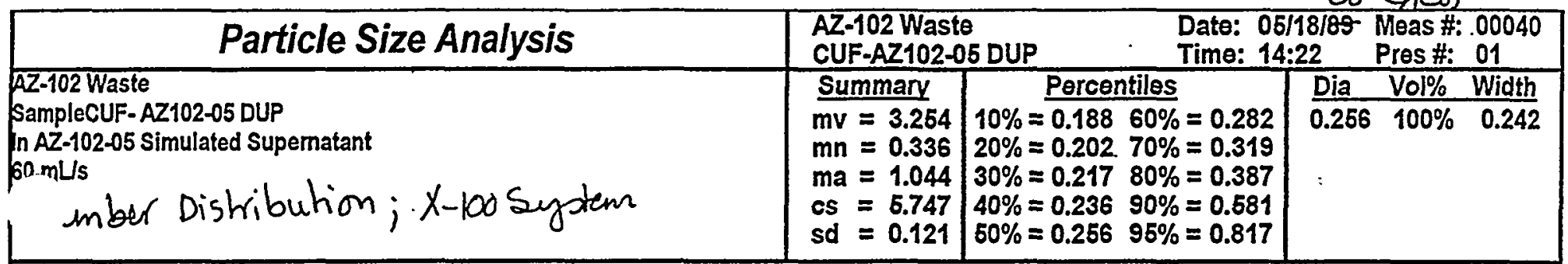

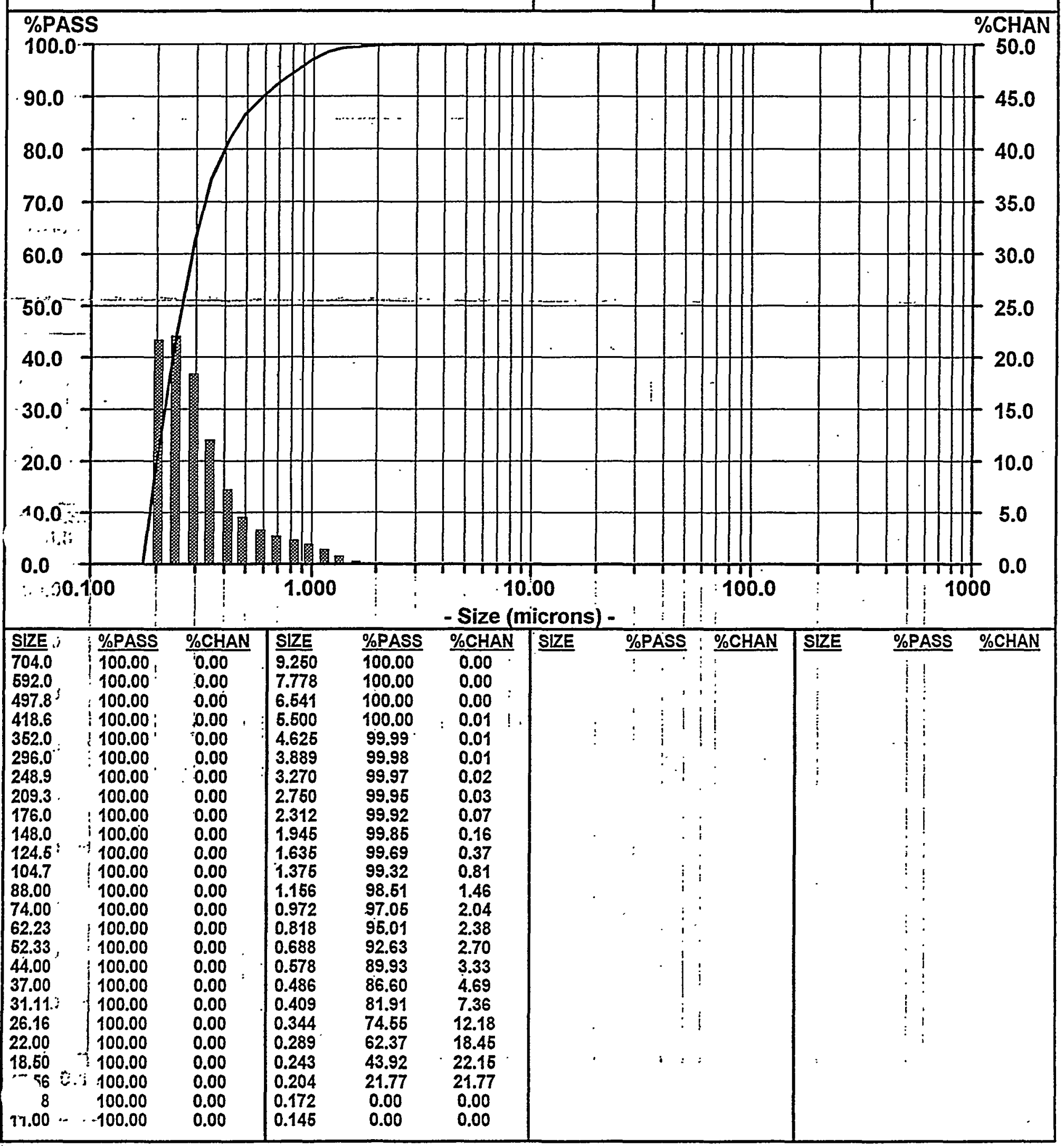


:DO GKR

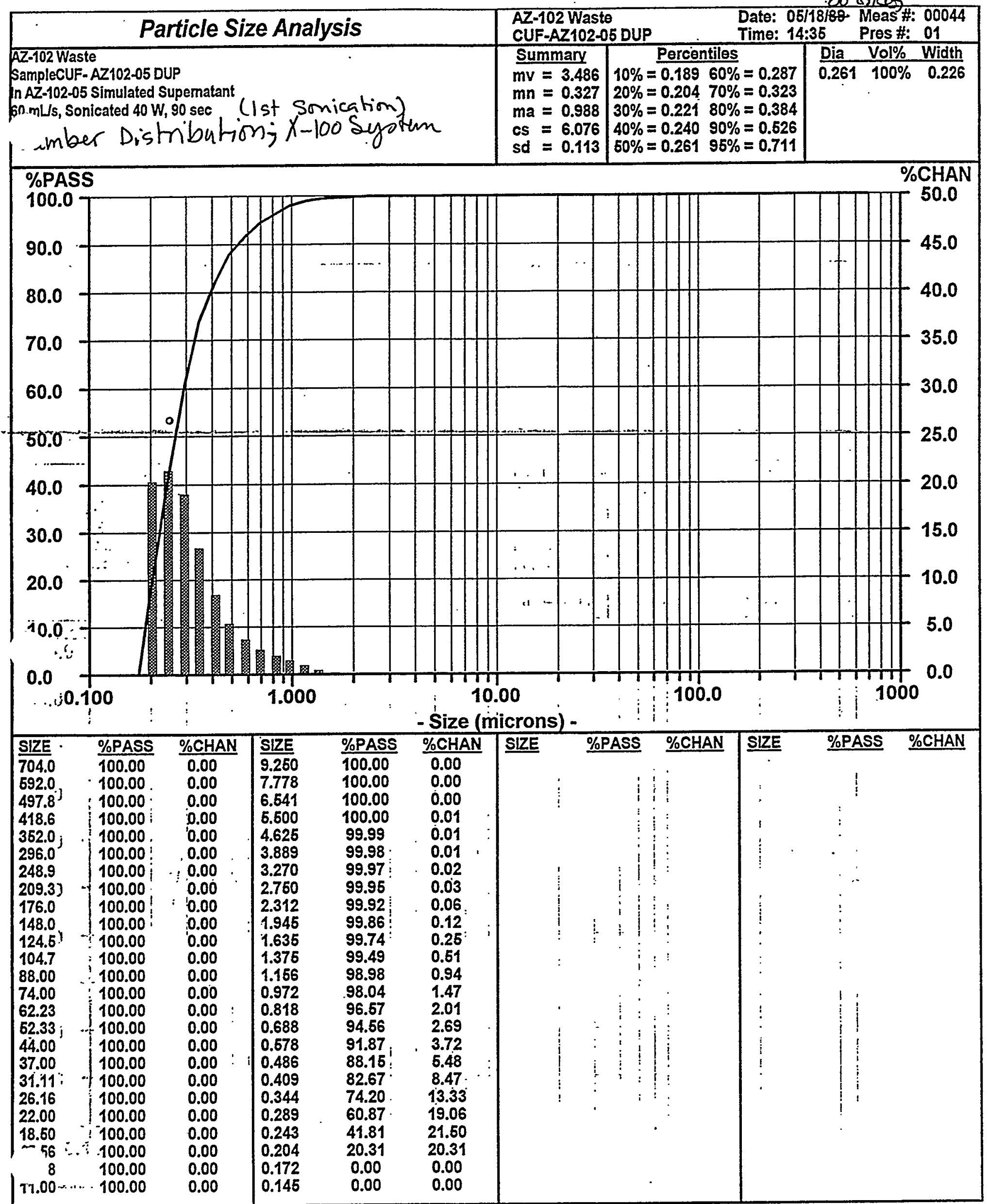




\section{Particle Size Analysis}

\section{AZ-102 Waste}

SampleCUF-AZ102-05 DUP

In AZ-102-05 Simulated Supernatant

$60 \mathrm{~mL} / \mathrm{s}$, 2nd Sonication $40 \mathrm{~W}, 90 \mathrm{sec}$

Volume Distribution; $x-100$ System
AZ-102 Waste

Summary

$m v=3.628$

$\mathrm{mn}=0.323$

$\mathrm{ma}=0.986$

cs $=6.084$

sd $=2.870$ CUF-AZ102-05 DUP

Date: 05/18/89 Meas \#: 00048 Time: 14:46 Pres \#: 01

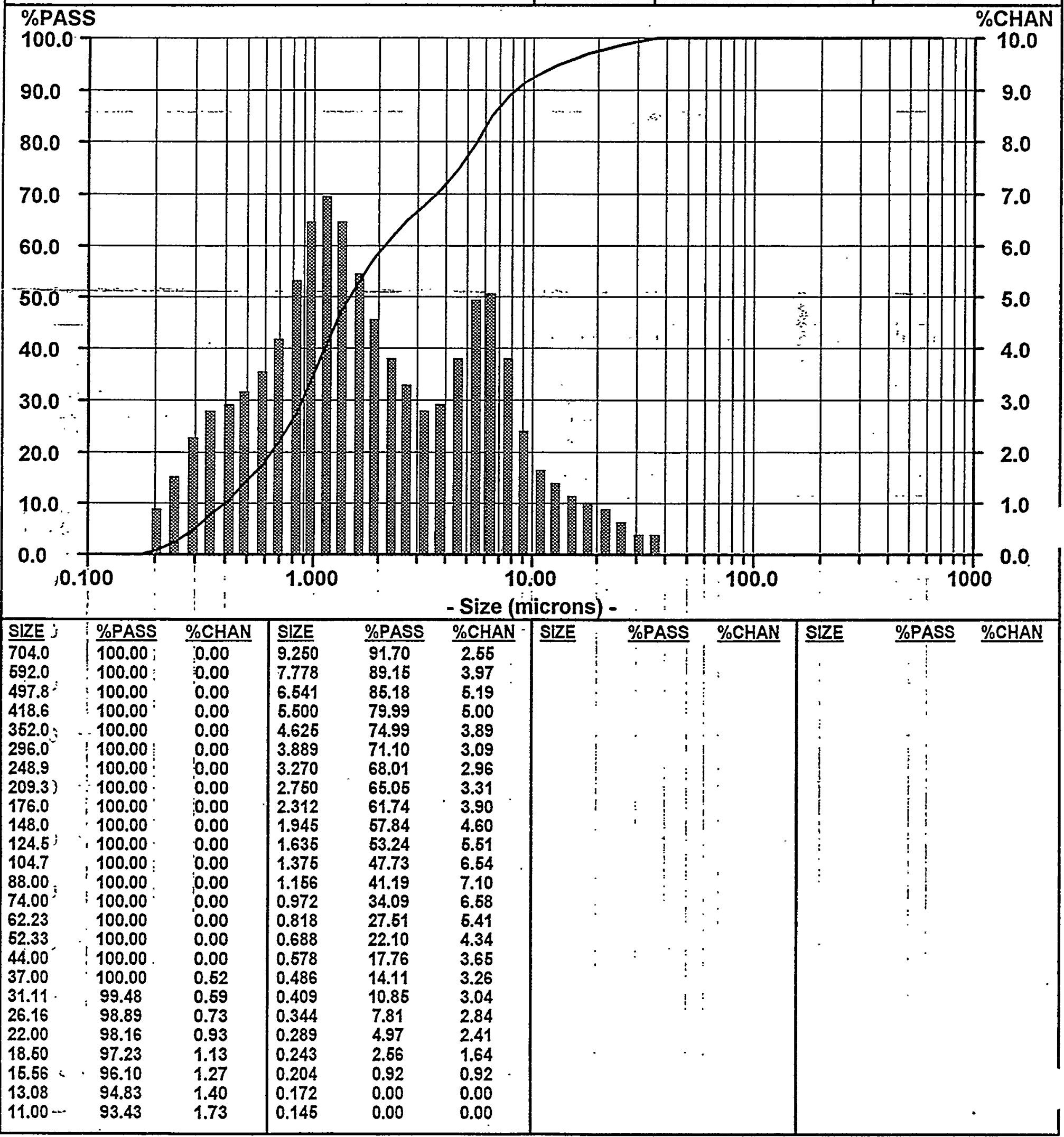




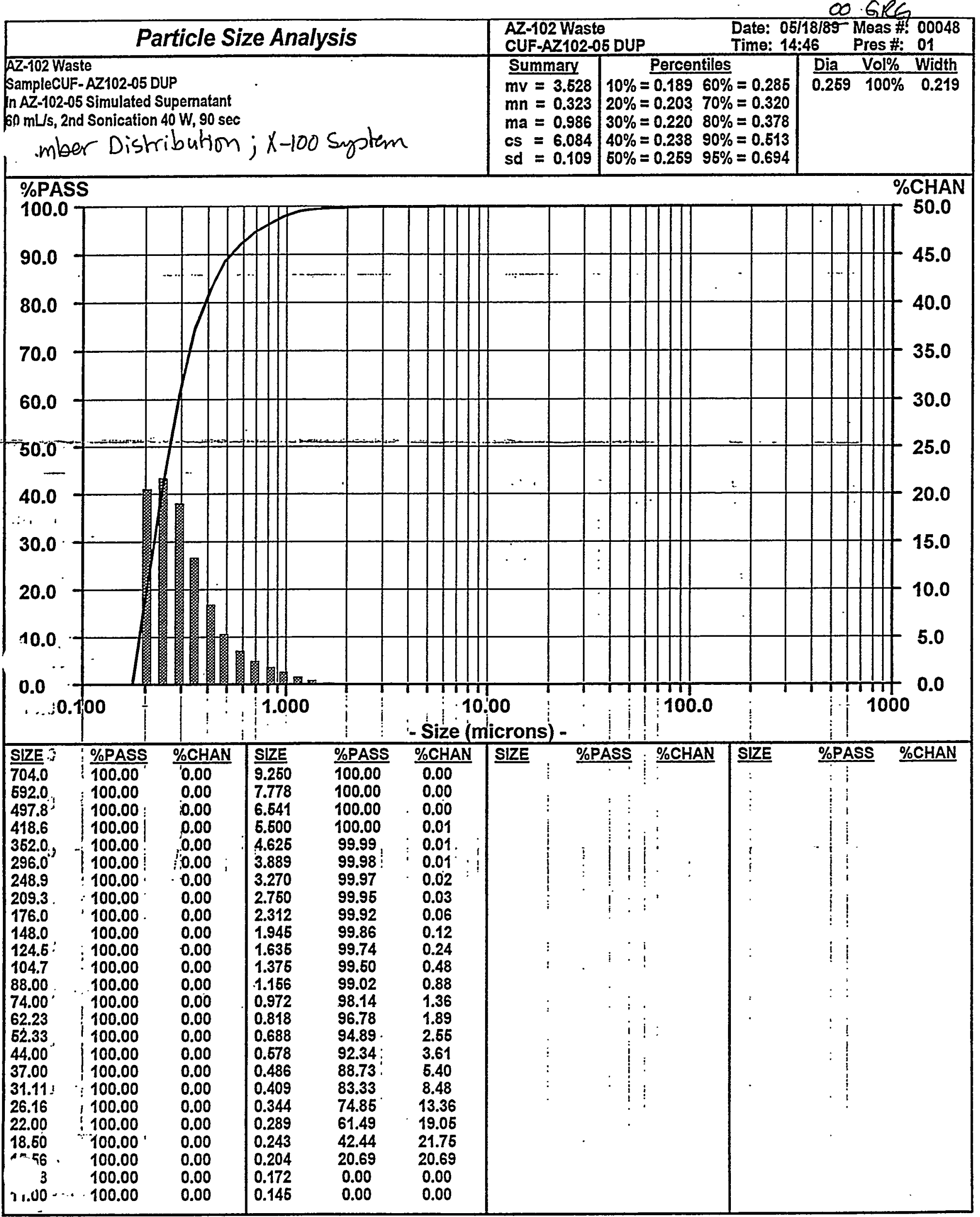


DGRG

Meas \#: 00013

Pres \#: 01

Vol\% Width

$32 \quad 96 \% \quad .9169$

$65 \quad 4 \% \quad .1483$

\%CHAN

50.0

45.0

40.0

35.0

30.0

25.0

20.0

15.0

10.0

5.0

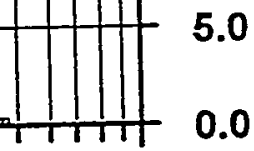

10.00

\%PASS \%CHAN

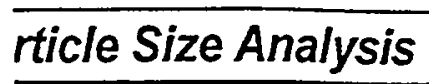

UP ibution; UPA System
CUF AZ-102 Waste
CUF-AZ102-05 DUP

Summary $\quad$ Percentiles

$m v=1.673$

$m n=.5358$

$\mathrm{ma}=1.365$

$c s=4.396$

sd $=.3385$
$10 \%=.261560 \%=.3684$

$20 \%=.2759 \quad 70 \%=.4282$

$30 \%=.291180 \%=.6642$

$40 \%=.310490 \%=1.300$

$60 \%=.334695 \%=1.694$
D GRG

Date: 06/20/09 Meas \#: 00013 ime: 10:42 Pres \#: 01

\begin{tabular}{|ccc|}
\hline Dia & Vol\% & Width \\
\hline 1.310 & $20 \%$ & .8324 \\
.3108 & $80 \%$ & .1425
\end{tabular}

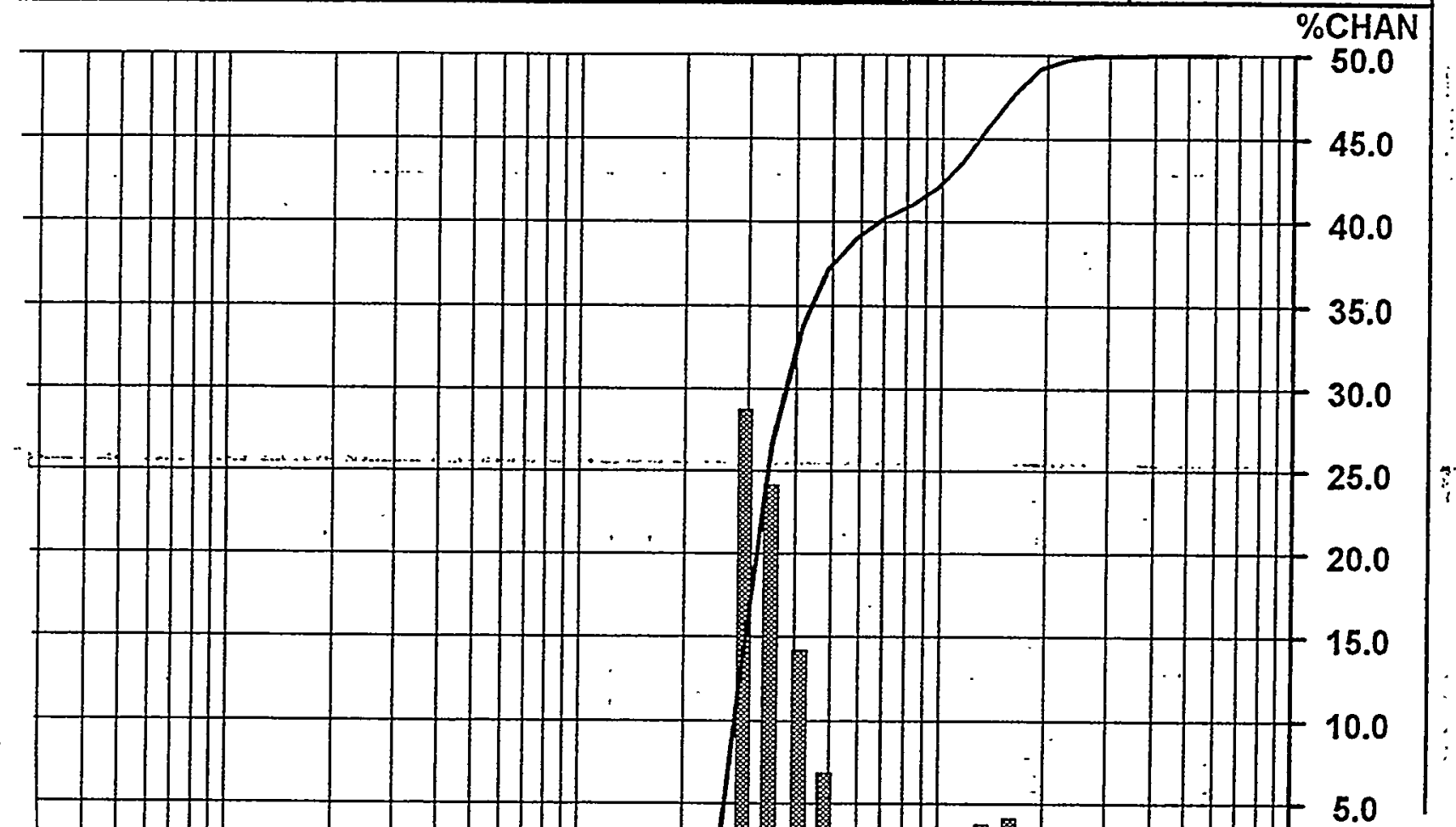

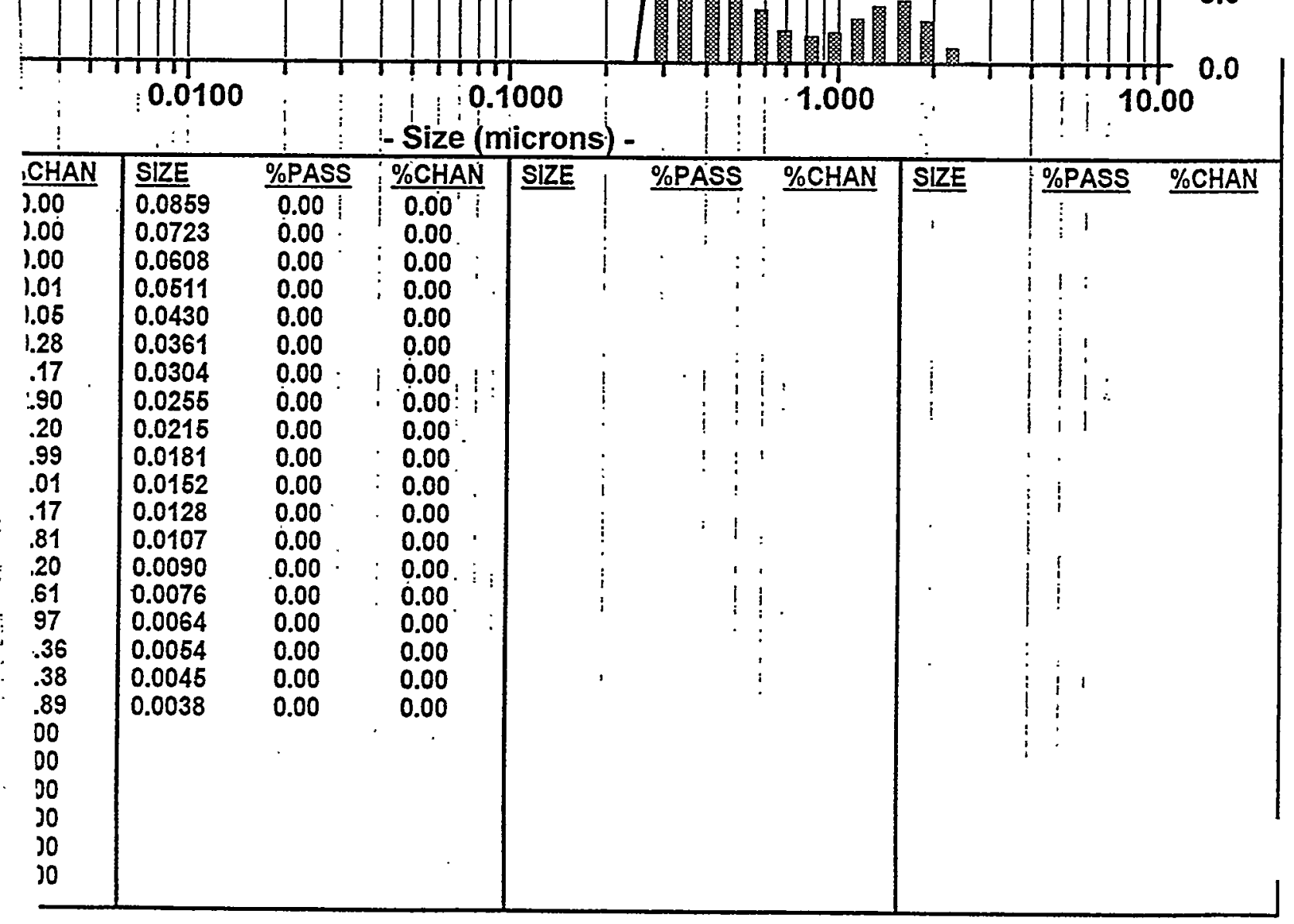




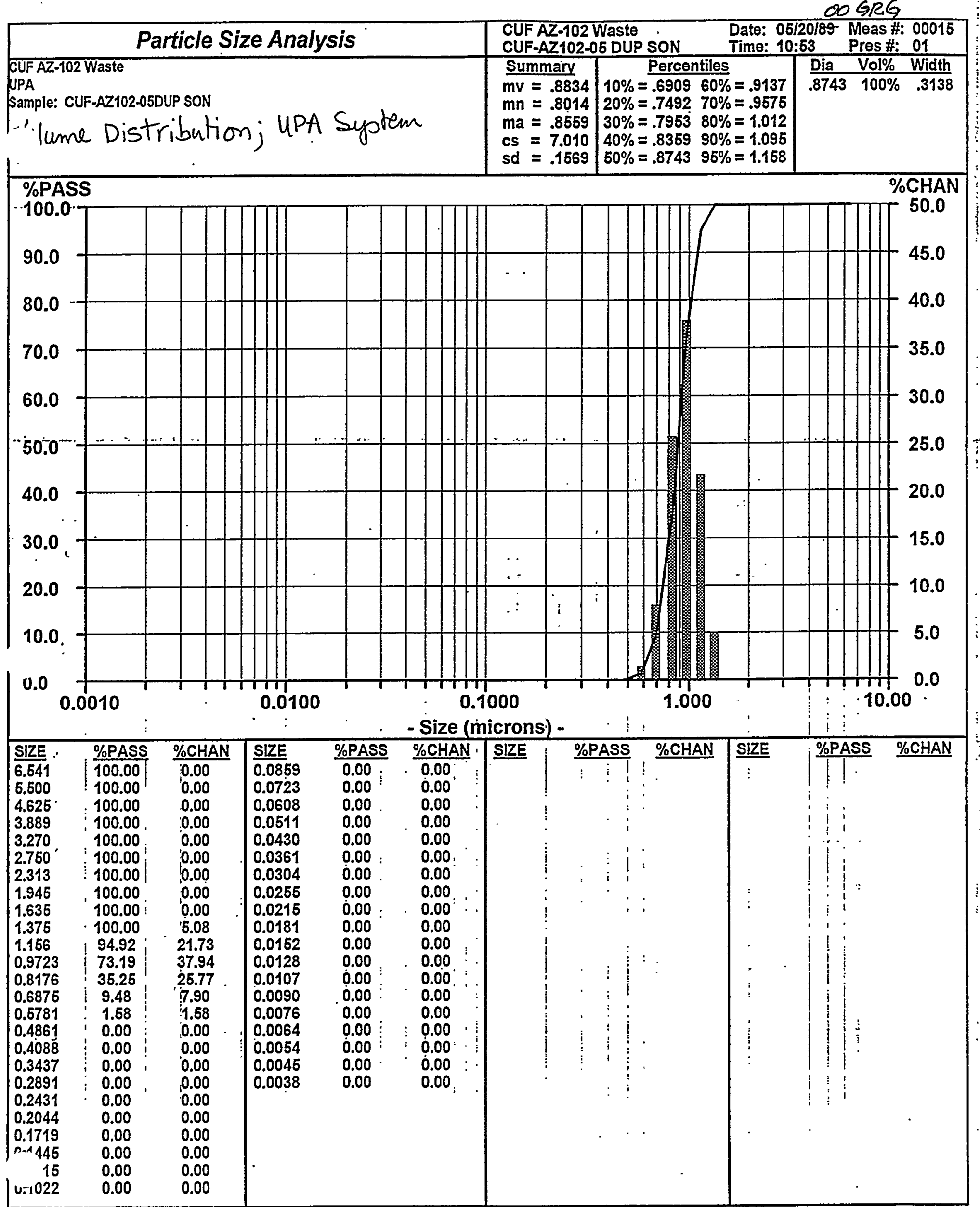




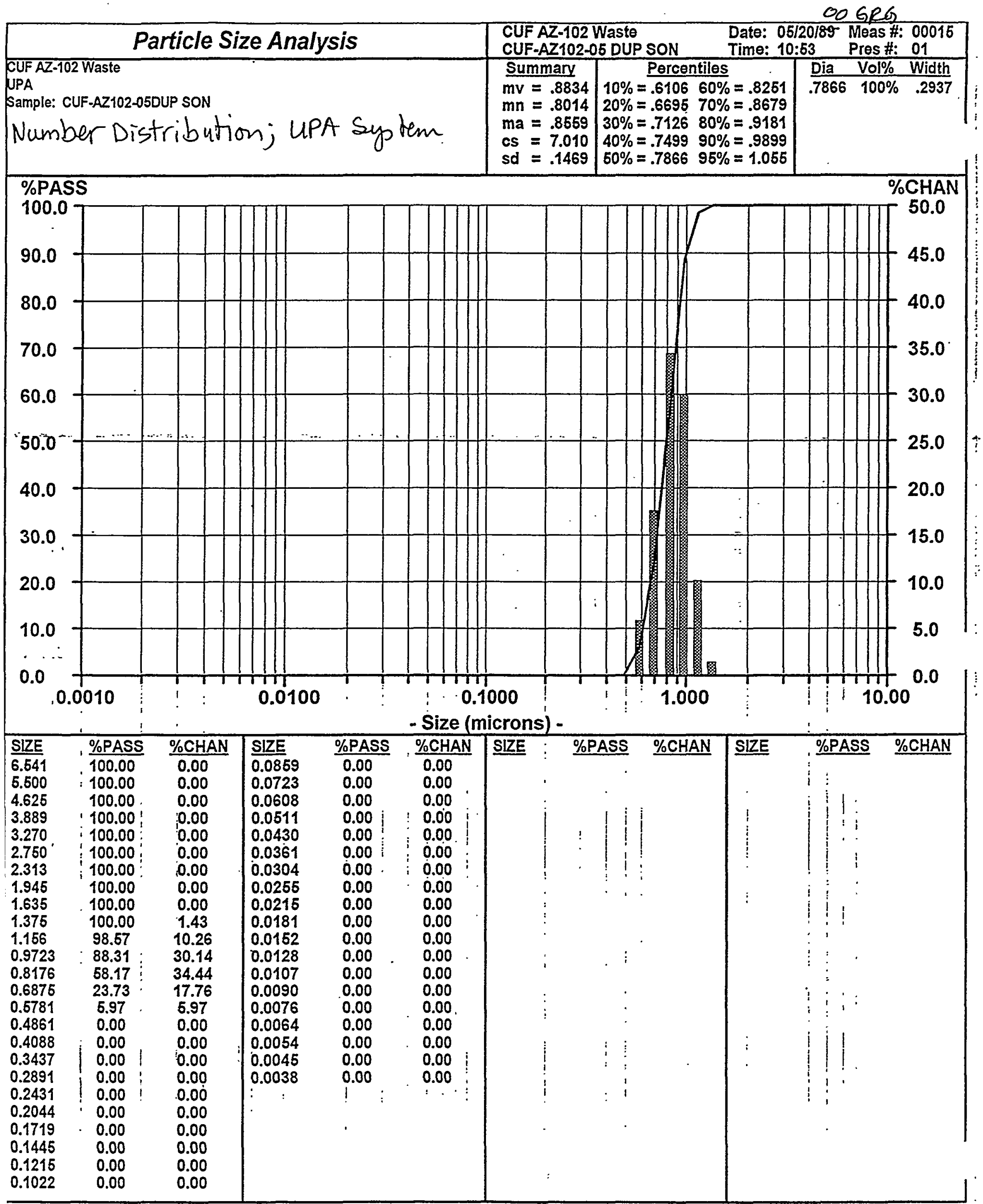




\section{Particle Size Distribution Plots}

For Final Slurry: Sample CUF-AZ-102-024

Replicate No: 1 


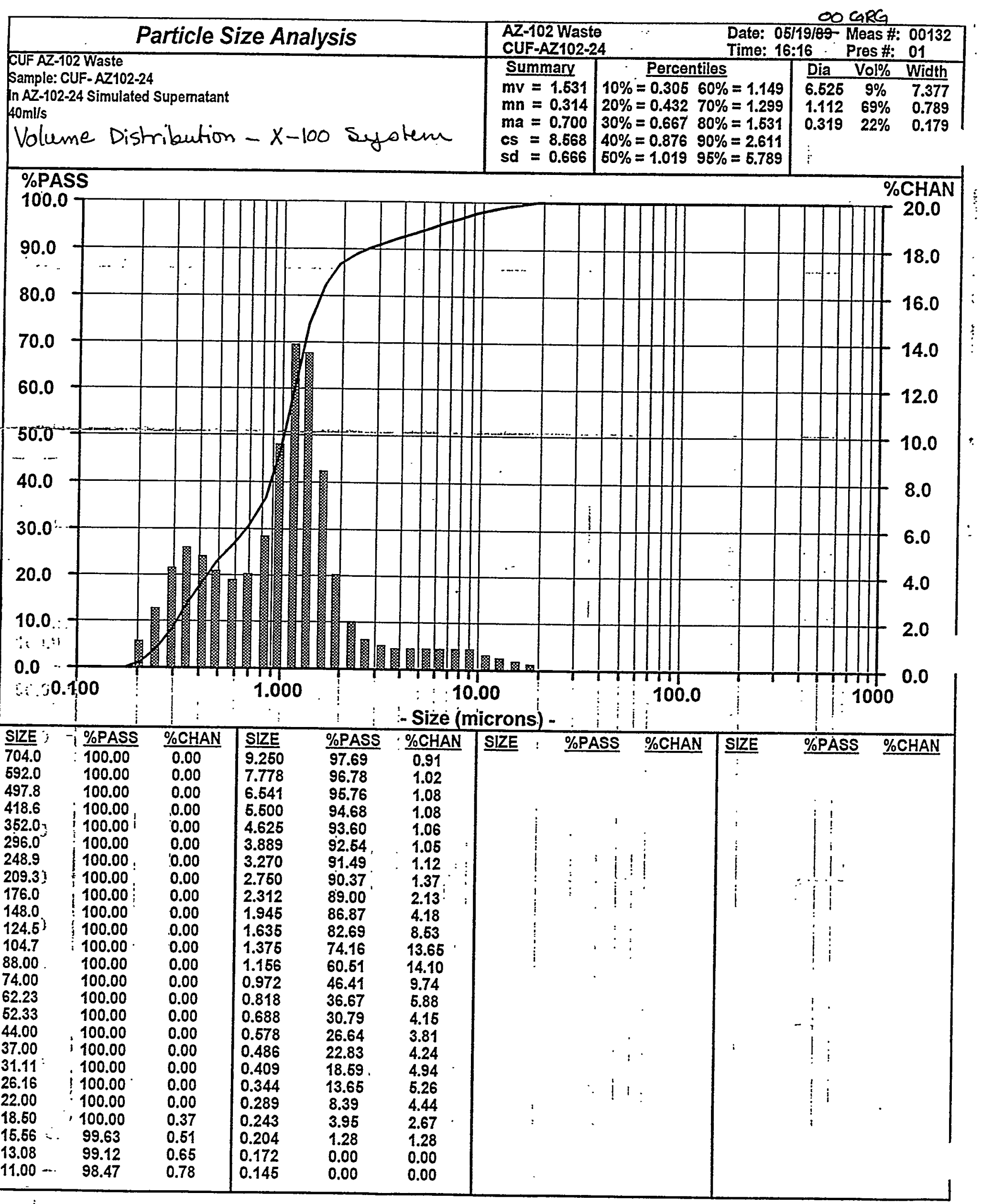




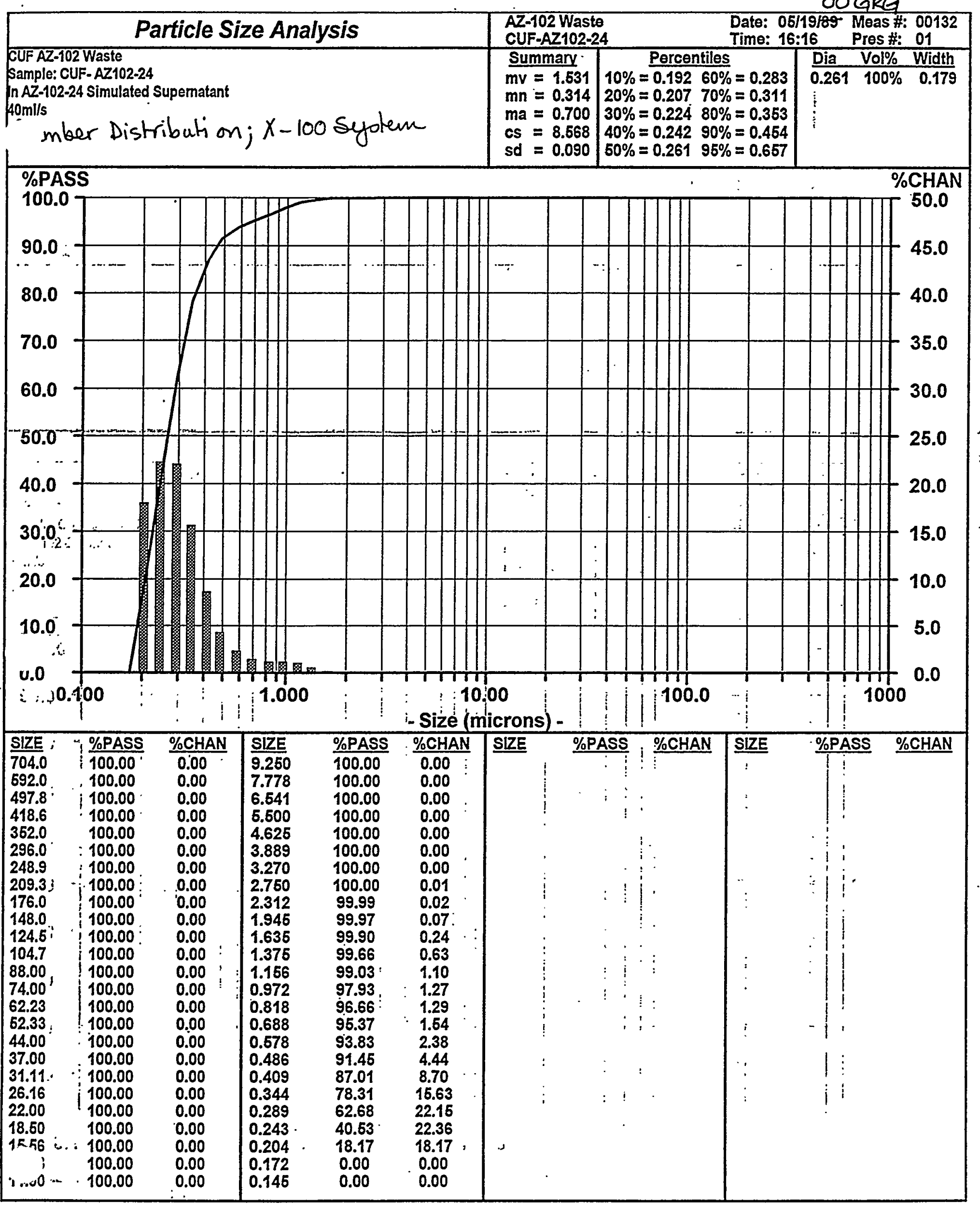


- o GRG

\begin{tabular}{|c|c|c|c|c|c|}
\hline Particle Size Analysis & $\begin{array}{l}\text { AZ-102 Wast } \\
\text { CUF-AZ102-2 }\end{array}$ & $\begin{array}{l}\text { Date: } 06 \\
\text { Time: } 16\end{array}$ & $\begin{array}{l}19189 \\
33\end{array}$ & $\begin{array}{l}\text { Meas \# } \\
\text { Pres \#: }\end{array}$ & $\begin{array}{l}00136 \\
01\end{array}$ \\
\hline $\begin{array}{l}\text { CUF AZ-102 Waste } \\
\text { Sample: CUF-AZ102-24 } \\
\text { In AZ-102-24 Simulated Supernatant } \\
\text { S0mls } \\
\text { Volume Dishribution; X-100 Syotem }\end{array}$ & $\begin{array}{l}\text { Summary } \\
\text { mv }=1.432 \\
m n=0.314 \\
m a=0.683 \\
\mathrm{cs}=8.783 \\
\mathrm{sd}=0.609\end{array}$ & $\begin{array}{l}\text { Percentiles } \\
10 \%=0.30260 \%=1.106 \\
20 \%=0.425 \quad 70 \%=1.244 \\
30 \%=0.65080 \%=1.443 \\
40 \%=0.84990 \%=2.197 \\
60 \%=0.98595 \%=5.147\end{array}$ & $\begin{array}{l}\text { Dia } \\
6.488 \\
1.081 \\
0.318\end{array}$ & $\begin{array}{c}\text { Vol\% } \\
7 \% \\
69 \% \\
24 \%\end{array}$ & $\begin{array}{c}\text { Width } \\
7.258 \\
0.738 \\
0.178\end{array}$ \\
\hline
\end{tabular}

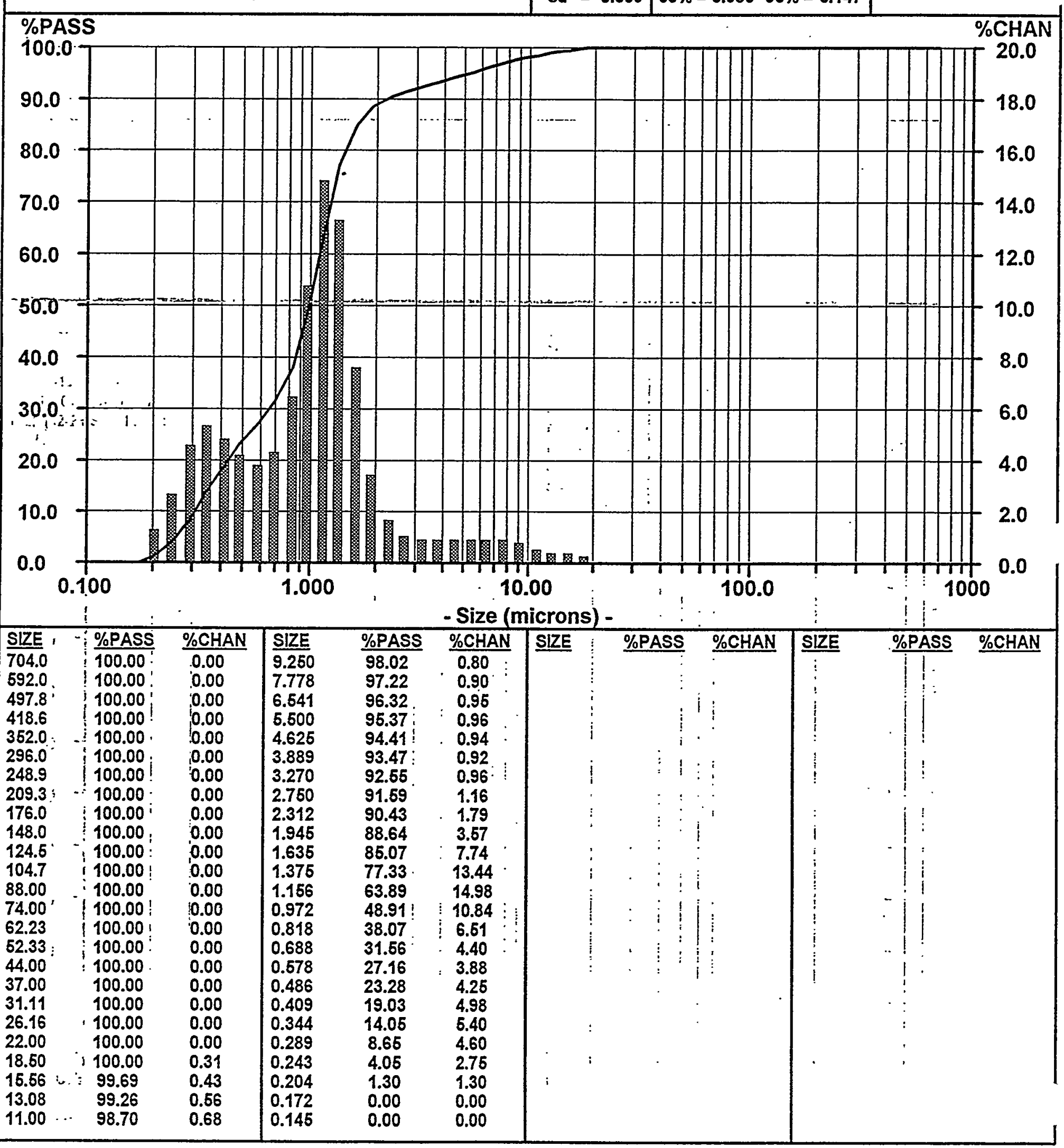




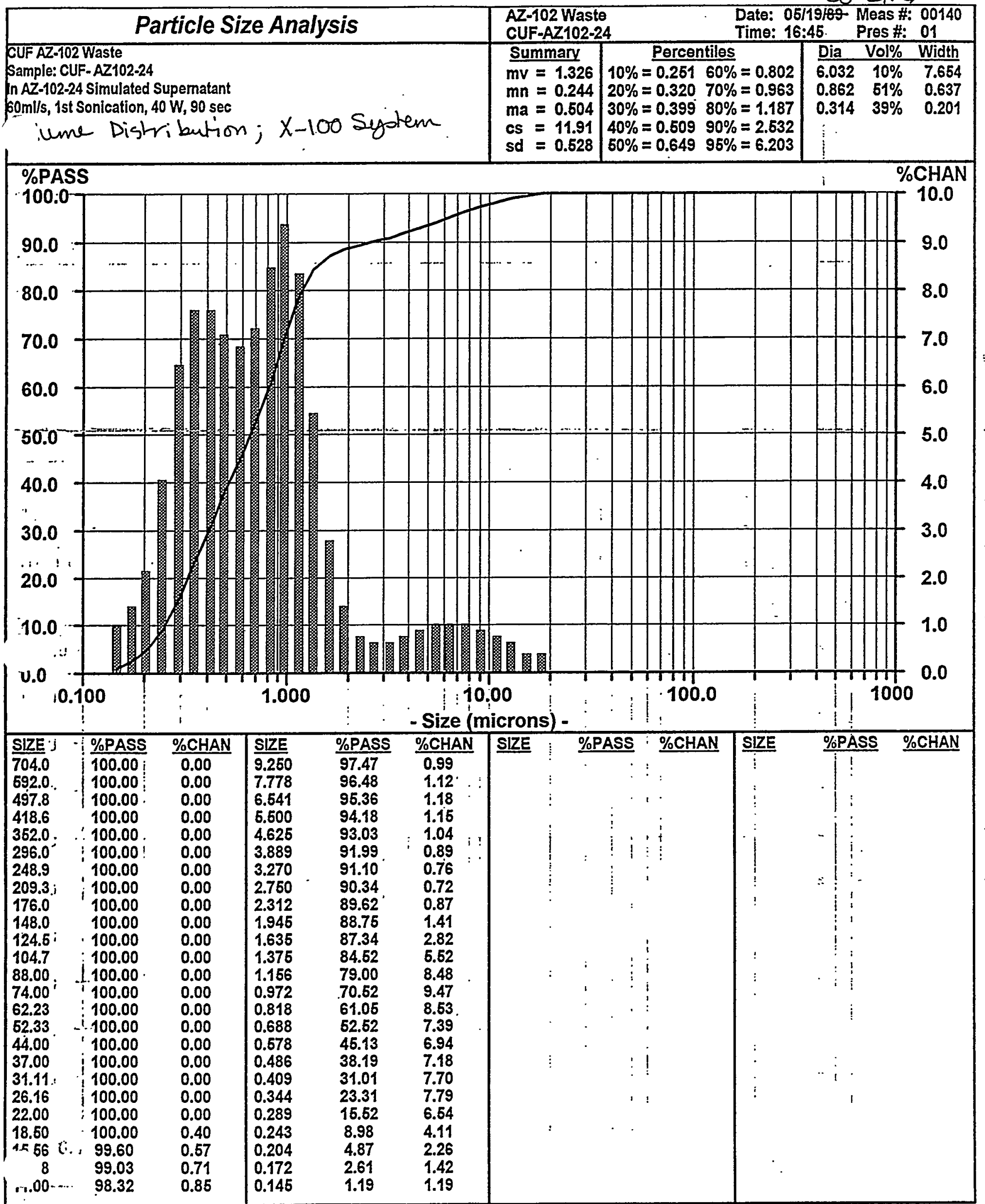


OO GRG

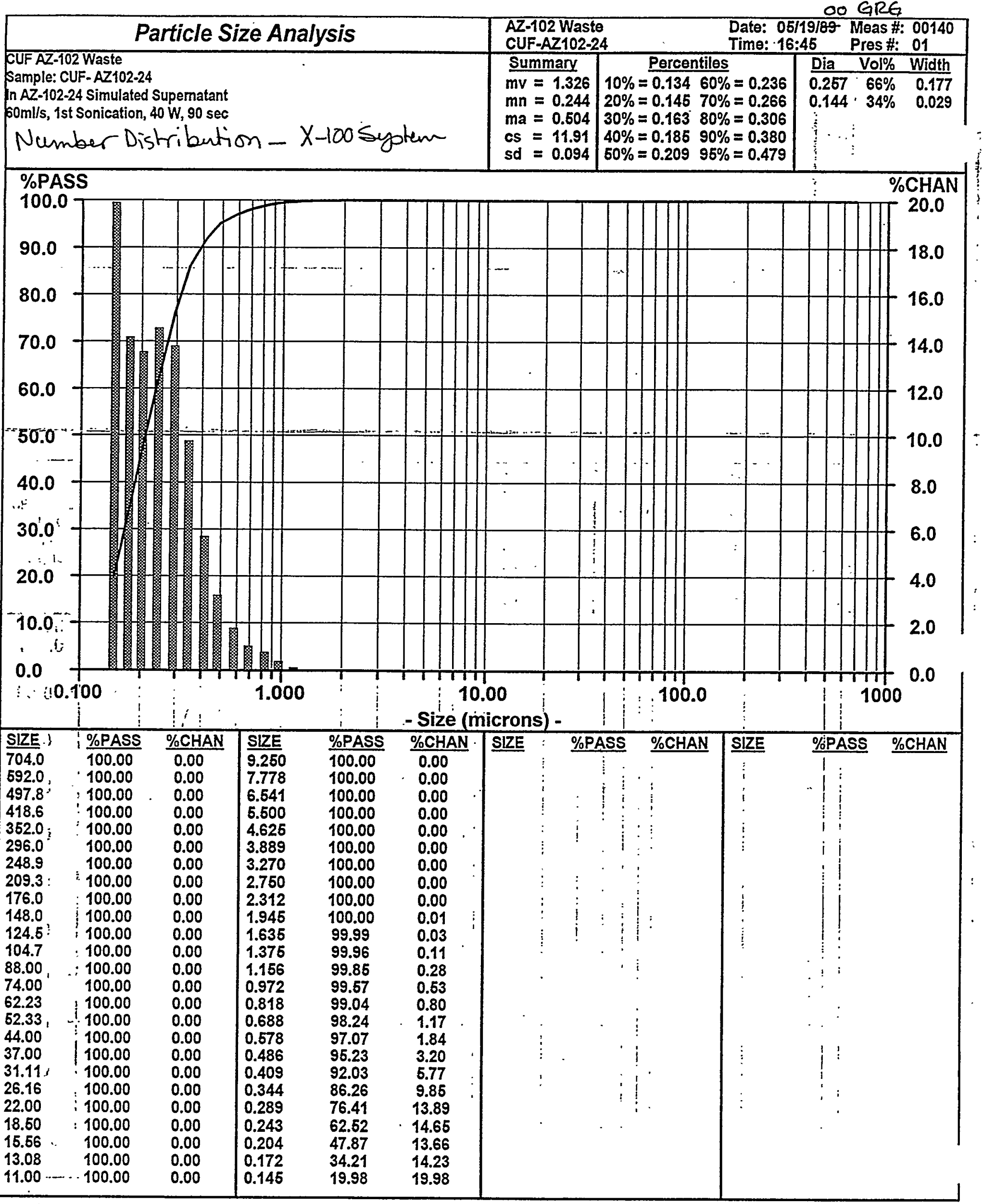




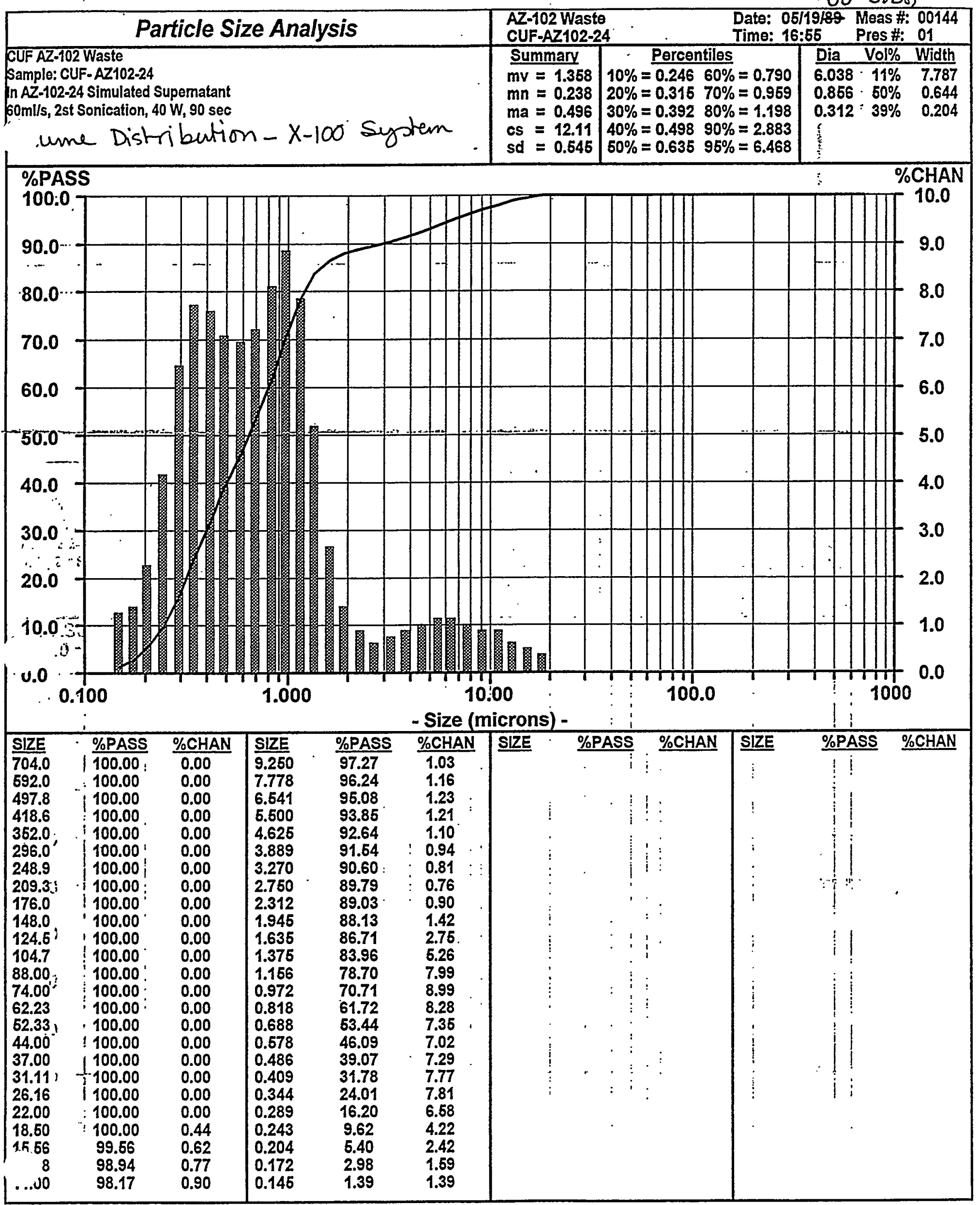




\section{Particle Size Analysis}

\section{CUF AZ-102 Waste}

Sample: CUF-AZ102-24

In AZ-102-24 Simulated Supematant

Number Dishribution; $X-100$ Syptem
AZ-102 Waste CUF-AZ102-24

Summary

$\mathrm{mv}=1.358$

$\mathrm{mn}=0.238$

$\mathrm{ma}=0.496$

$c s=12.11$

sd $=0.092$

m cape

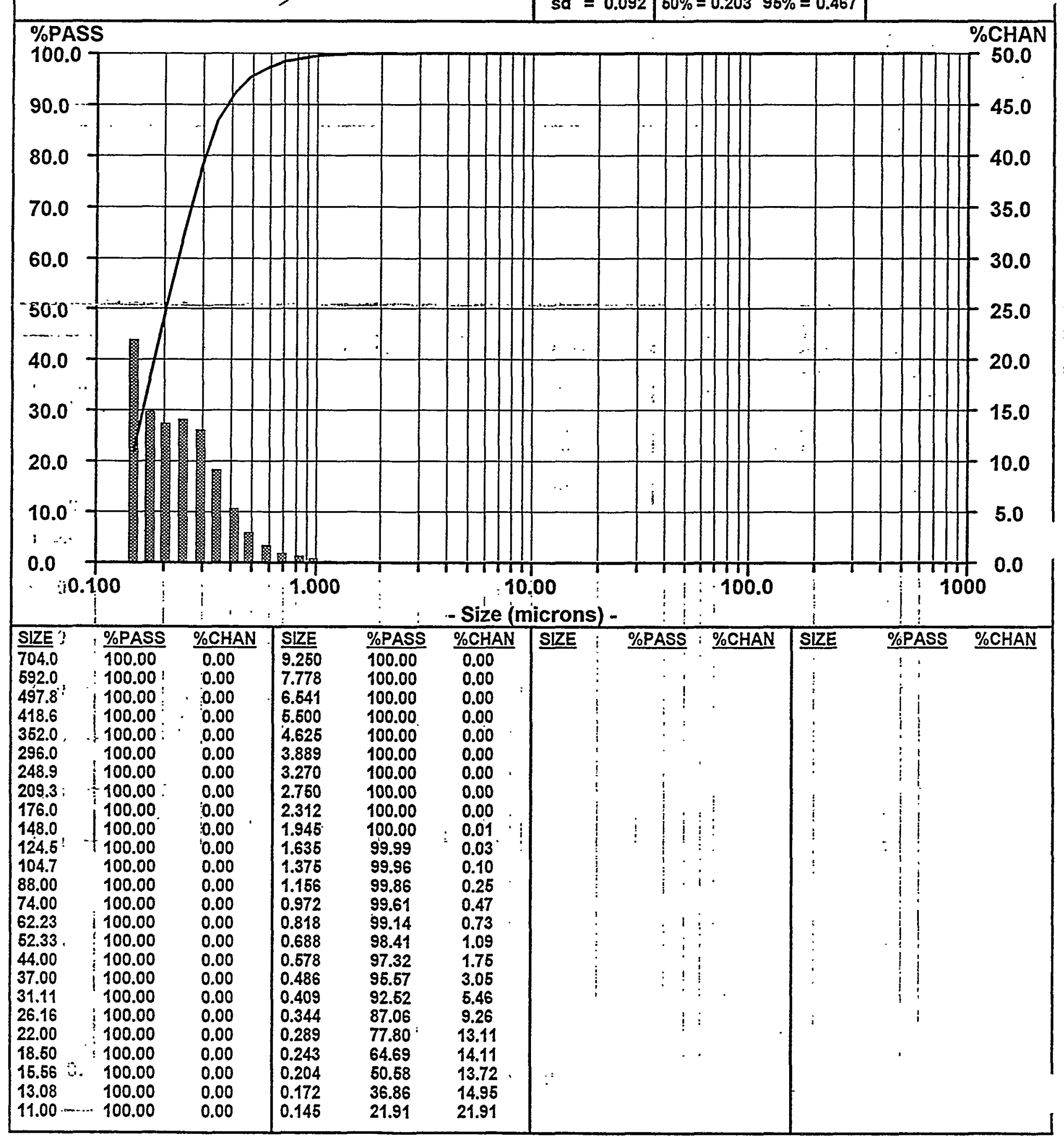
Date: 05/19/89 Meas \#: 00144 Time: 16:65 Pres \#: 01

\begin{tabular}{|c|c|c|c|}
\hline \multirow{2}{*}{ Time: 16:6 } & \multicolumn{3}{|c|}{ Pres \#: 01} \\
\hline & Dia & Vol\% & Width \\
\hline $\begin{array}{l}10 \%=0.133 \quad 60 \%=0.230 \\
20 \%=0.143 \quad 70 \%=0.260 \\
30 \%=0.158 \quad 80 \%=0.300\end{array}$ & $\begin{array}{l}0.256 \\
0.143\end{array}$ & $\begin{array}{l}63 \% \\
37 \%\end{array}$ & $\begin{array}{l}0.176 \\
0.029\end{array}$ \\
\hline
\end{tabular}

$40 \%=0.17890 \%=0.373$

$50 \%=0.203 \quad 95 \%=0.467$ 


\begin{tabular}{|c|c|c|c|c|}
\hline Particle Size Analysis & $\begin{array}{l}\text { CUF AZ-1021 } \\
\text { UPA CUF-AZ }\end{array}$ & $\begin{array}{l}\text { Date: } 08 \\
\text { Time: } 09\end{array}$ & $\begin{array}{l}20 / 89 \text { Meas \# } \\
66\end{array}$ & $\begin{array}{l}00006 \\
01\end{array}$ \\
\hline $\begin{array}{l}\text { CUFAZ-102 Waste } \\
\text { UPA } \\
\text { Sample: CUF-AZ102-24 } \\
\text { I/slume Distribution; Kags UPA Syplem }\end{array}$ & $\begin{array}{l}\text { Summary } \\
\mathrm{mv}=2.434 \\
\mathrm{mn}=.2155 \\
\mathrm{ma}=1.209 \\
\mathrm{cs}=4.962 \\
\mathrm{sd}=1.307\end{array}$ & $\begin{array}{l}\text { Percentiles } \\
10 \%=.487160 \%=2.863 \\
20 \%=1.35470 \%=3.097 \\
30 \%=2.050 \quad 80 \%=3.372 \\
40 \%=2.38290 \%=3.762 \\
60 \%=2.63495 \%=4.099\end{array}$ & $\begin{array}{lr}\text { Dia } & \text { Vol\% } \\
2.826 & 83 \% \\
.4113 & 17 \%\end{array}$ & $\begin{array}{l}\frac{\text { Width }}{1.658} \\
.6335\end{array}$ \\
\hline
\end{tabular}

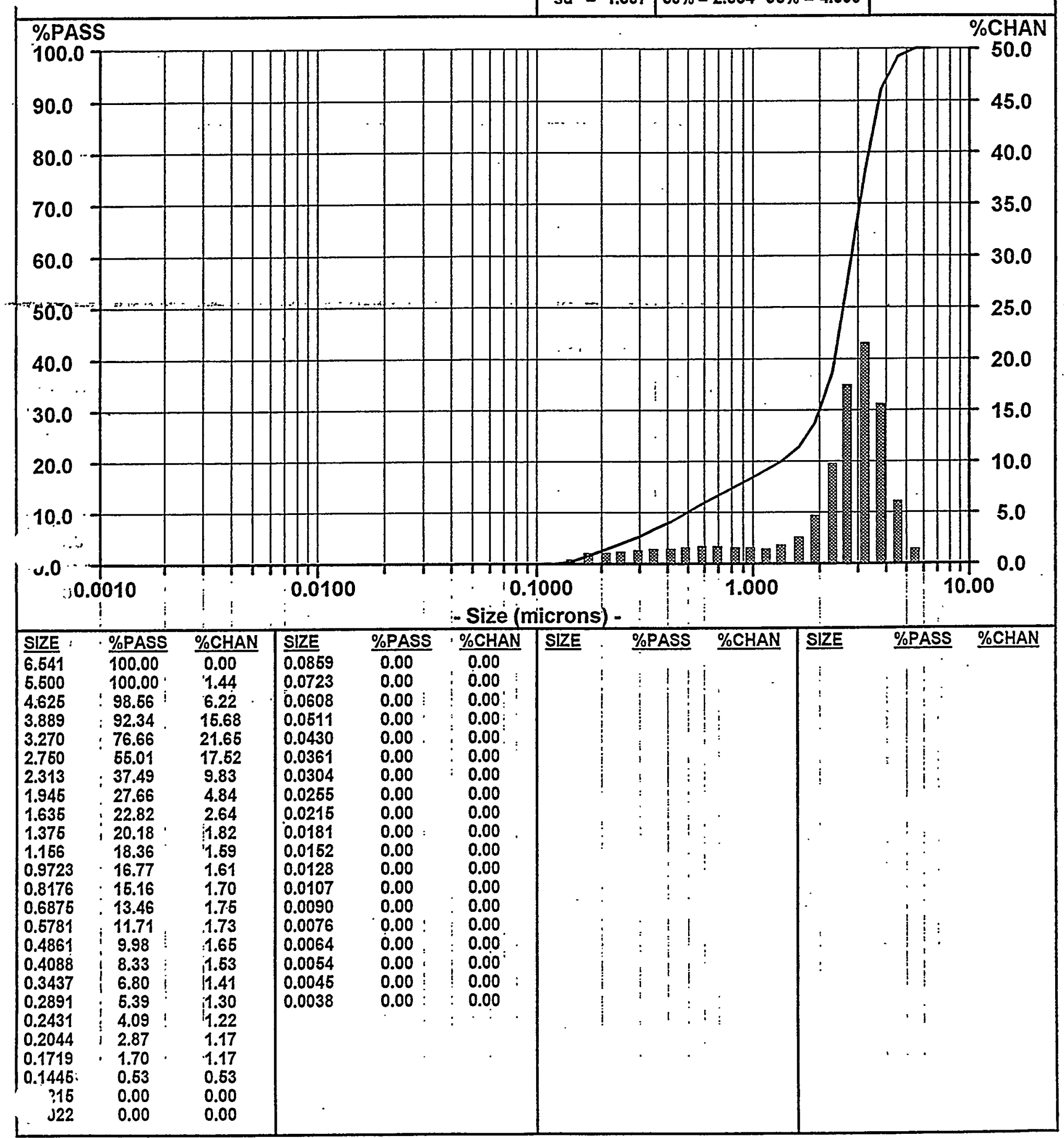


UN CKO

CUF AZ-102 Waste

Particle Size Analysis

UPA

Sample: CUF-AZ102-24

Number Distribution; UPA System

CUF AZ-102 Waste

Date: 05/20/89 Meas \#: 00006 Time: 09:56 Pres\#: 01

Summary $\quad$ Percentiles $\quad$ Dia Vol\% Width

$m v=2.434 \quad 10 \%=.1335 \quad 60 \%=.1834$

$\begin{array}{lll}.1695 & 100 \% & .1227\end{array}$

$\mathrm{mn}=.2165 \quad 20 \%=.1423 \quad 70 \%=.2060$

$\mathrm{ma}=1.209 \quad 30 \%=.1507 \cdot 80 \%=.2398$

$c s=4.962 \quad 40 \%=.1595 \quad 90 \%=.3140$

$\mathrm{sd}=.0613 \quad 50 \%=.169595 \%=.4098$

\section{\%PASS}

100.0

90.0

80.0

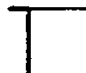
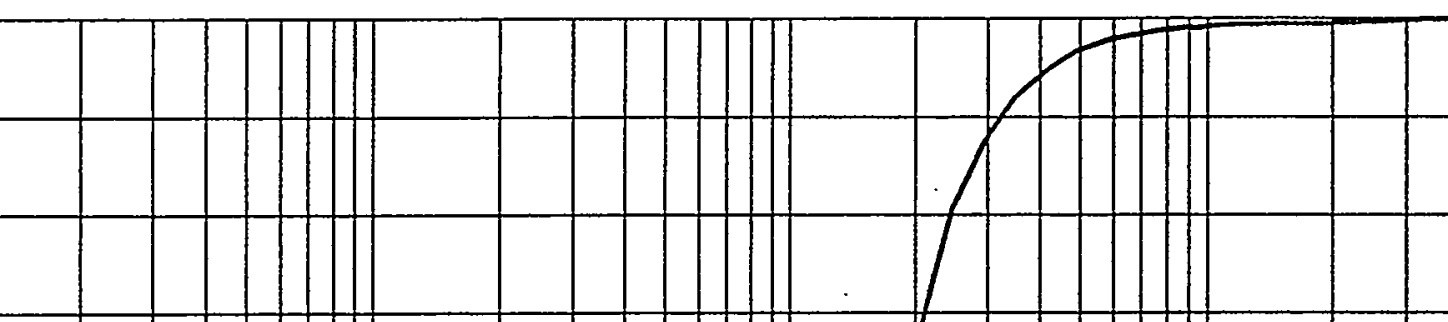

\%CHAN

70.

60.

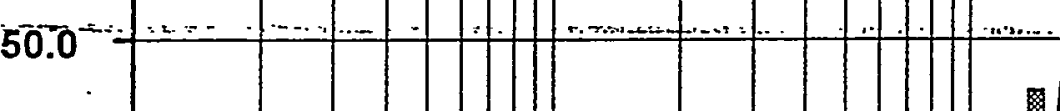

40.

20.0

10.0

0.

$+$

0.0010

0.0100

0.1000

1.000

- Size (microns) -

\section{$\underline{S \mid Z}$ \\ 6.54}

5.500

4.625

3.889

3.270

2.750

2.313

1.945

1.635

1.375

1.156

0.9723

0.8176

0.6875

0.5781

0.4861

0.4088

0.3437

0.2891

0.2431

0.2044

0.1719

0.1445

0.1215

0.1022

\begin{tabular}{cc}
\hline$\%$ PASS & $\%$ CHAN \\
\cline { 1 - 2 } 100.00 & 0.00 \\
100.00 & 0.00 \\
100.00 & 0.01 \\
99.99 & 0.03 \\
99.96 & 0.08 \\
99.88 & 0.11 \\
99.77 & 0.10 \\
99.67 & 0.08 \\
99.59 & 0.08 \\
99.51 & 0.09 \\
99.42 & 0.13 \\
99.29 & 0.23 \\
99.06 & 0.40 \\
98.66 & 0.69 \\
97.97 & 1.15 \\
96.82 & 1.85 \\
94.97 & 2.88 \\
92.09 & 4.46 \\
87.63 & 6.91 \\
80.72 & 10.91 \\
69.81 & 17.61 \\
52.20 & 29.63 \\
22.57 & 22.57 \\
0.00 & 0.00 \\
0.00 & 0.00
\end{tabular}

:

SIZE

$\frac{0.0859}{0.0723}$

0.0723

0.0608

0.0511

0.0430

0.0361

0.0304

0.0255

0.0215

0.0181

0.0152

0.0128

0.0107

0.0090

0.0076

0.0064

0.0054

0.0045

0.0038

50.0

45.0

40.0

35.0

30.0

25.0

20.0

15.0

10.0

5.0

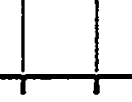

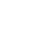

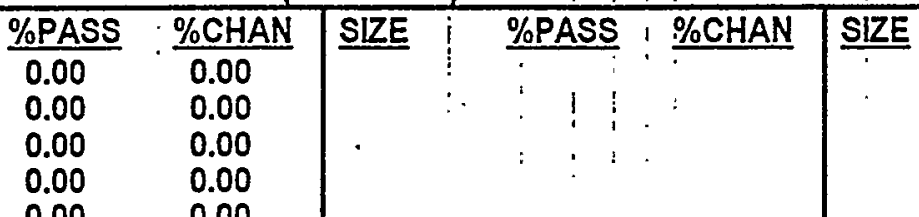

\%PASS

10.00

0.0 
Particle Size Analysis CUF AZ-102 Waste UPA Sample: CUF-AZ102-24 Sonicated -. slume Distribution; UPA System
CUF AZ-102 Waste CUF-AZ102-24 SON

Summary Percentiles

$m v=1.409 \quad 10 \%=.3156 \quad 60 \%=1.119$

$m n=.3173 \quad 20 \%=.5968 \quad 70 \%=1.220$

$\mathrm{ma}=.7587 \quad 30 \%=.8394 \quad 80 \%=1.384$

cs $=7.908$

sd $=.5947$
Date: 05/20/89 Meas \#: 00009 Time: 10:14 Pres \#: 01

\begin{tabular}{crr}
\hline Dia & Vol\% & Width \\
\hline 4.228 & $15 \%$ & .8392 \\
1.044 & $67 \%$ & .4532 \\
.3018 & $18 \%$ & .1621 \\
& & \\
& &
\end{tabular}

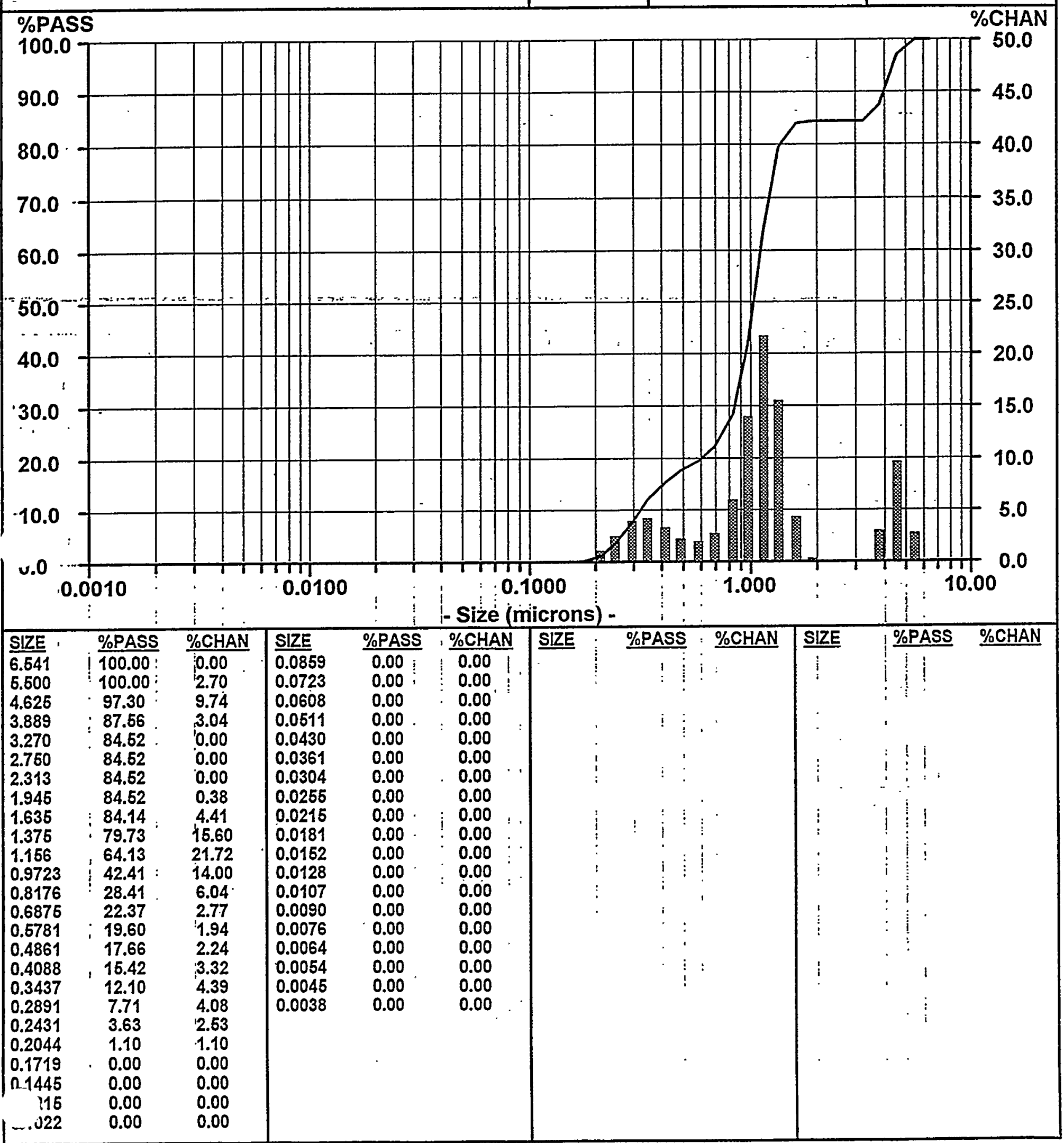


00 caks

\begin{tabular}{|c|c|c|c|c|c|}
\hline Particle Size Analysis & $\begin{array}{l}\text { CUF AZ-1021 } \\
\text { CUF-AZ102-2 }\end{array}$ & $\begin{array}{l}\text { Date: } 0 \\
\text { Time: } 1\end{array}$ & 1881 & $\begin{array}{l}\text { Meas \# } \\
\text { Pres \#: }\end{array}$ & $\begin{array}{l}00009 \\
01\end{array}$ \\
\hline $\begin{array}{l}\text { UUF AZ-102 Waste } \\
\text { UPA } \\
\text { Sample: CUF-AZ102-24 Sonicated } \\
\text { Number Distribution; UPA Syptem }\end{array}$ & $\begin{array}{l}\text { Summary } \\
\mathrm{mv}=1.409 \\
\mathrm{mn}=.3173 \\
\mathrm{ma}=.7587 \\
\mathrm{cs}=7.908 \\
\mathrm{sd}=.0806\end{array}$ & $\begin{array}{l}\text { Percentiles } \\
10 \%=.192060 \%=.2751 \\
20 \%=.207570 \%=.2996 \\
30 \%=.222980 \%=.3374 \\
40 \%=.238990 \%=.4558 \\
60 \%=.255895 \%=.8247\end{array}$ & $\begin{array}{l}\text { Dia } \\
.9029 \\
.2490\end{array}$ & $\begin{array}{l}\text { Vol\% } \\
8 \% \\
92 \% \\
\end{array}$ & $\begin{array}{l}\text { Width } \\
.4337 \\
.1260\end{array}$ \\
\hline
\end{tabular}

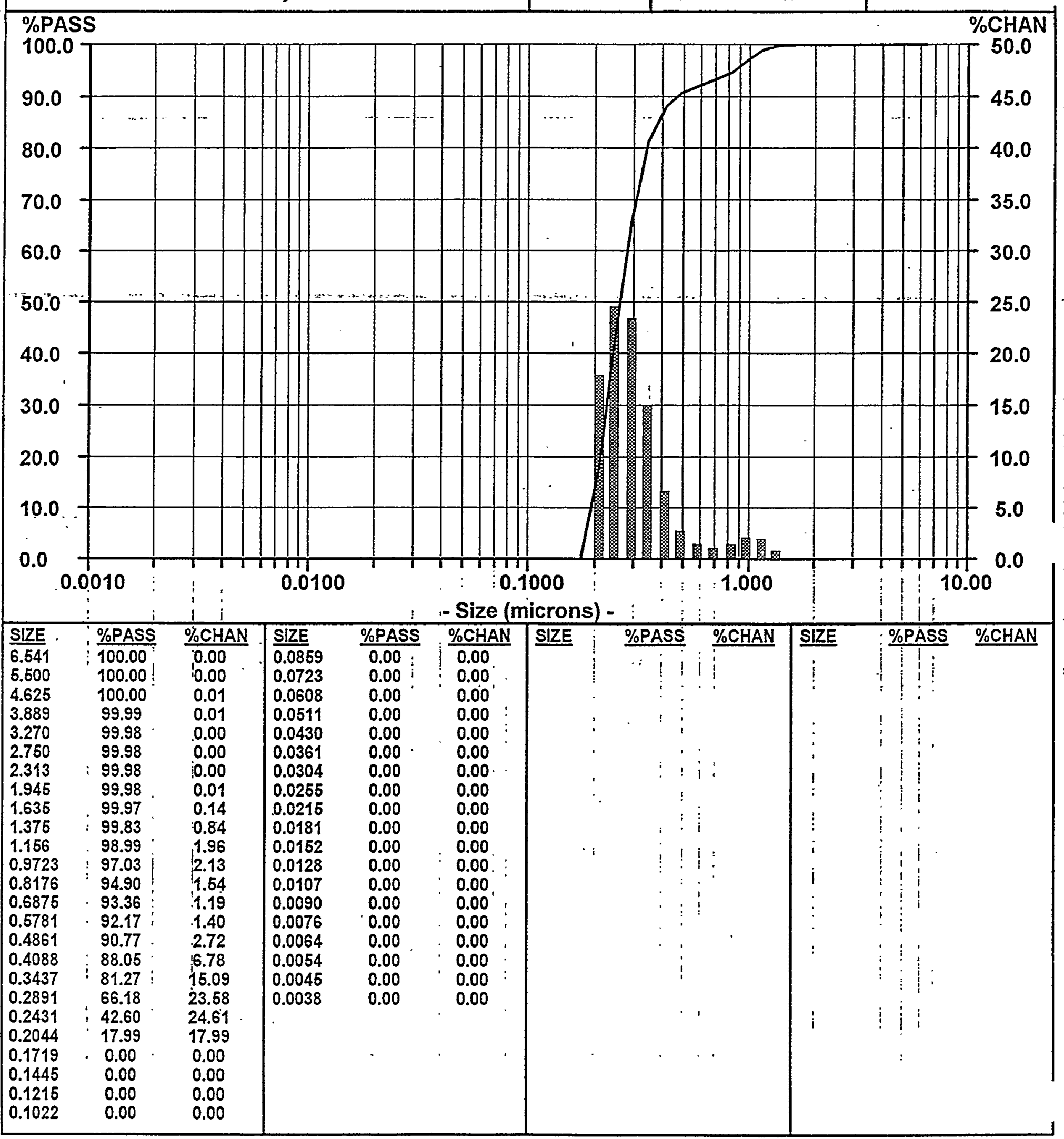


Particle Size Distribution Plots

For Final Slurry: CUF-AZ-102-024 DUP

Replicate No: 2 


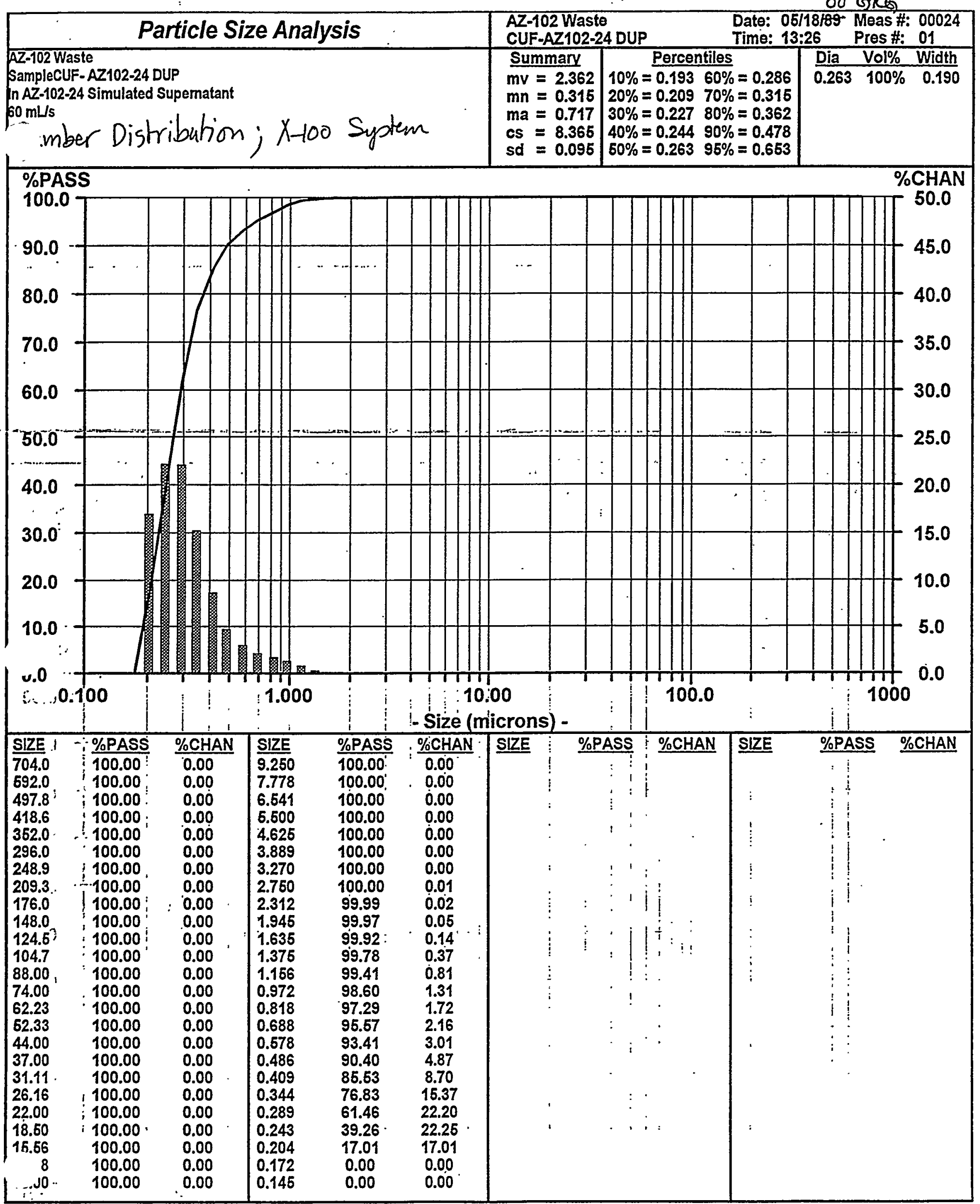


$\infty$ Glus

Particle Size Analysis AZ-102 Waste

SampleCUF- AZ102-24 DUP

In AZ-102-24 Simulated Supematant (Ist Sonication)
So mLs; Sonicated at 40 W, 90 sec
Volume Distribution; $X-100$ Syptent
AZ-102 Waste CUF-AZ102-24 DUP

Summary

$m v=3.061$

$m n=0.282$

$\mathrm{ma}=0.613$

$c s=9.790$

$s d=2.274$
Date: 05/18/89 Meas \#: 00028 Time: 13:41

Pres \#: 01

\begin{tabular}{ccc} 
Dia & Vol\% & Width \\
\hline 23.06 & $7 \%$ & 17.86 \\
5.719 & $12 \%$ & 3.624 \\
1.016 & $: 42 \%$ & 0.881 \\
0.349 & $39 \%$ & 0.243
\end{tabular}

\section{\%PASS}

9

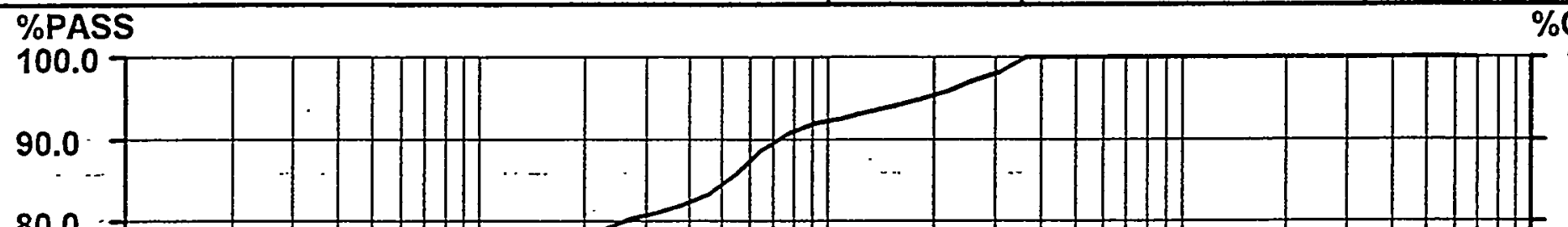

80.0

70.0

60.0

$50:$

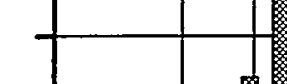

40.0

30.0

20.0

10.0

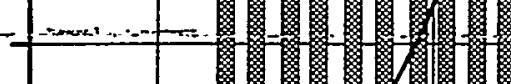

0.0

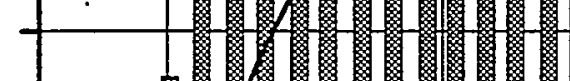

网

同

0.100

药

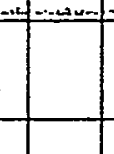

Percentiles
$10 \%=0.277 \quad 60 \%=1.034$
$20 \%=0.357 \quad 70 \%=1.375$
$30 \%=0.461-80 \%=2.563$
$40 \%=0.608 \quad 90 \%=7.161$
$50 \%=0.80195 \%=18.37$

10.0

9.0

8.0

.0

6.0

5.0

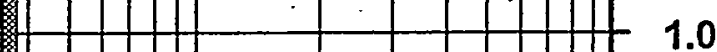

10.00

100.0

1000

- Size (microns) -

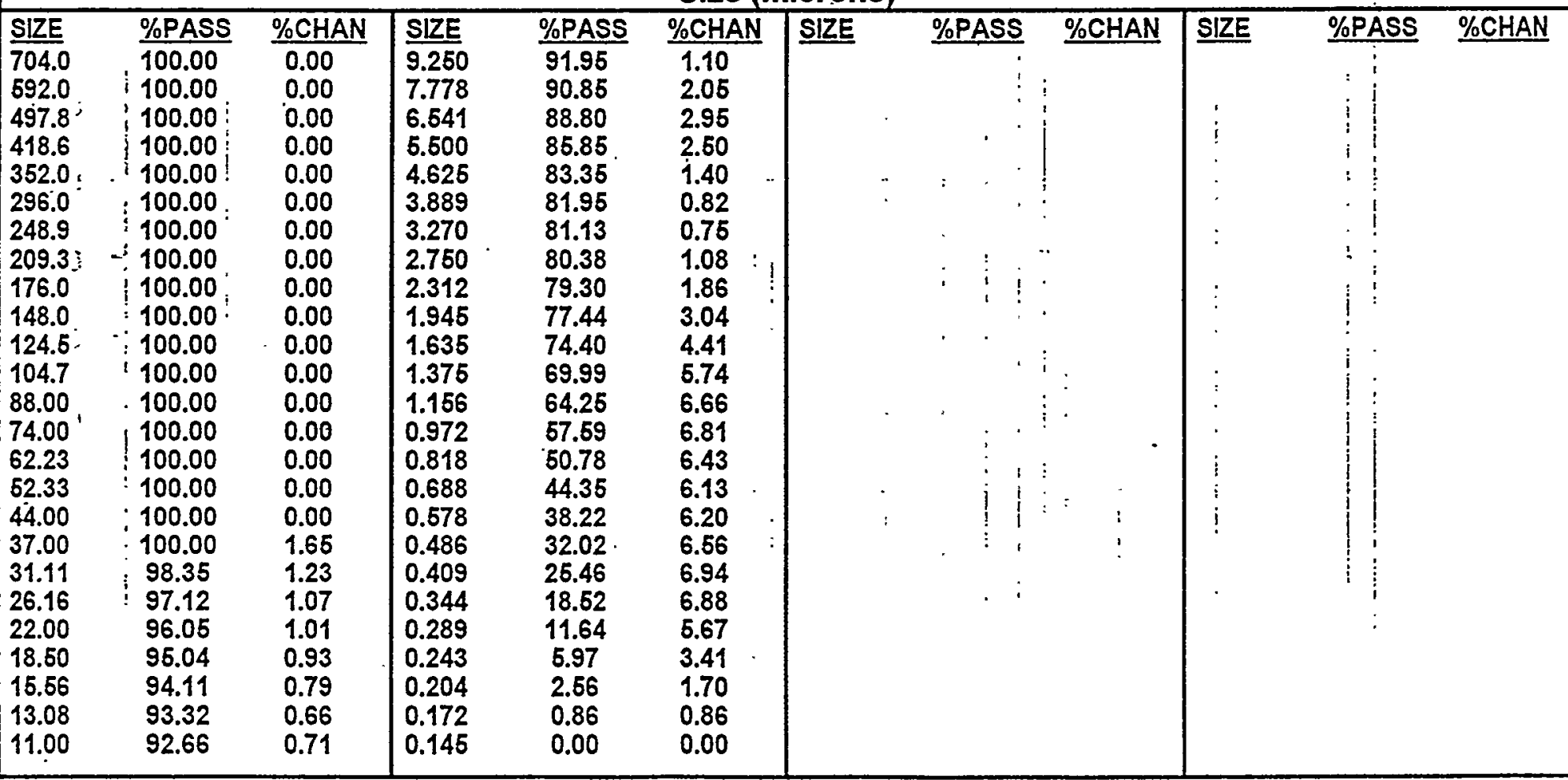




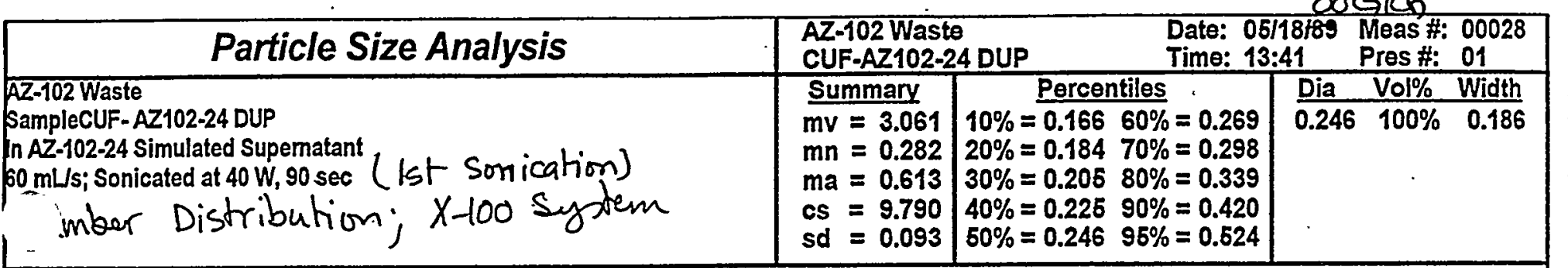

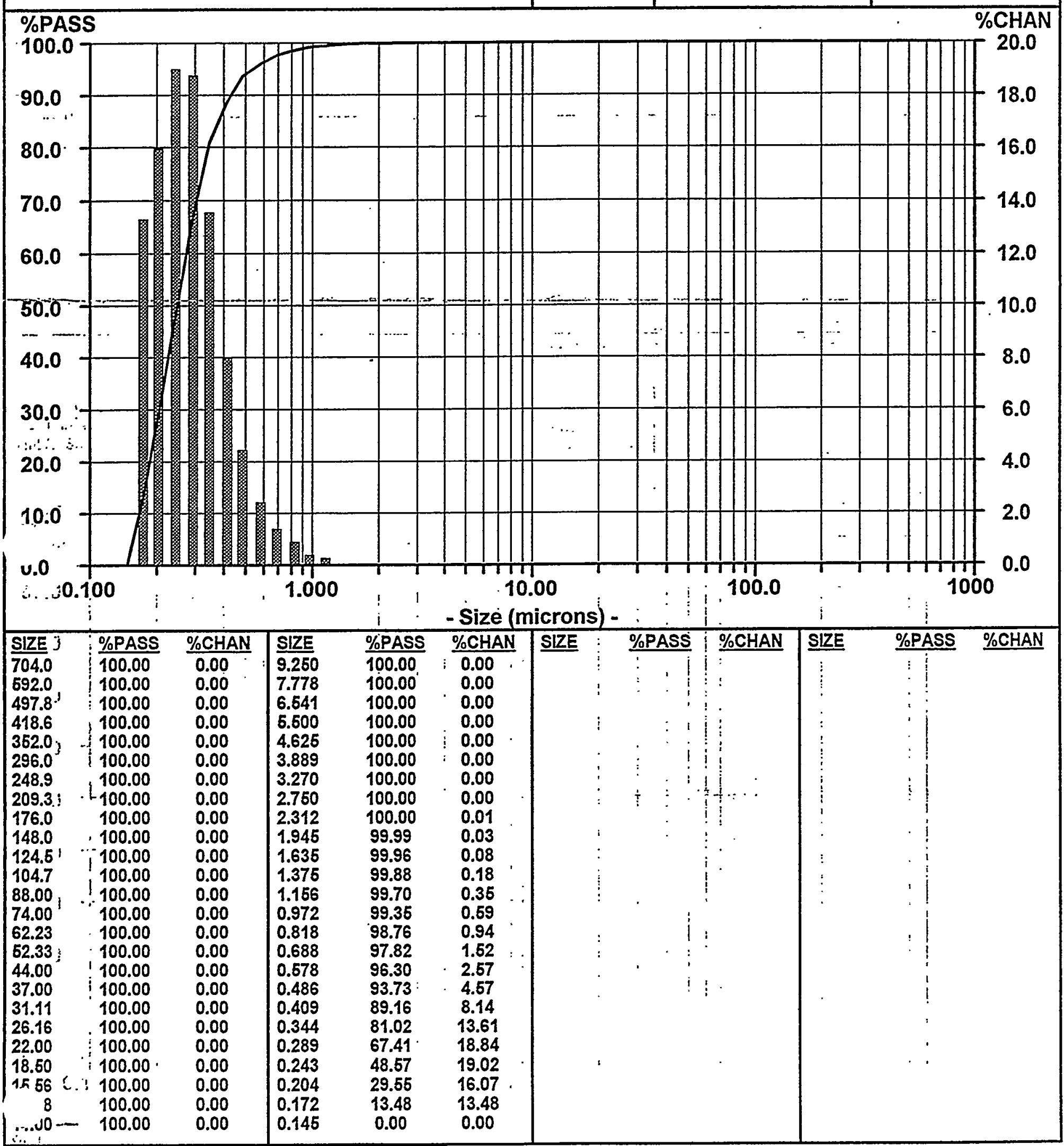


ou corcos

\section{AZ-102 Waste}

SampleCUF-AZ102-24 DUP

In AZ-102-24 Simulated Supematant

$60 \mathrm{mLs}$; Sonicated at $40 \mathrm{~W}, 90 \mathrm{sec}$ (2nd Sorication)

Volume Distribution; $x-100$ System
AZ-102 Waste - Date: 05/18/89 Meas \#: 00032 CUF-AZ102-24 DUP

Summary $\quad$ Percentiles

$m v=2.965 \quad 10 \%=0.282 \quad 60 \%=1.033$

$m n=0.286 \quad 20 \%=0.365 \quad 70 \%=1.365$

$\mathrm{ma}=0.622 \quad 30 \%=0.472 \cdot 80 \%=2.424$

$c s=9.650 \quad 40 \%=0.619 \quad 90 \%=6.971$

sd $=2.209 \quad 50 \%=0.80795 \%=17.23$

\begin{tabular}{ccc} 
Dia & Vol\% & Width \\
\hline 22.64 & $7 \%$ & 17.80 \\
5.730 & $12 \%$ & 3.631 \\
1.010 & $43 \%$ & 0.875 \\
0.354 & $38 \%$ & 0.24
\end{tabular}

\section{\%PASS}

100.0

T

(2)

\%CHAN

90.0

80.0

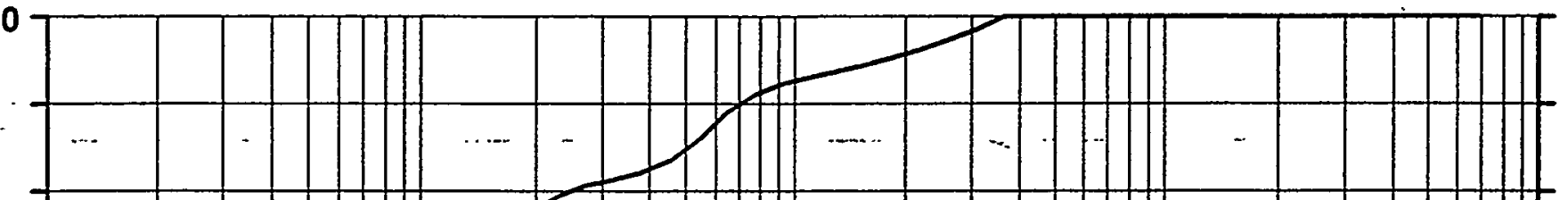

70.0

60.0

50.0

30.0

20.0

10.0

0.0
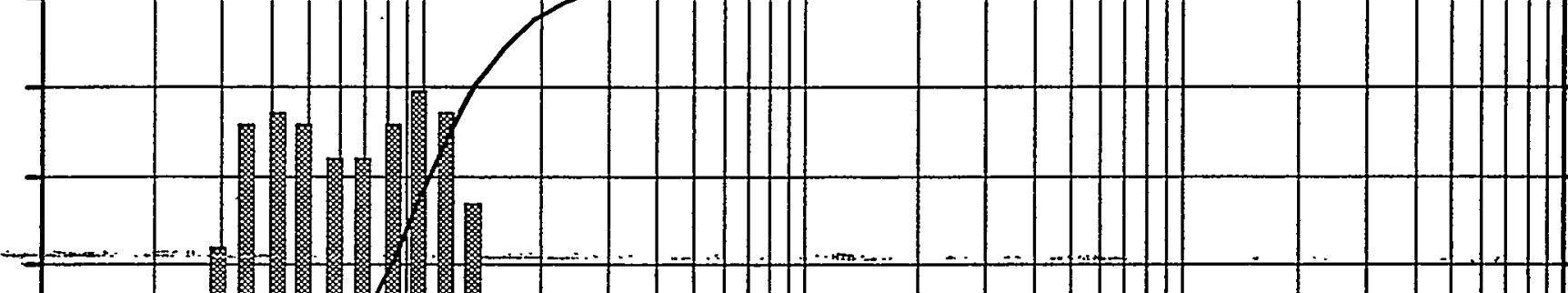

7.0

40.0

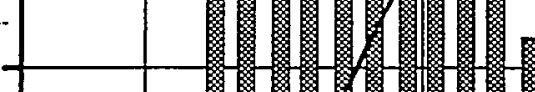

10.100

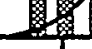

r
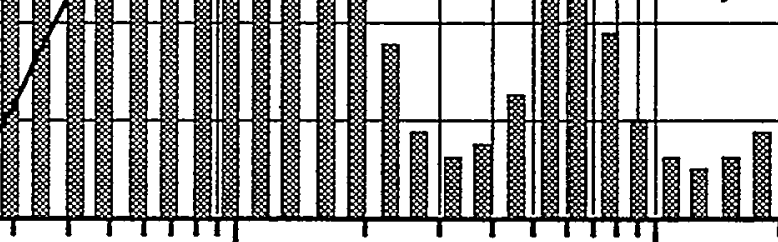

1.000

10.00

- Size (microns) -

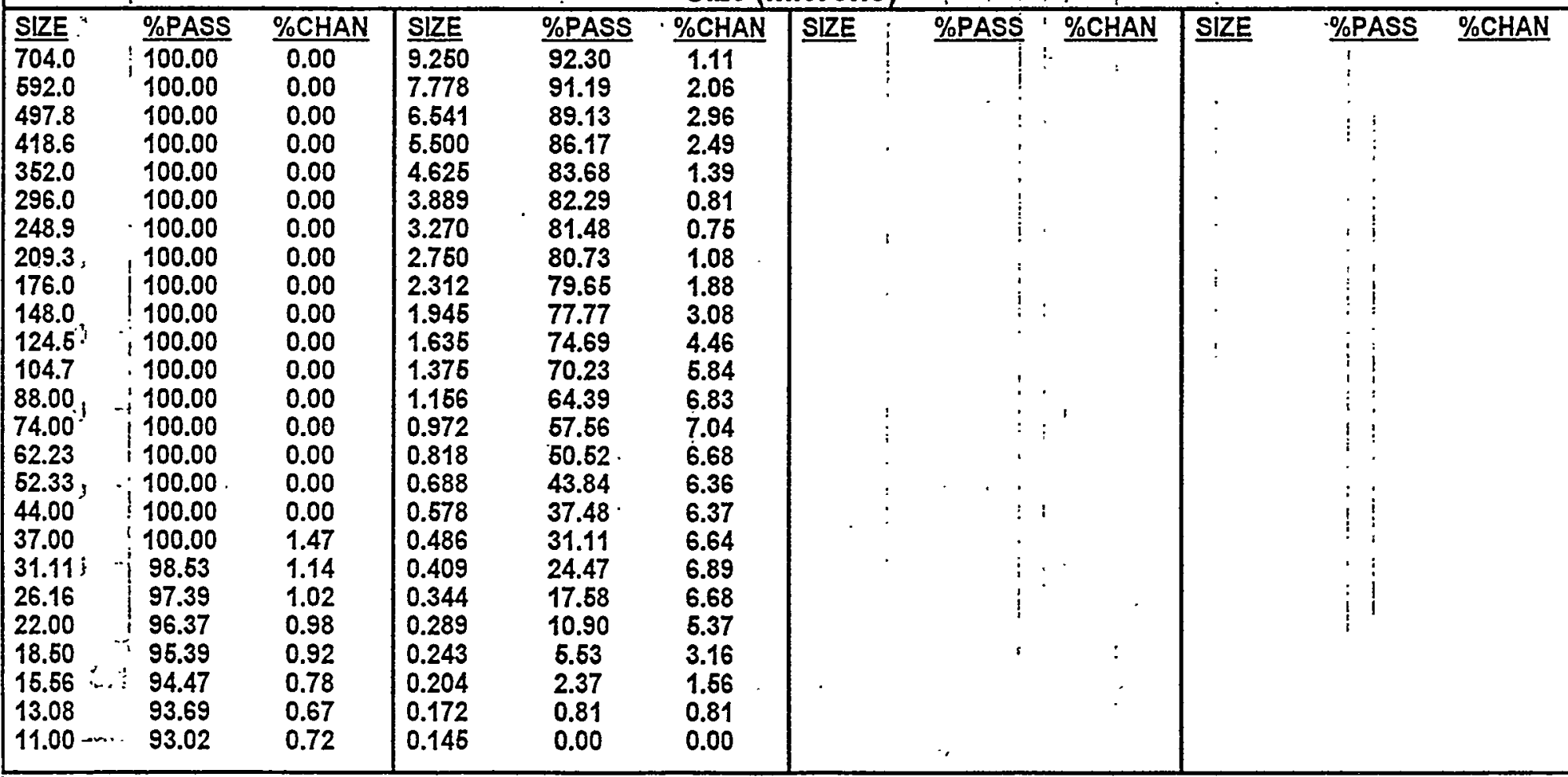


Particle Size Analysis

CUF AZ-102 Waste

JPA

Sample: CUF-AZ102-24 DUP

Number Distribution; UPA System
CUF AZ-102 Waste

Date: 05/20/90 Meas \#: 00004

Time: 09:44 Pres \#: 01

\begin{tabular}{|c|c|c|}
\hline Summary & Percentiles & Dia Vol\% Width \\
\hline $\begin{array}{l}m v=1.457 \\
m n=.0343 \\
m a=.3630 \\
c s=16.53 \\
s d=.0083\end{array}$ & $\begin{array}{l}10 \%=.023260 \%=.0312 \\
20 \%=.024670 \%=.0340 \\
30 \%=.025980 \%=.0381 \\
40 \%=.027590 \%=.0474 \\
50 \%=.029295 \%=.0605\end{array}$ & $100 \%$ \\
\hline
\end{tabular}

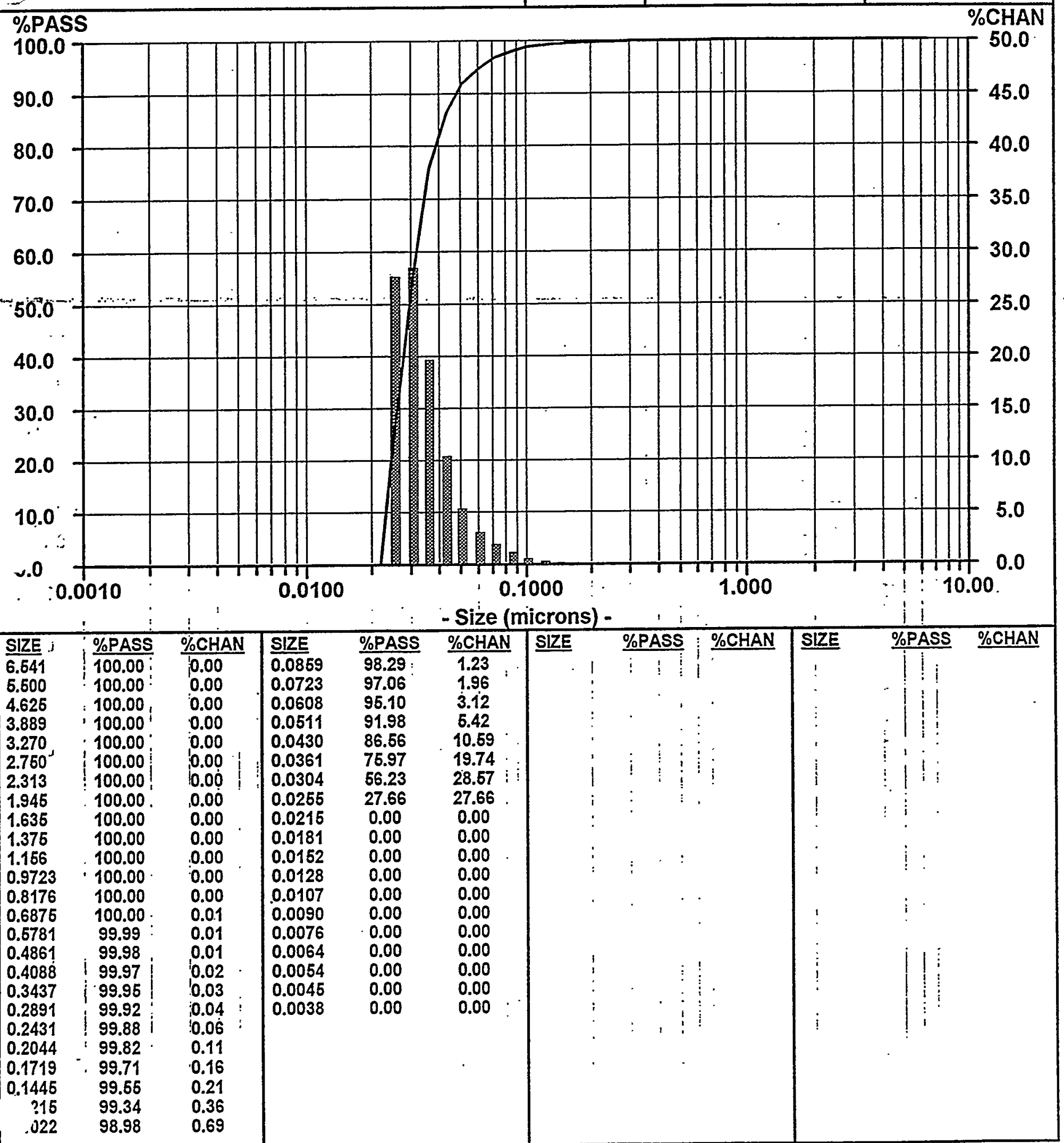




\section{Particle Size Analysis}

CUF AZ-102 Waste

UPA

Sample: CUF-AZ102-24DUP Sonicated -

Volume Distribution; 100 Su UPA Syst.
CUF AZ-102 Waste CUF-AZ102-24DUP SON

Summary

$m v=.7494$

$m n=.6038$

$\mathrm{ma}=.5991$

$c s=10.02$

$\mathrm{sd}=.4921$

Date: 05/20/89 Meas \#: 00007 Time: 10:04 Pres \#: 01

\section{\%PASS}

100.0

90.0

80.0

70.0

60.0

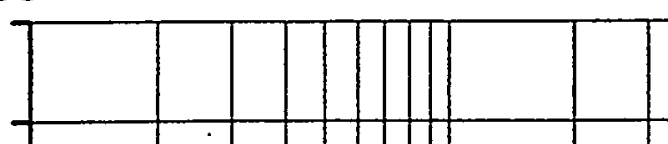
$10 \%=.440760 \%=.6649$ $20 \%=.469170 \%=.6092$ $30 \%=.4930 \cdot 80 \%=1.337$

$40 \%=.515290 \%=1.663$
$50 \%=.538195 \%=1.688$

\begin{tabular}{lrr} 
Dia & Vol\% & Width \\
\hline 1.638 & $22 \%$ & .3604 \\
.6124 & $78 \%$ & .1343
\end{tabular}

$\%$ CHAN

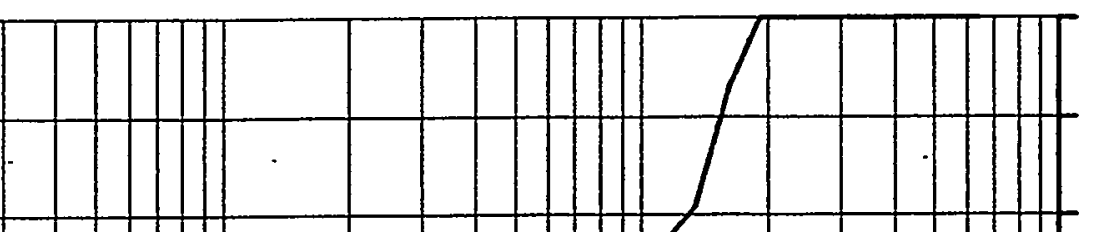

50.0

45.0

40.0

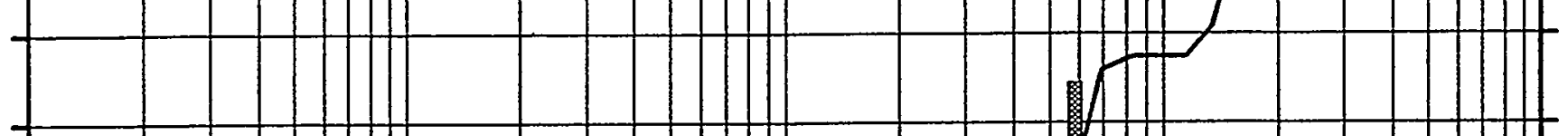

35.0

60

40.

30.0

20.0

10.0

0.0

$+$
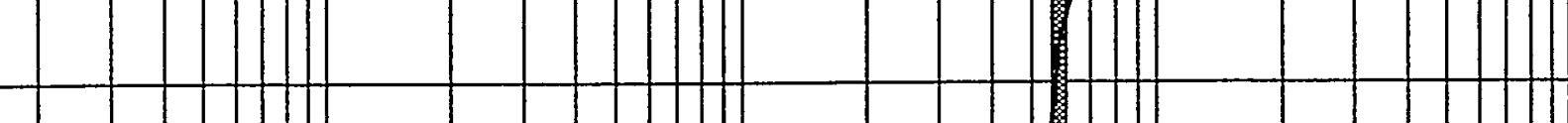

30.0

\begin{tabular}{l}
$50.0 \%$ \\
\hline
\end{tabular}
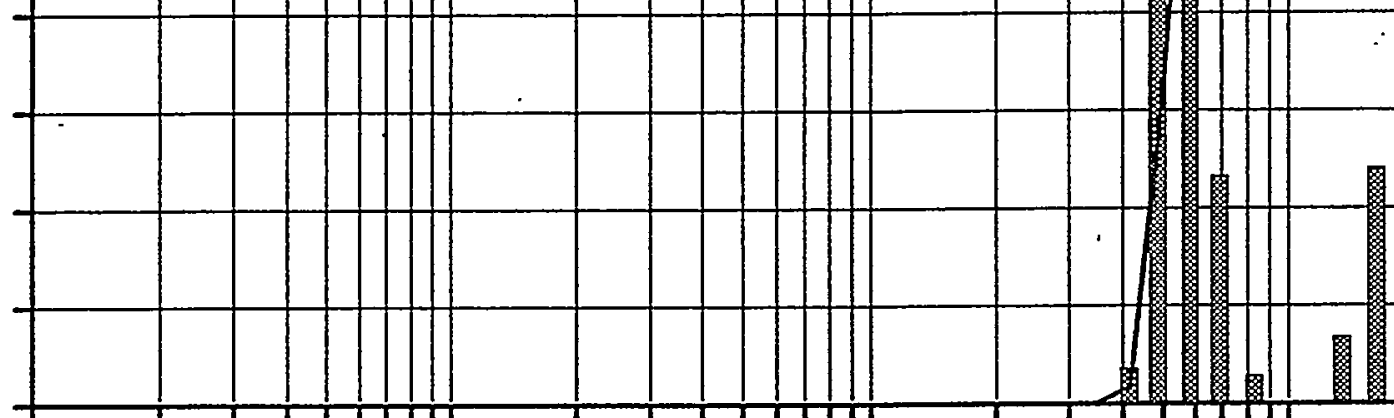

0.0010

0.0100

0.1000

1.000

- Size (microns) -

\section{S12}

6.54

5.500

4.625

3.889

3.270

$2.750^{\circ}$

2.313

1.945

1.635

1.375

1.156

0.9723

0.8176

0.6875

0.5781

0.4861

0.4088

0.3437

0.2891

0.2431

0.2044

0.1719

0.1445

0.1215

0.1022

\begin{tabular}{|c|c|c|}
\hline $\begin{array}{c}: \frac{\% \text { PASS }}{100.00} \\
100.00 \\
100.00 \\
100.00 \\
100.00 \\
100.00 \\
100.00 \\
100.00 \\
93.22 \\
81.06 \\
77.54 \\
77.54 \\
77.54 \\
76.04 \\
64.26 \\
26.91 \\
1.86 \\
0.00 \\
0.00 \\
0.00 \\
0.00 \\
0.00 \\
0.00 \\
0.00 \\
0.00\end{array}$ & 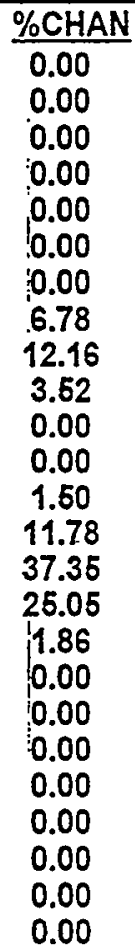 & $\begin{array}{l}\text { SIZE } \\
0.0859 \\
0.0723 \\
0.0608 \\
0.0511 \\
0.0430 \\
0.0361 \\
0.0304 \\
0.0255 \\
0.0215 \\
0.0181 \\
0.0152 \\
0.0128 \\
0.0107 \\
0.0090 \\
0.0076 \\
0.0064 \\
0.0054 \\
0.0045 \\
0.0038\end{array}$ \\
\hline
\end{tabular}

\%PASS \%CHAN SIZE

0.00 .

0.00

0.00

0.00

0.00

0.00

0.00

0.00

0.00

0.00

0.00

0.00

0.00

0.00

0.00

0.00

0.00

0.00

0.00

0.00

$$
0.00
$$

0.00

0.00

$: 0.00$ :

0.00 :

0.00 :

0.00

0.00

0.00

0.00

0.00 .

0.00

$$
0.00^{\circ}
$$

0.00

0.00

0.00

0.00

25.0

20.0

15.0

10.0

5.0

0.0

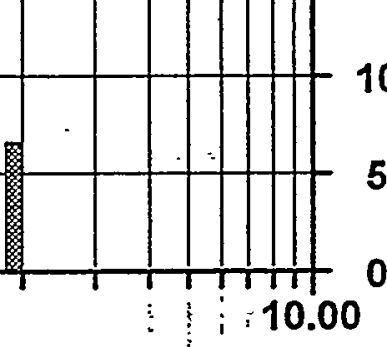

\%PASS \%CHAN SIZE . \%PASS \%CHAN




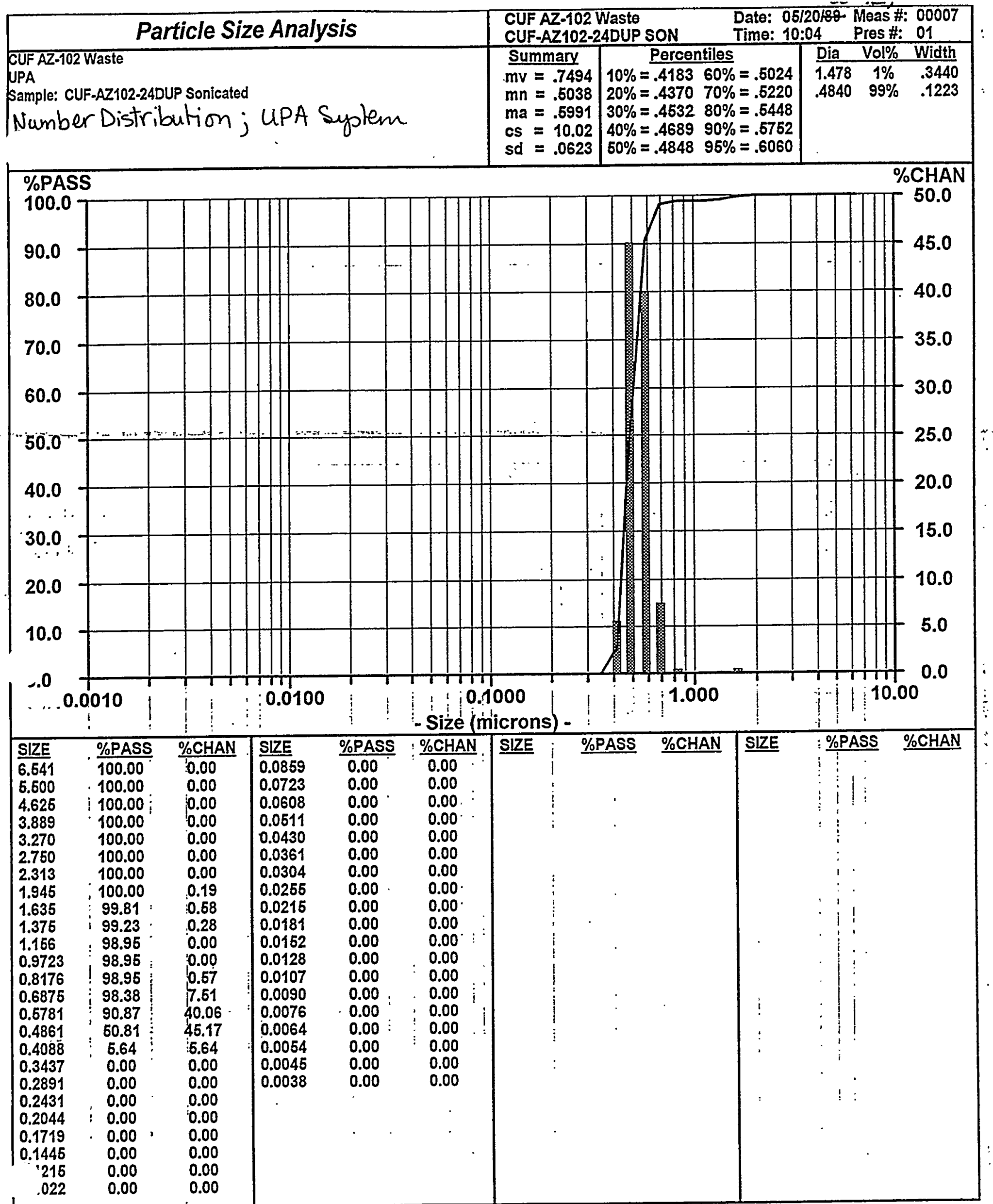


PNWD-3045

BNFL-RPT-038 Rev. 0

\section{Distribution}

No. of

Copies

\section{OFFSITE}

2 DOE/Office of Scientific and Technical Information
No. of

Copies

ONSITE

$5 \quad$ British Nuclear Fuels, Limited

M. E. Johnson (4) BN-FL

E. Higginbotham

$\mathrm{BN}-\mathrm{FL}$

$1 \quad \mathrm{CHG}$

D. J. Washenfelder H6-15

20 Pacific Northwest National Laboratory

P. R. Bredt

K. P. Brooks (5)

P7-25

G. R. Golcar

K6-24

R. T. Hallen

K $6-24$

S. K. Cooley

K2-12

L. K. Jagoda

$\mathrm{K} 5-12$

D. E. Kurath (2)

K6-24

P7-28

E. V. Morrey

$\mathrm{P} 7-28$

K. G. Rappe

K6-28

M. W. Urie

$\mathrm{P} 7-22$

Technical Report Files (5) K1-06 